\title{
Characterization of particulate matter and hydrocarbon emissions from in-use heavy-duty diesel engines
}

\author{
Aleksandar Djordje Bugarski \\ West Virginia University
}

Follow this and additional works at: https://researchrepository.wvu.edu/etd

\section{Recommended Citation}

Bugarski, Aleksandar Djordje, "Characterization of particulate matter and hydrocarbon emissions from inuse heavy-duty diesel engines" (1999). Graduate Theses, Dissertations, and Problem Reports. 2333. https://researchrepository.wvu.edu/etd/2333

This Dissertation is protected by copyright and/or related rights. It has been brought to you by the The Research Repository @ WVU with permission from the rights-holder(s). You are free to use this Dissertation in any way that is permitted by the copyright and related rights legislation that applies to your use. For other uses you must obtain permission from the rights-holder(s) directly, unless additional rights are indicated by a Creative Commons license in the record and/ or on the work itself. This Dissertation has been accepted for inclusion in WVU Graduate Theses, Dissertations, and Problem Reports collection by an authorized administrator of The Research Repository @ WVU.

For more information, please contact researchrepository@mail.wvu.edu. 


\title{
Characterization of Particulate Matter and Hydrocarbon Emissions from
} In-Use Heavy-Duty Diesel Engines

\author{
Aleksandar D. Bugarski \\ Doctoral Dissertation submitted to the \\ College of Engineering and Mineral Resources \\ at West Virginia University \\ in partial fulfillment of the requirements \\ for the degree of \\ Doctor of Philosophy \\ in \\ Mechanical Engineering \\ Mridul Gautam, Ph.D., Chair \\ Nigel Clark, Ph.D. \\ Gary Morris, Ph.D. \\ Michael McCawley, Ph.D. \\ Alberto Ayala, Ph.D.
}

Department of Mechanical and Aerospace Engineering

\author{
Morgantown, West Virginia \\ 1999
}

Keywords: Diesel particulate matter, size distribution, size resolved chemical analysis, hydrocarbon speciation 


\title{
ABSTRACT \\ Characterization of Particulate Matter and Hydrocarbon Emissions from In-Use Heavy-Duty Diesel Engines
}

\begin{abstract}
Aleksandar D. Bugarski
A continued increase in the use of diesel engines in light-duty and heavy-duty vehicles, and the uncertainties about the effects of their emissions on human health have focused attention on risk assessments of diesel engine exhaust. The characterization of diesel particulate matter (PM) and hydrocarbon (HC) emissions from in-use heavy-duty diesel engines and vehicles is the primary objective toward assessing potential health hazard with exposure to the diesel exhaust. The nature of particulate matter emissions from diesel engines is dependent on the engine type, engine conditions, fuel type, exhaust after-treatment process and other parameters. The results are also strongly dependent on the applied measurement technique. The effects of those parameters on the size-resolved DPM emissions were explored in detail. The study on sizeresolved chemical analysis of DPM from diesel engines and in-use heavy-duty diesel vehicles was performed with the goal of obtaining profiles of major DPM constituents. In addition, diesel exhaust was speciated with the purpose of establishing qualitative and quantitative hydrocarbon profiles of diesel exhaust from heavyduty diesel engine/vehicles, and calculating its ozone forming potential.

The effects of engine/vehicle operating conditions, fuel type, different after-treatment processes, and measurement process on the size-resolved PM emissions were examined by operating the test engines and vehicles under steady-state and transient conditions. The regional deposition of DPM in the human respiratory tract was assessed, for several cases, by applying a semi-empirical model developed by Köbritch et al. (1994) to the PM size distribution and concentration profiles that were generated in this study. The results of this analysis showed that lower PM mass emissions do not necessarily correspond to lower number count emissions and a reduced health hazard. In fact, the fractional deposition efficiency of DPM, on a count basis was higher in the case of using "cleaner" fuels than Federal diesel no. 2.

The chemical analyses yielded distribution profiles of the major DPM constituents that were detected in the exhaust for selected steady-state and transient conditions. The sulfate, chloride, ammonium, potassium, sulfur and silicon distribution profiles were determined for range of engine operating conditions. Carbon analysis showed that organic carbon was the major constituent of the particulate matter collected on the MOUDI after-filters (cut-off diameter less that $56 \mathrm{~nm}$ ) regardless of the engine operating conditions. Elemental carbon was the dominant constituent of the DPM collected on the stages VII through X, accounting for nearly $86.5 \%$ of total carbon detected. The analyses indicate that sulfate and organic carbon were the major constituents of nanoparticles.

The samples for study on hydrocarbon speciation were collected using custom designed sampling system. The system was used to collect particle bound $\mathrm{HC}$ on a pre-washed $70 \mathrm{~mm}$ Teflon coated glass fiber filters, semi-volatile $\mathrm{HC}$ on a PUF/XAD-2/PUF adsorbent cartridge and volatile $\mathrm{HC}$ in a black coated Tedlar bag. The analysis on the particle bound and semi-volatile HC was performed by GC/MS. The bag samples were analyzed by GC/FID. The hydrocarbon profiles and ozone forming potential of diesel exhaust were calculated for selected steady-state and transient conditions.
\end{abstract}




\section{ACKNOWLEDGMENTS}

I would like to dedicate this work to my son Luka and wife Tanja whose love and wholehearted support helped me to bring this work and my degree to completion. I would also like to give thanks to my father, mother and sister for encouraging me in pursuing my education. I love you all.

I would like to take this opportunity to express my gratitude to Dr. Mridul Gautam, a great man and an excellent teacher and advisor, for giving me the opportunity to work on all these interesting projects, and for providing me with the guidance, support and resources necessary for accomplishing my research objectives.

I would like to thank Dr. Gary Morris and Dr. Reda Bata for giving me the opportunity to work as a TA and to gain a valuable teaching experience.

My sincere appreciation also goes to Dr. Mike McCawley, who was my teacher and served as a member on my committee, for his excellent lectures in the aerosol science and valuable corrections and suggestions. I would like to thank Dr. Gary Morris, Dr. Nigel Clark and Dr. Alberto Ayala who served as members of my committee and whose wise advice and valuable suggestions helped significantly improve the quality of my work.

Richard Byers and Sandeep Mehta deserve thanks for giving me valuable instructions and helping me perform measurements with MOUDI and SMPS. A special thanks go to Dan Carder, Dr. Greg Thompson, Dr. Scott Wayne and WVU Engine and Emissions Research Center and Transportable Emission Laboratories crews for helping me conduct measurements during engine and vehicle tests. I would like to thank Kim Donghee and experts from DRI for the excellent laboratory work done on the chemical analyses. I would like to thank my office mates and friends Sriram Popuri,

Bret Rankin, Leo Marbun, Wesley Riddle, and Ryan Barnett for being my colleagues and friends all these years.

I would like to express sincere appreciation to my brother-in-law Saša for his proofreading efforts on this document.

Thanks to all. 


\section{TABLE OF CONTENT}

Page

$\begin{array}{ll}\text { ABSTRACT } & \text { ii }\end{array}$

ACKNOWLEDGMENTS $\quad$ iii

TABLE OF CONTENT $\quad$ iv

LIST OF TABLES $\quad$ ix

LIST OF FIGURES X xii

NOMENCLATURE $\quad$ Xxv

$\begin{array}{ll}1.0 \text { INTRODUCTION } & 1\end{array}$

2.0 LITERATURE REVIEW 6

2.1 Size Selective Measurement of Diesel Particulate Matter 6

2.1.1 Sampling Methodology and Instrumentation 8

2.1.2 Effects of Dilution Ratio on Size Selective Measurements of Diesel

$\begin{array}{ll}\text { Particulate Matter } & 17\end{array}$

2.1.3 Effects of Engine Operating Conditions on Size-Resolved Diesel

Particulate Matter Emissions 19

2.1.4 Effects of Fuel Type on Size-Resolved Diesel Particulate Matter

$\begin{array}{ll}\text { Emissions } & 20\end{array}$

2.1.5 The Other Effects on Size Resolved Diesel Particulate Matter

$\begin{array}{ll}\text { Emissions } & 22\end{array}$

2.2 Size-Resolved Chemical Analysis of Diesel Particulate Matter 24

2.3 Speciation of Particulate Bound, Semi-Volatile and Volatile Hydrocarbons from Diesel Exhaust 26

2.3.1 Hydrocarbon Compounds as Constituents of Diesel Exhaust 27

2.3.2 Sampling Methodology 29

2.3.3 Extraction and Sample Preparation 30

2.3.4 Analysis Technique 31 
2.3.5 Effects of Engine Operating Conditions on Hydrocarbon Emissions 32

2.3.6 Effects of Fuel Type on Hydrocarbon Emissions 33

3.0 TEXT OF INVESTIGATION

3.1 EXPERIMENTAL EQUIPMENT AND PROCEDURES 35

3.1.1 Engines and Vehicles Testing Parameters 35

3.1.1.1 Testing Facilities 35

3.1.1.2 Engine and Vehicle Operating Conditions 41

3.1.1.2.1 Size Selective Measurements of Diesel Particulate Matter 41

3.1.1.2.2 Size Resolved Chemical Analysis of Diesel Particulate Matter $\quad 45$

3.1.12.3 Speciation of Hydrocarbons 46

3.1.1.3 Fuels 46

3.1.1.3.1 Size Selective Measurements of Diesel Particulate Matter 46

3.1.1.3.2 Size Resolved Chemical Analysis of Diesel Particulate 48

Matter and Speciation of Hydrocarbons

3.1.2 Sampling Equipment and Instrumentation 48

3.1.2.1 Size Selective Measurements of Diesel Particulate Matter 48

3.1.2.2 Size-Resolved Chemical Analysis of Diesel Particulate Matter 60

3.1.2.3 Speciation of Hydrocarbons $\quad 61$

3.1.2.4 Uncertainty Analysis $\quad 64$

3.1.3 Sampling Methodology $\quad 65$

3.1.3.1 Size Selective Measurements of Diesel Particulate Matter 65

3.1.3.2 Size-Resolved Chemical Analysis of Diesel Particulate Matter 67

3.1.3.3 Speciation of Hydrocarbons $\quad 69$

3.1.3.3.1 Volatile Hydrocarbons 69

3.1.3.3.2 Semi-Volatile Hydrocarbons $\quad 70$

3.1.3.3.3 Particle Bound Hydrocarbons $\quad 70$ 
$\begin{array}{ll}\text { 3.1.4 Data Analysis } & 71\end{array}$

3.1.4.1 Size Selective Measurements of Diesel Particulate Matter 71

3.1.4.1.1 Data Inversion for SMPS Measurements 71

3.1.4.1.2 Data Inversion for MOUDI Measurements 76

3.1.4.1.3 Lognormal Particle Size Distribution 76

3.1.4.1.4 Data Presentation 78

3.1.5 Regional Deposition of Diesel Particulate Matter in Human Respiratory Tract 78

3.1.6 Size-Resolved Chemical Analysis of Diesel Particulate Matter 81

3.1.7 Hydrocarbon Analysis $\quad 81$

3.2 RESULTS AND DISCUSSION

3.2.1 Total Particulate Matter Emissions $\quad 83$

3.2.1.1 Isuzu C240 Study 83

3.2.1.2 Orion/DDC Study $\quad 84$

3.2.1.3 Mack E7-400 Study 86

3.2.2 Size Selective Measurements of Diesel Particulate Matter - Sampling System

Performance 86

3.2.3 Repeatability of Size Selective Measurements of Diesel Particulate Matter

Diesel Particulate Matter Measurements 87

3.2.3.1 Repeatability of Size Selective Measurements of Diesel Particulate Matter Diesel Particulate Matter Measurements with SMPS 87

3.2.3.1.1 Isuzu C240 Study $\quad 87$

$\begin{array}{ll}\text { 3.2.3.1.2 Mack E7-400 Study } & 88\end{array}$

3.2.3.2 Repeatability of Size Selective Measurements of Diesel Particulate

Matter Diesel Particulate Matter Measurements with MOUDI 91

3.2.3.2.1 Orion/DDC 6V92 Study 91

3.2.3.2.2 Mack E7-400 Study 92 
3.2.4 Effects of Dilution Ratio on Size Selective Measurements of Diesel Particulate Matter

3.2.4.1 Isuzu C240 Study

3.2.4.2 Orion/DDC 6V92 Study

3.2.5 Variation of Size-Resolved Diesel Particulate Matter Emissions from Vehicle to Vehicle

\subsubsection{Orion/DDC 6V92 Study-Transient Conditions}

3.2.6 Effects of Engine Operating Conditions and Vehicle Driving Speed on SizeResolved Diesel Particulate Matter Emissions

3.2.6.1 Isuzu C240 Study

3.2.6.2 Orion/DDC 6V92 Study

3.2.6.3 Mack E7-400 Study

3.2.7 Effects of Fuel Type on Size-Resolved Diesel Particulate Matter Emissions

\subsubsection{Orion/DDC 6V92 Study}

3.2.7.2.2 Transient Conditions

3.2.8 Effects of After-Treatment Process on Size-Resolved Diesel Particulate Matter Emissions

3.2.9 Real Time Tracking with SMPS

3.2.9.2 Mack E7-400 Study

3.2.10 Size Selective Measurements of Diesel Particulate Matter with MOUDI 
3.2.10.2 Mack E7-400 Study 155

3.2.11 Regional Deposition of Diesel Particulate Matter in Man 161

3.2.11.1 Isuzu C240 Study 161

3.2.11.2 Orion/DDC 6V92 Study 174

3.2.11.3 Mack E7-400 Study 181

3.2.12 Size-Resolved Chemical Analysis of Diesel Particulate Matter 185

3.2.12.1 Elemental and Inorganic Ion Analysis 185

3.2.12.2 Carbon Analysis 197

3.2.13 Hydrocarbon Speciation of Diesel Exhaust 208

3.2.13.1 Effects of Engine Operating Conditions on Hydrocarbon Emissions 208

3.2.13.2 Effects of Engine Operating Conditions on Ozone Forming Potential 209

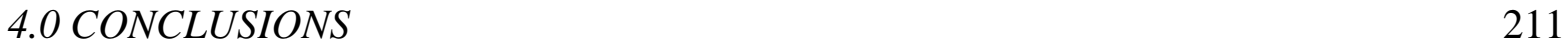

5.0 RECOMMENDATIONS 216

$\begin{array}{ll}\text { REFERENCES } & 218\end{array}$

$\begin{array}{ll}\text { APPENDIX } & 233\end{array}$

Appendix A: Results of Fuel Analysis $\quad 234$

Appendix B: Size-Resolved Chemical Analysis of PM, Mack E7-400,

Elemental and Inorganic Ions Analysis, Tables 236

Appendix C: Hydrocarbon Speciation of Diesel Exhaust,

Cummins ISM 370 ESP, Tables 245

$\begin{array}{ll}\text { VITA } & 254\end{array}$ 


\section{LIST OF TABLES}

Table Page

3.1 Specifications for the Engines 40

3.2 ISO 8178-C Steady-State 8-Mode Test Cycle 42

3.3 Coefficients for Single Charge Correction, Borrowed from

$\begin{array}{ll}\text { Wiedensohler (1987) } & 73\end{array}$

3.4 Isuzu C240, Total Particulate Matter, [(g/bhp-hr) / (g/kWh)] 83

3.5 Orion/DDC 6V92, Total Particulate Matter Emissions, [g/mile] 84

3.6 Mack E7-400, Total Particulate Matter Emissions 86

3.7 Isuzu C240, Exhaust Temperatures, Bare Engine and Engine

Equipped with Oxidation Catalytic Converter and Trap (Rohmac/DCL

$\begin{array}{ll}\text { System }),\left[{ }^{\circ} \mathrm{C}\right] & 114\end{array}$

3.8 Isuzu C240, Steady State, Engine, Regional Deposition of DPM in

Man, Effects of Fuel Type and Engine Operating Conditions, Count,

Diesel and Synthetic Diesel

3.9 Isuzu C240, Steady State, Engine, Regional Deposition of DPM in

Man, Effects of Fuel Type and Engine Operating Conditions, Mass,

Diesel and Synthetic Diesel

3.10 Isuzu C240, Steady State, R75, Regional Deposition of DPM in Man,

Effects of After-Treatment Process, Count, Diesel

3.11 Isuzu C240, Steady State, R75, Regional Deposition of DPM in Man,

Effects of After-Treatment Process, Mass, Diesel

3.12 Orion/DDC 6V92, Steady State, 30mph, Regional Deposition of DPM

in Man, Vehicle to Vehicle Variation and Effects of Fuel Type and

Driving Speed, Count

3.13 Orion/DDC 6V92, Steady State, 30mph, Mossgas, Regional

Deposition of DPM in Man, Vehicle to Vehicle Variation and Effects

of Fuel Type and Driving Speed, Mass 
3.14 Mack E7-400, Steady State, Engine, Regional Deposition of DPM in Man, Effects of Engine Operating Conditions, Count and Mass, Diesel

3.15 Mack E7-400, Transient, FTP, Diesel, Chemical Analysis, Carbon, $\left[\mathrm{mg} / \mathrm{m}^{3}\right]$

3.16 Mack E7-400, Steady-State, R75, Diesel, Chemical Analysis, Carbon, $\left[\mathrm{mg} / \mathrm{m}^{3}\right]$

3.17 Mack E7-400, Steady-State, R50, Diesel, Chemical Analysis, Carbon, $\left[\mathrm{mg} / \mathrm{m}^{3}\right]$

3.18 Mack E7-400, Steady-State, I50, Diesel, Chemical Analysis, Carbon, $\left[\mathrm{mg} / \mathrm{m}^{3}\right]$

3.19 Mack E7-400, Results of Chemical Analyses: $\mathrm{SO}_{4}^{-}$, Organic vs.

Elemental Carbon

A.1 Results of the Fuel Analyses 235

B.1 Mack E7-400, Transient, FTP, Diesel, Chemical Analysis, Elements and Inorganic Ions, $\left[\mu \mathrm{g} / \mathrm{m}^{3}\right]$

B.2 Mack E7-400, Steady-State, R75, Diesel, Chemical Analysis,

Elements and Inorganic Ions, $\left[\mu \mathrm{g} / \mathrm{m}^{3}\right]$

B.3 Mack E7-400, Steady-State, R50, Diesel, Chemical Analysis,

Elements and Inorganic Ions, $\left[\mu \mathrm{g} / \mathrm{m}^{3}\right]$

B.4 Mack E7-400, Steady-State, I50, Diesel, Chemical Analysis, Elements and Inorganic Ions, $\left[\mu \mathrm{g} / \mathrm{m}^{3}\right]$

C.1 Cummins ISM 370 ESP, Polycyclic Aromatic Hydrocarbons, SemiVolatile Phase (PUF/XAD-2/PUF), [ $\mu \mathrm{g} / \mathrm{kWh}]$

C.2 Cummins ISM 370 ESP, Polycyclic Aromatic Hydrocarbons, Particle Bound Phase (Filter), [ $\mu \mathrm{g} / \mathrm{kWh}]$

C.3 Cummins ISM 370 ESP, Ozone Forming Potential, Semi-Volatile Phase (PUF/XAD-2/PUF), [ $\mu \mathrm{g} / \mathrm{kWh}]$ 
C.4 Cummins ISM 370 ESP, Ozone Forming Potential, Particle Bound

Phase (Filter), [ $\mu \mathrm{g} / \mathrm{kWh}]$ 


\section{LIST OF FIGURES}

Figure Page

3.1 Layout for WVU Engine Research Center Laboratory 38

3.2 Central Business District (CBD) Transient Cycle, Actual Test Data 43

3.3 EPA Engine Dynamometer Schedule for Heavy-Duty Diesel Engines (FTP Cycle), RPM and Torque 45

3.4 Mobile Partial-Dilution System for Size Selective Measurements of

Particulate Matter, Schematic Presentation $\quad 50$

3.5 Mobile Partial-Dilution System for Size Selective Measurements of

Particulate Matter, Partial Dilution Tunnel 52

3.6 Mobile Partial-Dilution System for Size Selective Measurements of

Particulate Matter, Scanning Mobility Particle Sizer 55

3.7 Mobile Partial-Dilution System for Size Selective Measurements of

Particulate Matter, MOUDI Sampling Train 58

3.8 CPC Counting Efficiency Curves, (TSI Model 3934 SMPS Instruction

Manual, Figure B-9, pp B-15, 1996). 62

3.9 Mobile Exhaust Sampling System for Speciation of Particulate

Bounded Semi-Volatile and Volatile Hydrocarbons, Front View 63

3.10 Mobile Exhaust Sampling System for Speciation of Particulate

Bounded Semi-Volatile and Volatile Hydrocarbons, Side View 75

3.11 Deposition in the human respiratory tract as function of the diameter for $\mathrm{Q}=500 \mathrm{~cm}^{3} \mathrm{~s}^{-1}, \mathrm{~V}=1500 \mathrm{~cm}^{3}, \mathrm{FRC}=3300 \mathrm{~cm}^{3}$ and $\mathrm{f}=10 \quad 80$

3.12 Orion/DDC 6V92, Transient, CBD, Average Total Particulate Matter

Emissions, Effects of Fuel Type, [g/mile] 85

3.13 Isuzu C240, Steady-State, R75, Paper Filter, Diesel, Number

Concentrations, Repeatability 
3.14 Isuzu C240, Steady-State, I100, Bare Engine, Synthetic Diesel,

Number Concentrations, Repeatability.

3.15 Mack E7-400, Steady-State, R75, Diesel, DR = 4.3, SMPS, Number

Concentration, Repeatability

3.16 Mack E7-400, Steady-State, R50, Diesel, DR = 4.3, SMPS, Number

Concentration, Repeatability

3.17 Orion/DDC 6V92, Bus 2034 Without OCC, Diesel, MOUDI, Mass

Frequency, Transient, CBD, Repeatability

3.18 Orion/DDC 6V92, Bus 2034 Without OCC, Mossgas Synthetic

Diesel, MOUDI, Mass Frequency, Transient, CBD, Repeatability

92

3.19 Mack E7-400, Steady-State, R75, Diesel, DR = 4.3, MOUDI, Mass

Frequency, Repeatability

3.20 Mack E7-400, Steady-State, R50, Diesel, DR = 4.3, MOUDI, Mass

Frequency, Repeatability

3.21 Mack E7-400, Steady-State, I50, Diesel, DR = 4.3, MOUDI, Mass

Frequency, Repeatability

3.22 Mack E7-400, Transient, FTP, Diesel, DR = 4.3, MOUDI, Mass

Frequency, Repeatability

3.23 Isuzu C240, Steady-State, Bare Engine, Diesel, Number

Concentrations, Effects of Dilution Ratio

3.24 Isuzu C240, Steady-State, Bare Engine, Synthetic Diesel, Number

Concentrations, Effects of Dilution Ratio

3.25 Isuzu C240, Steady-State, Paper Filter, Diesel, Number

Concentrations, Effects of Dilution Ratio and Engine Operating

Conditions

3.26 Isuzu C240, Steady-State, Trap, Diesel, Number Concentrations, 
3.27 Isuzu C240, Steady-State, I100, Catalytic Converter and Trap, Diesel, Number Concentrations, Effects of Dilution Ratio

3.28 Isuzu C240, Steady-State, I100, Catalytic Converter and Trap, Synthetic Diesel, Number Concentrations, Effects of Dilution Ratio

3.29 Isuzu C240, Steady-State, Catalytic Converter, Trap and Paper Filter, Diesel, Number Concentrations, Effects of Dilution Ratio

3.30 Isuzu C240, Steady-State, Catalytic Converter, Trap and Paper Filter, Synthetic Diesel, Number Concentrations, Effects of Dilution Ratio

3.31 Orion/DDC 6V92, Steady-State, $20 \mathrm{mph}$, Diesel, Number

Concentration, Effects of Dilution Ratio

3.32 Orion/DDC 6V92, Steady-State, $40 \mathrm{mph}$, Diesel, Number

Concentration, Effects of Dilution Ratio

3.33 Orion/DDC 6V92, Bus 2029 Without OCC, Transient, CBD, Diesel, Number Concentration, Effects of Dilution Ratio

3.34 Orion/DDC 6V92, Bus 2048 With OCC, Transient, CBD, Diesel, Number Concentration, Effects of Dilution Ratio

3.35 Orion/DDC 6V92, Bus 2034 Without OCC, Transient, CBD, Diesel, Number Concentration, Effects of Dilution Ratio

3.36 Orion/DDC 6V92, Steady-State, $20 \mathrm{mph}, \mathrm{DR}=22$, Diesel, Number

Concentration, Vehicle to Vehicle Variation

3.37 Orion/DDC 6V92, Steady-State, $30 \mathrm{mph}, \mathrm{DR}=22$, Diesel, Number

Concentration, Vehicle to Vehicle Variation

3.38 Orion/DDC 6V92, Steady-State, $40 \mathrm{mph}, \mathrm{DR}=22$, Diesel, Number

Concentration, Vehicle to Vehicle Variation

3.39 Orion/DDC 6V92, Steady-State, $20 \mathrm{mph}, \mathrm{DR}=22$, Mossgas Synthetic

Diesel, Number Concentration, Vehicle to Vehicle Variation

3.40 Orion/DDC 6V92, Steady-State, $30 \mathrm{mph}$, DR = 22, Mossgas Synthetic

Diesel, Number Concentration, Vehicle to Vehicle Variation 
3.41 Orion/DDC 6V92, Steady-State, $40 \mathrm{mph}$, DR = 22, Mossgas Synthetic Diesel, Number Concentration, Vehicle to Vehicle Variation

3.42 Orion/DDC 6V92, Transient, CBD, Diesel, $\mathrm{D}_{\mathrm{p}}=50 \mathrm{~nm}$, Number Concentration, Vehicle to Vehicle Variation

3.43 Orion/DDC 6V92, Transient, CBD, Diesel, $\mathrm{D}_{\mathrm{p}}=100 \mathrm{~nm}$, Number Concentration, Vehicle to Vehicle Variation

3.44 Orion/DDC 6V92, Transient, CBD, Diesel, $\mathrm{D}_{\mathrm{p}}=200 \mathrm{~nm}$, Number Concentration, Vehicle to Vehicle Variation

3.45 Orion/DDC 6V92, CBD, Diesel, Exhaust Temperature 112

3.46 Orion/DDC 6V92, CBD, Mossgas Synthetic Diesel, Exhaust

Temperature

3.47 Isuzu C240, Steady-State, Engine, Diesel, DR = 28, Number

Concentration, Effects of Engine Operating Conditions

3.48 Isuzu C240, Steady-State, Engine, Diesel, DR = 15, Number

Concentration, Effects of Engine Operating Conditions

3.49 Isuzu C240, Steady-State, Engine, Synthetic Diesel, DR = 28, Number

Concentration, Effects of Engine Operating Conditions

3.50 Isuzu C240, Steady-State, Engine, Synthetic Diesel, DR = 15, Number

Concentration, Effects of Engine Operating Conditions

3.51 Orion/DDC 6V92, Steady-State, DR = 22, Diesel, Number

Concentration, Effects of Driving Speed

3.52 Orion/DDC 6V92, Steady-State, DR = 22, Mossgas Synthetic Diesel, Number Concentration, Effects of Driving Speed

3.53 Mack E7-400, Steady-State, Diesel, DR = 4.3, SMPS, Number

Concentration, Effects of Engine Opearting Conditions

3.54 Isuzu C240, Steady-State, Bare Engine, Dilution Ratio = 28, Number

Concentrations, Effects of Fuel Type 
3.55 Isuzu C240, Steady-State, Engine, Dilution Ratio = 15, Number

Concentrations, Effects of Fuel Type

3.56 Isuzu C240, Steady-State, Catalytic Converter, Trap and Paper Filter,

Dilution Ratio $=28$, Number Concentrations, Effects of Fuel Type

3.57 Orion/DDC 6V92, Steady-State, $20 \mathrm{mph}$, DR = 22, Number

Concentration, Effects of Fuel Type

3.58 Orion/DDC 6V92, Steady-State, $30 \mathrm{mph}, \mathrm{DR}=22$, Number

Concentration, Effects of Fuel Type

3.59 Orion/DDC 6V92, Steady-State, $40 \mathrm{mph}, \mathrm{DR}=22$, Number

Concentration, Effects of Fuel Type

3.60 Orion/DDC 6V92, Bus 2048 With OCC, Transient, CBD, DR = 22,

Number Concentration, Effects of Fuel Type

3.61 Orion/DDC 6V92, Bus 2030 Without OCC, Transient, CBD,

$\mathrm{DR}=22$, Number Concentration, Effects of Fuel Type

3.62 Orion/DDC 6V92, Bus 2034 Without OCC, Transient, CBD,

$\mathrm{DR}=22$, Number Concentration, Effects of Fuel Type

3.63 Orion/DDC 6V92, Bus 2029 With OCC, Transient, CBD, DR = 22,

Number Concentration, Effects of Fuel Type

3.64 Isuzu C240, Steady-State, Mode R100, Diesel, DR = 28, Number

Concentration, Effects of After-Treatment Process

3.65 Isuzu C240, Steady-State, Mode R75, Diesel, DR = 28, Number

Concentration, Effects of After-Treatment Process

3.66 Isuzu C240, Steady-State, Mode I100, Diesel, DR = 28, Number

Concentration, Effects of After-Treatment Process

3.67 Isuzu C240, Steady-State, Mode R100, Diesel, DR = 15, Number

Concentration, Effects of After-Treatment Process

3.68 Isuzu C240, Steady-State, Mode R75, Diesel, DR = 15, Number

Concentration, Effects of After-Treatment Process 
3.69 Isuzu C240, Steady-State, Mode I50, Diesel, DR = 28, Number Concentration, Effects of After-Treatment Process

3.70 Isuzu C240, Steady-State, Mode I50, Diesel, DR = 15, Number

Concentration, Effects of After-Treatment Process

3.71 Isuzu C240, Steady-State, Mode R75, F-T Synthetic Diesel, DR = 28,

Number Concentration, Effects of After-Treatment Process

3.72 Isuzu C240, Steady-State, Mode R75, F-T Synthetic Diesel, DR = 15,

Number Concentration, Effects of After-Treatment Process

3.73 Isuzu C240, Steady-State, Mode I100, Diesel, DR = 15, Number

Concentration, Effects of After-Treatment Process

3.74 Isuzu C240, Steady-State, Mode I100, F-T Synthetic Diesel, DR = 28,

Number Concentration, Effects of After-Treatment Process

3.75 Isuzu C240, Steady-State, Mode I100, F-T Synthetic Diesel, DR = 15,

Number Concentration, Effects of After-Treatment Process

3.76 Isuzu C240, Steady-State, Mode R100, F-T Synthetic Diesel, DR = 28, Number Concentration, Effects of After-Treatment Process

3.77 Isuzu C240, Steady-State, Mode R100, F-T Synthetic Diesel, DR = 15, Number Concentration, Effects of After-Treatment Process

3.78 Isuzu C240, Steady-State, Mode I50, F-T Synthetic Diesel, DR = 28,

Number Concentration, Effects of After-Treatment Process

3.79 Isuzu C240, Steady-State, Mode I50, F-T Synthetic Diesel, DR = 15,

Number Concentration, Effects of After-Treatment Process

3.80 Orion/DDC 6V92, Bus 2029 Without OCC, Transient, CBD, Diesel,

$\mathrm{DR}=22$, Number Concentration, Real Time Tracking

3.81 Orion/DDC 6V92, Bus 2048 With OCC, Transient, CBD, Diesel,

$\mathrm{DR}=22$, Number Concentration, Real Time Tracking

3.82 Orion/DDC 6V92, Bus 2030 Without OCC, Transient, CBD, Diesel, $\mathrm{DR}=22$, Number Concentration, Real Time Tracking 
3.83 Orion/DDC 6V92, Bus 2034 Without OCC, Transient, CBD, Diesel, $\mathrm{DR}=22$, Number Concentration, Real Time Tracking

3.84 Orion/DDC 6V92, Bus 2029 With OCC, Transient, CBD, Diesel, $\mathrm{DR}=22$, Number Concentration, Real Time Tracking

3.85 Orion/DDC 6V92, Bus 2029 Without OCC, Transient, CBD, Diesel, $\mathrm{DR}=5$, Number Concentration, Real Time Tracking

3.86 Orion/DDC 6V92, Bus 2048 With OCC, Transient, CBD, Diesel,

$\mathrm{DR}=5$, Number Concentration, Real Time Tracking

3.87 Orion/DDC 6V92, Bus 2034 Without OCC, Transient, CBD, Diesel,

$\mathrm{DR}=5$, Number Concentration, Real Time Tracking

3.88 Orion/DDC 6V92, Bus 2048 With OCC, Transient, CBD, Mossgas

Synthetic Diesel, DR = 22, Number Concentration, Real Time

Tracking

3.89 Orion/DDC 6V92, Bus 2030 Without OCC, Transient, CBD, Mossgas

Synthetic Diesel, DR = 22, Number Concentration, Real Time

Tracking

3.90 Orion/DDC 6V92, Bus 2034 Without OCC, Transient, CBD, Mossgas

Synthetic Diesel, DR = 22, Number Concentration, Real Time

Tracking

3.91 Orion/DDC 6V92, Bus 2029 With OCC, Transient, CBD, Mossgas

Synthetic Diesel, DR = 22, Number Concentration, Real Time

Tracking

3.92 Mack E7-400, Transient, FTP, Diesel, DR = 4.3, SMPS, Number

Concentration, Real Time Tracking

3.93 Orion/DDC 6V92, Bus 2034 Without OCC, Diesel, MOUDI, Mass

Frequency, Steady-State, $40 \mathrm{mph}$

3.94 Orion/DDC 6V92, Bus 2034 Without OCC, Mossgas Synthetic

Diesel, MOUDI, Mass Frequency, Steady-State, $40 \mathrm{mph}$ 
3.95 Orion/DDC 6V92, Bus 2034 Without OCC, Mossgas Synthetic

Diesel, MOUDI, Mass Frequency, Steady-State, $20 \mathrm{mph}$

3.96 Orion/DDC 6V92, Bus 2034 Without OCC, Transient, CBD,

MOUDI, Mass Frequency, Effects of Fuel Type

3.97 Orion/DDC 6V92, Bus 2034 Without OCC, Steady-State, 40 mph,

MOUDI, Mass Frequency, Effects of Fuel Type

152

3.98 Orion/DDC 6V92, Bus 2034 Without OCC, Diesel, MOUDI, Mass

Frequency, Effects of Engine Operating Conditions

3.99 Orion/DDC 6V92, Bus 2034 Without OCC, Mossgas Synthetic,

Diesel, MOUDI, Mass Frequency, Effects of Engine Operating

Conditions

3.100 Orion/DDC 6V92, Bus 2034 Without OCC, Diesel, 40 mph, Mass

Frequency, MOUDI vs. SMPS

3.101 Orion/DDC 6V92, Bus 2034 Without OCC, Mossgas Synthetic,

Diesel, 20 mph, Mass Frequency, MOUDI vs. SMPS

3.102 Mack E7-400, Diesel, DR = 4.3, MOUDI, Mass Frequency, Effects of

Engine Operating Conditions

3.103 Mack E7-400, Diesel, DR = 4.3, MOUDI, Mass Concentration,

Effects of Engine Operating Conditions

3.104 Mack E7-400, Steady-State, R75, Test 1, Diesel, DR = 4.3, Mass

Concentrations, MOUDI vs. SMPS

3.105 Mack E7-400, Steady-State, R75, Test 2, Diesel, DR = 4.3, Mass

Concentrations, MOUDI vs. SMPS

3.106 Mack E7-400, Steady-State, R50, Test 1, Diesel, DR = 4.3, Mass

Concentrations, MOUDI vs. SMPS

3.107 Mack E7-400, Steady-State, R50, Test 2, Diesel, DR = 4.3, Mass

Concentrations, MOUDI vs. SMPS 
3.108 Mack E7-400, Steady-State, I50, Test 1, Diesel, DR = 4.3,

Mass Concentrations, MOUDI vs. SMPS

3.109 Mack E7-400, Steady-State, I50, Test 2, Diesel, DR = 4.3,

Mass Concentrations, MOUDI vs. SMPS

3.110 Isuzu C240, Steady-State, Engine, DR = 28, Number Concentration, Regional Deposition of DPM in Man, Effects of Fuel Type

3.111 Isuzu C240, Steady-State, Engine, DR = 28, Normalized Particle

Number, Regional Deposition of DPM in Man, Estimated Deposition in Alveolar Region, Effects of Fuel Type

3.112 Isuzu C240, Steady-State, Engine, DR = 28, Mass Concentration,

Regional Deposition of DPM in Man, Effects of Fuel Type

3.113 Isuzu C240, Steady-State, Engine, DR = 28, Normalized Particle Mass, Regional Deposition of DPM in Man, Estimated Deposition in Alveolar Region, Effects of Fuel Type

3.114 Isuzu C240, Steady-State, Engine, DR = 28, Number Concentration, Regional Deposition of DPM in Man, Effects of Engine Operating Conditions

3.115 Isuzu C240, Steady-State, Engine, DR = 28, Normalized Particle

Number, Regional Deposition of DPM in Man, Estimated Deposition in Alveolar Region, ffects of Engine Operating Conditions

3.116 Isuzu C240, Steady-State, Engine, DR = 28, Mass Concentration, Regional Deposition of DPM in Man, Effects of Engine Operating Conditions

3.117 Isuzu C240, Steady-State, Engine, DR = 28, Normalized Particle Mass, Regional Deposition of DPM in Man, Estimated Deposition in Alveolar Region, Effects of Engine Operating Conditions 
3.118 Isuzu C240, Steady-State, R75, Diesel, DR = 28, Number

Concentration, Regional Deposition of DPM in Man, Effects of After-

Treatment Process

3.119 Isuzu C240, Steady-State, R75, Diesel, DR = 28, Normalized Particle

Number, Regional Deposition of DPM in Man, Estimated Deposition

in Alveolar Region, Effects of After-Treatment Process

3.120 Isuzu C240, Steady-State, R75, Diesel, DR = 28, Mass Concentration,

Regional Deposition of DPM in Man, Effects of After-Treatment

Process

3.121 Isuzu C240, Steady-State, R75, Diesel, DR = 28, Normalized Particle

Mass, Regional Deposition of DPM in Man, Estimated Deposition in Alveolar Region, Effects of After-Treatment Process

3.122 Orion/DDC 6V92, Steady-State, $30 \mathrm{mph}$, Mossgas Synthetic Diesel,

$\mathrm{DR}=22$, Number Concentration, Regional Deposition of DPM in

Man, Vehicle to Vehicle Variation

3.123 Orion/DDC 6V92, Steady-State, $30 \mathrm{mph}$, Mossgas Synthetic Diesel,

$\mathrm{DR}=22$, Normalized Particle Number, Regional Deposition of DPM in Man, Estimated Deposition in Alveolar Region, Vehicle to Vehicle Variation

3.124 Orion/DDC 6V92, Steady-State, $30 \mathrm{mph}$, Mossgas Synthetic Diesel,

$\mathrm{DR}=22$, Mass Concentration, Regional Deposition of DPM in Man, Vehicle to Vehicle Variation

3.125 Orion/DDC 6V92, Steady-State, $30 \mathrm{mph}$, Mossgas Synthetic Diesel, $\mathrm{DR}=22$, Normalized Particle Mass, Regional Deposition of DPM in Man, Estimated Deposition in Alveolar Region, Vehicle to Vehicle Variation 
3.126 Orion/DDC 6V92, Bus 2034 Without OCC, Steady-State, DR = 22, Number Concentration, Regional Deposition of DPM in Man, Effects of Fuel Type and Driving Speed

3.127 Orion/DDC 6V92, Bus 2034 Without OCC, Steady-State, DR = 22, Normalized Particle Number, Regional Deposition of DPM in Man, Estimated Deposition in Alveolar Region, Effects of Fuel Type and Driving Speed

3.128 Orion/DDC 6V92, Bus 2034 Without OCC, Steady-State, DR = 22,

Mass Concentration, Regional Deposition of DPM in Man, Effects of

Fuel Type and Driving Speed

3.129 Orion/DDC 6V92, Bus 2034 Without OCC, Steady-State, DR = 22,

Normalized Particle Mass, Regional Deposition of DPM in Man,

Estimated Deposition in Alveolar Region, Effects of Fuel Type and

Driving Speed

3.130 Mack E7-400, Steady-State, Diesel, DR = 4.3, Number Concentration, Regional Deposition of DPM in Man, Effects of Engine Operating Conditions

3.131 Mack E7-400, Steady-State, Diesel, DR = 4.3, Normalized Particle Number, Regional Deposition of DPM in Man, Estimated Deposition in Alveolar Region, Effects of Engine Operating Conditions

3.132 Mack E7-400, Steady-State, Diesel, DR = 4.3, Mass Concentration, Regional Deposition of DPM in Man, Effects of Engine Operating Conditions

3.133 Mack E7-400, Steady-State, Diesel, DR = 4.3, Normalized Particle Mass, Regional Deposition of DPM in Man, Estimated Deposition in Alveolar Region, Effects of Engine Operating Conditions

3.134 Mack E7-400, Diesel, MOUDI, Mass Frequency, $\mathrm{SO}_{4}{ }^{++}$, Effects of Engine Operating Conditions 
3.135 Mack E7-400, Diesel, MOUDI, Mass Concentration, $\mathrm{SO}_{4}{ }^{++}$, Effects of Engine Operating Conditions

3.136 Mack E7-400, Diesel, MOUDI, Mass Frequency, Sulfur, Effects of Engine Operating Conditions

3.137 Mack E7-400, Diesel, MOUDI, Mass Concentration, Sulfur, Effects

of Engine Operating Conditions

189

3.138 Mack E7-400, Diesel, MOUDI, $\mathrm{SO}_{4}{ }^{++}$vs S, Effects of Engine

Operating Conditions

3.139 Mack E7-400, Diesel, MOUDI, Mass Frequency, $\mathrm{NH}_{4}{ }^{+}$, Effects of Engine Operating Conditions

190

3.140 Mack E7-400, Diesel, MOUDI, Mass Concentration, $\mathrm{NH}^{+}$, Effects of Engine Operating Conditions

3.141 Mack E7-400, Diesel, MOUDI, Mass Frequency, $\mathrm{Cl}^{-}$, Effects of Engine Operating Conditions

3.142 Mack E7-400, Diesel, MOUDI, Mass Concentration, $\mathrm{Cl}^{-}$, Effects of Engine Operating Conditions

192

3.143 Mack E7-400, Diesel, MOUDI, Mass Frequency, $\mathrm{K}^{+}$, Effects of Engine Operating Conditions

3.144 Mack E7-400, Diesel, MOUDI, Mass Concentration, $\mathrm{K}^{+}$, Effects of Engine Operating Conditions

3.145 Mack E7-400, Diesel, MOUDI, Mass Frequency, Silicon, Effects of Engine Operating Conditions

3.146 Mack E7-400, Diesel, MOUDI, Mass Concentration, Silicon, Effects of Engine Operating Conditions

3.147 Mack E7-400, Diesel, MOUDI, Mass Frequency, Total Particulate Matter, Effects of Engine Operating Conditions

3.148 Mack E7-400, Diesel, MOUDI, Mass Concentration, Total Particulate Matter, Effects of Engine Operating Conditions 
3.149 Mack E7-400, Diesel, FTP, MOUDI, Mass Concentration, Carbon Analysis, Distributions

3.150 Mack E7-400, Diesel, FTP, MOUDI, Mass Concentration, Carbon Analysis, Organic vs. Elemental Carbon

3.151 Mack E7-400, Diesel, R75, MOUDI, Mass Concentration, Carbon Analysis, Distributions

3.152 Mack E7-400, Diesel, R75, MOUDI, Mass Concentration, Carbon Analysis, Organic vs. Elemental Carbon

3.153 Mack E7-400, Diesel, R50, MOUDI, Mass Concentration, Carbon Analysis, Distributions

3.154 Mack E7-400, Diesel, R50, MOUDI, Mass Concentration, Carbon Analysis, Organic vs. Elemental Carbon

3.155 Mack E7-400, Diesel, I50, MOUDI, Mass Concentration, Carbon Analysis, Distributions

3.156 Mack E7-400, Diesel, I50, MOUDI, Mass Concentration, Carbon Analysis, Organic vs. Elemental Carbon

3.157 Mack E7-400, Diesel, MOUDI, Mass Concentration, Organic Carbon, Effects of Engine Operating Conditions

3.158 Mack E7-400, Diesel, MOUDI, Mass Concentration, Elemental

Carbon, Effects of Engine Operating Conditions

3.159 Mack E7-400, Diesel, MOUDI, Mass Concentration, Total Carbon, Effects of Engine Operating Conditions

3.160 Mack E7-400, Diesel, MOUDI, Mass Fraction, Organic Carbon, Effects of Engine Operating Conditions

3.161 Mack E7-400, Diesel, MOUDI, Mass Fraction, Elemental Carbon, Effects of Engine Operating Conditions 
NOMENCLATURE

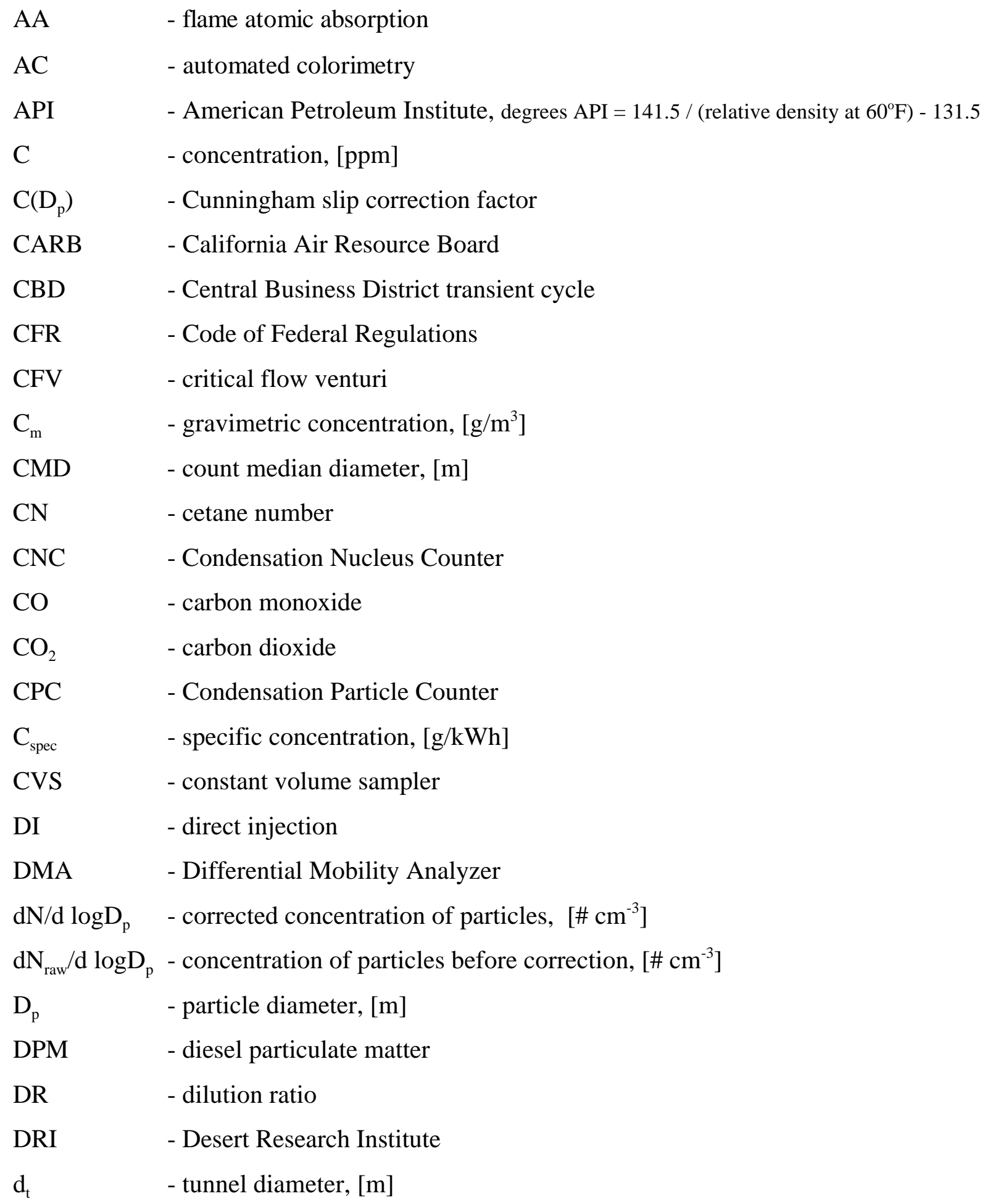




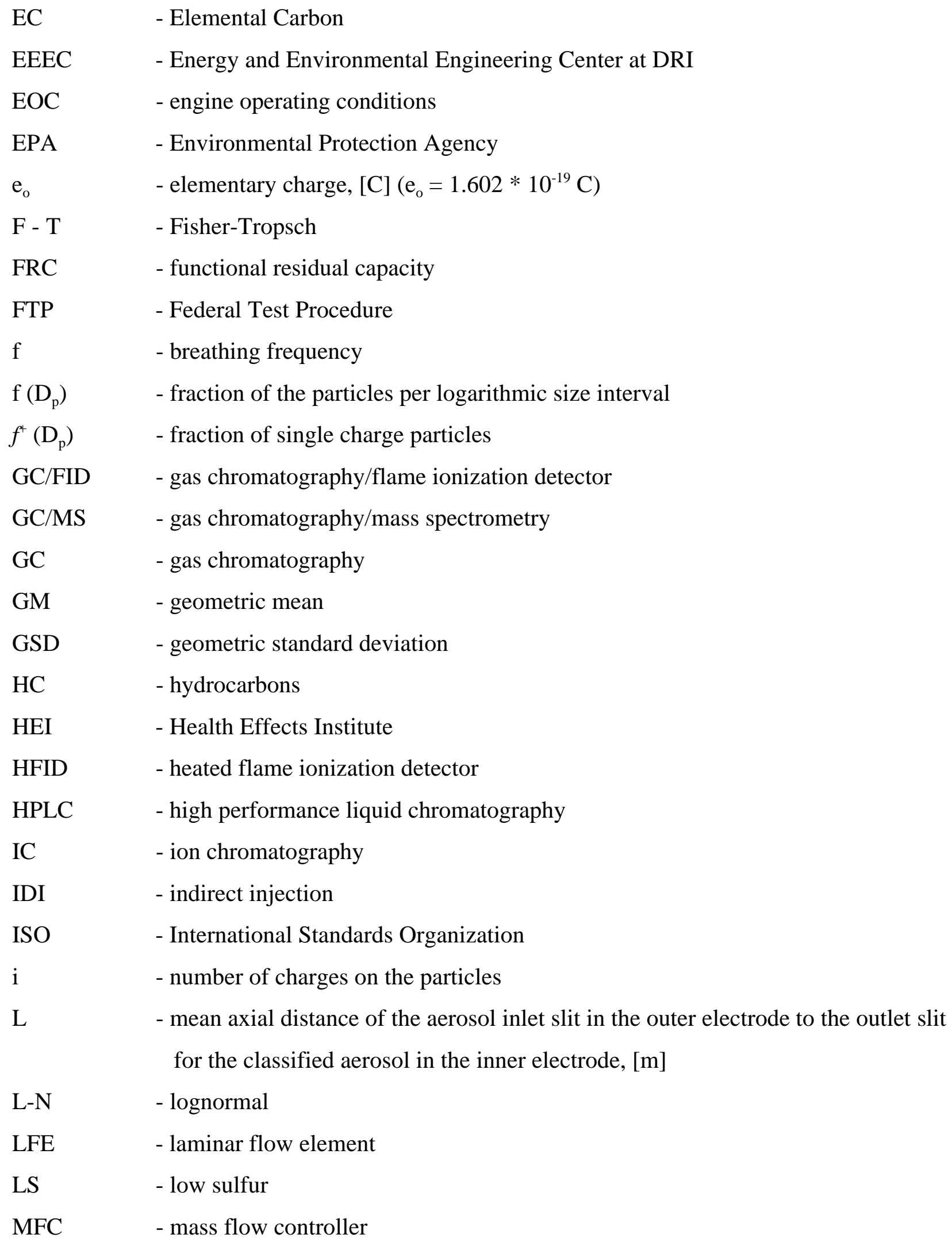




\begin{tabular}{|c|c|}
\hline MIR & - maximum incremental reactivity \\
\hline MMD & - mass median diameter, $[\mathrm{m}]$ \\
\hline MOR & - maximum ozone reactivity \\
\hline MOUDI & - Microorifice Uniform Deposit Impactor \\
\hline $\mathrm{N}$ & - total particle number, $[\sim]$ \\
\hline NDIR & - non-dispersive infrared \\
\hline NIST & - National Institute of Standards and Technology \\
\hline NMHC & - non-methane hydrocarbons \\
\hline NMOG & - non-methane organic gases \\
\hline NO & - nitric oxide \\
\hline $\mathrm{NO}_{2}$ & - nitrogen dioxide \\
\hline $\mathrm{NO}_{\mathrm{x}}$ & - oxides of nitrogen \\
\hline $\mathrm{n}$ & - number of particle charge \\
\hline $\mathrm{OC}$ & - organic carbon \\
\hline $\mathrm{P}$ & - pressure \\
\hline PAH & - polynuclear aromatic hydrocarbons \\
\hline PM & - particulate matter \\
\hline ppm & - parts per million \\
\hline PUF & - polyurethane foam \\
\hline Q & - volumetric flow rate, $\left[\mathrm{m}^{-3} \mathrm{~s}^{-1}\right]$ \\
\hline $\mathrm{Q}_{\mathrm{a}}$ & - volumetric flow rate of polydisperse aerosol, $\left[\mathrm{m}^{-3} \mathrm{~s}^{-1}\right]$ \\
\hline $\mathrm{Q}_{\mathrm{da}}$ & - volumetric flow rate of dilution air at standard conditions, $\left[\mathrm{m}^{-3} \mathrm{~s}^{-1}\right]$ \\
\hline $\mathrm{Q}_{\mathrm{e}}$ & - volumetric flow rate of the raw exhaust at standard conditions, $\left[\mathrm{m}^{-3} \mathrm{~s}^{-1}\right]$ \\
\hline $\mathrm{Q}_{\mathrm{ex}}$ & - volumetric flow rate of the excess gas flow (excess air), $\left[\mathrm{m}^{-3} \mathrm{~s}^{-1}\right]$ \\
\hline $\mathrm{Q}_{\mathrm{m}}$ & - volumetric flow rate of monodisperse aerosol, $\left[\mathrm{m}^{-3} \mathrm{~s}^{-1}\right]$ \\
\hline $\mathrm{Q}_{\mathrm{s}}$ & - volumetric flow rate of the sample at standard conditions, $\left[\mathrm{m}^{-3} \mathrm{~s}^{-1}\right]$ \\
\hline $\mathrm{Q}_{\mathrm{sh}}$ & - volumetric flow rate of the clean gas flow (sheath air), $\left[\mathrm{m}^{-3} \mathrm{~s}^{-1}\right]$ \\
\hline$Q_{t}$ & - volumetric flow rate of diluted exhaust at standard conditions, $\left[\mathrm{m}^{-3} \mathrm{~s}^{-1}\right]$ \\
\hline $\mathrm{R}_{1}$ & - outer radius of inner electrode, $[\mathrm{m}]$ \\
\hline $\mathrm{R}_{2}$ & - inner radius of outer electrode, $[\mathrm{m}]$ \\
\hline
\end{tabular}




\begin{tabular}{|c|c|}
\hline $\operatorname{Re}$ & - Reynolds number, $\operatorname{Re}=\mathrm{v} \mathrm{d}_{\mathrm{t}} / \mathrm{v}$ \\
\hline RH & - relative humidity \\
\hline $\mathrm{rpm}$ & - revolutions per minute \\
\hline SAE & - Society of Automotive Engineers \\
\hline SFE & - supercritical fluid extraction \\
\hline SMPS & - Scanning Mobility Particle Sizer \\
\hline SOF & - soluble organic fraction \\
\hline SOP & - standard operating procedure \\
\hline SwRI & - Southwest Research Institute \\
\hline $\mathrm{T}$ & - temperature \\
\hline TC & - total carbon \\
\hline TEOM & - Tapered Element Oscillating Microbalance \\
\hline TPM & - total particulate matter \\
\hline $\mathrm{T}_{\mathrm{r}}\left(\mathrm{D}_{\mathrm{p}}\right)$ & - DMA transfer function \\
\hline $\mathrm{U}$ & - potential difference between the inner and outer electrode, [Volts] \\
\hline $\mathrm{V}$ & - total particle volume, $\left[\mathrm{m}^{3}\right]$ \\
\hline $\mathrm{v}$ & - velocity, $\left[\mathrm{m} \mathrm{s}^{-1}\right]$ \\
\hline WVU & - West Virginia University \\
\hline $\mathrm{Z}_{\mathrm{p}}$ & - electrical mobility of a spherical charged particle, $\left[\mathrm{m}^{2} \mathrm{~V}^{-1} \mathrm{~s}^{-1}\right]$ \\
\hline $\mathrm{Z}_{\mathrm{pc}}$ & - mean electrical mobility of the classified particles, $\left[\mathrm{m}^{2} \mathrm{~V}^{-1} \mathrm{~s}^{-1}\right]$ \\
\hline$\Delta \mathrm{Z}_{\mathrm{p}}$ & - mobility range of the particles classified using DMA, $\left[\mathrm{m}^{2} \mathrm{~V}^{-1} \mathrm{~s}^{-1}\right]$ \\
\hline$\epsilon_{\mathrm{CPC}}$ & - counting efficiency of the condensation particle counter \\
\hline$\epsilon_{\mathrm{IMP}}$ & - efficiency of impactor at entrance to the electrostatic classifier \\
\hline$\lambda$ & - gas mean free path, $[\mathrm{m}]$ \\
\hline$v$ & - kinematic viscosity, $\left[\mathrm{m}^{2} \mathrm{~s}^{-1}\right]$ \\
\hline$\sigma_{\mathrm{G}}$ & - geometric standard deviation of the distribution \\
\hline
\end{tabular}




\subsection{INTRODUCTION}

Continuous expansion of the use of diesel engines in light-duty and heavy-duty vehicles and the uncertainties associated with the effects of exhaust emissions on human health have focused attention on risk assessments of diesel engine exhaust. The complexity of chemical and physical composition of diesel exhaust emissions makes the assessment a very daunting task. Particulate matter (PM), organic compounds such as unburned or partially burned hydrocarbons ( $\mathrm{HC})$, oxides of nitrogen ( $\mathrm{NO}$ and $\mathrm{NO}_{2}$ - collectively known as $\mathrm{NO}_{\mathrm{x}}$ ), carbon monoxide $(\mathrm{CO})$, and sulfur oxides are recognized as major pollutants in diesel engine exhaust emissions. Particulate matter, organic compounds and carbon monoxide are primary products of the fuel combustion process. However, nitrates and sulfates are formed as a result of post combustion and post tailpipe reactions and therefore, not considered as direct products of combustion. Inorganic constituents of diesel exhaust such as metals, acids and salts are also among the chemical constituents hypothesized to be toxic.

Diesel particulate matter consists mainly of agglomerated solid carbonaceous material and ash, and volatile organic and sulfur compounds. Diesel PM particle diameter ranges from $5 \mathrm{~nm}$ to $1 \mu \mathrm{m}$, depending on engine design and operating conditions. Two distinct modes characterize PM distribution, agglomeration and nucleation mode. Most of the particle mass is in agglomeration mode $(50 \mathrm{~nm}$ to $1 \mu \mathrm{m})$. Agglomeration mode consists mainly of carbonaceous agglomerates and adsorbed volatile compounds. The nuclei mode contains the majority of the particle number but does not contribute significantly to the total PM mass. Particles in the nuclei mode are mostly volatile organic and sulfur compounds. More commonly, atmospheric particles are classified according to their size as nano-particles $\left(D_{p}<50 \mathrm{~nm}\right)$, ultrafine particles $\left(D_{p}<100 \mathrm{~nm}\right), \mathrm{PM}_{2.5}$ or fine particles $\left(D_{p}<2.5 \mu \mathrm{m}\right)$, and $\mathrm{PM}_{10}\left(\mathrm{D}_{\mathrm{p}}<10 \mu \mathrm{m}\right)$. The size distribution of diesel PM is an important factor

because of potential health impact on human health. Diesel PM size distribution indicates the ability of the particles to be inhaled and eventually trapped in the slow-cleared regions of the human lungs. Some recent epidemiological studies suggest a weak correlation between elevated particulate matter concentration in ambient air and cardiopulmonary health effects. Using statistical methods, these epidemiological studies have shown that the daily mortality and morbidity correlate with long-term 
exposure to increased particulate matter level $\left(\mathrm{PM}_{10}\right)$. The correlation is even stronger for smaller particles combustion generated particles $\left(\mathrm{PM}_{2.5}\right)$. Mortality is mostly due to respiratory and cardiac problems. It occurs mostly among elderly individuals, presumably those having pre-existing respiratory and cardiac disorders. Morbidity is most significant for respiratory conditions (HEI, 1999).

Hydrocarbons, one of the major organic pollutants in diesel exhaust, are emitted as particulate matter bound heavier organics and gaseous compounds. The phase of hydrocarbons in diesel exhaust depends on molecular weight, temperature and concentration and is expressed as a partition coefficient, which is the ratio of the mass of compound in the particulate phase to the mass of compound in the vapor phase. Higher molecular weight and some intermediate molecular weight compounds known as soluble organic fraction (SOF) are adsorbed on the particulate matter. Linearand branched- chain hydrocarbons with 14 to 35 carbon atoms, polynuclear aromatic hydrocarbons (PAH), alkylated benzenes, nitro-PAHs, and variety of polar, oxygenated PAH derivatives are common particulate bound compounds. These compounds are of particular concern because several of them have shown carcinogenicity and mutagenicity, as reported in various laboratory studies. Some of the vapor phase compounds which could potentially affect human health include formaldehyde, methanol, acrolein, benzene, 1,3-butadiene and low molecular weight PAHs and their oxygenated and nitrated derivatives. Aldehydes, generated by partial oxidation of hydrocarbons, have a very high maximum incremental and hence contribute to smog formation. Hydrocarbons, when emitted into the troposphere in the presence of oxides of nitrogen $\left(\mathrm{NO}_{\mathrm{x}}\right)$ contribute to the photochemical formation of ozone. Ground level ozone or tropospheric ozone, the main harmful ingredient in smog, is classified as secondary pollutant and presents an important air quality problem in many urban areas. Ozone has been reported to cause throat irritation, congestion and chest pains. Another public health concern is that prolonged exposure to ozone might damage the airways and contribute to the development of noncancerous respiratory diseases.

Diesel particulate matter and hydrocarbons have raised a host of health and environment concerns and have gained considerable attention of researchers and various regulatory agencies. The California Air Resources Board, after a near-decade long scientific investigation into the health effects of exposure to the fine particles and other pollutants in diesel exhaust, identified particulate emissions from diesel-fueled engines as toxic air contaminants (CARB, 1999). Current 
particulate matter emissions legislation is based on the total mass of particulate matter emitted (per mile or Bhp-hr) while air quality standards are based on mass per unit volume. Neither of these contains a reference to size of the particles or to the number concentration of particles emitted. Gravimetric analysis of PM is non-specific with respect to the chemical composition and the aerosol properties and, hence, delivers no toxically relevant information. The HC emissions legislation is based on the total hydrocarbon emissions and does not give enough importance to the aforementioned aspects.

The impact of inorganic constituents of diesel exhaust on mortality and morbidity has been the subject of numerous epidemiological and toxicological studies (Mauderly et al. 1995) and should not be underestimated. Transitional metals can cause production of hydroxyl radicals which are considered toxic products. Residual oil fly ash is also toxic to cells and lungs. A wide range of inorganic and organic sulfur and nitrogen compounds has irritating, cytotoxic, and mutagenic properties. Evidence from studies with animals (Schlesinger, 1995) indicates that nitrates, sulfates and sulfuric acid particles impair pulmonary functions such as mucociliary clearance and airway resistance.

\section{Objectives}

The first step toward assessing potential health hazard with exposure to the diesel exhaust is detailed characterization of the size-resolved diesel particulate matter emissions from inuse heavy-duty diesel engines. The formation and transformation of particulate matter in the exhaust is vary dynamic and complex process. The nature of particulate matter emissions from diesel engines is dependent on parameters such as measurement process engine type, engine condition, fuel type, and exhaust after-treatment process. The objective of this experimental study was to explore those parameters and obtain detailed characterization of particulate matter and hydrocarbon emissions from in-use heavy-duty diesel engines and vehicles. To achieve this objective, it was imperative to design and build sampling systems and establish procedures and methodologies for size-selective measurements of particulate matter, size-resolved chemical analysis of particulate matter, and speciation of particulate bound, semi-volatile and volatile components of diesel exhaust. Sampling systems and test procedures were developed to permit an investigation of the various parameters that 
influence size-selective measurements of diesel exhaust particle matter as well as effects of fuel types, driving cycles and after-treatment devices on size distribution of the diesel exhaust particles. The second goal of the study was to conduct a size-resolved chemical characterization of diesel particulate matter. The aim was to identify the content of the elemental and organic carbon and also to analyze the inorganic compounds in size-classified diesel particulate matter. This exercise was undertaken to further our understanding of physical and chemical processes leading to formation of diesel exhaust particulate matter from a variety of emission source categories and assist in evaluating the potential health impacts. The objective of the speciation component of the study was to determine mass emissions of individual organic compounds from heavy-duty engines and apply the maximum incremental reactivity (MIR) scale to speciated emissions data in order to determine their theoretical ozone-forming potential under different vehicle/engine operating conditions. To achieve these objectives, it was necessary to:

i Design, build, and qualify a transportable system for sampling and analysis of exhaust particulate matter size distributions. A mini-dilution tunnel and the associated sampling devices had to be incorporated into a single mobile system. This system will be referred to as partial flow dilution tunnel sampling system in the rest of the text;

ii Obtain reliable and repeatable measurements of concentrations and size-distribution of particulate matter from in-use heavy-duty diesel vehicles/engines using mini-dilution system for steady-state and transient engine operating conditions;

iii Make a comparative study on the results obtained through simultaneous sampling with a Scanning Mobility Particle Sizer (SMPS) and the Micro Orifice Uniform Deposit Impactor (MOUDI). It is understood that the SMPS provides a number concentration using electrical mobility diameter of the particle and the MOUDI does a size classification based on the aerodynamic diameter and gives a mass weighted distribution. This would help in gaining insight in the performance of the sampling systems and two different techniques for size selective measurement;

iv Study influence of dilution ratio on size-selective PM measurements;

v Study the effects of fuel, driving modes and after-treatment devices on size-resolved PM emissions from in use heavy-duty diesel vehicles/engines; 
vi Use actual measurement data to assess regional deposition of DPM in the human respiratory tract;

vii Establish the procedure for collecting PM samples in order to provide size-resolved chemical analysis of diesel exhaust particulate matter from in-use heavy-duty vehicles;

viii Provide size-resolved analysis of elemental and organic carbon fractions, metals, acids and salts;

ix Design, build and qualify a transportable sampling system for the specition of particulate bound, semi-volatile and volatile components of diesel exhaust. This system will be referred to below as the speciation sampling system;

$\mathrm{x} \quad$ Perform a qualitative and quantitative analysis of heavy-duty diesel engine/vehicle hydrocarbon emissions and report ozone forming potential (mg/Bph-hr) for different vehicle/fuel/test mode combinations. 


\subsection{LITERATURE REVIEW}

\section{1. Size Selective Measurement of Diesel Particulate Matter}

Fine particles in urban environments are mainly the result of fossil fuel combustion in mobile sources such as motor vehicles and in stationary sources such as power plants. Hilderman et al. (1991) estimated that direct emissions from diesel- and gasoline-powered vehicles contributed $21 \%$ of the fine aerosol organic carbon emissions in Los Angeles in 1982. A modeling study (Lowenthal et al., 1994) in Phoenix showed that motor vehicle emissions from spark-ignition and compression-ignition powered vehicles accounted for about $40 \%$ of $\mathrm{PM}_{10}$ during the winter of 19891990. In addition to direct emissions of particulate matter, the combustion sources emit gaseous pollutants that are subsequently converted in the atmosphere into fine particles, such as sulfate and acid aerosols.

Diesel particulate matter is considered a potential human health hazard because of its chemical composition and size. The soluble organic fraction (SOF) compounds adsorbed on the surface of the particles, particularly the polynuclear aromatic hydrocarbons (PAH) and the nitroPAH, significantly contribute to the overall particulate matter carcinogenic effects. Recent studies (Donaldson, 1994 ) showed that the diesel particles themselves, stripped of the organic compounds and other materials on the surface, may also be carcinogenic. The biochemical research published by Donaldson (1994) also suggests that particles smaller than $100 \mathrm{~nm}$ in diameter are toxic by virtue of their size and cause stress of the epithelial cells lining the lung, which in some cases has lead to lung irritation and inflammation. According to the study, the deposition of given material in the lung and toxicity vary conversely with particle size. This is due to a better penetration into the cell, greater surface area, and more rapid dissolving of the finer particles (Mauderly et al., 1995). The

Health Effects Institute (HEI, 1999) verified these conclusions. Several studies (Ferin, 1992; Donaldson, 1994 ) conducted on rats suggest that the small respirable soot particles in diesel exhaust are primarily responsible for lung cancer developing in rats that were exposed to high concentration of diesel emissions, and that at high particle concentrations the mutagenic compounds adsorbed onto the soot play a lesser role, if any, in tumor development in this species.

Diesel particulate matter is essentially sub-micrometer in diameter. The count and mass distributions appear to have a unimodal or bimodal log-normal form (Pataky et al., 1994; 
Rickeard et al., 1996) depending on engine type and test conditions. Kerminen et al. (1997) reported trimodal size distributions fitted to results of cascade impactor measurements. Generally, three modes can be expected (Kittelson et al., 1999), specifically the nuclei, the agglomeration and the coarse mode, but they might not always be distinct. The nuclei mode contains particles with diameters ranging from 5 to $40 \mathrm{~nm}$ (Pataky et al.,1994; Rickeard et al.,1996; Abdul-Khalek et al., 1998; Kittelson et al., 1999) and volume diameters 0.0075 to $0.056 \mu \mathrm{m}$ (Pataky et al.,1994) depending on the engine test mode and after-treatment devices. The chemical composition and mechanism of generation of particles in the nuclei mode is still the subject of research. The agglomeration (accumulation) mode with a count diameter of 30 - $40 \mathrm{~nm}$ (Abdul-Khalek et al., 1998) and the volume diameter of 0.056 to $1.0 \mu \mathrm{m}$ (Pataky et al., 1994; Kittelson et al., 1999) typically consists of agglomerates formed by coagulation during the expansion stroke of primary carbonaceous nuclei generated early in the exhaust. The coarse mode contains particles with volume diameter of $1 \mu \mathrm{m}$ to $10 \mu \mathrm{m}$ and 5 to $20 \%$ of the particle mass (Kittelson et al., 1999).

Particle morphology studies showed that particle shape is very size dependable. Smaller size particles (nucleation mode) are predominantly monodisperse single spheres, while large particles (agglomeration mode) are typically nonuniform agglomerates (Dolanet al., 1980). Treating particles as amorphous agglomerates with nonuniform density makes the problem of particle size classification extremely complicated. Therefore, when dealing with particles of unknown morphology and density, it is common practice to express their behavior in aerosol samplers in terms of an equivalent diameter. The amorphous particles are then related to spheres through particle density and dynamic shape factor. Several different equivalent diameters are defined in literature. An electrostatic classifier classifies particles according to their mobility equivalent diameter. The mobility equivalent diameter is the diameter of a sphere that has the same dynamic mobility as the particle in question. As inertial impactor, MOUDI classifies particles according to their aerodynamic equivalent diameter. The aerodynamic equivalent diameter is the diameter of a unit density sphere which settles at the same speed as the particle.

Density plays an important role in determining particle transport properties. In order to convert the size distribution data, that are collected using instruments based on inertial classification (aerodynamic diameter), into the geometric size distribution and to be able to compare results obtained using different techniques, it is necessary to account for the effects of density. 
Estimating particle density from measurements of chemical composition can lead to errors because particles often consist of complex mixtures of species and phases (Kelly and McMurry, 1992). Kelly and McMurry (1992) developed a technique using a DMA and an impactor for measuring submicrometer particle density. The authors also introduced the term effective particle density $\left[\mathrm{C}\left(\mathrm{d}_{\mathrm{m}}\right) /\left(\mathrm{C}\left(\mathrm{d}_{\mathrm{b}}\right) \chi\right]^{3} \rho_{\mathrm{p}}\right.$, where $\mathrm{C}\left(\mathrm{d}_{\mathrm{m}}\right)$ is the slip correction factor based on mass equivalent diameter, $C\left(d_{b}\right)$ slip correction factor based on mobility equivalent diameter, $\chi$ the shape factor and $\rho_{p}$ the density of the particle. They successfully measured the density of spherical shaped laboratory aerosols like DOP, $\mathrm{H}_{2} \mathrm{SO}_{4}$ and $\left(\mathrm{NH}_{4}\right)_{2} \mathrm{SO}_{4}$. The irregular shape and nonhomogeneous composition of diesel exhaust particles makes determination of effective particle density almost impossible. The dynamic nature of processes governing the formation and transformation of particulate matter make the concept of effective particle density inadequate for diesel exhaust particles. For this reason, diesel exhaust particles have been treated in this study as spheres of unit density.

\subsubsection{Sampling Methodology and Instrumentation}

Diesel exhaust aerosols are a highly dynamic system. Particles may change size, mass, and composition as a result of aging, heating, cooling, and dilution. Coagulation, nucleation, condensation, evaporation, adsorption, desorption, and filter/substrate related gas-to-particle conversion are some of the processes that influence diesel aerosol measurements. Since numerous physical and chemical processes influence the sampling of diesel exhaust, obtaining representative samples and interpreting results requires meticulous care and close consideration of all parameters.

The importance of iso-axial and iso-kinetic sampling in obtaining the representative aerosol samples is underlined by many authors (Hinds, 1982; Willeke and Baron, 1993). Non-isokinetic sampling errors and particle deposition in bends and contractions result from the inability of particles, due to their inertia, to follow fluid streamlines. Ahlvik et al.(1998) studied the effects of non-iso-kinetic sampling and found that penetration (above 95 percent) of the majority of diesel particles is satisfactory even for non-iso-kinetic conditions. Flow velocity plays a very important role in any sampling procedure. It is important to maintain a sufficiently small Stokes number $\left(\tau \mathrm{U}_{\mathrm{o}} / \mathrm{D}_{\mathrm{p}}\right)$ in the sampling system, since the particles above a critical Stokes number will not accurately follow the fluid. Sampling inlets with larger diameters are less susceptible to deposition 
caused by free steam turbulence. Gravitation settling velocities cause inertial losses but they are quite small for 0.001 to $1.0 \mu \mathrm{m}$ diameter range particles typical of diesel exhaust. Diffusion may cause particles to be lost through the boundary layer to the walls of sampling system. Diffusion is important for particles with diameters less than $0.05 \mu \mathrm{m}$. Turbulent deposition results from the particles being thrown from turbulent eddies, through the laminar sub-layer into the wall. The turbulent deposition depends upon the inertia of the particles and is not important for particles smaller than several $\mu \mathrm{m}$ in diameter and does not effect the combustion generated particles. Particles also experience phoretic forces when they are exposed to either temperature or concentration gradients. Thermophoretic force is exerted on the particles when a temperature gradient is present in the surrounding gas. This force tends to drive the particles down the temperature gradient. In general it can be stated that for typical insulated raw exhaust lines and dilution tunnels operating at dilution ratios in order of 10:1, thermophoresis could be responsible for 1-2\% deposition loss of fine particles (Ahlvik et al.,1998). Diffusiophoretic force is exerted on particles when a concentration gradient is present in the surrounding gas. Diffusiophoretic force does not play a very important role in diesel exhaust sampling because of relatively smaller concentration gradients.

The dilution process plays an important role in measuring diesel exhaust aerosols by affecting the saturation ratio, temperature and volatile fractions of diluted exhaust. In steady-state and transient testing of engines and vehicles, a dilution tunnel is the most frequently used concept for diluting the exhaust. The dilution tunnels are used to reproduce environmental aerosol conditions in the laboratory. Dilution air lowers the sampling zone and filter face temperature and attenuate flow rate fluctuations inherent in exhaust. The dilution process considerably affects the particulate matter measurements and presents potential source for artifact generation (Kittelson and Johnson, 1991; Kayes and Hochgreb, 1998; Kittelson et al., 1999; Maricq et al., 1999). On the other hand, the dilution air decreases particle concentration making it difficult to collect enough mass for accurate measurements. In order to obtain a sufficiently large PM sample from a clean engine, while still complying with the peak temperature limits, it is imperative to use highly non-adiabatic dilution (Kittelson and Johnson, 1991). Cooling by dilution is also desirable in order to minimize thermophoretic deposition. Dilution of the exhaust can be obtained in one or two stages. The primary dilution ratio is defined as the ratio of the standard volumetric flow of diluted sample in the primary tunnel to the standard volumetric flow of exhaust. The secondary dilution ratio is the ratio 
of the mass flow rate exiting the tunnel and the sample entering it. The Federal Test Procedure ( 40 CFR part 86, Subpart N, 1994) specifies the use of a full-flow constant volume sampler (CVS) dilution system for testing heavy-duty diesel engines. The role of dilution air, per the Federal Test Procedure is to lower the temperatures of the diluted exhaust in the primary mixing zone and at filter face to $375^{\circ} \mathrm{F}$ and $125^{\circ} \mathrm{F}$, respectively.

A partial-flow dilution tunnel is an alternative to full flow dilution tunnel for diluting and sampling diesel engine emissions. Some of the advantages of partial-flow dilution tunnel include smaller size and lower capital cost. These characteristics also make them suitable for transportable sampling systems. Accurate determination of the partial exhaust sample is a major problem associated with application of partial-flow dilution tunnel (Miller, 1997). Partial dilution tunnels are an accepted method for measurement of particulate emission from heavy duty diesel engines in Europe and Japan. These standards and regulations define a sequence of steady-state setpoints for the steady-state cycle. Partial dilution systems are not accepted by any standard or regulation for transient measurements of gaseous and particulate matter emission measurements. There are four basic types of partial-flow dilution tunnels: iso-kinetic, single venturi, twin venturi, and multi-tube type.

Mayer et al. (1995) compared size distribution of diesel particulate matter for different particulate trap systems. They employed an iso-kinetic type partial dilution tunnel, the Smart Sampler manufactured by AVL, for integral and size-selective measurements of PM. The Swiss Federal Material Testing Labs estimated that the total scatter in the particulate measurements with the Smart Sampler system, including engine emission scatter, to be approximately $\pm 15 \%$. Engeljehringen and Schindler (1997) carried out a series of tests to compare the partial-flow dilution system AVL SPC 472 to full-flow CVS system. They found that the mass-flow controlled partialflow dilution system, which was controlled by intake air or exhaust flow signals, also gave reliable particulate results for transient test cycles within the acceptable accuracy. The system can also be applied for measurement of gaseous emissions. The authors conducted simultaneous measurements on the partial-flow dilution tunnel and the CVS full-flow dilution tunnel and reported agreement within $3 \%$.

The most popular instruments in combustion engine particulate matter size-selective measurements are low pressure impactors (MOUDI, Hering, Berner), Electrical Aerosol Analyzer 
(EEA), Scanning Mobility Particle Sizer (SMPS) and the Electric Low Pressure Impactor (ELPI). These instruments, which were originally developed for ambient aerosol applications are successfully applied by numerous researchers in the sampling of diluted IC engine exhaust. Devices based on light extinction have recently become of interest to researchers because of their excellent time response, relative simplicity, and low cost, but they are unable to measure soluble fractions and have a somewhat poor sensitivity to low soot mass concentrations (Hofeldt and Chen, 1996). Tapered Element Oscillating Microbalance (TEOM) is designed for analyzing real-time particulate total mass. A review of the most recent studies on size selective measurements of PM and used instrumentation is given below.

Marple et al. (1991) used MOUDI to measure aerosol size distribution in underground coal mines using diesel-powered equipment. The data indicate a bimodal distribution with the lower and upper modes consisting of diesel exhaust particles and coal dust, respectively.

Hildermann et al. (1991) sampled emissions from 13 gasoline fueled automobiles under transient (FTP) and steady-state driving conditions (idle, $40 \mathrm{~km} / \mathrm{h}$, and $90 \mathrm{~km} / \mathrm{h}$ ) and two heavy-duty trucks operated on a customized transient cycle. All size distribution and particle concentration measurements were conducted using an EAA. The authors stressed the complexity of the aerosol formation processes in automotive exhaust emissions. They found that gasoline noncatalyst vehicles had PM emission rates 10-30 times higher than most tested catalyst vehicles. A uni-modal distribution with a peak between 0.1 and $0.3 \mu \mathrm{m}$ was observed for most gasoline vehicles. Bimodal distribution was observed just for several of the catalyst-equipped automobiles. The submicron aerosol mass distribution for diesel showed a single mode with peak around $200 \mathrm{~nm}$. The integration of the emission rate measured by EAA resulted with comparable mass to that determined by gravimetric analysis.

Hammerle et al. (1994) measured emissions from five European diesel passenger cars using the European Motor Vehicle Emissions Group (MVEG) cycle and the U.S. Federal (FTP 75) test procedure. The particle size distribution from these vehicles was measured using the Electrical Aerosol Analyzer (EEA). The samples were collected in a bag and then measured. The number distribution exhibited a bi-modal character, but the volume distribution did not. The observed PM distributions were characterized by the nuclei mode containing particles from $13 \mathrm{~nm}$ to $42 \mathrm{~nm}$ diameter, and the accumulation mode containing particles from $75 \mathrm{~nm}$ to $750 \mathrm{~nm}$. They found that 
about $60 \%$ of particles were in the nuclei mode for naturally aspirated engines, and $30 \%$ to $50 \%$ for turbocharged engines.

Mayer et al. (1995) measured particle size distribution in the exhaust of the off-road engine employing partial dilution tunnel. The count median diameter of the raw exhaust emissions was at $100 \mathrm{~nm}$. There were few particles larger than $200 \mathrm{~nm}$.

Fanick et al. (1996) measured particle size distribution in the exhaust of a flexible fuel vehicle operated on five different fuels with a Sierra Series 220 In-Stack Cascade Impactor using a $0.95 \mathrm{~cm}$ internal iso-kinetic sampling nozzle. The particles in range from $200 \mathrm{~nm}$ to $3 \mu \mathrm{m}$ were collected on stainless steel substrates. The last stage was followed by fluorocarbon-coated glass fiber filter to collect particles below $200 \mathrm{~nm}$. Those experiments with a spark-ignited engine showed that at a stoichometric fuel/air equivalence ratio particle size range contained about $65 \%$ of the mass was less than about $200 \mathrm{~nm}$., and next largest percentage (about 26\%) of particle cutoff diameter was in the 2 to $3 \mu \mathrm{m}$ range.

Rickeard et al. (1996) studied the influence of vehicle and fuel on exhaust particulate size distribution by performing tests on European diesel light-duty vehicles using a range of production diesel fuels. The results obtained on the diesel vehicles were compared with simultaneously tested gasoline vehicles. Quartz Crystal Microbalance (QCM) Cascade Impactor and SMPS were used for size-selective measurements. The mass recovery of the QCM was found to be very low, because this type of instrument is susceptible to diffusion-based losses of particles with aerodynamic diameters smaller than $500 \mathrm{~nm}$. For this reason the authors considered only the results obtained from the SMPS. The SMPS was employed for steady-state (idle, $50 \mathrm{~km} / \mathrm{h}$ and $120 \mathrm{~km} / \mathrm{h}$ ) and transient engine operating conditions (ECE+EUDC driving cycle). The count median diameter for steady state vehicle operating conditions ranged from 70 to $100 \mathrm{~nm}$, with a tendency for larger particles at the highest test speed. For certain test conditions, some of the vehicles showed a second peak in the distribution at a smaller size range, around $40 \mathrm{~nm}$. Transient size selective measurements were performed for five discrete sizes, namely 25, 50, 100, 200, and $400 \mathrm{~nm}$. The largest number of particles was collected at the $100 \mathrm{~nm}$. Particles emissions were highest under accelerating and high speed conditions. The variation in diesel fuel quality had no systematic effect on the median size of particulate matter emissions. Hence, the authors concluded that size selective measurements 
did not introduce any new factor in evaluating relative fuel performance. The car equipped with a three-way catalyst produced very low emissions both in terms of particle mass and particle number.

Greenwood et al. (1996) used a 0.20 m full-flow dilution tunnel with a dilution ratio of about 20 and for size-selective measurements of PM from a number of diesel, gasoline and compressed natural gas fueled vehicles. The vehicles were tested on a chassis dynamometer. The inertial settling was selected according to the European 93/59/EC Type I test procedure. The tested diesel vehicles were a small passenger car with a naturally aspirated IDI engine and a medium sized turbo-charged IDI diesel truck with a catalyst. The results showed that the both vehicles produced similar-shaped distributions (unimodal). However, the normally aspirated engine produced a substantially higher concentration of particulate matter. The diesels also produced significant quantities of particulate matter under idle operation. The count median diameters were in the range 70 - $90 \mathrm{~nm}$ for naturally aspirated diesel and 50 - $60 \mathrm{~nm}$ for the turbo charged diesel equipped with catalyst. The size of particulate matter emitted at idle was significantly smaller with count median diameters of 32 and $46 \mathrm{~nm}$, respectively. The authors found that the particulate diameter reach a maximum in the medium power range before decreasing again. Gasoline and compressed natural gas (CNG) fueled vehicles were also tested. The gasoline engine produced much lower particulate concentration than the diesel, particularly at low and medium power. The distribution was bimodal in nature. The particulate numbers at high power were similar to those seen in the diesel experiments. The natural gas vehicles produced few particles at low load. At high load, the distributions were very narrow and had peak values in order of magnitude higher than for diesel and gasoline. This allowed the total number of particulates under the distributions to be quite significant even in comparison to the diesel and gasoline vehicles.

Dickens et al. (1997) evaluated the performance of currently available aerosol instrumentation that is used for characterization of vehicle particulate emissions. They reported good repeatability in SMPS and ELPI data. The authors recommend SMPS as an excellent instrument for steady state testing, and good for near-real time testing. They found that the ELPI number concentrations were on an average $24 \% \pm 6 \%$ of the SMPS measured concentrations and ELPI measured mean particle diameters were much larger than those measured by the SMPS. This was attributed to different measurement principles that are adopted by the two instruments. 
Kerminen et al. (1997) used a chassis dynamometer, full-flow dilution tunnel and a constant volume sampler to test a turbo charged diesel passenger car. Particles were collected with a Berner low-pressure impactor. Submicron diesel-particle mass size distribution displayed three log-normal modes that were centered at $0.09,0.2$, and $0.7-1.0 \mu \mathrm{m}$ of particle aerodynamic diameter and that had average geometric standard deviation of 1.34, 1.61, and 1.34. The first two modes overlapped strongly and had approximately the same mass. The third mode, containing about $10 \%$ of the overall particulate mass, was clearly separated from the two other modes. They estimated that some $80-90 \%$ of the particles were located in mode 1 , with most of the remaining ones being found in mode 2 . The third mode contained less than $0.1 \%$ of the particles.

Abdul-Khalek et al. (1998) performed measurements on the exhaust of a mediumduty, turbocharged and aftercooled direct injection diesel engine using a mini-dilution system. Test modes of C1 8 Mode (R100, R75, R50, R10, I100, I75, I50, idle) schedule and type B Universal 11 Mode schedule (R100, R75, R50, R25, R10, I100, I75, I50, I25, I10, idle) were employed for engine operation. The diluted exhaust streams were characterized using electrical size classification (SMPS and EAA). The bimodal distribution function characterized particles for steady-state 11 Mode test and 8 Mode test used in this study. The nuclei mode contained more than $50 \%$ particles by number and less than $1.5 \%$ by volume. It appeared that the nuclei mode particles emitted by that engine were essentially solid. They also noticed that catalytic converter produced extremely tiny particles with diameters in the 7 to $15 \mathrm{~nm}$ range downstream of the catalyst. These particles are likely to be mainly sulfuric acid.

Ahlvik et al. (1998) used an ELPI and a DMA to perform real time and steady state measurements, respectively, of diesel particle size distributions. Real time measurements were possible due to the instrument's fast time response. The particle size classification of the two instruments was based on different physical principles and direct comparison of the results was the subject of study. The particle effective density values were obtained by fitting ELPI data to DMPS data. Results show a marked decrease in effective density for larger particles. The authors explain this by the fact that small particles are spherical and that the effective density equals the primary particle density. The larger particles are generated by agglomeration of smaller particles. This leads to much lower values of effective density. No reference data were found for the effective density as a function of diameter for realistic exhaust aerosol. The measurements during transient cycles 
showed that during acceleration the number of particles was considerably increased compared to levels at idle. Peak levels of the number of particles during acceleration seemed to increase as the engine warmed up.

Maricq et al. (1999) used both the SMPS and ELPI for transient measurements of particulate matter emissions from a series of recent model gasoline engines. The study reported that is feasible to make reliable and reproducible transient measurements of particle size distributions for gasoline vehicles. The authors used an ELPI and claimed excellent agreement with transient, number weighed, size distributions that were obtained from SMPS measurements. They found that the majority of particles, based on a number weighted distribution, ranged from 10 to $300 \mathrm{~nm}$. The mean diameters for the gasoline test vehicles were found to range from $45-80 \mathrm{~nm}$. The corresponding mass-weighted mean diameters were in the vicinity of $200 \mathrm{~nm}$. The transient particle measurements revealed that spark ignition vehicles emit particles principally during very specific short times, under heavy acceleration.

Graskow et al. (1998) studied exhaust particulate emissions from a spark ignition engine equipped with a catalytic converter. They employed an ejector pump for dilution of a portion of the exhaust, a catalytic striper (Abdul-Khalek and Kittelson, 1995), CNC, and SMPS for sizeselective measurements of PM under steady-state operating conditions. They found that emissions were periodically unstable during the steady-state operating conditions (baseline emissions and unsteady spiking emissions). The authors suggested that the small nanosized particles $(<30 \mathrm{~nm})$, detected in the spikes, were formed through the homogeneous nucleation of gas-phase heavyhydrocarbons. After comparison of the size distribution of PM emissions from gasoline and diesel engines the authors concluded that the mechanism for aerosol formation may be different for these two engines types.

Kauffeldt and Schmidt-Ott (1998) studied the effects of a particulate trap on a diesel engine passenger car exhaust. Integration of the trap in the exhaust system resulted in a significant decrease in particle number for particles greater than $50 \mathrm{~nm}$, but also in a significant increase in particle number for particles smaller than $50 \mathrm{~nm}$. The nuclei mode particles were found to be composed of volatile compounds (SOF and sulfuric acid). They also found that the formation of ultrafine droplets depends strongly on the applied dilution ratio. Those results suggested that the 
ultrafine particle peak would completely vanish in a high traffic situation, where the dilution ratio is higher.

Special Task Force AE/STF-10 (CONCAWE, 1998) conducted a study on the number and mass distribution of PM emitted from diesel and gasoline vehicles under steady-state and transient driving conditions. SMPS, DMPS, EAA, and DMA were employed for PM size distribution measurements. PM size distributions by mass were determined using QCM and Berner low pressure impactor. The size selective PM data were found to have an intrinsically greater variability than the regulated emissions. The impactor results showed 40 to 85 times higher PM mass emissions from diesel than from gasoline vehicles. The authors compared the mass distributions obtained with an impactor and those obtained by converting concentration and size distribution data measured with an SMPS. The authors showed that converting number to mass on the base of assumption on spherical shape of particles resulted in an overestimation of the mass. In terms of mass, more than $85 \%$ of diesel particulate matter was found to be less than $1 \mu \mathrm{m}$. Difference between diesel and gasoline particulate number emissions were much smaller at 120 $\mathrm{km} / \mathrm{h}$ than at $50 \mathrm{~km} / \mathrm{h}$. Fuel effects were found to be less pronounced than vehicle effects. Diesel particulate number distributions for steady state operating conditions were found to be unimodal and lognormal in form, peaking between $80-200 \mathrm{~nm}$. Gasoline particulate number distribution, for same operating conditions, was also unimodal and lognormal, but with well-defined peak at around 30-40 nm. 


\subsubsection{Effects of Dilution Ratio on Size Selective Measurements of Diesel Particulate Matter}

The evidence presented in the published literature shows that variation in the dilution ratio significantly affects the mass and number concentration of particles by changing the adsorption, condensation, and coagulation rates. Ahlvik et al. (1998) experienced a higher number of ultra-fine particles $(<100 \mathrm{~nm})$ during operation of the tunnel at high dilution ratios. In contrast, larger particles (170-1000 nm) increased in number at low dilution, but their number concentration remains several order of magnitude below that of the small particles. The total number concentration was thus higher when higher dilution was applied. The HC adsorption, more likely than condensation (MacDonald et al., 1980 and Reichler et al.,1983), caused significant increase in mass concentration of the collected particles when the dilution ratio factor was reduced. Condensation should not be neglected, specially when heavy hydrocarbon species are present in the exhaust gas. Saturation ratio is the ratio of partial pressure of condensable species to its local vapor pressure. At low values of saturation ratio, an increase in saturation ratio results in an increase in the organic adsorption or so-called heterogeneous condensation. At high values of saturation ratio, new particles may form by homogeneous nucleation. Homogeneous and heterogeneous condensation of hydrocarbons affects both the number and the mass concentration. Dilution ratio also affected the number but not the mass concentration by coagulation. The lower dilution ratio should result in the lower number concentration for the same collected mass of particles. Kittelson et al. (1990) suggested that the effects of dilution ratio on the soluble organic fractions can be estimated from known saturation ratio of representative hydrocarbon as a function of dilution ratio.

Kittelson et al. (1992) studied oxidation of soot agglomerates in a direct injection diesel engine using a mini-dilution tunnel followed by an ejector dilutor. The fresh exhaust was diluted approximately 20 to 60 times in the dilution tunnel, depending on the engine speed/load and sampling orifice used. The size particle distribution was measured using EAA and MOUDI. Samples for MOUDI were taken from the primary dilution. The diluted exhaust was further diluted another 17 times by the ejector dilutor so that the EAA and CNC could be used. The results obtained by two devices were compared upon introducing an assumption that the particles were spherical in shape and had a constant density of $1.0 \mathrm{~g} / \mathrm{cm}^{3}$. The mass concentration calculated from volume, assuming 
constant soot density was relatively greater than measured mass by filtration. Moreover, the total mass obtained by summation of all the MOUDI stages was less than that obtained by filtration. The authors suggested that inter-stage losses were responsible for this phenomena. The authors found that MOUDI results can be considered to be more accurate than EAA results when significant submicron mode exists.

Abdul-Khalek et al. (1998) used the partial iso-kinetic mini-dilution system with the primary and secondary dilution to study the effect of dilution ratio on the number and volume concentration of diesel particulate matter. Ejector pumps were used for primary and secondary dilution of exhaust, providing overall dilution ration ranging from 65 to 3000. For dilution ratio above about 60, number and volume concentrations for their system were essentially independent of dilution ratio. For dilution ratios under 60, number as well as volume concentrations increased with decreasing dilution ratio. Nucleation was favored by the lower dilution ratios and more than likely increased the number concentration in the nuclei mode under those conditions. The authors expected coagulation to have the opposite effect. The authors concluded that dilution ratio effects needed further study.

Klein et al. (1998) investigated diesel particulate mass and their corresponding size distribution on a diesel passenger car at steady state and transient conditions using standard filters and a low pressure cascade impactors (Hauke, LPI 25 and ELPI). The researchers studied the influence of oxidation catalyst volume on particulate size distribution. Two diesel fuels differing in their sulfur content (150 ppm and $2500 \mathrm{ppm} \mathrm{S}$ ) were used for the investigations. The impactor substrates were analyzed for sulfate content using ion chromatography. The authors found that the catalyst caused a decrease in emitted particle mass. The observed size distribution for steady state conditions with low exhaust gas temperature conditions were shifted toward smaller sizes. This mass reduction was attributed to the removal of unburned $\mathrm{HC}$ through oxidation in the catalyst. For high exhaust gas temperature conditions, use of a catalyst resulted in a shift in the size distribution toward larger particulate size. This was attributed to the production of sulfur trioxide which acts as a "glue". Authors hypothesized that the water/sulfuric acid vapor, forming nuclei mode, was created in the dilution tunnel and in ambient dilution, does not occur. The results of the experiments with and without catalytic converter, showed small effects of catalytic process for real-time engine operating conditions. 
Hildemman et al. (1991) sampled emissions from two heavy-duty diesel dump trucks operated over a customized transient driving cycle. Transient acceleration/deceleration modes were included because of field observations that truck emissions are most apparent when the truck is changing its operating mode. The sub-micrometer aerosol mass distribution, based on the average of 10-12 EAA measurements for each distribution, showed a single mode with a peak around 200 $\mathrm{nm}$ in particle diameter. Emissions from 13 gasoline automobiles were also sampled during both FTP driving cycle, and under steady-state conditions. For many catalyst-equipped vehicles, singlemode, broad mass distribution was seen, with a peak between 0.1 and $0.3 \mu \mathrm{m}$ in particle diameter. Bimodal size distributions were obtained for several of the catalyst-equipped vehicles under certain conditions (nucleation mode with a peak value around $0.01 \mu \mathrm{m}$ and agglomeration mode with pronounced peak between 0.1 and $0.2 \mu \mathrm{m}$ in particle diameter).

Panne et al. (1995) used two DMPS systems operated in parallel at two fixed channel settings to measure diesel exhaust particle size distribution under dynamic conditions. The FTP-75 cycle was recorded at 6 different mobilities, thereby yielding an approximation for the particle size spectrum between $20 \mathrm{~nm}$ and $120 \mathrm{~nm}$. The authors reported temporal resolution for size distribution measurements of less then 1 second. They also reported reproducibility of the measurements and the strong link between particle emissions and driving velocity.

Abdul-Khalek et al. (1998) tested of a medium-duty, turbocharged and aftercooled direct injection diesel engine over ISO 11 Mode and 8 Mode tests and found that the lowest particle number concentrations appeared at $75 \%$ load at both rated and maximum torque (intermediate) speed.

Rickeard et al. (1996) used SMPS for measuring size-distributions of particulate matter emissions from diesel light-duty vehicles during steady-state tests. The authors operated vehicles at idle, $50 \mathrm{~km} / \mathrm{h}$ and $120 \mathrm{~km} / \mathrm{h}$ to cover the range from city to highway speed. The observed median size range was from 70 to $110 \mathrm{~nm}$, with particle size tending towards larger values at the highest test speed. The number of emitted particles rose dramatically as the test speed was increased 
from idle through $50 \mathrm{~km} / \mathrm{h}$ to $120 \mathrm{~km} / \mathrm{h}$. They also used SMPS to do real time tracking of the particles at five discrete size categories 25, 50, 100, 200 and $400 \mathrm{~nm}$ for the diesel light- duty van over ECE+EUDC driving cycle. The highest particle emissions were produced during acceleration and at the higher speed conditions.

\subsubsection{Effects of Fuel Formulation on Size-Resolved Diesel Particulate Matter Emissions}

Particulate matter emissions from heavy-duty diesel engines tested over both steadystate and transient modes of operation were found to be significantly affected by fuel sulphur content (Den Ouden et al., 1994). Sulfur content in current low sulfur diesel fuels in the USA is $\leq$ $0.05 \%(500 \mathrm{ppm})$ and, most likely, will be further reduced in the future. The sulfur oxidizes to produce sulfur dioxide, $\mathrm{SO}_{2}$, of which a fraction can be oxidized to sulfur trioxide, $\mathrm{SO}_{3}$, which combines with water to form a sulfuric acid aerosol (Heywood, 1988). Studies with low sulfur fuel revealed that the number of relatively large particles $(>0.040 \mu \mathrm{m})$ remain unaffected when using fuel with low sulfur content. In contrast, low sulfur content is found to reduce concentration of nanoparticles $(<0.040 \mu \mathrm{m})$ by several orders of magnitude, revealing that the majority of particles of this size are sulfur related. Opris et al. (1993), as well as Baumgard et al. (1996) concluded that most nuclei particles were formed in the dilution tunnel and considered them to be $\mathrm{H}_{2} \mathrm{SO}_{4}-\mathrm{H}_{2} \mathrm{O}$ by composition. Opris et al. (1993) measured particle size distribution in diesel exhaust. They performed measurements using an EEA. Total dilution ratio, primary and secondary, varied from 250 to 1675 , depending on the engine mode. The diesel particles exhibited a bi-modal distribution: a nuclei mode ( 0.0075 to $0.056 \mu \mathrm{m}$ volume diameter) and accumulation mode $(0.056$ to $1.0 \mu \mathrm{m}$ volume diameter). They found that the majority of particles in nuclei mode originated from the fuel sulfur. They noticed that the percentage of particles in the nuclei mode was reduced from $98 \%$ to less than $33 \%$ with low sulfur fuel. These particles consisted of sulfate particles or the sulfate particles provided the nuclei necessary for the nucleation process to occur.

Den Ouden et al. (1994) established empirical correlation between fuel sulfur content and integral particulate emissions for heavy-duty and light-duty diesel vehicles, not equipped with catalytic converter. According to the authors these correlations can be used to predict change in particulate emissions with change in fuel sulfur content. Contribution of other fuel effects to 
emissions from heavy-duty vehicles are small in comparison to contribution of sulfur and can be described by a combination of cetane number and density.

Havranek et al. (1997) studied fuel effects on the particulate emission from gasoline powered vehicles. They found that mass size distribution of aerosol was bimodal, with fine particle mode about $0.1 \mu \mathrm{m}$ and a coarse particle mode at about $0.5 \mu \mathrm{m}$. For leaded gasoline the lead was concentrated on particles with aerodynamic diameter $<0.78 \mu \mathrm{m}$.

Schaberg et al.(1997) examined diesel exhaust emissions using Sasol Slurry Phase Distillate (SSPD) process fuel. It was found that the SSPD fuels produce significantly lower emissions than the diesel no. 2 and CARB fuels in all four regulated emission categories. The exhaust emissions were lower owing to a very high quality of the synthetic diesel fuel (cetane number $>70$, aromatic content $<1 \%$, sulfur content $<10 \mathrm{ppm}$ ). The soluble organic fraction of the integrated PM was found to significantly lower when cetane number was increased, but the benefit was offset by an increase in the insoluble (carbon) portion of the TPM. The net result was that total PM was either unaffected or increased. It has been shown that at the low engine speed and loads particulate PAH emissions can be entirely accounted for by unburned fuel PAH, although at high speeds and loads, there was evidence of additional source of PAH. Schaberg et al. (1997) found a linear relationship between fuel sulfur and sulfate portion of total particulate emissions. Influence on size resolved PM emissions was not examined.

Klein et al. (1998) studied the effects of fuel sulfur content on the particulate matter emissions from diesel passenger cars equipped with oxidation catalysts. Cars were tested at steadystate conditions. The particulate matter was collected employing standard filters, a low pressure cascade impactor Hauke LPI 25, and the ELPI. They found that for the low sulfur fuel and low exhaust temperature, the mass reduction was linked to a shift in particulate size distribution toward smaller sizes. For low sulfur fuel and high exhaust temperature, the particulate mass emission rate increased with the use of an oxidation catalyst. This was attributed to the production of sulfur trioxide and shift in particulate size distribution toward larger sizes. For high sulfur fuel and low exhaust temperature, PM emissions had the same trend as that for low sulfur fuel and low exhaust temperature. For high sulfur fuel and high exhaust temperature, PM emissions exhibited the same trend as that for low sulfur fuel and high exhaust temperature. 
According to Kittelson et al. (1999), nanoparticles may include hydrocarbons, carbon fragments, sulfates, and metallic ash. They are of the opinion that hydrocarbons are the main source of nuclei mode particles for engines running on low sulfur fuels. Reduction of total carbonaceous material mass emitted by low emission engines is a possible reason for the formation of large concentrations of nanoparticles.

Norton et al. (1999) examined regulated emissions from older model operated transit busses operated on Mossgas synthetic diesel fuel using WVU's transportable chassis dynamometer. Three buses without and three with catalytic converters were tested. Compared to their emissions when operating on no. 2 diesel fuel, buses without catalytic converters emitted $20 \%$ lower PM, while buses with catalytic converters emitted $31 \%$ lower PM when operating on neat Mossgas fuel. The size resolved PM emissions from the buses were measured in parallel to regulated emissions and presented in this study.

\subsection{5}

The Other Effects on Size Resolved Diesel Particulate Matter Emissions

Chaffin and Ullman, (1994) studied effects of increased altitude on the heavy-duty diesel engine emissions by testing emissions from the vehicles operating at different altitude conditions. High altitude conditions were simulated using specially designed CVS unit. Authors found that emissions of $\mathrm{HC}, \mathrm{CO}, \mathrm{CO}_{2}$, smoke, and particulate matter generally increased with increased altitude for both steady-state and transient testing. Humidity related PM emissions increased 47 percent when apparent barometric pressure was decreased from $98.9 \mathrm{kPa}$ to $77.9 \mathrm{kPa}$. Gautam et al. (1998) found PM emissions from a heavy-duty truck in Mexico City (elevation 2240 m) was $100 \%$ higher than in Peoria, IL (elevation 200).

Pataky et al. (1994) studied the effects of an oxidation catalytic converter on the regulated and unregulated emissions and found that more than 98 percent of the total number of particles and 27 to 47 percent of the total volume of particles was in the nuclei mode depending on the engine operating mode and after-treatment device. The authors pointed out the low resolution of the Electrical Aerosol Analyzer (EAA) that was used by several researchers. Pataky et al. (1994) were unable to justify the conclusion, made in some of the previous studies, that nuclei mode likely consisted mainly of $\mathrm{SO}_{4}{ }^{2-}$ particles. 
Mayer et al. (1998a, 1998b, 1999) concluded that reformulated fuel, new lubricants, oxidation catalytic converters, and optimization of engine combustion are not yet proven to be an efficient means of curtailing the ultra-fine particulates under the exposure limit of $0.05 \mathrm{~nm}^{3} / \mathrm{m}^{3}$ that was recently proposed by the American Conference of Government Industrial Hygienists (ACGIH). The investigation into the effects of fuel formulation on nanoparticle emissions showed no improvement using the synthetic fuel with a high cetane number, low aromatics and low sulfur content over standard diesel. It was found that oxidation catalytic converters (OCC) were incapable of reducing the combustion particles. OCCs were found to promote sulfate particulates, and had unfavorable gaseous phase reactions. Mayer et al. (1998b) reported that the new low emission engines with high supercharging, air intercooling, and high injection pressures emitted more ultrafine particulate at all tested loads(R100, R50, I100, I50) than an older technology engine from the same family. Particulate traps were found to be the best available technology for removal of ultrafine DPM. The researchers found that traps were effective in the entire size range of DPM, starting from primary particulate of about $10 \mathrm{~nm}$. The tested traps exhibited high filtration rates of removing $78-86 \%$ of TPM, 93 - 99\% of elemental carbon, and 86 - 92\% particulates by count.

The complexity of the problem and variability of the applied research methodologies and experimental parameters made the comparison of the results difficult. Research in the field of size segregated particulate matter emissions benefitted greatly with development of the new measurement techniques. There is very sparse information available on the effects of engine operating conditions, fuel formulation, and after treatment processes on the size resolved DPM emissions. Data on size resolved PM emissions from the in-use vehicles is even more limited. The effects of alternative fuels such as synthetic diesels also merits more attention. Diesel exhaust aftertreatment started receiving more attention due to fact that other available methods of PM emissions reduction did not give adequate results. The effects of different after treatment processes on size distribution of the particles in the diesel exhaust needs to be more thoroughly explored, particularly with respect to the effects on human health.

The effects of engine operating conditions on particle size distribution are of great interest for further engine and regulations development, so real time measurements have become a very important aspect of engine research. The instruments such as SMPS and ELPI open new possibilities for real-time tracking of the number and mass particles matter emissions. The results 
of measurements with such instrumentation should provide more insight on the effects of transient operating conditions on the size resolved PM emissions.

\subsection{Size-Resolved Chemical Analysis of Diesel Particulate Matter}

Recently, researchers (Leonardy et al.,1992; Venkataraman et al., 1994; Kerminen et al., 1997; Allen et al., 1997, and Cass et al., 1999) reported work on the size-resolved chemical analysis of diesel particulates. Their work was based on the chemical analysis of particulate matter collected in the laboratory conditions or road tunnels. Size-resolved chemical analysis of the diesel exhaust PM should contribute to a better understanding of processes governing the formation of the particulate phase of diesel exhaust and their health effects. Distribution of elemental and organic carbon, inorganic compounds as sulfates and nitrates as well as metals, and PAHs over different size classes were of the main interest.

Venkataraman et al. (1994) measured ten polycyclic aromatic hydrocarbons (PAHs) in size-segregated aerosol sample from two traffic tunnels. The particles were collected by Hering low pressure impactor. The authors employed ultrasonication and HPLC-grade methylene chloride as solvent for PAHs extraction. Ten PAHs were analyzed using an HPLC. The elemental hydrocarbon, EC size distribution in both tunnels were unimodal with over $80 \%$ of the EC mass attributed to particles smaller than $0.12 \mu \mathrm{m}$. Particulates smaller than $0.12 \mathrm{~nm}$ aerodynamic diameter were responsible for over $80 \%$ of the PAH mass.

Kerminen et al. (1997) conducted size-resolved diesel particulate chemical analysis on the samples collected using Berner low pressure impactor. They used an in-house-built, computer controlled analyzer (Hydrocarb-System) to determine elemental and organic carbon content. The NDIR spectrometer was used for monitoring production of the carbon dioxide and water after the samples were heated in the oven from ambient to $1000{ }^{\circ} \mathrm{C}$. Argon and oxygen were employed as carrier gas. The quantification was performed by comparison against an external standard. From total particulate carbon, about $15-20 \%$ was estimated to be organic in mode 1 (GM=0.09, $\mathrm{GSD}=1.34)$, about $30 \%$ in mode $2(\mathrm{GM}=0.2, \mathrm{GSD}=1.61)$, and about $50-60 \%$ in mode $3(\mathrm{GM}=0.7$ $1.0, \mathrm{GSD}=1.34)$. 
Allen et al. (1997) collected size-segregated atmospheric particles using a MOUDI. The samples were analyzed for oxygenated polycyclic aromatic hydrocarbons (OPAH) using GC/MS. Sonication and dichloromethane were used for extraction. The OPAH fraction of the samples was separated from dibutyl phthalate and other pollutants by high-performance liquid chromatography (HPLC).

Abdul-Khalek et al. (1998) used rapid dilution of diesel exhaust to prevent nucleation and growth of particles and concluded that nuclei mode appeared to be solid, formed by volatilization of lube oil metallic ash components and subsequent nucleation of these materials during the expansion stroke. The authors also found that for the full load, rated speed testing mode use of a converter resulted in an increased number concentration, mostly particles under $10 \mathrm{~nm}$. The source of these particles was attributed to the oxidation of $\mathrm{SO}_{2}$ and $\mathrm{SO}_{3}$ by the catalyst and the production of sulfuric acid particles during dilution and cooling of the exhaust.

Havranek et al. (1997) collected the gasoline car exhaust particles on ungreased Tedlar foils with Berner LPI BLPI 25/0.018/2. The elemental analysis of the collected particulate matter was done using PIXE (Protone-Induced X-ray emission) method on the van de Graaff accelerator. Concentration of Fe in particles for lead-free gasoline, was $3.8 \mu \mathrm{g} / \mathrm{m}^{3}$ and $\mathrm{Zn} 5.7 \mu \mathrm{g} / \mathrm{m}^{3}$.

Klein et al. (1998) studied effects of fuel sulfur content on the particulate matter emissions from diesel passenger cars equipped with oxidation catalyst. The Hauke LPI 25 and Tedlar foils (Du Pont, USA) were used for collection of particles for sulfate analysis. The sulfate concentration was determined by ion chromatography (Dionex 4000i). The sulfate/water content in the diesel particulate matter emissions from the car without a catalytic converter was found to be very low. For the car equipped with a catalytic converter, sulfate/water content was found to be dependent on the engine operating conditions. The operating mode with high exhaust gas temperatures favored production of $\mathrm{SO}_{3}$.

Leonardy et al. (1992) used an alternative method to make size-dependent measurement of PAH concentration on particles in diesel exhaust. They used the aerosol photoemission (APE) method suitable for in-situ measurement of the amount of hydrocarbons that get adsorbed on the surface of particulate matter. Method is based on the emission of electrons by irradiation with ultraviolet light at a wavelength close to the ionization threshold. The sizedependent measurements of the photoelectric yield of diesel particles indicated that with an increase 
in engine load, the PAH concentration on the very small-inhalable-particles showed a strong increase, and increased only slightly on the larger particles. The authors concluded that observed distribution of PAH on diesel particles was not in agreement with a model that assumes that the PAH concentration was controlled by diffusion flux to particles, but rather, related to the way in which particles were created in the high-pressure combustion.

There is a limited amount of information on size resolved chemical composition of the diesel particulate matter. Such chemical analysis is imperative for better understanding of the physical and chemical processes leading to the formation and transformation of particles in the engine, transfer lines and dilution process. A knowledge of the content of sulfates, sulfur and some other elements and inorganic ions, as well as the ratio of organic and elemental carbon in the size segregated particulate matter samples might help in better understanding the aforementioned processes. The presence of transitional metals and some other elements and ions might be valuable information for judging the toxicity of diesel particulate matter.

Speciation of Particulate Bound, Semi-Volatile and Volatile Hydrocarbons from

\section{Diesel Exhaust}

The hydrocarbon fraction of the exhaust emissions from an internal combustion engine is a complex mixture of burned and unburned fuel and lubricating oil compounds. To fully assess the environmental impact of the $\mathrm{HC}$ fraction, it is necessary to speciate individual $\mathrm{HC}$ compounds. The speciation of hydrocarbon fraction in diesel exhaust represents a particular challenge to the analytical chemistry as a large number of compounds (at least several hundreds) of varying functionalities are adsorbed on particulate matter or dispersed in gaseous phase.

Most of the studies on diesel exhaust hydrocarbons focus on PAHs, nitro-PAHs and oxy-PAHs because they are potentially mutagenic and carcinogenic. The other health concern related to the diesel exhaust hydrocarbons is their potential to promote ozone formation. The ultimate goal of all these efforts is the reduction of non-methane organic gas (NMOG) emission levels and a subsequent reduction of the ozone-forming potential of exhaust gases.

It has long been recognized that volatile organic components differ significantly in how rapid they react in the atmosphere and the extent to which their reactions promote or inhibit 
ozone formation. In November 1991, the Californian Air Resource Board adopted the maximum incremental reactivity (MIR) scale. The MIR scale was developed by Carter (1989). Computer model simulations have been carried to determine the compounds' incremental reactivity, which is defined in terms of relative change in ozone formation and NO oxidation caused by addition of the hydrocarbon compound to the total emissions. The principal advantage of this scale is that it defines reactivity where hydrocarbon control has its greatest benefits, in the upwind areas where the highest emission densities are found. MIRs are defined as grams of ozone per gram of specific VOC emitted. The author published recently updated list of MIRs for number of volatile organic compounds (Carter,1999).Ozone forming potential (OFP), which is product of the MIR and the NMOG mass emission rates, is defined in grams of ozone formed per mile traveled for vehicles and in grams of ozone formed per KW-hr for engines. The determination of the OFP is based on the detailed speciation of the exhaust.

\subsubsection{Hydrocarbon Compounds as Constituents of Diesel Exhaust}

Black and High (1979) used two different gas chromatographic systems and techniques to analyze gaseous diesel exhaust samples $\left(\mathrm{C}_{1}-\mathrm{C}_{10}\right)$ and particulate bounded and semivolatile hydrocarbons $\left(\mathrm{C}_{10}\right.$ and $\left.\mathrm{C}_{40}\right)$. They investigated source of the hydrocarbons in the exhaust. It appeared that the major source of hydrocarbons above $\mathrm{C}_{25}$ was lubricant since hydrocarbons $\mathrm{C}_{14^{-}}$ $\mathrm{C}_{25}$ originate from fuel and lubricant. They also concluded that mass and distribution of organic compounds in the gas and particulate phase were essentially insensitive to dilution ratio and particle sampling rate over the range examined.

Hsieh et al. (1993) found that mutagenic activity of the vapor-phase mutagens was comparable in magnitude to that of the PM-associated mutagens and therefore constituted a substantial portion of the total mutagenicity present in sampled diesel exhaust.

Nine et al. (1995) found that the major portion of the ozone forming potential of the volatile hydrocarbon species was a sum of the contributions from ethene, propene, and 1,3butadiene, and BTEX (Benzene, Toluene, Ethylbenzene, and Xylene) compounds. These species, according to authors, accounted for 90 and $95 \%$ of the ozone forming potential of volatile hydrocarbons. The semi-volatile hydrocarbons contributed between 5 and $15 \%$ to the overall 
forming potential. The authors suggested that aldehydes must be sampled in conjunction with speciated hydrocarbons to give accurate OFP values.

Gautam et al. (1994) concluded that aldehydes, ketones, esters, and olefins, because of their high MIR value, and diesel exhaust components with high concentrations in diesel exhaust should be of the major concern regarding ozone forming potential.

Hammerle et al. (1995) observed that the range of carbon numbers for diesel fuel was typically $\mathrm{C}_{9}$ to $\mathrm{C}_{26}$, with most mass lying between $\mathrm{C}_{12}$ and $\mathrm{C}_{18}$. They found the hydrocarbon composition for the tested vehicle and fuel to be as follows: $14 \%$ methane, $45 \%$ light hydrocarbons (LHC), 9\% heavy hydrocarbons (HHC), $18.9 \%$ aldehydes, and 12\% particulate soluble organic fraction. Presence of similar aliphatic fuel components in the exhaust led the authors to conclude that most of heavy hydrocarbons exhaust fraction was composed of unburned fuel. The $\mathrm{C}_{12}, \mathrm{C}_{13}, \mathrm{C}_{14}$, $\mathrm{C}_{15}$ paraffins accounted for $34 \%$ of the HHC mass, and the methyl- and dymethylnaphtalenes account for another $21 \%$. Fifty-three percent of the HHC mass was identified as aliphatic and $31 \%$ as aromatic. The 20 most abundant species accounted for $85 \%$ of the HHC mass.

Gupta (1996) speciated heavy-duty diesel engine exhaust emissions using GC/FID for the analysis. He found that cyclohexene, because of high mass emission rates, had the highest ozone forming potential among all of the volatile compounds. The aromatics contributed to more than $80 \%$, alkenes more than $10 \%$, and n-alkanes to the rest of the ozone forming potential of the semi-volatile phase $\left(\mathrm{C}_{8}-\mathrm{C}_{24}\right)$ of exhaust for $27.7 \%$ aromatic content diesel fuel. The contribution

of particulate matter bounded compound $\left(\mathrm{C}_{9}-\mathrm{C}_{24}\right)$ toward the total speciated emissions was negligible as compared to the contribution of volatile and semi-volatile phase. Gupta (1996) found that the reactivity of alkenes $>$ aromatics $>$ alkynes $>$ cyclo-alkanes $>$ branched alkanes $>$ n-alkanes.

\subsubsection{Sampling Methodology}

Particulate matter sampled on a filter medium is often used for chemical analysis. The most important factor that should be considered on while selecting filter media for chemical analysis is the mass of particulate matter required for analysis, and minimization of interference arising from the background response of the blank filters, and artifact formation from chemical transformations occurring on the filter during and after filter sampling. Glass fiber filters suffer 
from a positive artifact mass in ambient air sampling due to their slight alkalinity that results in the in situ conversion of sulfur dioxide to sulfate. Particulate nitrate can also be formed on glass fiber filters, depending on the gaseous nitric acid concentration. Pre-washing is an efficient way for removal of any possible contaminants from the filters.

A glass fiber Teflon ${ }^{\circledR}$ (Polytetrafluoroethylene, PTFE) coated filter is the most commonly used filter media in engine and vehicle testing (Black and High, 1979; Benner et al., 1989; Hildermann et al.,1991; Bagley et al., 1993; Opris et al., 1993; Hsieh et al., 1993; Pataky el al.,1994; and Gupta, 1996). These filters have relatively high efficiency (greater than 99\% for particles $>0.3 \mu \mathrm{m}$ at $3.20 \mathrm{~m} / \mathrm{s}$ ), cause relatively low pressure drop, have good thermal stability, have low trace contamination level, and are relatively inert. Quartz fiber filters are customarily used for collection of the ambient organic aerosol samples ( Hildermann et al., 1991). All quartz fiber filters are pre-baked at $750{ }^{\circ} \mathrm{C}$ for at least 2 hours to lower their carbon blank. However, quartz fiber filters require meticulous care during handling.

Collection of the semi-volatile hydrocarbon phase in diesel exhaust is very complex. The gas-particle partitioning of most organic compounds is sensitive to changes in temperature and pressure. Solid adsorbents are most commonly used for the sampling of semi-volatile and volatile compounds. The most important properties of the adsorbent material are heat resistance, particle size and size distribution, pore size and size distribution, surface area and chemical properties. Granularbed filters, consisting of polymeric adsorbent resins made of spherical granulates like XAD-2 (Bagley et al., 1993; Opris et al., 1993; Pataky el al., 1994; Gautam et al., 1994; Gupta, 1996), XAD-4 (Hsieh et al., 1993), Tenax (Bailey et al., 1992; Hammerle et al., 1995; Nine et al., 1995 ), and polyurethane foam (Benner et al.,1989; Bagley et al., 1993; Lowenthal et al., 1994) are usually employed for collection of semi-volatile hydrocarbons from diesel exhaust. Solvent extraction and thermal desorption are the commonly used techniques for extraction of sample from adsorption resins. The XAD-2 and XAD-4 are considered better adsorption resins in cases where the sample treatment involves solvent extraction, while Tenax TA has proven to be better for thermal desorption. Tenax TA is widely accepted for air and water analysis because its sorption power is nearly unaffected by water and repeated re-use of the sorbent. Hammerle et al. (1995) chose Tenax TA as the adsorbent because of it high thermal stability and because it can be thermally disorbed. Nine et al. (1995) concluded that Tenax TA has limited application for sampling diesel exhaust 
because higher sampling steam temperature $\left(>100^{\circ} \mathrm{C}\right)$ might reduce the ability of the Tenax TA to adsorb lower hydrocarbon number semi-volatile hydrocarbons. Some early work was done with Chromosorb 102 (Black and High, 1979).

Tedlar sample bags appeared to be the most popular media for collection of volatile phase hydrocarbons from diesel exhaust ( Black and High, 1979; Bailey et al., 1992; Newkirk et al., 1995; Gautam et al., 1994; Gupta, 1996).

\subsubsection{Extraction and Sample Preparation}

The extraction efficiencies of various methods have been investigated repeatedly, but conclusions are contradictory. Soxlet extraction (Hare and Bradow, 1979; Shimpi and Yu, 1981; Alsberg et al., 1985; Opris et al., 1993; Lowenthal et al., 1994; Gupta, 1996), sonication (Gautam et al.,1994; Gupta, 1996) and supercritical fluid extraction (Hsieh et al., 1993) are the most commonly employed methods for the solvent extraction. Gautam et al.(1994) compared performance of the Fisher Scientific Model No. 550 Sonic Dismembrator and soxlet extraction for extraction of hydrocarbons from $70 \mathrm{~mm}$ filters and XAD-2 resin. The sonication technique was shown to be more efficient because of the shorter extraction time and lower process temperature. Hsieh et al. (1993) found that the 30 min supercritical fluid extraction (SFE) process yield better recoveries than those achieved in 4 hours of sonication and 8 hours of Soxhlet extraction. Thermal disorption was mostly used for extraction from Tenax (Bailey et al.,1992). Solvent selection is crucial for an effective extraction. The criteria for choosing a particular solvent include its extraction efficiency, purity, volatility, toxicity, expense, and compatibility with subsequent analytical procedures. Most commonly employed solvents for Soxlet extraction and sonication were methylene chloride (Alsberg et al., 1985; Niles and Tan, 1989; Opris et al., 1993; Lowenthal et al.,1994; Gupta, 1996), cyclohexane (Hare and Bradow, 1979), and acetone (Nine et al. ,1995). Black and High (1979) studied different solvents and methods for extraction of the SOF from filters and found that methylene chloride removed a greater fraction of the total organic than any other single solvent system that was investigated. According to Levsen (1988), dichloromethane has poor recovery in particulates of the higher PAHs (5 and 6 rings). Levsen and Schilhabel (Scilhabel et al., 1989) suggest that aromatic solvents, such as toluene or a combination of aromatic solvents such as 
alcohols, are best suited to extract PAHs and nitro-PAHs from the particulate. Solvents from the extracted solution need to be evaporated after extraction. The most popular instruments for evaporation are rotary evaporators (Niles and Tan, 1989; Gautam et al.,1994; Gupta, 1996).

\subsubsection{Analysis Techniques}

Gas chromatography-mass spectrometry GC/MS (Black and High, 1979; Hare and Bradow, 1979; Niles and Tan,1989; Hsieh et al.,1993; Lowenthal et al.,1994; Gupta, 1996; Nine et al.,1995) and high performance liquid chromatography HPLC (Hsieh et al., 1993; Pataky el al., 1994) are the most widely used analytical techniques for identification and quantification of the hydrocarbon compounds present in the diesel samples. Alsberg et al. (1985) used HPLC for subfractionation of PM extracts. Application of on-line HPLC-GC analysis of PAH fraction has been reported by Levsen (1988). Total hydrocarbons in the exhaust are usually measured with a heated flame ionization detector (HFID). Since the enforcement of stricter standards in the coming years will result in lower HC concentration in vehicle exhaust emissions, it will be necessary to use more sensitive analytical methods than the techniques employed at present (Koike et al., 1994).

Hildermann et al. (1991) analyzed diesel particulate matter collected on Teflon filters, by X-ray fluorescence for trace metal content. Sulfate, nitrate, and chloride emission rate were measured by ion chromatography (IC) and sodium and magnesium were analyzed by flame atomic adsorption (FAA). Bagley et al. (1993), Opris et al. (1993), and Klein (1998) used ion chromatography to determine $\mathrm{SO}_{4}$ levels of the PM samples. Lowenthal et al. (1994) used Teflon membrane and pre-fired filters to collect aerosol samples from WVU Transportable heavy-duty vehicle emissions laboratory's total exhaust dilution tunnel. Teflon filters were weighed and subjected to elemental analysis by X-ray fluorescence (XRF). Part of the quartz filters were analyzed for sulfates, nitrates, and chlorides using ion chromatography, ammonium using automated colorimetry and the indophenol method, soluble potassium using flame atomic absorption and bulk organic and elemental carbon using thermal/optical reflectance (TOR). Most of the detected mass in the samples was comprised of elemental and organic carbon and sulfates, with small amount of nitrates and ammonium. Reported portions of organic carbon, elemental carbon and sulfates for 
diesel trucks and diesel No. 2 were $30 \%, 51 \%, 14 \%$ respectively. The ratio of sulfate to elemental sulfur was 5.1.

There are hundreds of compounds belonging to various compound classes of hydrocarbons which, in general, makes it impossible to analyze the extracts directly. It is, therefore, necessary to fractionate the exhaust into various compound classes. Open-column liquid chromatography is by far the most frequently used method to fractionate, according to functional groups, the compounds adsorbed on diesel particulate matter. Niles and Tan (1989) found that an effective separation of long-chain aliphatics and three- to six-ring aromatics in various sample matrices can be accomplished by using gel-filtration chromatography. The fractions were examined using GC/FID to trace the presence of analytes. The final fractionation of these extracts was achieved by semi-preparative normal-phase liquid chromatography.

\subsubsection{Effects of Engine Operating Conditions on Hydrocarbon Emissions}

The character of diesel exhaust is highly dependent upon the engine operating mode, so any survey of diesel engine emissions should and must be based on measurements over widely varying engine operating modes (Marshall and Fleming, 1971).

Gupta (1996) found that mass emission rates of semi-volatile compounds were closely related to engine operating conditions and fuel aromatic content. He found that semi-volatile mass emission rates at R50 (rated speed and 50\% load) were $126 \%$ greater than at I100 (intermediate speed and 100\% load), and ozone forming potential at R50 was $98 \%$ higher than at I100. He also found that mass emission rates of particulate bounded compounds were $147 \%$ higher at R50 than at I100, and ozone forming potential at R50 was $158 \%$ higher than at I100. 


\subsubsection{Effects of Fuel Type on Hydrocarbon Emissions}

Numerous investigations have been carried out to clarify the relationship between fuel characteristics and emissions using various combinations of engines and fuels. There is a large number of fuel characteristics that affect emissions, but the most prominent and investigated are specific gravity, viscosity, distillation temperature, cetane number, aromatics content, and sulfur content.

Fuel composition affects many aspects of engine performance, including fuel economy and exhaust emissions. Diesel fuels are a mixture of alkane, alkene, anphthenic and aromatic compounds, with boiling points in the approximate range $200-370^{\circ} \mathrm{C}$. Fuels with high alkane contents are preferable and this is reflected in their high cetane number. The aromatic component degrades the fuel, giving rise to extended ignition delays and high initial heat release rates with consequently high noise, particulate matter and nitrogen oxide emissions (Mills et al., 1983).

Mills et al. (1983) studied the effects of a diesel fuel aromaticity on the polynuclear aromatic hydrocarbon exhaust emissions. They used six specially blended gas oil having aromatic content of $10 \%, 30 \%, 40 \%, 50 \%, 60 \%$, and $70 \%$. The sampling stream was filtered on a high efficiency filter for collection of the PM and than transferred to condensation traps for the removal of the vapor-phase PAHs. He found that total PAH emissions increase with an increase in fuel aromaticity for all engine operating conditions. No-load and low speed full load operating conditions produced the greatest PAH exhaust concentrations. Higher loads also tended to produce larger molecular mass, and more biologically active PAHs.

Newkirk and Bass (1995) conducted a comparative study on the exhaust emissions from heavy-duty engines operated on gasoline, diesel, and alternative fuels. Each engine/fuel combination was tested using the EPA heavy-duty transient cold- and hot- start test protocol. They conducted detailed speciation of $\mathrm{C}_{1}-\mathrm{C}_{12}$ hydrocarbons, including the determination of aldehyde and ketone emissions. The analysis on diesel indicated that almost all of the potential ozone, formed in both cold- and hot- start cycles, was derived from roughly equal portions of olefins and carbonyls. 
Almost 95 percent of the total reactivity for the diesel engine in this study was derived from $\mathrm{C}_{1}-\mathrm{C}_{6}$ hydrocarbon compounds. 


\subsection{TEXT OF INVESTIGATION}

\subsection{EXPERIMENTAL EQUIPMENT AND PROCEDURE}

\subsubsection{Engine and Vehicle Testing Parameters}

\subsubsection{Testing Facilities}

Engine and vehicle exhaust emissions testing was conducted at West Virginia University Engine Research Center's (WVU ERC) heavy-duty engine and vehicle testing facilities, including Federal Test Procedure engine test cell at Engine and Emissions Research Center (EERC) and one of the Transportable Emissions Laboratories (TEL). A schematic of the engine testing facilities in the WVU ERC Laboratory is shown in Figure 3.1. Design and construction of the sampling trains for stationary and transportable systems are almost identical. These facilities routinely sample and analyze the regulated and unregulated gaseous and PM emissions from heavy-duty engines and vehicles. The Transportable Emission Laboratories are fully self-contained units and the transportability of these chassis dynamometer-based laboratories allows the emissions tests on the heavy-duty vehicles to be conducted at remote sites all over the world. Design details of the laboratories have been presented in several previous reports (Bata et al., 1992; Clark et al., 1995).

\section{Full Flow Dilution Tunnel}

The laboratories used in this study are equipped with a total exhaust double dilution system based on the critical flow venturi constant volume (CFV-CVS). Figure 3.1 shows the size selective measurements and speciation sampling trains incorporated in the typical layout of the WVU stationary and transportable emission testing laboratories. The CVS dilution tunnel meets all requirements of the CFR 40 Part 86, Subpart N (1994) for testing heavy duty engines except that dilution air is not conditioned. The total exhaust double dilution tunnels consist of an 18 "( $0.457 \mathrm{~m})$ diameter stainless steel primary tunnel and a $4 "(0.102 \mathrm{~m})$ diameter secondary tunnel. The exhaust is injected upstream of a 10" $(0.254 \mathrm{~m})$ mixing orifice in the primary dilution tunnel. The exhaust and 
the ambient dilution air are mixed as they are drawn down the tunnel by a $75 \mathrm{hp}(56 \mathrm{~kW})$ blower at the end of the tunnel. The sampling probes are located more than ten diameters ( $15 \mathrm{ft})$ downstream of the mixing orifice, which ensures complete mixing in fully turbulent flow regime at the sampling zone. Diluted exhaust is drawn through the secondary dilution tunnel across primary and secondary filters. Secondary dilution air is introduced in the tunnel to ensure that the filter face temperature does not exceed $125^{\circ} \mathrm{F}$.

Maintaining a constant diluted exhaust flow rate in the tunnel results in undesirable dilution ratio scenarios during steady-state and transient engine operating conditions. Constant total flow rate through the primary dilution tunnel results in reduced dilution ratios for the cases of higher engine loads and consequently higher exhaust flow rates. This is just the opposite of the desirable scenario which requires higher dilution air flow rate for higher loads and vice versa. Calculation of the dilution ratio for constant volume sampler tunnel requires an estimate of exhaust flow rate. Introducing flow measurement devices in the exhaust transfer line may generate sampling artifacts. Alternatively, exhaust flow rate can be estimated from fuel and engine air intake mass flow rates measurements under assumption of negligible losses inside the system or by $\mathrm{CO}_{2}$ or $\mathrm{NO}_{\mathrm{x}}$ (raw and dilute exhaust) concentration measurements (Graskow et al., 1998). The Engine Research Center test cell is equipped with positive displacement (piston) type Max Flow Media 710 Series Fuel Measurement System Model 214 used for fuel flow rate measurements and Meriam Model 50MC2-6 Laminar Flow Element for air flow rate measurements. In the case of Transportable Laboratories dilution ratio calculation require measurements of the concentration of $\mathrm{CO}_{2}$ or $\mathrm{NO}_{\mathrm{x}}$ in the raw and diluted exhaust. During dynamic testings dilution ratio becomes the function of the time and requires control over double loop high speed data acquisition system.

The dilution factor calculations increase uncertainty of the emission measurements. As the engine technology improves the pollutant, concentrations will approach those of the ambient air and error introduced by dilution ratio calculations will be more significant.

The above mentioned procedures and assumptions make the data analysis of DPM size distributions and concentrations obtained using the full flow dilution tunnel both cumbersome and potentially unreliable. Also, the extent of dilution ratios that can be attained from the total dilution tunnels is limited to approximately 1 to 5 or less at high loading conditions. For these reasons, the 
samples for size-distribution measurements and size-segregated chemical analysis of particulate matter were drawn from an on-purpose designed partial flow dilution tunnel.

\section{Gaseous Emissions}

The gas analysis train included four analyzers which were fed with samples taken from the sampling zone in the primary dilution tunnel. The heated flame ionization detector (HFID), Rosemount Model 402, was employed for total hydrocarbon analysis. The FID was calibrated with sample gases containing known amounts of hydrocarbon. The hydrocarbons present in the exhaust gas sample were burned in a small hydrogen-air flame, producing ions in the amount proportional to the number of carbon atoms burned. Model 402 is capable of measuring hydrocarbon concentration from 0 ppm to 250,000 ppm and produces a full-scale linear output.

Three non-dispersive infrared (NDIR) Rosemount Model 868 analyzers were employed for $\mathrm{CO} / \mathrm{CO}_{2}$ analysis. Infrared absorption, in a sample cell containing exhaust gas, was compared to absorption in a reference cell. NDIR detectors were calibrated with sample gases of known composition. One of the NDIR analyzers was set aside to measure high CO concentrations in ranges of 0 to 2 percent and 0 to 10 percent. The other was employed for measuring lower $\mathrm{CO}$ concentrations from 0 to $1000 \mathrm{ppm}$ and 0 to $5000 \mathrm{ppm}$. The third analyzer was used for measuring $\mathrm{CO}_{2}$ concentrations in the range of 0 to 5 percent and 0 to 20 percent. Since the NDIR's do not produce a linear output, it was necessary to generate calibration curves for each of the analyzers.

A Rosemount Model 955 chemiluminescent analyzer was used for $\mathrm{NO} / \mathrm{NO}_{\mathrm{x}}$ analysis. This analyzer determines the total concentration of $\mathrm{NO}$ and $\mathrm{NO}_{2}$, that is reported as $\mathrm{NO}_{\mathrm{x}}$. $\mathrm{The} \mathrm{NO}_{2}$ is first converted to the NO in a heated converter, whereupon the NO in the exhaust gas sample stream reacts with ozone in a flow reactor. The generated chemiluminescence, which is measured with a photo multiplier, is proportional to the amount of NO. The chemiluminescent analyzer outputs the concentration of the total $\mathrm{NO}_{\mathrm{x}}$. 


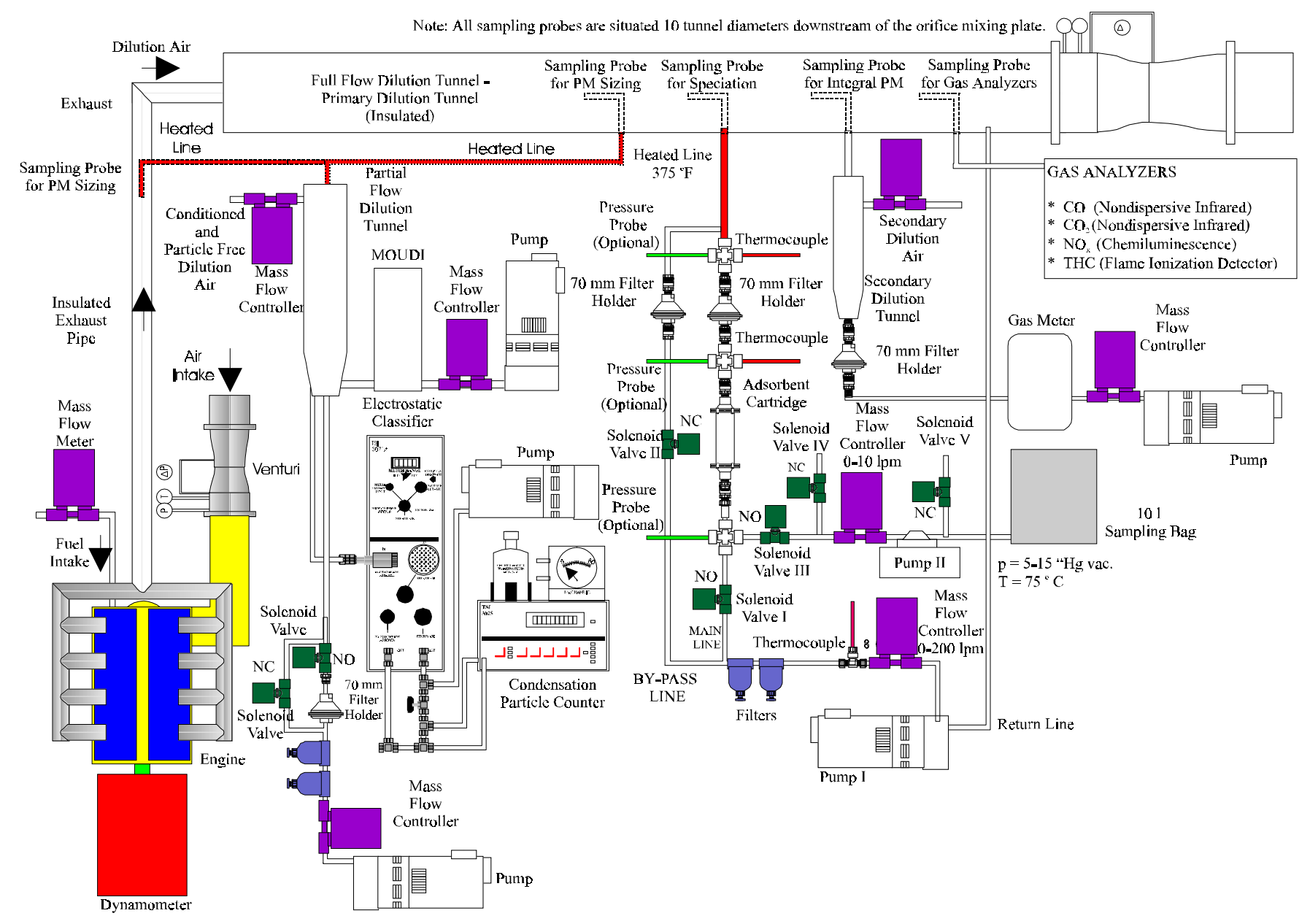

Figure 3.1 Layout of WVU Engine and Emissions Research Center Laboratory 


\section{Total Particulate Matter (TPM) Emissions}

Particulate matter was collected using a PM sampling system located at the outlet of secondary dilution tunnel. The sample of a diluted exhaust was drawn from the secondary dilution tunnel across the primary and back-up filters housed in a stainless steel filter holder. A rotary vane vacuum pump was employed to draw the PM sample. A Sierra Series 740 mass flow controller was employed for maintaining the constant mass flow rate in the sampling system. The flow rate was maintained at a level that would prevent excessive PM loading and filter clogging during a test cycle.

Owing to its flexibility, simplicity and economy, filtration is probably the most widely utilized technique for aerosol measurement. Regulated and non regulated engine and vehicle testing procedures rely on the filters for collection of PM for gravimetric and chemical analysis. The EPA (1994) defines particulate matter as any mass collected on a fluorocarbon-coated glass fiber or fluorocarbon-based (membrane) filter, from a diluted exhaust stream, at a fiter face temperature of less than $52^{\circ} \mathrm{C}\left(125^{\circ} \mathrm{F}\right)$.

The Pallflex ${ }^{\circledR}$ T60A20 and TX40HI20-WW 70 mm Teflon ${ }^{\circledR}$ coated glass fiber filters were selected for total of particulate matter sampling. To assure complete collection of total PM, two filters were employed in the series. The filter holders were designed to provide support for filters, leak-tightness and uniform filter face flow distribution. Liu et al. (1983) reported the filtration efficiency range of the Pallflex ${ }^{\circledR}$ T60A20 filter as 55-98.8 \% for a particle diameter range 35-1000 nm. Filtration efficiency range of the Pallflex ${ }^{\circledR}$ TX40HI20 filter has been reported to be 92.6-99.99 $\%$ for a particle diameter range 35-1000 nm (Willeke and Baron, 1993). Guerrieri et al. (1996) investigated the effects of filter face velocity on particulate mass from heavy-duty diesel engines and suggested that for the range 40 to $100 \mathrm{~cm} / \mathrm{sec}$, filter face velocity should exhibit little, if any, influence on a collected particulate mass. During TPM sampling for this study, the flow rate was maintained in the recommended range.

Gravimetric analysis of the filters has been found to be most sensitive to the effects of moisture/relative humidity and static charge buildup on the filter materials. A standard means of minimizing the relative humidity interference in gravimetric analysis involves equilibrating the filters at a constant temperature and humidity (for example $20^{\circ} \mathrm{C}, 50 \% \mathrm{RH}$ ) for 24 hours before and after 
sampling (40 CFR recommends 1-80 hours). The weight of the load on the filters may reduce due to evaporation of water or volatile hydrocarbons. Moreover, PAH can degrade on the filter during longer storage periods. For this study, the filters were stored in glass petri dishes and equilibrated in an Envirotronic Model No. SH8 environmental chamber both before and after the tests for the recommended period of time.

The gravimetric method requires a highly precise filter weighing and enhanced quality assurance effort to obtain reliable measurements. The CAHN 32 micro-balance with a $1250 \mu \mathrm{g}$ weighing capacity and $0.1 \mu \mathrm{g}$ sensitivity was available for this study. The remote weighing chamber was placed inside the environmental chamber on a vibration isolation table, while the electronic unit was kept outside of the chamber. NIST traceable weights were used to calibrate the micro-balance.

Table 3.1 Specifications for the Engines

\begin{tabular}{|c|c|c|c|c|}
\hline & Isuzu C240 & DDC 6V92 & Mack E7-400 & $\begin{array}{c}\text { Cummins ISM } \\
370 \text { ESP }\end{array}$ \\
\hline Ignition & compression & compression & compression & compression \\
\hline \multirow[t]{2}{*}{ Injection } & indirect & direct & direct & direct \\
\hline & $\begin{array}{l}\text { naturally } \\
\text { aspirated }\end{array}$ & $\begin{array}{l}\text { turbocharged } \\
\text { aftercooled }\end{array}$ & $\begin{array}{l}\text { turbocharged } \\
\text { intercooled }\end{array}$ & $\begin{array}{l}\text { turbocharged } \\
\text { intercooled }\end{array}$ \\
\hline Engine Type & $\begin{array}{l}\text { four stroke } \\
\text { inline-4 }\end{array}$ & $\begin{array}{l}\text { two stroke } \\
\text { in-line } 6\end{array}$ & $\begin{array}{l}\text { four stroke } \\
\text { in-line } 6\end{array}$ & $\begin{array}{l}\text { four stroke } \\
\text { in-line } 6\end{array}$ \\
\hline Displacement, 1 & 2.4 & 9.5 & 12 & 11 \\
\hline $\begin{array}{l}\text { Rated Torque, } \\
\text { Nm@rpm }\end{array}$ & 133@1960* & 1193@1200 & 1980@1200 & $\begin{array}{c}\text { 1830/1966 } \\
@ 1200\end{array}$ \\
\hline $\begin{array}{l}\text { Rated Power, } \\
\text { kW@rpm }\end{array}$ & $35 @ 3000 *$ & 186@2100 & $\begin{array}{c}294 \\
@ 1600-1800\end{array}$ & $\begin{array}{l}272 / 301 \\
\text { @1800 }\end{array}$ \\
\hline $\begin{array}{l}\text { Transmission } \\
\text { Type }\end{array}$ & N/A & $\begin{array}{c}\text { automatic } \\
4 \text { speed }\end{array}$ & N/A & N/A \\
\hline
\end{tabular}




\subsubsection{Engine and Vehicle Operating Conditions}

3.1.1.2.1 Size Selective Measurement of Diesel Particulate Matter

The experimental work on the size selective measurements of PM was performed on the exhaust from an Isuzu C240 off-road engine, six transit buses powered with DDC 6V92 engines, and a Mack E7-400 engine targeted toward on-highway applications. The major engine specifications for the tested engines and vehicles are listed in the Table 3.1. The engine testing took place at the WVU EERC stationary engine test facility. The WVU Transportable Laboratory facilities stationed at Morgantown location were employed for testing the transit buses.

\section{Isuzu C240 Study}

A series of size selective measurements of DPM under steady-state engine operating conditions were conducted on the exhaust from off-road Isuzu C240 engine, equipped with different combinations of exhaust after-treatment devices. The engine exhaust was treated using several combinations of the DCL/Rohmac exhaust after-treatment system components and Pallflex ${ }^{\circledR}$ paper filter. The DCL/Rohmac after-treatment system included the oxidation catalytic converter and the particulate trap.

The steady-state measurements were performed as per ISO 8178-C Steady-State 8-Mode Test Cycle (see Table 3.2) at four operating points. Mode 1 ( 112 Nm @ 3000 rpm), mode 2 (56 Nm @ $3000 \mathrm{rpm}$ ), mode 5 (133 Nm @ $1960 \mathrm{rpm}$ ) and mode 7 (66 Nm @ $1960 \mathrm{rpm}$ ) were used for each of the engine/after-treatment system combinations. An air cooled eddy-current dynamometer (Mustang PAU 300) was used to apply load on the engine. The fuel rack was controlled manually. A Dyne System Co., Dyn-Loc IV dynamometer control unit was employed to control the dynamometer operation. 
Table 3.2 ISO 8178-C Steady-State 8-Mode Test Cycle

\begin{tabular}{|c|c|}
\hline Mode & Operating Condition \\
\hline \hline 1 & Rated Speed, 100 \% Load \\
\hline 2 & Rated Speed, 75\% Load \\
\hline 3 & Rated Speed, 50\% Load \\
\hline 4 & Rated Speed, 10\% Load \\
\hline 5 & Intermediate Speed, 100\% Load \\
\hline 6 & Intermediate Speed, 75\% Load \\
\hline 7 & Intermediate Speed, 50 \% Load \\
\hline 8 & Idle, No Load \\
\hline
\end{tabular}

\section{Orion/DDC 6V92 Study}

The study on the size distribution of DPM tailpipe emissions from in-use heavy duty vehicles was conducted in tandem with extensive emissions testing of the Port Authority of Allegheny County Pittsburgh (PAT) transit buses. These Orion transit buses were powered by Detroit Diesel Corporation 6V92 diesel engines. The specifications for the engines are listed in the Table 3.1.

Three of the six tested buses (buses 2029, 2030, 2034) used engines with high mileage accumulation and were not equipped with any exhaust gas after-treatment device. The other three buses (buses 2025, 2029, 2048) had engines that were recently rebuilt in accordance with the requirements of the Environmental Protection Agency's Urban Bus Retrofit/Rebuilt Program and were fitted with an oxidation catalytic converters. Bus number 2029 was tested early in the study without an oxidation catalytic converter. It was then fitted with a rebuilt engine and an oxidation catalytic converter and retested. The test buses were not modified in any way for the Mossgas synthetic diesel fuel (see Chapter 3.1.1.3).

The city buses were exercised through the Central Business District (CBD) speed-versustime cycle described in the Society of Automotive Engineers Recommended Practice J1376 (Figure 3.2). The CBD cycle simulates the driving pattern in an urban area. This test consists of several transients in which engine approaches its maximum power. The cycle has 14 identical ramps, each of which is 40 seconds long. Each ramp allows 10 seconds for acceleration, 18.5 seconds for a constant speed of $32 \mathrm{~km} / \mathrm{h}$ 
(20 mph), 4.5 seconds for deceleration, and 7 seconds for idling. The total driving distance of the cycle is approximately 2 miles. Each vehicle test consists of a warmup, a 547.4 seconds test, and a cool-down period.

The size distribution measurements of DPM emissions from PAT transit buses were performed on the vehicles driven under different steady state vehicle/engine operating conditions ( $20 \mathrm{mph}$, $30 \mathrm{mph}, 40 \mathrm{mph}$, and idle). The measurements were commenced at the end of a five-minute period, which was necessary for setting up the engine and the sampling system.

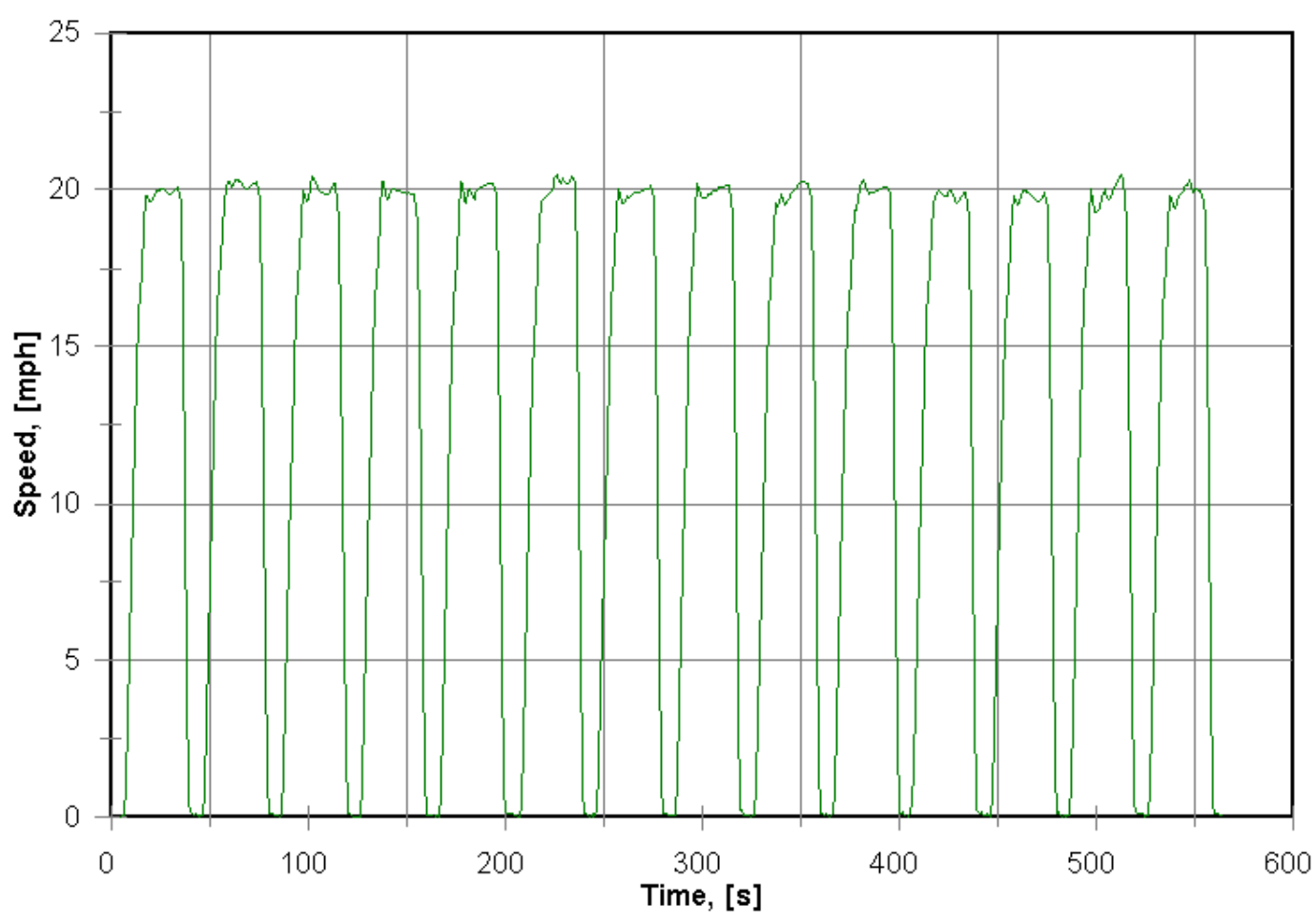

Figure 3.2. Central Business District (CBD) Transient Cycle, Actual Test Data 


\section{Mack E7-400 Study}

A series of size selective DPM measurements were conducted on a Mack E7-400 engine exhaust. The tests were done in Federal Test Procedure engine test cell at the WVU ERC. The engine was operated under transient and steady-state conditions. An air cooled direct current dynamometer General Electric Type DYC243 was used to apply loads on the engine.

The engine was operated under transient and steady-state conditions. Hot-start transient emissions tests on Mack E7-400 engines were conducted in accordance with the requirements of the Code of Federal Regulations (CFR), Title 40, Part 86, Subpart N (see Figure 3.3). The FTP heavy-duty transient cycle is currently, in the USA, used for certification of heavy-duty on-road engines. The transient test was developed to take into account the variety of heavy-duty trucks and buses on the US highways and cities, including the traffic in and around the cities on roads and expressways. Average load factor in this test is about 20 to $25 \%$ of the maximum horsepower available at a given speed. The equivalent average speed is about $30 \mathrm{~km} / \mathrm{h}$ and the equivalent distance traveled is $10.3 \mathrm{~km}$ for a running time of $1200 \mathrm{~s}$. The variation of normalized speed and torque with time is shown in Figure 3.3. Heavy duty diesel engines tested on the FTP cycle produce medium to high exhaust gas temperatures. Generally, the temperature is at a medium level between $250^{\circ} \mathrm{C}$ and $350^{\circ} \mathrm{C}$, but there are some hot sections with temperatures reaching as high as $450^{\circ} \mathrm{C}$. In this study, mass emission rates of total $\mathrm{HC}, \mathrm{NO}_{x}, \mathrm{CO}$, and $\mathrm{TPM}$ were measured in accordance with the prescribed test procedure.

The DPM size distribution and concentration measurements on the Mack E7-400 engine exhaust were made under steady-state operating conditions. Steady state tests were performed per ISO 8178-C Steady-State 8-Mode Test Cycle (see Table 2) at three operating points: modes 2 (1271 Nm@1800 rpm), 3 (848 Nm@1800 rpm), and 7 (1033 Nm@1325 rpm). The set points were derived from an engine map that was determined prior to the test.

Each of the steady-state test modes was performed twice. The steady-state engine operating conditions were maintained constant for 1320 seconds. The sampling with MOUDI from partial dilution tunnel was initiated after 120 second stabilization period and took place for the next 1200 seconds at a constant sampling rate of $30 \mathrm{lpm}$. The size selective measurements of PM with SMPS were performed from the partial dilution tunnel in parallel to the MOUDI sampling. The regulated gaseous and 
total PM emissions were sampled from the full flow dilution tunnel during the last 300 seconds of the test period.

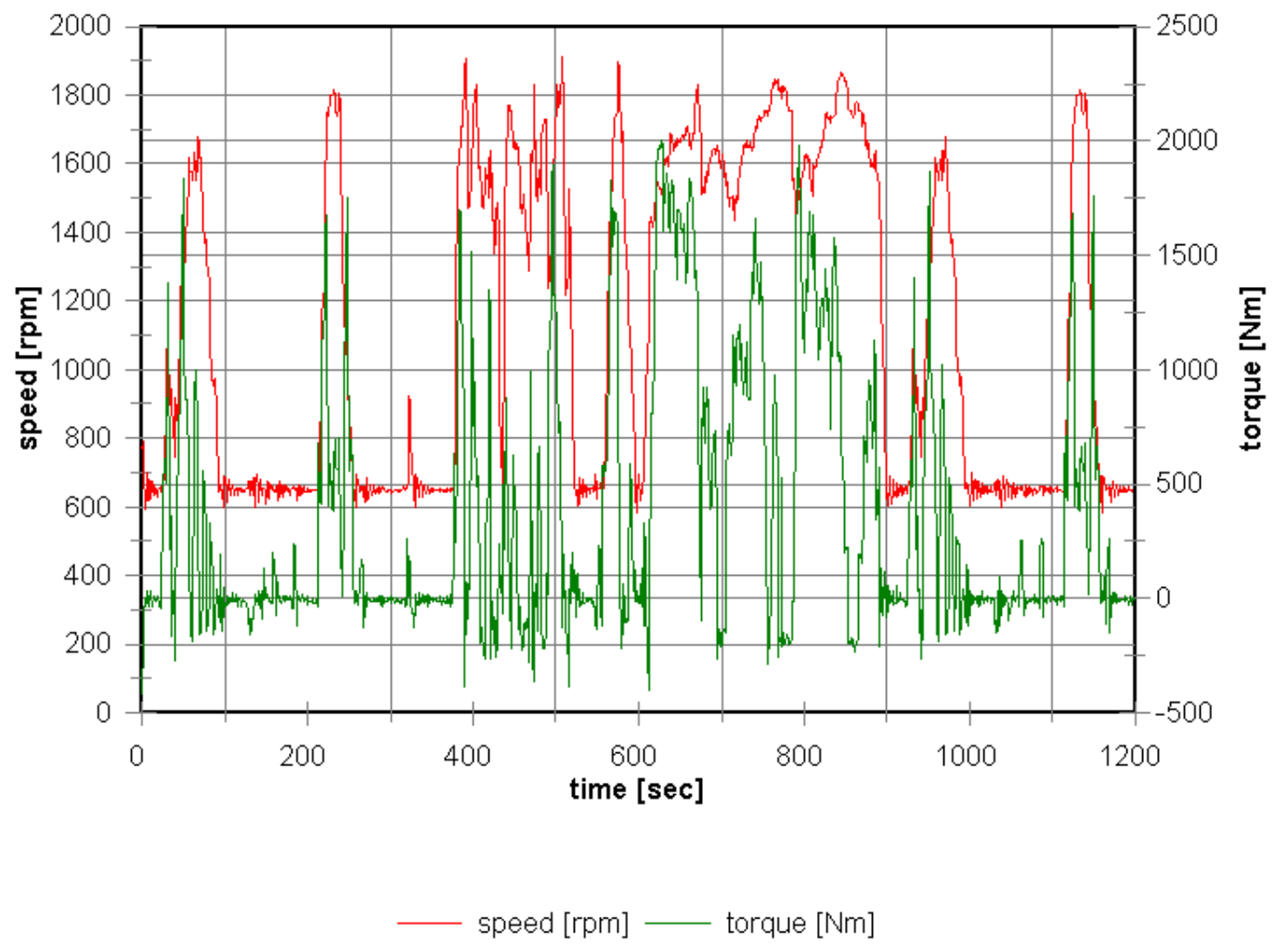

Figure 3.3 EPA Engine Dynamometer Schedule for Heavy-Duty Diesel Engines, RPM and Torque

\subsection{Size-Resolved Chemical Analysis of Diesel Particulate Matter}

Size resolved chemical analysis was performed on the MOUDI samples, which were collected from the exhaust of Mack E7-400 engine, in parallel to the size selective measurements of DPM. The engine was operated under transient and steady-state conditions. Exercising engines and vehicles through different cycles allowed an investigation on the impact of different operating and driving conditions on the size-resolved DPM emissions. However, the comparison of results from different test 
procedures required a careful consideration of the factors influencing PM emissions, not only under different driving modes, but also under different exhaust sampling and sample processing conditions.

\subsection{Speciation of Hydrocarbons}

The samples for speciation of hydrocarbons were collected from exhaust of a Cummins ISM 370 ESP. The engine was exercised under the same transient and steady-state engine operating conditions as Mack E7-400 engine. The laboratory set-up was identical to that employed for the testing of Mack E7-400 engine. Set points for mode 2 (1820 rpm/1079 Nm), 3 (1820rpm/720 Nm), and 7 (1225 $\mathrm{rpm} / 875 \mathrm{Nm}$ ) were based on the engine map determined prior to the tests.

\subsubsection{Fuels}

\subsection{Size Selective Measurement of Diesel Particulate Matter}

One of the objectives of the work reported here was to study the influence of fuel formulation on the size distribution of particulate matter from heavy-duty diesel engines/vehicles. The tested engines/vehicles have been supplied with a variety of fuels with different chemical composition and physical properties. To prevent potential uncertainties related to the fuel properties, large quantities of the employed fuels were stocked up and used throughout emission tests on a particular engine.

\section{Isuzu C240 Study}

In order to study the effects of fuel formulation on size distribution of particulate matter, the emission tests on the Isuzu C240 engine were performed with two different fuels: the Federal low sulfur diesel no. 2 and a synthetic diesel fuel. The Federal diesel no. 2 fuel (BP pump fuel) used in the Isuzu C240 study was analyzed by Analyst Inc., California, and its properties are listed in the Table A.1. The synthetic diesel supplied to the Isuzu engine was produced using Shell distillate process based on the Fisher-Tropsch (F-T) conversion. The synthesis gas was obtained from natural gas. The F-T process was used for synthesis of hydrocarbons from carbon monoxide and hydrogen. The synthetic diesel produced 
by this process is of a very high quality and has the potential for significantly reducing exhaust emissions. The relevant properties of the fuel are listed in the Table A.1. Significantly lower content of sulfur and aromatics in the F-T synthetic diesel than in the Federal diesel no. 2 (10 ppm vs 400 ppm, and 0.1\% vs. 29.1 percent) was expected to result in significant reductions in PM mass emissions and different size distributions. The drawback of F-T process is a low efficiency which makes this fuel expensive at the time of report.

\section{Orion/DDC 6V92 Study}

Study on the effects of fuel formulation on size resolved PM emissions was continued with emission testing of PAT transit buses. The buses were tested using Federal diesel no. 2 (Exxon pump fuel) and Mossgas synthetic diesel (100 \% MGSD). The properties of the no. 2 diesel were determined by laboratory analysis (Analysts, Inc., Georgia) and are listed in Table A.1. The Mossgas synthetic diesel fuel was produced using the Mossgas conversion of olefins to distillate process. The analyses of the relevant properties of Mossgass synthetic diesel were provided by supplier Mossgas LTD. and SwRI and are listed in Table A.1. The cetane number of Mossgas synthetic diesel was relatively low in comparison to typical F-T fuel and comparable to that of Federal diesel no. 2. The aromatic content was significantly lower for Mossgas synthetic diesel than for diesel no. 2 (10.1\% vs 24.7\%). Major impact of PM emissions was expected due to significantly lower sulfur content in the Mossgass synthetic diesel than in diesel no. 2 (10 ppm vs 200 ppm). A commercially available lubricity improver (Paradyne 655) was added to meet the required lubricity levels.

The measurements were also performed on the buses fueled with no. 2 diesel/ Mosgass blend fuel. The results of those measurements exhibited inconsistent behavior and were not used for the analysis. The results of PM sizing obtained with blend were found to be affected with inadequate mixing of two fuels with different densities (see Table A.1), which resulted in a nonhomogeneous mixture of the fuels in the reservoir. Due to stratification in the reservoir the buses were not supplied with uniform mixture throughout the testing. 


\section{Mack E7-400 Study}

The size selective measurements on the Mack E7-400 were conducted using Federal no.2 diesel fuel. This fuel's properties were not analyzed.

\subsection{Size-Resolved Chemical Analysis of Diesel Particulate Matter and Speciation of The Hydrocarbons}

The size-resolved chemical analysis of the exhaust from Mack E7-400 and speciation of the hydrocarbons from Cummins ISM 370 ESP were conducted using identical Federal no.2 diesel fuel. The analyses were not performed on this fuel.

\subsubsection{Sampling Equipment and Instrumentation}

\subsubsection{S Size Selective Measurements of Diesel Particulate Matter}

The size selective measurements of particulate matter in the diluted exhaust of Isuzu C240 of-road engine, six PAT buses powered with DDC 6V92 engines, and Mack E7-400 on-highway engine were performed using custom designed and fabricated sampling system. The sampling system includes a partial flow dilution tunnel, flow measurement and control instrumentation, a dilution air supply system, sampling lines and the instrumentation for size selective measurements. The system's mobility and selfsufficiency make it suitable for size-selective measurements of particulate matter from in-use heavy-duty engines/vehicles exhaust in laboratory and in-field conditions. The system allows the estimation of concentration of PM and chemical species in raw exhaust.

The SMPS and MOUDI (Section 3.1.1.4.1), the state-of-the art aerosol instruments most commonly used for atmospheric and combustion aerosol measurements, were used for measurements on the diluted exhaust. The SMPS was found to be more efficient for conducting extensive studies such as this one. Therefore, the SMPS was employed to study the effects of dilution ratios on size selective measurements of PM and also to study the effects of engine operating conditions, fuel type, and aftertreatment device on size resolved PM distribution in diesel exhaust. The MOUDI was employed for a 
limited number of tests designated for a comparative study (SMPS vs. MOUDI), and collection of samples for size-resolved chemical analysis. Detailed description of the sampling system and instrumentation follows.

Partial Flow Dilution Tunnel and Sampling Train

A manageable size of the system and a good control over the relevant flow and sampling parameters make the partial dilution tunnel (Figure 3.4) approach most suitable for the present study. The system, shown in Figure 3.5, was designed to sample raw exhaust from the transfer line or diluted exhaust from the full-flow dilution tunnel (Figure 3.1). The system incorporated a mini-dilution tunnel, pumps, mass flow and temperature measurement and control instrumentation, and accompanying transfer lines. The tunnel body was built from 3.25" (73 mm) ID stainless steel pipe. The tunnel had two distinct compartments; a dilution air inlet with a mixing plenum and a sampling chamber. The mixing plenum and an orifice plate ensured well mixed flow and concentration distribution profiles for the diluted exhaust at the sampling zone. The partial-flow dilution tunnel, the pumps, and the mass flow measurement instrumentation were designed to achieve repeatable and accurate dilution ratios of up to 1:30.

Dilution ratio (DR) is defined for the sampling system as diluted exhaust flow rate divided by the raw exhaust sample flow rate. It may be expressed in terms of diluted exhaust flow rate $Q_{t}$, dilution air flow rate $\mathrm{Q}_{\mathrm{d}}$, sampling flow rate $\mathrm{Q}_{\mathrm{s}}$, and raw exhaust flow rate drawn into the tunnel $\mathrm{Q}_{\mathrm{e}}$.

$$
\mathrm{DR}=\frac{\mathrm{Q}_{\mathrm{t}}+\mathrm{Q}_{\mathrm{s}}}{\mathrm{Q}_{\mathrm{e}}}=\frac{\mathrm{Q}_{\mathrm{d}}+\mathrm{Q}_{\mathrm{s}}+\mathrm{Q}_{\mathrm{e}}}{\mathrm{Q}_{\mathrm{e}}}=\frac{\mathrm{Q}_{\mathrm{t}}+\mathrm{Q}_{\mathrm{s}}}{\mathrm{Q}_{\mathrm{t}}+\mathrm{Q}_{\mathrm{s}}-\mathrm{Q}_{\mathrm{d}}}
$$

To avoid sample disturbance, dilution ratio was determined using an indirect approach illustrated by the third expression in the Equation 3.1. Once the dilution ratio was known, then the diluted exhaust concentrations, measured by the SMPS and MOUDI, could be converted to raw exhaust concentrations. The diluted exhaust flow rates were maintained between $120 \mathrm{slpm}(\sim 4 \mathrm{scfm})$ and $150 \mathrm{slpm}$ $(\sim 5 \mathrm{scfm})$ throughout the experiments. The corresponding residence times were approximately $0.15 \mathrm{~s}$. 
The tunnel was designed to satisfy the major criteria for achieving uniform distribution in the sampling zone. The ratio of the length of tunnel (distance between mixing orifice plate and sampling zone) and the tunnel diameter was about 10. Calculated values of the Reynolds number $\left(\operatorname{Re}=v d_{t} / v\right)$ for

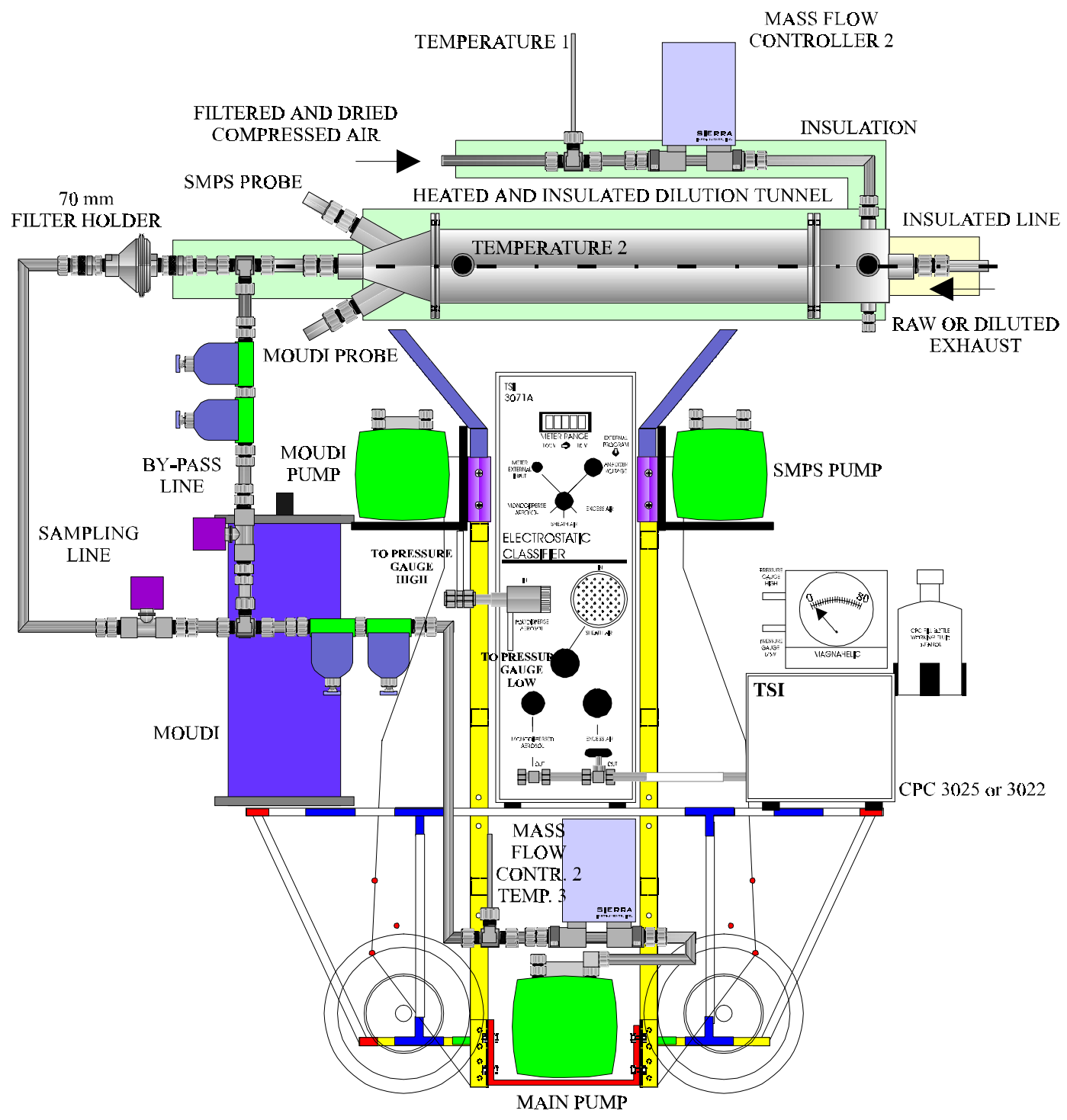

Figure 3.4 Mobile Partial-Dilution System for Size Selective Measurements of Particulate Matter, Partial Dilution Tunnel 
the different anticipated flow conditions indicated turbulent regime and good mixing. The tunnel was wrapped with a heating tape and was well insulated. The use of a microprocessor base temperature controller helped in maintaining constant fluid temperature. The mass flow controllers were calibrated for temperatures in range from $15^{\circ} \mathrm{C}$ to $25^{\circ} \mathrm{C}$. Hence, the fluid temperatures in the system were maintained in the range which allowed most accurate flow measurements.

The raw exhaust was sampled with a 3/4" (19 mm) probe inserted into the exhaust stack in the case of vehicles or several feet downstream of the turbocharger in the case of engine tests. The sampling probe was followed by a short section of 3/4" (19 mm) well insulated stainless steel transfer pipe. The length of the transfer line was kept as short as possible depending upon what the test conditions allowed. The exhaust transfer line was well insulated to minimize sample losses, particularly diffusion and thermophoretic deposition to the walls. Moreover, sharp bends and other restrictions in the transfer line were avoided as much as possible.

An oil-free compressor (Craftsman Model no.16420) provided stable hydrocarbon-free stream of dilution air. The dilution air was filtered through a pre-filter, cooled in a counter-flow heat exchanger, treated in a refrigerated drier, and passed through a HEPA filter in order to remove water and particulate matter. Oilless rotary vane vacuum pumps were used for drawing diluted exhaust samples for size selective measurements from the dilution tunnel. These rotary vane pumps provided a pulsation- free flow and were very suitable for high flow and vacuum applications.

The diluted exhaust sampling probes were located on the downstream end of the minidilution tunnel. The probes and their locations were designed to minimize sampling artifacts, wall deposition and re-entrainment. To avoid particle losses due to electrostatic effects, anti-static Tygon or carbon impregnated silicon tubing were utilized for aerosol transfer from the tunnel to the instruments. The $70 \mathrm{~mm}$ filters enclosed in the stainless steel filter holder, situated at the outlet of the tunnel, were designated for integrated total particulate matter sampling. However, the total PM sampling was not done in the mini-dilution tunnel. By-pass lines on the main stream line and MOUDI sampling train helped minimize transient effects (Figure 3.7) during collection of samples for size-resolved PM analysis. Use of bypass line in the sampling system protected the pump from excessive load and prevented generation of artifacts. Diverting flow from the sampling line to the bypass line was managed by remotely controlled solenoid valves. The integrated PM sampling train was removed from the system when it was not in use. 

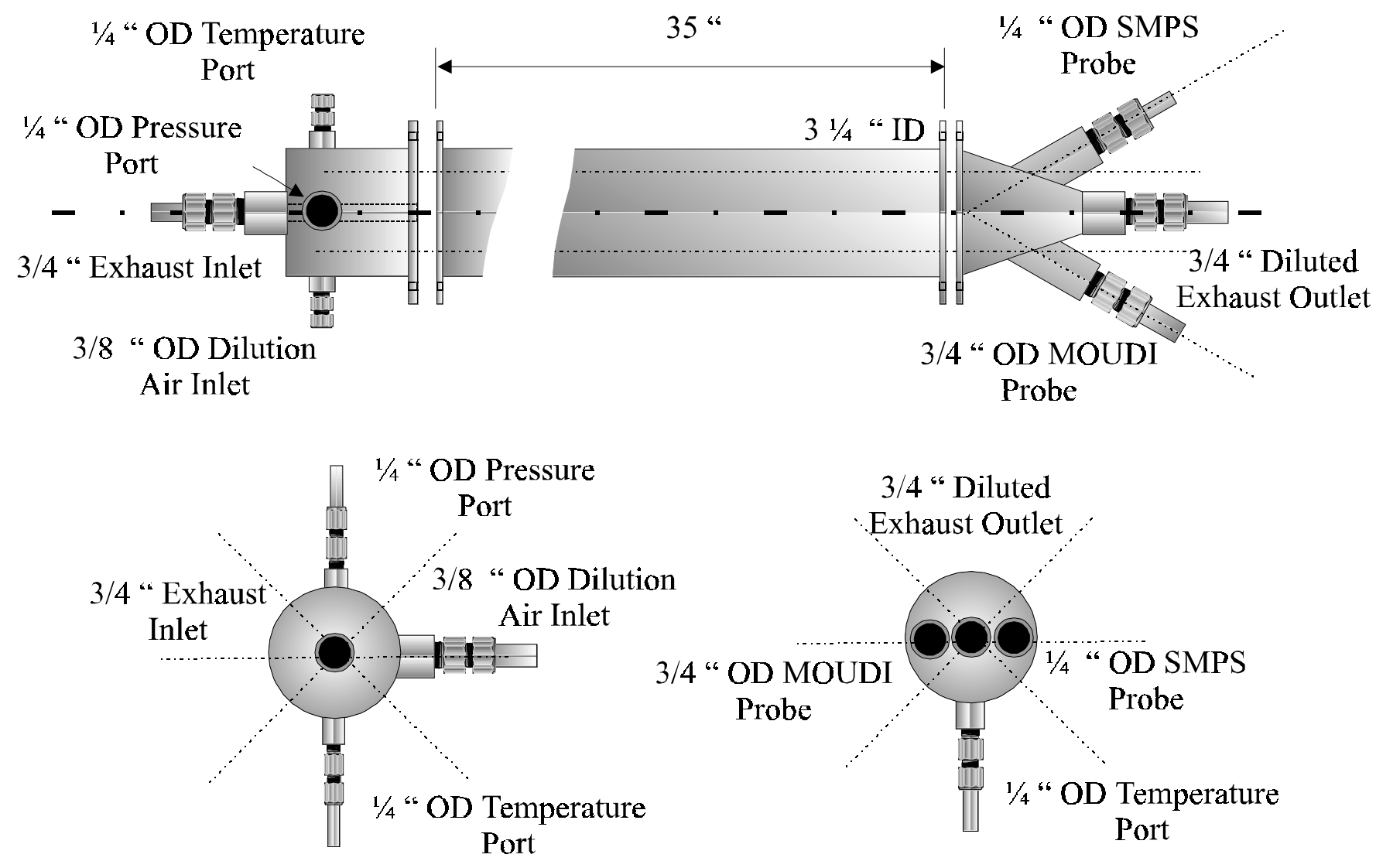

Figure 3.5 Mobile Partial-Dilution System for Size Selective Measurements of Particulate Matter, Partial Dilution Tunnel 
This resulted in reduction of pressure losses through the system and minimized the restrictions on the diluted exhaust flow.

The precise measurement and control of the gas flow rates was crucial for accurate calculation of the dilution ratios and particle concentrations. For this reason, two Sierra Series 740 mass flow controllers, calibrated for flow rates ranging from 0 to 200 slpm were employed for dilution air and diluted exhaust mass flow rate measurements and control. The mass flow controllers had an accuracy of \pm 2 percent (full scale) up to $50^{\circ} \mathrm{C}$ and 0.3 to $3 \mathrm{~atm}$ and a response time of four seconds to reach within \pm 3 percent of set point. Mass flow controllers were operated through Sierra Series 900 Flo-Box System Unit. To assure accurate flow rate measurements, temperatures of the dilution air and the main diluted exhaust flow stream were maintained in the range specified by the manufacturer. The exhaust and diluted exhaust flow rates were regularly checked using a Sierra Series 822 mass flow meter with an accuracy of \pm 1 percent of full scale including linearity over $15-25^{\circ} \mathrm{C}$ and 0.3 to $4 \mathrm{~atm}$, and time constant of $800 \mathrm{~ms}$, and two seconds to within \pm 2 percent of final value. The dilution air mass flow controller was protected by a HEPA filter and the main stream flow mass controller was protected by two coalescing Headline C70 and C50 filters (or Balston DX and BX filters). The role of the filters was to prevent potential damage to the mass flow controllers due to excessive particulate matter or water vapor load.

The diluted exhaust was drawn through the system by an oil-less rotary vane pump (Gast 1023 Series) located at the outlet of the system. Stainless steel tubing and fittings were used for all sections of the sampling system that were exposed to diesel exhaust.

\section{Scanning Mobility Particle Sizer (SMPS)}

Two 3934 SMPS configurations, including two Electrostatic Classifiers (EC) 3071 and two Condensation Particle Counter (CPC) units, Model 3022A and 3025A, have been used in this study for steady-state full scan size-selective measurements and real time tracking of the diesel exhaust particulate matter. The SMPS systems were used in conjunction with personal computers and custom software, to control the instruments and perform data acquisition and reduction (Figure 3.6).

The SMPS configuration, incorporating CPC Model 3022A, is good for measurements of size distribution of aerosols in the size range from $7 \mathrm{~nm}$ to $1000 \mathrm{~nm}$ and the concentration range from 
2 particles $/ \mathrm{cm}^{3}$ to $10^{8}$ particles $/ \mathrm{cm}^{3}$ (TSI SMPS manual). The SMPS configuration, incorporating CPC Model 3025A, is good for measurements of the size distribution of aerosols in the size range from $5 \mathrm{~nm}$ to $1000 \mathrm{~nm}$ and the concentration range from 20 particles $/ \mathrm{cm}^{3}$ to $10^{7}$ particles $/ \mathrm{cm}^{3}$ (TSI SMPS manual, 1996). Bischof (1998) reported the SMPS accuracy and repeatability of 14 measurements as follows: $\mathrm{CV}=0.2 \%$, random error of $0.1 \%$ and total uncertainty $-3.3 \% /+3 \%$.

The instrument uses an electrical mobility detection technique to measure number and size distribution of particles. Electrical mobility analysis gives results based upon particulate number density as function of the Stokes diameter. The role of the electrostatic classifier is to classify polydisperse aerosol to particles with narrow range of electrical mobility, the so-called monodisperse aerosol, and transfer then to the CPC where the particle concentration has to be determined. Large particles ( $>1 \mu \mathrm{m}$ ) are removed at the inlet of the EC by means of an impactor. Different orifice size nozzles $(0.127 \mathrm{~nm}$ and $0.457 \mathrm{~nm})$ are used depending on the selected flow rates. The polydispersed aerosol is charged in $\mathrm{Kr}-85$ Bipolar Charger to obtain the Boltzman equilibrium charge distribution. The laminar flow of polydisperse aerosol and filtered sheath air are maintained through annular space between two concentric metal cylinders. The inner cylinder is kept at a controlled negative voltage, while the outer cylinder is electrically grounded. The resulting electric field attracts positively charged particles to the negatively charged rod. The location of the precipitating particles depends on their mobility. Particles within narrow range of electrical mobilities exit as monodisperse air through a small slit located at the bottom of the collector rod. The axial distance of the aerosol inlet to the outlet slit is $\mathrm{L}=43.6 \mathrm{~cm}$. The distance was selected to provide residence time which is long enough for the classification of particles at upper size limit of the instrument and results in a reasonable diffusion losses of particles at the lower size limit of the instrument. The outer radius of the inner electrode is $R_{1}=0.937 \mathrm{~cm}$ and the inner radius of the outer electrode is $R_{2}=1.985 \mathrm{~cm}$. There have been some attempts (Kuosaka et al., 1986; Winklmayr et al., 1991; Seto et al., 1997) to improve the accuracy of electrostatic classification for ultra small aerosol distribution measurements by decreasing axial distance between slits and operating the device under low pressure conditions. The most recent model of electrostatic classifier by TSI (Series 3080) offer long, radial, and nano differential mobility analyzed. The last design offer lower diffusional losses and better performance at particle sizes below $150 \mathrm{~nm}$. 


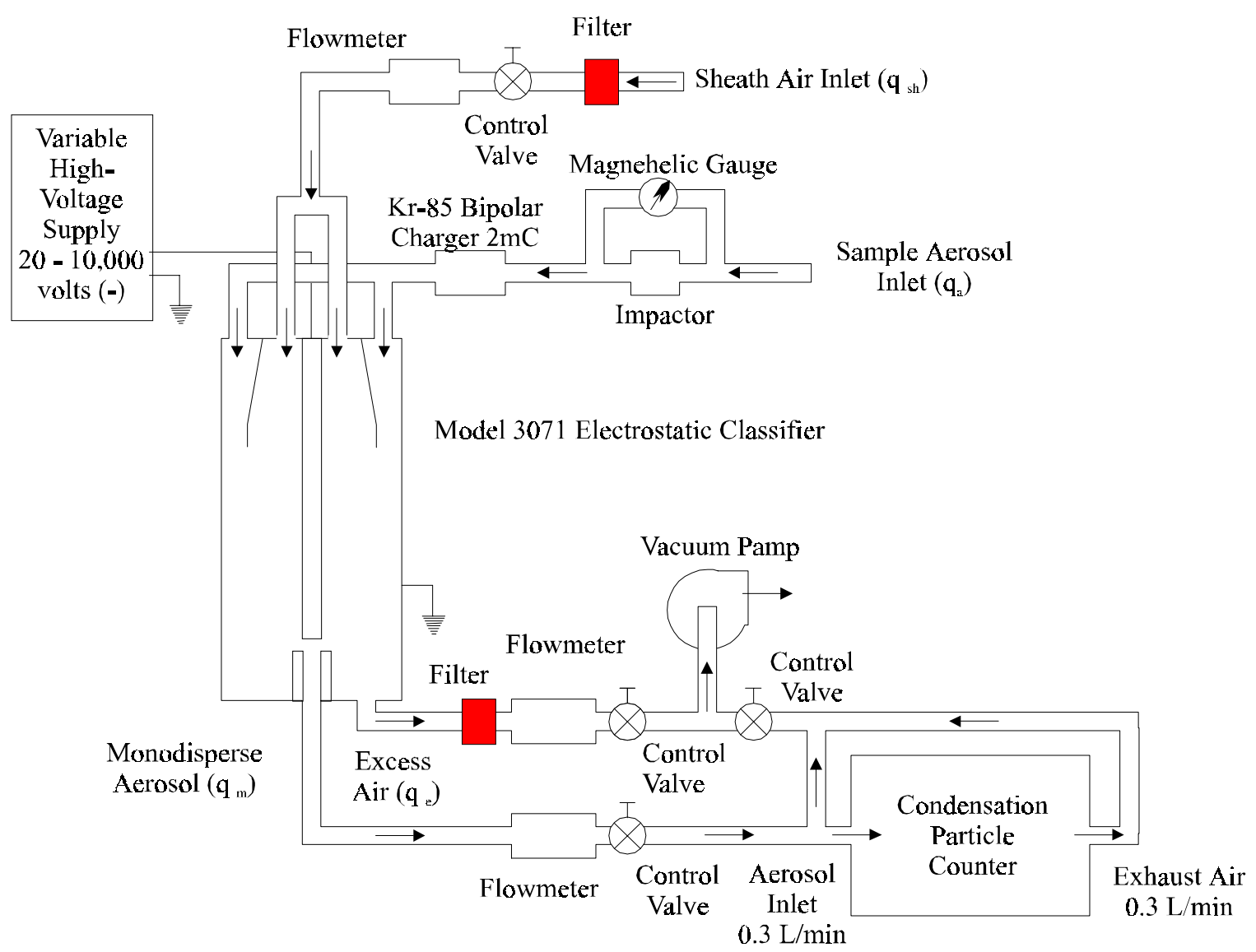

Figure 3.6 Mobile Partial-Dilution System for Size Selective Measurements of Particulate Matter, Scanning Mobility Particle Sizer 
The Condensation Particle Counter (CPC) measures the concentration of submicrometer particles by utilizing heterogeneous condensation to enlarge the particles to about micrometer size (5-10 $\mu \mathrm{m}$ according to Abdul-Khalek et al. (1998) and 5-15 $\mu \mathrm{m}$ according to Cheng (1993)), so they can be counted optically. The heterogeneous nucleation of small droplets is described by Kelvin equation (Hinds, 1982):

$$
\frac{p}{p_{s}}=\exp \left[\frac{4 \gamma M}{\rho R T d_{k}}\right]
$$

where $p, p_{s}, R, T$ are partial pressure, saturation vapor pressure, gas constant, and temperature. $\gamma, \mathrm{M}$, and $\rho$ are the surface tension, molecular weight, and density of the liquid and $d_{k}$ is the Kelvin diameter. Kelvin diameter is defined as diameter of the droplet which will neither grow nor evaporate at the saturation ratio $\mathrm{p} / \mathrm{p}_{\mathrm{s}}$. For greater saturation ratio, particle will grow, for smaller it will evaporate. The Kelvin effect is significant only for particles less then $0.1 \mu \mathrm{m}$. The nuclei counters shows a decrease in counting efficiency for particles below $10 \mathrm{~nm}$ because of high supersaturations needed to activate the particles for their condensation growth . The activated and enlarged particles pass through a light beam and the scattered light is used to count them. Model 3022 uses photodetector which operate as a single-particle counter for counting at concentrations below 10,000 particles $/ \mathrm{cm}^{3}$. At concentrations below 10,000 particles $/ \mathrm{cm}^{3}$, the pulse of the light scattered by each particle is counted separately and the concentration is computed from the frequency of pulse. The limiting factor of single-particle counting mode is coincidence. When the instrument is in single-particle counting mode and concentrations of particles are high, two or more particles might be in the viewing volume at the same time. The pulse they generate overlap and are counted as one particle. CPC models 3022A and 3025A have a built-in coincidence correction. Calibrated photometer is employed for counting at concentrations higher than 10000 particles $/ \mathrm{cm}^{3}$. The CPC Model 3022 is sensitive to mode change, and is essential to maintain the concentration below or above 10,000 particles $/ \mathrm{cm}^{3}$. The CPC Model 3025, also known as ultra fine condensation particle counter, has only single-particle-counting mode.

A personal computer with custom software was used for the instrument control and data acquisition and data reduction. Both of the SMPS configurations have been operated in the under-pressure mode. During under-pressure operation, air is drawn through DMA and is set by the CPC. This is common 
practice when sampling is from aerosol at or near atmospheric pressure. Symmetric flow conditions were maintained through all measurements. At symmetric flow conditions, flow rates of polydisperse and monodisperse aerosol, as well as sheath air and excess air are equal. Such flow conditions provided two separate laminar streams inside DMA, polydispers aerosol stream next to the inner electrode and sheath air stream at the outer portion of annulus. Selection of the adequate flow rates was found to be crucial for obtaining representative data. The selected flow rates influence size range of the particles included in the scan and generate potential measurement artifacts, as described by Keady et al. (1983). The flow rates on the electrostatic classifier were set according to the existing pressure and temperature conditions in the sampling systemand the ambient. A consequence of the deviation of pressure and temperature with respect to those under which the instrument was calibrated was that voltages corresponding to those flow rates were different than voltages provided in the calibration sheets. Therefore, flow rates were routinely measured by Gilibrator bubble flow meter and adjusted accordingly.

The steady-state SMPS measurements for this study were performed with scan times of 60 seconds and longer. Quant et al. (1993) found that scans faster than 60 seconds show a smearing of the measured particle distribution due to the effects of the detector response time. For transient size distribution measurements the SMPS has been adjusted to pre-selected fixed narrow size ranges to register the time variation in the size selected particle emissions.

To assure accurate measurements, the SMPS was tested for possible internal and external leaks prior to each series of runs. The leak check procedure recommended by the manufacturer was followed for each major component of the SMPS system. In addition, potential leaks were detected by running 300 second long full scan with the HEPA filter attached to the aerosol inlet. Detection of more than a few dozen particles indicated a potential leak.

\section{Micro Orifice Uniform Deposit Impactor (MOUDI)}

Cascade impactors are commonly used aerosol sampling instruments for both stationary source and process stream evaluations because of their rather inexpensiveness, design and simple operation. The particles in an impactor are classified by their aerodynamic diameter. The smallest aerodynamic cutoff particle diameter achieved by impactor stage operating at atmospheric pressure and 


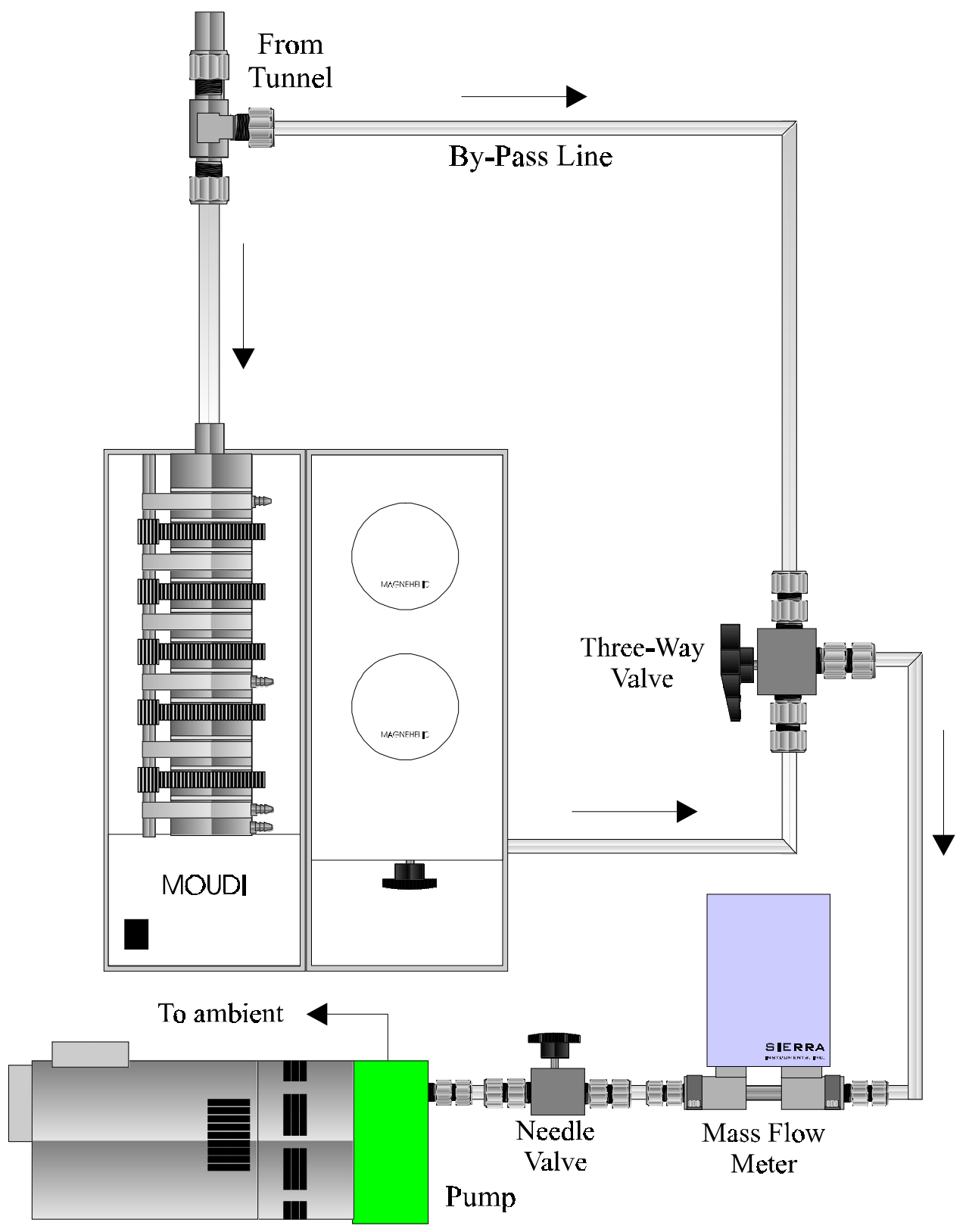

Figure 3.7 Mobile Partial-Dilution System for Size Selective Measurements of Particulate Matter, MOUDI Sampling Train 
drilled orifice is about $0.3 \mu \mathrm{m}$. To extend the size range below $0.3 \mu \mathrm{m}$, a smaller orifice or a reduced pressure at high jet velocities are required. The former is used in the micro-orifice uniform deposit impactor, MOUDI. Cascade impactors which employ the latter approach are commonly called the low pressure impactors. Different number of holes on the last stage of the impactors illustrates difference in design (1, 130, and 2000 for the Hering, Berner and MOUDI impactors, respectively).

MOUDI is a cascade impactor available in both eight and ten stage versions. Figure 3.7 shows a ten stage version of MOUDI Model 110 which was used in this study. Model 110 has ten stages with nominal $50 \%$ efficiency curve aerodynamic diameters of $0.056,0.100,0.180,0.320,0.560,1.0,1.8$, 3.2, 5.6, 10 and $18.0 \mu \mathrm{m}$. MOUDI moderates the pressure drop needed to size submicron aerosols by using nozzles of very small diameter (2000 nozzles of $52 \mu \mathrm{m}$ in diameter in the final stage). It operates at a rather high flow rate of $30 \mathrm{lpm}$. The flow rate through the instrument is determined by measuring pressure drop across upper stages and across lower stages by Magnehelic differential pressure gauge and using a needle valve for adjustments.

MOUDI consists of two basic assemblies, the cascade impactor and the rotator. The use of rotating stages helps achieve relatively uniform particle deposit on the impaction plates. The rotor contains a control valve for controlling the flow through MOUDI and two pressure gauges. The upper pressure gauge monitors the pressure drop across the first five stages to indicate the air flow rate through the impactor. The lower pressure gauge monitors the pressure drop across the lower stages. The increase in pressure drop across the lower stages results from an accumulation of PM on the nozzle walls and this suggests that the final stages of the impactor should be cleaned.

The type of impaction substrate and the method of substrate preparation significantly affect measurement with an impactor. The type of substrate required in MOUDI is primarily determined by the type of aerosol to be collected and the method by which the deposits are to be analyzed. Mass distribution measurements require the substrate with a stable tare weight and low mass. The MOUDI is designed for and calibrated with 0.001 inch thick substrate material(Instruction Manual for MOUDI, MSP Corporation, 1998). Howel et al. (1998) used $25 \mu \mathrm{m}$ thick PTFE film for $47 \mathrm{~mm}$ impaction substrates and $1 \mu \mathrm{m}$ pore size Fluoropore (Millipore) filters. Materials such as aluminum foil and plastic film made of teflon or mylar may do well. The chemical analysis of the sample requires a chemically clean substrate with low weight 
such as teflon filters or pre-fired quartz filters. The diameter of the impaction substrates is $47 \mathrm{~mm}$, while diameter of the after-filter is $37 \mathrm{~mm}$. Impaction plate holders for $37 \mathrm{~mm}$ substrates are also available.

A major problem associated with collecting particulate matter on the impactor stages is particle bounce. Particles in the fluid stream are passed through a nozzle and directed toward the impaction plate. Particles with sufficient inertia are unable to follow the streamlines and therefore impact on the plate. Smaller size particles follow the streamlines and avoid hitting the plate. At the impact, the particle loses part of kinetic energy by deforming itself at the contact with the impaction plate. The other part of energy is converted to kinetic energy of rebound. If the rebound energy is greater than the adhesion energy, a condition that may occur for sufficiently high impact velocity, a solid particle will "bounce", i.e. move away after the contact with the surface. The particle bounce can be prevented by applying grease or an oil layer over the substrates. Greasing the substrate for MOUDI is a very delicate task and requires meticulous care and strict adherence to the established procedures. Unfortunately most of the procedures published in literature are inefficient. Substrate greasing procedures established by Cantrell (1998) have been found to be very effective. According to the majority of researchers, particle bounce is not an important issue in diesel particulate matter sampling. Also, greased substrates are not suitable for chemical analysis. Therefore, ungreased $47 \mathrm{~mm}$ aluminum foils (MSP) were used as impaction substrates for PM distribution measurements. The $37 \mathrm{~mm} 0.1 \mu \mathrm{m}$ pore size filters (Pall Gelman) were found to be most suitable as afterfilters. The samples for elemental and ion analysis were collected on the fluorinated ethylene-propylene (FEP) impaction substrates and teflon membrane after- filters. The carbon analysis was performed on the samples collected on the aluminum substrates and quartz fiber after-filters. The conditioning and weighing procedures, and the equipment employed for gravimetric analysis of TPM filters (described in Chapter 3.1.1.1) were also used for treatment and weighing of the substrates for size-selective measurements of particulate matter and size-resolved chemical analysis employing the MOUDI.

\subsubsection{Size-Resolve Chemical Analysis of Diesel Particulate Matter}

Samples for size-resolved chemical analysis ofDPM were collected by using the previously described sampling system based on a partial dilution tunnel (see Section 3.1.1.4.1 and Figures 3.4 and 3.7) and sampling procedures that were developed for size-selective measurements of DPM with MOUDI (see 
Section 3.1.1.4.1). The samples were collected from the exhaust of MACK E7-400 on-road engine exercised over FTP heavy duty diesel transient cycle and three steady-state conditions, R75, R50 and I50 (see Section 3.1.1.2.1).

\subsubsection{Speciation of Hydrocarbons}

The sampling system for speciation of diesel exhaust was designed to collect a proportional sample of diluted exhaust from the primary tunnel of the CVS or from the partial flow dilution tunnel (Figures 3.10 and 3.11). The system was designed for simultaneous sampling of particulate matter, semivolatile and volatile compounds from diluted diesel exhaust.

The sample temperature in the transfer line from the primary dilution tunnel to the sampling train was maintained at $190^{\circ} \mathrm{C}\left(375^{\circ} \mathrm{F}\right)$. This prevented condensation of semi-volatile compounds in the transfer line. A temperature controller and a heating tape were used for maintaining a constant fluid temperature. The particulate matter was captured on the primary and the secondary $70 \mathrm{~mm}$ filters, enclosed in the a stainless steel holder, at the inlet to the sampling train. The PUF/XAD-2/PUF tube (SKC Model 226-129, Pennsylvania), situated downstream of the filter holder, was employed for the collection of semivolatile compounds. The cartridge made of the glass tube, $65 \mathrm{~mm}$ (2.56 in) in diameter and $125 \mathrm{~mm}$ ( $5 \mathrm{in}$ ) in length, contained $50 \mathrm{~mm}$ PUF plug, $10 \mathrm{gm}$ of XAD-2, and $25 \mathrm{~mm}$ plug. Polyurethane foam (PUF) plugs were placed over fine stainless-steel screen to retain the PUF plugs and XAD-2 resin in the glass tube. The glass tube was sealed in the custom made holder. Volatile compounds were sampled into Tedlar bags by a Thomas Model 917 CA18TFEL-C, Teflon coated sealed diaphragm pump.

The precise measurement and control of the sampling mass flow rates was crucial for accurate quantitative analysis. A Sierra Series 840 mass flow controller, calibrated in the range from 0 to $200 \mathrm{lpm}$, was employed to maintain constant flow rate across the filters and resin. The other Sierra Series 840 mass flow controller, calibrated in the range from 0 to $10 \mathrm{lpm}$, ensured uniform filling of the bag for the duration of the tests. The accuracy of the mass flow controllers was \pm 1 percent of full scale over a temperature range of $15-25^{\circ} \mathrm{C}$ and pressure range of 0.7 to $4.2 \mathrm{~atm}$. The accuracy was \pm 2 percent of full scale over $5-50^{\circ} \mathrm{C}$ and 0.35 to $10.5 \mathrm{~atm}$. The response time for the larger unit was two seconds to reach within \pm 2 percent of set point, and for the smaller unit it was one second to reach within \pm 2 percent of 


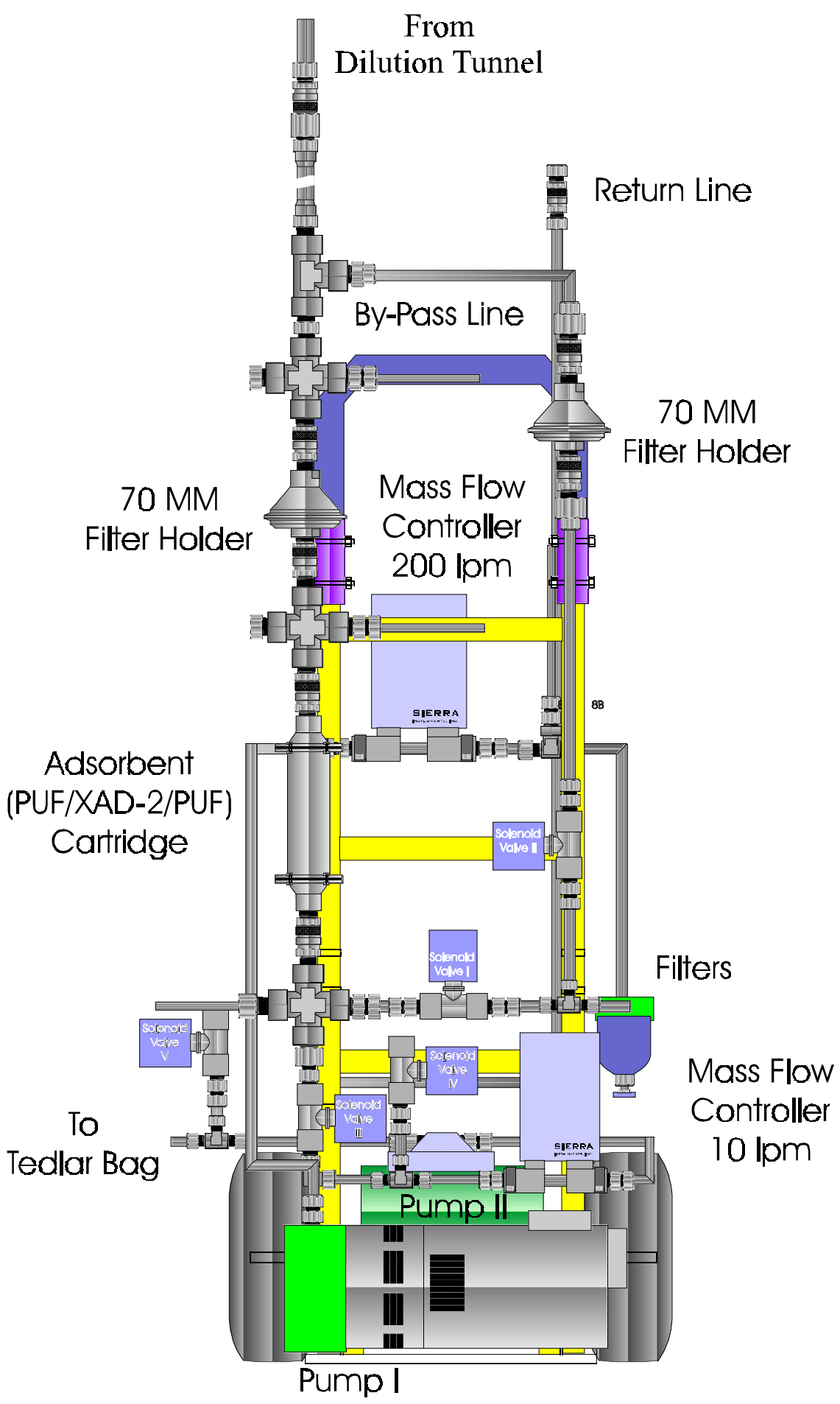

Figure 3.8 Mobile Partial-Dilution System for Speciation of Particulate Bound, Semi-Volatile, and Volatile Hydrocarbon, Front View 


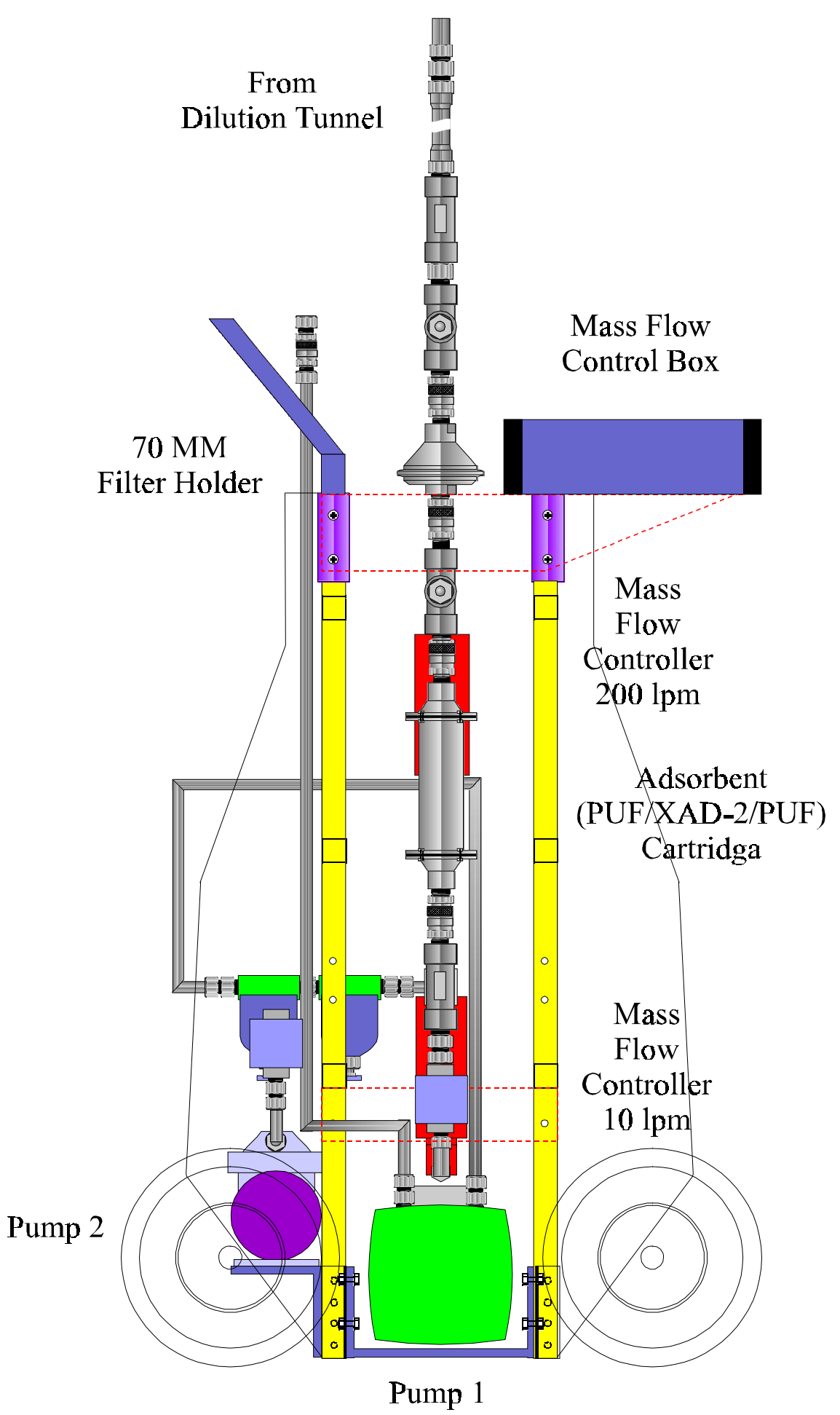

Figure 3.9 Mobile Partial-Dilution System for Speciation of Particulate Bound, Semi-Volatile, and Volatile Hydrocarbon, Side View 
set point. Mass flow controllers were operated by Sierra Series 900 Flo-Box System Unit. The diluted exhaust and the main stream flow rates were checked occasionally by the Sierra Series 822 mass flow meter which had accuracy of \pm 1 percent of full scale including linearity over $15-25^{\circ} \mathrm{C}$ and 0.3 to 4 atm, a time constant of $800 \mathrm{~ms}$, and a response time of two seconds to within \pm 2 percent of final value. The main stream mass flow controller was protected by two coalescing Headline C70 and C50 filters (or Balston DX and BX filters) connected in a series. The filters protected the mass flow controllers from excessive particulate matter or water vapor load.

A critical flow venturi (CFV), operated under choked flow conditions, maintained the constant mass flow rate in the dilution tunnel during testing. The error associated with dilute exhaust flow rate measurement was estimated by Gautam et al. (1998) to be app. 3\%.

The diluted exhaust was driven through the system by Gast 1023 Series oil-free rotary vane pump located at the outlet of the system. The pump allowed sampling flow rates of up to $150 \mathrm{slpm}(\sim 5$ $\mathrm{scfm})$. Two bypass lines, circumventing the sampling train, were incorporated into the system to minimize transient effects at the beginning and at the end of a sampling period. The by-pass line also allowed replacement of the filters and the cartridge without disturbing flow, and prevented sampling before and after the scheduled period. The flow rates and temperature profile along the sampling system were established prior drawing the sampl stream sampling stream through the bypass lines. Remotely controlled solenoid valves were used to divert the sample from the bypass lines to the sampling train and vice versa. All the parts of the system that were exposed to the sample were made of stainless steel.

\subsubsection{Uncertainty Analysis}

The calculation of the dilution ratio was found to be a major source of uncertainty in the inversion of the results of size selective measurements and size-resolved chemical analysis. Indirect approach of calculating dilution ratio employed in this study suffers from a relatively higher level of uncertainty than a direct approach. When tunnel exhaust flow rate is not measured, but rather calculated from diluted exhaust flow rate $Q_{t}$, dilution air flow rate $Q_{d}$, and sampling flow rate $Q_{s}$, as it was in this study (see Section 3.1.1.4.1), then the uncertainty of the dilution ratio is much higher than the uncertainty in the either of the measured flows. Following the assumption that uncertainty will behave much like 
standard deviation, Kline and McClintock (Beckwith et al., 1993) suggested the formula for calculating uncertainty $\mathrm{u}(\mathrm{y})$ :

$$
u(y)=\sqrt{\left(\frac{\partial y}{\partial x_{1}} u(x 1)\right)^{2}+\left(\frac{\partial y}{\partial x_{2}} u\left(x_{2}\right)\right)^{2}+\ldots+\left(\frac{\partial y}{\partial x_{n}} u(x n)\right)^{2}}
$$

where $\mathrm{y}$ is a linear function of the several independent variables $\mathrm{x}_{\mathrm{n}}$ and measurement uncertainty $\mathrm{u}$. Applying the formula given in the Equation 3.2 for the variables given in Equation 3.1 yields the following expression for estimating the dilution ratio uncertainty:

$$
u(D R)=(D R-1) \sqrt{u\left(Q_{t}\right)^{2}+u\left(Q_{s}\right)^{2}+u\left(Q_{d}\right)^{2}}
$$

The uncertainty in this situation increases linearly with increase in dilution ratio. For uncertainty in flow measurements of $\pm 1 \%$ and dilution ratios of 10,15 and 30 , the uncertainties for the situation described by Equation 3.3 are $15.58 \%, 24.25 \%$, and $50.23 \%$, respectively.

\subsubsection{Sampling Methodology}

\subsubsection{Size Selective Measurement of Diesel Particulate Matter}

\section{Isuzu C240 Study}

Model 3934 Scanning Mobility Particle Sizer coupled with Model 3022/A Condensation Particle Counter outlined in Section 3.1.1.4.1 was employed for the measurements of size-resolved particulate matter emissions from the diluted exhaust of Isuzu C 240 engine. A 60 second up-scan and a 30 second down-scan were used for scanning particulate matter distribution in diluted exhaust generated under steady-state engine operating conditions. Time restrictions as well as concerns for good repeatability were the main reasons for adopting a 60 second scan. Symmetric flow conditions were maintained through the instrument. Polydisperse and monodisperse aerosol flow rates were maintained at $0.5 \mathrm{lpm}$. Sheath air and excess air flow rates were fixed at $5 \mathrm{lpm}$. Those flow conditions allowed for scanning of particles with electrical mobility diameter ranging from $11 \mathrm{~nm}$ to $469 \mathrm{~nm}$. This size range 
was found to be adequate for the scanning of diesel engine combustion generated particulate matter. The flow rates through the instrument were calibrated and occasionally double-checked using the bubble flow meter.

\section{Orion/DDC 6V92 Study}

A Model 3934 Scanning Mobility Particle Sizer along with Model 3022/A and 3025/A Condensation Particle Counters (CPC) were employed in the size selective measurements of PM in the diluted exhaust of six PAT transit buses. The measurements on the exhaust from the bus 2025 were performed with SMPS coupled to CPC 3025. The emissions from all the other buses were measured with SMPS coupled to CPC 3022. To avoid uncertainties due to different calibrations and accuracies of the instruments, the results obtained by CPC 3022 were exclusively used in the analysis. A 60 second up-scan and 30 second down-scan were used for full distribution scan under steady-state engine operating conditions. Symmetric flow conditions (see Section 3.1.1.4.1) were maintained through the instruments. Polydisperse and monodisperse aerosol flow rates were set at 2 lpm, while sheath and excess air flow rates were set at $20 \mathrm{lpm}$ for transient measurements. The highest recommended flow rates through the instruments were selected in order to provide a fast system response required for real time tracking. Steady-state full scan measurements were performed with $0.5 / 5 \mathrm{lpm}$ flow conditions. These flow conditions allowed the scanning of particles with electrical mobility diameter ranging from $11 \mathrm{~nm}$ to 469 $\mathrm{nm}$. The flow rates through the instruments were calibrated and frequently verified using a bubble flow meter. The dilution ratio of 21 was selected as adequate for maintaining particle concentrations in the range acceptable for the instruments at all steady-state and transient vehicle operating conditions.

Size selective measurements of DPM with MOUDI were performed on the diluted exhaust of the bus 2034 in parallel to the measurements with SMPS. 


\section{Mack E7-400 Study}

The Model 3934 Scanning Mobility Particle Sizer and Model 3025/A Condensation Particle Counters were employed for size selective measurements of PM mater from the diluted exhaust of Mack E7-400 on-highway engine. SMPS up-scans of 120 and 200 seconds and a 30 second downscan were used for scanning the particulate matter distributions in the diluted exhaust generated under steady-state engine operating conditions. No significant differences were observed in the results obtained with two different up-scan times. The identical symmetric flow conditions (see 3.1.1.4.1) were maintained through the instrument for the full scan steady-state measurements and real-time tracking. Polydisperse and monodisperse aerosol flow rates were maintained at $2 \mathrm{lpm}$, while sheath and excess air flow rates were maintained at $20 \mathrm{lpm}$. These flow conditions allowed the scanning of particles with electrical mobility diameter ranging from $5 \mathrm{~nm}$ to $198 \mathrm{~nm}$ and relatively short response time suitable for transient measurements.

Measurements of DPM mass distributions for steady-state and transient operating conditions were performed with MOUDI Model 110 in parallel to the measurement with SMPS. During simultaneous sampling with SMPS and MOUDI, the dilution ratio in the tunnel was maintained constant at 4.3 throughout the steady-state tests and throughout FTP cycles. Dilution ratio was maintained constant at 21 when sampling was only with SMPS.

The results of the steady-state measurements are presented as histograms and fitted lognormal distributions of normalized number concentration $\left(\# / \mathrm{cm}^{3}\right)$, while the results of real time tracking are presented as temporal distributions of normalized concentrations (\# / $\mathrm{cm}^{3}$ ) of selected particle size class.

\subsubsection{Size-Resolved Chemical Analysis of Diesel Particulate Matter}

The goal of this component of the study was to conduct detailed size-resolved chemical analysis of particulate matter collected from exhaust of in-use heavy-duty engines/vehicles operated under steady-state and transient engine/vehicle conditions. Samples for size-resolved chemical analysis of DPM were collected by using the previously described sampling system based on a partial dilution tunnel (see 
Section 3.1.1.4.1 and Figures 3.4 and 3.7) and sampling procedures that were developed for size-selective measurements of DPM with MOUDI (see Section 3.1.1.4.1).

Samples for the size-resolved chemical analysis of PM were collected from the exhaust of the Mack E7-400 engine that was operated over FTP transient cycle and three steady-state conditions, R75, R50, and I50. The samples were collected on the substrates and after-filters of MOUDI Model 110. An after-filter in the MOUDI is the filter in the last stage that collects all the particles that are less than 56 $\mathrm{nm}$. Two different types of the substrates were used. The samples for the elemental and the inorganic ion analysis were collected on ungreased FEP ( 0.002 in) substrates and Teflon membrane after-filters (Gelman Sciences, Teflo W/Ring $37 \mathrm{~mm}, 2.0 \mu \mathrm{m}$ ). The samples for the carbon (EC/OC) analysis were collected on ungreased aluminum substrates and quartz after-filters. The FEP and aluminum substrates, as well as Teflon membrane after-filters were pre-washed in DCM and methanol according to the procedure described in DRI standard operating procedure for analysis of PAH. Each of the steady-state mode and transient cycle test was performed twice in order to collect enough samples for the analysis. The sampling for the transient conditions took place over the complete length of the FTP cycle, 1200 seconds. The samples for the steady-state conditions were collected over period of 1800 seconds. To allow for the engine and sampling system to achieve steady-state conditions the engine was operated at the selected steady-state conditions for period of 120 seconds prior to sampling.

The length of the tests and procedural restrictions imposed on the MOUDI operation, limited the amount of the diesel particulate matter that could be collected on the various stages. The results of gravimetric analysis performed on the substrates and after-filters revealed that the stages with cut-off diameters larger than $1.0 \mu \mathrm{m}$ (stages 0 through $\mathrm{V}$ ) were very lightly loaded with DPM, irrespective of the test conditions, and therefore, neither suitable nor of any value for chemical analysis. The masses of the DPM collected on the stages with cut-off diameters smaller than $1.0 \mu \mathrm{m}$ (stages VI through X) and after-filters were satisfactory but still less than ideal amount for the battery of analyses that were planned for this study. It was recognized that this was a previously unproven and a novel technique for conducting sub-micron size-selective chemical analyses. The uncertainties in the analytical results were expected to be high. 


\subsubsection{Speciation of Hydrocarbons}

The speciation component of the study was aimed at a detailed analysis of mass emission rates for particulate-bound, semi-volatile and volatile phase hydrocarbons in the diesel exhaust fromin-use heavy-duty engines/vehicles for steady-state and transient engine/vehicle operating conditions. The specific goals were to calculate the mass emission rate (mass/KW-hr) of detectable compounds, and their ozone forming potential (mass of ozone /KW-hr) for test fuel.

Designing and building of the sampling system and establishing collection procedures were the first steps toward achieving this goal. Published research work in the field suggests that sampling processes, if not properly designed and performed, might result in generation of various artifacts. Hence, it was critical to build reliable sampling system, select appropriate collection media and establish collection procedures for obtaining representative samples with a satisfactory repeatability.

\subsection{Particulate Bound Hydrocarbons}

The $70 \mathrm{~mm}$ Teflon coated glass fiber filters Palflex ${ }^{\circledR}$ TX40HI20WW were used for the collection of particulate-bound hydrocarbons. To decrease organic background, the filters were sonicated twice for ten minutes in dicloromethane and twice for ten minutes in methanol. A Fisher Scientific Model No. 550 Sonic Dismembrator was available for the purpose. Sonication dismembrator uses a lead zirconate titanate electroresistive (piezoelectric) crystal to convert $20 \mathrm{kHz}$ AC electrical energy to mechanical vibrations. The converter vibrates in the longitudinal direction and transmits this motion to a horn tip immersed in the solution. Microscopic vapor bubbles that are generated undergo an implosion, causing powerful shock waves to radiate from tip face through the sample. The solvent was drawn through $0.2 \mu \mathrm{m}$ unlaminated Fluoropore filter to remove fine particles.

Pre-washed filters were placed in the glass petri dishes, dried in the oven for 24 hours, and conditioned for at least 24 hours at $50 \% \mathrm{RH}$ and $20^{\circ} \mathrm{C}$ before and after the tests in the Environtronics Model No. SH8 environmental chamber. The filters were weighed using a CAHN 32 micro-balance.

The soluble organic fraction associated with PM, that was collected on the Teflon coated glass fiber filters (Pallflex TX40HI20WW), were extracted per DRI standard operating procedure (SOP) 
for PAHs. The technique employed microwave extraction for 15 minutes at $80 \mathrm{psi}$ and $45 \mathrm{ml}$ of dichloromethane $\left(\mathrm{CH}_{2} \mathrm{Cl}_{2}\right)$.

\subsection{Semi-Volatile Hydrocarbons}

PUF/XAD-2/PUF (SKC Model 226-129, Pennsylvania) glass tubes were selected as the media for the collection of semi-volatile compounds. The major criteria for the adsorbent selection were thermal stability and compatibility with the type of the extraction technique employed in this study. Good thermal stability $\left(200{ }^{\circ} \mathrm{C}\right)$ qualifies XAD-2 for diesel exhaust sampling. The PUF and XAD-2 are considered as good adsorbents in the case where sample treatment involves solvent extraction.

$\mathrm{XAD}-2$ resin is a nonionic styrene-divinylbenzene copolymer with a large surface area and is an efficient collector of gaseous-phase hydrocarbons with seven or more carbon atoms, as well as the volatile four-ring PAHs. Bagley et al. (1993) reported that the XAD-2 resin was very effective for collection of n-pentane, n-hexane, benzene, and xylenes, but was only moderately effective for collection of acetaldehyde and it was ineffective for collection of propane. The flow rate of 29.6 1/min was assumed to be low enough to prevent potential hydrocarbon breakthrough.

The XAD-2 and PUF were also extracted per DRI standard operating procedure for PAHs. The XAD-2 samples were microwave extracted for 15 minutes at 80 psi and $45 \mathrm{ml}$ of dichloromethane $\left(\mathrm{CH}_{2} \mathrm{Cl}_{2}\right)$. The PUF plugs were extracted separately using microwave extractor with $10 \%$ diethyl ether in hexane for over 6 hours at a rate of at least 3 cycles per hour.

\subsection{Volatile Hydrocarbons}

Black coated Tedlar bags (10 liter) were selected for the collection of volatile phase samples. These bags were found to be convenient because they, (i) are made of the chemically-inert material that is impermeable to gases, (ii) are rated for a wide temperature range (up to $225^{\circ} \mathrm{F}$ ) and (iii) have low memory of the previous sample. The black coating blocks out ultraviolet light action and makes black layered clear Tedlar bags very suitable for sampling of diesel exhaust that consists partially of light- 
sensitive compounds. To prevent artifact formation, the volatile samples were analyzed by GS/FID in a short period of time after collection.

\subsubsection{Data Analysis}

\subsubsection{Size Selective Measurements of Diesel Particulate Matter}

The contemporary aerosol instrumentation use indirect measurement techniques to determine aerosol size distributions based on their dynamic, electrical or optical behavior. The raw data from these instruments need to be inverted to obtain the aerosol size distribution. Details on data reduction for SMPS and MOUDI measurements follows.

\subsection{Data Inversion for SMPS Measurements}

Electrostatic Classifier or a differential mobility analyzer classifies aerosol based on the electrical mobility. The major factors that affect measurements are the charge of aerosol, influence of the input aerosol characteristics on the output aerosol characteristics, efficiency of the Condensation Particle Counter and efficiency of the inlet impactor. To obtain the number size distribution of the input aerosol $\left(\mathrm{dN} / \mathrm{d} \ln \mathrm{D}_{\mathrm{p}}\right)$ from the number distribution of the classified aerosol $\left(\mathrm{dN}_{\text {raw }} / \mathrm{d} \ln \mathrm{D}_{\mathrm{p}}\right)$, corrections must be made for the presence of multiple charged particles and transfer function. In addition, corrections for CPC efficiency and inlet impactor efficiency need to be employed:

$$
\frac{d N}{d \log D_{p}}=\frac{\frac{d N_{r a w}}{d \log D_{p}}}{f^{+}\left(D_{p}\right) \cdot T_{r}\left(D_{p}\right) \cdot \varepsilon_{C P C} \cdot \varepsilon_{I M P}}
$$

where $\mathrm{dN} / \mathrm{d} \log \mathrm{D}_{\mathrm{p}}$ is the corrected concentration of particles in $\left[\# / \mathrm{cm}^{3}\right], \mathrm{dN}_{\text {raw }} / \mathrm{d}_{\log } \mathrm{D}_{\mathrm{p}}$ is the concentration of particles before the correction in $\left[\# / \mathrm{cm}^{3}\right], \mathrm{T}_{\mathrm{r}}\left(\mathrm{D}_{\mathrm{p}}\right)$ is the transfer function, $f^{+}\left(\mathrm{D}_{\mathrm{p}}\right)$ is the fraction of single charge particles, $\varepsilon_{\mathrm{CPC}}$ is the counting efficiency of the condensation particle counter, and $\varepsilon_{\mathrm{IMP}}$ is the efficiency of the impactor at the inlet to the electrostatic classifier.

The measurements obtained during steady-state engine/vehicle operating conditions have been corrected by activating the Charge Correction option, an internal algorithm incorporated in the TSI 
SMPS software. TSI real time tracking software (CPCount Version 2.0) does not offer this option and the aforementioned corrections have to be performed on the output data..

\section{Fraction of single charged particles}

The electrical mobility of a spherical charged particle with diameter $D_{p}[\mathrm{~m}]$ is defined by:

$$
Z_{p}=\frac{i * e_{o}}{3 * \pi * \mu} \frac{C\left(D_{p}\right)}{D_{p}} \quad\left[m^{2} V^{-1} s^{-1}\right]
$$

where $\mathrm{i}$ is the number of charges on the particles, $e_{\mathrm{o}}$ is the elementary charge $\left(\mathrm{e}_{\mathrm{o}}=1.602 * 10^{-19} \mathrm{C}\right) \mathrm{C}\left(\mathrm{D}_{\mathrm{p}}\right)$ is the slip correction factor $\left(\mathrm{C}\left(\mathrm{D}_{\mathrm{p}}\right)=1+2.492 *\left(\lambda \mathrm{D}_{\mathrm{p}}\right)+0.84 *\left(\lambda \mathrm{D}_{\mathrm{p}}\right) * \exp \left(-0.435 *\left(\lambda \mathrm{D}_{\mathrm{p}}\right)\right)\right), \lambda[\mathrm{m}]$ is the gas mean free path, and $\mu\left[\mathrm{kg} \mathrm{m}^{-1} \mathrm{~s}^{-1}\right]$ is the gas viscosity. Multiple charges on the particle increase its mobility. The effect of multiple charges on the particle makes the particle susceptible to incorrect classification into smaller sized particles.

The raw data from SMPS can be converted into size distribution if the bipolar charge distribution for the aerosol is known. The calculated values for the concentration are substantially influenced by the choice of the charging theory. The single-charged particle correction applied to the raw data in this work is calculated by employing the empirical expression developed by Wiedensohler (1988). The expression is based on Fuchs model:

$$
f^{+}(n)=10^{\left[\sum_{i=0}^{4} a_{i}(n)\left(\log \left(D_{p}[n m]\right)^{i}\right]\right.}
$$

where $a_{i}(n)$ are approximation coefficients listed in the Table 4 . The equation is valid for the size ranges $1 \mathrm{~nm} \leq \mathrm{D}_{\mathrm{p}} \leq 1000 \mathrm{~nm}$ for $\mathrm{n}=-1,0,1$. 
Table 3.3. Coefficients for Single Charge Correction, Wiedensohler (1987)

\begin{tabular}{|c|c|c|c|c|c|}
\hline \multirow[b]{2}{*}{$a_{i}(n)$} & \multicolumn{5}{|c|}{$\overline{\mathrm{n}}$} \\
\hline & -2 & -1 & 0 & 1 & 2 \\
\hline$a_{o}$ & -26.3328 & -2.3197 & -0.0003 & -2.3484 & -44.4756 \\
\hline$a_{1}$ & 35.9044 & 0.6175 & -0.1014 & 0.6044 & 79.3772 \\
\hline$a_{2}$ & -21.4608 & 0.6201 & 0.3073 & 0.4800 & -62.8900 \\
\hline$a_{3}$ & 7.0867 & -0.1105 & -0.3372 & 0.0013 & 26.4492 \\
\hline$a_{4}$ & -1.3088 & -0.1260 & 0.1023 & -0.1553 & -5.7480 \\
\hline$a_{5}$ & 0.1051 & 0.0297 & -0.0105 & 0.0320 & 0.5049 \\
\hline
\end{tabular}

Transfer function, $T_{r}\left(D_{p}\right)$

Transfer function is defined as the probability that an aerosol particle which enters the mobility analyzer via the aerosol inlet will leave via sampling slot, given that its mobility is $\mathrm{Z}_{\mathrm{p}}$ (Knutson and Whitby 1975). Triangular, Gaussian and other forms may be used to define the transfer function. For the investigation presented here, the triangle function was used in order to provide a DMA transfer function data of the form that was used in the existing evaluation procedures (SMPS software).

The mean electrical mobility of the classified particles, $\mathrm{Z}_{\mathrm{pc}}$, contained in $\mathrm{Q}_{\mathrm{s}}$, can also be expressed in terms of DMA flowrates (Knutson and Whitby 1975, and Reichle1991):

$$
Z_{p c}=\left(\frac{Q_{s h}+Q_{e x}}{2}\right) \cdot \frac{\ln \left(R_{2} / R_{1}\right)}{2 \cdot \pi \cdot L} \cdot \frac{1}{U} \quad\left[m^{2} V^{-1} s^{-1}\right]
$$

where $\mathrm{Q}_{\mathrm{sh}}$ is the volume flow rate of the clean gas flow (sheath air) in $\left[\mathrm{m}^{-3} \mathrm{~s}^{-1}\right], \mathrm{Q}_{\mathrm{ex}}$ is the volume flow rate of the excess gas flow (excess air) in $\left[\mathrm{m}^{-3} \mathrm{~s}^{-1}\right], \mathrm{R}_{1}$ is the outer radius of the inner electrode in $[\mathrm{m}]$, $\mathrm{R}_{2}$, is the inner radius of the outer electrode in [m], $\mathrm{L}$ is the mean axial distance of the aerosol inlet slit in the outer electrode to the outlet slit, for the classified aerosol in the inner electrode in [m], and $U$ is the potential difference between the inner and outer electrode in [Volts].

The mobility range of the particles classified using DMA, $\Delta Z_{\mathrm{p}}$, is given by

$$
\Delta Z_{p}=Q_{a} \cdot \frac{\ln \left(R_{2} / R_{1}\right)}{2 \cdot \pi \cdot L} \cdot \frac{1}{U} \quad\left[m^{2} V^{-1} s^{-1}\right]
$$


which means that the classified particles are in range from $Z_{p 1}\left(=Z_{p c}-\Delta Z_{p}\right)$ to $Z_{p 2}\left(=Z_{p c}+\Delta Z_{p}\right)$

The transfer function for the symmetric conditions $\left(\mathrm{Q}_{\mathrm{a}}=\mathrm{Q}_{\mathrm{s}}, \mathrm{Q}_{\mathrm{sh}}=\mathrm{Q}_{\mathrm{ex}}\right)$ can be written as:

$$
T_{r}\left(Z_{p}\right)=\frac{Z_{p}-Z_{p 1}}{\Delta Z_{p}}, Z_{p 1}<Z_{p}<Z_{p c} \quad T_{r}\left(Z_{p}\right)=\frac{Z_{p 2}-Z_{p}}{\Delta Z_{p}}, Z_{p c}<Z_{p}<Z_{p 2}
$$

The DMA transfer function might significantly deviate from the theoretically derived function. Brownian diffusion is responsible for degrading the transfer function by causing particle losses in connecting tubing and inlets of the DMA and for broadening the particle trajectories inside the analyzer column (Birmili et al., 1997). Birmilli et al. (1997) used several types of identical DMAs in series to determine the DMA transfer functions for particles in the diameter range of 3-100 $\mathrm{nm}$. He found that the height of the transfer function decreases toward a lower particle size, whereas its width increases. In addition, the area of the transfer function drops toward a lower particle size. Size distribution can be improved by utilizing more accurate, size-dependent transfer functions for data reduction, especially for ultra-fine particles (Stratmann, 1995; Fissan, 1996).

The data obtained in this study were corrected with the values of transfer function obtained by employing the aforementioned equations.

CPC counting efficiency, $\varepsilon_{C P C}$

CPC counting efficiency correction was applied to the part of raw data generated by CPC Model 3022A. All the data obtained with CPC Model 3022 was corrected by applying the factors graphed in Figure 3.8. For the particle size range, of interest to this study, the data obtained with CPC Model 3025 did not require any corrections for the CPC counting efficiency (Figure 3.8).

Impactor efficiency, $\varepsilon_{I M P}$

Particle sizes tracked in this study were substantially smaller than the inlet impactor cutoff diameters for the observed flow rates (TSI Model 3934 SMPS Instruction Manual) so impactor efficiency is assumed to be 1.0 throughout the study. 


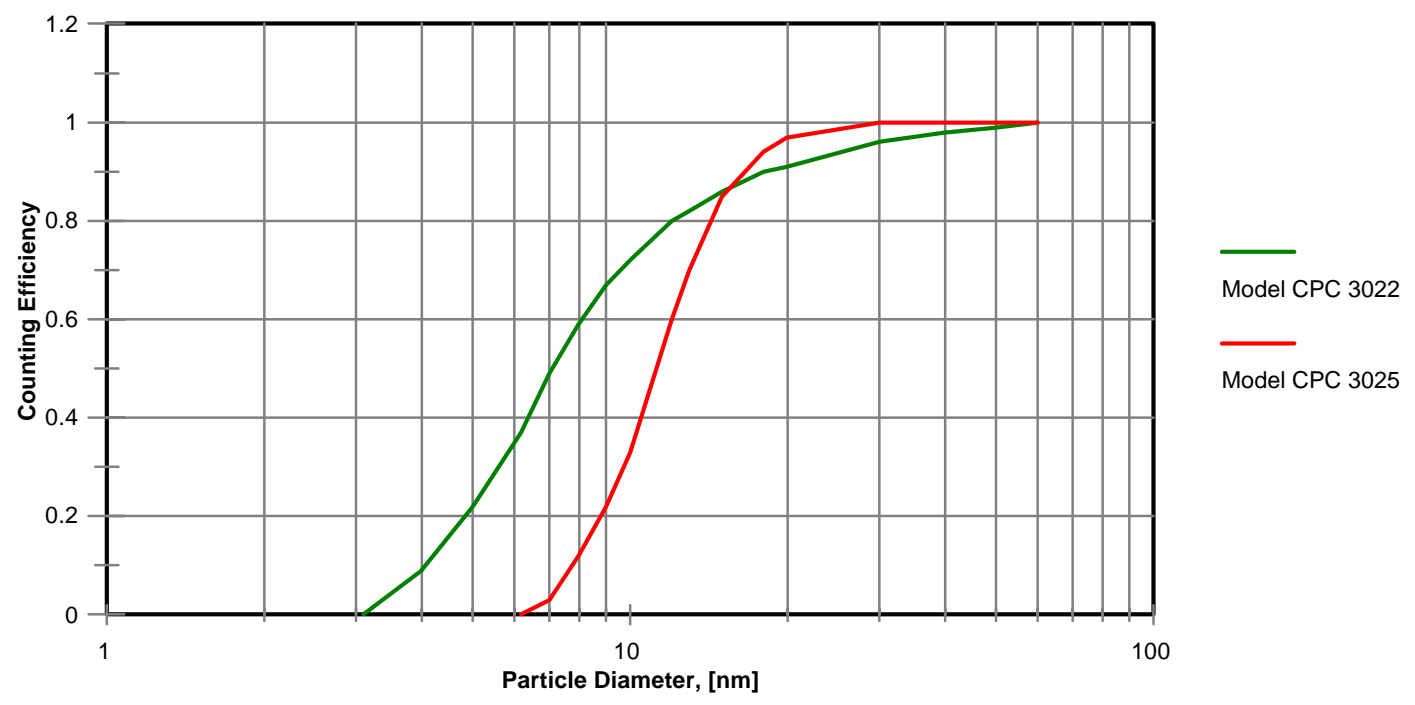

Figure 3.10 CPC Counting Efficiency Curves, (TSI Model 3934 SMPS Instruction Manual, Figure B-9, pp B-15, 1996)

\section{Data Reduction Codes}

Two Visual Basic codes were written to handle steady-state and transient SMPS measurement data. The code for reduction of steady-state data take output files from SMPS software as input and prepare the data for presentation in terms of actual measurement data histogram and fitted single log-normal distribution using parameters calculated by the TSI software. Uni-modal distribution was omitted when it did not closely follow the actual distribution. The code for the reduction of real time tracking data uses CPCount Version 2 output file as input and performs all the aforementioned corrections. The results were presented as time-resolved count based concentrations $\left[\# / \mathrm{cm}^{3}\right]$ of particles with a specific mobility diameter.

Total particle mass collected during steady-state tests can be estimated by assuming that particles are spherical shape with a unit density $\left(\rho=1 \mathrm{~g} / \mathrm{cm}^{3}\right)$ and obey log-normal distributions. Total particle mass can be calculated by multiplying the total volume with the assumed density. The estimated 
integrated particulate mass for steady-state measurements was compared to the total mass of particulate matter collected on the filters and the integrated mass collected on the MOUDI stages.

\subsection{Data Inversion for MOUDI Measurements}

MOUDI as a cascade impactor, classifies particles according to their aerodynamic diameter. Therefore, the weighing procedure results in the mass distribution of particulate matter in diluted exhaust as a function of aerodynamic diameter. Sampling was performed over a predetermined time at a constant flowrate (30 lpm) that was maintained through MOUDI. The size-resolved concentrations of particulate matter in diluted exhaust were calculated using measured values of the sampling flow rates and the sampling times. The calculated dilution ratios were used to estimate the PM concentrations in the raw exhaust.

The results of size-selective measurements using MOUDI were presented, in the form of the histogram, as normalized mass vs. aerodynamic diameter or concentration. The optimizer was used to fit single mode log-normal distribution curve to the measured data. The observed mass distributions for diesel exhaust appeared to be bimodal with the majority of mass concentrated in submicron range. The second coarse mode was not of the interest and hence it was neglected.

\subsection{Lognormal Particle Size Distribution}

The lognormal distribution has gained wide acceptance in modeling aerosol-related physical and chemical processes. The justification for the use of log-normal functions to fit aerosol size distributions is mainly empirical. The log-normal functions describe well the aerosol distribution data and have convenient mathematical properties. The data obtained in this study were also reduced applying the log-normal fit.

The normalized lognormal distribution can be mathematically expressed as:

$$
f\left(D_{p}\right)=\frac{1}{\sqrt{2 \cdot \pi} \cdot \log \sigma_{G}} \cdot \exp \left[-\frac{\left(\ln D_{p}-\ln D_{G M}\right)^{2}}{2 \cdot\left(\ln \sigma_{G}\right)^{2}}\right]
$$


Here $f\left(D_{p}\right)$ is the fraction of particles (or mass) per logarithmic size interval, $D_{p}$ the particle size diameter, $\sigma_{\mathrm{G}}$ the geometric standard deviation of the distribution, and $\mathrm{D}_{\mathrm{GM}}$ the geometric mean diameter which is equal to the count median diameter (CMD) for a lognormal distribution.

The power of the lognormal distribution is that any type of average diameter can be easily calculated from any known lognormal distribution, that is, a distribution for which one average diameter and the geometric standard deviation $\sigma_{\mathrm{G}}$ are known. These quantities can be calculated directly using lognormal conversion equation originally derived by Hatch and Choate and called the Hatch-Choate equation (Hinds, 1982).

The count distributions measured with SMPS were fitted with the log normal distributions by TSI software. The known $\mathrm{CMD}\left(\mathrm{D}_{\mathrm{GM}}\right)$ and $\sigma_{\mathrm{G}}$ were used to calculate mass median diameter MMD, used in the regional deposition calculations, employing the following expression:

$$
\operatorname{MMD}=\mathrm{CMD} \quad \exp \left(3 \quad \ln ^{2} \sigma_{\mathrm{g}}\right)
$$

The mathematical properties of lognormal functions allow calculation of the total particle volume (V) from a given SMPS number-size distributions using the following expression (Heintzenberg, 1994):

$$
V=\frac{4 \cdot \pi}{3}\left(\frac{C M D \cdot \exp \left[3 \cdot\left(\ln \sigma_{G}\right)^{2}\right]}{2}\right)^{3} \cdot N \cdot \exp \left[-\frac{\left[\ln \left(C M D \cdot \exp \left(3 \cdot\left(\ln \sigma_{G}\right)^{2}\right)\right)-\ln C M D\right]^{2}}{2 \cdot\left(\ln \sigma_{G}\right)^{2}}\right]
$$

where $\mathrm{N}$ is the total particle number.

Diesel exhaust particulate matter size distributions do not always follow a single log-normal distribution. For engines equipped with a catalytic converter, bimodal distributions are quite common. The software provided with the SMPS fit a single lognormal distribution to all data obtained by the SMPS. This practice might be misleading. It is preferable to use histograms to analyze the data for steady-state engine/vehicle operating conditions obtained using SMPS. The procedure for fitting multimodal lognormal size distribution to cascade impactor data is available in the literature (Dzubay and Hasan,1990), but have not been applied to data from this study. 


\subsection{Data Presentation}

Results of SMPS measurements of diluted exhaust particulate matter size distribution for steady-state engine/vehicle operating conditions, are presented as histograms and lognormal fits of count base concentrations of particulate matter in raw exhaust $\left(\# / \mathrm{cm}^{3}\right)$. Single log normal distributions were found to very well fit into the most of the actual PM histograms. Therefore, the lognormal fit parameters are readily used in discussion of the results. The SMPS measurements for transient engine/vehicle operating conditions are given as time distributed count base concentrations of selected size particulate matter for raw exhaust $\left(\# / \mathrm{cm}^{3}\right)$. The results of MOUDI measurements are shown as histograms and fitted single log-normal distributions of normalized and actual mass based concentrations of particulate matter in the raw exhaust $\left(\mathrm{mg} / \mathrm{cm}^{3}\right)$.

Since the exhaust flow rates were not measured, dilution ratios in the full flow dilution tunnel remained unknown. Because of this limitation, a direct comparison of TPM emissions estimated by integration of distributions obtained by SMPS and TPM emissions determined by gravimetric analysis on the samples collected from full flow dilution tunnel was not possible. Therefore, integrated particulate matter data were preferred to be used for justification of trends observed for the size selective measurements of particulate matter rather than for establishing correlations between the two methods.

\subsubsection{Regional Deposition of Diesel Particulate Matter}

Extensive research and development in the fields of engine powertrains, exhaust and after-treatment technology and fuel reformulation has resulted in significantly lower total particulate matter emission rates from heavy duty engines/vehicles. There is still concern that modern engines tend to increase the toxicity of the exhaust emissions by virtue of the higher number and substantially smaller size of the emitted PM. Ultra-fine particles are able to penetrate deep in the lung and cause serious lung disorders. For estimating the dose, delivered and for assessing the health risks associated with inhalation of such aerosol, the particle number and mass deposited in a region is of interest. The results of the measurements of size-selective DPM emissions from Isuzu C240 engine, Mack E7-400 engine, and 
Orion/DDC 6V92 buses were used for an assessment of regional deposition of DPM in the human respiratory tract.

The model for regional deposition of the polydispersed aerosol used in this study was developed by Köbritch, Rudolf, and Stahlhofen (1994). Regional deposition in the model is defined as the fraction of the particles inspired which is deposited in the region of interest. The model is derived from algebraic regional deposition model of Stahlhofen et al. (1989) and Rudolf et al. (1994) which was developed for monodisperse, non-hydroscopic and non-fibrous particles. The polydisperse aerosols depositions were obtained by numerical integration of the results obtained using monodisperse regional deposition model. Those models are based on statistical analysis of the available data on regional deposition in human subjects. The models cover the particle diameter range from $0.5 \mathrm{~nm}$ to $15 \mu \mathrm{m}$. However, regional deposition in man has so far only measured with particles above $0.1 \mu \mathrm{m}$ in diameter. Where data are missing the model is based on theoretical data. The models distinguish five anatomical regions:

(i) nasal region,

(ii) extrathoracic region during mouth breathing including pharynx, larynx and the upper part of the trachea,

(iii) tracheobronchial airway,

(iv) bronchiolar airway,

(v) alveolar region,

and four physiological regions of the respiratory tract:

(i) nose,

(ii) extrathoracic,

(iii) fast-cleared thoracic airway,

(iv) slow-cleared thoracic airway.

Deposition in the nose, extrathoracic region, and tracheobronchial region is mainly due to inertial impaction and Brownian diffusion (see Figure 3.9). Sedimentation and Brownian diffusion are primary mechanisms of deposition in bronchial airways. Deposition in the alveolar region is determined by gravitational settling and Brownian diffusion. The fractional efficiencies, for selected parameters, which were predicted by the model, were presented in Figure 3.9. Depositions in this study were calculated for 
nasal breathing and selected respiratory parameters: $Q=500 \mathrm{~cm}^{3} \mathrm{~s}^{-1}, \mathrm{~V}=1500 \mathrm{~cm}^{3}, \mathrm{FRC}=3300 \mathrm{~cm}^{3}$ and $\mathrm{f}=10$.

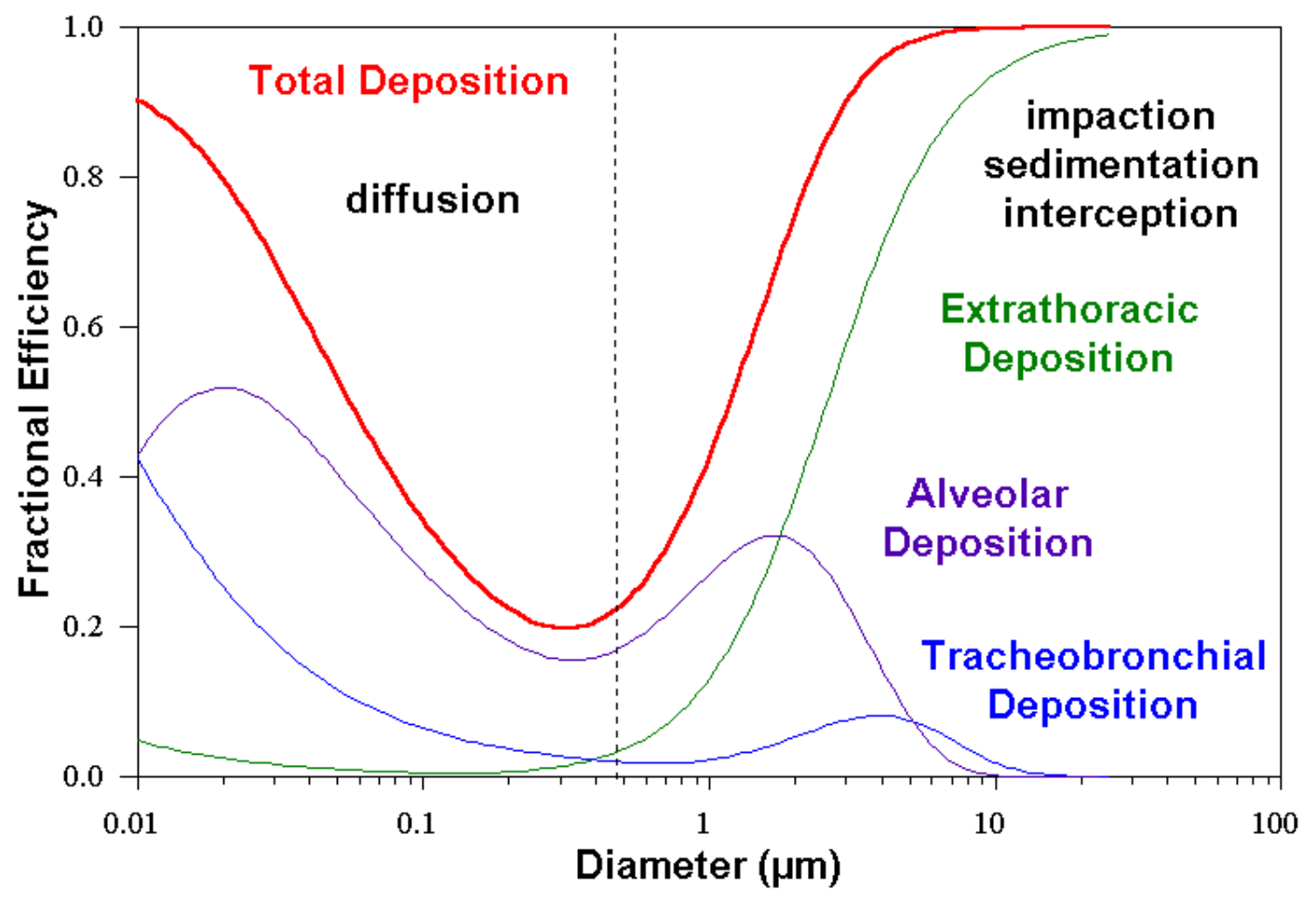

Figure 3.11. Deposition in the human respiratory tract as function of the particle diameter for nasal breathing and selected parameters: $Q=500 \mathrm{~cm}^{3} \mathrm{~s}^{-1}, \mathrm{~V}=1500 \mathrm{~cm}^{3}, \mathrm{FRC}=3300$ $\mathrm{cm}^{3}$ and $\mathrm{f}=10$

The regional deposition in the human lungs was estimated for several steady-state engine operating conditions, fuel formulations and combinations of the after-treatment devices. The single-mode lognormal curves were fitted to normalized count distributions detected by SMPS. The mass median diameters (MMD) of mass distributions were calculated from count median diameters and geometric standard deviations of corresponding number distributions using Hatch-Choate equation. The total volume of the particles was estimated by applying the equation 3.6. The mass of the particles was estimated on a basis of the assumed particle density of $1 \mathrm{~g} / \mathrm{cm}^{3}$. The obtained number and mass depositions 
were modeled as algebraic functions of the number and mass median diameters and of the geometric standard deviations of the size distributions.

Particle numbers and masses deposited in the alveolar region were obtained by multiplying total particle mass by fraction of alveolar deposition. The total particle numbers and masses and particle number and mass deposited in the alveolar region were normalized with respect to the highest total number and mass of the particles observed for each of the studied cases

\subsubsection{Size-Resolved Chemical Analysis of Diesel Particulate Matter}

After the PM samples were acquired and the substrates/filters were weighed, and then shipped under refrigeration to DRI for chemical analysis. The FEP substrates and Teflo membrane back-up filters were subjected to elemental analysis by X-ray fluorescence. The FEP substrates and Teflo membrane back-up filters were also analyzed for sulfate and chloride by ion chromatography, ammonium by automated colorimetry using the indophenol method, and soluble potassium by flame atomic absorption. The aluminum substrates and quartz after filters were analyzed for bulk organic (OC) and elemental (EC) carbon by thermal/optical reflectance technique (TOR) (Chow et al., 1993).

The results of the analysis were reported as size resolved mass concentrations $\left[\mu \mathrm{g} / \mathrm{m}^{3}\right]$ of the selected compounds along with associated uncertainties of the employed technique. Unimodal lognormal curves were fitted to the distribution data. The statistical parameters of the fitted lognormal distributions were used in the data analysis.

\subsubsection{Hydrocarbon Analysis}

The volatile samples were analyzed by GC/FID Varian Model 3600 GC in WVU MAE GC Laboratory. A $30 \mathrm{~m}$ x 0.53 mm capillary column with $1.5 \mu \mathrm{m}-1.0 \mu \mathrm{m}$ filter thickness (J\&W Scientific type DB-1) was used for the analysis of volatile compounds. The $0.32 \mathrm{~mm}$ i.d. fused silica pre-column was fitted to the GC. Carrier gas was helium. The results of the analysis were reported as volumetric hydrocarbon concentrations $\mathrm{C}$ [ppm]. The specific mass emission rates [g/kWh] were calculated as shown below: 


$$
\mathrm{C}_{\text {spec }}[\mathrm{g} / \mathrm{kWh}]=\frac{\mathrm{C}[\mathrm{ppm}] \quad \mathrm{MW}[\mathrm{g} / \mathrm{mol}] \quad \mathrm{V}_{\text {mix }}[\mathrm{l}]}{10^{6} \quad 24.04[1 / \mathrm{mol}] \quad \mathrm{W}[\mathrm{kWh}]}
$$

The quantitative and qualitative analyses of the semi-volatile and particle bound samples were performed by EEEC at DRI employing the electron impact (EI) GS/MS technique (HP MSD with Selective Ion Monitoring). A $30 \mathrm{~m}$ long 5\% phenylmethylsilicone fused silica capillary column (J\&W Scientific type DB-5) was used.The results of the analysis were reported in terms of concentrations C $\left[\mathrm{ng} / \mathrm{m}^{3}\right]$. The brake specific mass emission rates $[\mathrm{g} / \mathrm{kWh}]$ were calculated as shown below:

$$
\mathrm{C}_{\text {spec }}[\mathrm{g} / \mathrm{kWh}]=\frac{\mathrm{C}\left[\mathrm{g} / \mathrm{m}^{3}\right] \mathrm{V}_{\text {mix }}\left[\mathrm{m}^{3}\right]}{\mathrm{W}[\mathrm{kWh}]}
$$

The ozone forming potential (grams of ozone/gram of HC) of the identified compounds was determined using the recently updated Maximum Incremental Reactivity (MIR) data (Carter, 1999). The values of the MIR and estimated ozone forming potential of the identified semi-volatile and particle bound compounds are listed in Tables C.3 and C.4, respectively. The atmospheric chemical mechanism for the most of the PAH compounds identified in the semi-volatile and particle bound phase are still not known. Therefore, the effects of those compounds on ozone forming potential were not calculated and not considered in the estimate of the total ozone forming potential for different engine operating conditions. 


\subsection{RESULTS AND DISCUSSION}

\subsubsection{Total Particulate Matter Emissions}

\subsubsection{Isuzu C240 Study}

The TPM samples were drawn from the full flow dilution tunnel at a constant mass flow rate $(5 \mathrm{scfm})$ through the secondary dilution tunnel. $70 \mathrm{~mm}$ Teflon coated glass fiber filters (Pallflex T60A20) were equilibrated in an environmental chamber and then pre-weighed using CAHN 32 microbalance. The filters were equlibrated and weighed again after a test. The summary of the total particulate matter emissions for the bare engine and the engine equipped with different combinations of the after-treatment devices is presented in Table 3.4. The results of gravimetric analysis are presented in terms of brake-specific PM emissions (g/bph-hr).

Table 3.4. Isuzu C240 Study: Total Particulate Matter, [(g/bhp-hr) / (g/kWhr)]

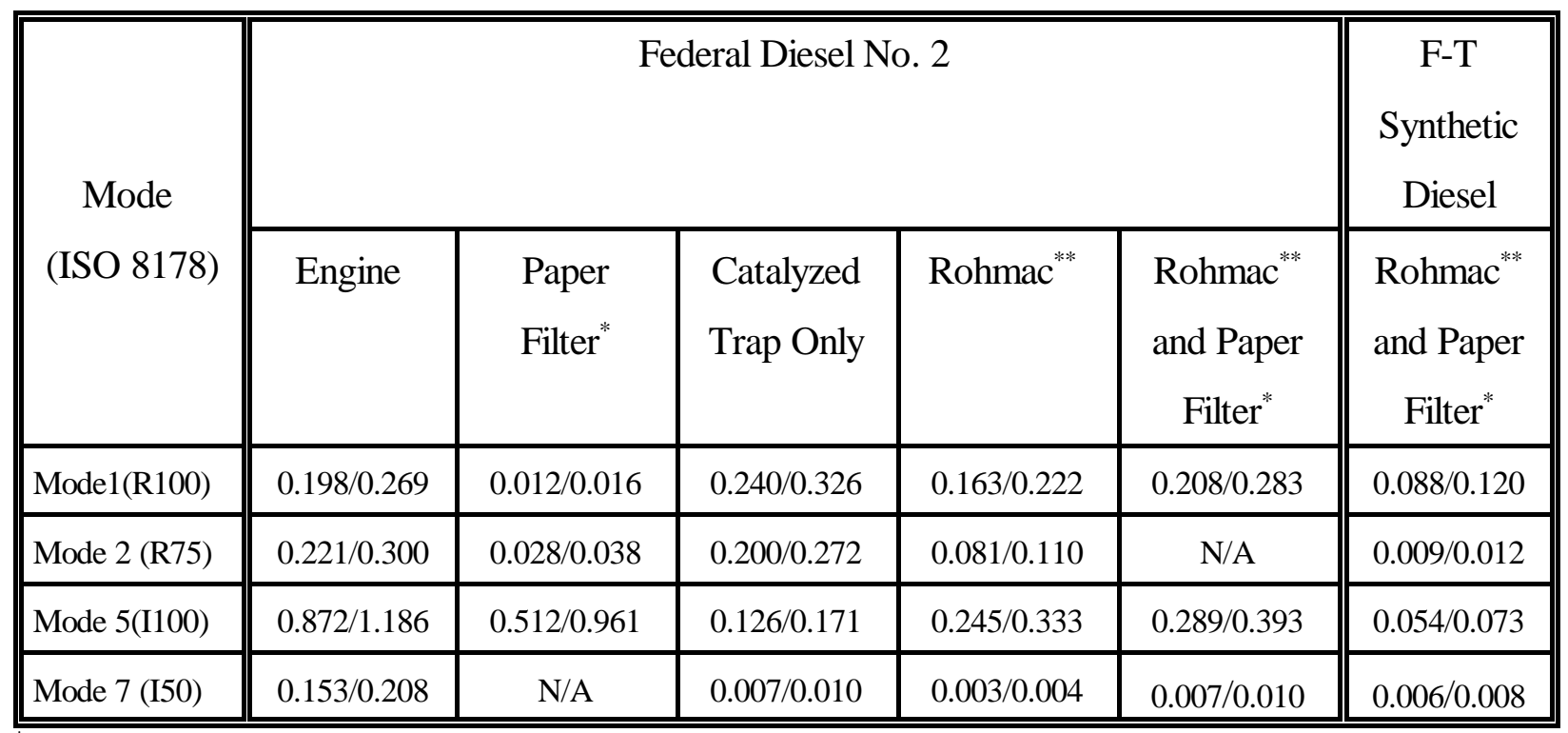

High temperature paper filter manufactured by Pallflex

** $\quad$ Rohmac/DCL system: Catalyzed trap plus diesel oxidation catalyst fabricated by Rohmac Inc.

using catalytic components from Diesel Control Limited

The results of the integrated PM emission analysis show that the performance of aftertreatment devices was highly dependable on the engine operation conditions. For example, the paper filter 
was very efficient in removing PM emissions from the exhaust during R100 and R75 engine operating modes, but not nearly as efficient for I100 operating conditions. The trap exhibited much greater efficiency under I100 engine operating conditions than the paper filter, but also very poor performance for R100 and R75 operating modes. Increase in the integrated PM mass from the reference level for R100 and R75 engine operating modes can be attributed to the abundant sulfuric acid aerosol formation induced by oxidation of $\mathrm{SO}_{2}$ on the oxidation catalyst coating of the trap. The Rohmac/DCL System, consisting of the oxidation catalytic converter and a catalyzed particulate trap, appeared to have performed better without Pallflex paper filter than with the filter. The efficiency of these exhaust after treatment devices will be discussed in details in the following sections.

\subsubsection{Orion/DDC 6V92 Study}

The routine measurements of the exhaust gases and total PM emissions were performed in parallel with the measurements of size-resolved PM emissions, for the Orion/DDC 6V92 transit buses exercised over CBD cycles. PM mass emission rates averaged over several tests are listed in Table 3.6. The regulated emissions were not recorded for the steady-state tests.

Table 3.5 Orion/DDC 6V92, Average Total Particulate Matter Emissions, [g/mile]

\begin{tabular}{||l|c|c|c|c|c|c||}
\hline \hline Fuel & $\begin{array}{c}\text { Bus 2025 } \\
\text { With OCC }\end{array}$ & $\begin{array}{c}\text { Bus 2048 } \\
\text { With OCC }\end{array}$ & $\begin{array}{c}\text { Bus 2029 } \\
\text { With OCC }\end{array}$ & $\begin{array}{c}\text { Bus 2029 } \\
\text { W/O OCC }\end{array}$ & $\begin{array}{c}\text { Bus 2030 } \\
\text { W/O OCC }\end{array}$ & $\begin{array}{c}\text { Bus 2034 } \\
\text { W/O OCC }\end{array}$ \\
\hline \hline $\begin{array}{l}\text { Federal } \\
\text { Diesel }\end{array}$ & 1.23 & 1.12 & 1.89 & 1.79 & 1.18 & 9.03 \\
\hline $\begin{array}{l}\text { Mossgas } \\
\text { Synthetic } \\
\text { Diesel }\end{array}$ & 1.01 & 0.76 & 1.16 & 1.34 & 1.16 & 7.07 \\
\hline
\end{tabular}




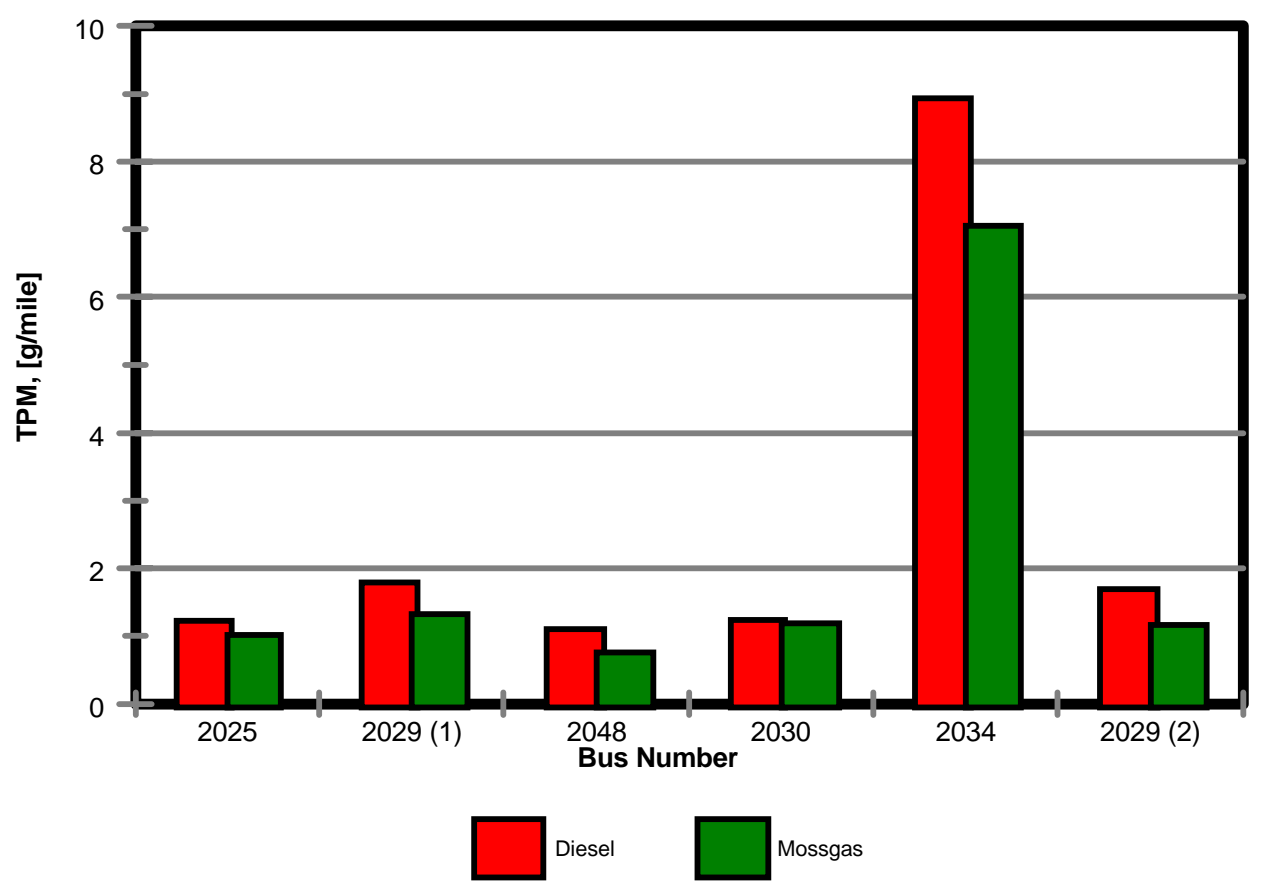

Figure 3.12 Orion/DDC 6V92, Transient, CBD, Average Total Particulate Matter Emissions, Effects of Fuel Type, [g/mile]

These results of TPM mass emissions are also presented in Figure 3.12. The bus 2034 emitted PM and CO in substantially higher concentrations and had a significantly higher exhaust temperature than the rest of the vehicles. Norton et al. (1999) suggested that the higher fuel consumption and lower $\mathrm{NO}_{\mathrm{x}}$ indicated that the injection timing in bus 2034 was retarded relative to manufacture specifications. The total PM mass emission rates indicate that the impact of an OCC on reducing TPM emissions was very inconsistent. DDC 6V92 produce TPM with fairly high levels of SOF that could be treated very effectively with an OCC. The TPM emissions from bus 2029 fueled with diesel no. 2 were found to increase after the bus was fitted with a rebuilt engine and catalytic converter This might have contributed to the increase in sulfate emissions. The use of Mossgas fuel resulted in reduction of TPM emissions from less then $2 \%$ (Bus 2030) to 39\% (Bus 2048). These data indicated potential problems in the TPM measurement process. 


\subsubsection{Mack E7-400 Study}

The measurements of the regulated emissions were performed in parallel with the measurements of size-resolved PM emissions for Mack E7-400 engine. The regulated emissions were monitored for the tests performed under steady-state and transient conditions. The samples were taken from the total exhaust dilution tunnel. The reduced results of the gravimetric analysis on TPM samples are listed in Table 3.7. The results of gravimetric analysis indicated good repeatability of the measurements.

Table 3.7. Mack E7-400, Total Particulate Matter

\begin{tabular}{|c|c|c|c|}
\hline Test & $\begin{array}{c}\text { Mass, } \\
{[\mathrm{mg} / \text { filter }]} \\
\end{array}$ & $\begin{array}{c}\text { Mass Rate, } \\
{[\mathrm{mg} / \mathrm{s}]} \\
\end{array}$ & $\begin{array}{c}\text { Brake-Specific Mass, } \\
{[\mathrm{g} / \mathrm{kWh}]} \\
\end{array}$ \\
\hline FTP, Test 1 & 4.512 & 1.884 & 0.107 \\
\hline FTP, Test 2 & 5.053 & 2.110 & 0.120 \\
\hline FTP, Test 3 & 4.898 & 2.046 & 0.117 \\
\hline FTP, Test 4 & 4.851 & 2.025 & 0.115 \\
\hline FTP, Test 5 & 4.893 & 2.043 & 0.116 \\
\hline R75, Test 1 & 3.838 & 5.130 & 0.044 \\
\hline R75, Test 2 & 4.300 & 5.717 & 0.049 \\
\hline R50, Test 1 & 2.691 & 3.597 & 0.046 \\
\hline R50, Test 2 & 2.270 & 3.034 & 0.038 \\
\hline I50, Test 1 & 0.956 & 1.597 & 0.023 \\
\hline I50, Test 2 & 0.935 & 1.561 & 0.022 \\
\hline
\end{tabular}

\subsubsection{Size Selective Measurements of Diesel Particulate Matter - Sampling System Performance}

The system for size-selective measurement of particulate matter was custom designed and fabricated. Flow rates and temperatures were found to be the parameters that critically impacted size distribution and concentration measurement uncertainties. The flow and temperature profiles in the 
system were recognized through a series of the simulated experiments. The mini-dilution tunnel and other components of the system were checked for leaks under high pressure and vacuum conditions. The continuity of the flow schemes was also verified by simultaneous measurements of the dilution air flow rate, exhaust flow rate, and diluted exhaust flow rate. To ensure integrity of the flow schemes and accuracy of flow measurements during testing, the system was checked for leaks on a routine basis. A refrigerated drier helped to maintain dilution air and diluted exhaust temperatures in the desired range.

A series of the preliminary tests were conducted with a system in an effort to gain experience and identify the necessary modifications to the partial flow dilution tunnel and other components of the system. The major modifications aimed at the reduction of the losses on the sampling probes, minimizing pressure losses in the system and optimizing flow rate. Those modifications improved the overall performance of the system and accuracy of the measurements.

\subsubsection{Repeatability of Size Selective Measurements Diesel Particulate Matter}

3.2.3.1 Repeatability of Size Selective Measurements Diesel Particulate Matter with SMPS

3.2.3.1.1 Isuzu C240 Study

The repeatability was examined on the results of measurements performed on the exhaust from Isuzu C240 engine by conducting a series of several consecutive SMPS scans performed with all system parameters fixed. The full scan sampling (60 s up scan and $30 \mathrm{~s}$ down scan) with SMPS, which was done after new engine/system operating conditions were established, showed that the engine and the sampling system require a relatively long period for achieving steady state conditions (Figure 3.13). During this transitional period, the results were found to be significantly influenced by previous engine and system operating conditions. Once steady-state operating conditions for the engine and system were achieved, the repeatability of the SMPS measurements were found to be satisfactory (Figure 3.14). A period of five minutes was determined to be sufficiently long for achieving steady-state conditions once a change was made. Two minute settling period was accepted as long enough to eliminate all transient occurrences after establishing new tunnel flow conditions. Abdul-Khalek et al. (1998) had reported similar findings. Establishing a strict sampling protocol played a significant role in obtaining reliable and repeatable results. 


\subsection{Mack E7-400 Study}

The repeatability of the measurements with SMPS was also examined on the results of the measurements performed on the Mack E7-400 engine. Three consecutive measurements with SMPS (designated as T1, T2, and T3 in Figure 3.15) were performed for steady-state R75 engine operating conditions. The measurements were performed after the five-minute stabilization period. First two measurements were performed using 120-second up-scan and 30-second down-scan (120/30). The third measurement was performed with 200-second up-scan and 30-second down-scan (200/30). The third distribution had two unusual isolated peaks which are most probably result of incorrect data post processing. Figure 3.16 shows results of four consecutive measurements (designated as T1, T2, T3, and T4) performed with SMPS for R50 engine operating conditions. First two measurements were performed with 120-second up-scan and 30-second down-scan. The other two measurements were performed with 200/30 second scan.

The repeatability of the measurements performed with SMPS were found to be excellent regardless of the scanning time used (Figures 3.15 and 3.16). 


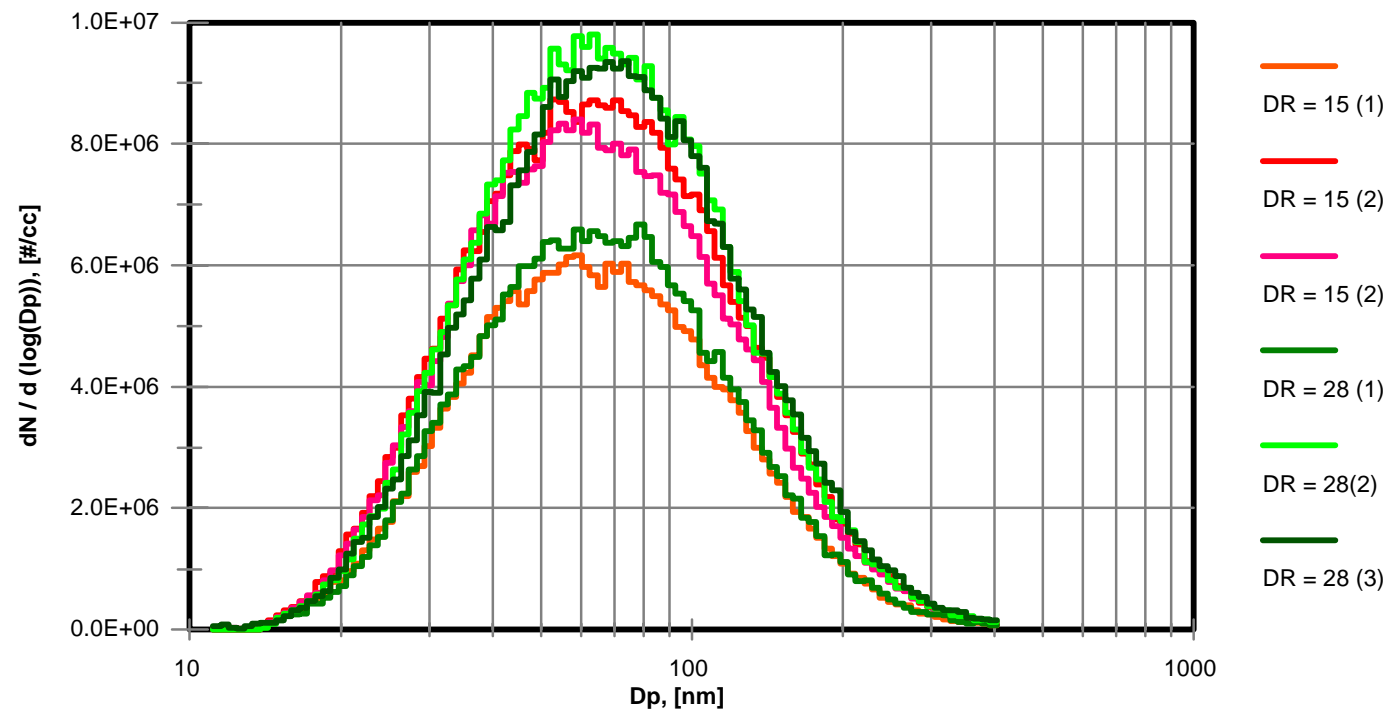

Figure 3.13 Isuzu C240, Steady-State Operating Conditions, R75, Paper Filter, Diesel, Number Concentrations, SMPS, Repeatability

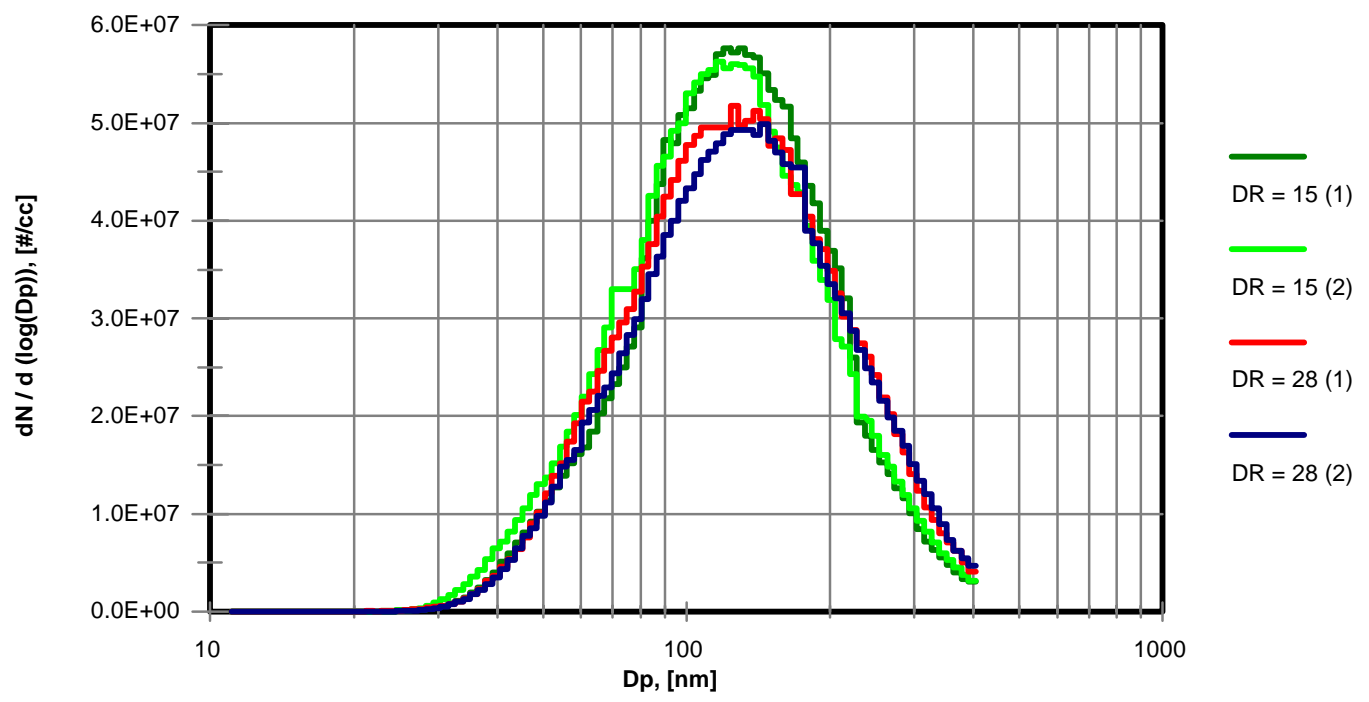

Figure 3.14 Isuzu C240, Steady-State Operating Conditions, I100, Bare Engine, Fisher-Tropsch, Number Concentrations, SMPS, Repeatability 


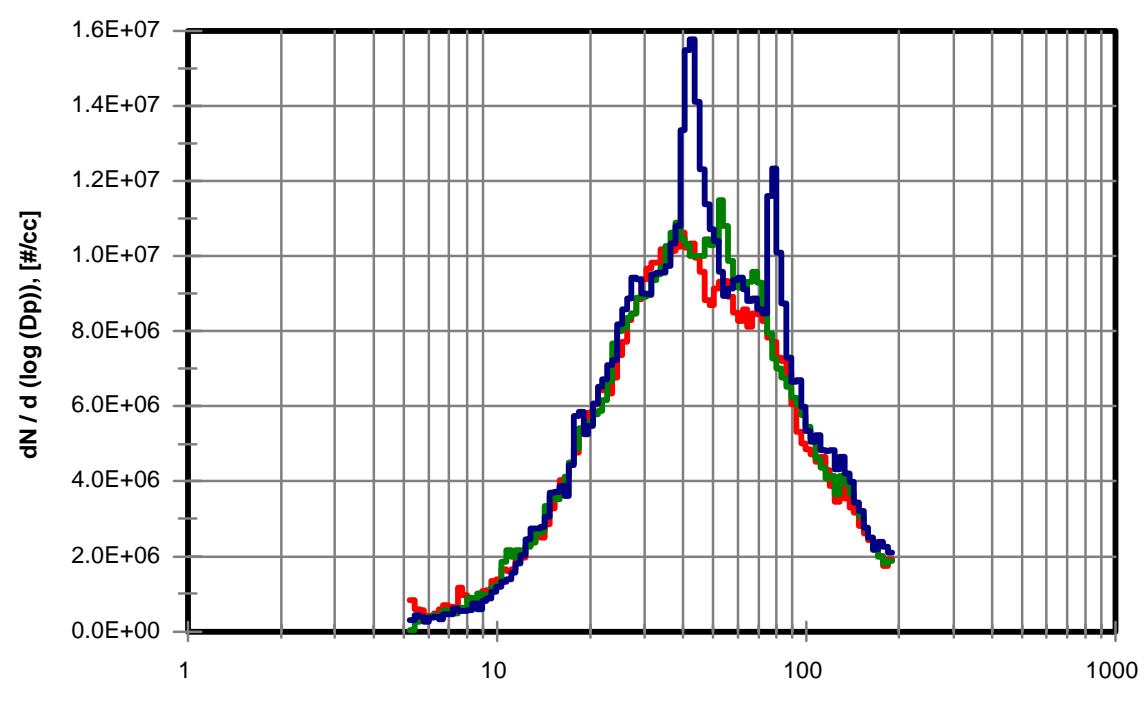

$\mathrm{T} 1$, Scan Time $=120 / 30 \mathrm{~s}$

T2, Scan Time $=120 / 30 \mathrm{~s}$

T3, Scan Time $=200 / 30 \mathrm{~s}$

Figure 3.15 Mack E7-400, Steady-State, R75, Diesel, DR = 4.3, Count Concentrations, SMPS, Repeatability

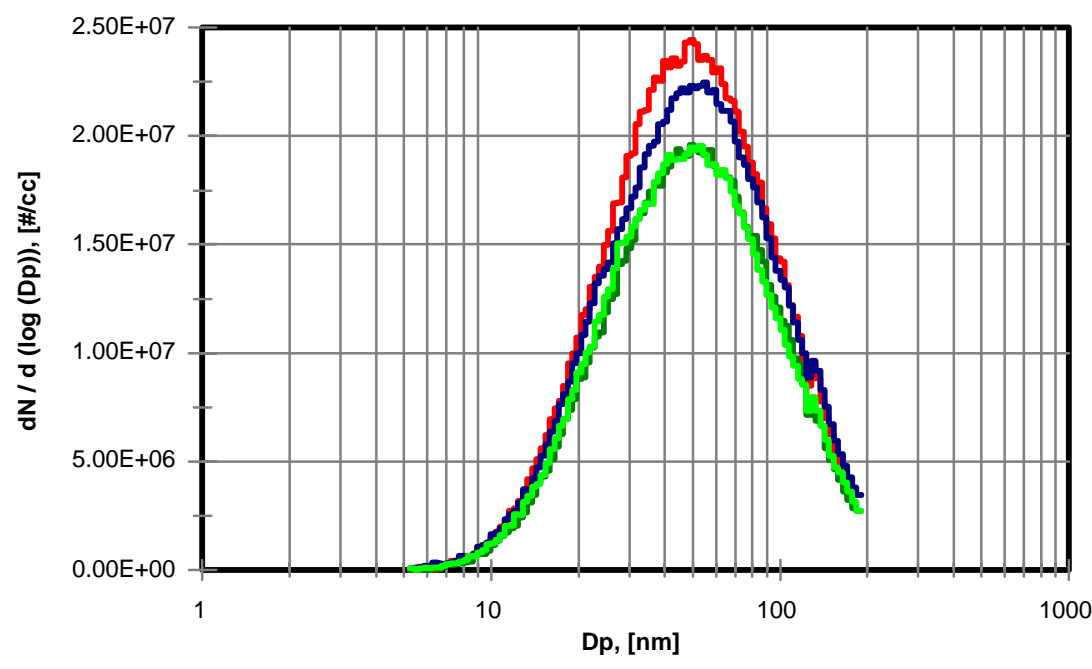

T1, Scan Time $=120 / 30 \mathrm{~s}$

T2, Scan Time $=120 / 30 \mathrm{~s}$

- T3, Scan Time $=200 / 30 \mathrm{~s}$

T4, Scan Time $=200 / 30 \mathrm{~s}$

Figure 3.16 Mack E7-400, Steady-State, R50, Diesel, DR = 4.3, MOUDI, Count Concentrations, Repeatability 


\subsubsection{Repeatability of Size Selective Measurements Diesel Particulate Matter with MOUDI}

\subsection{Orion/DDC 6V92 Study}

Repeatability of the size selective measurements of DPM with MOUDI was examined on the results of measurements performed in parallel to the several SMPS measurements on the exhaust from bus 2034. The bus was exercised over CBD cycle and fueled with Federal diesel no. 2 and Mossgas synthetic diesel. The repeatability of the measurements was found to be excellent (Figures 3.17 and 3.18).

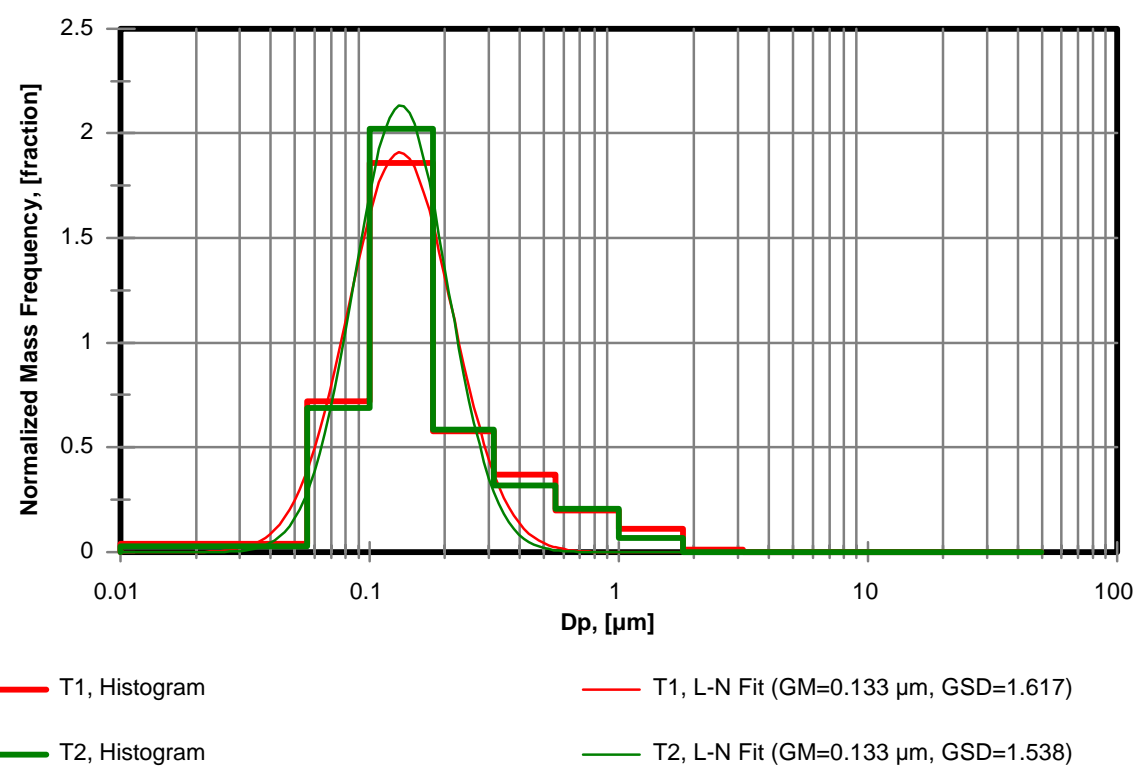

Figure 3.17 Orion/DDC 6V92, Bus 2034 Without OCC, Diesel, Normalized Mass Frequency, Transient, CBD, MOUDI, Repeatability 


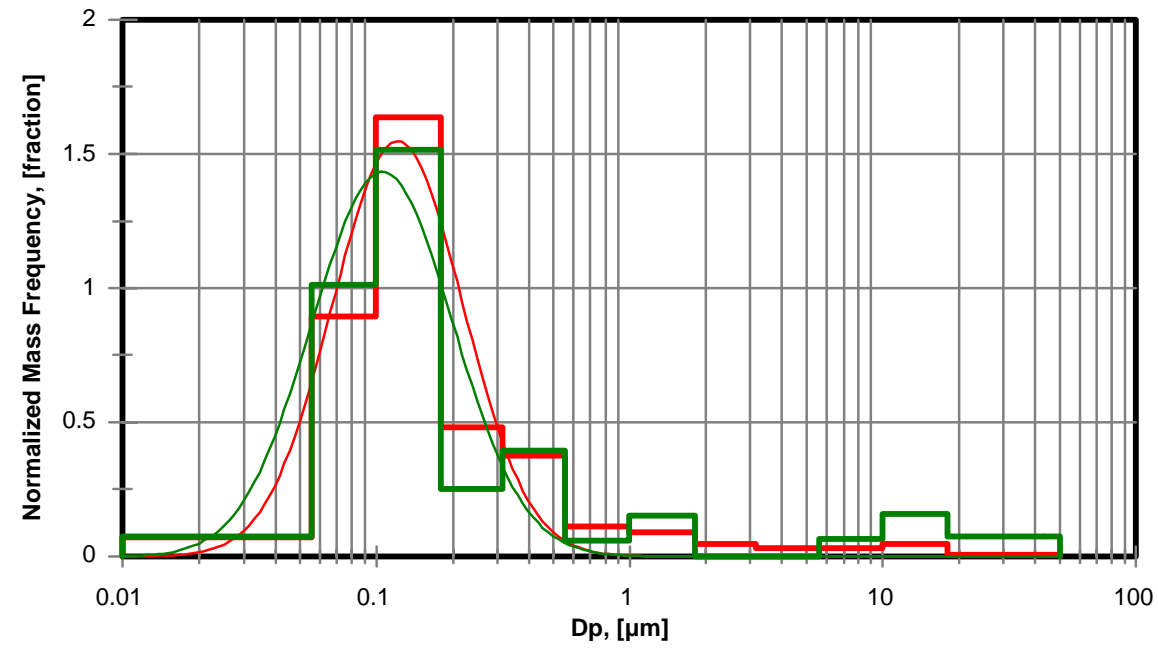

T1, Histogram

T1, L-N Fit $(\mathrm{GM}=0.122 \mu \mathrm{m}, \mathrm{GSD}=1.810)$

T2, Histogram

- T2, L-N Fit (GM=0.106 $\mu \mathrm{m}, \mathrm{GSD}=1.898)$

Figure 3.18 Orion/DDC 6V92, Bus 2034 Without OCC, Mossgas Synthetic Diesel, Normalized Mass Frequency, Transient, CBD, MOUDI, Repeatability

\subsection{Mack E7-400 Study}

The repeatability was also examined on the results of measurements performed with MOUDI on the exhaust from Mack E7 engine. The engine was operated at the R75, R50, I50 steady-state conditions and over hot starts of FTP cycle. The measurements at each of the selected modes and transient cycle were repeated twice. The Figures 3.19 through 3.22 show that the repeatability of the measurements was excellent except for the I50 engine operating conditions. 


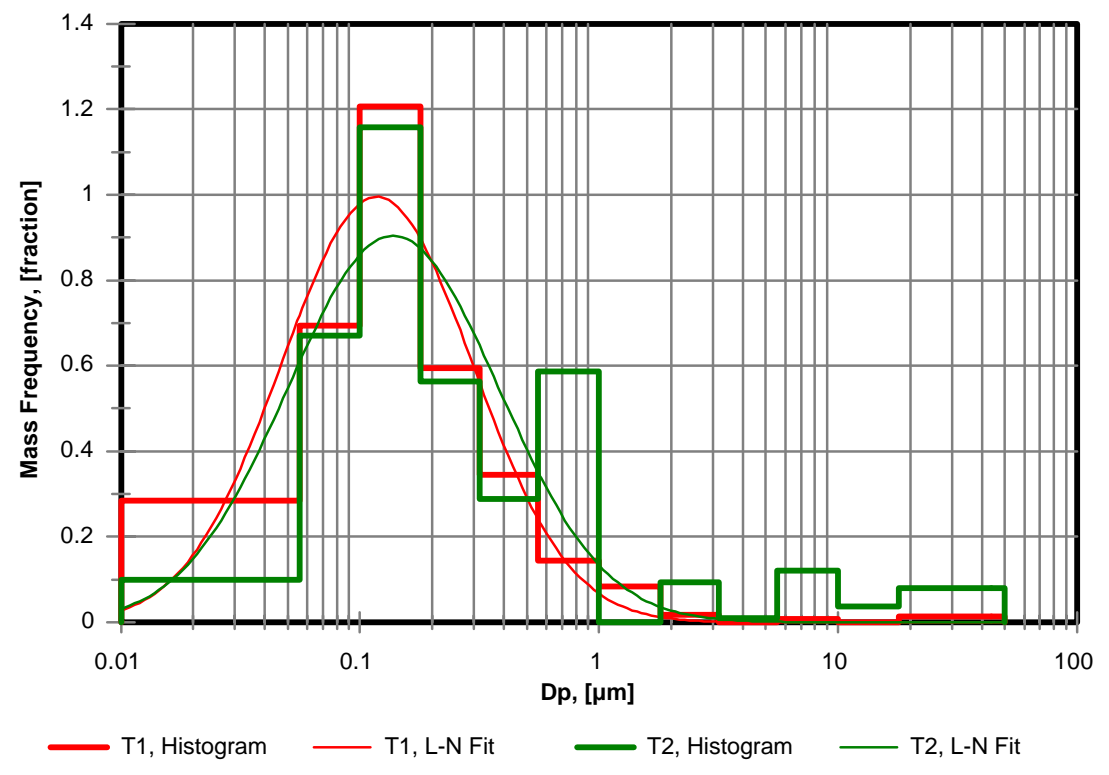

Figure 3.19 Mack E7-400, Diesel, DR = 4.3, Mass Frequency, Steady-State, R75, MOUDI, Repeatability

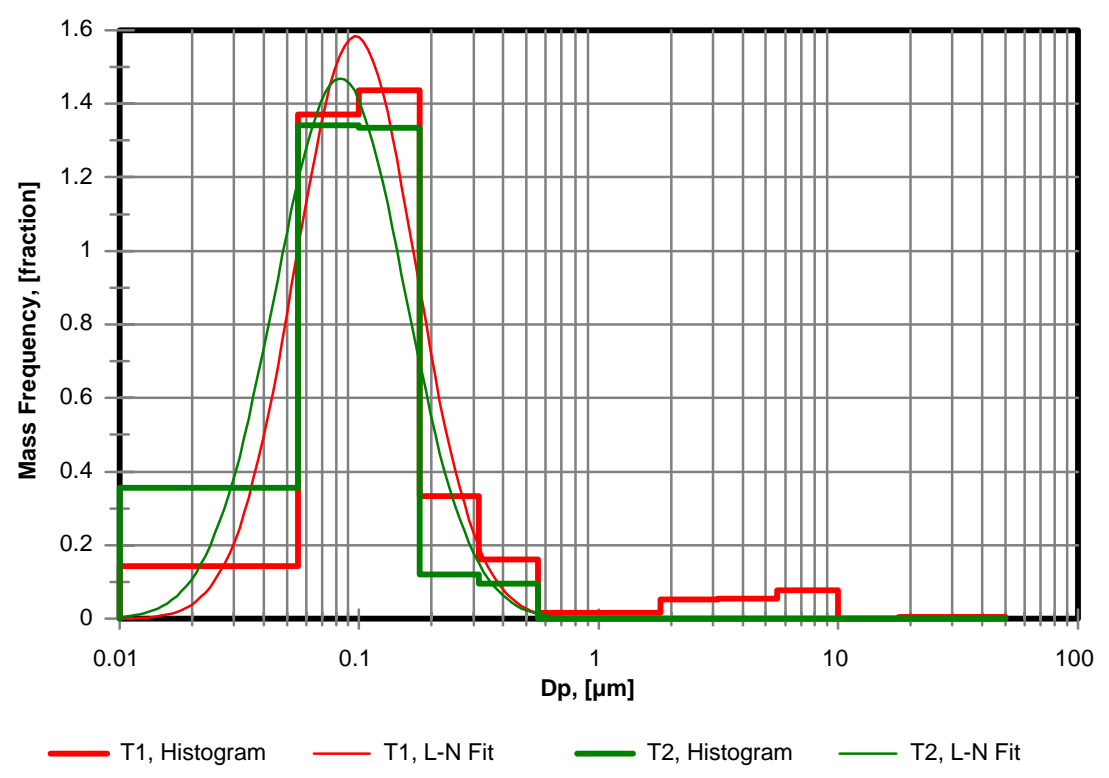

Figure 3.20 Mack E7-400, Diesel, DR = 4.3, Mass Frequency, Steady-State, R50, MOUDI, Repeatability 


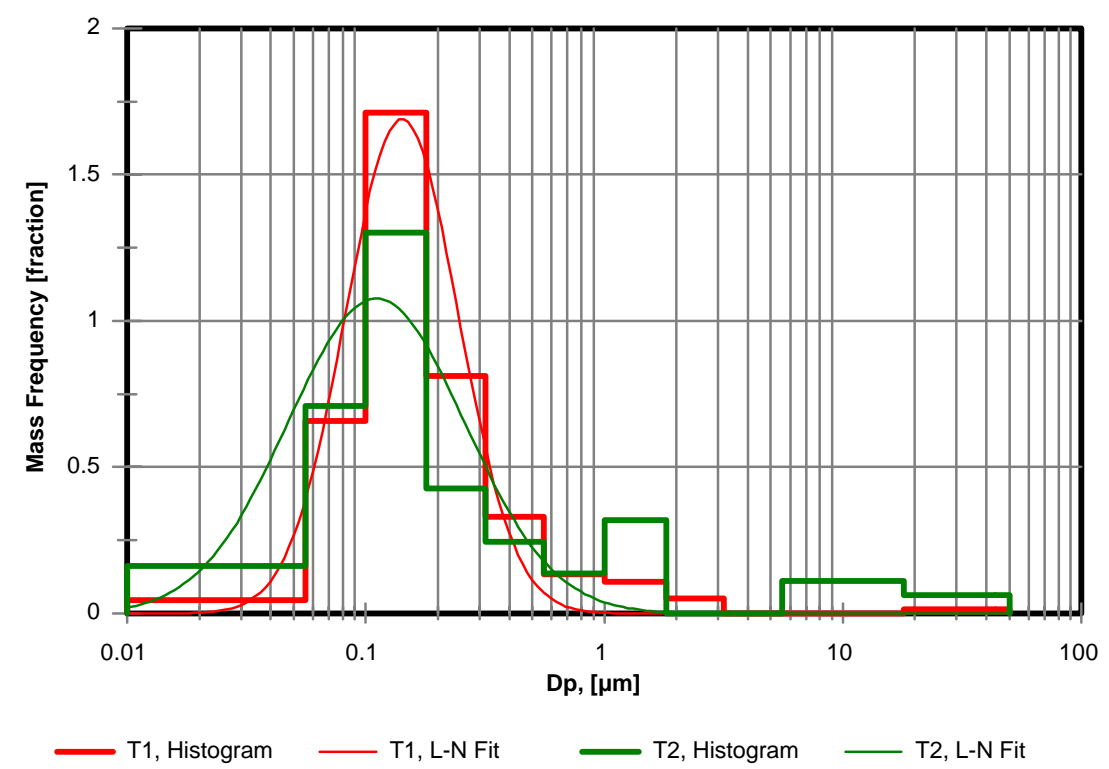

Figure 3.21 Mack E7-400, Diesel, DR = 4.3, Mass Frequency, SteadyState-State, I50, MOUDI, Repeatability

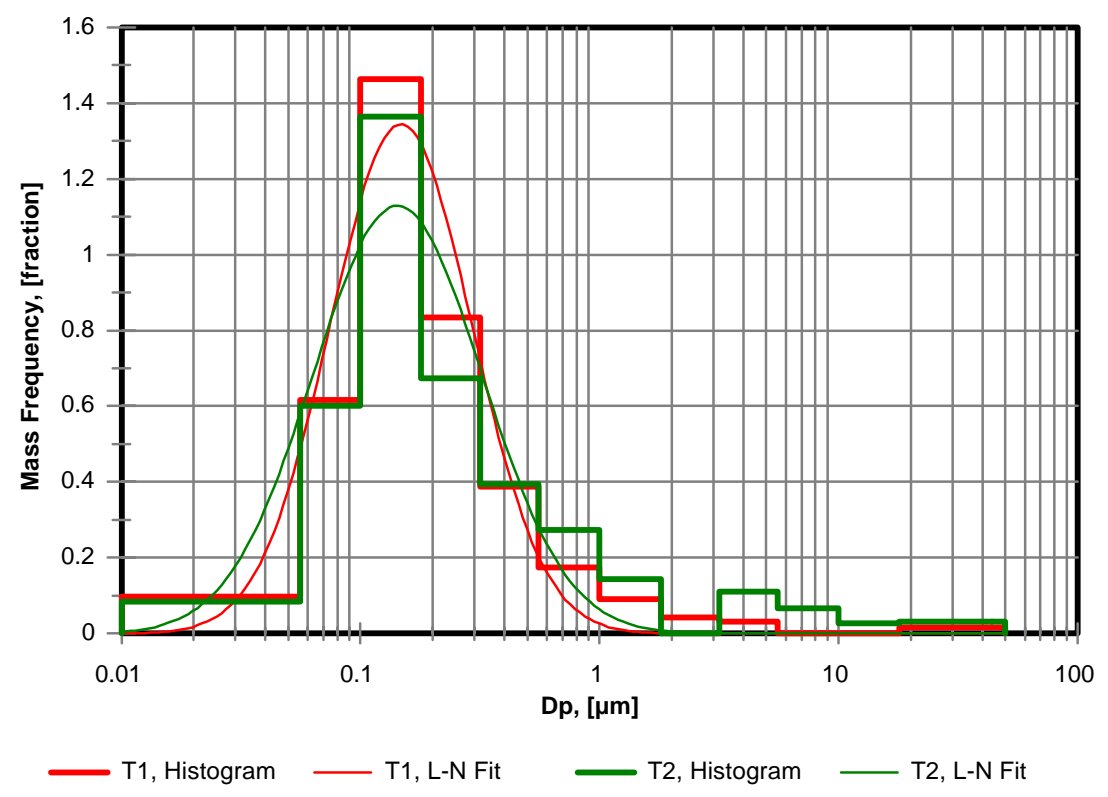

Figure 3.22 Mack E7-400, Diesel, DR = 4.3, Mass Frequency, Transient, FTP, MOUDI, Repeatability 


\subsubsection{Effects of Dilution Ratio on Size Resolved Measurements of Diesel Particulate Matter}

\subsubsection{Isuzu C240 Study}

Treated and untreated exhaust of Isuzu C240 engine generated under different engine operating cycles was diluted with conditioned ambient air (see Section 3.1.1.4.1). Dilution ratios ranging from 10 to 28 were employed for the various experiments undertaken in this study. The measurements obtained using range of dilution ratios allowed the examination of their effects on the size selective measurements of diesel exhaust particulate matter. A minimum of two different dilution ratios was applied for each engine operating condition/fuel/after-treatment device combination.

The results of extensive testing on the Isuzu C240 engine indicate that dilution ratio effects must be analyzed in conjunction with engine operating modes, fuel type and after-treatment device effects.

Bare engine test results showed that at higher dilution ratios, slightly higher concentrations of particles were measured throughout the full scan range. Lower dilution ratios seemed to yield slightly higher concentrations of smaller sized particles and slightly lower concentrations of larger sized particles. Still, the CMD for observed distributions did not seem to be significantly affected by dilution ratio. The same trends were observed for all engine operating conditions and for both fuels (Figures 3.23 and 3.24).

A limited number of tests was performed on the exhaust which was filtered through Pallflex paper filter. The applied dilution ratios had the same effect on PM distributions and concentrations as they did on bare engine exhaust (Figure 3.25).

The dilution ratio significantly influenced the measured size distributions in the diluted exhaust treated with the catalyzed trap. A lower dilution ratio $(D R=15)$ resulted in higher concentrations of smaller sized particles and lower concentrations of larger sized particles for R100, R75, and I50 engine operating modes. This is much less pronounced for I100 engine operating mode (Figure 3.26). Large concentrations of the nanoparticles, ranging from 15 to $70 \mathrm{~nm}$, might be attributed to homogeneous and heterogeneous nucleation due to the presence of sulfuric acid aerosol downstream of the trap. The catalytic coating was applied on the trap to lower ignition temperature and enhance trap regeneration, but it also enhanced the oxidation of $\mathrm{SO}_{2}$ to $\mathrm{SO}_{3}$ which combine with water to form sulfuric acid and consequently a binary mixture of $\mathrm{H}_{2} \mathrm{O}-\mathrm{H}_{2} \mathrm{SO}_{4}$ (Baumgard and Johnson, 1996) 
Dilution ratio effects on the exhaust gases drawn through oxidation catalytic converter and a catalyzed trap combination (Rohmac/DCL exhaust treatment system) were dominated by nucleation of sulfuric acid at lower dilution ratios, and condensation and adsorption of sulfuric acid aerosol and semivolatile hydrocarbon compounds for higher dilution ratios. The exhaust temperature played a dominant role in the catalyst performance as well as in the condensation of semi-volatile compounds. A reduction in the dilution ratio for the engine operating mode I100 resulted in the PM distributions shifting to the smaller size range for both the fuel types. Hence, a higher concentrations of smaller size particles and smaller CMD (Figures 3.27 and 3.28) were observed. For the I50 mode higher dilution ratio resulted in a higher concentration and slightly large CMD (Figure 3.29 and 3.30).

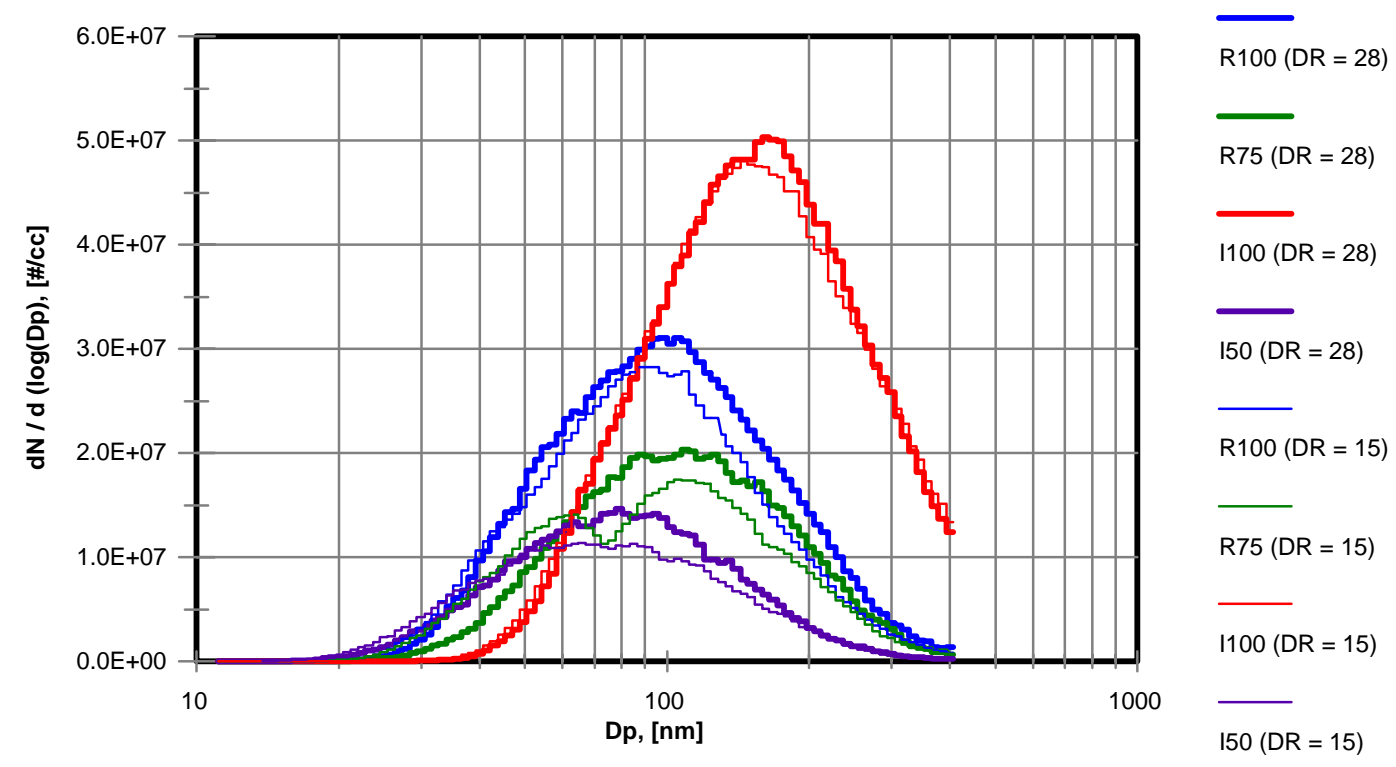

Figure 3.23 Isuzu C240, Steady-State Operating Conditions, Bare Engine, Diesel, Number Concentrations, Effects of Dilution Ratio 


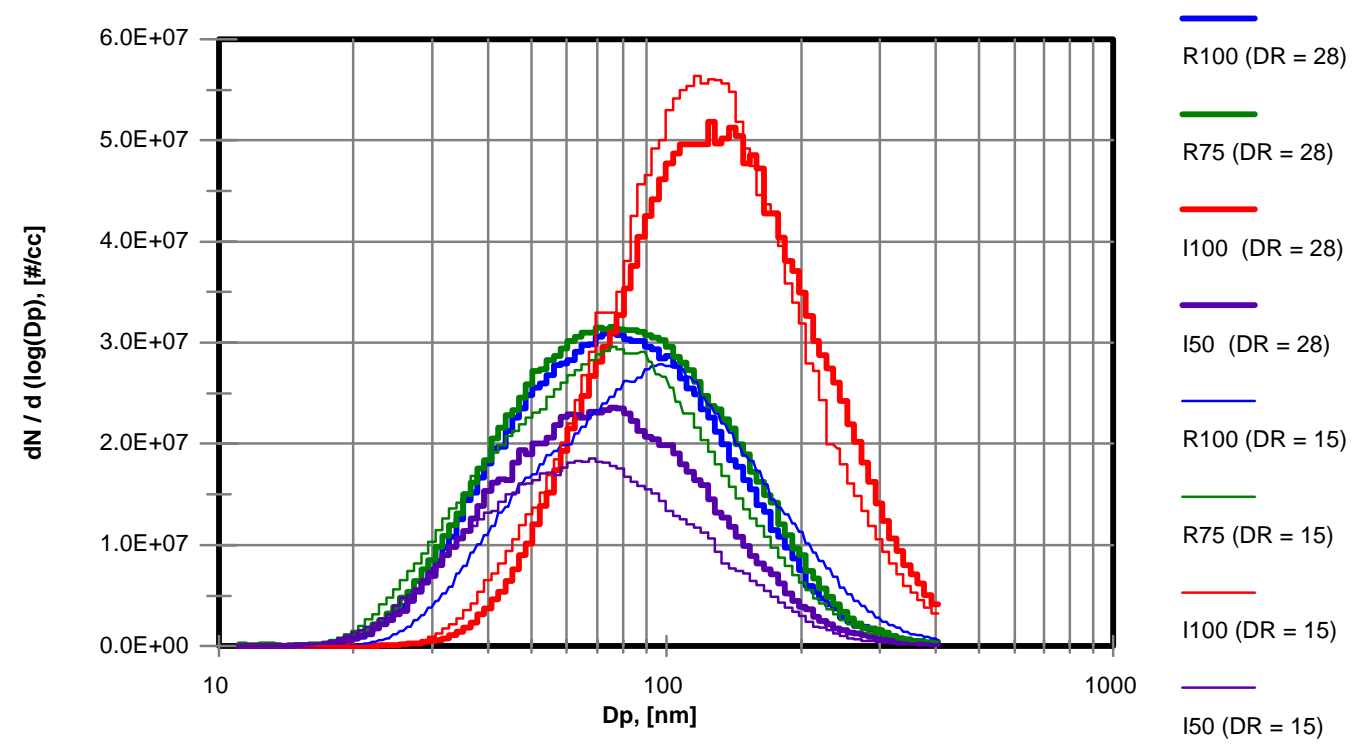

Figure 3.24 Isuzu C240, Steady-State Operating Conditions, Bare Engine, Synthetic Diesel, Number Concentrations, Effects of Dilution Ratio

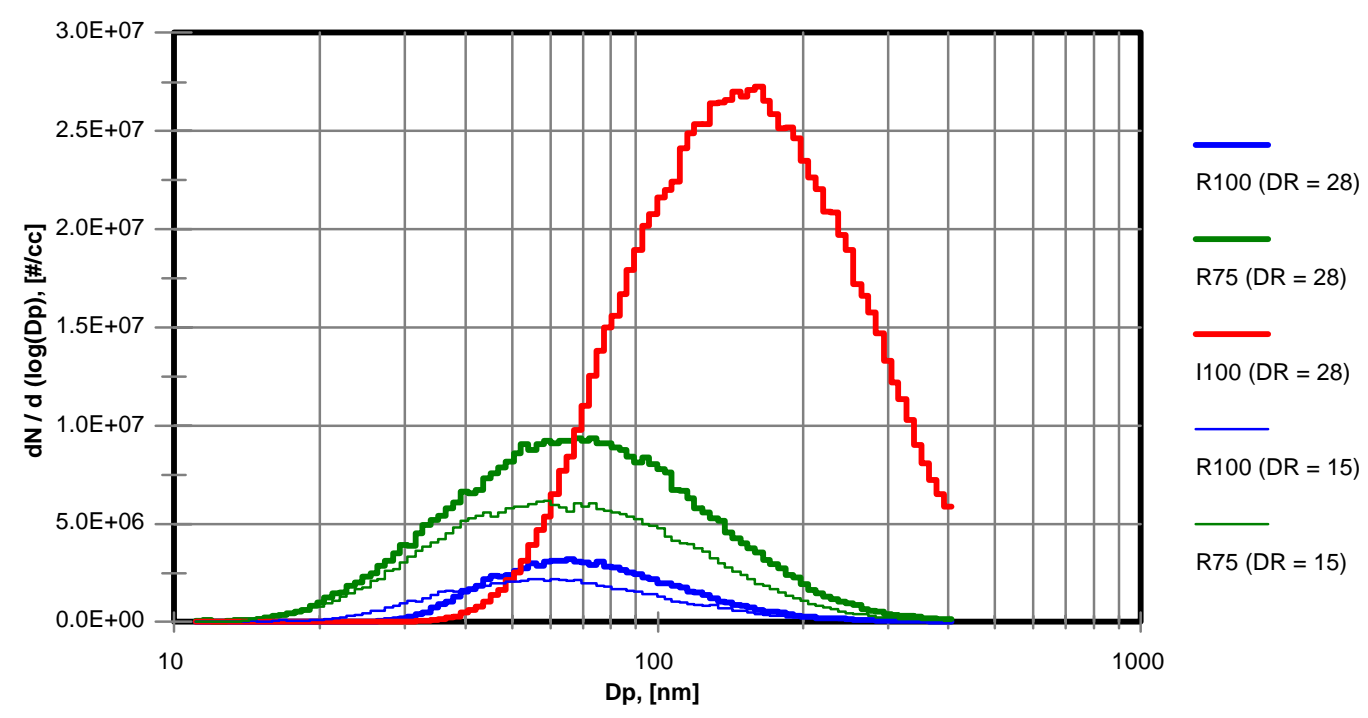

Figure 3.25 Isuzu C240, Steady-State, Paper Filter, Diesel,

Number Concentrations, Effects of Dilution Ratio and Engine Operating Conditions 


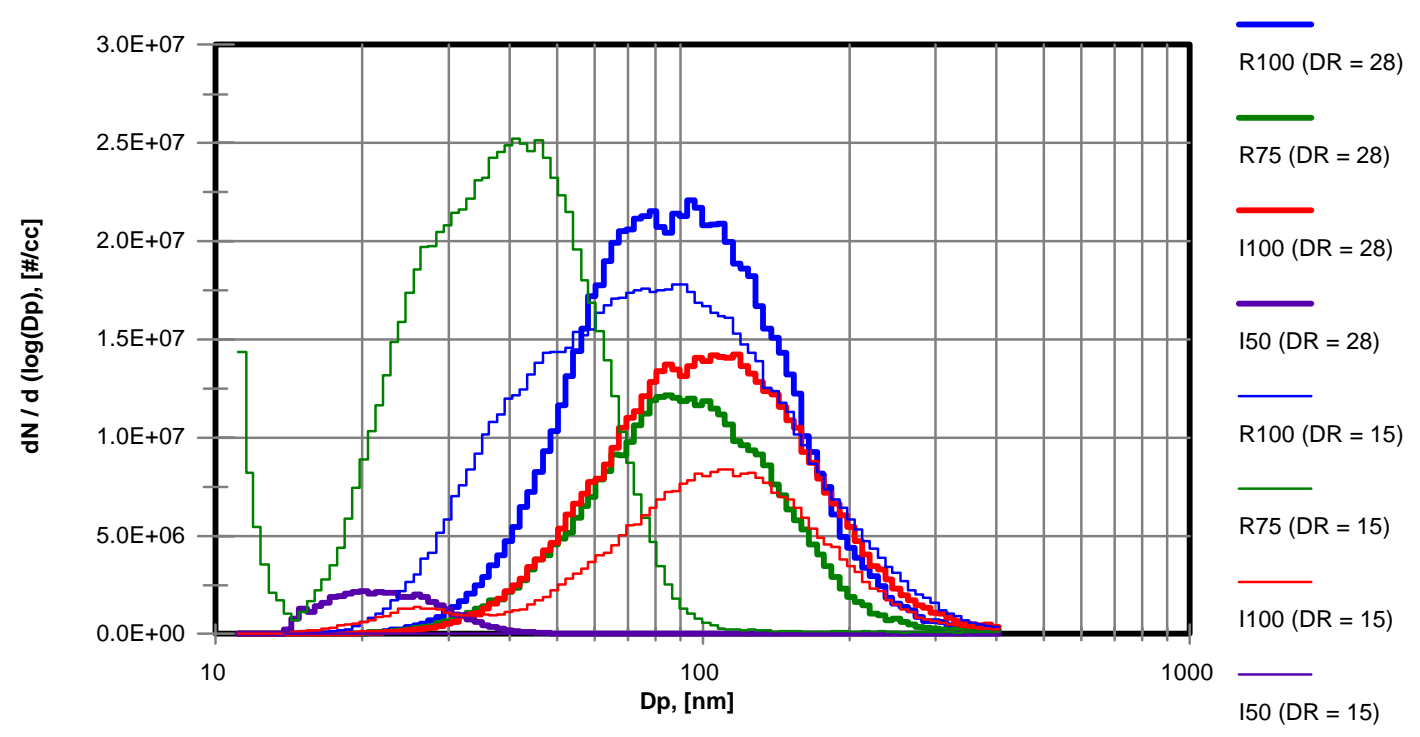

Figure 3.26 Isuzu C240, Steady-State Operating Conditions, Trap, Diesel, Number Concentrations, Effects of Dilution Ratio

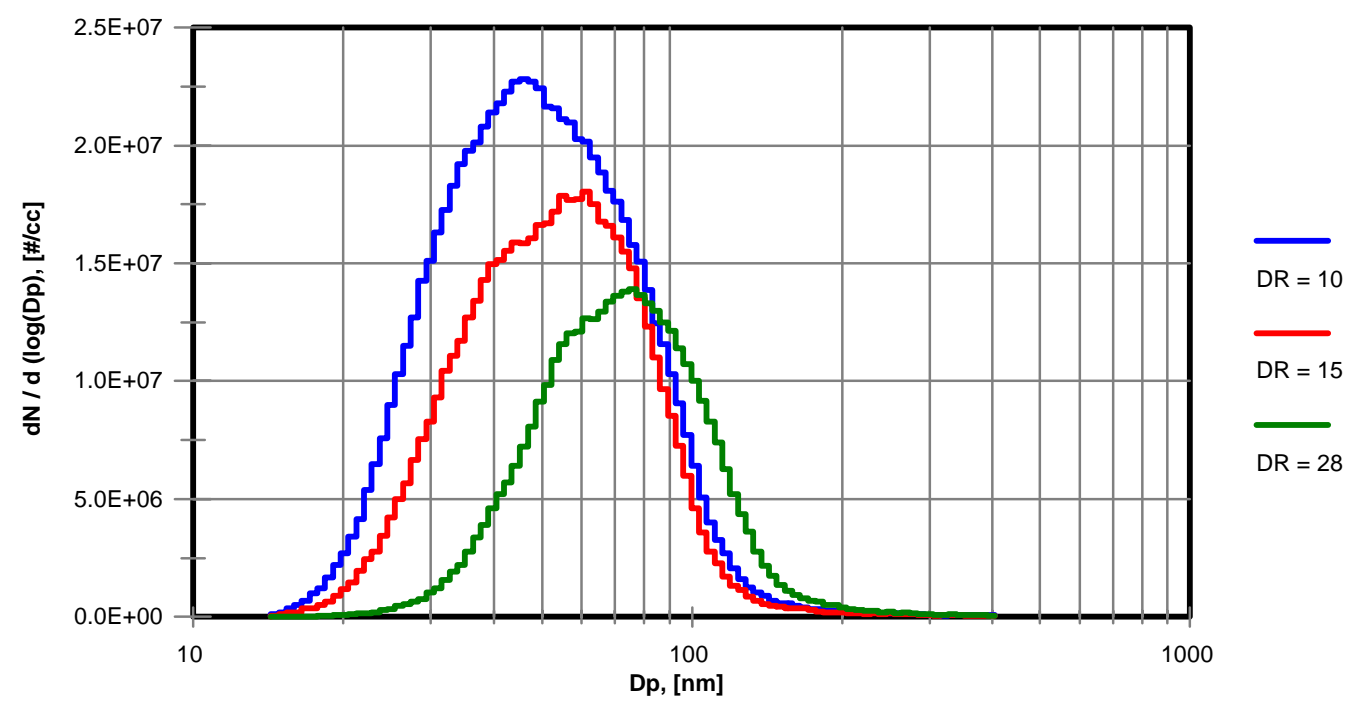

Figure 3.27 Isuzu C240, Steady-State Operating Conditions, I100, Catalytic Converter and Trap, Diesel, Number Concentrations, Effects of Dilution Ratio 


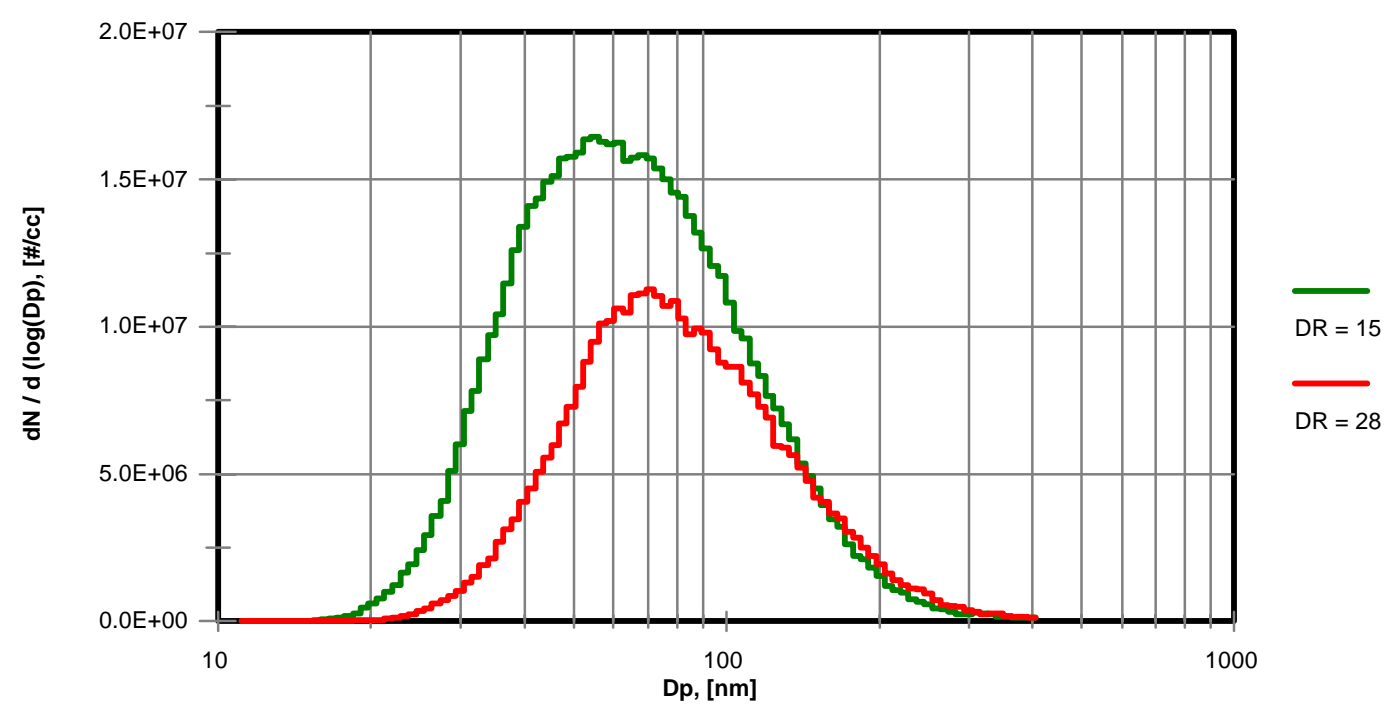

Figure 3.28 Isuzu C240, Steady-State Operating Conditions, I100, Catalytic Converter and Trap, Fisher-Tropsch, Number Concentrations, Effects of Dilution Ratio

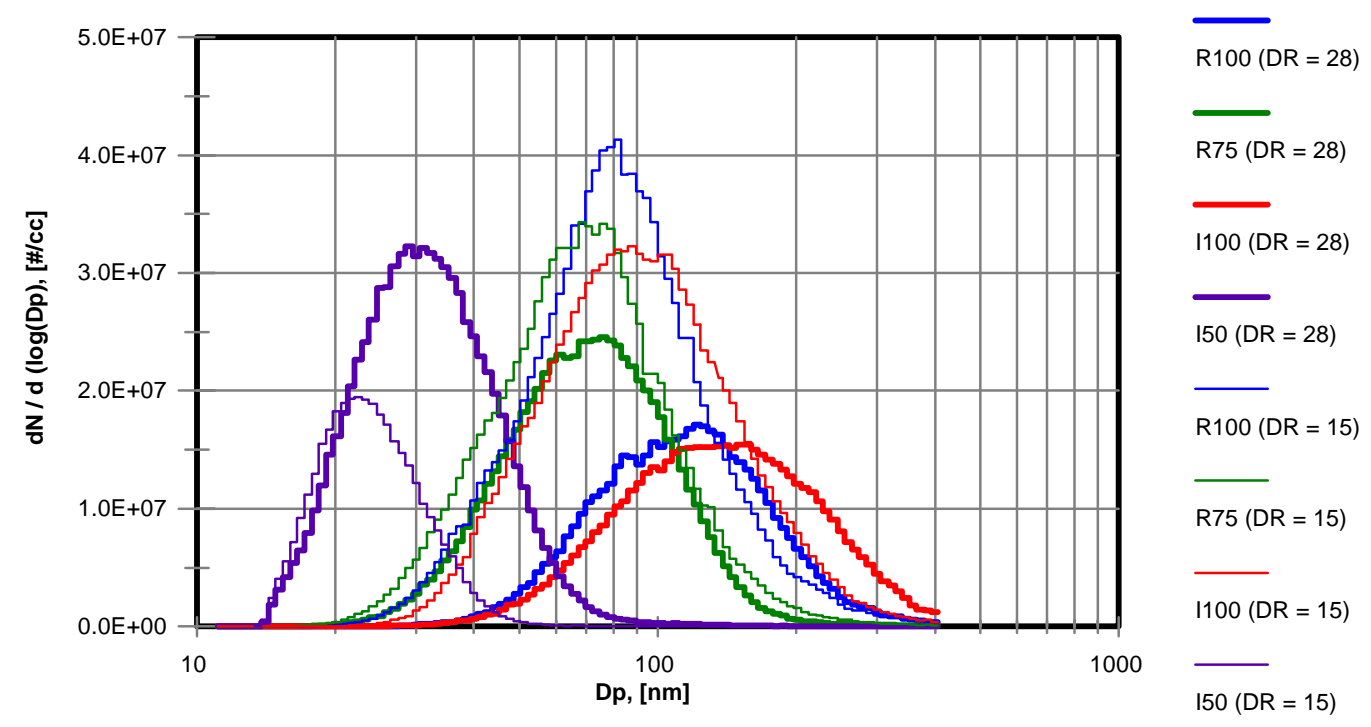

Figure 3.29 Isuzu C240, Steady-State Operating Conditions, Catalytic Converter, Trap and Paper Filter, Diesel, Number Concentrations, Effects of Dilution Ratio 


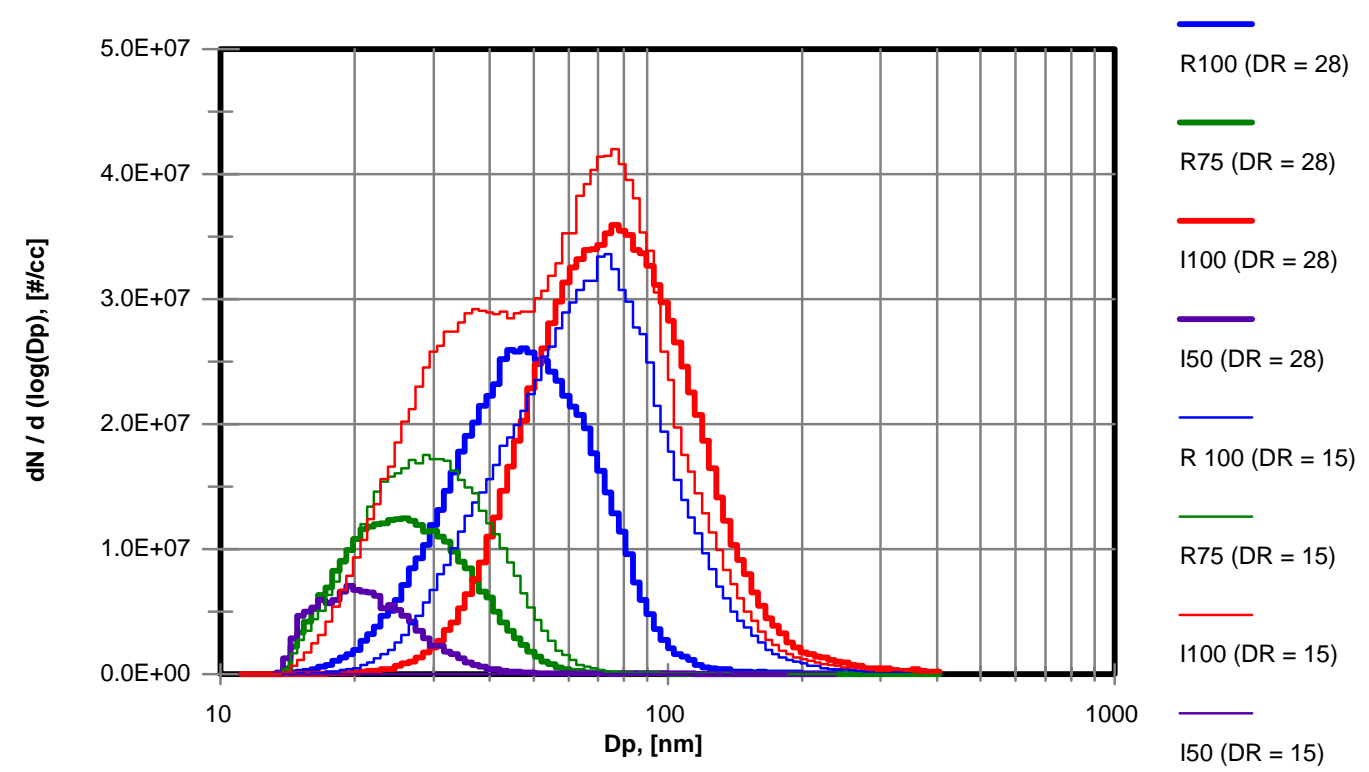

Figure 3.30 Isuzu C240, Steady-State Operating Conditions, Catalytic Converter, Trap and Paper Filter, Synthetic Diesel, Number Concentrations, Effects of Dilution Ratio

The size distributions when the engine fueled with the diesel no. 2, was equipped with a catalytic converter and the trap combination along with a Pallflex paper filter, exhibited similar trends as the distributions for the case of catalytic converter and trap combination only (Figure 3.29). Lower dilution ratios for modes R100, R75 and I100 resulted in smaller CMD aerosols and substantially higher concentrations. Bimodal distribution was observed for $\mathrm{I} 100$ conditions and F-T fuel (DR $=15)$. The CMD of $25 \mathrm{~nm}$ may be attributed to the presence of higher concentrations of semi-volatile hydrocarbons along with high concentrations of $\mathrm{H}_{2} \mathrm{SO}_{4}$. Lower dilution ratio resulted in a decrease in concentrations and $\mathrm{CMD}$ for the mode I50. The same engine/after-treatment device combination exhibited similar distribution and concentration results for I100 mode when fueled with F-T diesel fuel (Figure 3.30). For R100 and R75 modes and F-T fuel, a lower dilution ratio $(\mathrm{DR}=15)$ produced slightly higher concentrations and larger CMD particles. It appears that condensation and adsorption processes dominated over the nucleation 
process. The paper filter and trap efficiently removed larger sized particles. Smaller sized particles, which were most probably generated in the catalytic converter and catalyzed trap, were detected in significant concentrations in the treated exhaust. This will be discussed in details in the following sections.

\subsubsection{Orion/DDC 6V92 Study}

\subsection{Steady-State Conditions}

The effects of dilution ratio (DR) on size selective measurements of DPM were studied on exhaust from buses 2048 and 2034 driven at 20 and $40 \mathrm{mph}$. The raw exhaust was diluted in the partial dilution tunnel. The dilution ratios of 22 and 5 were used to investigate DR effects. DR as low as 5 was selected because it is commonly encountered in heavy-duty vehicle emission measurements that use the total exhaust double dilution system. For the range of the dilution ratios applied in this study, the DR values were maintained within the limits of the the flow measurements uncertainty.

The results are presented in Figures 3.31 and 3.32. It appeared that diluting raw exhaust at lower dilution rate $(\mathrm{DR}=5)$ resulted in DPM count distributions which were characterized with slightly smaller CMD and in most cases slightly higher concentrations. Higher concentrations of smaller size particles at lower dilution ratio $(\mathrm{DR}=5)$ can be explained by higher concentration of the nucleated semivolatile compounds which at higher dilution ratio $(\mathrm{DR}=22)$, due to further cooling, were condensed and adsorbed on the larger sized particles. 


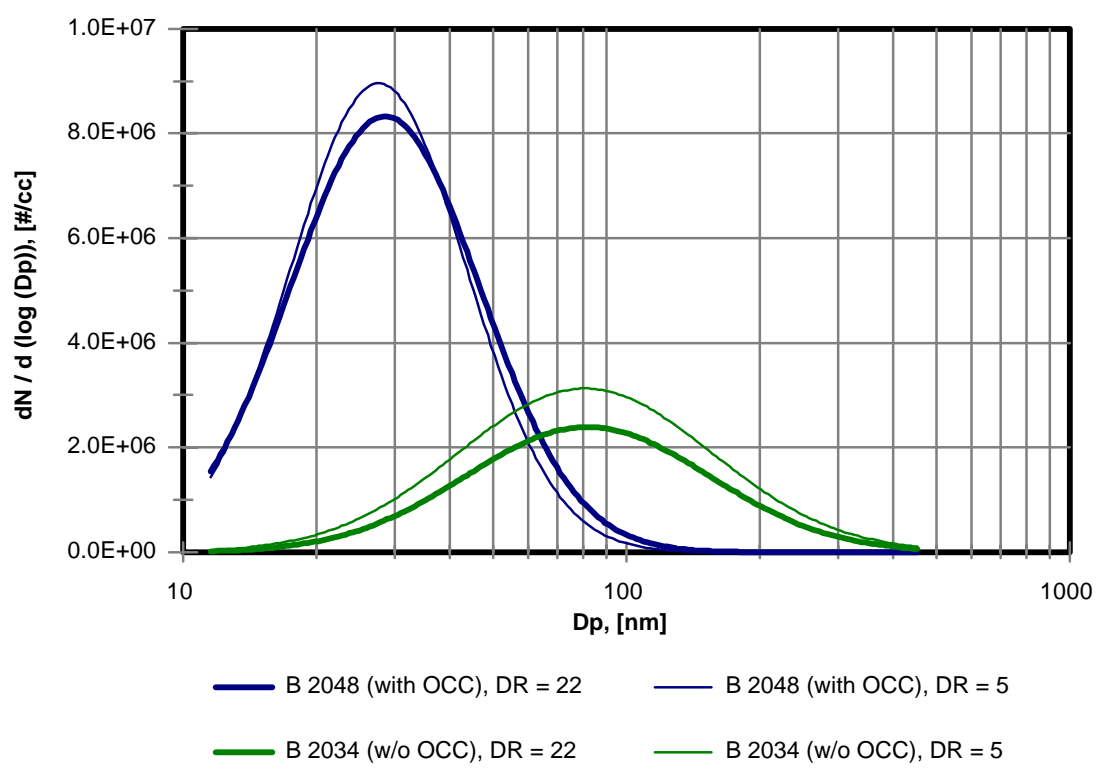

Figure 3.31 Orion/DDC 6V92, Steady-State, $20 \mathrm{mph}$, Diesel, Number Concentrations, Effects of Dilution Ratio

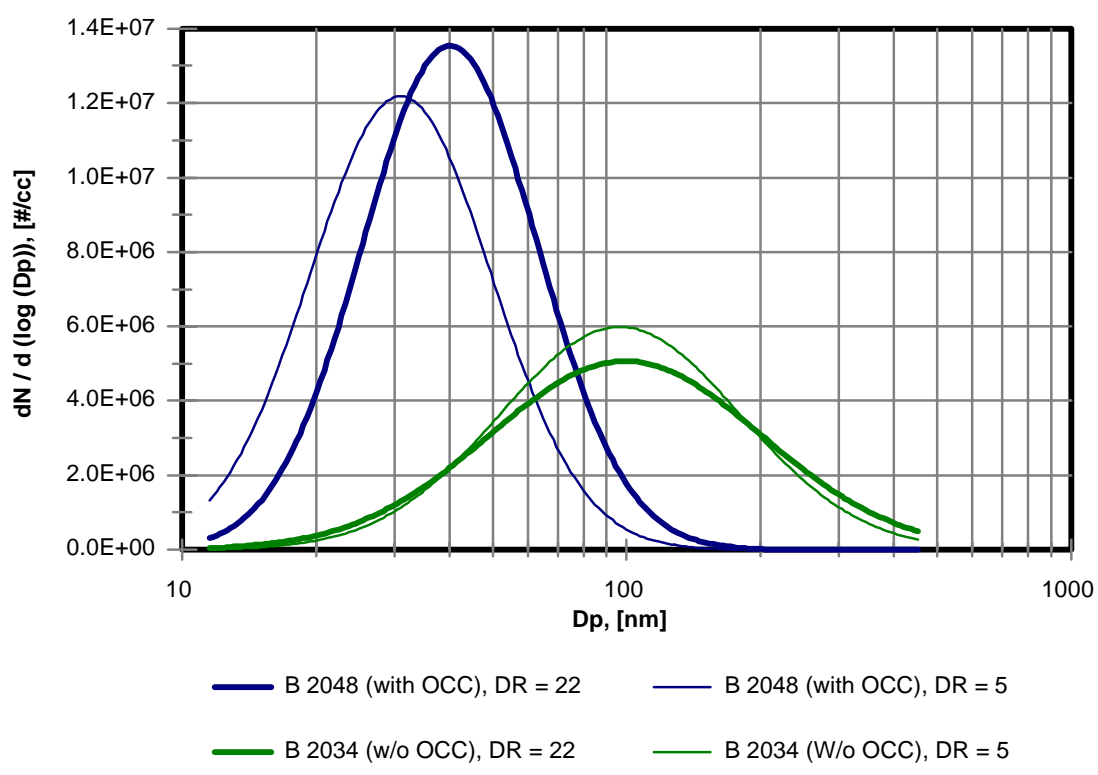

Figure 3.32 Orion/DDC 6V92, Steady-State, $40 \mathrm{mph}$, Diesel, Number Concentrations, Effects of Dilution Ratio 


\subsection{Transient Conditions}

The effects of dilution ratio on size selective measurements of DPM during transient vehicle operating conditions were examined, with SMPS, on the exhaust from buses 2029 (before it was fitted with rebuilt engine and OCC), 2048, and 2034. Dilution ratios of 22 and 5 were used in this comparison study.

Concentrations of the particles with mobility diameters of 50, 100 , and $200 \mathrm{~nm}$, for both the dilution ratios, are shown in the Figures 3.33 through 3.35. The effects of dilution ratio were found to be strongly vehicle dependent. The results for the bus 2029 showed a DR $=5$ resulted in lower concentrations of 50,100, and $200 \mathrm{~nm}$ particles. The detected concentrations of particles with mobility diameters of 50, 100, and $200 \mathrm{~nm}$ for diluted exhaust from bus 2048 and a mobility diameter of $50 \mathrm{~nm}$ for bus 2034 were found to be higher for the $\mathrm{DR}=5$. However, the concentrations of particles with diameters of 100 and $200 \mathrm{~nm}$ were found to be unaffected with a change in the dilution ratio.

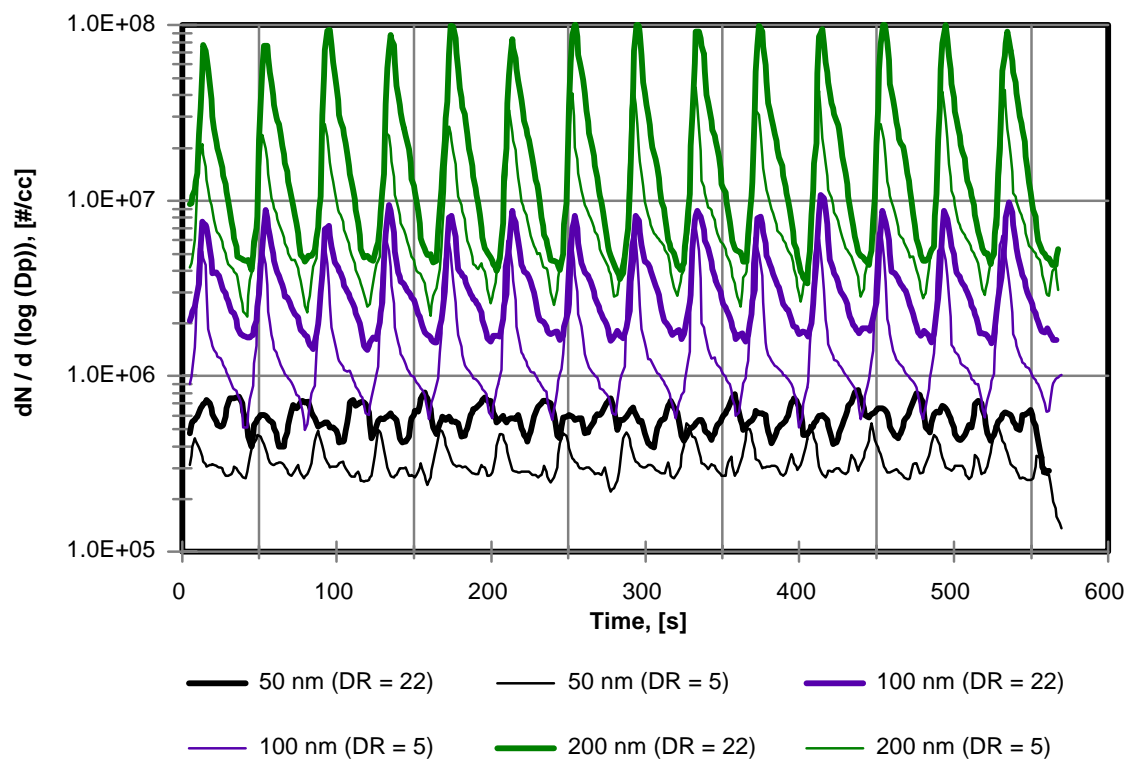

Figure 3.33 Orion/DDC 6V92, Bus 2029 Without OCC, Transient, CBD, Diesel, Number Concentration, Effects of Dilution Ratio 


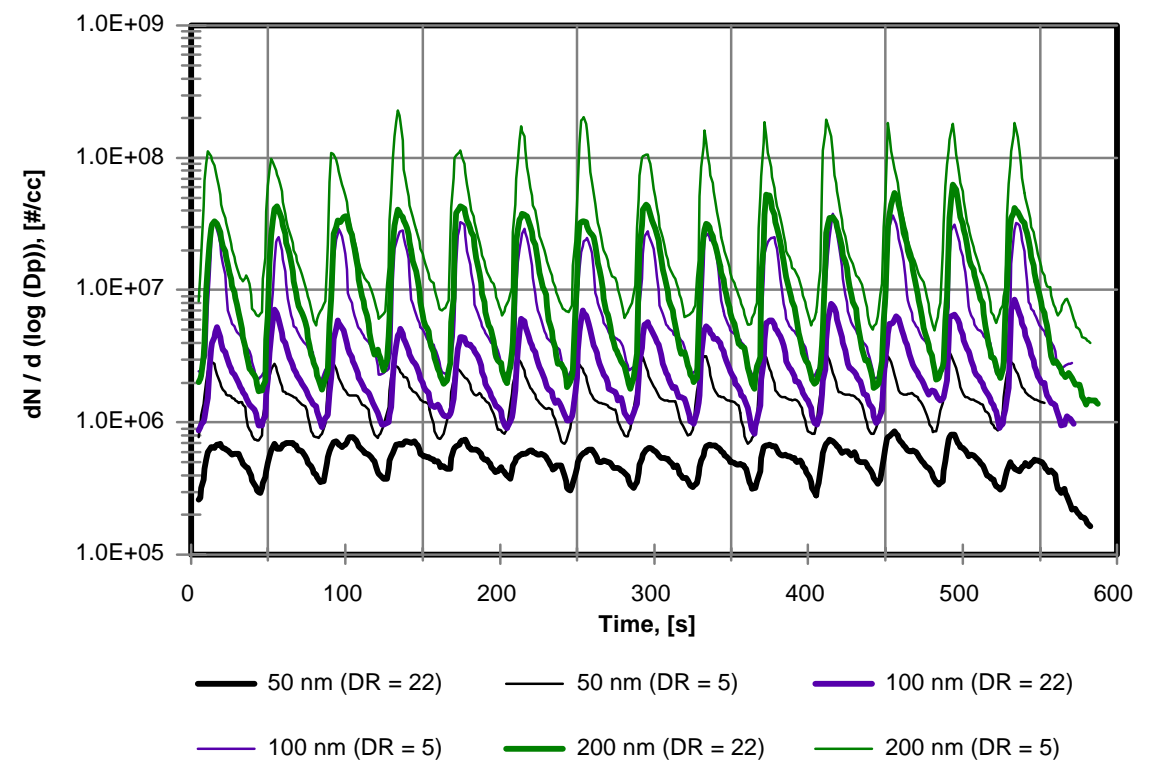

Figure 3.34 Orion/DDC 6V92, Bus 2048 With OCC, Transient, CBD, Diesel, Number Concentration, Effects of Dilution Ratio

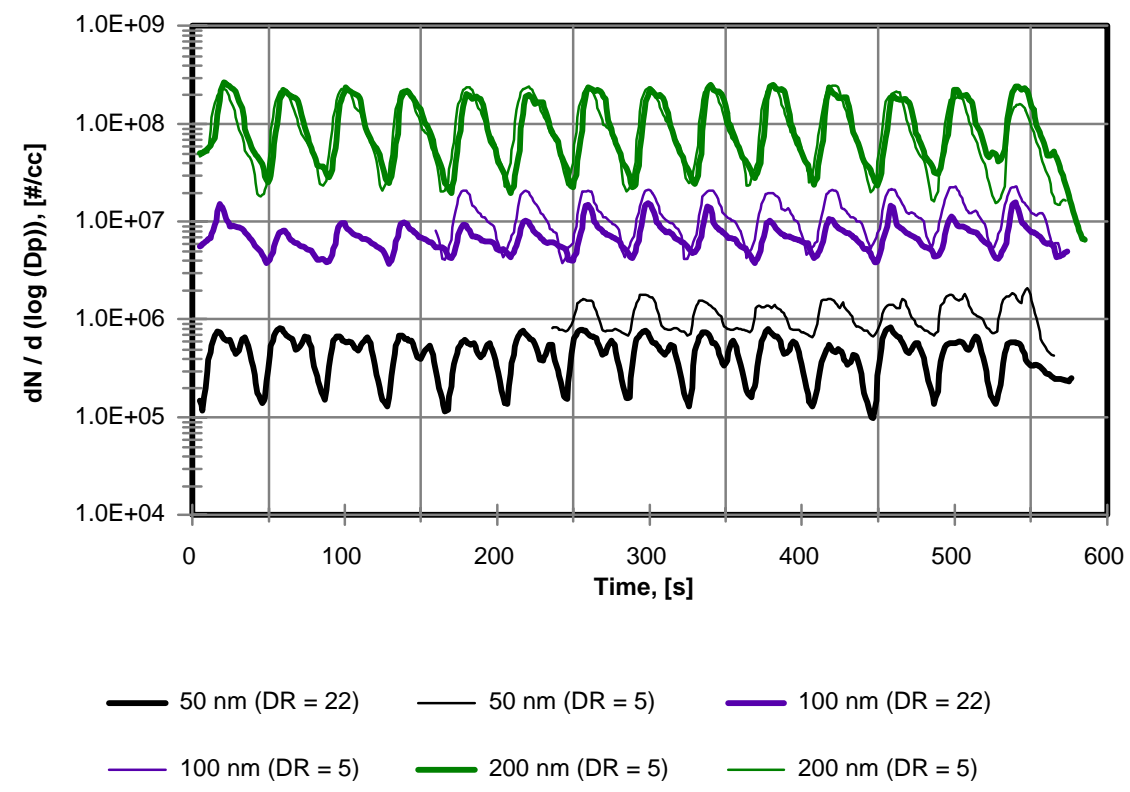

Figure 3.35 Orion/DDC 6V92, Bus 2034 Without OCC, Transient, CBD, Diesel, Number Concentration, Effects of Dilution Ratio 
Keeping in mind the uncertainty introduced with testing and measurement techniques as well as the narrow range of applied dilution ratios, it was impossible to draw general conclusions on the effects of dilution ratio on size selective measurements of DPM from in-use vehicle operated at transient conditions. However, dilution ratio of 22 was found to be more suitable for measurements with SMPS. For this dilution ratio, measured particle concentrations in the diluted exhaust for all tested vehicles and operating conditions were found to be in the concentration range (CPC 3022A: 2 particles $/ \mathrm{cm}^{3}$ to $10^{8}$ particles $/ \mathrm{cm}^{3}$ ) specified by TSI.

\subsubsection{Variation of Size-Resolved Diesel Particulate Matter Emissions from Vehicle to Vehicle}

\subsubsection{Orion/DDC 6V92 - Steady-State Conditions}

Testing of the PAT transit buses gave good opportunity for examining uncertainties related to testing of in-use vehicles. The results from buses 2029 (before was fitted with rebuilt engine and OCC), 2034, 2030, and 2048 were used to study the effects of vehicle condition on the size-resolved DPM emissions from vehicle to vehicle. Former three vehicles were powered with engines with high milage accumulation and were not equipped with exhaust gas aftertreatment. Bus 2048 was fitted with rebuilt engine and OCC. The vehicles were driven at constant speeds of 20, 30, and $40 \mathrm{mph}$ and fueled with Federal diesel no. 2 and Mossgas synthetic diesel.

The analysis was performed on the distributions presented in Figures 3.36 through 3.41. The distributions were mostly bimodal, with one dominant mode. The single mode log-normal distributions which were fitted to the data were employed for the sake of the simplicity. Statistical parameters indicated that no significant errors were introduced by applying single modal log-normal distributions to the actual data.

The count distributions of particles emitted from the bus 2034 significantly differed from the distributions measured for buses 2029 and 2030 (Figures 3.36 through 3.41). The distribution of DPM in the exhaust from bus 2034 were characterized with largest CMDs and lowest peak concentrations. This is somehow in agreement with the results of gravimetric analysis of TPM (see Table 3.6 and Figure 3.12) 


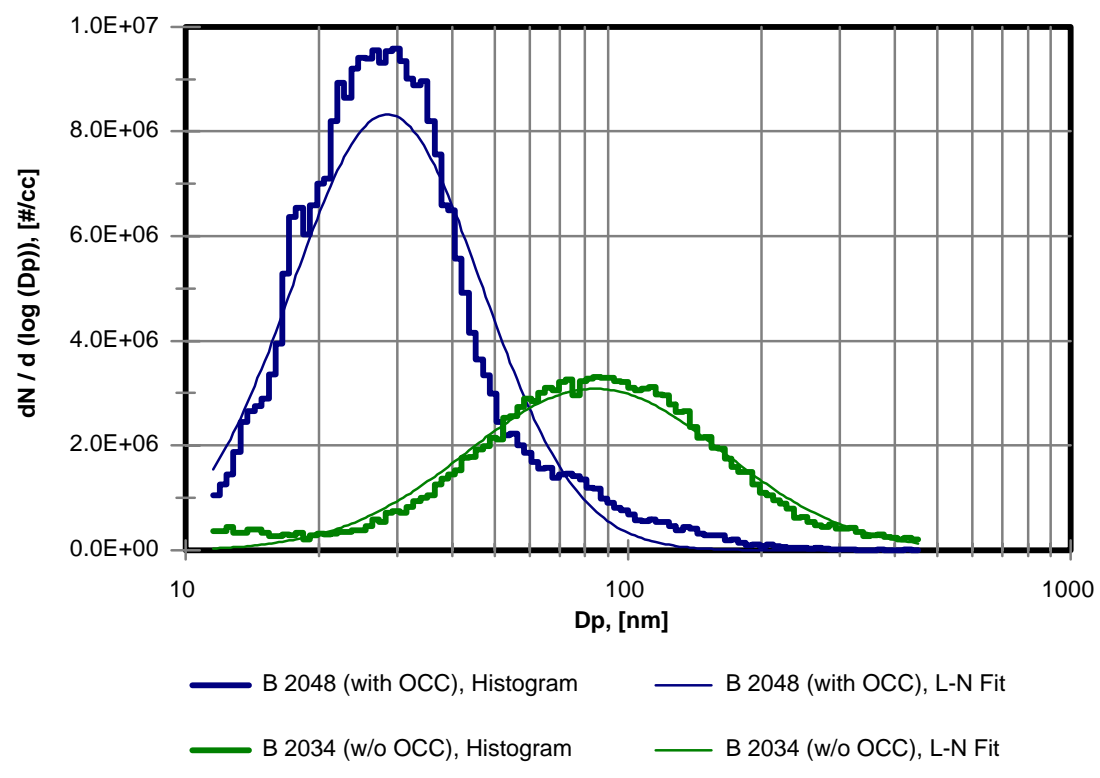

Figure 3.36 Orion/DDC 6V92, Steady-State, $20 \mathrm{mph}$, DR = 22, Diesel, Number Concentrations, Vehicle to Vehicle Variation
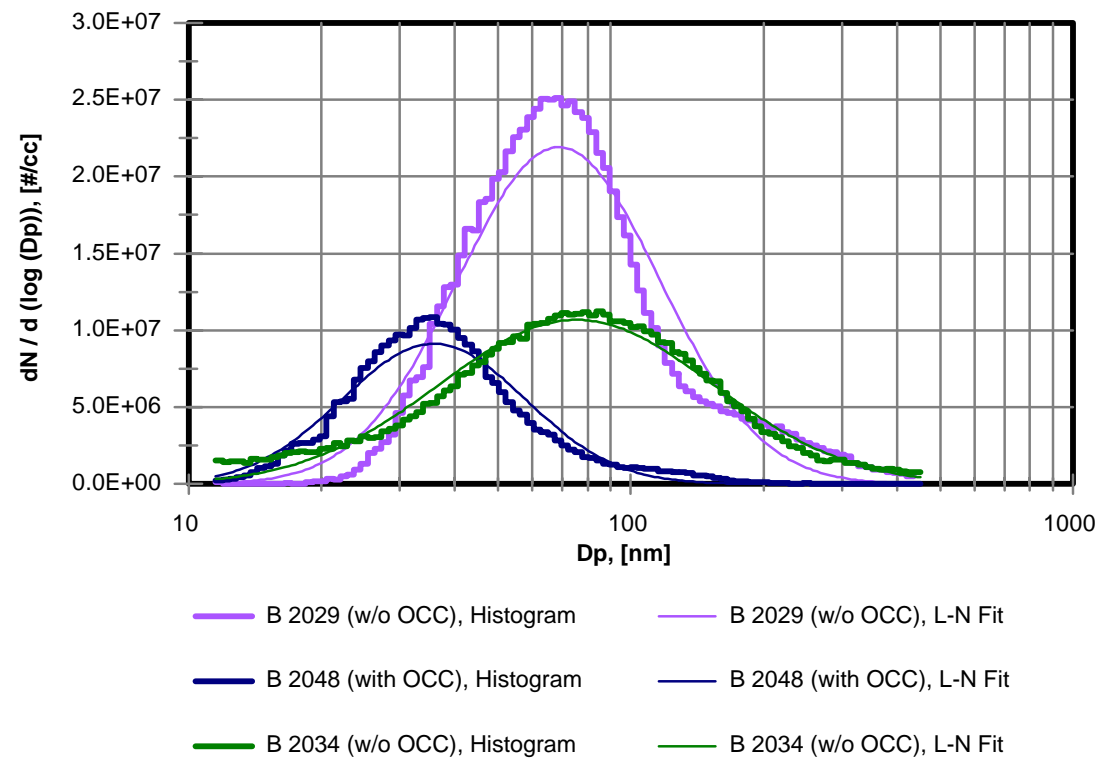

Figure 3.37 Orion/DDC 6V92, Steady-State, $30 \mathrm{mph}, \mathrm{DR}=22$, Diesel, Number Concentrations, Vehicle to Vehicle Variation 


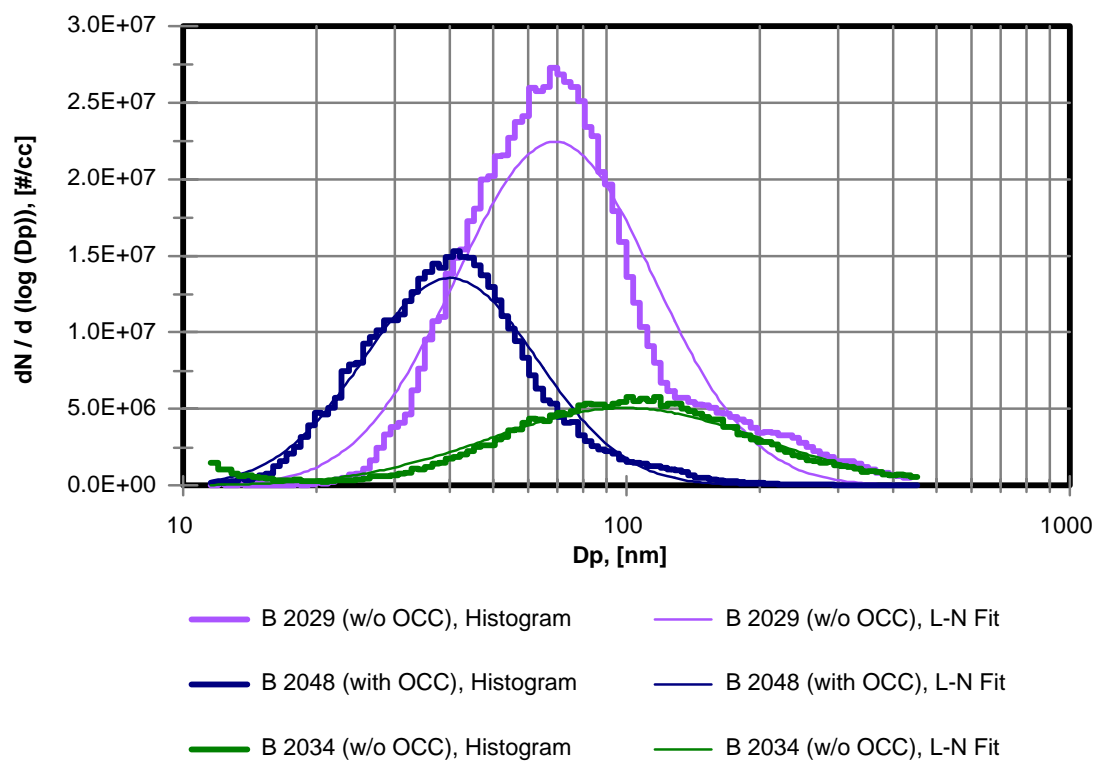

Figure 3.38 Orion/DDC 6V92, Steady-State, $40 \mathrm{mph}, \mathrm{DR}=22$, Diesel, Number Concentrations, Vehicle to Vehicle Variation
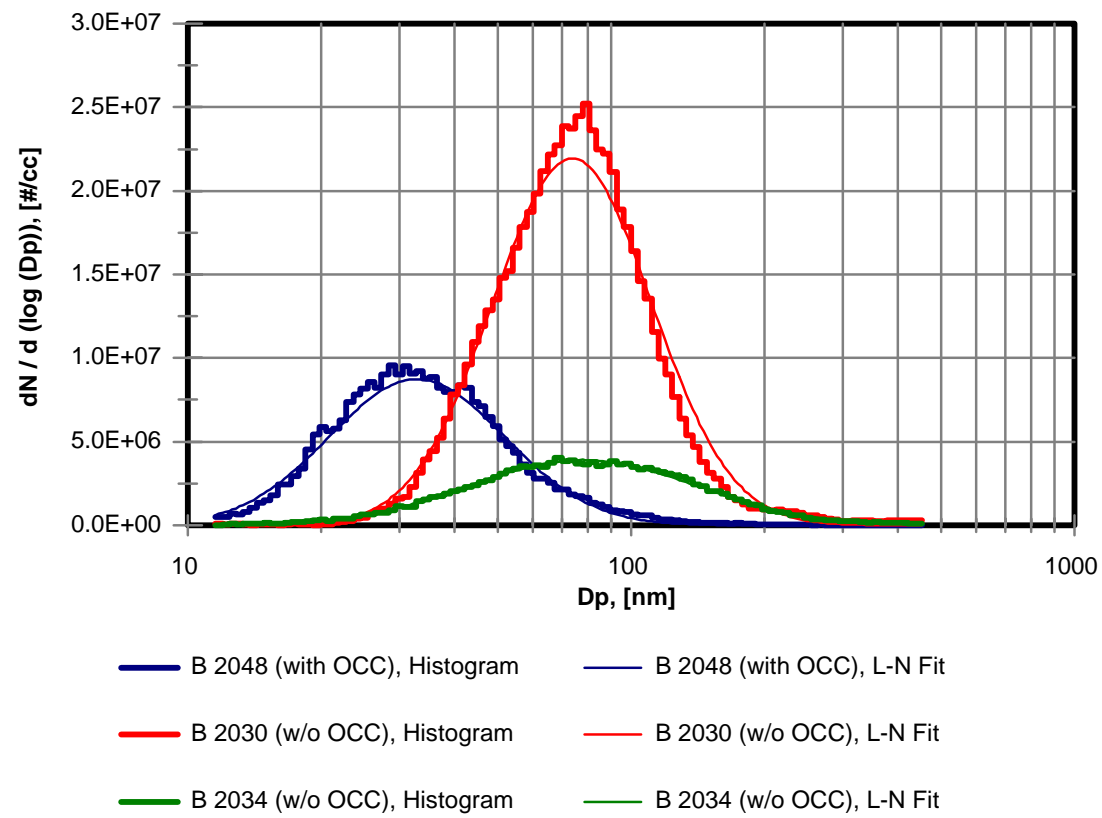

Figure 3.39 Orion/DDC 6V92, Steady-State, $20 \mathrm{mph}$, DR = 22, Mossgas, Number Concentrations, Vehicle to Vehicle Variation 

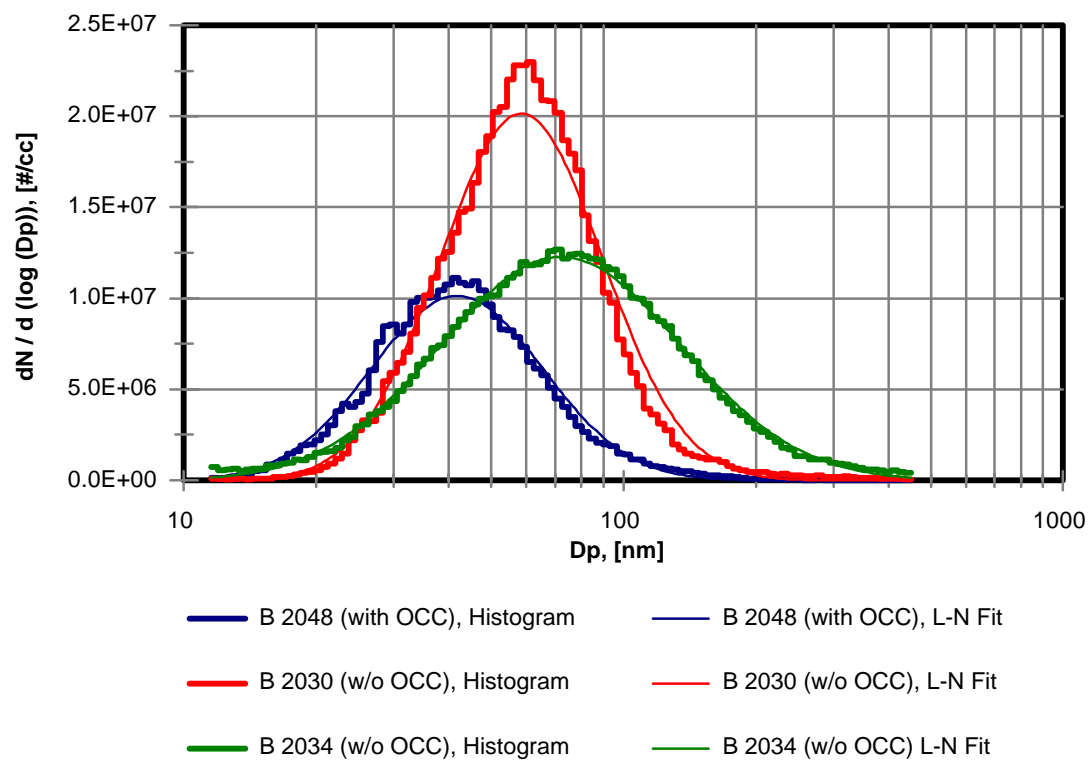

Figure 3.40 Orion/DDC 6V92, Steady-State, $30 \mathrm{mph}, \mathrm{DR}=22$, Mossgas, Number Concentrations, Vehicle to Vehicle Variation

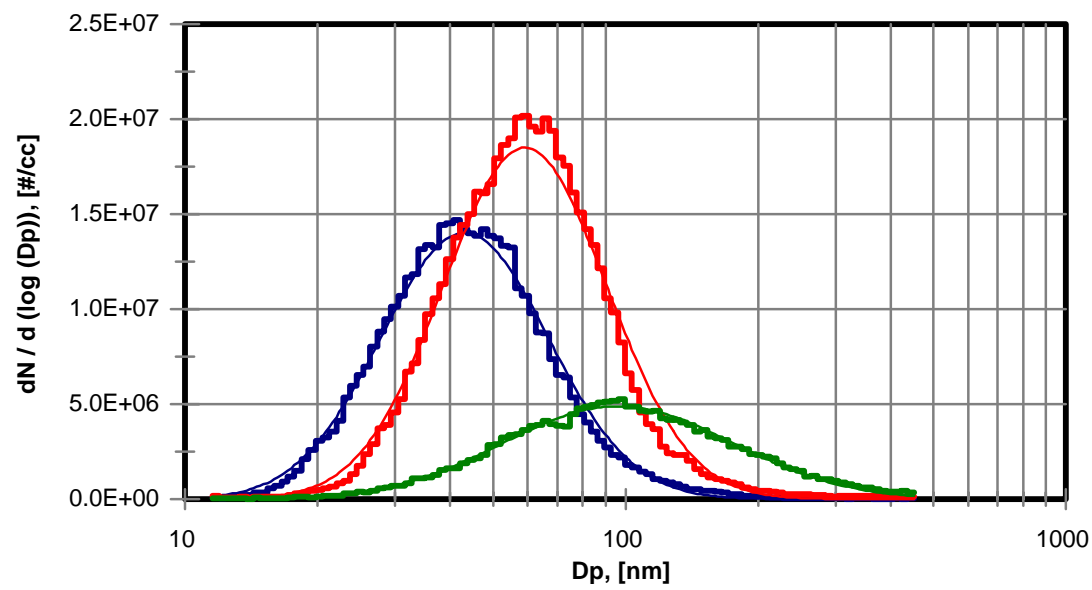
_ B 2048 (with OCC), Histogram
_ B 2048 (with OCC) L-N Fit
B 2030 (w/o OCC) Histogram
B 2030 (w/o OCC) L-N Fit
B 2034 (w/o OCC) Histogram
B 2034 (w/o OCC) L-N Fit

Figure 3.41 Orion/DDC 6V92, Steady-State, $40 \mathrm{mph}, \mathrm{DR}=22$, Mossgas, Number Concentrations, Vehicle to Vehicle Variation 
The distributions of particulate matter in the exhaust from the buses 2029 and 2030 were characterized with CMDs ranging from 60 to $75 \mathrm{~nm}$ and concentrations up to $2.5^{*} 10^{7}$ particles per $\mathrm{cm}^{3}$. It appeared that those PM emissions were slightly affected with steady-state speed or type of fuel.

The particle emissions from the bus 2048, the only bus which was powered with rebuilt engine and retrofitted with oxidation catalytic converter (OCC), were characterized with the high concentrations of the nanoparticles $\left(10^{7}\right.$ to $1.5^{*} 10^{7}$ particles per $\left.\mathrm{cm}^{3}\right)$. There is indication that those particles were most probably generated due to the processes in the OCC. The number of the larger diameter particles (> $70 \mathrm{~nm}$ ) appeared to be significantly reduced in comparison to number of the same particles emitted from the vehicles which were not fitted with rebuilt engines and OCC.

\subsubsection{Orion/DDC 6V92 - Transient Conditions}

Vehicle-to-vehicle variations of size-resolved DPM emissions during transient vehicle operating conditions were studied on the exhaust from Orion/DDC 6V92 buses 2029 (before engine was replaced with rebuilt one and retrofitted with OCC), 2048, 2034, 2030, and 2029 (after engine was

replaced with rebuilt one and retrofitted with OCC). Only the results of measurements performed for Federal diesel no. 2 and dilution ratio of 22 were taken in consideration.

The time-resolved concentrations of diesel particles with mobility diameters of 50, 100, and $200 \mathrm{~nm}$ are plotted in Figures 3.42 through 3.44. The time-resolved concentrations of 100 and 200 $\mathrm{nm}$ diesel particles emitted from the bus 2034, were found to be significantly higher than concentrations of the same size particles emitted from the rest of the tested buses (Figures 3.432 and 3.44). Bus 2034 had a high milage and most probably, retarded injection timing. This resulted in much higher mass of TPM emitted from this vehicle The measured concentrations of $50 \mathrm{~nm}$ particles in the bus 2034 were found to be lower than the concentrations detected for the rest of the tested fleet (Figure 3.42). The higher exhaust temperatures measured in bus 2034 most probably inhibited heterogeneous and homogeneous nucleation . At the same time higher concentration of particles in the exhaust of the bus 2034 is more conducive to coagulation than may have contributed to the formation of larger sized particles.

The concentration of the $50 \mathrm{~nm}$ particles from the bus 2029 was found to increase after the bus was fitted with rebuilt engine and retrofitted with an oxidation catalytic converter (Figure 3.42). 
This increase might be contributed to the oxidation of the $\mathrm{SO}_{2}$ in the catalytic converter. The sulfur originated from fuel and lube oil. The effects of engine rebuild/retrofit with OCC were not evident from the measurements of time-resolved concentrations of 100 and $200 \mathrm{~nm}$ diesel particles emitted from the bus 2029. This correlated well to the results of the gravimetric analysis performed on the total PM samples (Table 3.6).

The time-resolved concentrations of diesel particles with diameter of 100 and $200 \mathrm{~nm}$ were found to be the lowest for the vehicles 2030 and 2048. This was also in accordance with results of the results of gravimetric analysis performed on the total PM samples (Table 3.6).

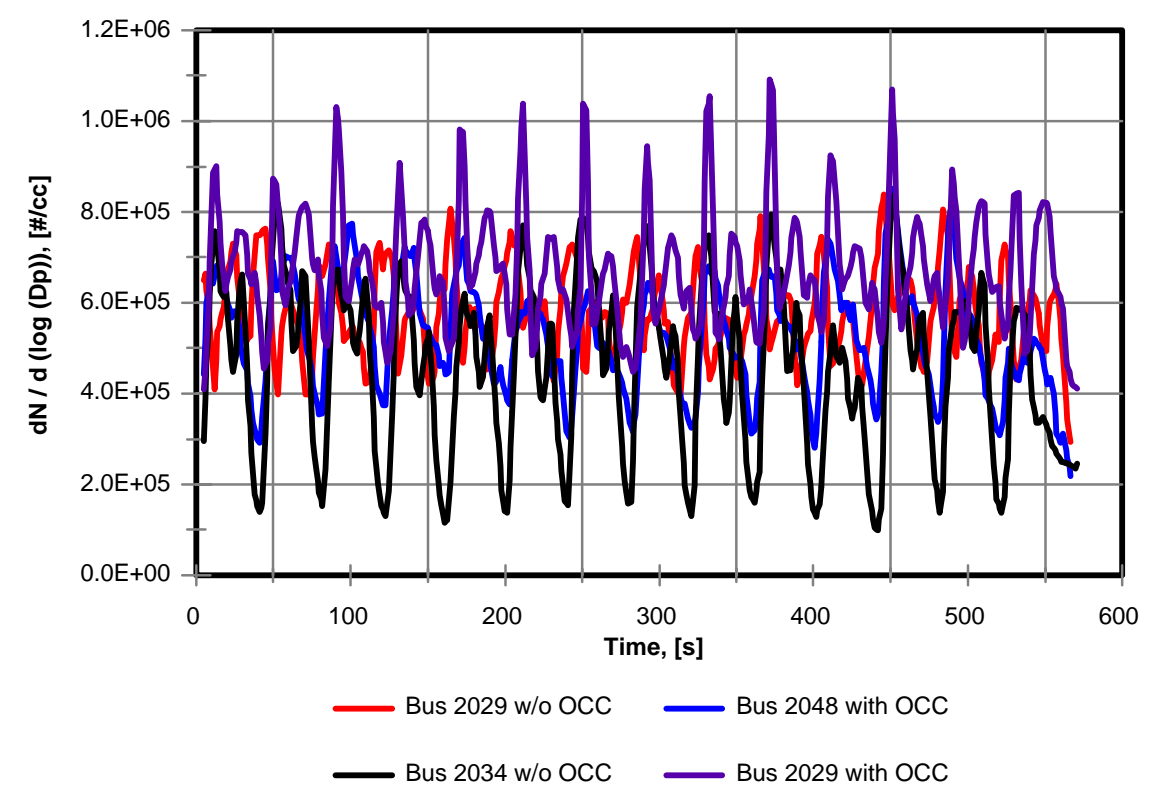

Figure 3.42 Orion/DDC 6V92, Transient, CBD, Diesel, $\mathrm{D}_{\mathrm{p}}=50 \mathrm{~nm}$, Number Concentration, Vehicle to Vehicle Variation 


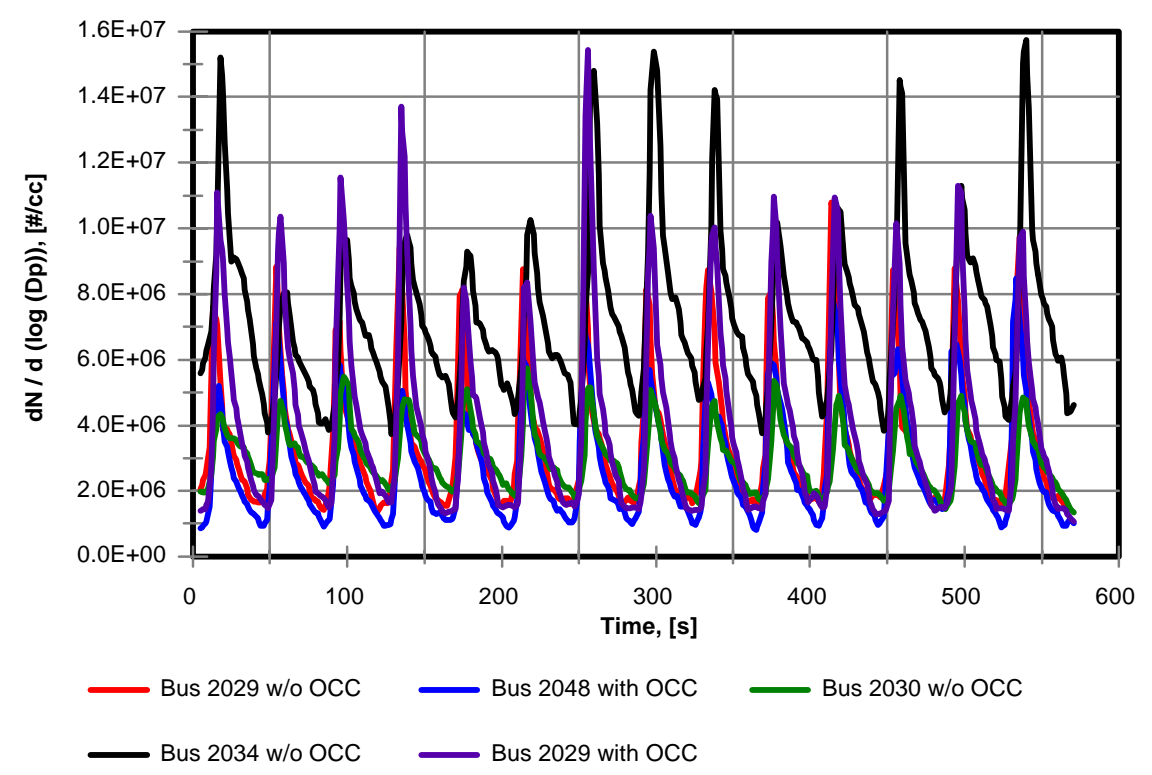

Figure 3.43 Orion/DDC 6V92, Transient, CBD, Diesel, $\mathrm{D}_{\mathrm{p}}=100 \mathrm{~nm}$, Number Concentration, Vehicle to Vehicle Variation

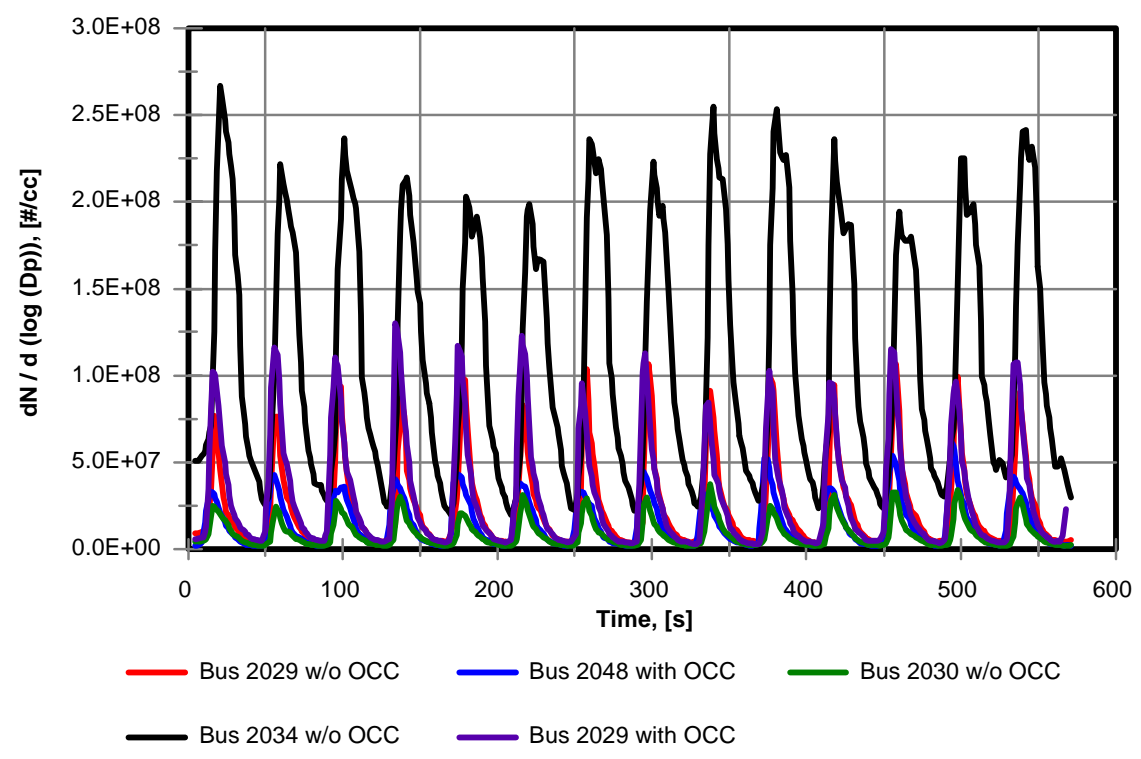

Figure 3.44 Orion/DDC 6V92, Transient, CBD, Diesel, $\mathrm{D}_{\mathrm{p}}=200 \mathrm{~nm}$, Number Concentration, Vehicle to Vehicle Variation 


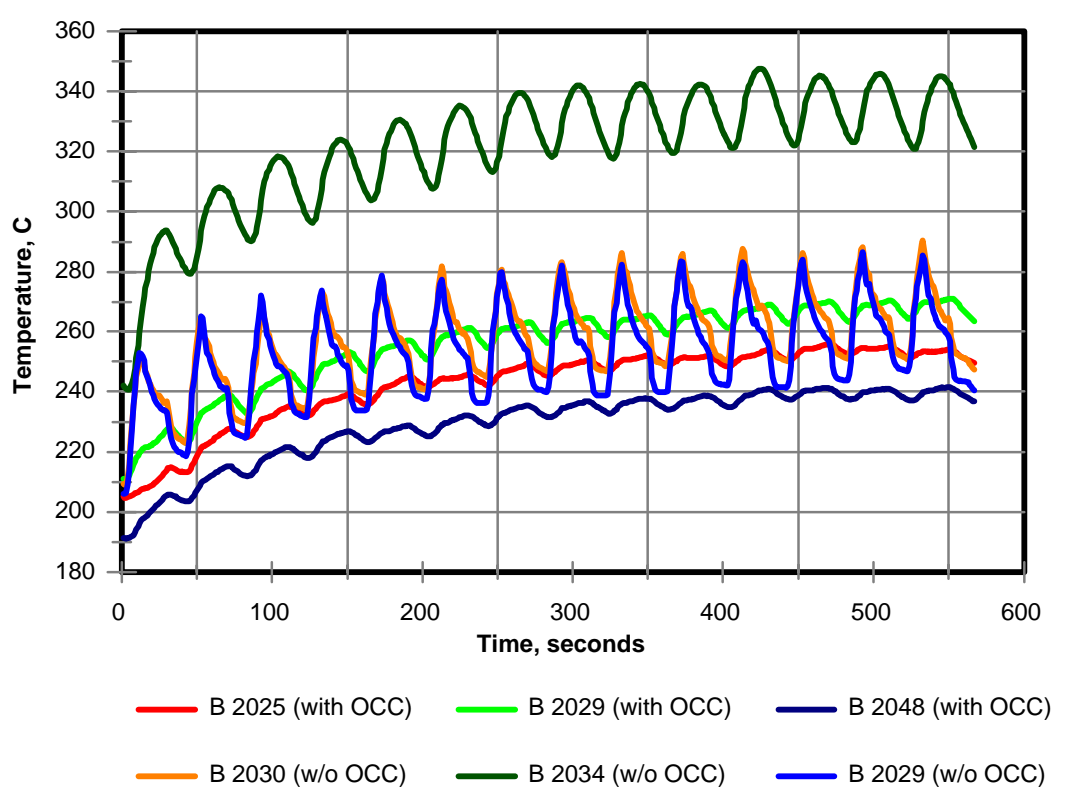

Figure 3.45 Orion/DDC 6V92, CBD, Diesel, Exhaust Temperature

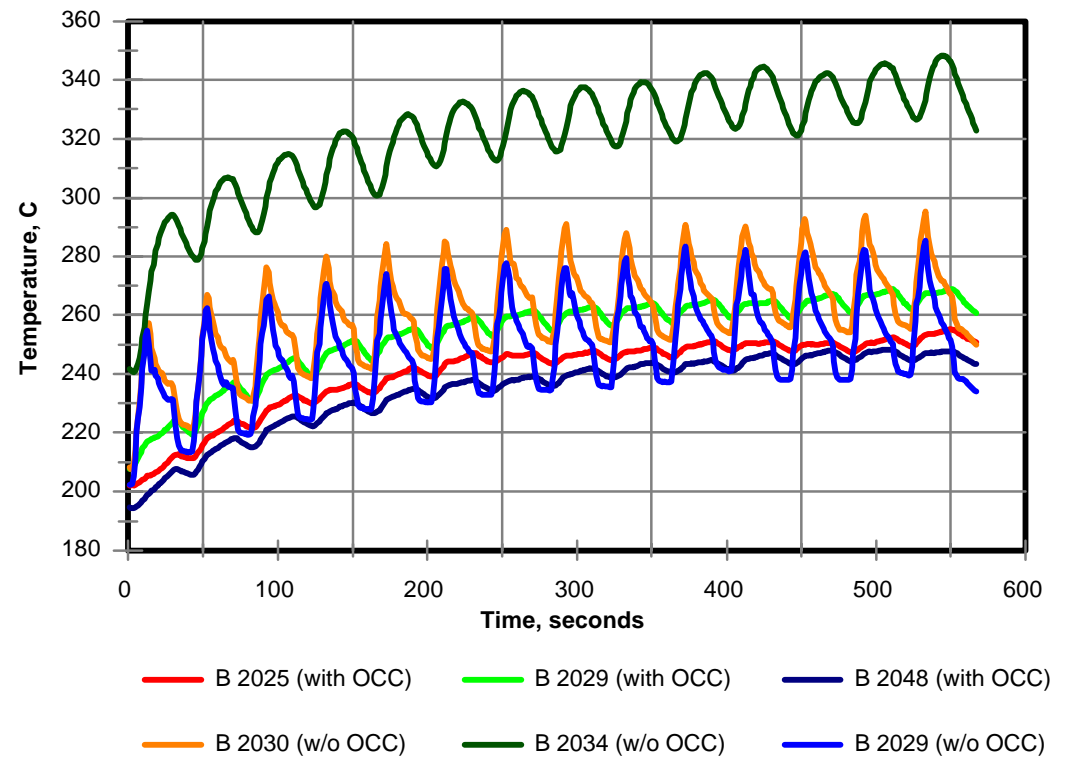

Figure 3.46 Orion/DDC 6V92, CBD, Mossgas Synthetic Diesel, Exhaust Temperature 
Exhaust temperature was one with most significant parameters affecting size distribution of the DPM. The exhaust temperature measured at the sampling zone are shown in Figures 3.45 and 3.46. Exhaust temperature profiles for the busses with OCC were found to be noticeably different than temperatures profiles for the busses without OCC. The fluctuations of the exhaust temperatures were significantly attenuate by presence of OCCs. Exhaust temperature primarily influenced generation and transformation of nanaoparticle ( $15 \mathrm{~nm}$ and $30 \mathrm{~nm}$ in diameter). Those particles, which were found to be mostly sulfuric acid and organic carbon in composition, were in significantly higher concentrations in the exhaust of the engines retrofitted with OCC. This can be attributed to the chemical processes in the OCC but also to the physical processes resulted from additional cooling in the OCC. 

Resolved Diesel Particulate Matter Emissions

\subsubsection{Isuzu C240 Study}

The Isuzu C240 engine was operated at the R100, R75, I100, and I50 steady-state operating conditions. Those steady-state operating conditions were selected to give a broad range of engine parameters affecting particulate matter formation. Exhaust temperature and fuel/air ratio appeared to be the most important parameters affecting PMemissions The average exhaust temperatures, measured for the bare engine, and the engine equipped with a catalytic converter and trap combination, are listed in Table 3.7. Significant variations in exhaust temperatures as a function of the engine operating mode and the employed after-treatment device made substantial impact on the performance of the converter/ trap system, as well as on the physical processes governing the aerosol formation and transformation.

Table 3.7. Isuzu C240 Study: Exhaust Temperatures, Bare Engine and Engine Equipped with Oxidation Catalytic Converter and Trap (Rohmac/DCL System), $\left[{ }^{\circ} \mathrm{C}\right]$

\begin{tabular}{||c||c|c||}
\hline \multicolumn{1}{|c||}{} & \multicolumn{2}{c||}{ Federal diesel no. 2 } \\
\cline { 2 - 3 } Mode & Engine & $\begin{array}{c}\text { Rohmac/DCL } \\
\text { System }\end{array}$ \\
\hline Mode1 (R100) & 577 & 648 \\
\hline Mode 2 (R75) & 442 & 493 \\
\hline Mode 5 (I100) & 589 & 639 \\
\hline Mode 7 (I50) & 284 & 321 \\
\hline
\end{tabular}

The peaks for the observed normalized PM concentrations of untreated raw exhaust ranged from $10^{7}$ to $6^{*} 10^{7}$ particles per $\mathrm{cm}^{3}$, depending on the engine operating conditions and the fuel type (see Figures 3.47, 3.48, 3.49, and 3.50). The concentrations measured by the SMPS during this study are comparable with diesel exhaust particulate matter concentrations measured by other researchers 


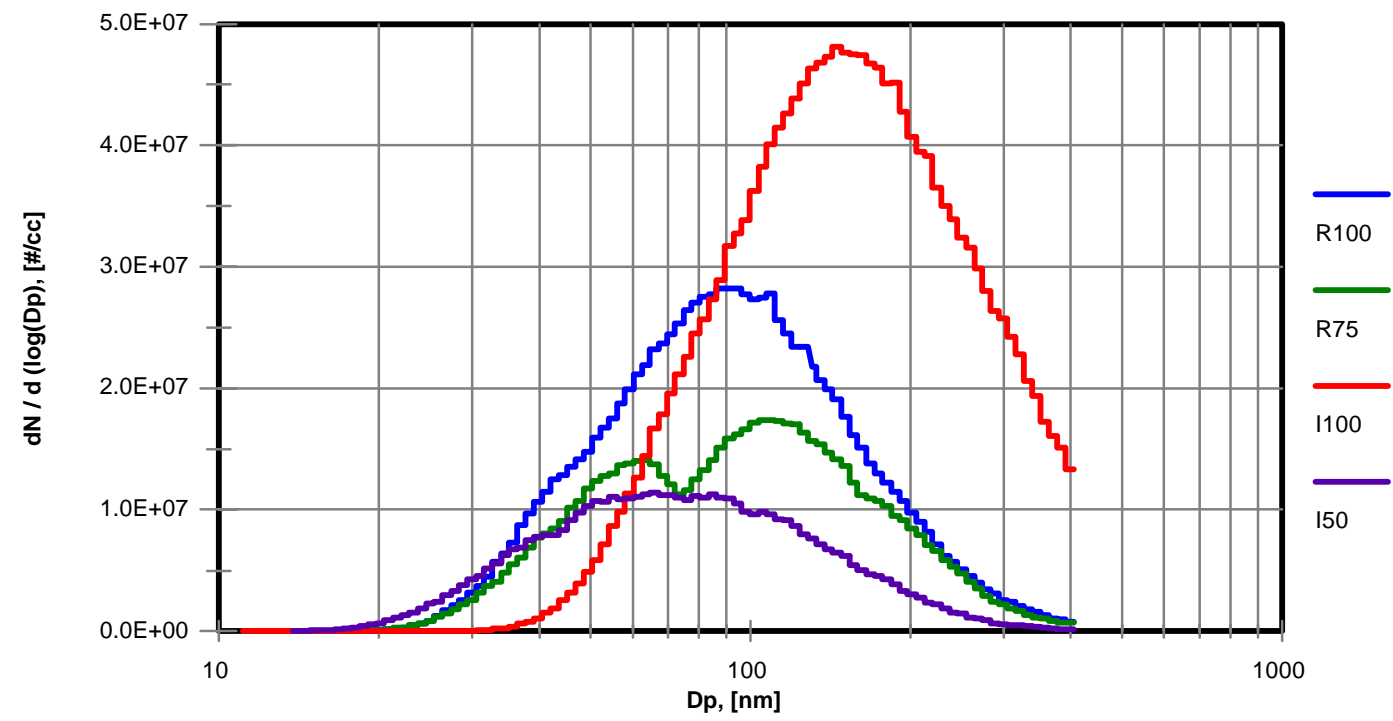

Figure 3.48 Isuzu C240, Steady-State Operating Conditions, Engine, Diesel, DR = 15, Number Concentrations, Effects of Engine Operating Conditions

(Graskow et al., 1998; Mohr, 1998). For bare engine, the highest concentrations and the largest CMD particles were observed for I100 mode which has the highest fuel/air ratio and exhaust temperature. This is in agreement with the highest mass emission rates that were determined by gravimetric analysis (Table 3.4). The I50 engine operation conditions resulted in the lowest concentrations and the smallest CMD and also the smallest brake specific mass emission rate. Size-resolved PM emission rates during R100 and R75 engine operation conditions seem to be comparable with CMD and concentrations, falling between those observed for I100 and I50 modes. All those emissions appeared to be in a direct functional relation with $\mathrm{EC} / \mathrm{OC}$ ratio, concentrations of sulfates and dilution ratio.

Engine operating conditions also affected performance of the after-treatment devices. The major factors were the particulate matter load, elemental and organic carbon split, concentration of $\mathrm{H}_{2} \mathrm{O}$ $\mathrm{H}_{2} \mathrm{SO}_{4}$ particles and the exhaust temperature. These effects have to be examined in conjunction with effects of the fuel type and dilution ratio. 


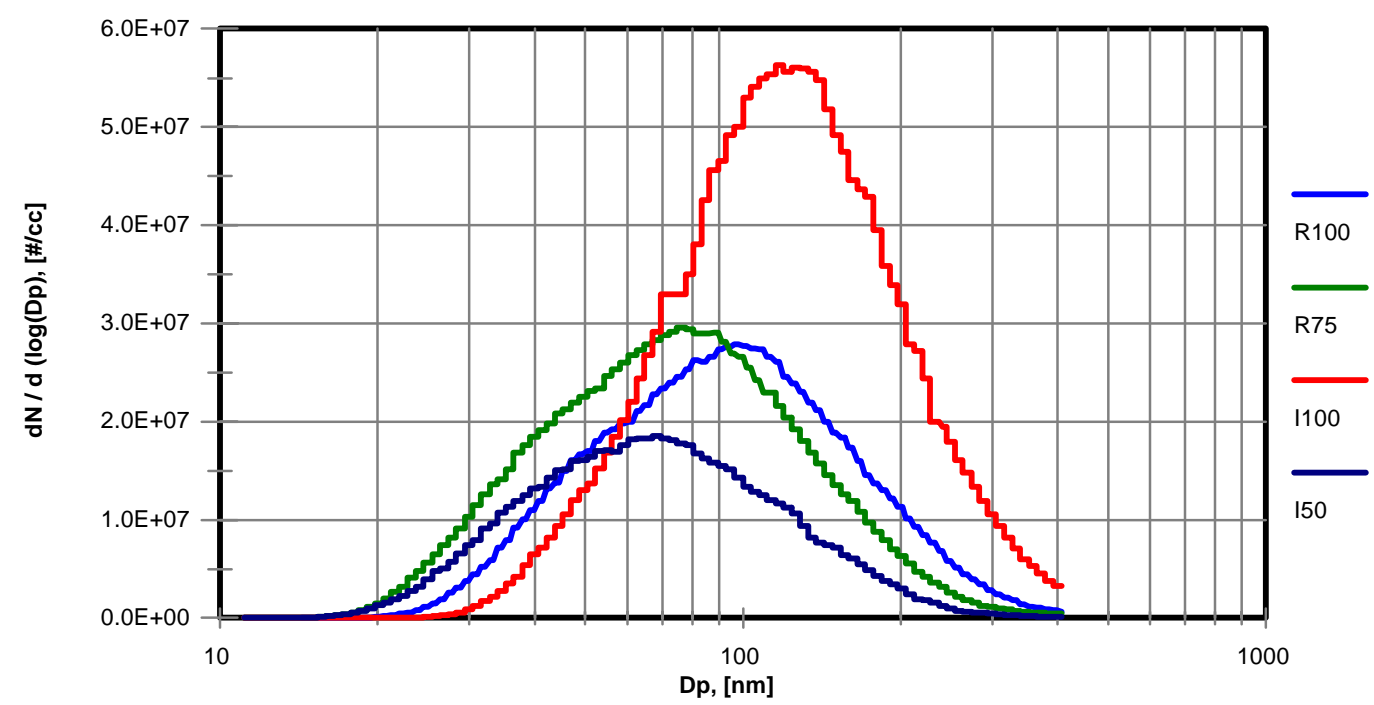

Figure 3.50 Isuzu C240, Steady-State Operating Conditions, Engine, Fisher-Tropsch, $\mathrm{DR}=15$, Number Concentrations, Effects of Engine Operating Conditions

3.

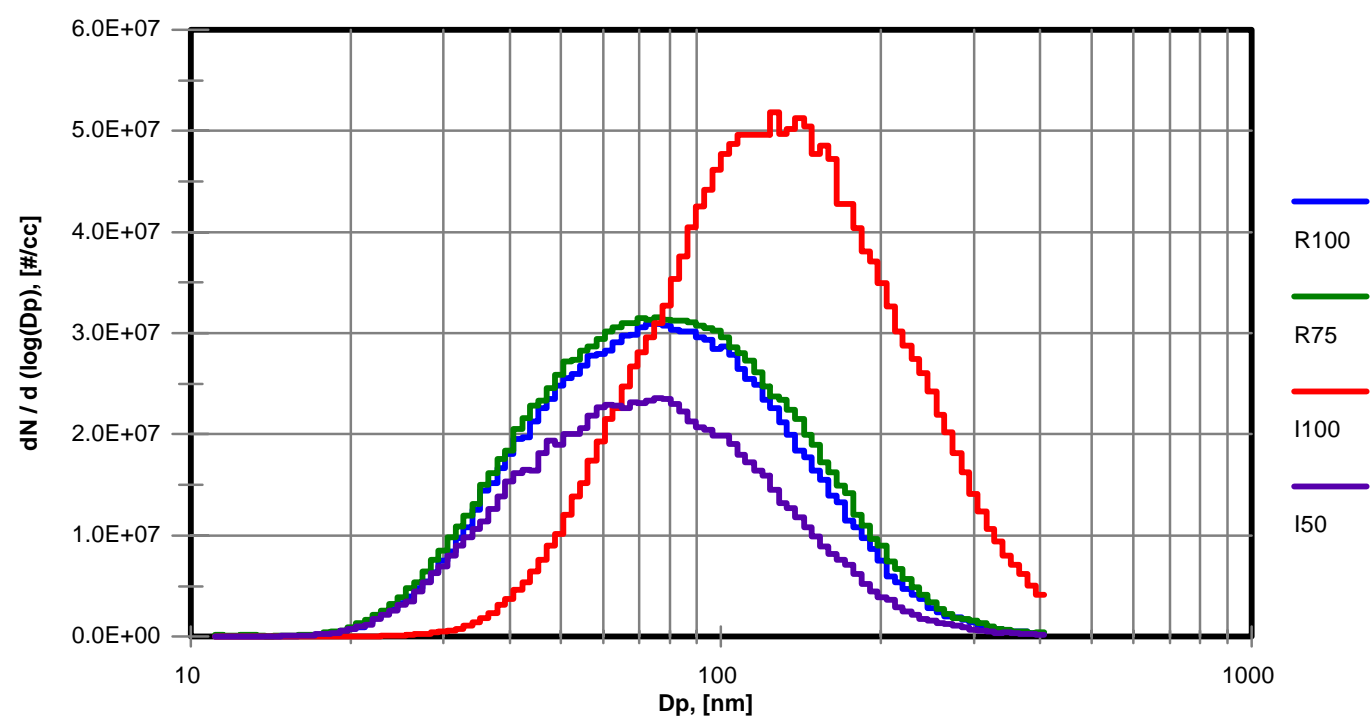

Figure 3.49 Isuzu C240, Steady-State Operating Conditions, Engine, Fisher-Tropsch, $\mathrm{DR}=28$, Number Concentrations, Effects of Engine Operating Conditions 


\subsubsection{Orion/DDC 6V92 Study}

The effects of the driving speed on size-resolved DPM emissions were examined on the buses 2048, 2030, and 2034 which were driven on the 20, 30 and $40 \mathrm{mph}$. The vehicles were fueled with diesel no. 2 and Mossgas synthetic diesel. The results of the measurements are shown in Figures 3.51 and 3.52 .

The effects of steady-state vehicle speed on size-resolved DPM emissions were found to be vehicle dependent. Vehicle 2048 emitted highest concentration of particles when it was driven at 40 mph, while vehicle 2034 emitted highest concentrations of DPM when driven at $30 \mathrm{mph}$. The emissions from the vehicle 2030 were highest at $20 \mathrm{mph}$. The exhaust particulate emissions are a function of the engine/vehicle parameters such as speed, load, exhaust temperature and fuel/air ratio. Additionally, the catalyst formulation and age play an important role in PM emission characteristics. Details on catalyst formulation were not available for this study. In the absence of the comprehensive data base on all of these critical parameters, it was difficult to draw any concrete conclusions. 

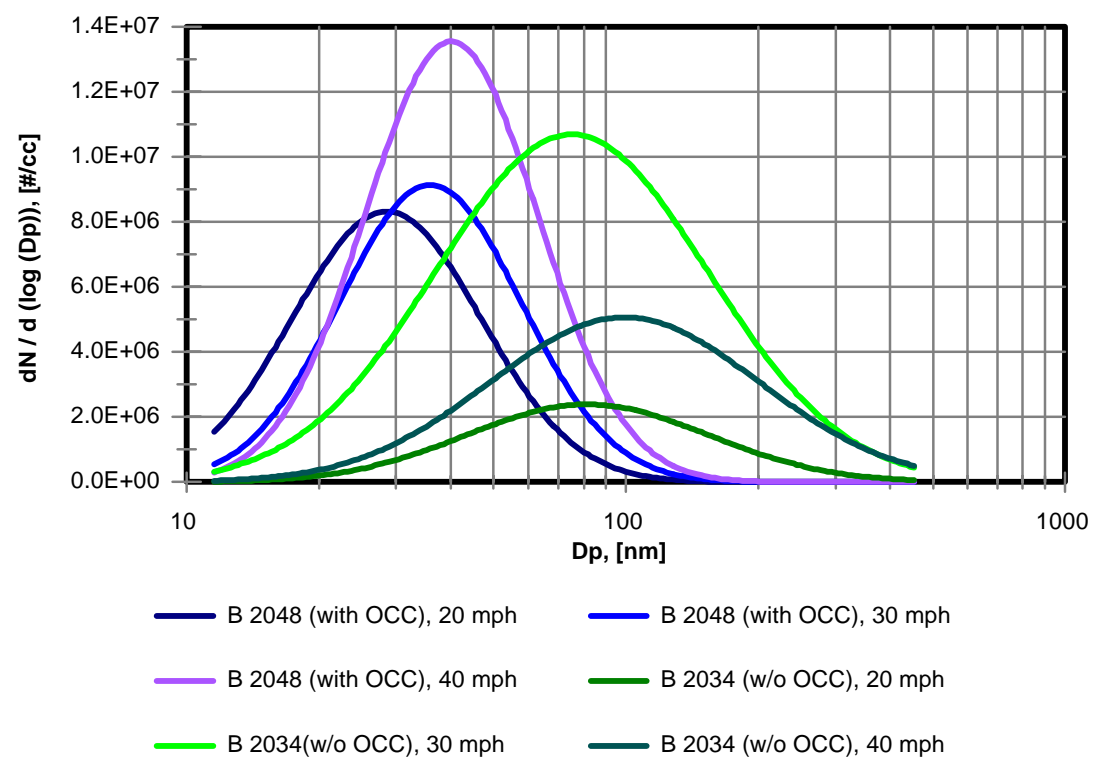

Figure 3.51 Orion/DDC 6V92, Steady-State, DR = 22, Diesel Number Concentrations, Effects of Driving Speed

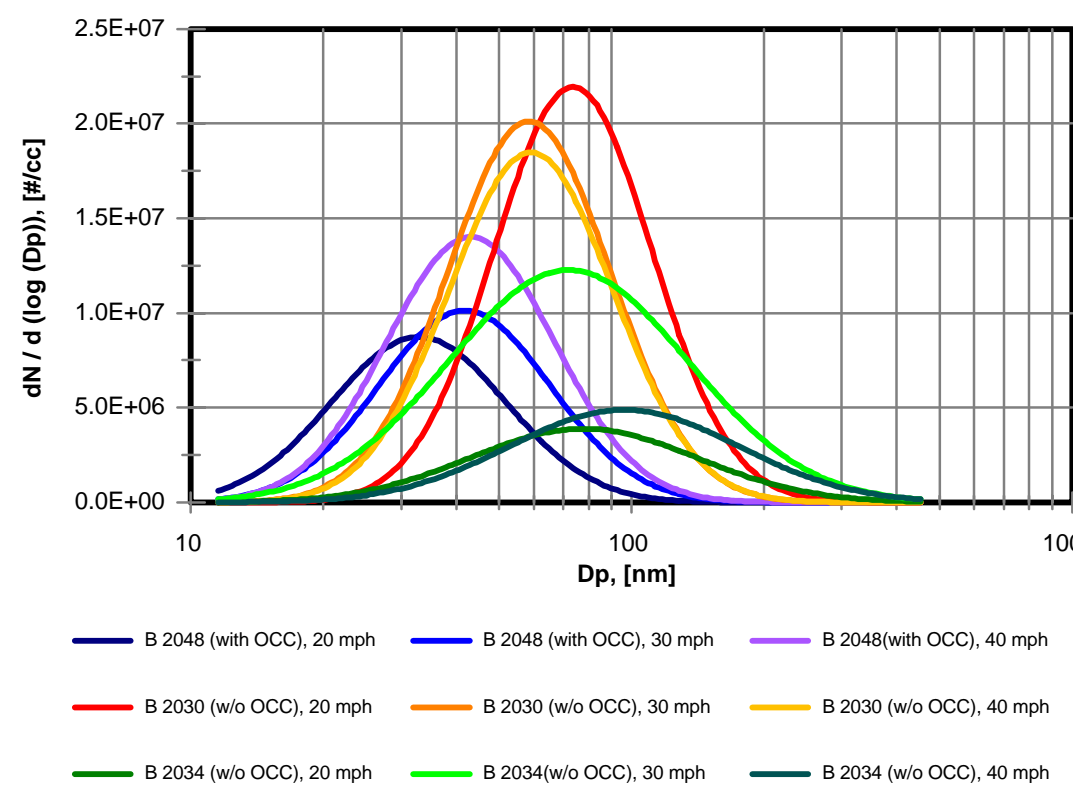

Figure 3.52 Orion/DDC 6V92, Steady-State, DR = 22, Mossgas Synthetic Diesel, Number Concentrations, Effects of Driving Speed 
The effects of engine operating conditions on size resolved DPM emissions were also examined with SMPS and MOUDI on Mack E7 engine. The engine was operated under steady-state conditions mentioned in the previous section. A dilution ratio of 4.3 was applied. The results of measurements are presented as histograms and fitted log-normal curves of normalized number concentrations in Figure 3.53. The PM distributions for all three modes exhibited similar CMDs. Concentration of particles was found to be highest for R50 engine operating conditions. The count distributions of the particles emitted under R75 and I50 engine operating conditions had similar CMD and normalized concentrations.

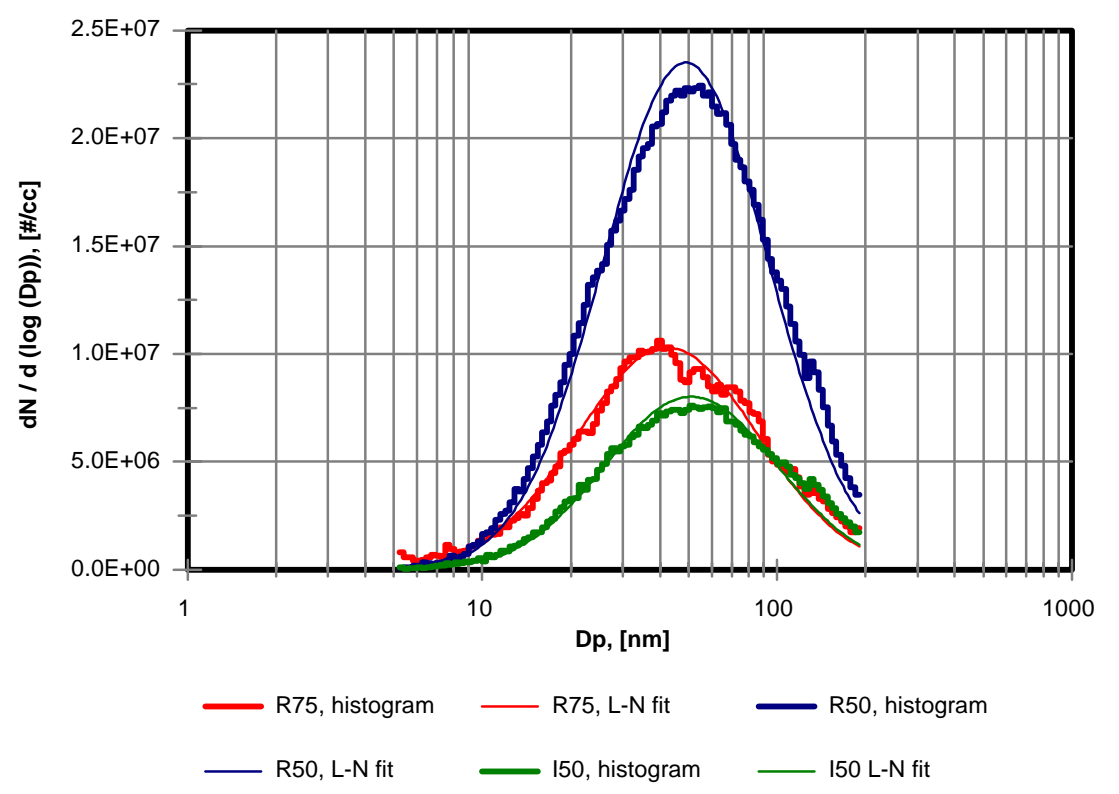

Figure 3.53 Mack E7-400, Steady-State, Diesel, DR = 4.3, SMPS, Number Concentration, Effects of Engine Operating Conditions 
Federal diesel no. 2 and synthetic diesel fuel obtained through Fisher-Tropsch synthesis (Shell) were used to study fuel type effects on the size-resolved PM emissions. Both fuels were used for tests on the engine equipped with a complete exhaust after-treatment system $(\mathrm{C}+\mathrm{T}+\mathrm{P})$, Rohmac/DCL System $(C+T)$, as well as on the engine stripped of after-treatment devices (E). Individual performance of the particulate trap $(\mathrm{T})$ and the Pallflex paper filter $(\mathrm{P})$ were examined using only diesel no. 2.

The PM distributions in the diluted exhaust $(\mathrm{DR}=28)$ from bare Isuzu C240 engine operated under R100 and I100 conditions and fueled with synthetic diesel were characterized with smaller sized CMDs than PM distributions in the diesel no. 2 exhaust collected under the same conditions (Figure 3.54). The concentrations of particles per cubic centimeter were comparable. For R75 and I50 engine operating conditions synthetic diesel resulted in PM size distributions with smaller CMDs and somewhat higher concentrations of smaller size particles (Figure 3.54). Similar trends in the size-resolved PM emissions, during R75 and I50 engine operating conditions, were observed with a lower dilution ratio, $\mathrm{DR}=15$ (Figure 3.55). It is observed that at $\mathrm{DR}=15$ the size distribution and concentrations, at R100, were not significantly dependent on the fuel type. F-T diesel, with lower sulfur and aromatic hydrocarbons content, resulted in lower brake specific total PM emissions for certain engine operating conditions (R100, I100). However, the concentration of smaller sized particles was higher with F-T diesel, that diesel no. 2, for all engine operating

Figure 3.56 shows the results of PM distribution measurements for exhaust gases treated with the catalytic converter, trap and paper filter ( $\mathrm{C}+\mathrm{T}+\mathrm{P}$ system). Operating the engine with F-T diesel fuel resulted in PM distributions characterized by smaller CMDs for all modes and higher peak concentrations for R100 and I100 modes and lower peaks for R75 and I50. Oxidation catalytic converter and the catalyzed trap enhanced the oxidation of $\mathrm{SO}_{2}$ to $\mathrm{SO}_{3}$, and the generation of the sulfuric acid aerosol. Significantly lower concentrations of nanoparticles observed for F-T diesel fuel then for Federal diesel no. 2 at $I 50\left(6^{*} 10^{6} \# / \mathrm{cm}^{3}\right.$ vs. $3.1^{*} 10^{7} \# / \mathrm{cm}^{3}$, respectively) and R75 $\left(1.2^{*} 10^{7} \# / \mathrm{cm}^{3}\right.$ vs. $2.5^{*} 10^{7}$ $\# / \mathrm{cm}^{3}$, respectively) modes confirmed the hypothesis that sulfuric acid aerosol significantly participates in the heterogeneous nucleation process. Nanoparticles in the exhaust from engine fueled with ultra-low sulfur F-T fuel could be in composition nucleated semi-volatile hydrocarbons or sulfuric acid. Sulfuric 
acid might be generated from the sulfur in lube oil. The nuclei mode particles were products of physical and chemical processes that occurred in the after-treatment devices rather that the products of engine combustion process.

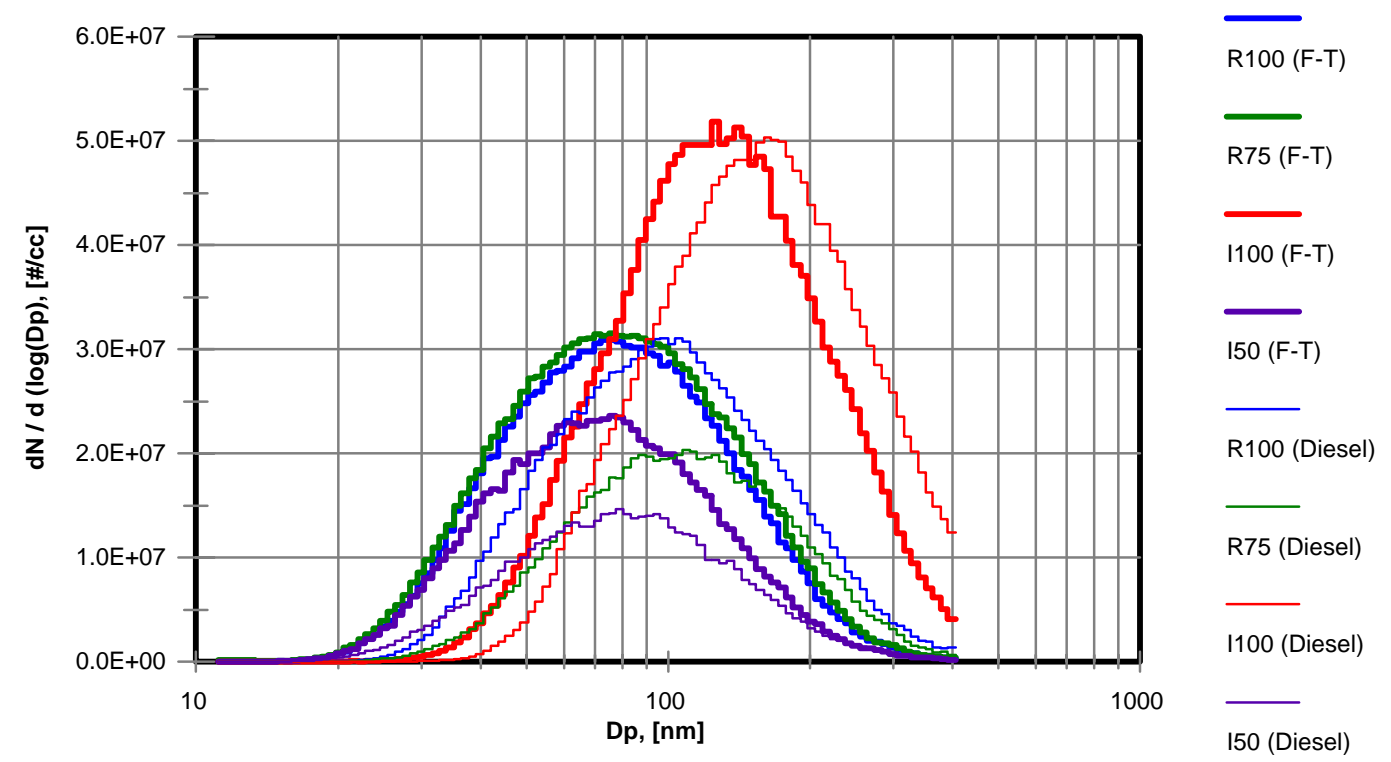

Figure 3.54 Isuzu C240, Steady-State Operating Conditions, Bare Engine, DR = 28, Number Concentrations, Effects of Fuel Type 


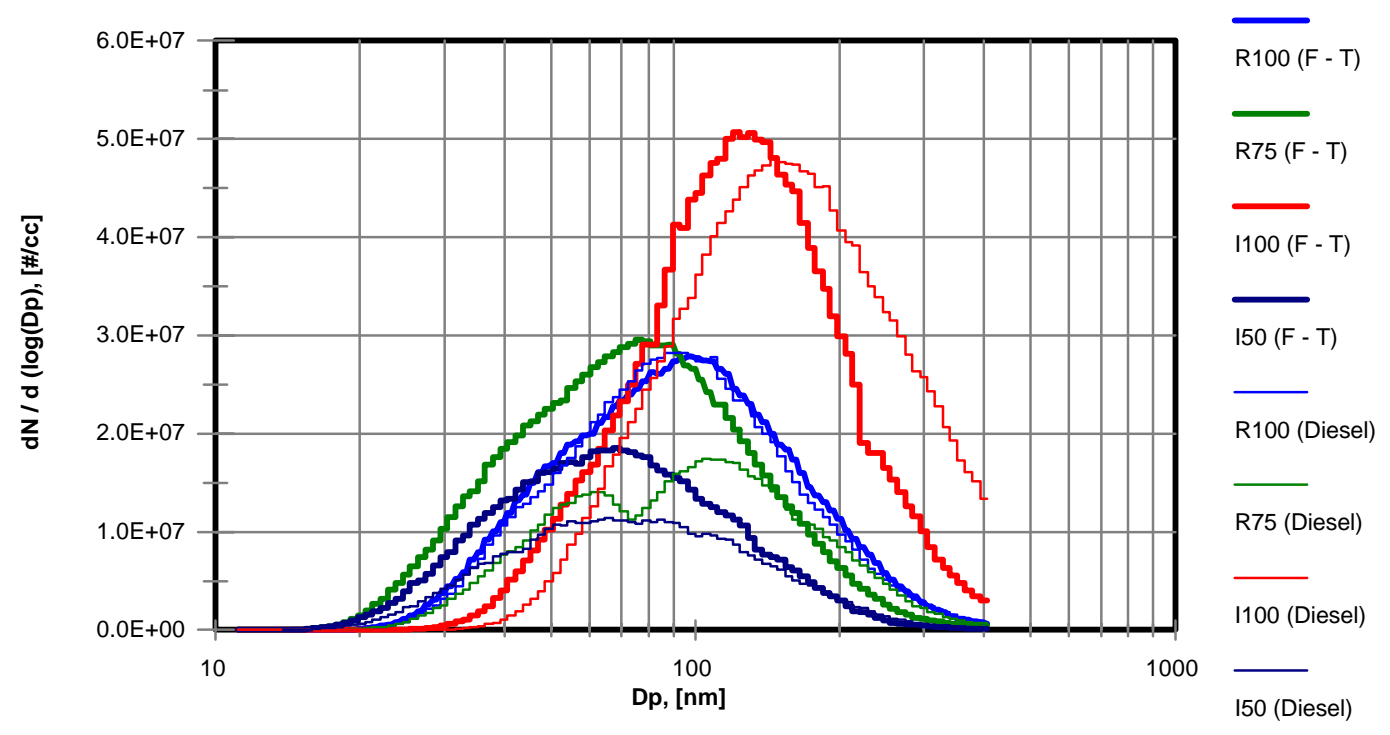

Figure 3.55 Isuzu C240, Steady-State Operating Conditions, Bare Engine, DR = 15, Number Concentrations, Effects of Fuel Type

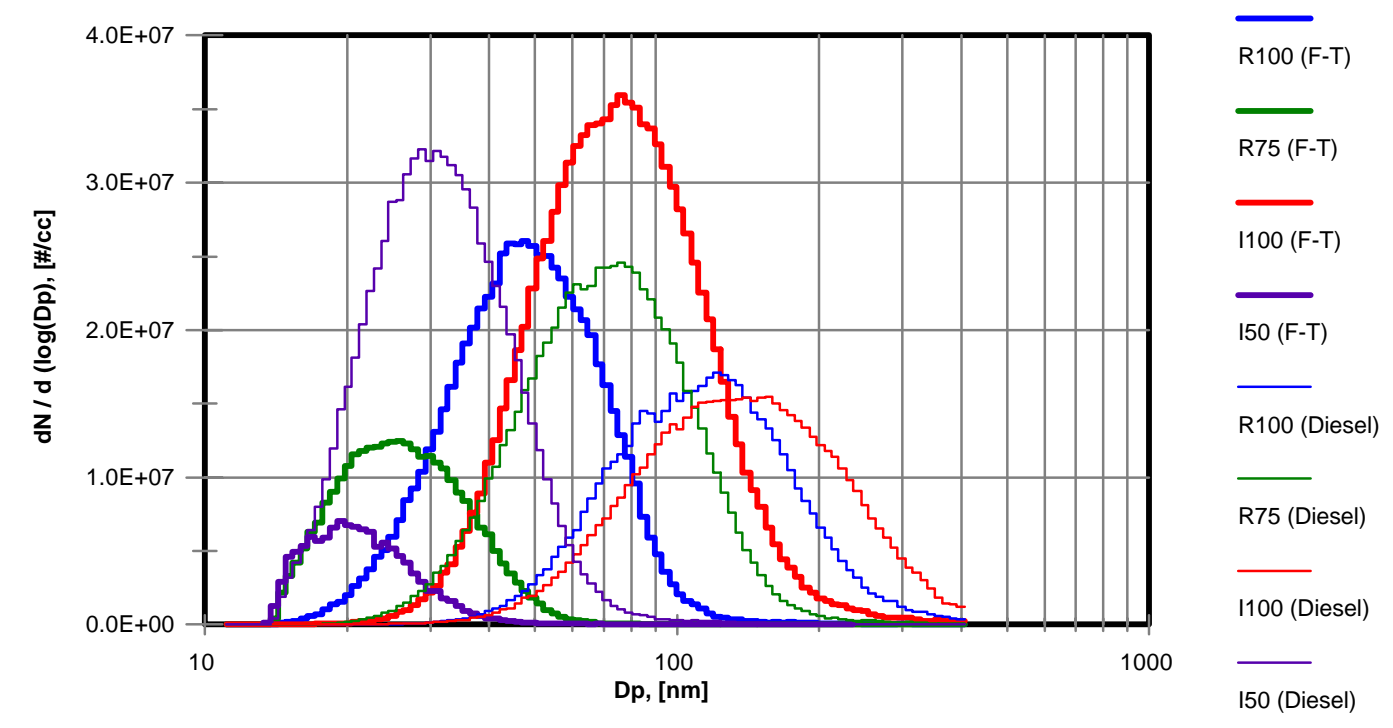

Figure 3.56 Isuzu C240, Steady-State Operating Conditions, Catalytic Converter, Trap and Paper Filter, DR = 28, Number Concentrations, Effects of Fuel Type 


\subsubsection{Orion/DDC 6V92 Study \\ 3.2.7.2.1 Steady-State Conditions}

The results from the buses 2048 and 2034, fueled with Federal diesel no. 2 and Mossgas synthetic diesel, were used to study the effects of fuel type on the size-resolved DPM emissions (Section 3.1.1.3 and Table A.1). The vehicles were driven at constant speeds of 20, 30, and $40 \mathrm{mph}$. From the distributions presented in Figures 3.57 through 3.59 was found that the effects of fuel on size-resolved DPM emissions were closely linked to the vehicle performance. It appeared that the bus 2048 emitted DPM at slightly higher concentrations and with slightly larger CMDs when fueled with synthetic diesel then with diesel no. 2, regardless of the operating speed. The DPM distributions of the particles in the exhaust gases emitted from the bus 2034 fueled with synthetic diesel were characterized with slightly higher concentrations and slightly smaller CMDs than distributions of the particles emitted from the same bus fueled with diesel no. 2. According to those cases, can be concluded that there were no major difference in size-resolved DPM emissions which can be attributed to the fuel effects. 


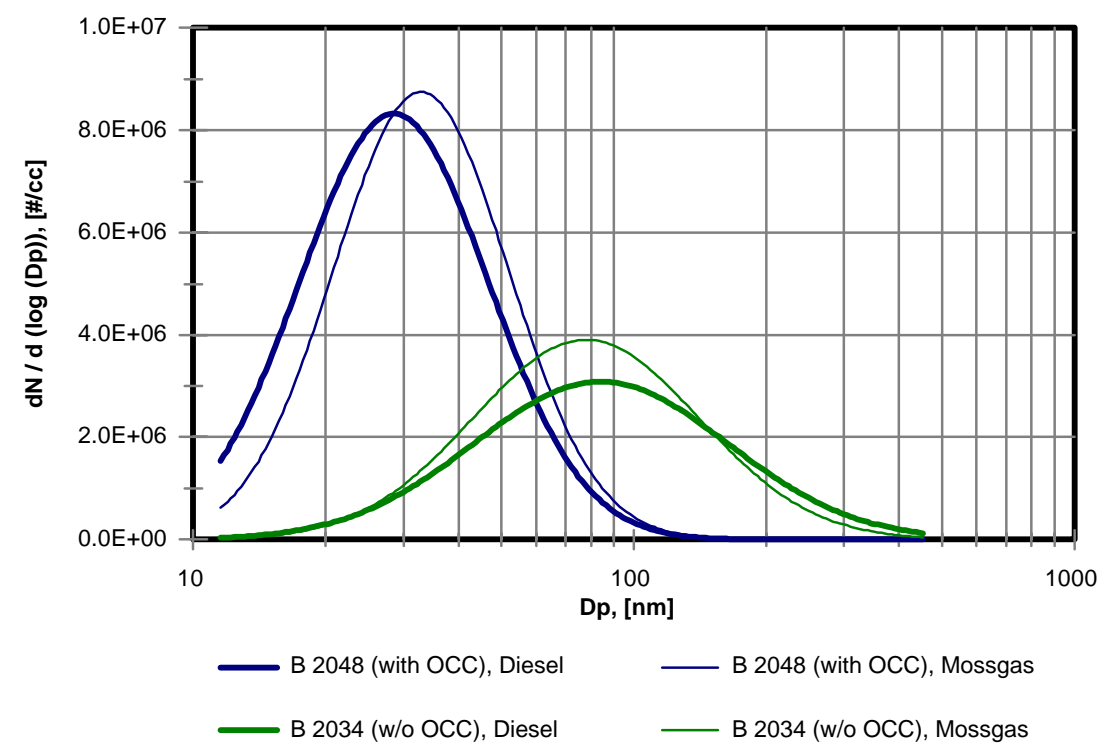

Figure 3.57 Orion/DDC 6V92, Steady-State, $20 \mathrm{mph}$, DR = 22, Number Concentrations, Effects of Fuel Type

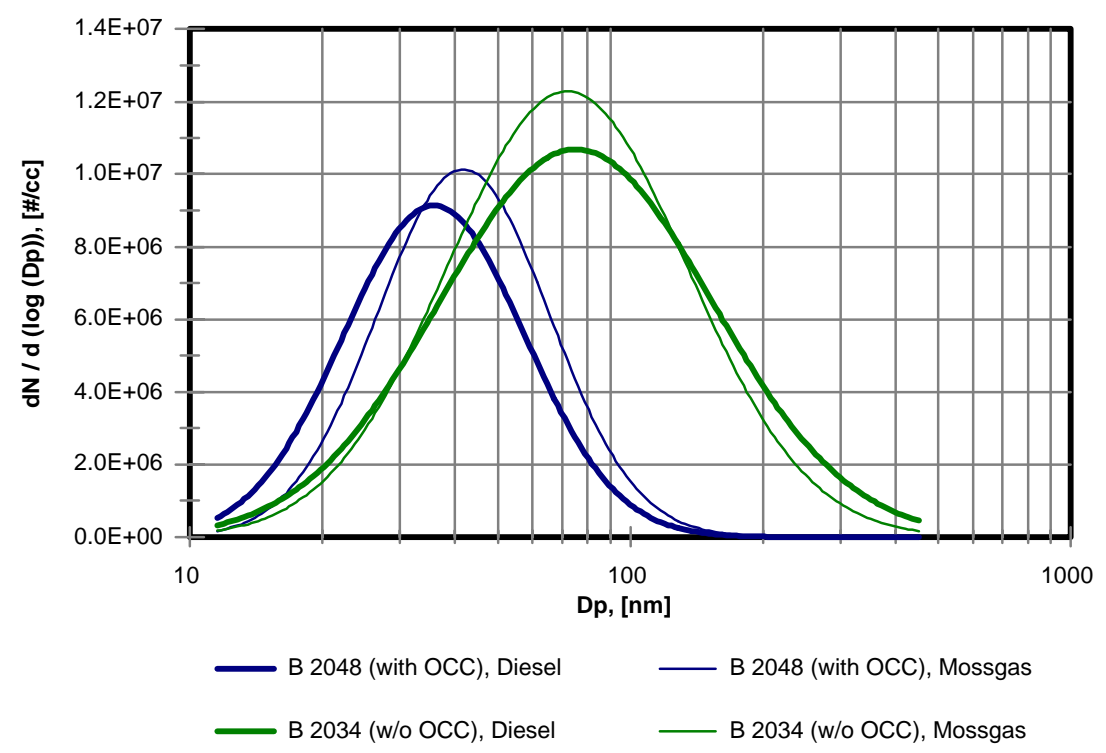

Figure 3.58 Orion/DDC 6V92, Steady-State, $40 \mathrm{mph}, \mathrm{DR}=22$, Number Concentrations, Effects of Fuel Type 


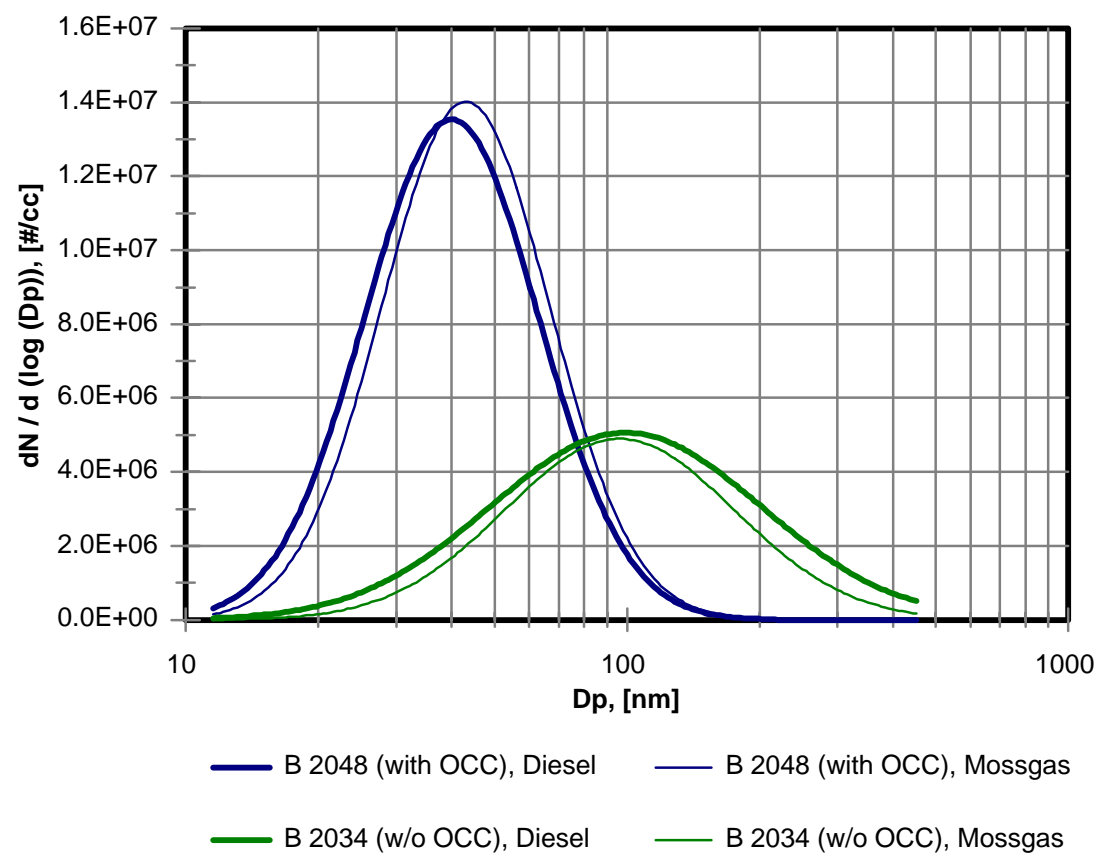

Figure 3.59 Orion/DDC 6V92, Steady-State, $40 \mathrm{mph}$, DR = 22, Number Concentrations, Effects of Fuel Type

\subsection{Transient Conditions}

The effects of fuel type on size-resolved DPM emissions during transient vehicle operating conditions were studied with an SMPS on the buses 2048, 2030, 2034, and 2029 (after it was fitted with rebuilt engine and retrofitted with OCC). The vehicles were operated with Federal diesel no. 2 and Mossgas synthetic diesel. The vehicles were exercised over the CBD cycle and dilution ratio was 22.

The graphs of time-resolved concentrations of particles emitted from afore mentioned vehicles operated with Federal diesel no. 2 and Mossgas synthetic diesel, which used for studding fuel type effects, are shown in Figures 3.60 through 3.63. The effects of fuel type on size-resolved PM emissions under transient vehicle/engine operating conditions are readily noticeable from the graphs of time resolved concentrations for the tested buses. 


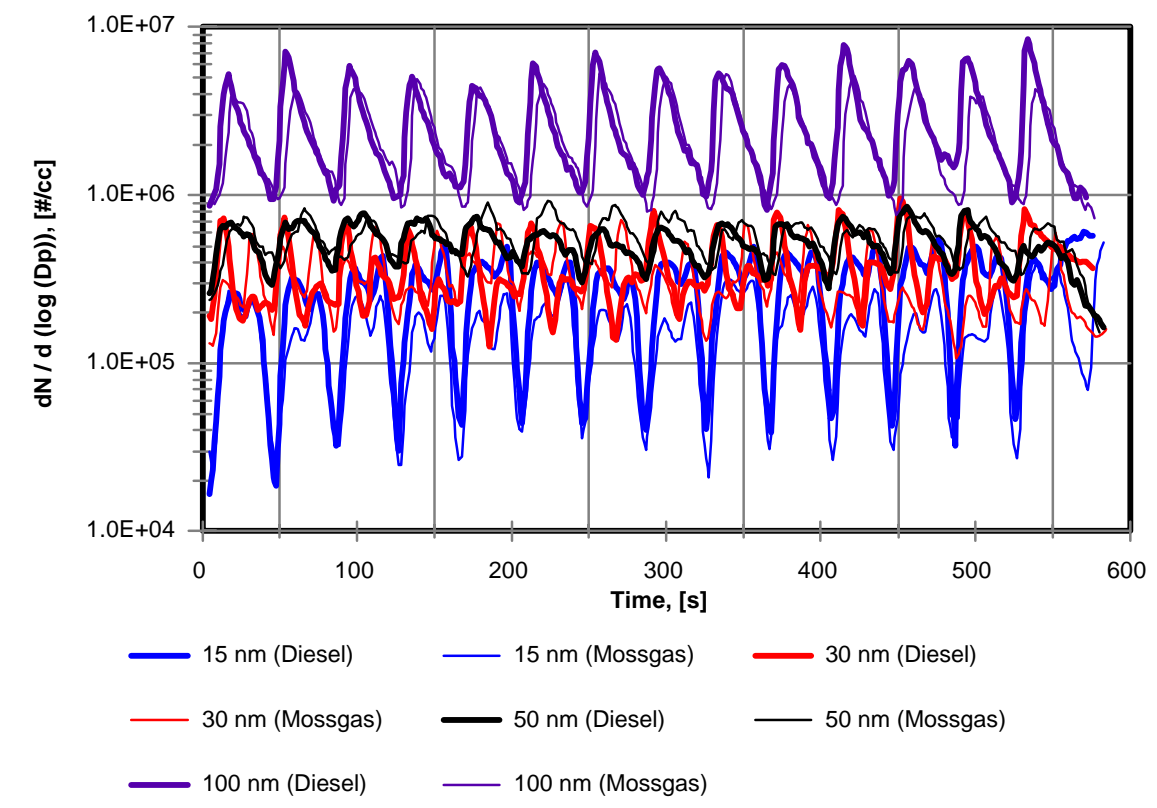

Figure 3.60 Orion/DDC 6V92, Bus 2048 With OCC, Transient, CBD, $\mathrm{DR}=22$, Number Concentration, Effects of Fuel Type

The use of Mossgas synthetic diesel resulted in the slightly lower emissions of the particles with diameters of 100 and $200 \mathrm{~nm}$. The lower concentrations of the larger observed particles indicated lower PM mass emissions found by gravimetric analysis performed on the total PM samples. The concentrations of 30 and $50 \mathrm{~nm}$ particles, were found to be similar or slightly higher for the engine operated with synthetic diesel than with diesel no. 2. The particles with diameter of 30 or $50 \mathrm{~nm}$ are most likely to be deposited deeper in the slow-cleared thoracic airways than the particles with diameter of 100 or $200 \mathrm{~nm}$. Therefore, the health benefits resulted from lowering particle count emissions of the larger diameter particles (100 and $200 \mathrm{~nm}$ ) and consequently reducing the total PM mass emissions might be annulated by higher emissions of the smaller size particles (30 and $50 \mathrm{~nm}$ ). 


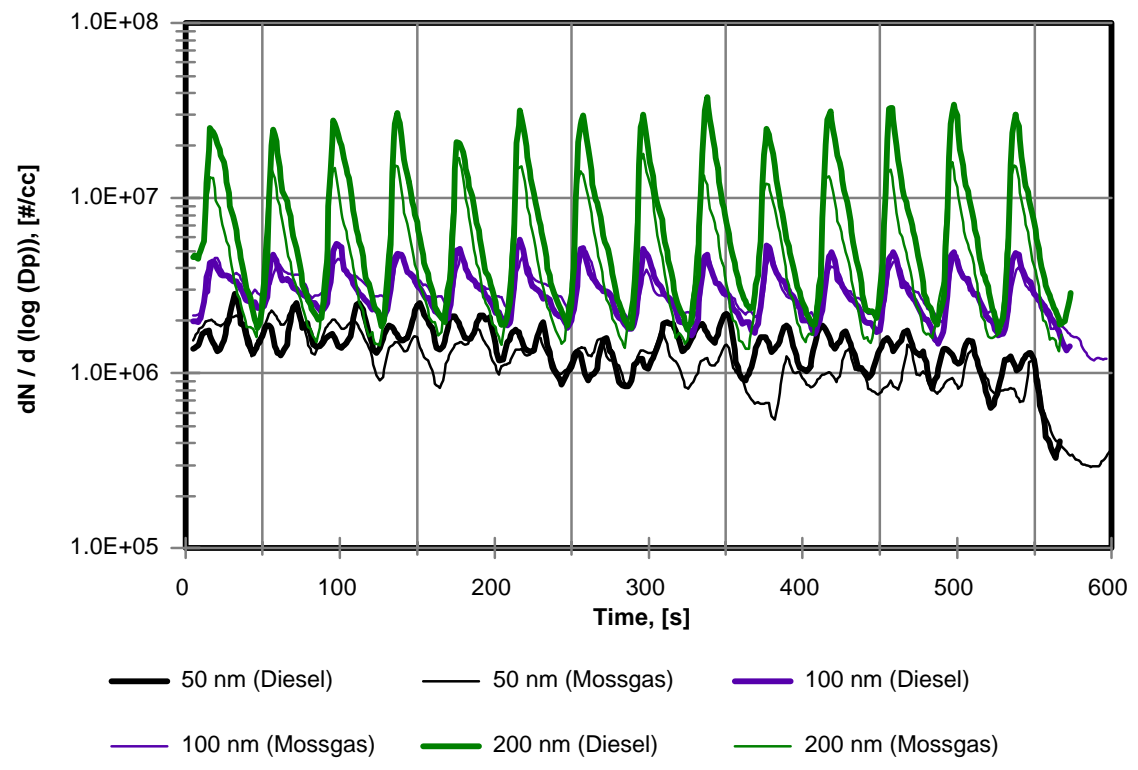

Figure 3.61 Orion/DDC 6V92, Bus 2030 Without OCC, Transient, $\mathrm{CBD}, \mathrm{DR}=22$, Number Concentration, Effects of Fuel Type

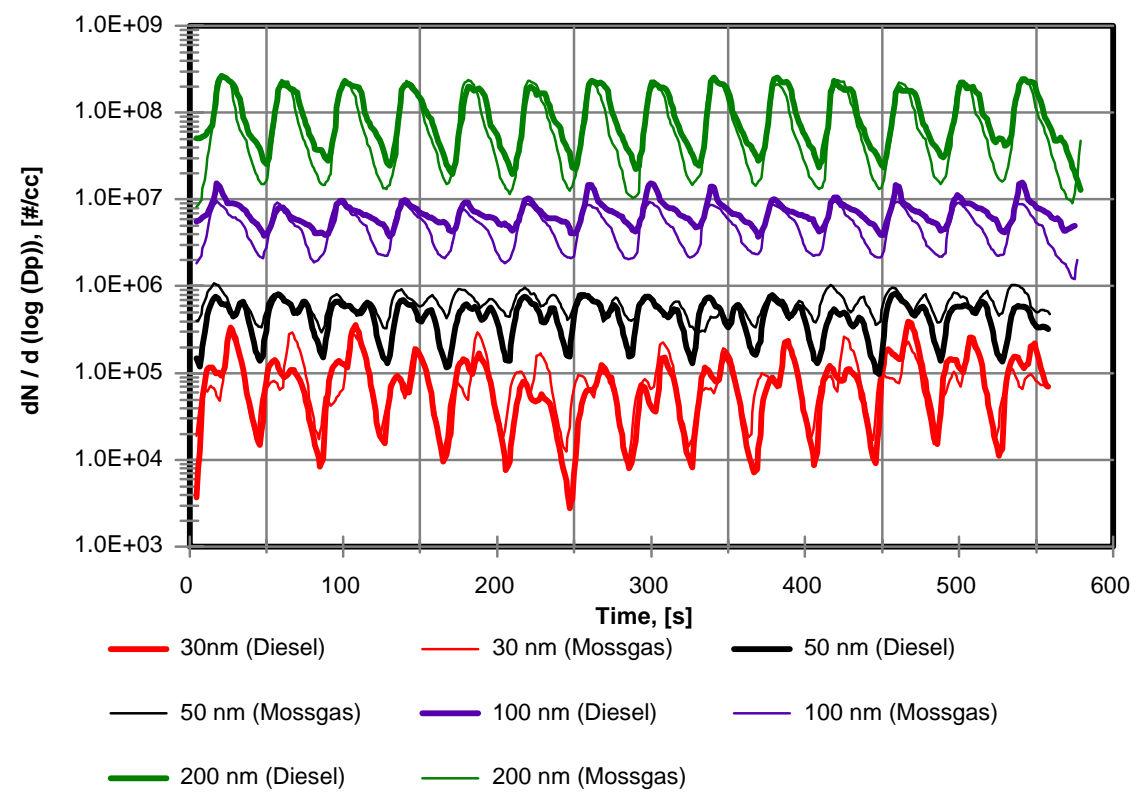

Figure 3.62 Orion/DDC 6V92, Bus 2034 Without OCC, Transient, $\mathrm{CBD}, \mathrm{DR}=22$, Number Concentration, Effects of Fuel Type 


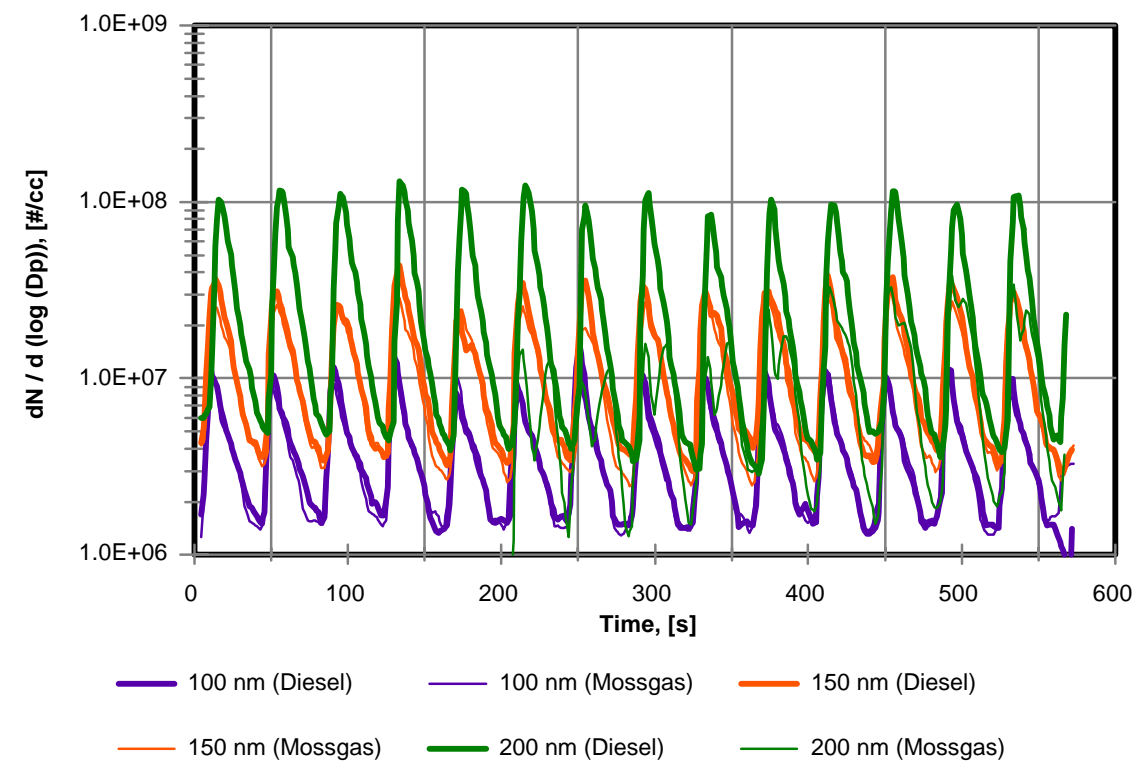

Figure 3.63. Orion/DDC 6V92, Bus 2029 With OCC, Transient, CBD, $\mathrm{DR}=22$, Number Concentration, Effects of Fuel Type 


\subsubsection{Performance of After-Treatment Devices}

The performances of individual after-treatment devices and their combinations were examined on Isuzu C240 engine and the results were compared with the bare engine results. The efficiencies of the Rohmac/DCL exhaust after-treatment system and Pallflex paper filter, individually and as a part of the system, were evaluated. The first series of the tests was conducted on the engine equipped with a complete after-treatment system which included the oxidation catalytic converter, the trap and the paper filter $(\mathrm{C}+\mathrm{T}+\mathrm{P})$. The paper filter was removed from the system for the second set of the experiments $(\mathrm{C}+\mathrm{T})$. The testing was continued with evaluation of the individual performances of the trap $(\mathrm{T})$ and the paper filter $(\mathrm{P})$. The testing was concluded with PM emission measurements on the engine stripped of all exhaust after-treatment devices (E). The individual performance of the oxidation catalytic converter was not examined.

The performances of the exhaust after-treatment devices were strongly linked to the engine operating conditions and fuel types. The engine operating mode was found to have a substantial influence on the performance of the exhaust after-treatment devices.

The efficiency of the paper filter was found to be strongly dependent on the engine operating mode (Figures 3.25, 3.64, 3.65, 3.66, 3.67, and 3.68). It was observed that the paper filter worked particularly well in reducing both CMD and concentration of particulates in the R100 and R75 engine operating mode. It should be noted that the results of the integrated total particulate matter listed in Table 3.4, show that the paper filter was very effective, for modes R100 and R75. The measurement of PM size distribution for engine operating at an intermediate speed and 100\% load (I100) showed that the paper filter did reduce concentrations over the whole size spectrum, but not as efficiently as for R100 and R75 modes. It should be noted, that the paper filter yield decrease in the CMD from $102 \mathrm{~nm}$ to 59 $\mathrm{nm}$ for R100 and from $105 \mathrm{~nm}$ to $63 \mathrm{~nm}$ for R75. Both analyses showed a relatively poor performance of the paper filter for I100 engine operating mode. This my be attributed to higher emission rates of semivolatiles in I100 mode

Measurements with SMPS show that the PM trap (T) was more efficient than the paper filter in removing the PM from the exhaust when the engine was operating at I100 (see Figure 3.66). The trap was catalyzed and the subsequent oxidation of the soluble organic fraction had an important impact on the size distribution and concentration of PM emissions. The trap performed poorly at R100 engine 
operating conditions (see Figures 3.64 and 3.67). SMPS measurements indicate a rather slight reduction in the total TPM mass rather than an increase in TPM mass emission rate determined by the gravimetric analysis (see Table 3.4). High concentrations of nanoparticles (CMD = app. $40 \mathrm{~nm}$ ), which were not present in bare engine exhaust, characterized lower dilution ratio $(\mathrm{DR}=15)$ distribution measurements for R100 and R75. This suggested a potential presence of sulfuric acid aerosol and hydrocarbons under conditions favorable for aerosol nucleation (see Figures 3.67 and 3.68). Unfortunately the data for engine operated under the same conditions and fueled with synthetic diesel fuel are not available for comparison purposes. The trap almost completely removed the particles from engine exhaust generated at I50 operating mode (see Figures 3.69 and 3.70). Distribution of PM for engine fueled with diesel and operated at mode 150 also had a small peak at app. $20 \mathrm{~nm}$. The distribution for synthetic diesel fuel did not show significant concentrations of nanoparticles. This also indicate that nanoparticles were most probably sulfuric acid in composition.

Rohmac/DCL system (C+T) substantially reduced number and mass of PM from the engine exhaust. The efficiency of the system in TPM mass reduction is evident from the results of integral PM gravimetric analysis (see Table 3.4). The system also reduced efficiently the concentrations of the combustion generated particulate matter in the exhaust gases for all tested engine operating modes (see Figures 3.64, 3.66, 3.67, and 3.74). Diesel exhaust emissions for R75 engine operating mode were characterized by high concentrations of nanaparticles, CMD $\sim 35 \mathrm{~nm}$ for $\mathrm{DR}=28$ and CMD $\sim 40 \mathrm{~nm}$ for $\mathrm{DR}=15$. Those particles were not detected in the bare engine exhaust (see Figures 3.65 and 3.68). The PM distributions measured for the synthetic diesel fuel did not show substantial concentrations of nanoparticles for the same engine operating conditions (see Figures 3.71 and 3.72). However, nanoparticles did characterize PM distributions of the exhaust treated in the Rohmac/DCL system for both fuels and I100 engine operating conditions (see Figures 3.66, 3.67, 3.74, and 3.75). This behavior was more pronounced for measurements made at lower dilution ratios. All these observations confirm that nanoparticles were not generated during the combustion process, but rather during various physical and chemical processes which the exhaust underwent in the after treatment system. Much larger concentrations of nanoparticles observed in the experiments with no. 2 diesel fuel indicated that the major constituents of nanoparticles were sulfuric acid and hydrocarbons.

An analysis of the integrated TPM measurements (see Table 3.4) and size selective measurements supports the conclusion that the complete after-treatment system $(\mathrm{C}+\mathrm{T}+\mathrm{P})$, which included 
filtration of the exhaust already treated in the Rohmac/DCL system exhibited a lower efficiency in treating diesel exhaust than Rohmac/DCL system alone. The system's ability to effectively lower PM emissions from exhaust was particularly low for R100 mode (see Figures 3.64, 3.67, 3.76, and 3.77). Basically, only the largest particles generated in the combustion process were efficiently removed by the system. The measurements performed with lower dilution ratios $(\mathrm{DR}=15)$ indicate an increase in the concentrations of smaller size particles. For R75, I100 and I50 engine operating modes the distributions for the complete system were characterized with larger CMDs and slightly higher concentrations than distributions for Rohmac/DCL system, regardless of fuel type (see Figures 3.65, 3.66, 3.68, 3.69, 3.70, $3.71,3.72,3.73,3.74,3.75,3.78$, and 3.79). At the I100 engine operating mode with F-T diesel fuel the measured concentrations of nanoparticles in the exhaust treated by the complete system were higher than the concentrations measured in the exhaust treated by Rohmac/DCL system. The various processes triggered by the introduction of the paper filter in the system changed the size distribution profiles quite significantly. Additionally, the paper filter further, reduced the temperature and increased the backpressure in the exhaust system, which resulted in the conditions favorable for hydrocarbon and sulfate nucleation. The presence of the nucleation mode in the exhaust gases when the engine was fuel by F-T diesel fuel indicates that sulfuric acid aerosol is not the only constituent of aerosol generated by physical and chemical processes in the exhaust system. Water vapor also nucleates due to the afore mentioned changes in the exhaust physical parameters and gives rise to a binary mixture of water and sulfuric acid. 


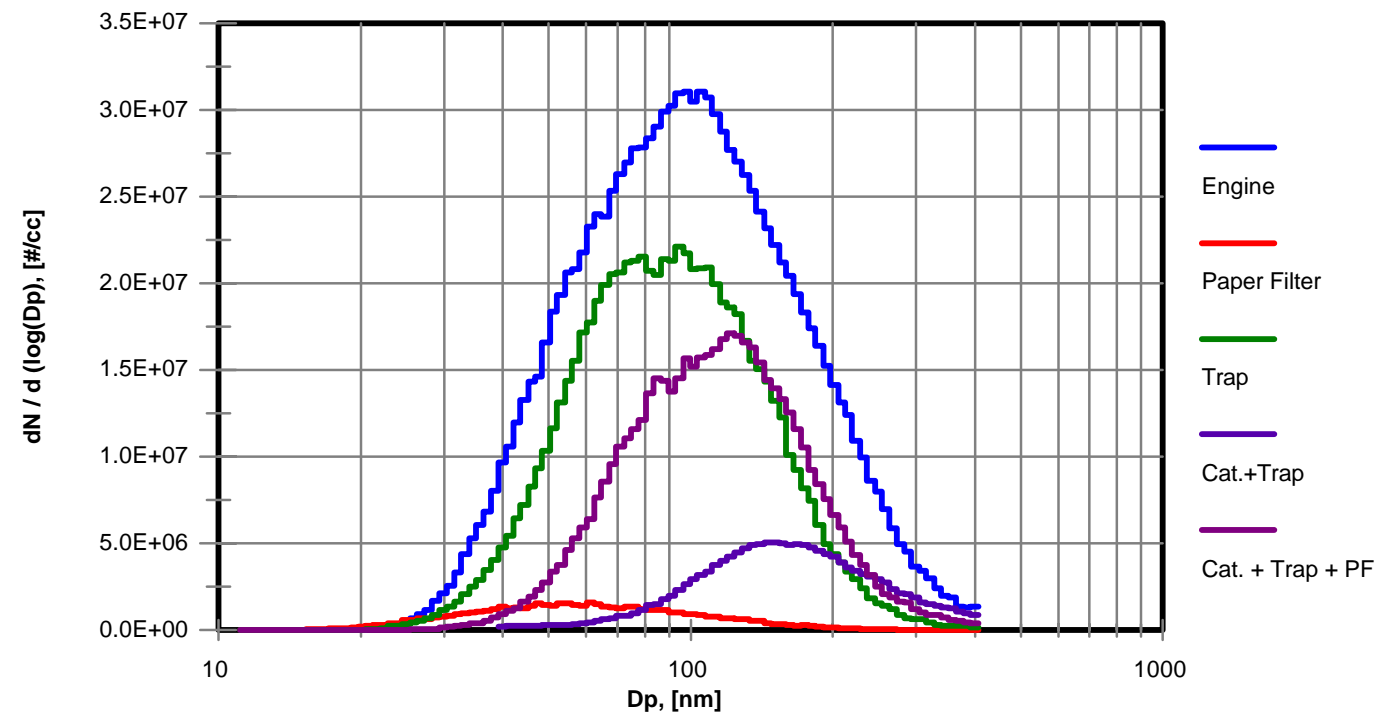

Figure 3.64 Isuzu C240, Steady-State Operating Conditions, Mode R100, Diesel, DR = 28, Number Concentrations, Effects of After-Treatment Process

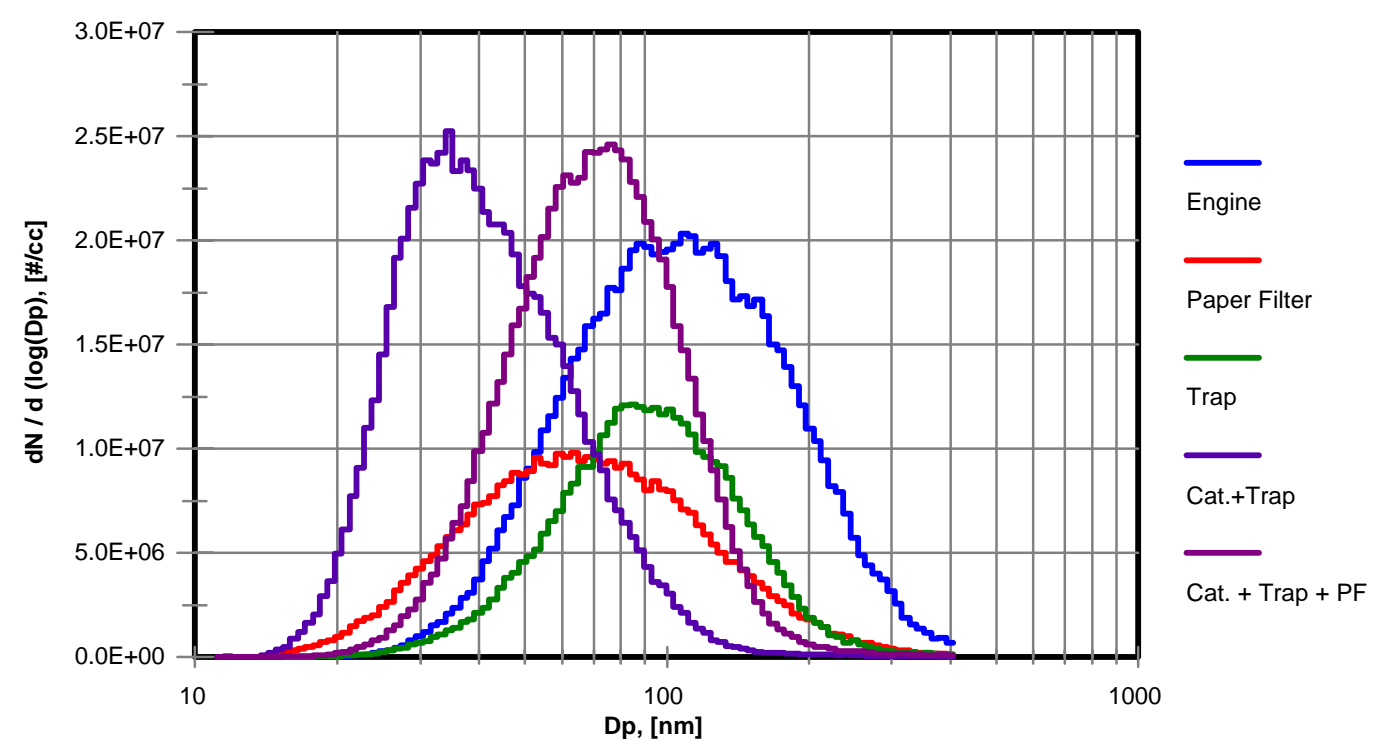

Figure3.65 Isuzu C240, Steady-State Operating Conditions, Mode R75, Diesel, DR = 28, Number Concentrations, Effects of After-Treatment Process 


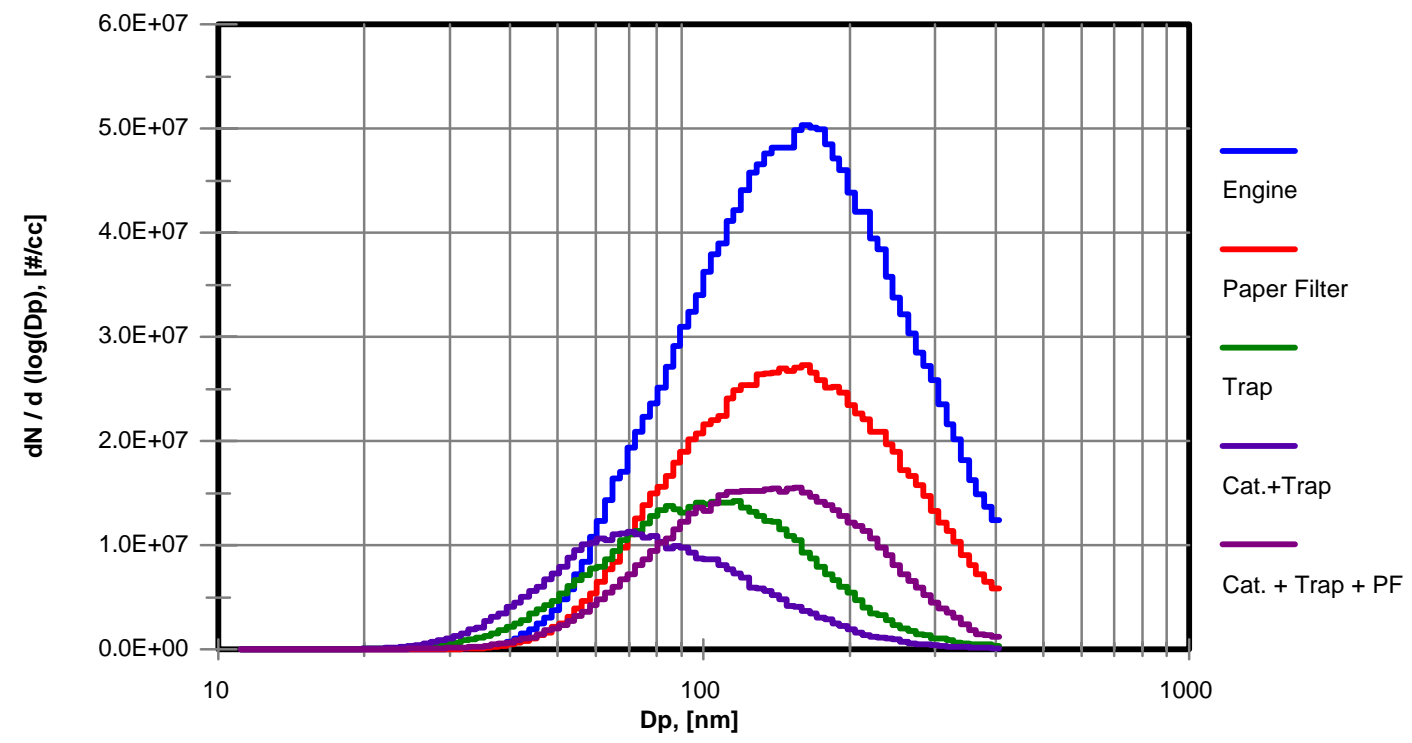

Figure 3.66 Isuzu C240. Steady-State Operating Conditions, Mode I100, Diesel, DR = 28, Number Concentrations, Effects of After-Treatment Process

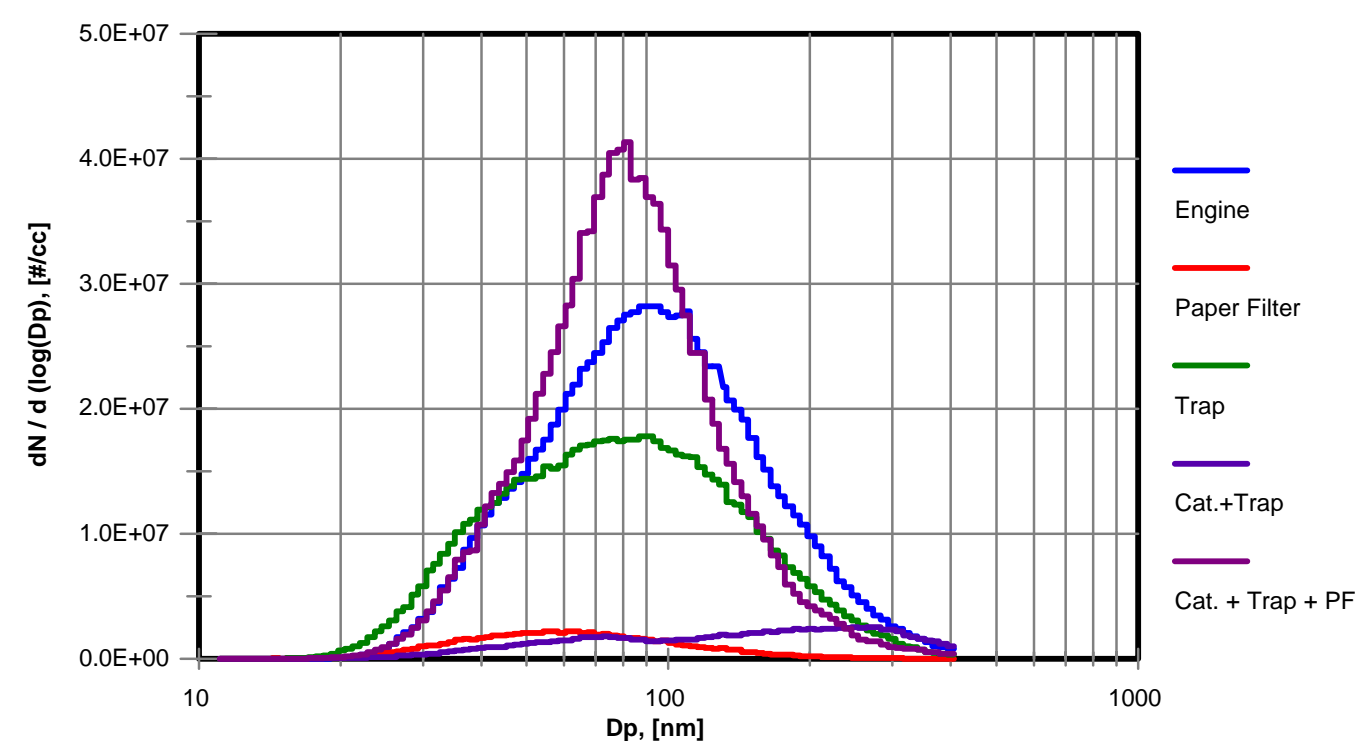

Figure 3.67 Isuzu C240, Steady-State Operating Conditions, Mode R100, Diesel, DR = 15, Number Concentrations, Effects of After-Treatment Process 


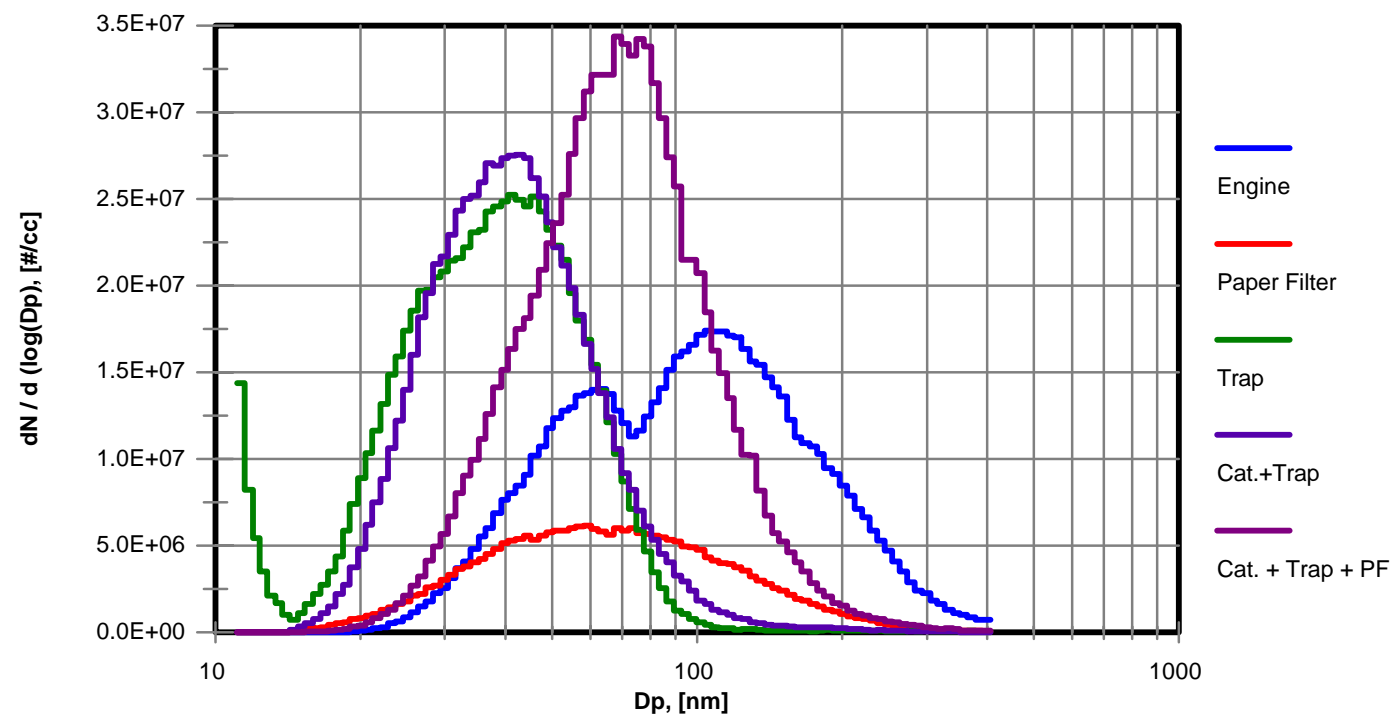

Figure 3.68 Isuzu C240, Steady-State Operating Conditions, Mode R75, Diesel, DR = 15, Number Concentrations, Effects of After-Treatment Process

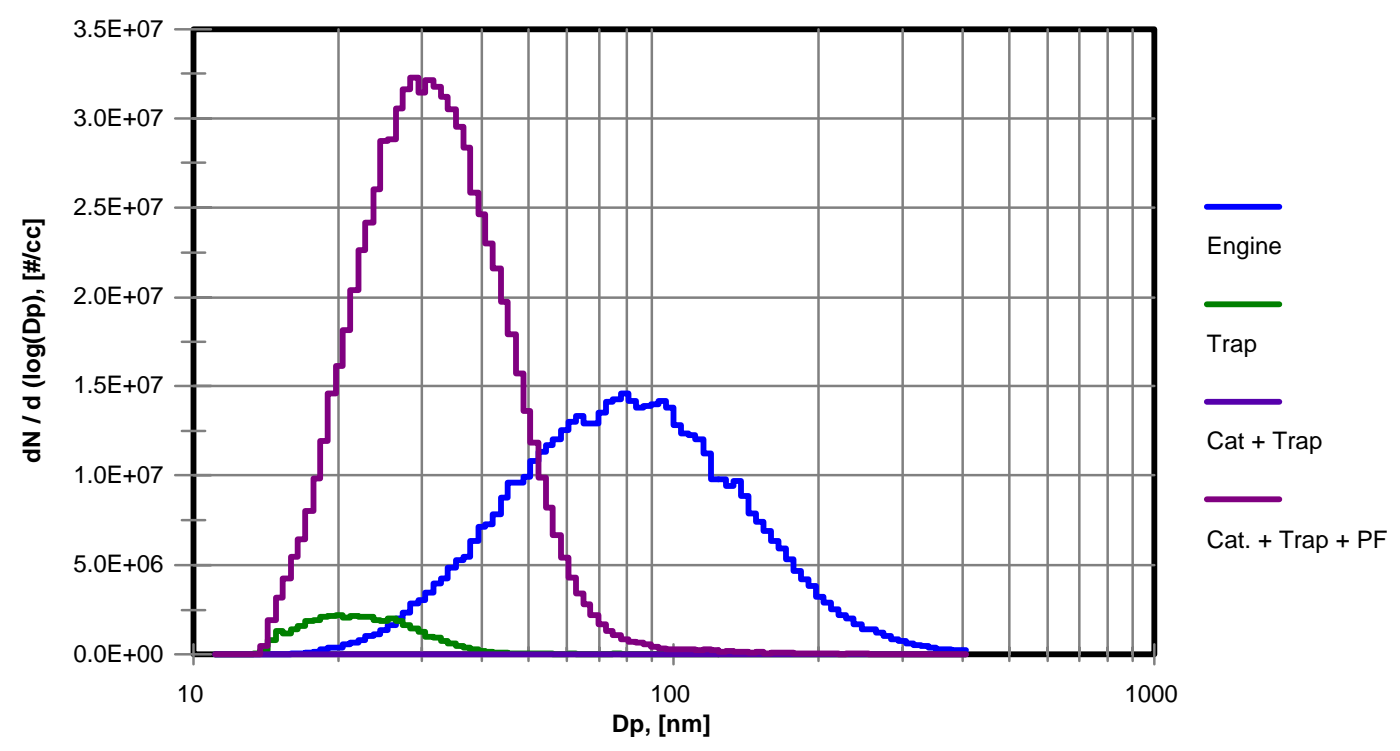

Figure 3.69 Isuzu C240, Steady-State Operating Conditions, Mode I50, Diesel, DR = 28, Number Concentrations, Effects of After-Treatment Devices 


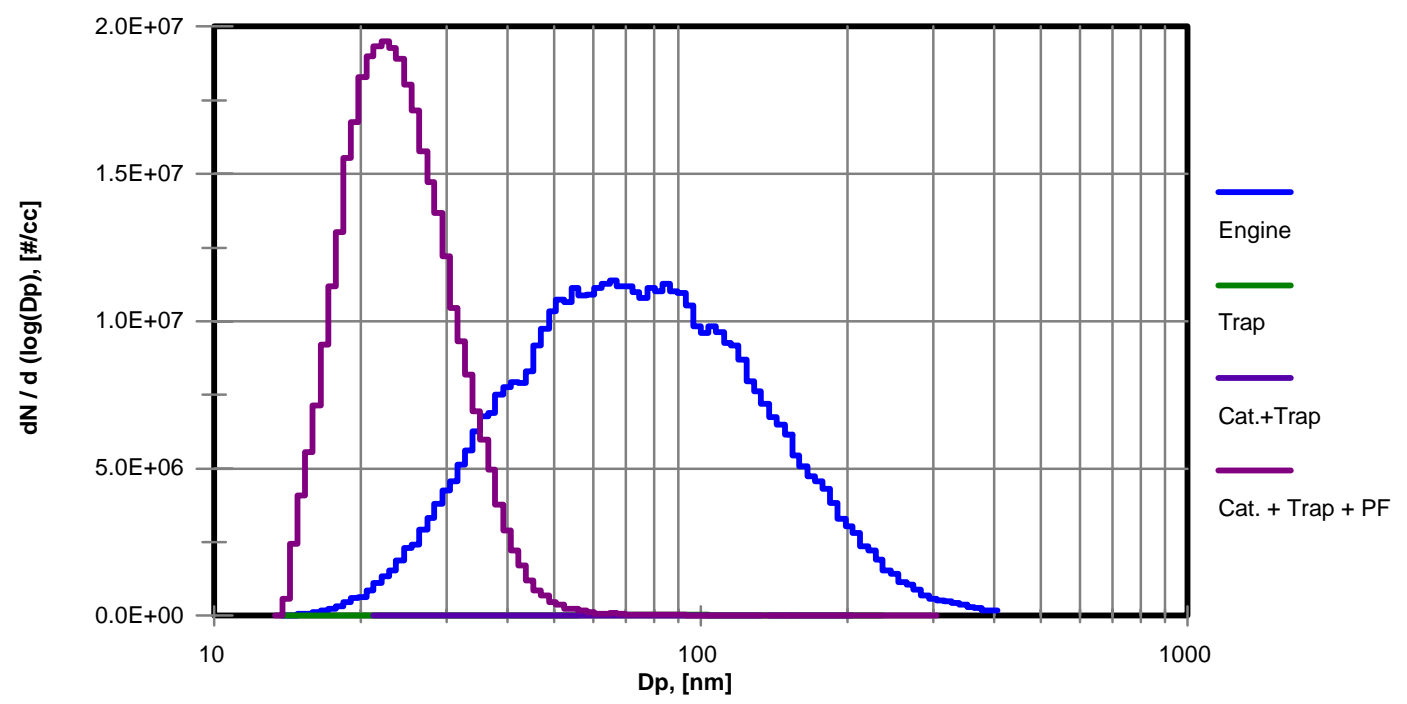

Figure 3.70 Isuzu C240, Steady-State Operating Conditions, Mode I50, Diesel, DR = 15, Number Concentrations, Effects of After-Treatment Process

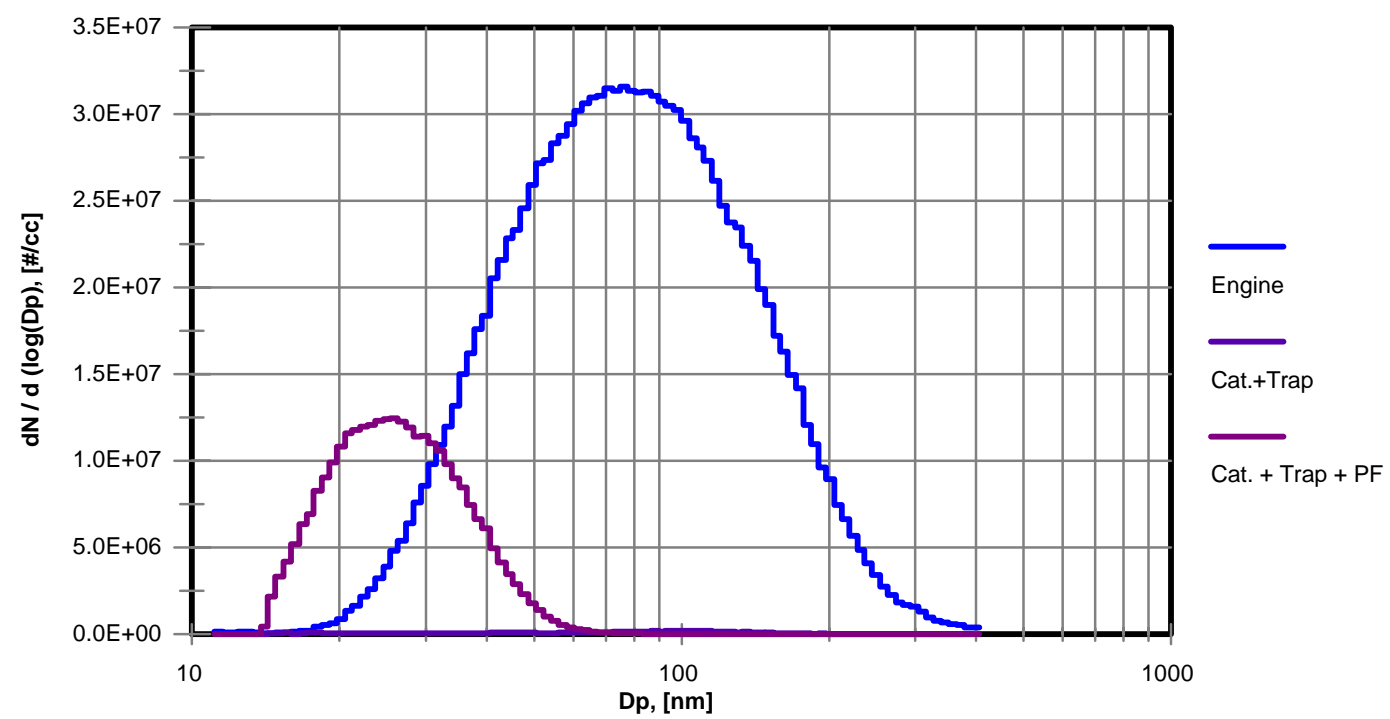

Figure 3.71 Isuzu C240, Steady-State Operating Conditions, Mode R75, F-T Synthetic Diesel, DR $=28$, Number Concentrations, Effects of After-Treatment Process 


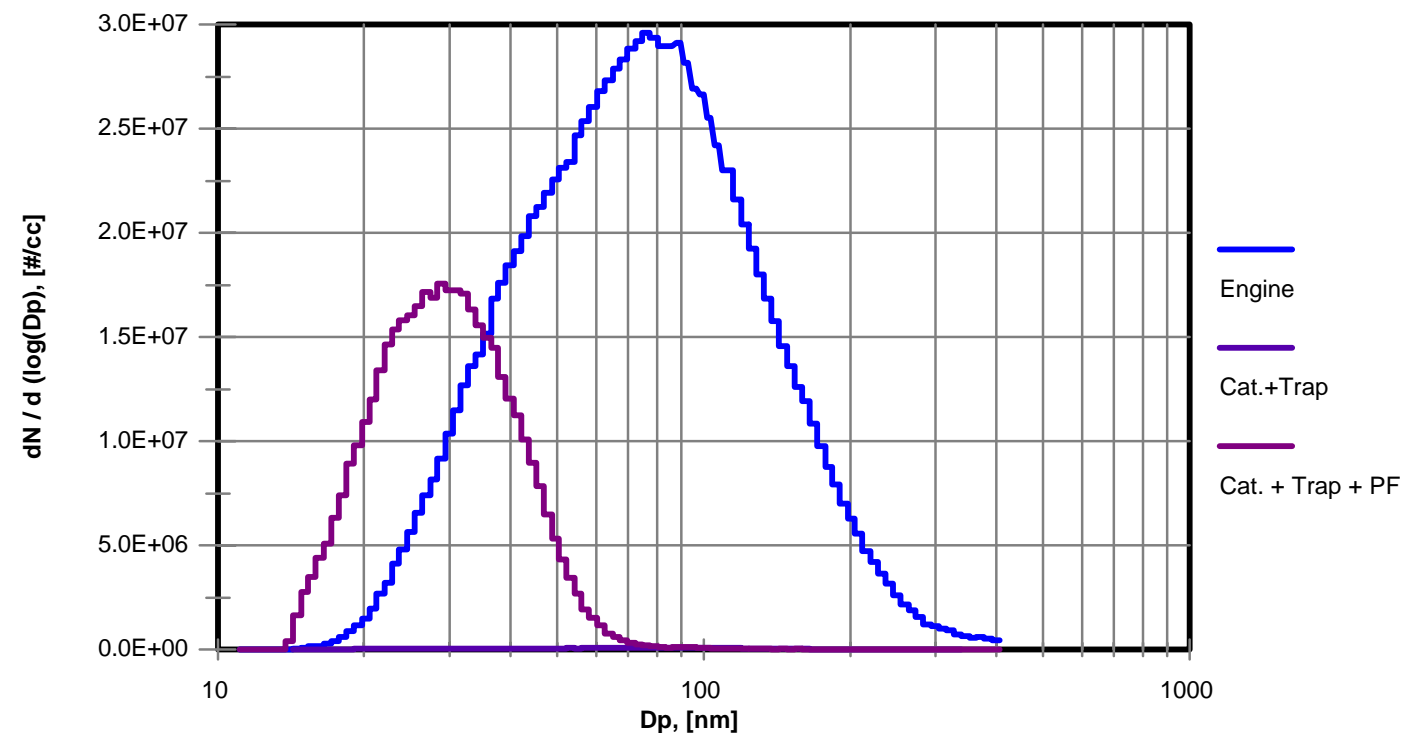

Figure 3.72 Isuzu C240, Steady-State Operating Conditions, Mode R75, F-T Synthetic Diesel, DR $=15$, Number Concentrations, Effects of After-Treatment Process

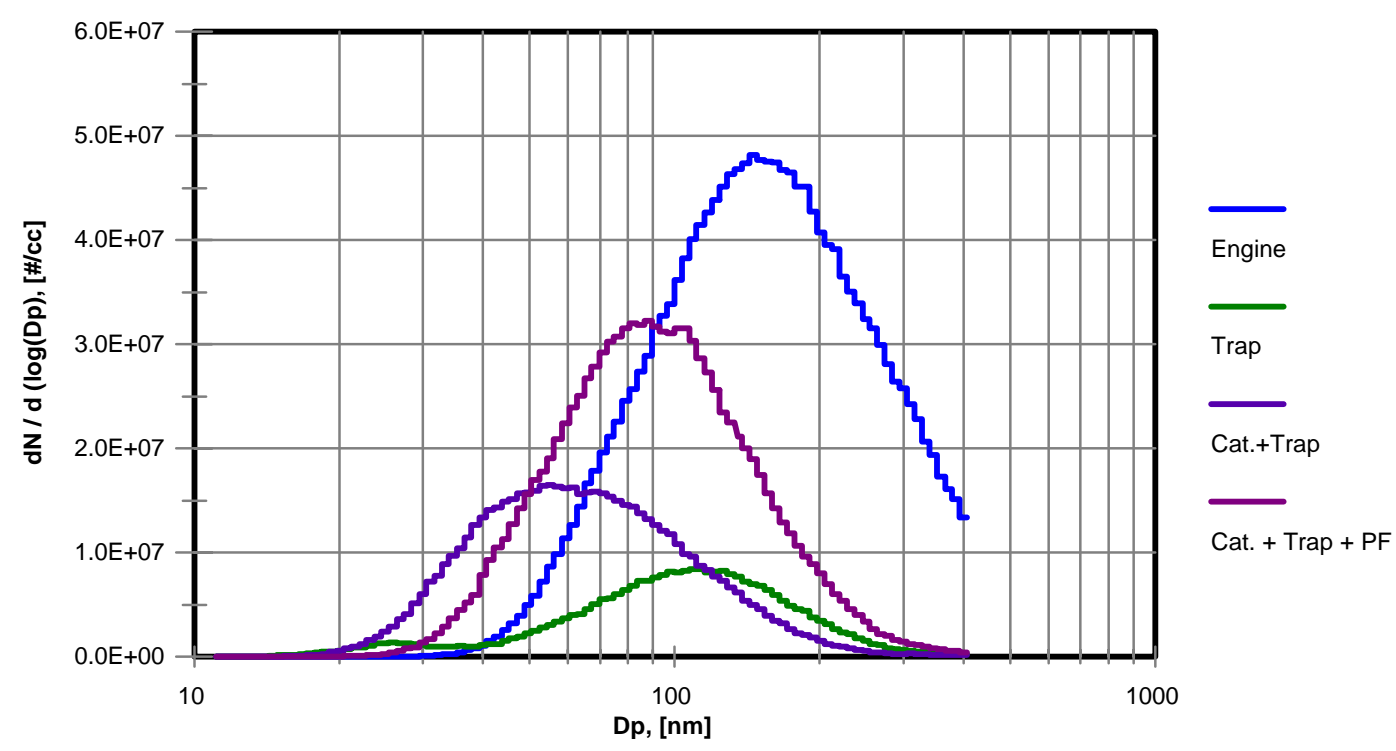

Figure 3.73 Isuzu C240, Steady-State Operating Conditions, Mode I100, Diesel, DR = 15, Number Concentrations, Effects of After-Treatment Process 


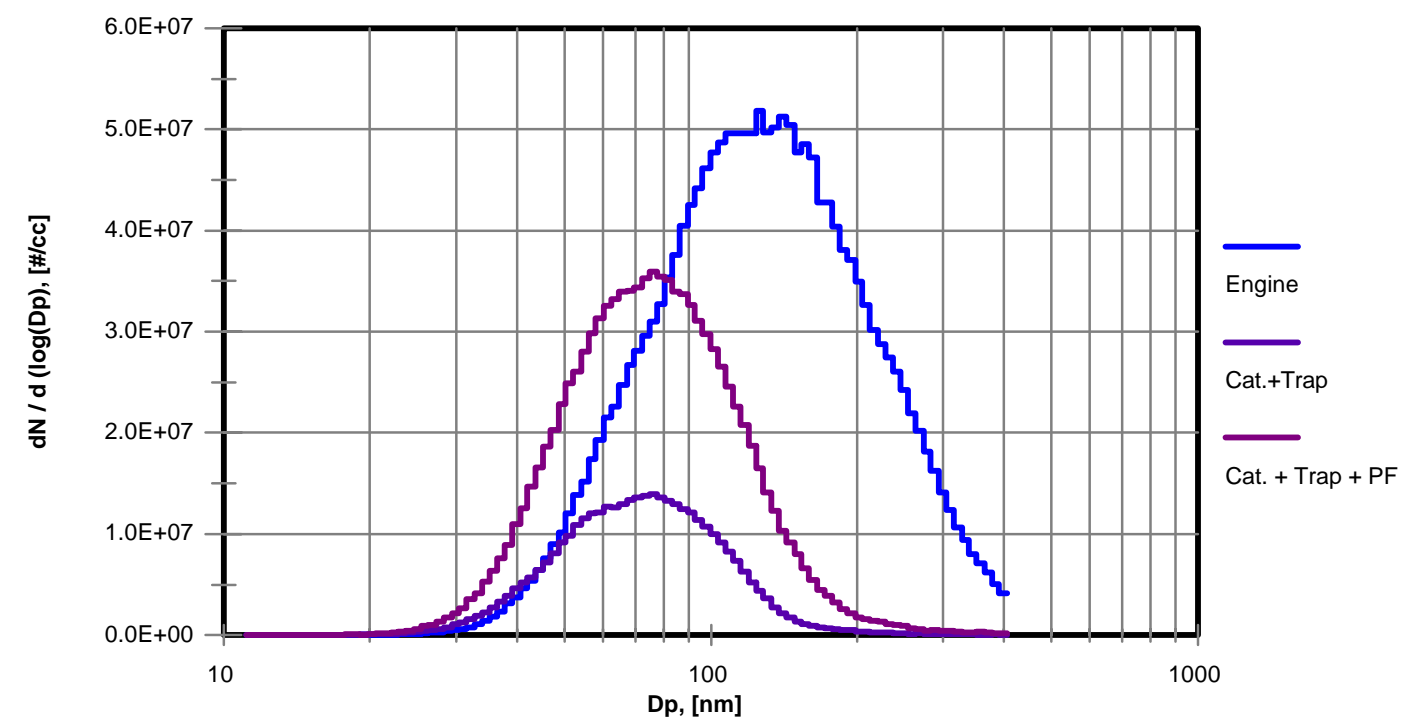

Figure 3.74 Isuzu C240, Steady-State Operating Conditions, Mode I100, F-T Synthetic Diesel, DR $=28$, Number Concentrations, Effects of After-Treatment Process

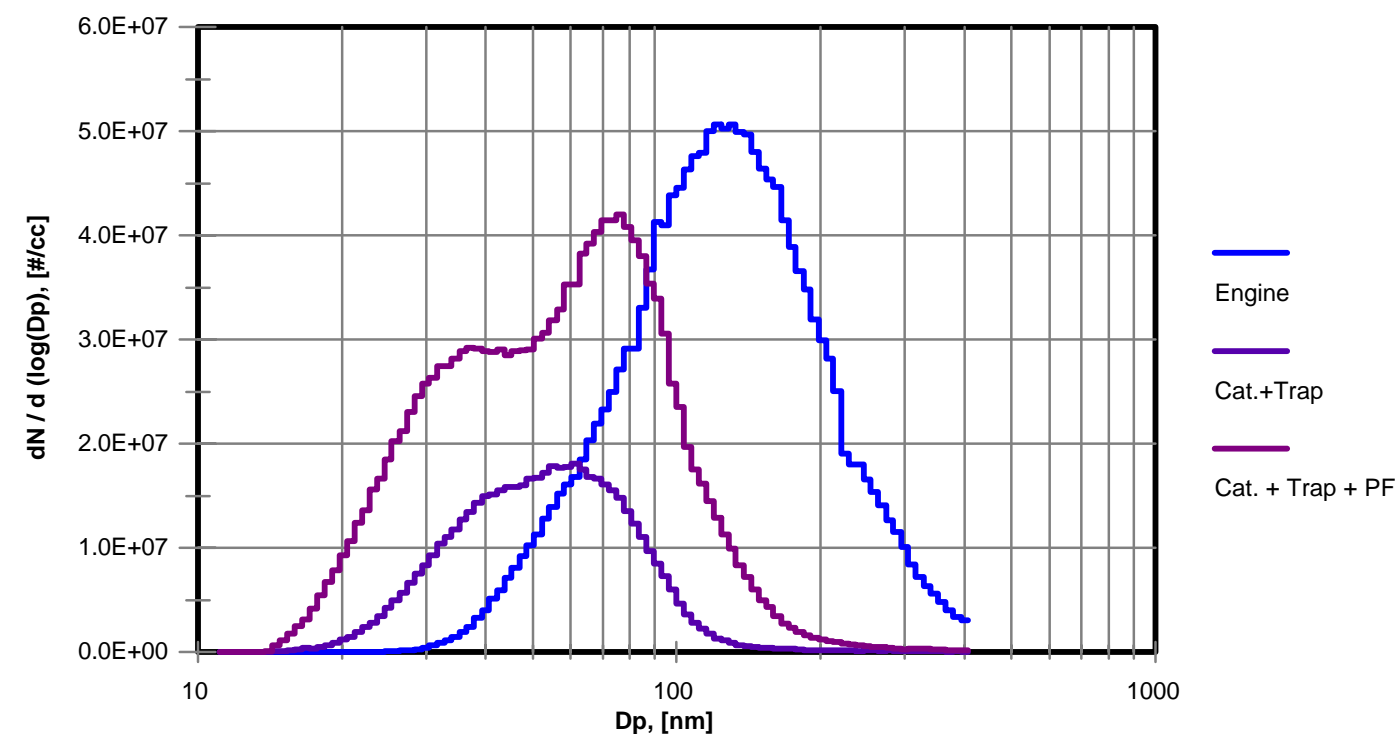

Figure 3.75 Isuzu C240, Steady-State Operating Conditions, Mode I100, F-T Synthetic Diesel, DR $=15$, Number Concentrations, Effects of After-Treatment Process 


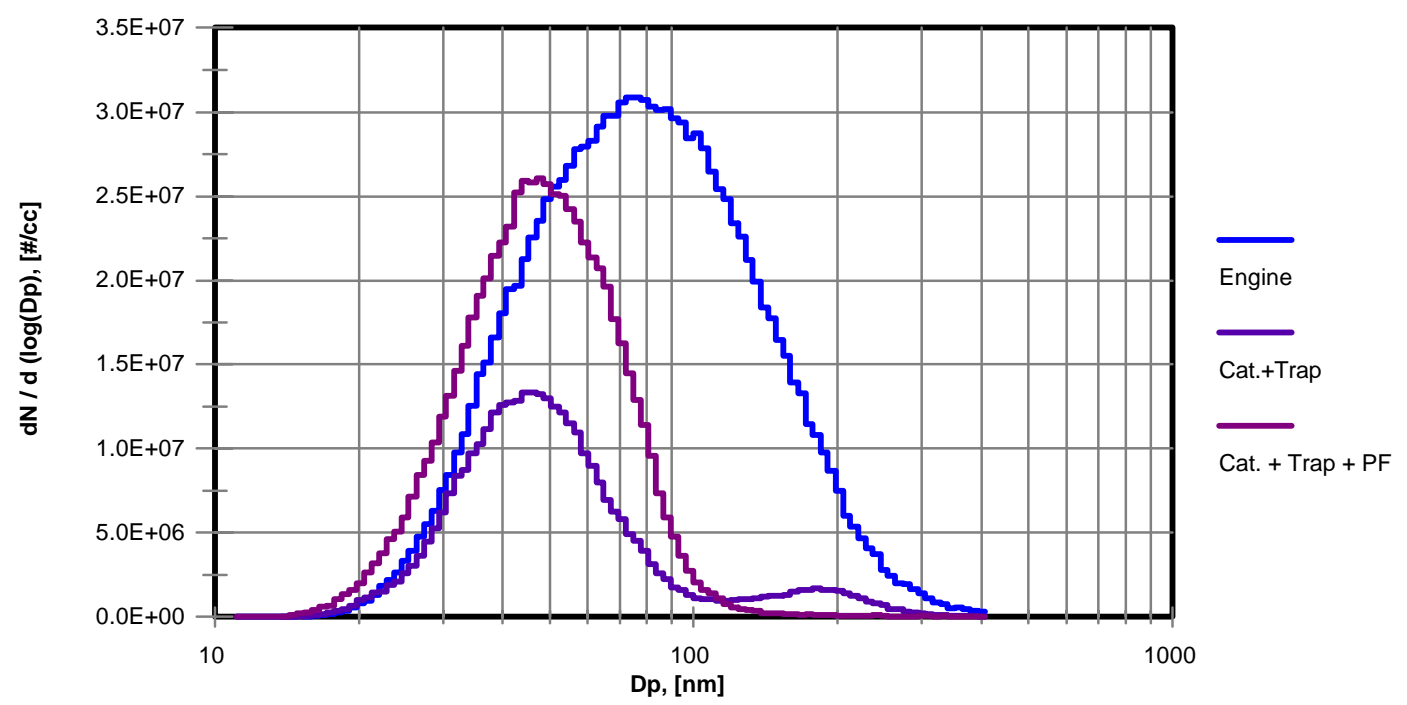

Figure 3.76 Isuzu C240, Steady-State Operating Conditions, Mode R100, F-T Synthetic Diesel, DR=28, Number Concentrations, Effects of After-Treatment Process

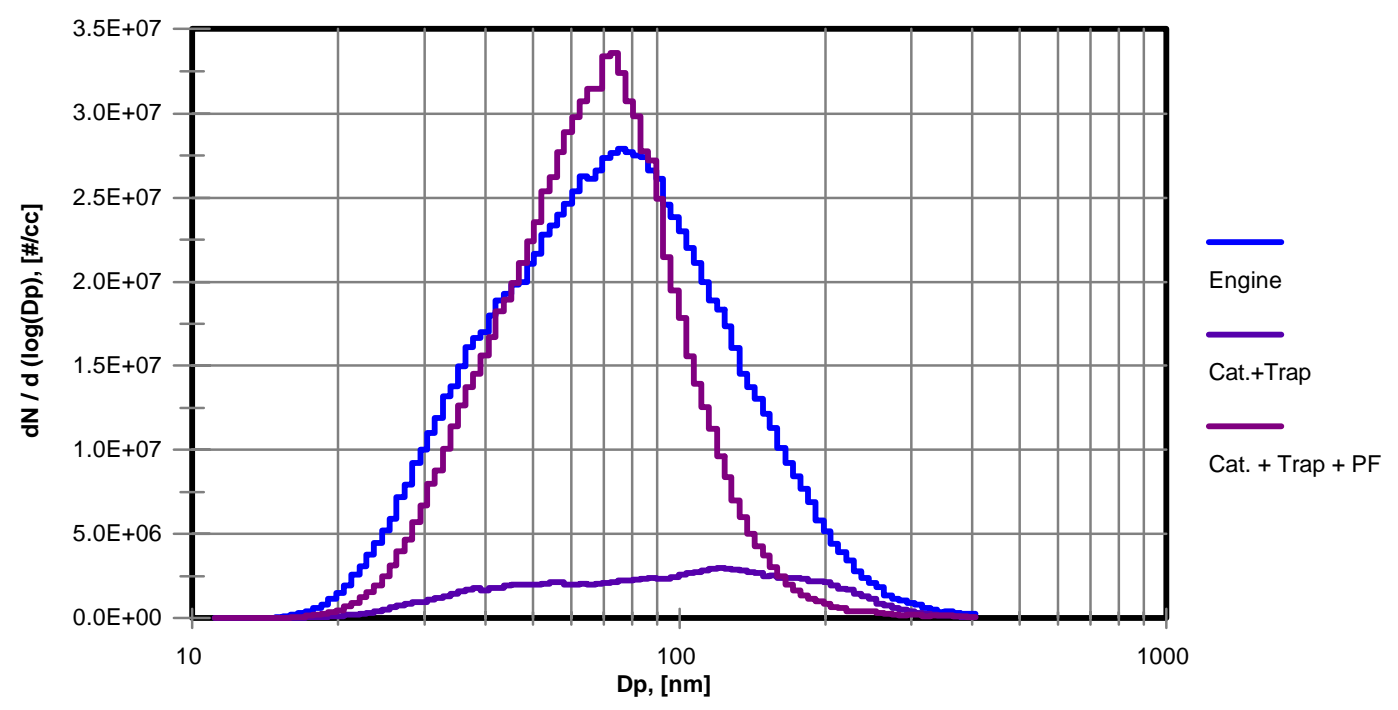

Figure 3.77 Isuzu C240, Steady-State Operating Conditions, Mode R100, F-T Synthetic Diesel, DR $=15$, Number Concentrations, Effects of After-Treatment Process 


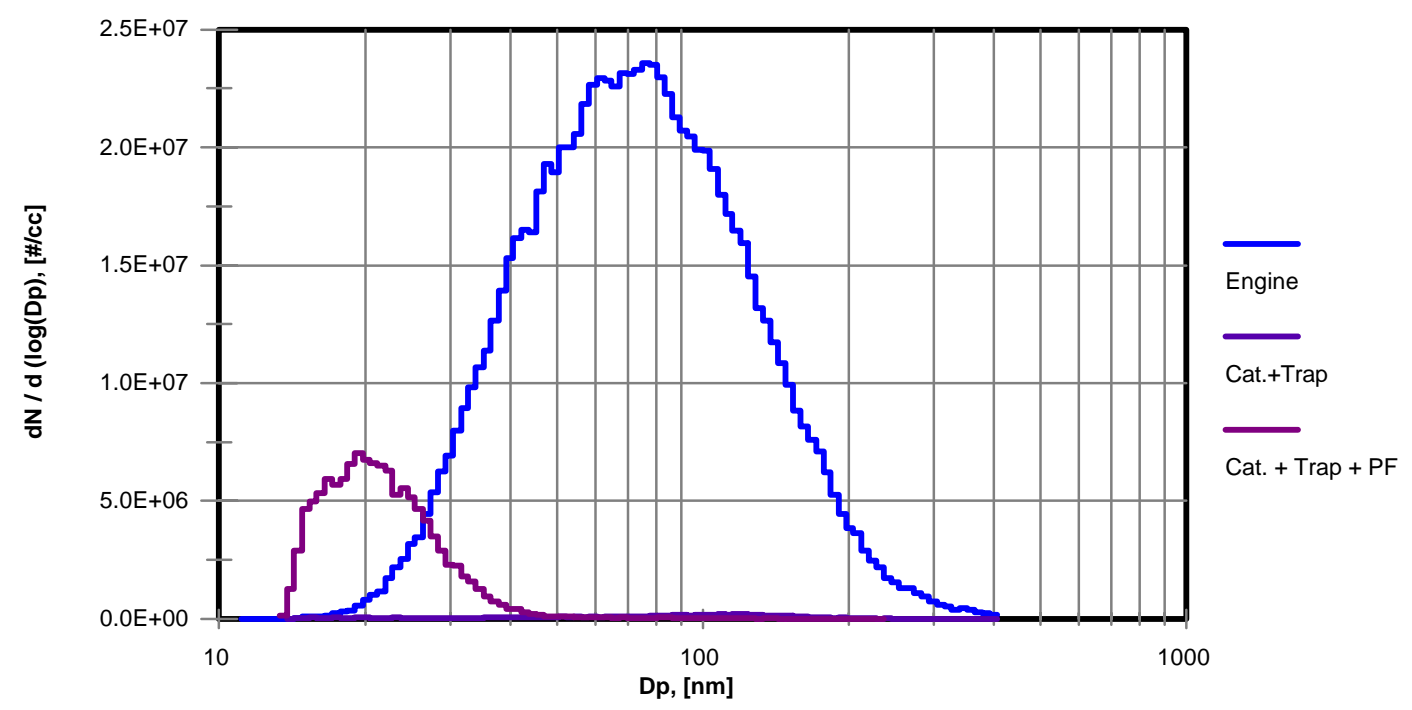

Figure 3.78 Isuzu C240, Steady-State Operating Conditions, Mode I50, F-T Synthetic Diesel, DR $=28$, Number Concentrations, Effects of After-Treatment Process

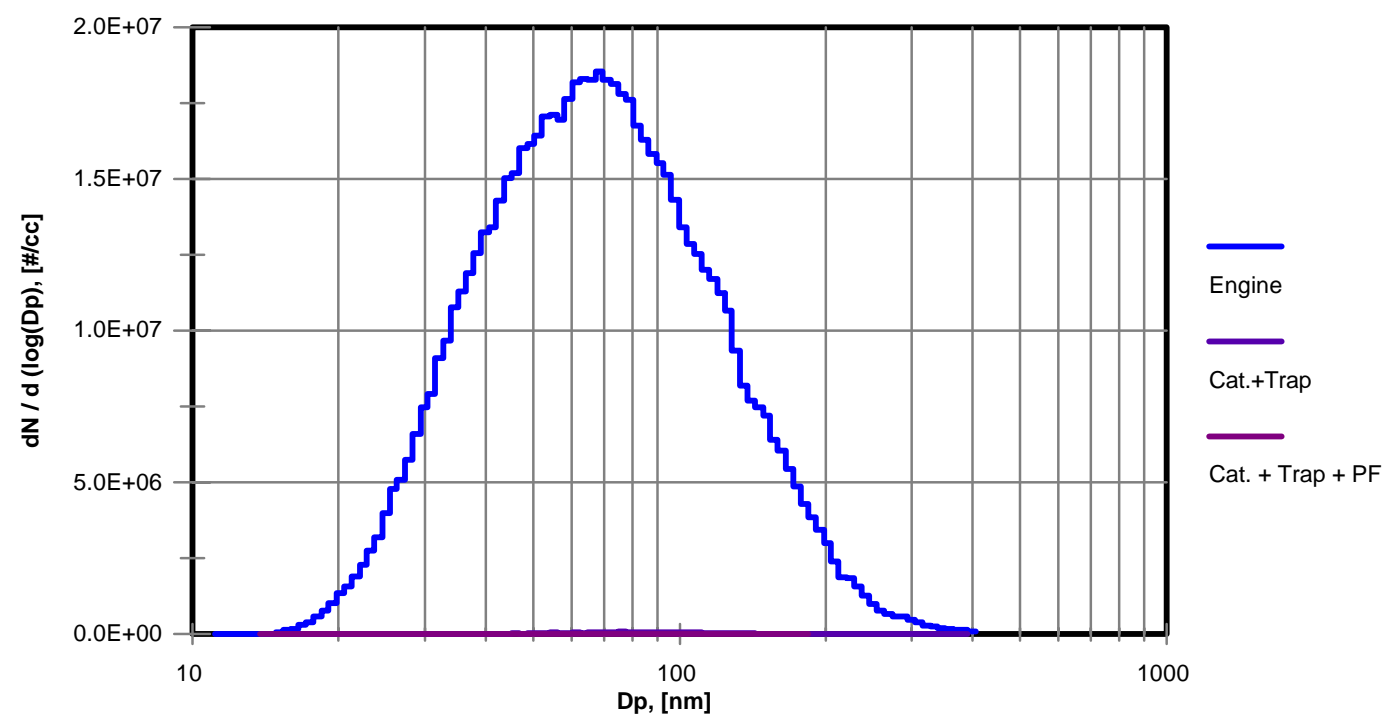

Figure 3.79 Isuzu C240, Steady-State Operating Conditions, Mode I50, F-T Synthetic Diesel, DR = 15, Number Concentrations, Effects of After-Treatment Process 
The "real-time" measurements of the DPM size-distributions and concentrations were performed on the exhaust from the PAT transit buses. The heavy-duty chassis dynamometer was used to exercise the vehicle over the CBD transient cycle (shown in Figure 3.2). The concentrations of particles with electrical mobility diameters ranging from 15 to $200 \mathrm{~nm}$ were tracked in real time using the SMPS and TSI CPCount software. The reduced results of the "real time" PM tracking for buses 2029 (before was fitted with rebuilt engine and OCC), 2048, 2030, 2034, and 2029 (after was fitted with rebuilt engine and OCC) are shown in Figures 3.80 through 3.92. Figures 3.80 and 3.92 also show the speed vs. time trace of the CBD driving schedule.

The particles with electrical mobility diameter of $200 \mathrm{~nm}$ had the highest concentrations of all the tracked particles. They were ranging from $10^{6}$ to $10^{8}$ particles per $\mathrm{cm}^{3}$ depending on the driving mode in the cycle, vehicle type and fuel type. Those concentrations were several orders of magnitude higher than the concentrations of the particles with electrical mobility diameter of $15 \mathrm{~nm}\left(10^{3}\right.$ to $10^{5}$ particles per $\mathrm{cm}^{3}$ ). Again, the concentrations were a function of the driving mode in the cycle, vehicle and fuel. The highest concentrations, for particles with diameters of 100, 150 and $200 \mathrm{~nm}$, were observed at the end of the acceleration modes. The highest concentrations of the 15,30, and $50 \mathrm{~nm}$ particles were found to be either at the end of the acceleration periods or at the end of the steady-state speed periods depending on the vehicle. The rise in the nanoparticles $(15,30,50 \mathrm{~nm})$ at the beginning of the deceleration mode (or the end of the cruise mode) is attributed to a high F/A ratio. The F/A ratio was affected by the sudden decrease in engine speed at the onset of the deceleration mode. The measured concentrations of particles for the transient engine operating conditions indicate completely different distributions than those observed for the steady-state conditions. This can be attributed to the processes occurring in the engine and the sampling system. More intensive mixing in the combustion chamber, the transfer lines and the partial dilution tunnel during transient tests provide more residence time and favored formation of the particles with larger diameters than those observed for steady-state engine operating conditions. 
It can be hypothesized that the differences in the distributions of particle concentrations, for different size classes, relative to the speed trace indicate potential differences in chemical composition and mechanisms of formation of particles in function of their size. The larger particles (100, 150, and 200 $\mathrm{nm}$ ) were most probably composed of carbonaceous cores with semi-volatile compounds adsorbed on them. The smaller particles $(15,30$, and $50 \mathrm{~nm})$ most probably comprised of semi-volatile hydrocarbons along with sulfuric acid (serving as nuclei). Nanoparticles were generally much more predisposed to generation and/or transformation due to variation of the major thermodynamic parameters in the sampling system. More extensive research on the size-resolved distribution of PM and size-resolved chemical analysis of PM is required to justify those hypotheses.

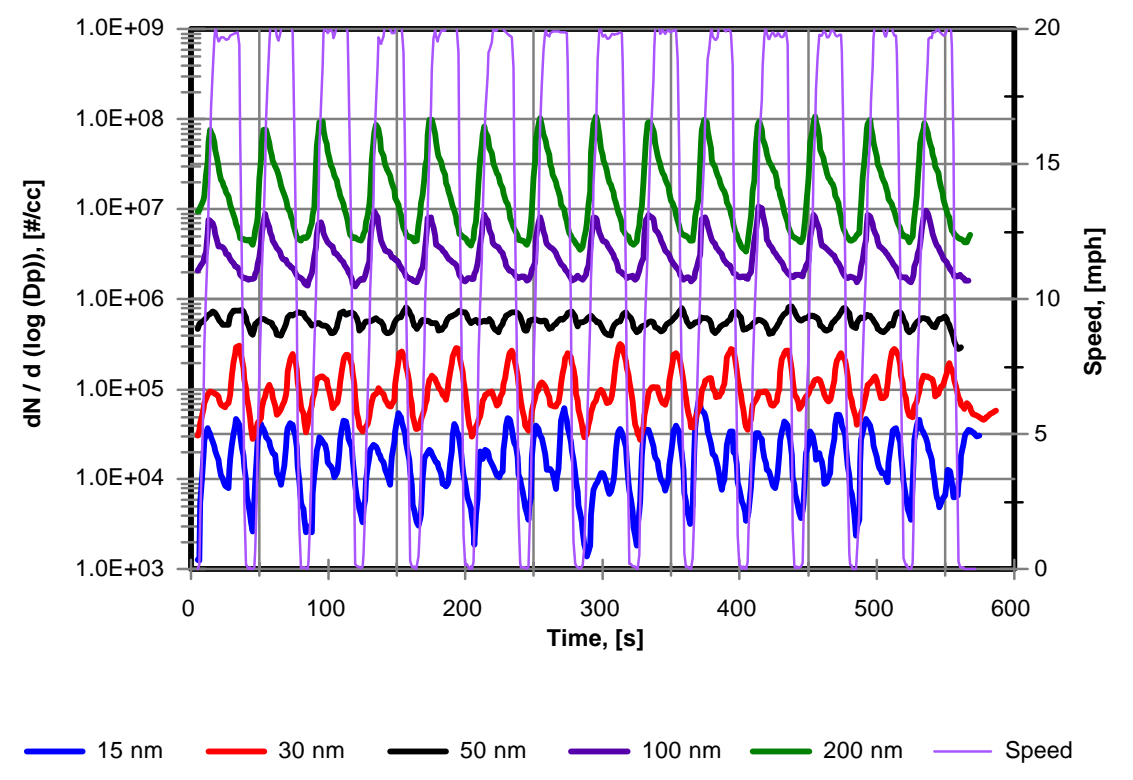

Figure 3.80 Orion/DDC 6V92, Bus 2029 Without OCC, Transient, CBD, Diesel, DR $=22$, Number Concentration, Real Time Tracking 


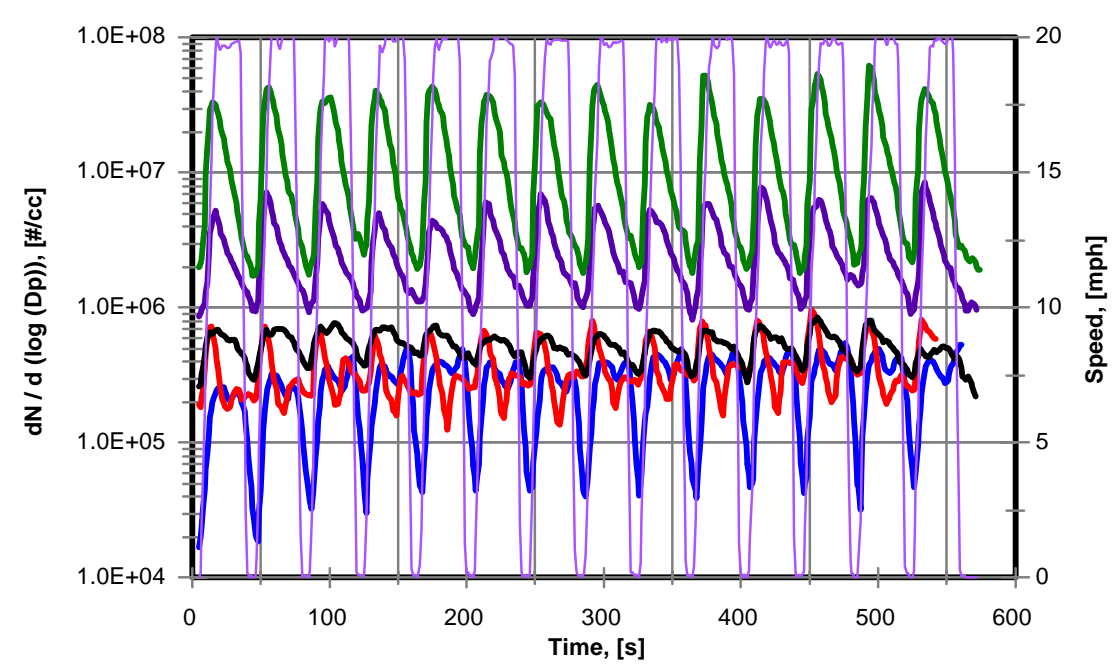

$\longrightarrow 15 \mathrm{~nm} \longrightarrow 30 \mathrm{~nm} \longrightarrow 50 \mathrm{~nm} \longrightarrow 100 \mathrm{~nm} \longrightarrow 200 \mathrm{~nm} \longrightarrow$ speed

Figure 3.81 Orion/DDC 6V92, Bus 2048 With OCC, Transient, CBD, Diesel, DR $=22$, Number Concentration, Real Time Tracking

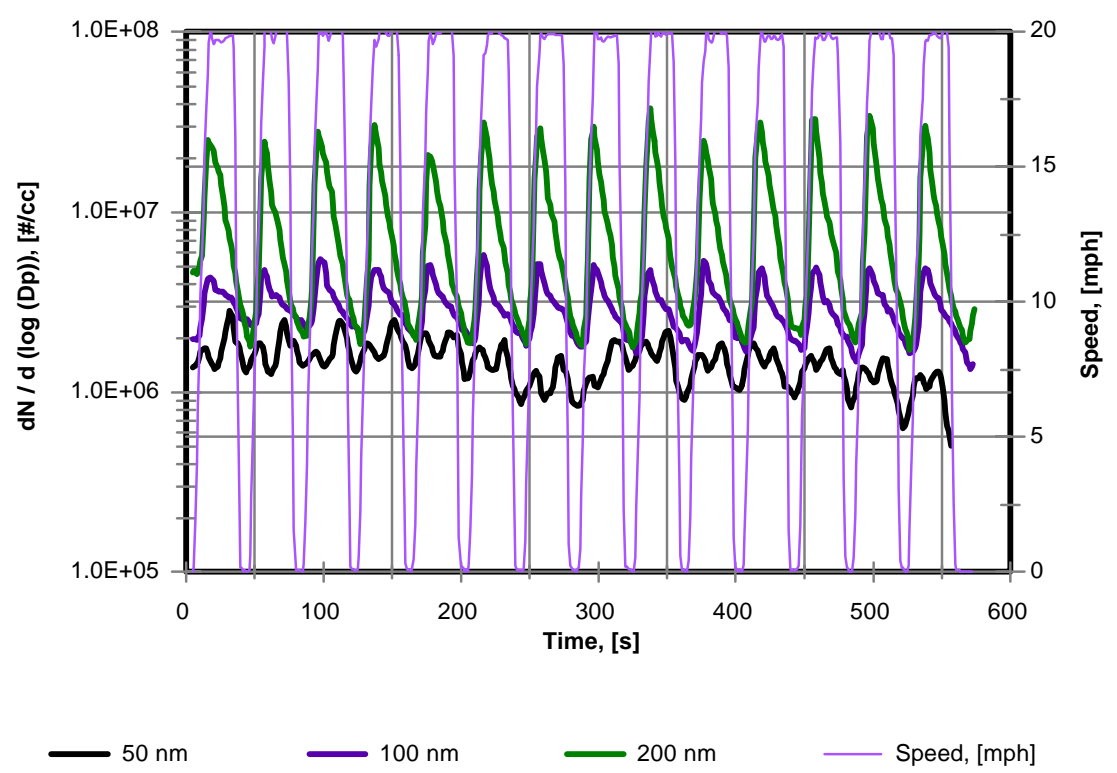

Figure 3.82 Orion/DDC 6V92, Bus 2030 Without OCC, Transient, CBD, Diesel, DR $=22$, Number Concentration, Real Time Tracking 


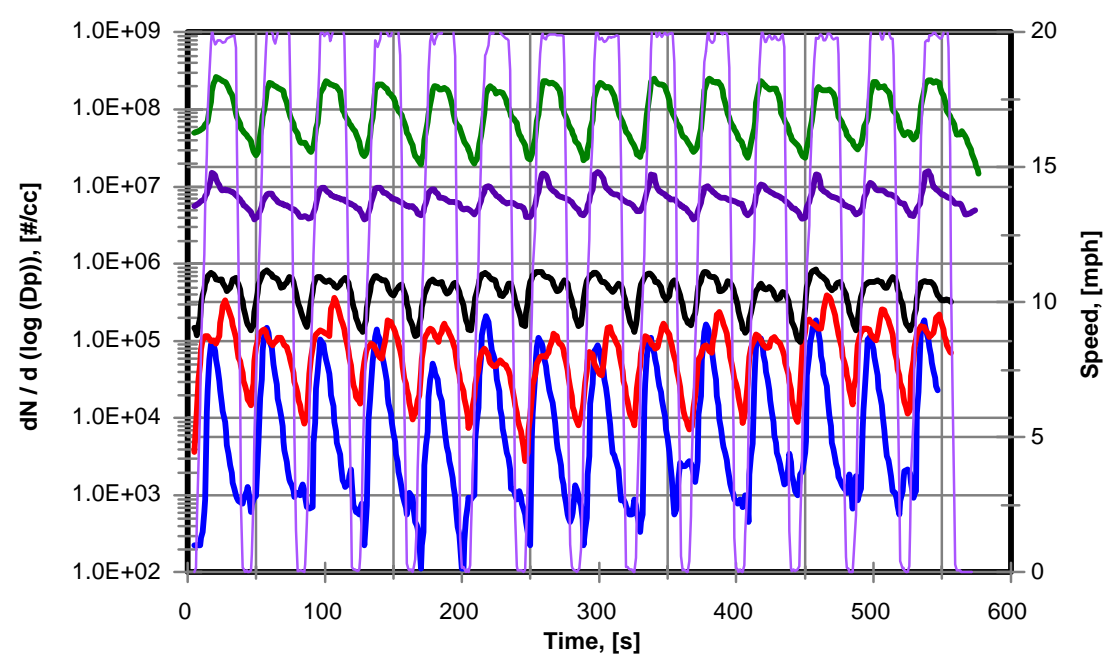

$\longrightarrow 15 \mathrm{~nm} \longrightarrow 30 \mathrm{~nm} \longrightarrow 50 \mathrm{~nm} \longrightarrow 100 \mathrm{~nm} \longrightarrow 200 \mathrm{~nm} \longrightarrow$ speed

Figure 3.83 Orion/DDC 6V92, Bus 2034 Without OCC, Transient, CBD, Diesel, DR = 22, Number Concentration, Real Time Tracking

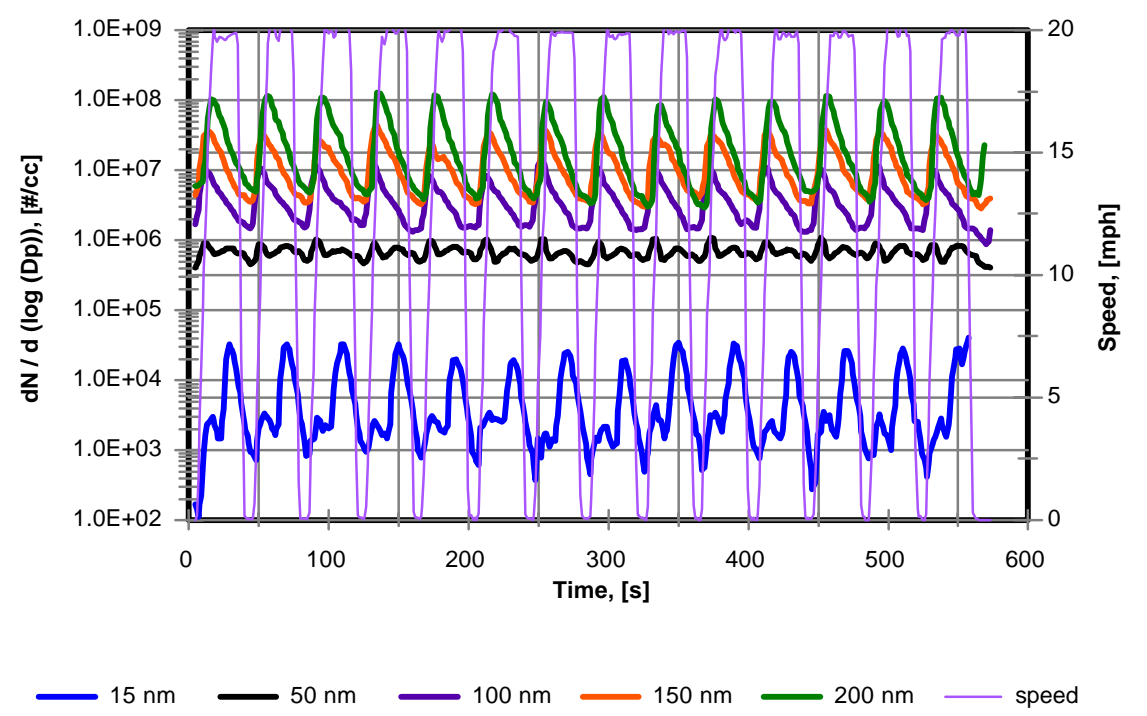

Figure 3.84 Orion/DDC 6V92, Bus 2029 With OCC, Transient, CBD, Diesel, $\mathrm{DR}=22$, Number Concentration, Real Time Tracking 


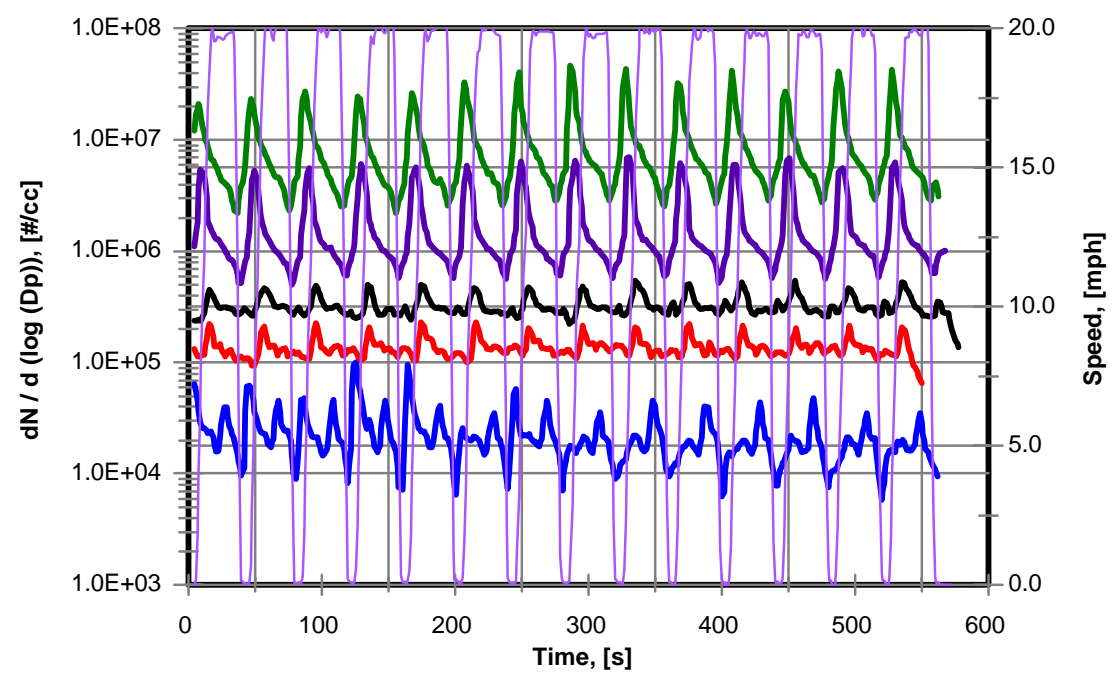

$\longrightarrow 15 \mathrm{~nm} \longrightarrow 30 \mathrm{~nm} \longrightarrow 50 \mathrm{~nm} \longrightarrow 100 \mathrm{~nm} \longrightarrow 200 \mathrm{~nm} \longrightarrow$ speed

Figure 3.85 Orion/DDC 6V92, Bus 2029 Without OCC, Transient, CBD, Diesel, DR = 5, Number Concentration, Real Time Tracking

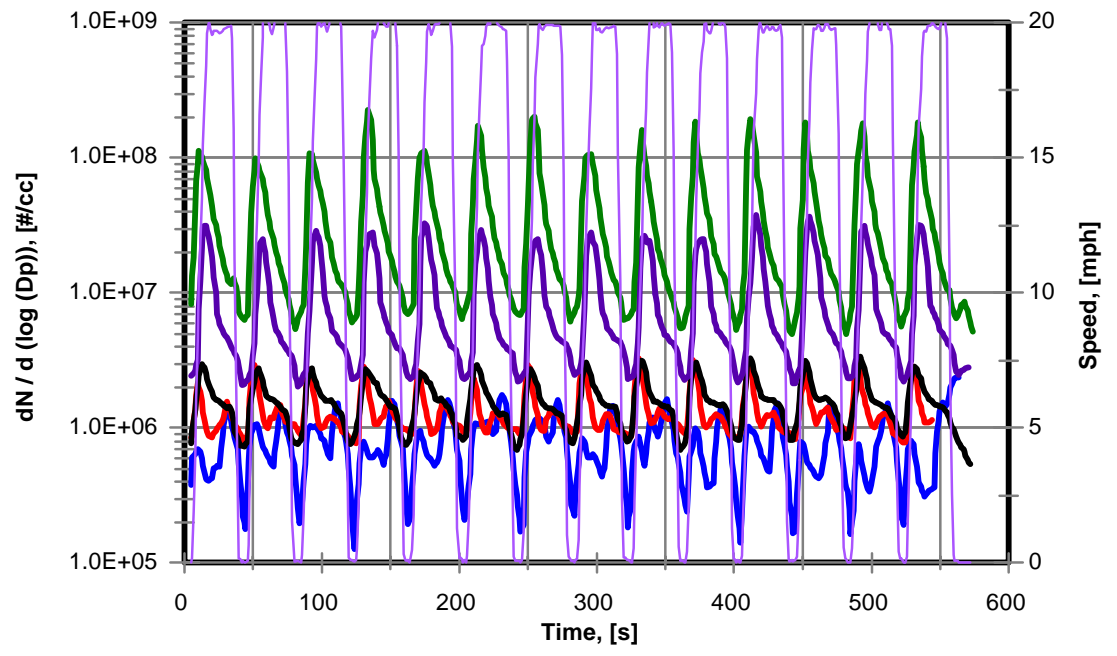

$\longrightarrow 15 \mathrm{~nm} \longrightarrow 30 \mathrm{~nm} \longrightarrow 50 \mathrm{~nm} \longrightarrow 100 \mathrm{~nm} \longrightarrow 200 \mathrm{~nm} \quad$ speed

Figure 3.86 Orion/DDC 6V92, Bus 2048 With OCC, Transient, CBD, Diesel, DR $=5$, Number Concentration, Real Time Tracking 


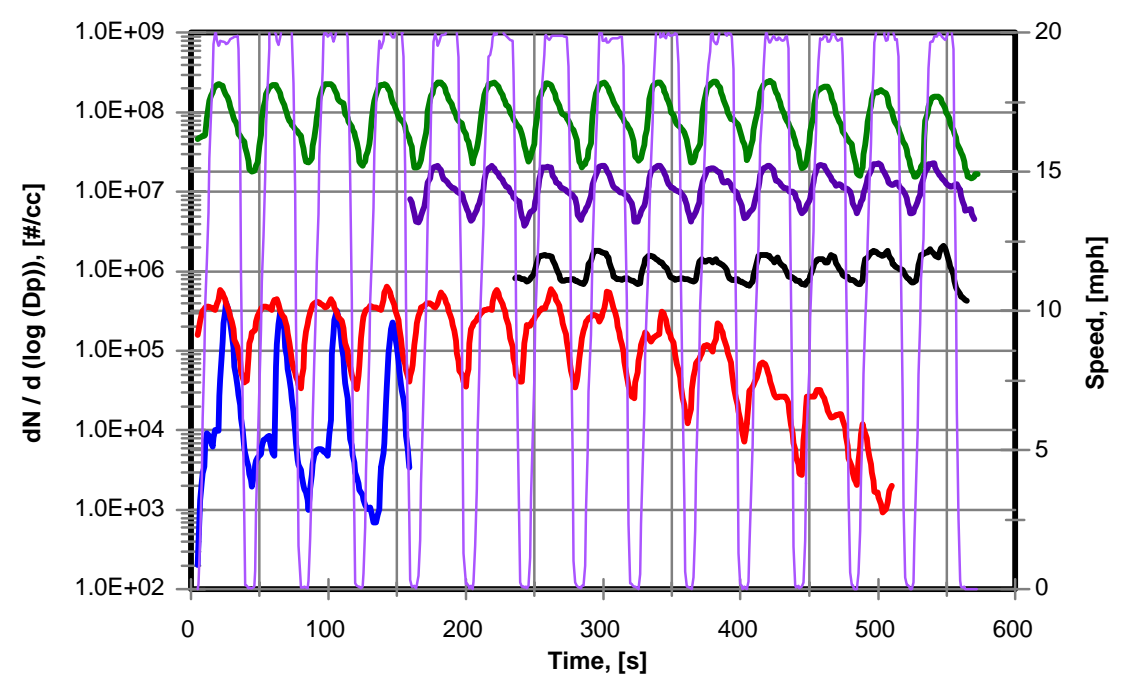

$\longrightarrow 15 \mathrm{~nm} \longrightarrow 30 \mathrm{~nm} \longrightarrow 50 \mathrm{~nm} \longrightarrow 100 \mathrm{~nm} \longrightarrow 200 \mathrm{~nm} \longrightarrow$ speed

Figure 3.87 Orion/DDC 6V92, Bus 2034 Without OCC, Transient, CBD, Diesel, DR = 5, Number Concentration, Real Time Tracking
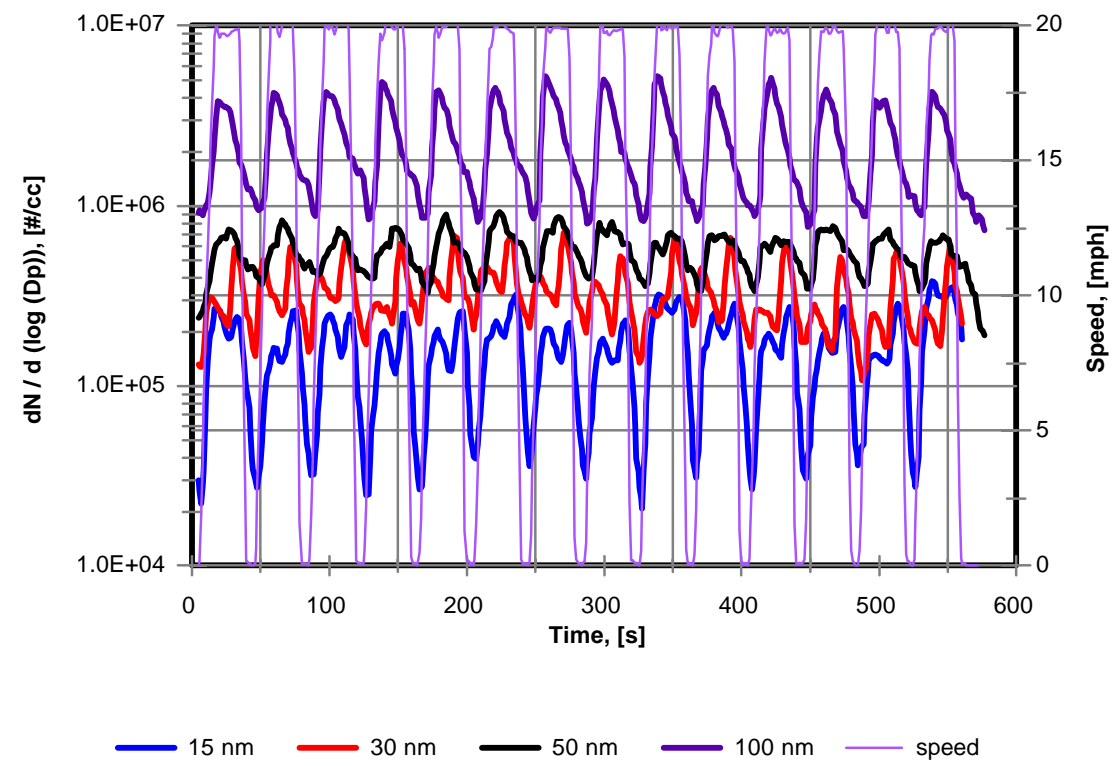

Figure 3.88 Orion/DDC 6V92, Bus 2048 With OCC, Transient, CBD, Mossgas Synthetic Diesel, DR = 22, Number Concentration, Real Time Tracking 


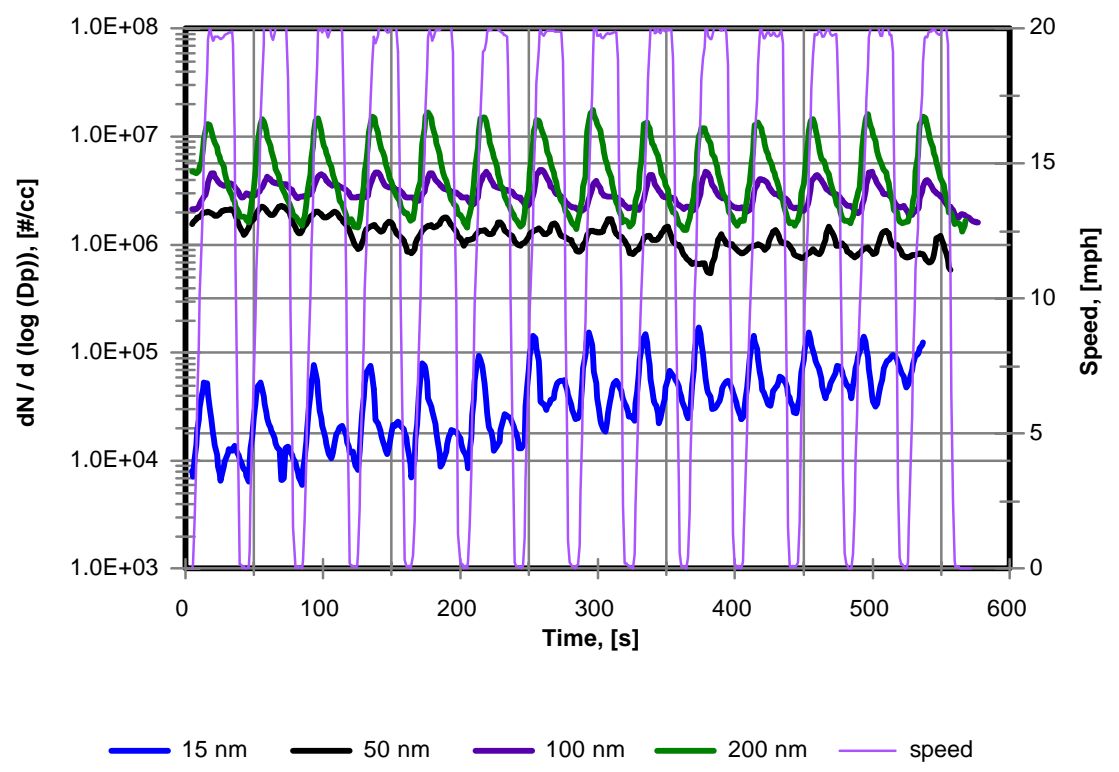

Figure 3.89 Orion/DDC 6V92, Bus 2030 Without OCC, Transient, CBD, Mossgas Synthetic Diesel, DR = 22, Number Concentration, Real
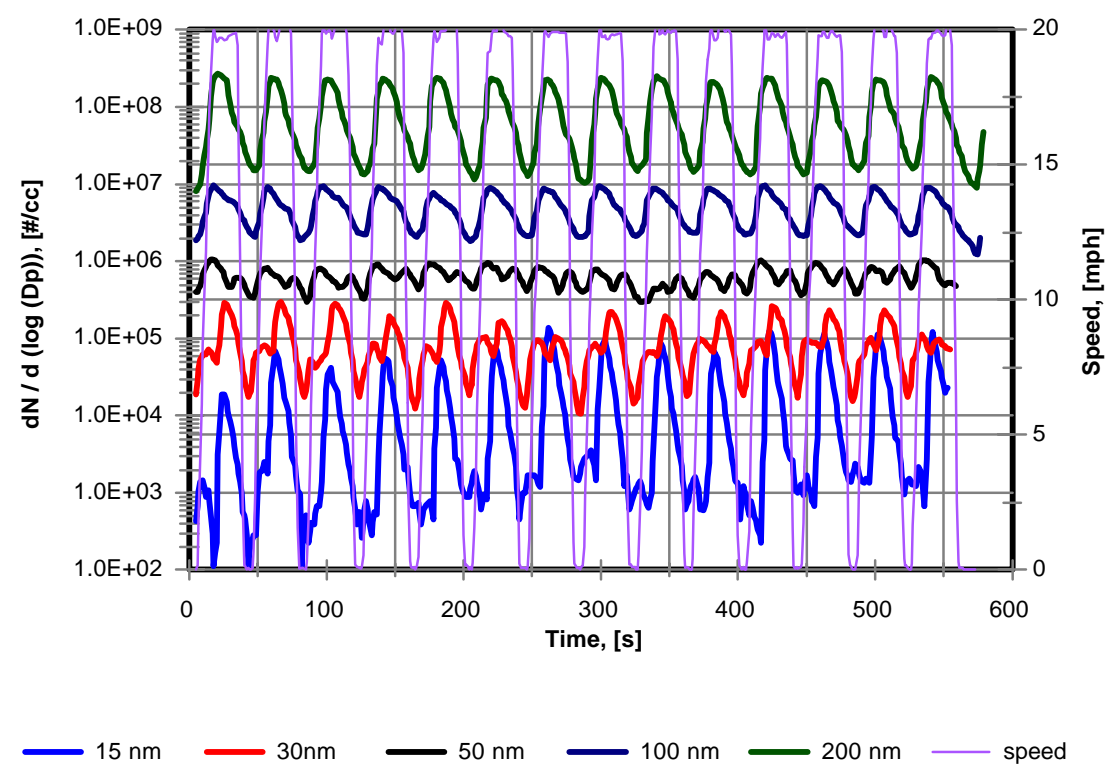

Figure 3.90 Orion/DDC 6V92, Bus 2034 Without OCC, Transient, CBD, Mossgas Synthetic Diesel, DR = 22, Number Concentration, Real Time Tracking 


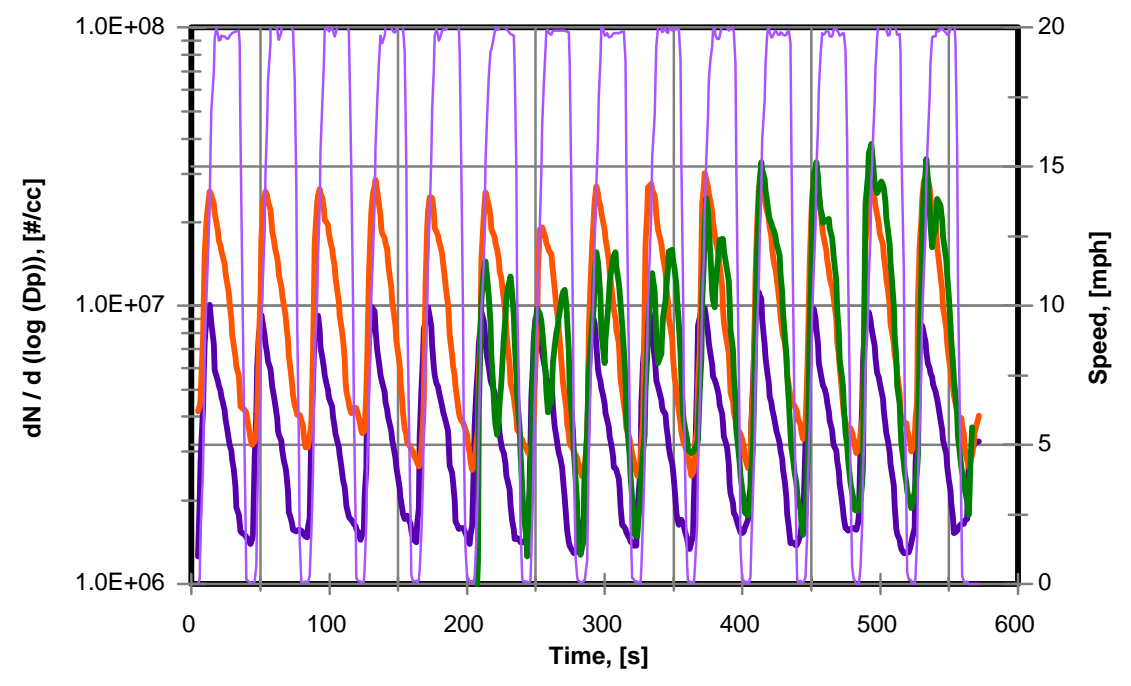

$\longrightarrow 100 \mathrm{~nm} \longrightarrow 150 \mathrm{~nm} \longrightarrow 200 \mathrm{~nm} \longrightarrow$ speed

Figure 3.91 Orion/DDC 6V92, Bus 2029 With OCC, Transient, CBD, Mossgas Synthetic Diesel, DR = 22, Number Concentration, Real Time Tracking

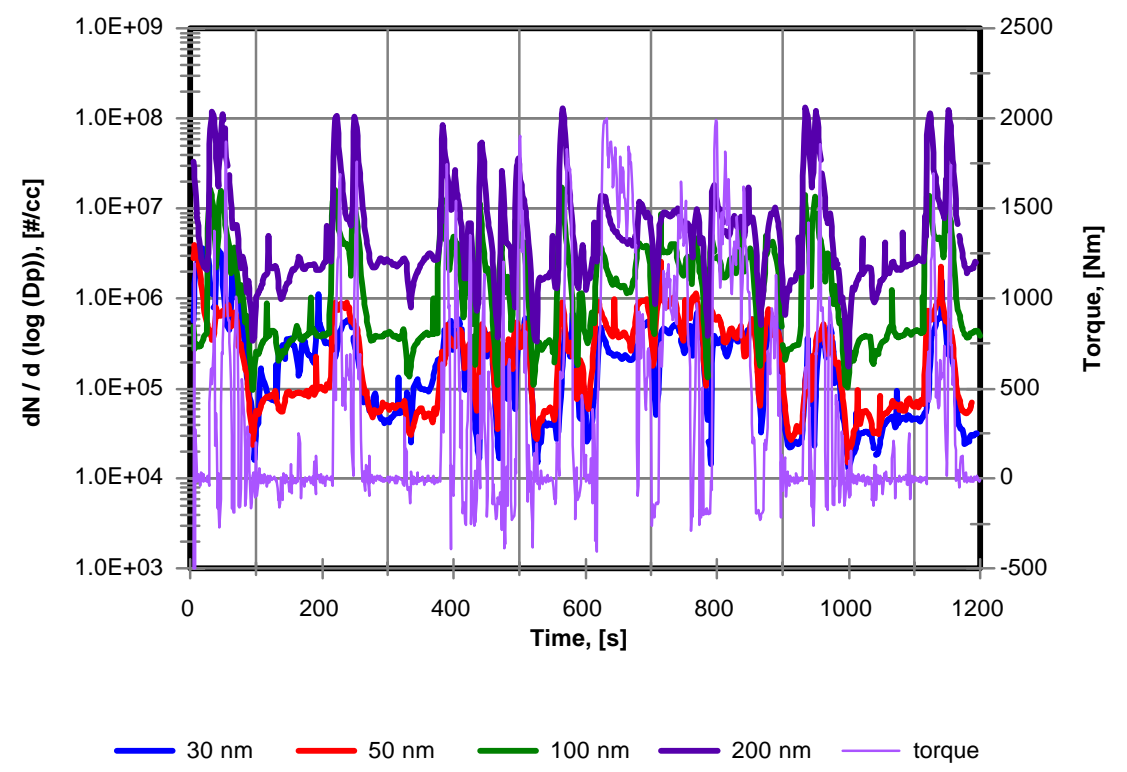

Figure 3.92 Mack E7-400, Transient, FTP, Diesel, DR = 4.3, Count Concentration, Real Time Tracking 


\subsubsection{Mack E7-400 Study}

The "real-time" tracking of the particle concentrations was also performed on the exhaust from Mack E7-400 engine. Measurements were conducted during the hot starts of the FTP cycles (see Figure 3.3). The concentrations of particles with electrical mobility diameters of 30, 50, 100, and $200 \mathrm{~nm}$ were tracked in real time using the SMPS and TSI CPCount software. The time resolved concentrations were plotted along with engine torque in Figure 3.92.

The particles with electrical mobility diameter of $200 \mathrm{~nm}$ exhibited the highest concentrations of all the tracked particles. The peak concentrations were about $10^{8}$ particles per $\mathrm{cm}^{3}$. The concentrations of "30 nm" particles were found to be of similar order of magnitude as the concentrations of "50 nm" particles, ranging from $10^{5}$ to $10^{6}$ particles per $\mathrm{cm}^{3}$. The concentrations of " $100 \mathrm{~nm}$ " particles were higher than the concentrations of "30nm" and "50 nm" but lower than concentrations of "200 nm" particles, ranging from $10^{5}$ to $10^{7}$ particles per $\mathrm{cm}^{3}$. 
Size selective measurements of DPM with MOUDI were conducted in parallel to the SMPS measurements on the exhaust from bus 2034. The MOUDI samples were collected employing partial flow dilution tunnel. The samples of the exhaust were collected from the engine operated with Federal diesel no. 2 and Mossgas synthetic diesel. The engine was driven at steady-state speeds of 20 and $40 \mathrm{mph}$ and over CBD transient cycle. The results of the gravimetric analysis were normalized with respect to total mass collected on all the stages. The results are presented in Figures 3.93 through 3.101. The repeatability of the measurements, which was examined on the results of the analysis performed on the bus exercised over CBD cycle and fueled with the both fuels, was found to be excellent (Figures 3.17 and 3.18). The effects of fuel type on size-resolved PM emissions were examined on the results of measurements performed on the bus operated at $40 \mathrm{mph}$ steady-state speed (Figure 3.96) and over the CBD cycle (Figure 3.97). The lower concentrations and slightly lower MMDs characterized normalized mass emissions when bus was operated with Mossgas synthetic fuel than with Federal diesel no. 2.

The averaged normalized PM emissions collected during CBD cycles were found to be almost identical to those for steady-state 40 mph mode (Figure 3.98 and 3.99). The mass distribution of particles for steady-state $20 \mathrm{mph}$ mode was characterized with larger MMD (150 nm vs.120 nm ) and higher normalized frequencies than those observed for $40 \mathrm{mph}$ mode and CBD cycle (Figure 3.99).

MOUDI vs. SMPS

The results of size selective measurements obtained by simultaneous sampling of the exhaust from the bus 2034 with SMPS and MOUDI were used to perform comparative study on the performance of instruments. The instruments employ two different techniques for size selective measurement. The SMPS classifies particles according to there electrical mobility and provide a number concentration as a function of electrical mobility diameter. The MOUDI does a size classification based on the aerodynamic diameter and gives a mass weighted distribution as function of aerodynamic diameter. The introduction of the assumptions about particle density of $1 \mathrm{~g} / \mathrm{cm}^{3}$ and spherical shape of the particles 
allowed comparison of the results obtained with SMPS and MOUDI. The SMPS volume based data $\left[\mathrm{nm}^{3} / \mathrm{cm}^{3}\right]$ were corrected for assumed density to obtain mass based data $\left[\mathrm{mg} / \mathrm{m}^{3}\right]$, comparable with MOUDI data.

The results of the comparison study are presented in Figures 3.100 through 3.102. It can be concluded that in spite of introduced assumptions and the fact that the instruments employing two different techniques, the results obtained with MOUDI and SMPS were comparable.

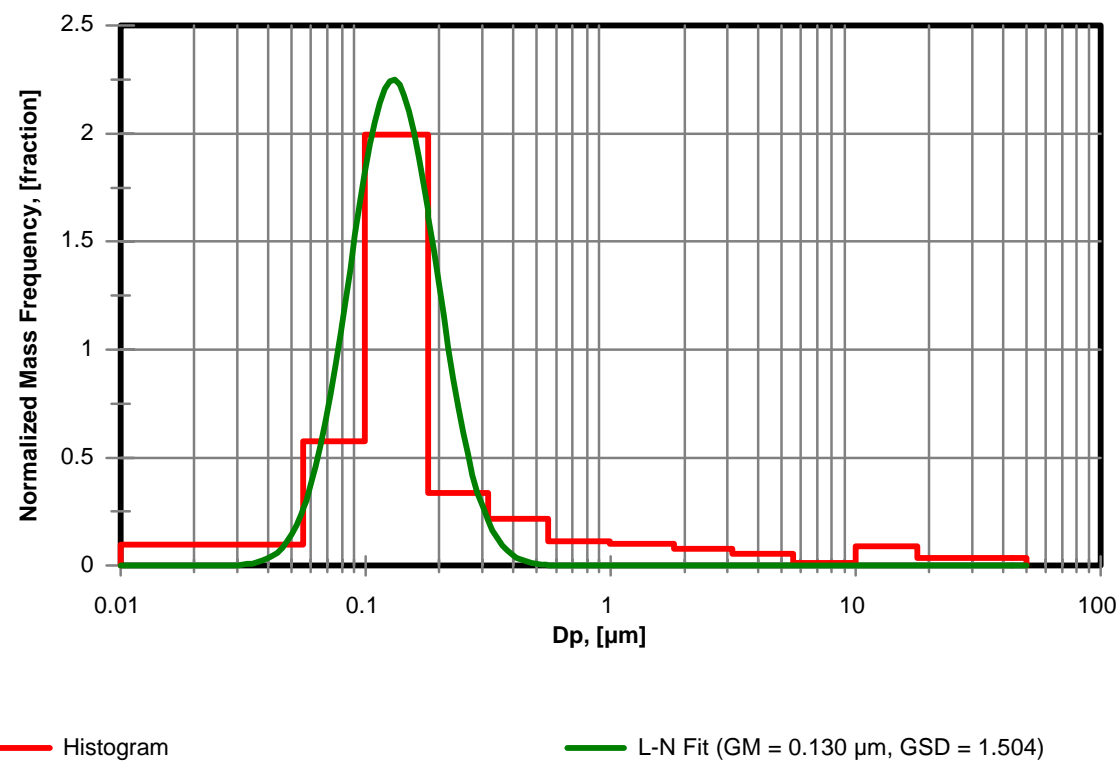

Figure 3.93 Orion/DDC 6V92, Bus 2034 Without OCC, Diesel, MOUDI, Normalized Mass Frequency, Steady-State, $40 \mathrm{mph}$ 


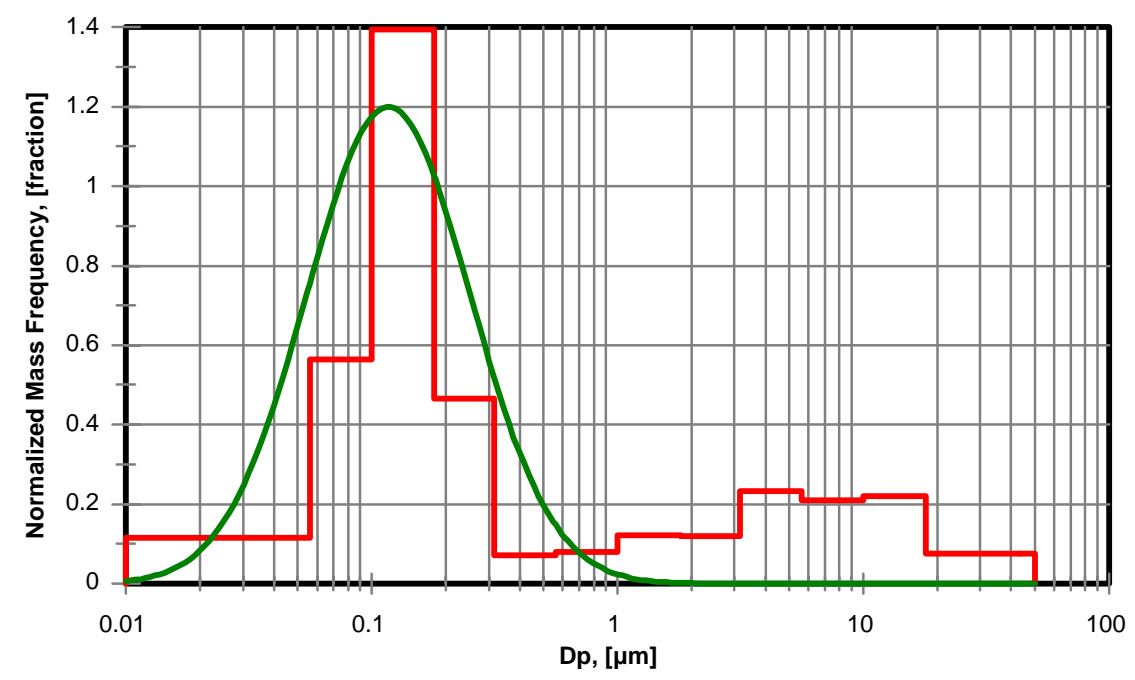

- Histogram

L-N Fit $(\mathrm{GM}=0.117 \mu \mathrm{m}, \mathrm{GSD}=2.149)$

Figure 3.94 Orion/DDC 6V92, Bus 2034 Without OCC, Mossgas Synthetic Diesel, MOUDI, Normalized Mass Frequency, Steady-State, $40 \mathrm{mph}$

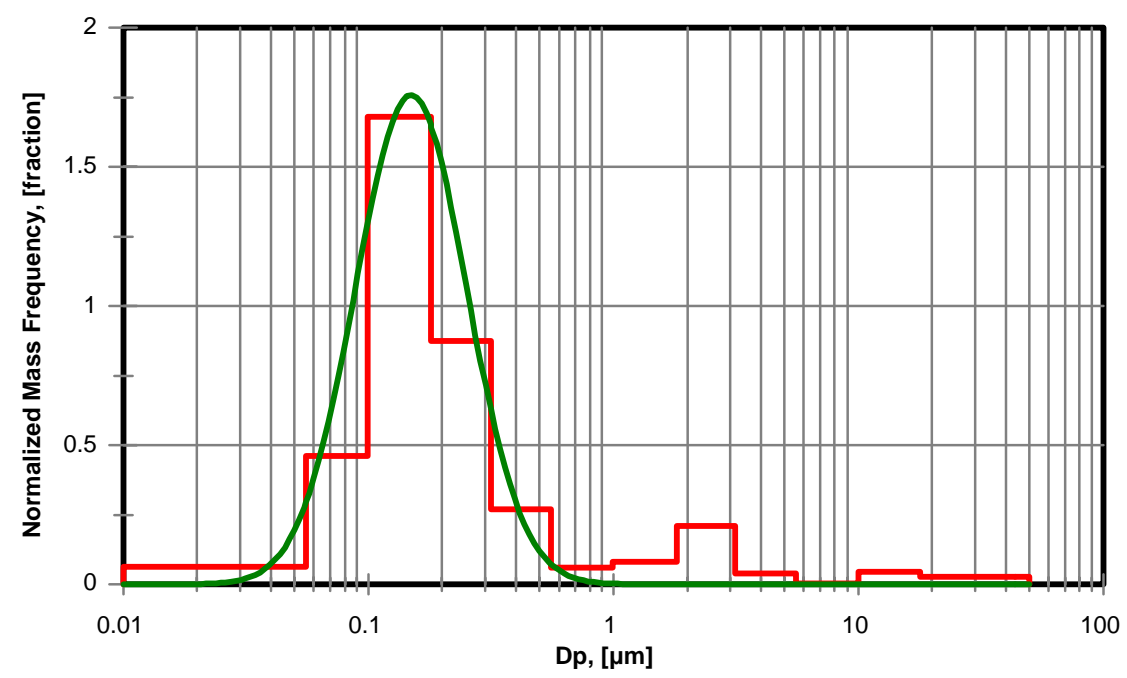

Figure 3.95 Orion/DDC 6V92, Bus 2034 Without OCC, Mossgas Synthetic Diesel, MOUDI, Normalized Mass Frequency, Steady-State, $20 \mathrm{mph}$ 

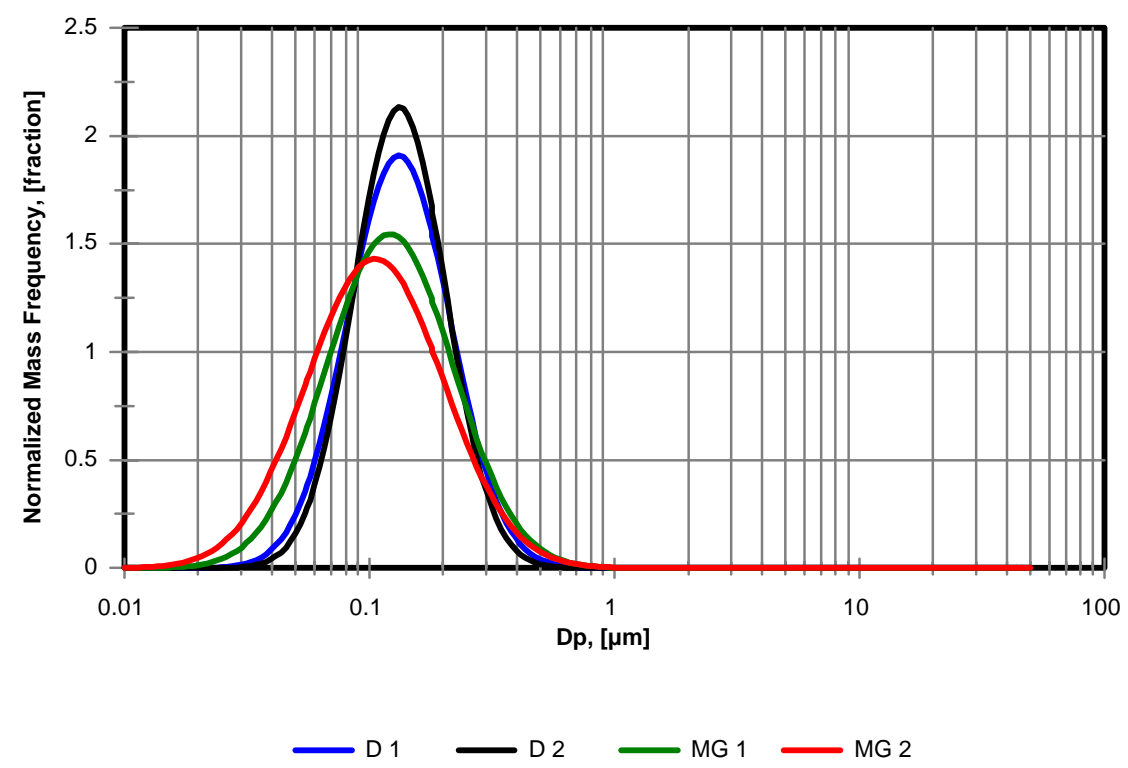

Figure 3.96 Orion/DDC 6V92, Bus 2034 Without OCC, Transient, CBD, MOUDI, Normalized Mass Frequency, Effects of Fuel Type

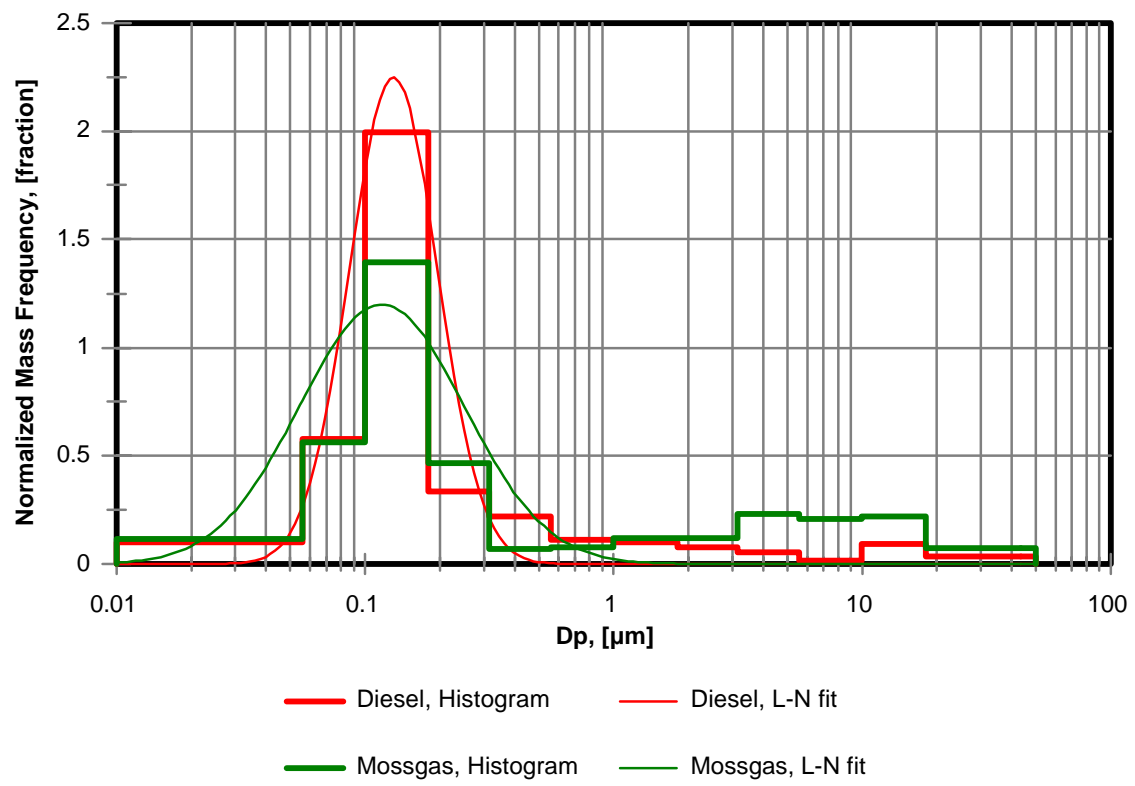

Figure 3.97 Orion/DDC 6V92, Bus 2034 Without OCC, Steady-State, $40 \mathrm{mph}$, MOUDI, Normalized Mass Frequency, Effects of Fuel Type 

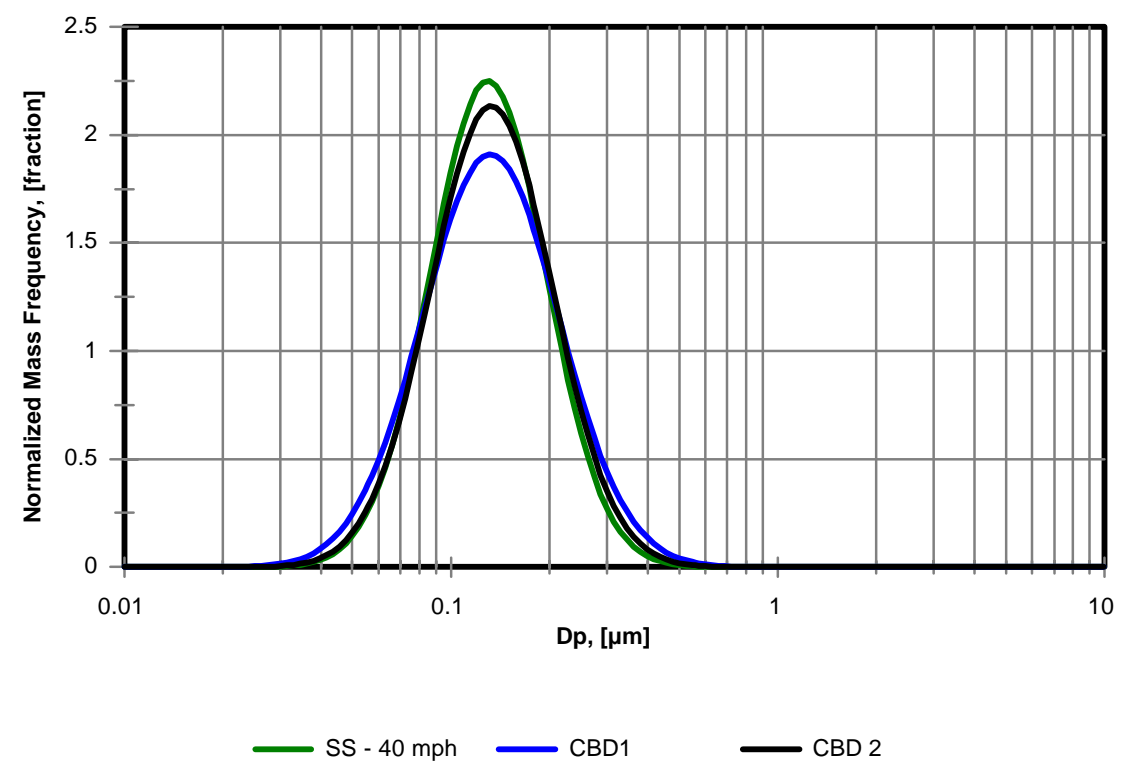

Figure 3.98 Orion/DDC 6V92, Bus 2034 Without OCC, Diesel, MOUDI, Mass Frequency, Effects of Engine Operating Conditions
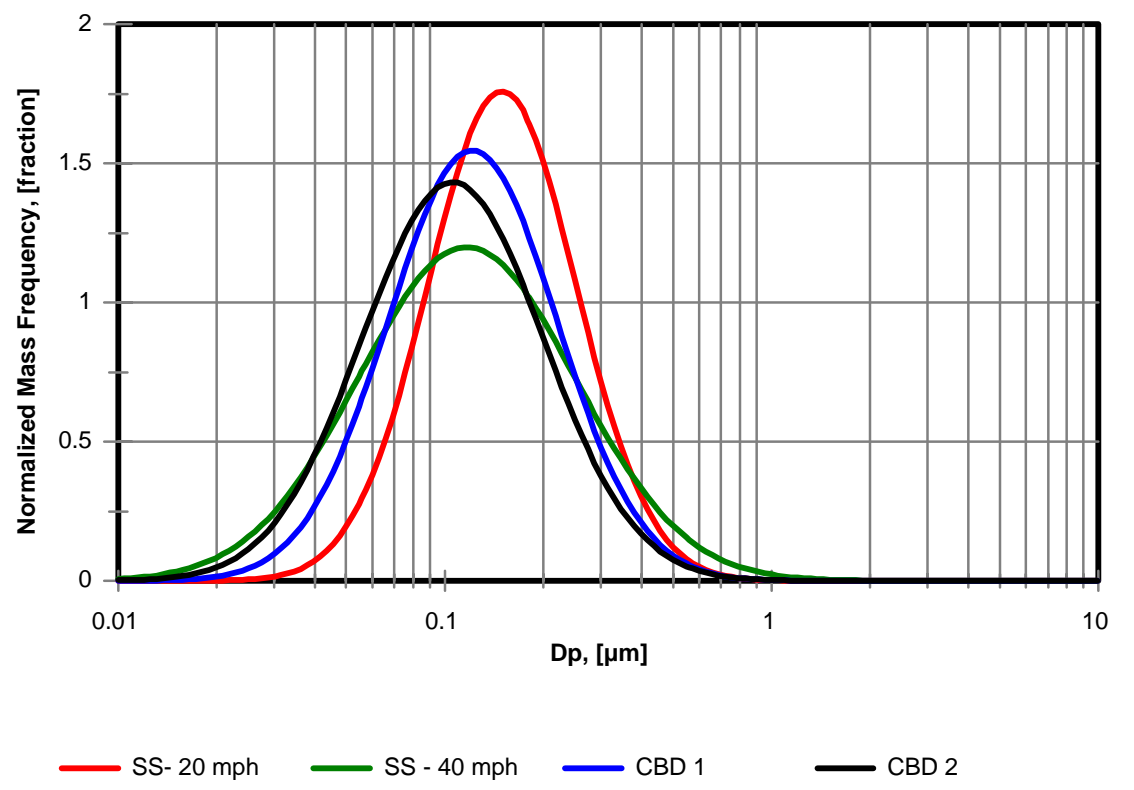

Figure 3.99 Orion/DDC 6V92, Bus 2034 Without OCC, Mossgas Synthetic Diesel, MOUDI, Mass Frequency,

Effects of Engine Operating Conditions 


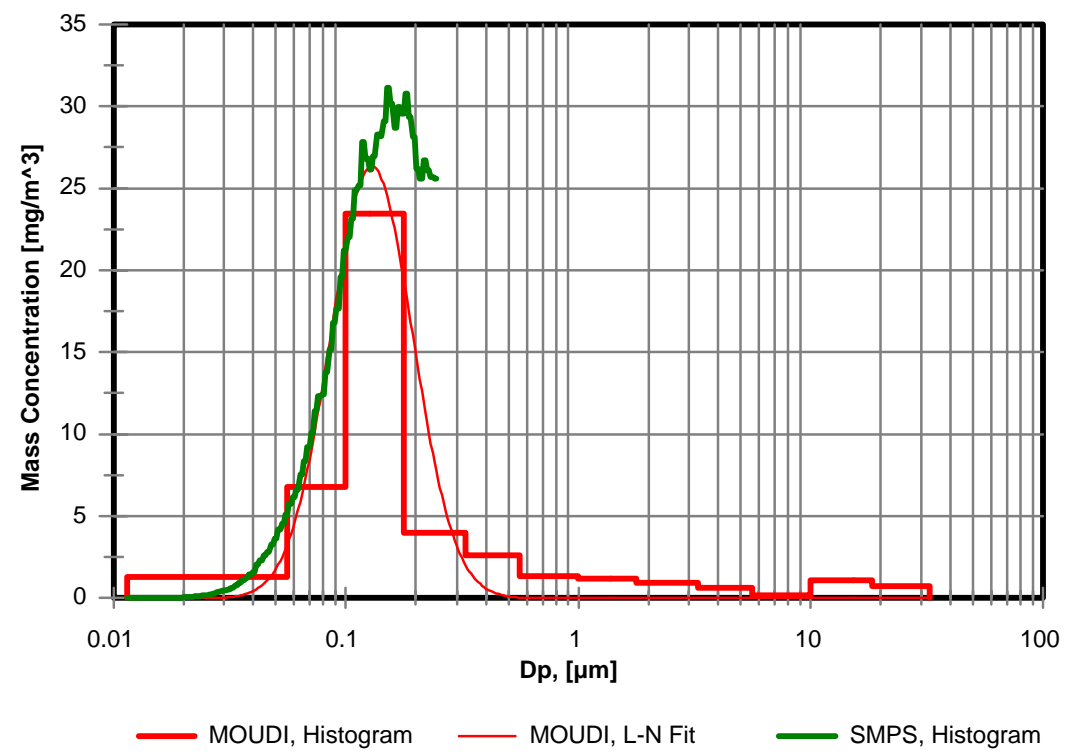

Figure 3.100 Orion/DDC 6V92, Bus 2034 Without OCC, Diesel, 40 mph, Mass Concentrations, MOUDI vs. SMPS

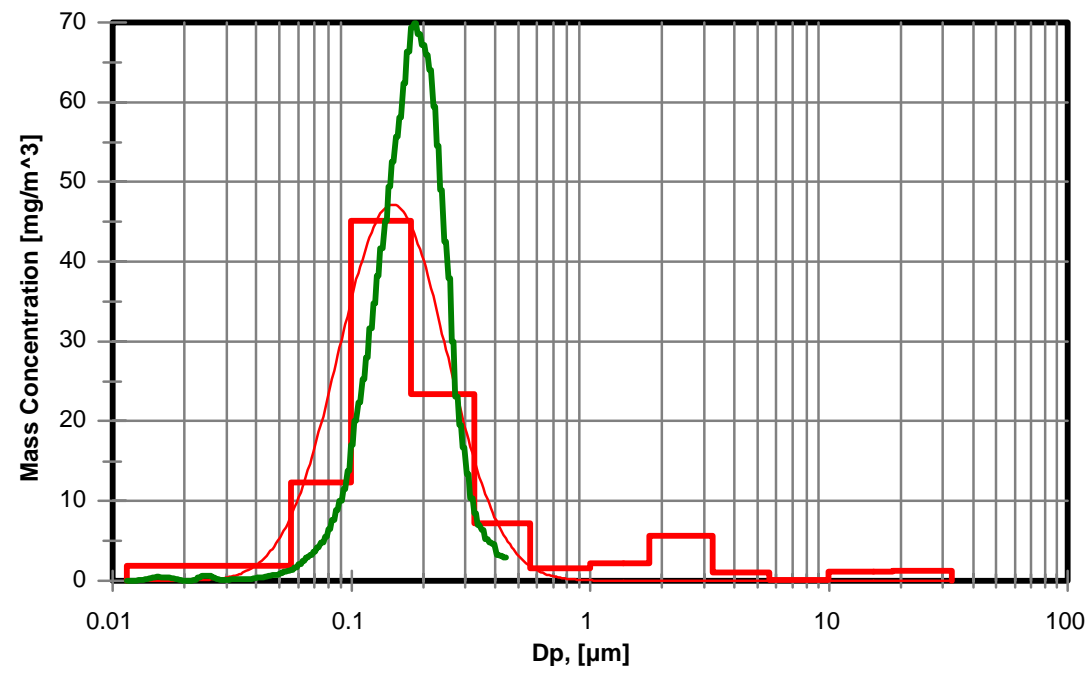

MOUDI, Histogram

MOUDI, L-N Fit

SMPS, Histogram

Figure 3.101 Orion/DDC 6V92, Bus 2034 Without OCC, Mossgas Synthetic Diesel, $20 \mathrm{mph}$, Mass Concentration, MOUDI vs. SMPS 


\subsubsection{Mack E7-400 Study}

The performance of the MOUDI Model 110 was examined on the exhaust of the MackE7-400 engine. Size selective measurements of DPM with MOUDI were conducted in parallel with the SMPS measurements. The samples were collected with both instruments from the same location in the partial flow dilution tunnel. Mack E7 engine operating at the R75, R50, I50 steady-state conditions and over hot starts of FTP cycle. The measurements at each of the selected modes and transient cycle were repeated twice. The results of gravimetric analysis are presented in Figures 3.19 through 3.22, 3.102, and 3.103. The Figures 3.19 through 3.22 show that the repeatability of the measurements was excellent except for the I50 engine operating conditions. The distributions at R75, I50 steady-state conditions and over the FTP cycle were found to have similar MMDs. The MMDs of the PM distributions at $\mathrm{I} 50$ conditions were found to be slightly lower than those for the other test conditions.

MOUDI vs. SMPS

Results from the simultaneous size selective measurements exercised with SMPS and MOUDI were compared. The calculations were based on the assumptions that particles had spherical shape and density of $1 \mathrm{~g} / \mathrm{cm}^{3}$ and of the particles. The SMPS volume based data $\left[\mathrm{nm}^{3} / \mathrm{cm}^{3}\right]$ were corrected for assumed unit density to obtain mass based data $\left[\mathrm{mg} / \mathrm{m}^{3}\right]$, comparable with MOUDI data. The analysis was conducted on the results from the aforementioned steady-state engine operating conditions. The results are presented in Figures 3.104 through 3.109. The selection of the flow rates through the SMPS $\left(Q_{\text {sh }}=20 \mathrm{lpm}\right.$ and $\left.\mathrm{Q}_{\mathrm{m}}=2 \mathrm{lpm}\right)$ limited the upper boundary of the scan range to198 $\mathrm{nm}$. Therefore, shown SMPS mass distributions covered only a portion of much wider distribution that was obtained with a MOUDI. The results obtained with these two completely different instruments appear to be in fairly good agreement. It should be noted that with the assumptions adopted for the purpose of comparison, the instruments and the employed methodology, the results of this analysis should be taken as an academic exercise. Conversion of number concentrations to mass concentrations and vice versa is brought with risk. 

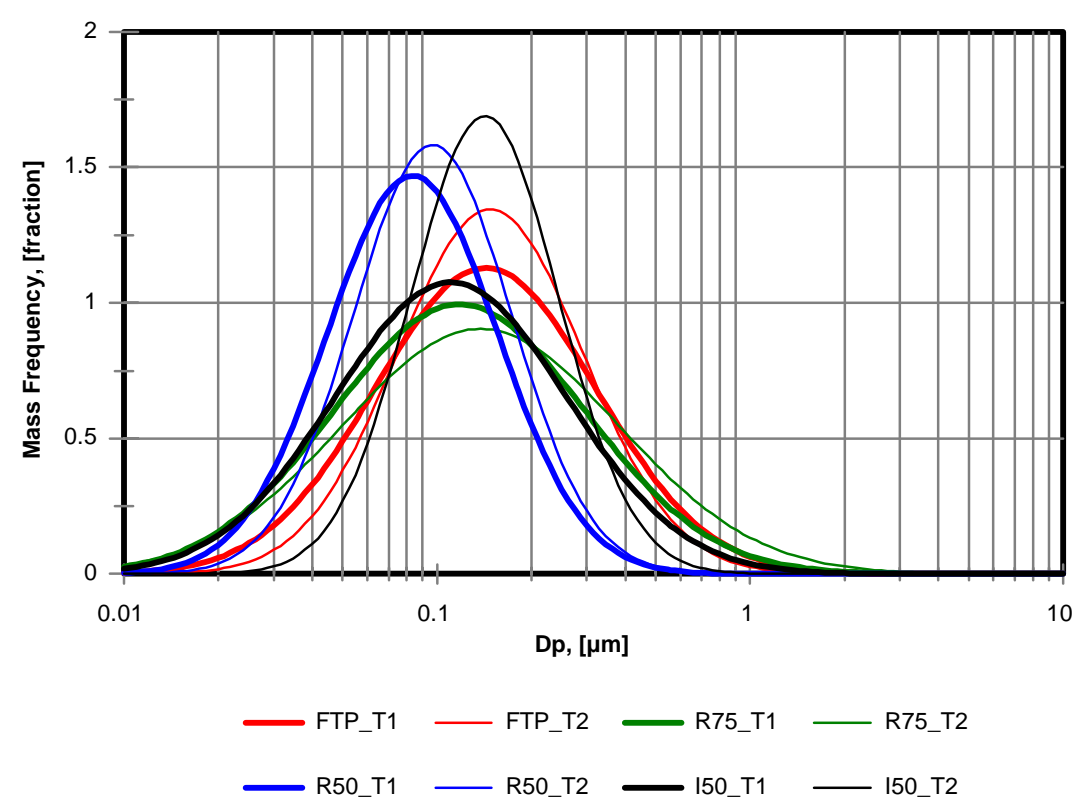

Figure 3.102 Mack E7-400, Diesel, DR = 4.3, MOUDI, Mass Frequency, Effects of Engine Operating Mode

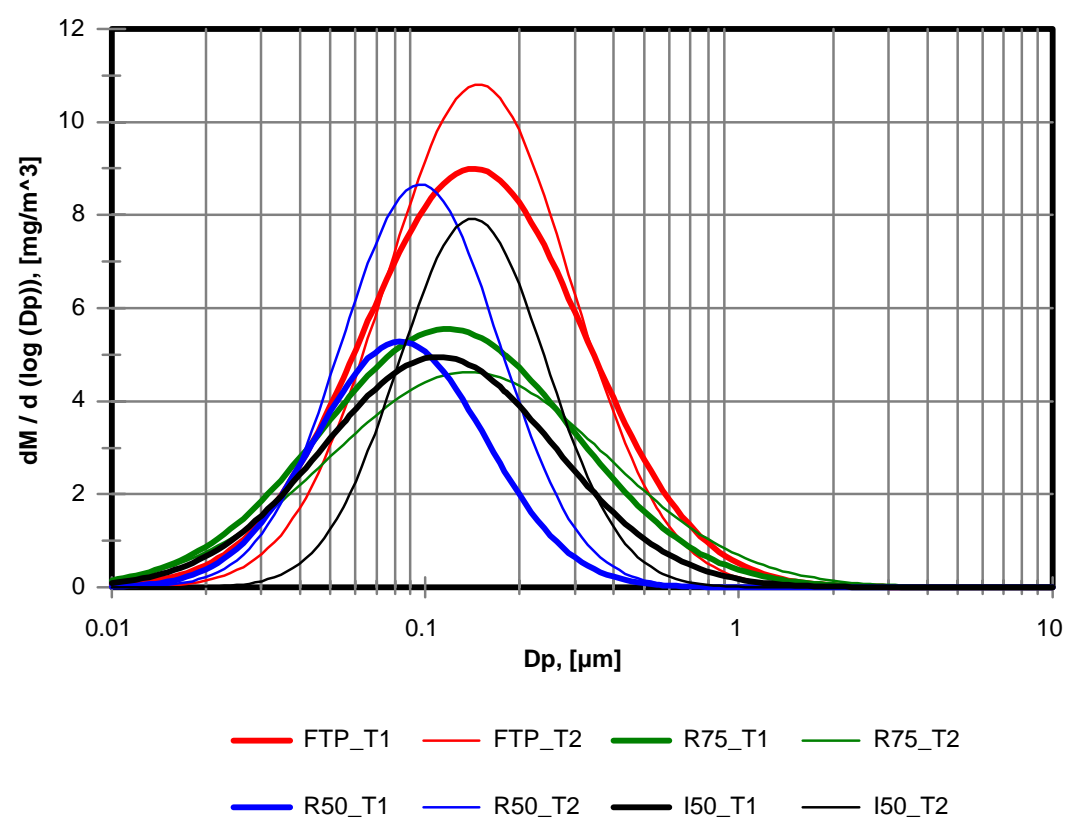

Figure 3.103 Mack E7-400, Diesel, DR = 4.3, MOUDI, Mass Concentration, Effects of Engine Operating Mode 


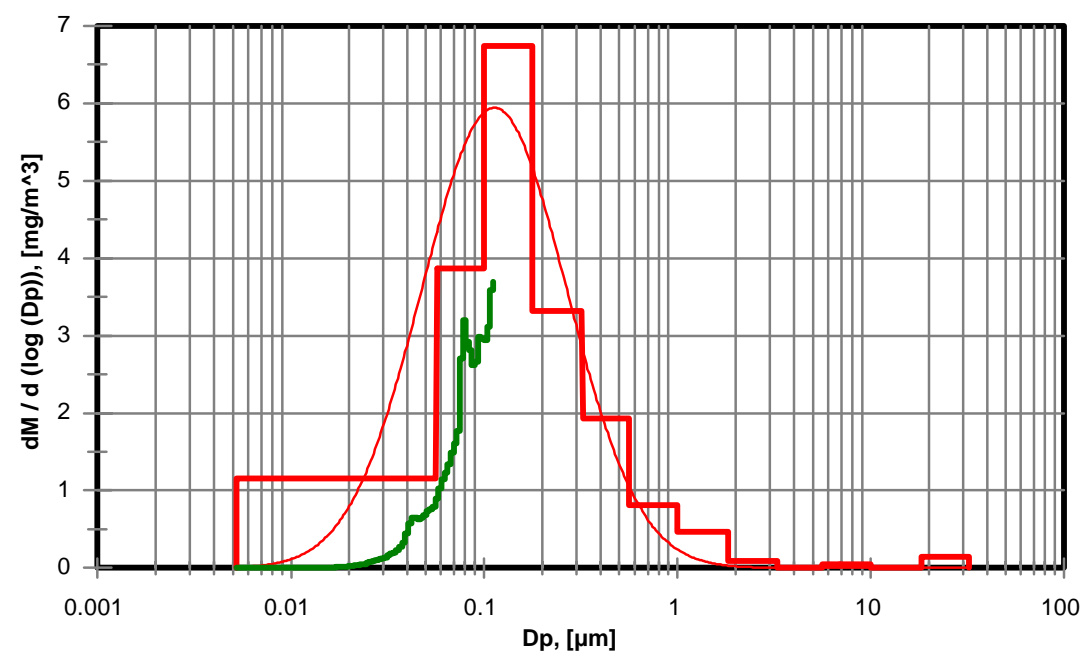

MOUDI, Histogram — MOUDI, L-N Fit _ SMPS, Histogram

Figure 3.104 Mack E7-400, Steady-State, R75, Test 1, Diesel, $\mathrm{DR}=4.3$, Mass Concentrations, MOUDI vs. SMPS

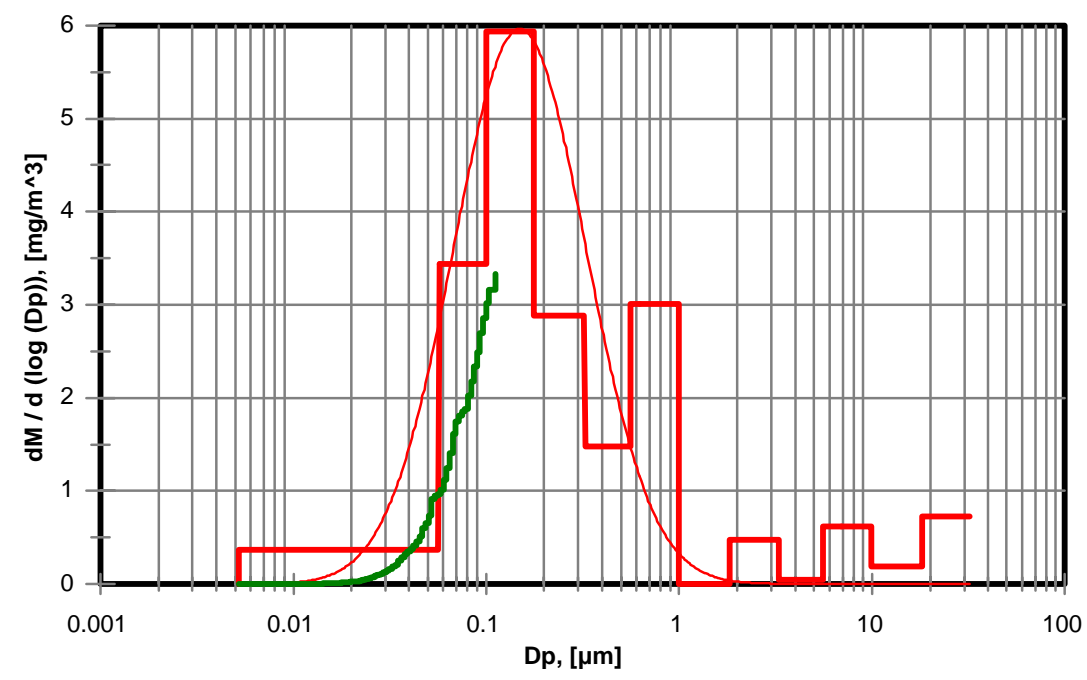

MOUDI, Histogram — MOUDI, L-N Fit _ SMPS, Histogram

Figure 3.105 Mack E7-400, Steady-State, R75, Test 2, Diesel, $\mathrm{DR}=4.3$, Mass Concentrations, MOUDI vs. SMPS 


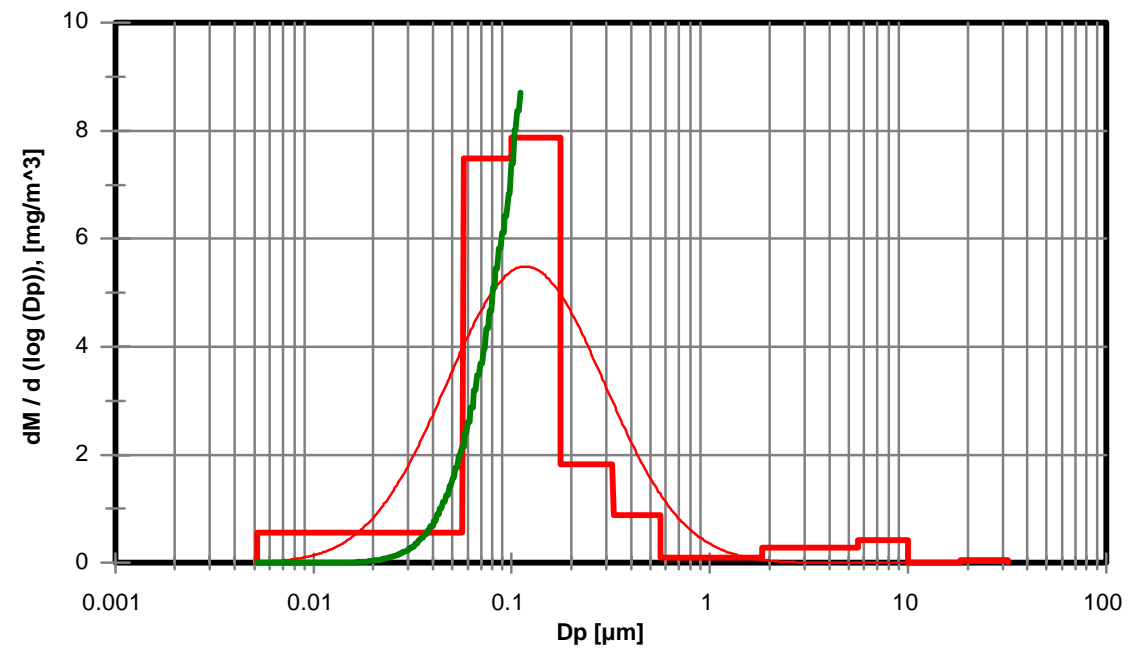

MOUDI, Histogram — MOUDI, L-N Fit $\quad$ SMPS, Histogram

Figure 3.106 Mack E7-400, Steady-State, R50, Test 1, Diesel, $\mathrm{DR}=4.3$, Mass Concentrations, MOUDI vs. SMPS

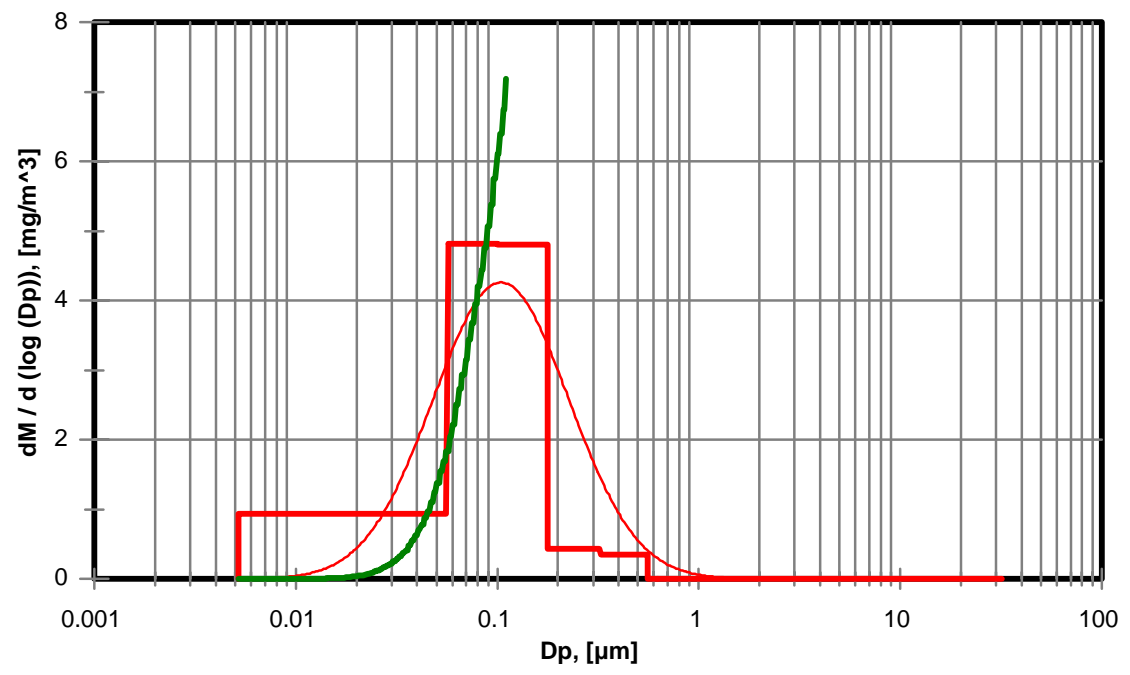

$\longrightarrow$ MOUDI, Histogram — MOUDI, L-N Fit $\quad$ SMPS, Histogram

Figure 3.107 Mack E7-400, Steady-State, R50, Test 2, Diesel, $\mathrm{DR}=4.3$, Mass Concentrations, MOUDI vs. SMPS 


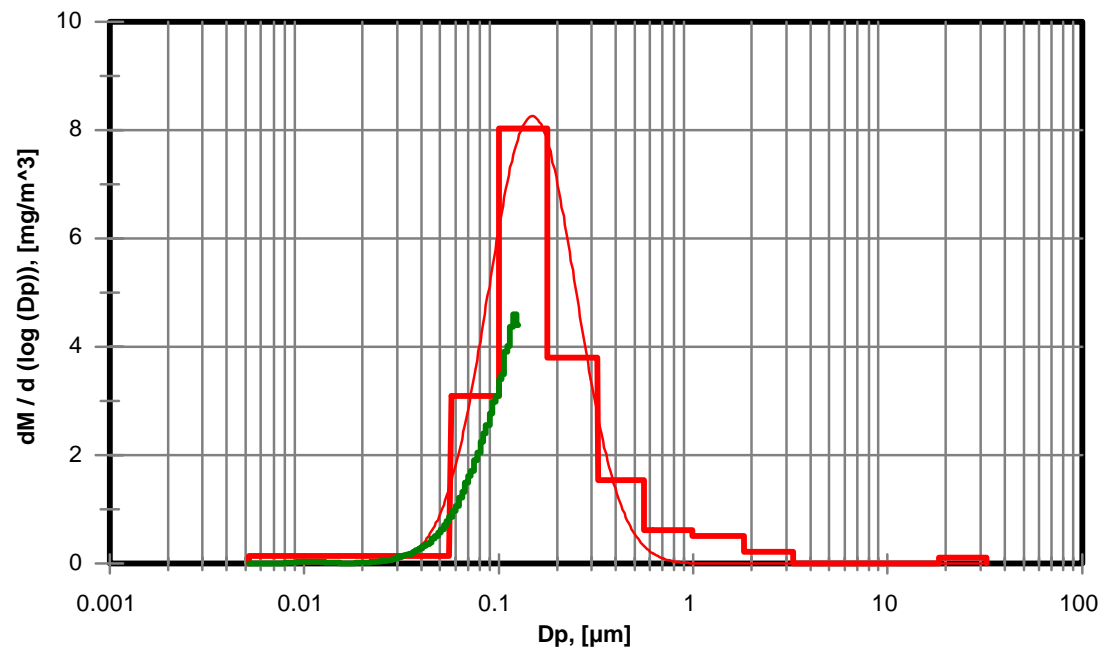

MOUDI, Histogram — MOUDI, L-N Fit $\quad$ SMPS, Histogram

Figure 3.108 Mack E7-400, Steady-State, I50, Test 1, Diesel, $\mathrm{DR}=4.3$, Mass Concentrations, MOUDI vs. SMPS

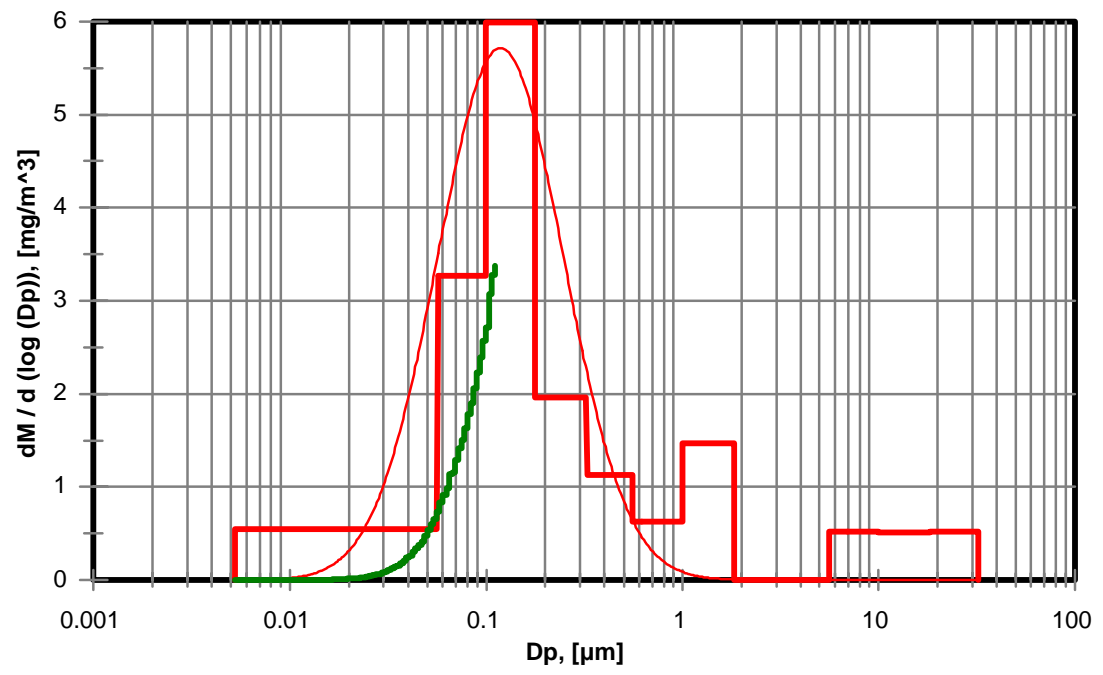

MOUDI, histogram — MOUDI, L-N fit $\quad$ SMPS, histogram

Figure 3.109 Mack E7-400, Steady-State, I50, Test 2, Diesel, DR = 4.3, Mass Concentrations, MOUDI vs. SMPS 
The mass distributions obtained by MOUDI are presented in Figures 3.53 and 3.54. Highest peak mass concentrations were observed for transient conditions (FTP). The mass distributions of the particles in the exhaust for R50 conditions had lowest MMDs and highest concentrations of the steady-state condition modes. The size resolved PM emissions for R50 conditions detected by SMPS were found to be significantly higher than those detected by MOUDI (Figures 3.106 and 3.107). It can be speculate that the volatile fractions detected by SMPS was lost due to evaporation in the substrate conditioning process. 


\subsubsection{Regional Deposition of Diesel Particulate Matter in Man \\ 3.2.11.1 Isuzu C240 Study}

The analysis of the regional deposition of DPM in the human respiratory tract was conducted on the basis of the measurements performed on the exhaust from Isuzu C 240 off-road engine operated at selected steady state conditions (R100, R75, I100, and I50). The regional deposition of particles was studied for different fuel types $\left(1^{\text {st }}\right.$ case $)$, engine operating conditions $\left(2^{\text {nd }}\right.$ case $)$, and aftertreatment processes $\left(3^{\text {rd }}\right.$ case).

\section{The First Case}

The regional deposition of the DPM was examined using the results of the SMPS measurements performed on the untreated exhaust from the Isuzu C240 engine fueled with diesel no. 2 and F-T diesel fuel. The engine was operated at R100, R75, I100, and I50 steady-state conditions. The count based calculations were performed using as input the statistical parameters of the lognormal functions fitted to the count distributions measured with the SMPS. The lognormal mass distribution parameters used in the regional deposition calculations were calculated using Hatch-Choate equation and the statistical parameters for lognormal count distributions.

The results of the analysis for the count distribution parameters are presented in Table B.8. The results of calculations for the mass distribution parameters are presented in Table B.9. The corresponding normalized fractional depositions for different operating conditions and fuel types for the count and mass distributions are plotted in the Figures 3.111 and 3.113, respectively. The number of particles were normalized with respect to the number of particles measured for engine operated at I100 conditions and diesel no. 2 fuel. The masses of particles were normalized with respect to the mass of the particles detected in the exhaust from the engine operated at I100 conditions and fueled with diesel no. 2 fuel.

The particle mass distributions from the F-T diesel fuel engines were characterized with slightly smaller MMDs than the corresponding distributions from the no. 2 diesel fuel engine (see Figure 3.112). The fractional depositions of the particle mass in the alveolar region, estimated on the basis of statistical parameters for mass distributions, were found to be in a fairly narrow range from $17.84 \%$ to 
$21.48 \%$ depending on the fuel type and engine operating conditions (see Table 3.111. Therefore, it may be concluded that the use of F-T diesel resulted in the reduction of PM mass emissions. Despite higher fraction of the particle mass deposited in the alveolar region, F-T synthetic diesel was found to have lower mass depositions in the alveolar region than Federal diesel no.2, regardless of the engine operating mode.

The count based particle distributions for synthetic diesel were found to be characterized with slightly lower CMDs and in the most of the studied cases with higher concentrations than particle distributions observed for diesel no. 2 (see Figure 3.110. The fraction of the particle number deposited in the alveolar region was found to range from 0.216 to 0.333 depending on fuel type and engine operating mode. The higher deposition rates and generally higher total number of emitted particles for synthetic diesel resulted in overall higher number of particles deposited in the alveolar region (see Figure 3.111. Therefore, it may be concluded that the use of the synthetic diesel resulted in higher number of particles emitted and higher number of particles deposited in the alveolar region regardless of the engine operating mode (Figure 3.111) 
Table 3.8 Isuzu C240, Steady State, Engine, Particle Number, Diesel No. 2 and Synthetic Diesel, Regional Deposition of DPM in Man, Effects of Fuel Type and Engine Operating Conditions

\begin{tabular}{|c|c|c|c|c|c|c|c|c|}
\hline Fuel & Diesel & Diesel & Diesel & Diesel & $\begin{array}{l}\text { Syn. } \\
\text { Diesel }\end{array}$ & $\begin{array}{l}\text { Syn. } \\
\text { Diesel }\end{array}$ & $\begin{array}{c}\text { Syn. } \\
\text { Diesel }\end{array}$ & $\begin{array}{l}\text { Syn. } \\
\text { Diesel }\end{array}$ \\
\hline $\begin{array}{l}\text { Engine Operating } \\
\text { Mode }\end{array}$ & R100 & R75 & I100 & $\mathrm{I} 50$ & R100 & R75 & I100 & I50 \\
\hline $\mathrm{GM},[\mathrm{nm}]$ & 97.559 & 106.133 & 161.294 & 79.561 & 77.379 & 77.871 & 130.338 & 72.092 \\
\hline$\sigma_{\mathrm{g}}$ & 1.709 & 1.680 & 1.624 & 1.712 & 1.713 & 1.736 & 1.629 & 1.702 \\
\hline $\begin{array}{l}\text { Total Particle Number } \\
(\mathrm{TPN}),\left[\# / \mathrm{cm}^{3}\right]\end{array}$ & 678080 & 441120 & 114640 & 310700 & 700310 & 749440 & 113900 & 514470 \\
\hline $\begin{array}{l}\text { Total Deposit, } \\
\text { [fraction] }\end{array}$ & 0.3650 & 0.3461 & 0.2718 & 0.4115 & 0.4183 & 0.4175 & 0.3049 & 0.4354 \\
\hline $\begin{array}{l}\text { Nasal Deposit, } \\
\text { [fraction] }\end{array}$ & 0.0076 & 0.0074 & 0.0086 & 0.0082 & 0.0084 & 0.0085 & 0.0074 & 0.0087 \\
\hline $\begin{array}{l}\text { Head Deposit, } \\
\text { [fraction] }\end{array}$ & $1.52 \mathrm{e}-5$ & $1.82 \mathrm{e}-6$ & $6.14 \mathrm{e}-6$ & $7.72 \mathrm{e}-7$ & $7.06 \mathrm{e}-7$ & $7.83 \mathrm{e}-7$ & $3.06 \mathrm{e}-6$ & $5.34 \mathrm{e}-7$ \\
\hline Total Lung, [fraction] & 0.3574 & 0.3388 & 0.2633 & 0.4033 & 0.4099 & 0.4091 & 0.2976 & 0.4267 \\
\hline $\begin{array}{l}\text { Tracheobronchial, } \\
\text { [fraction] }\end{array}$ & 0.0725 & 0.672 & 0.0472 & 0.0861 & 0.0882 & 0.0882 & 0.0561 & 0.0934 \\
\hline $\begin{array}{l}\text { Alveolar Region, } \\
\text { [fraction] }\end{array}$ & 0.2849 & 0.2716 & 0.2161 & 0.3172 & 0.3217 & 0.3209 & 0.2415 & 0.3333 \\
\hline $\begin{array}{l}\text { TPN in Alveolar } \\
\text { Region, }\left[\# / \mathrm{cm}^{3}\right]\end{array}$ & 193186 & 119806 & 247707 & 98551 & 225312 & 240497 & 275034 & 171473 \\
\hline $\begin{array}{l}\text { Normalized TPN, } \\
\text { [fraction] }\end{array}$ & 0.591 & 0.385 & 1.000 & 0.271 & 0.611 & 0.654 & 0.993 & 0.449 \\
\hline $\begin{array}{l}\text { Normalized TPN in } \\
\text { Alveolar Region, } \\
\text { [fraction] }\end{array}$ & 0.169 & 0.105 & 0.216 & 0.086 & 0.197 & 0.210 & 0.240 & 0.150 \\
\hline
\end{tabular}


Table 3.9 Isuzu C240, Steady State, Engine, Particle Mass, Diesel No. 2 and Synthetic Diesel, Regional Deposition of DPM in Man, Effects of Fuel Type and Engine Operating Conditions

\begin{tabular}{|c|c|c|c|c|c|c|c|c|}
\hline Fuel & Diesel & Diesel & Diesel & Diesel & $\begin{array}{l}\text { Syn. } \\
\text { Diesel }\end{array}$ & $\begin{array}{c}\text { Syn. } \\
\text { Diesel }\end{array}$ & $\begin{array}{c}\text { Syn. } \\
\text { Diesel }\end{array}$ & $\begin{array}{l}\text { Syn. } \\
\text { Diesel }\end{array}$ \\
\hline $\begin{array}{l}\text { Engine Operating } \\
\text { Mode }\end{array}$ & R100 & R75 & I100 & $\mathrm{I} 50$ & R100 & R75 & I100 & I50 \\
\hline GMM, [nm] & 230.915 & 237.967 & 326.552 & 189.382 & 184.536 & 193.989 & 266.258 & 168.408 \\
\hline$\sigma_{g}$ & 1.709 & 1.680 & 1.624 & 1.712 & 1.713 & 1.736 & 1.629 & 1.702 \\
\hline $\begin{array}{l}\text { Total Particle Mass } \\
(\mathrm{TPM}),[\mu \mathrm{g}]\end{array}$ & 1200 & 927 & 7260 & 301 & 626 & 729 & 3860 & 360 \\
\hline $\begin{array}{l}\text { Total Deposit, } \\
\text { [fraction] }\end{array}$ & 0.2432 & 0.2395 & 0.2324 & 0.2586 & 0.2613 & 0.2579 & 0.2317 & 0.2709 \\
\hline $\begin{array}{l}\text { Nasal Deposit, } \\
\text { [fraction] }\end{array}$ & 0.0154 & 0.0156 & 0.0256 & 0.0114 & 0.0110 & 0.0121 & 0.0179 & 0.0097 \\
\hline $\begin{array}{l}\text { Head Deposit, } \\
\text { [fraction] }\end{array}$ & $2.65 \mathrm{e}-5$ & $2.67 \mathrm{e}-5$ & $6.24 \mathrm{e}-5$ & $1.40 \mathrm{e}-5$ & $1.29 \mathrm{e}-5$ & $1.64 \mathrm{e}-5$ & $3.27 e-5$ & $9.2 \mathrm{e}-6$ \\
\hline Total Lung, [fraction] & 0.2278 & 0.2238 & 0.2067 & 0.2471 & 0.2502 & 0.2458 & 0.2137 & 0.2612 \\
\hline $\begin{array}{l}\text { Tracheobronchial, } \\
\text { [fraction] }\end{array}$ & 0.0366 & 0.0355 & 0.0283 & 0.0425 & 0.0433 & 0.0419 & 0.0324 & 0.0464 \\
\hline $\begin{array}{l}\text { Alveolar Region, } \\
\text { [fraction] }\end{array}$ & 0.1912 & 0.1883 & 0.1784 & 0.2047 & 0.2069 & 0.2038 & 0.1813 & 0.2148 \\
\hline $\begin{array}{l}\text { TPM in Alveolar } \\
\text { Region, }\left[\mu \mathrm{g} / \mathrm{m}^{3}\right]\end{array}$ & 230.0 & 175.0 & 1290.0 & 61.6 & 129.0 & 148.0 & 699.0 & 77.4 \\
\hline $\begin{array}{l}\text { Normalized TPM, } \\
\text { [fraction] }\end{array}$ & 0.165 & 0.128 & 1.000 & 0.041 & 0.086 & 0.100 & 0.531 & 0.050 \\
\hline $\begin{array}{l}\text { Normalized TPM in } \\
\text { Alveolar Region, } \\
\text { [fraction] }\end{array}$ & 0.032 & 0.024 & 0.178 & 0.008 & 0.018 & 0.020 & 0.096 & 0.011 \\
\hline
\end{tabular}




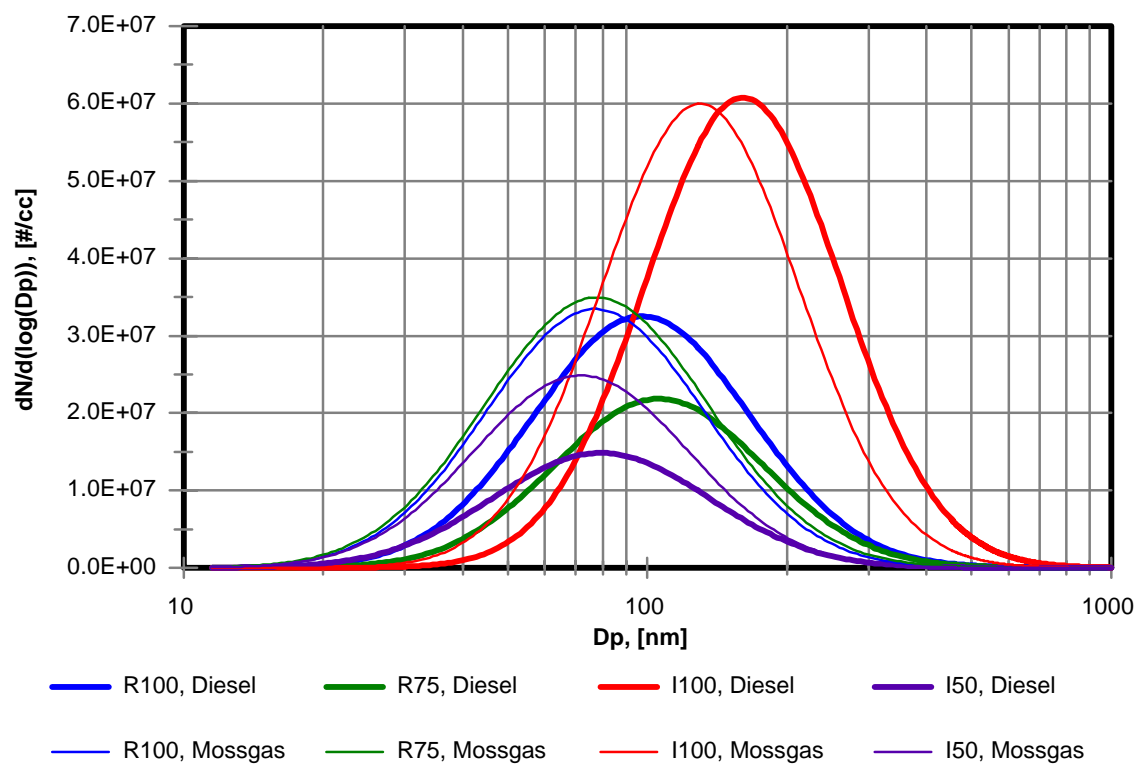

Figure 3.110 Isuzu C240, Steady-State, Engine, DR = 28, Number Concentration, Regional Deposition of DPM in Man, Effects of Fuel Type

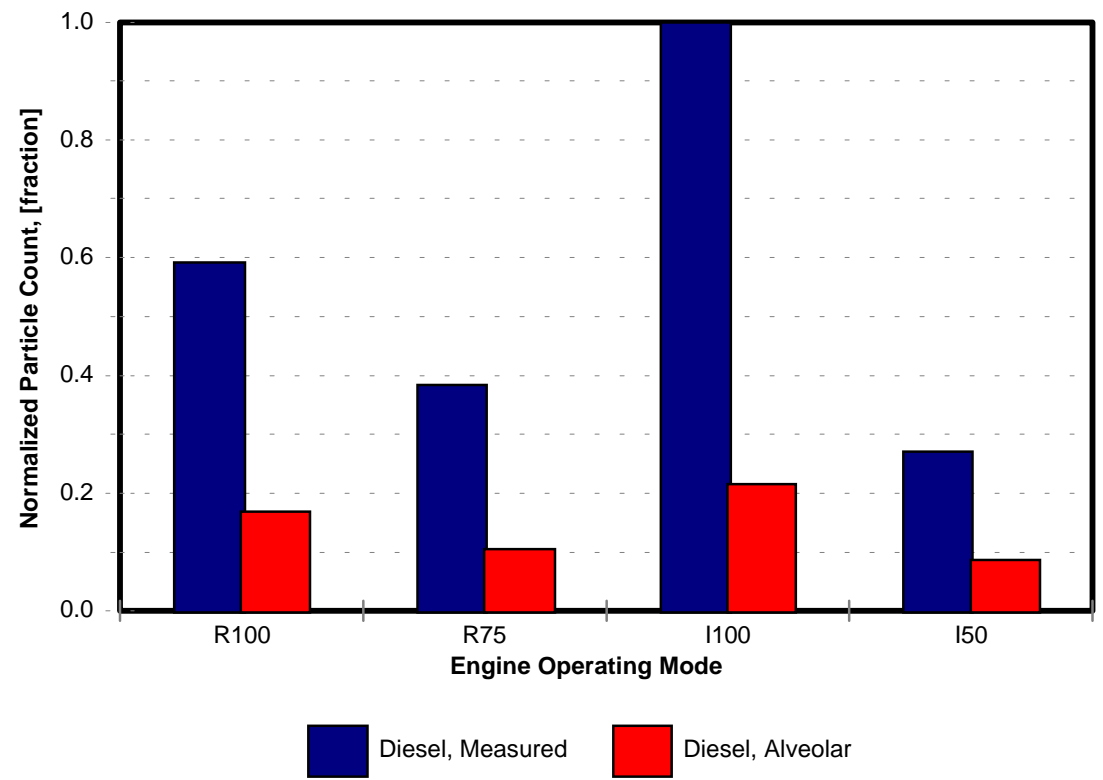

Figure3.115 Isuzu C240, Steady-State, Engine, DR = 28, Normalized Particle Number, Regional Deposition of DPM in Man, Effects of Engine Operating Conditions 


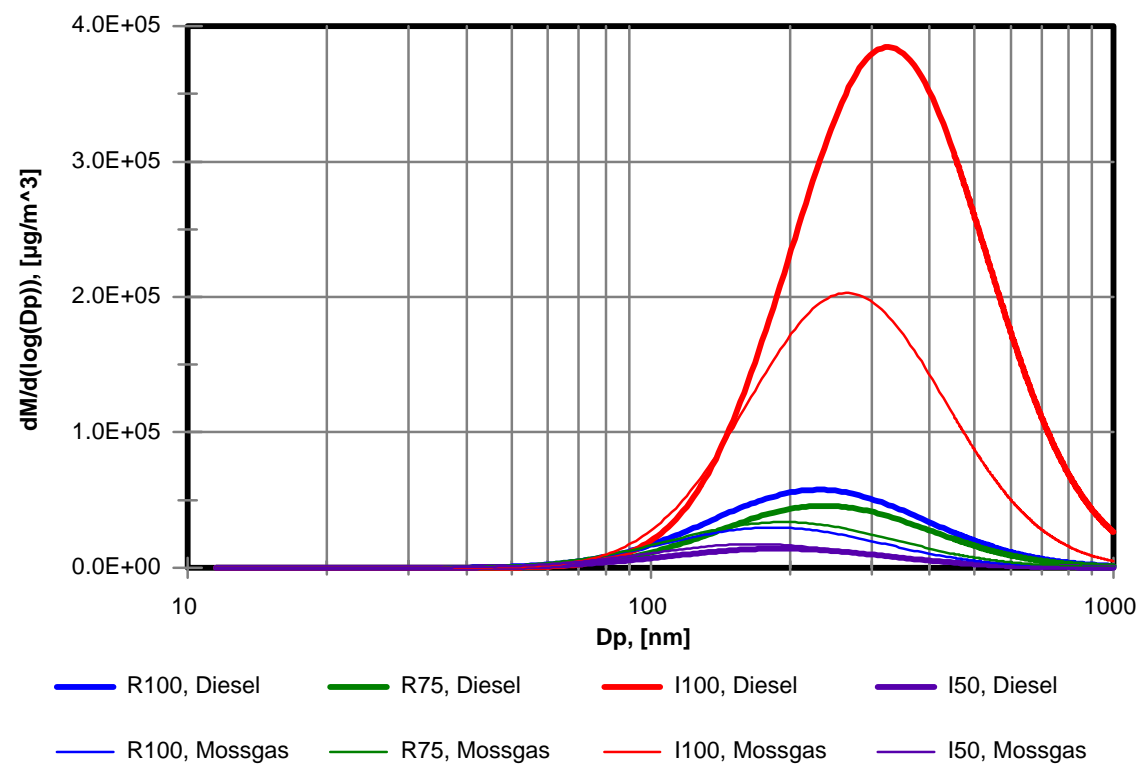

Figure 3.112 Isuzu C240, Steady-State, Engine, DR = 28, Mass

Concentration, Regional Deposition of DPM in Man, Effects of Fuel Formulation
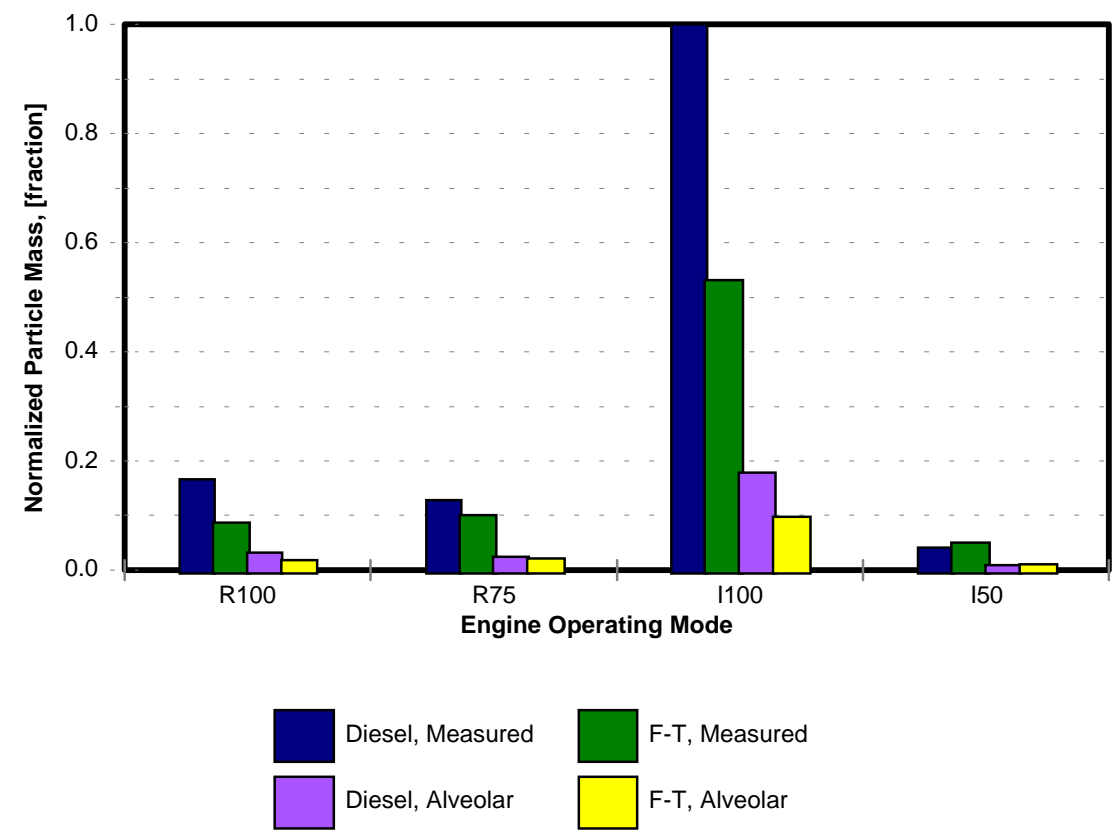

Figure 3.113 Isuzu C240, Steady-State, Engine, DR = 28, Normalized Particle Mass, Regional Deposition of DPM in Man, Effects of Fuel Formulation 


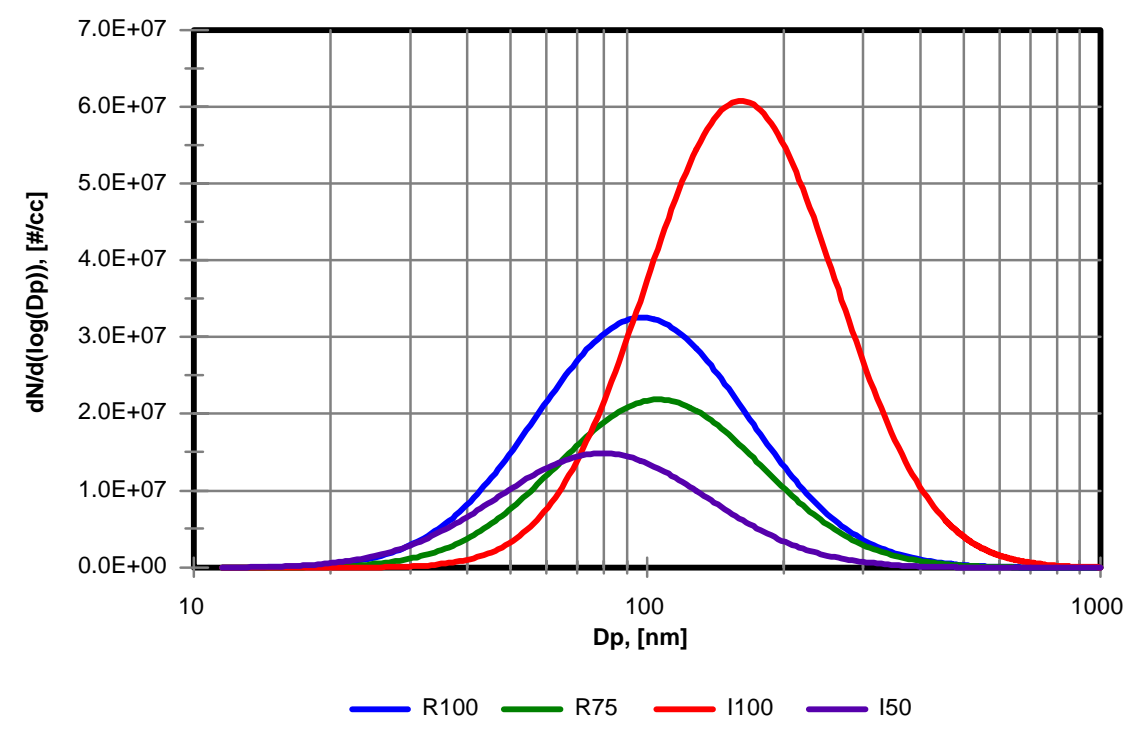

Figure 3.114 Isuzu C240, Steady-State, Engine, DR = 28, Number Concentration, Regional Deposition of DPM in Man, Effects of Engine Operating Conditions

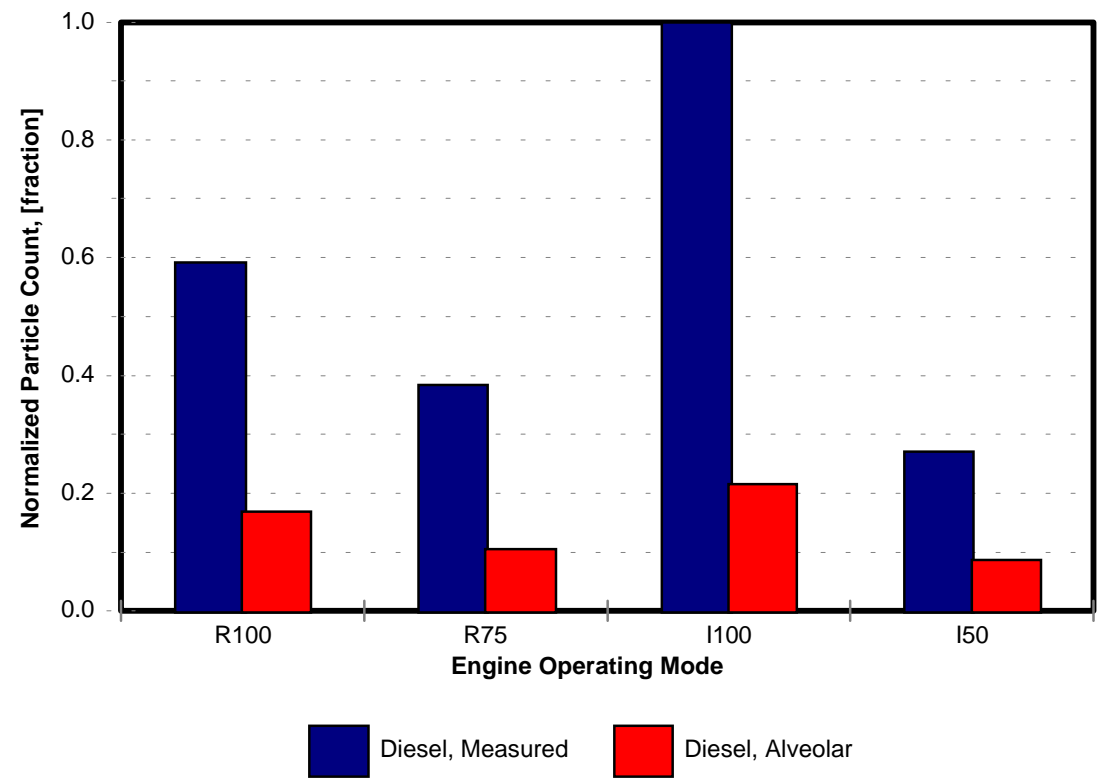

Figure3.115 Isuzu C240, Steady-State, Engine, DR = 28, Normalized Particle Number, Regional Deposition of DPM in Man, Effects of Engine Operating Conditions 


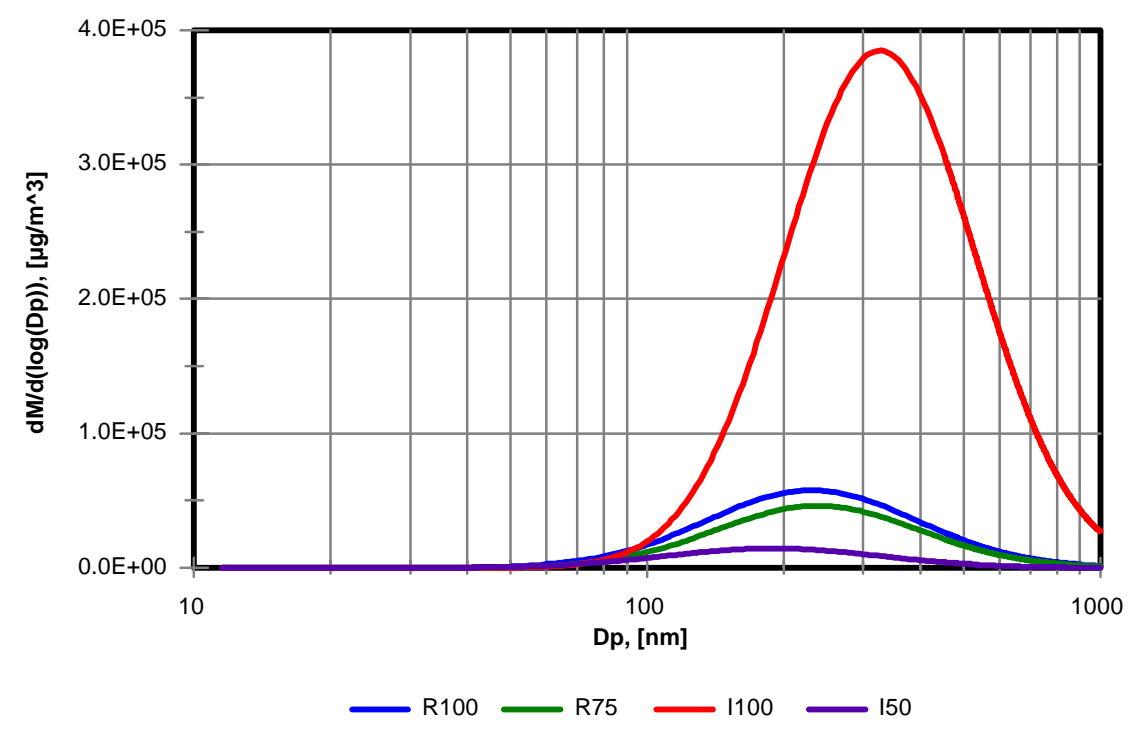

Figure 3.116 Isuzu C240, Steady-State, Engine, DR = 28, Mass Concentration, Regional Deposition of DPM in Man, Effects of Engine Operating Conditions

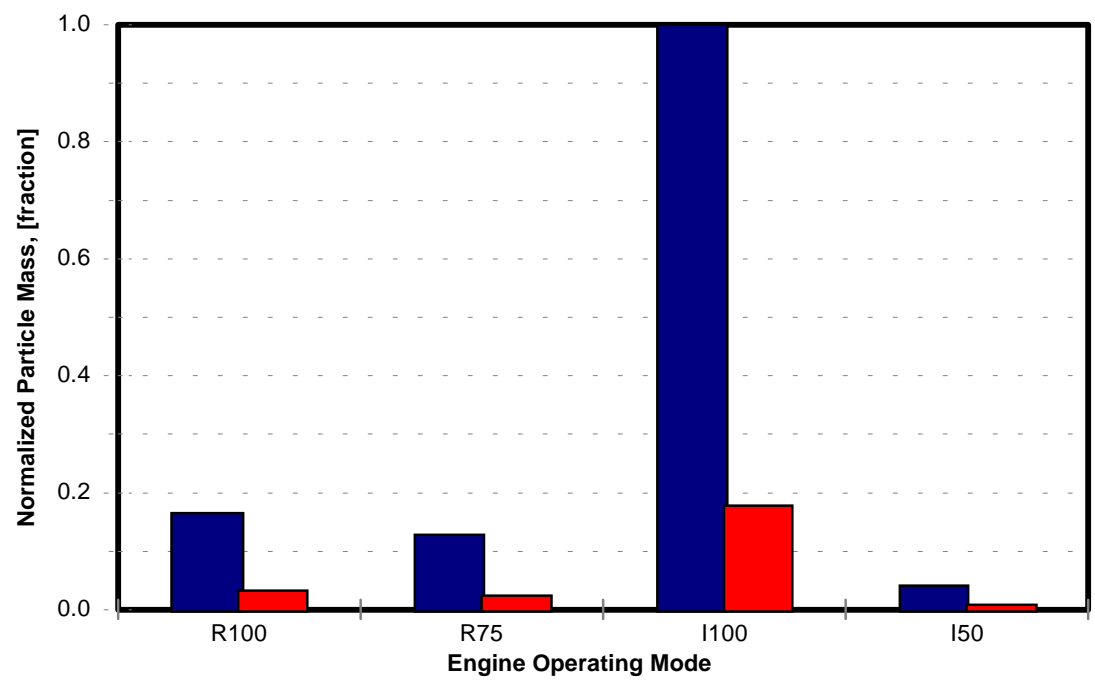

Diesel, Measured Diesel, Alveolar

Figure 3.117 Isuzu C240, Steady-State, Engine, DR = 28, Normalized Particle Mass, Regional Deposition of DPM in Man, Effects of Engine Operating Conditions 


\section{The Second Case}

The effects of Isuzu C240 engine operating conditions on the regional deposition of the DPM were studied more closely. SMPS data collected form the untreated exhaust from the Isuzu C240 engine fueled with diesel no. 2 and operated at R100, R75, I100, and I50 steady-state conditions were investigated. The results of the analysis are presented in the Tables 3.8 and 3.9.

Close examination of the results revealed slight differences in the fraction of particle mass deposited in the alveolar region for the observed cases (see Table 3.9). Consequently, the fractions of particle mass deposited in the alveolar region were found to be proportional to the total particle mass emitted (Figure 3.116and 3.117. Interestingly, the fractional depositions, on the particle count basis, were found to be much lower for I100 than for R100, R75, and I50 engine operating conditions. Number of particles deposited in the alveolar region for mode R100 was found to be almost as high as that for the I100 mode despite of a much lower total particle number emitted for mode R100 (see Table 3.8 and Figure 3.115). The fraction of the total number of particle deposited in the alveolar region was found to be highest for I50 engine operating conditions. In spite of that, the total number of particles deposited in the alveolar region was found to be lowest for I50 conditions.

\section{The Third Case}

The regional deposition of DPM in man was also estimated for the exhaust which was treated with several combinations of after-treatment devices. The emissions from diesel no. 2 fueled engine and operated at R75 conditions were examined. The results were normalized with respect to the total particle count and mass for the bare engine case.

The CMDs and MMDs for the particle distributions measured in the treated exhausts were found to be significantly smaller in comparison to those for the particle distribution observed for the untreated exhaust (see Figure 3.118 and 3.120). Figure 3.121 shows that the total particle mass was a considerably higher in the untreated than in the treated exhaust. The observed count distributions of the particles treated in the OCC/trap and OCC/trap/paper filter systems were characterized with higher concentrations of the nanoparticles and ultrafine particles (see Figure 3.118). However these particles, even in large concentrations, did not contribute significantly to the total particle mass (see Figure 3.120). 
The percentages of the particle mass deposited in alveolar regions ranged from $18.8 \%$ for the untreated exhaust to $34.5 \%$ for the exhaust treated in the OCC/trap system (see Table 3.11). The analysis showed that mass of the particles detected in the exhaust as well as mass of particles deposited in the alveolar region were substantially reduced for the cases when the exhaust was treated in the tested devices.

On the contrary, the number of the particles deposited in the alveolar region for the cases where the exhaust was treated with the OCC/trap $(\mathrm{C}+\mathrm{T})$ and $\mathrm{OCC} /$ trap/paper fiter $(\mathrm{C}+\mathrm{T}+\mathrm{P})$ was found to be higher than the number of particles deposited in the alveolar region for the case of bare engine. Should be noted that the total number of particles detected in the bare engine exhaust was much larger (see Figure 3.119). The total numbers of particles deposited in the alveolar region were found to be rather high for the cases of the paper filter and the trap. However, the total number of the particles that penetrated through these exhaust after-treatment devices was fairly small. Hence, these devices could be considered to be effective in the reducing the number and mass of the particle deposited in the alveolar region 
Table 3.10 Isuzu C240, Steady State, R75, Effects of After-Treatment Process, Particle Number, Diesel, Regional Deposition of DPM in Man,

\begin{tabular}{|l|r|r|r|r|r||}
\hline \hline After Treatment Process & \multicolumn{1}{|c|}{ Engine } & \multicolumn{1}{c|}{$\begin{array}{l}\text { Paper } \\
\text { Filter }\end{array}$} & \multicolumn{1}{c|}{ Trap } & \multicolumn{1}{c|}{$\begin{array}{c}\text { OCC }+ \\
\text { Trap }\end{array}$} & \multicolumn{1}{c|}{$\begin{array}{c}\text { OCC+ }+ \\
\text { TF }\end{array}$} \\
\hline \hline GM, [nm] & 106.133 & 66.602 & 91.159 & 39.442 & 76.787 \\
\hline$\sigma_{\mathrm{g}}$ & 1.680 & 1.777 & 1.563 & 1.524 & 1.503 \\
\hline Total Particle Number (TPN) & 441120 & 222060 & 208250 & 395400 & 397230 \\
\hline \hline Total Deposit, [fraction] & 0.3462 & 0.4574 & 0.3742 & 0.5983 & 0.4134 \\
\hline Nasal Deposit, [fraction] & 0.0074 & 0.0095 & 0.0071 & 0.0138 & 0.0077 \\
\hline Head Deposit, [fraction] & $1.82 \mathrm{E}-6$ & $5.36 \mathrm{E}-7$ & $7.34 \mathrm{E}-7$ & $3.75 \mathrm{E}-8$ & $3.38 \mathrm{E}-7$ \\
\hline Total Lung, [fraction] & 0.3388 & 0.4479 & 0.3671 & 0.5845 & 0.4057 \\
\hline Tracheobronchial, [fraction] & 0.0672 & 0.1015 & 0.0743 & 0.1499 & 0.0847 \\
\hline Alveolar Region, [fraction] & $\mathbf{0 . 2 7 1 6}$ & $\mathbf{0 . 3 4 6 4}$ & $\mathbf{0 . 2 9 2 8}$ & $\mathbf{0 . 4 3 4 6}$ & $\mathbf{0 . 3 2 1 0}$ \\
\hline TPN in Alveolar Region, [\#/cm ${ }^{3}$ ] & 119806 & 76914 & 60974 & 171845 & 127508 \\
\hline Normalized TPN, [fraction] & $\mathbf{1 . 0 0 0}$ & $\mathbf{0 . 5 0 3}$ & $\mathbf{0 . 4 7 2}$ & $\mathbf{0 . 8 9 6}$ & $\mathbf{0 . 9 0 1}$ \\
\hline Normalized TPN in Alveolar Region, [fraction] & $\mathbf{0 . 2 7 2}$ & $\mathbf{0 . 3 4 6}$ & $\mathbf{0 . 2 9 3}$ & $\mathbf{0 . 4 3 5}$ & $\mathbf{0 . 3 2 1}$ \\
\hline
\end{tabular}

Table 3.11 Isuzu C240, Steady State, R75, Effects of After-Treatment Process, Mass Concentration, Diesel, Regional Deposition of DPM in Man

\begin{tabular}{|c|c|c|c|c|c|}
\hline After Treatment Process & Engine & $\begin{array}{l}\text { Paper } \\
\text { Filter }\end{array}$ & Trap & $\begin{array}{c}\text { OCC + } \\
\text { Trap }\end{array}$ & $\begin{array}{l}\mathrm{OCC}+ \\
\mathrm{T}+\mathrm{PF}\end{array}$ \\
\hline GMM, [nm] & 237.967 & 179.532 & 165.833 & 67.182 & 126.357 \\
\hline$\sigma_{g}$ & 1.680 & 1.777 & 1.563 & 1.524 & 1.503 \\
\hline Total Particle Mass (TPM), $[\mu \mathrm{g}]$ & 927.1 & 152.0 & 202.67 & 28.24 & 198.78 \\
\hline Total Deposit, [fraction] & 0.2395 & 0.2684 & 0.2647 & 0.4486 & 0.3044 \\
\hline Nasal Deposit, [fraction] & 0.0156 & 0.0114 & 0.0083 & 0.0086 & 0.0065 \\
\hline Head Deposit, [fraction] & $2.67 \mathrm{E}-5$ & $1.46 \mathrm{E}-5$ & $5.53 \mathrm{E}-6$ & $2.30 \mathrm{E}-7$ & $1.83 \mathrm{E}-6$ \\
\hline Total Lung, [fraction] & 0.2238 & 0.2570 & 0.2564 & 0.4400 & 0.2978 \\
\hline Tracheobronchial, [fraction] & 0.0355 & 0.0450 & 0.0456 & 0.0953 & 0.0560 \\
\hline Alveolar Region, [fraction] & $\mathbf{0 . 1 8 8 3}$ & 0.2120 & 0.2109 & 0.3447 & 0.2419 \\
\hline TPM in Alveolar Region, $[\mu \mathrm{g}]$ & 174.6 & 32.2 & 42.7 & 9.7 & 48.9 \\
\hline Normalized TPM, [fraction] & 1.000 & 0.164 & 0.219 & $\mathbf{0 . 0 3 0}$ & 0.214 \\
\hline Normalized TPM in Alveolar Region, [fraction] & 0.188 & $\mathbf{0 . 0 3 5}$ & 0.046 & 0.010 & 0.052 \\
\hline
\end{tabular}




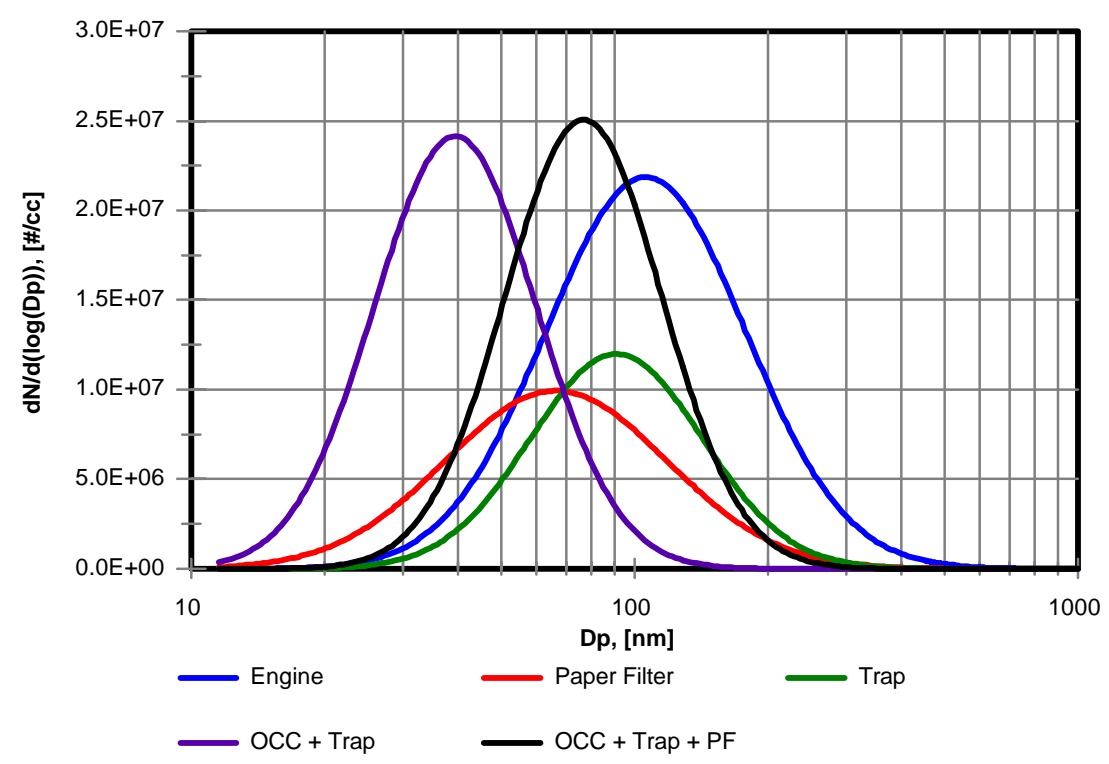

Figure 3.118 Isuzu C240, Steady-State, DR = 28, Number Concentration, Regional Deposition of DPM in Man, Effects of After-Treatment Process

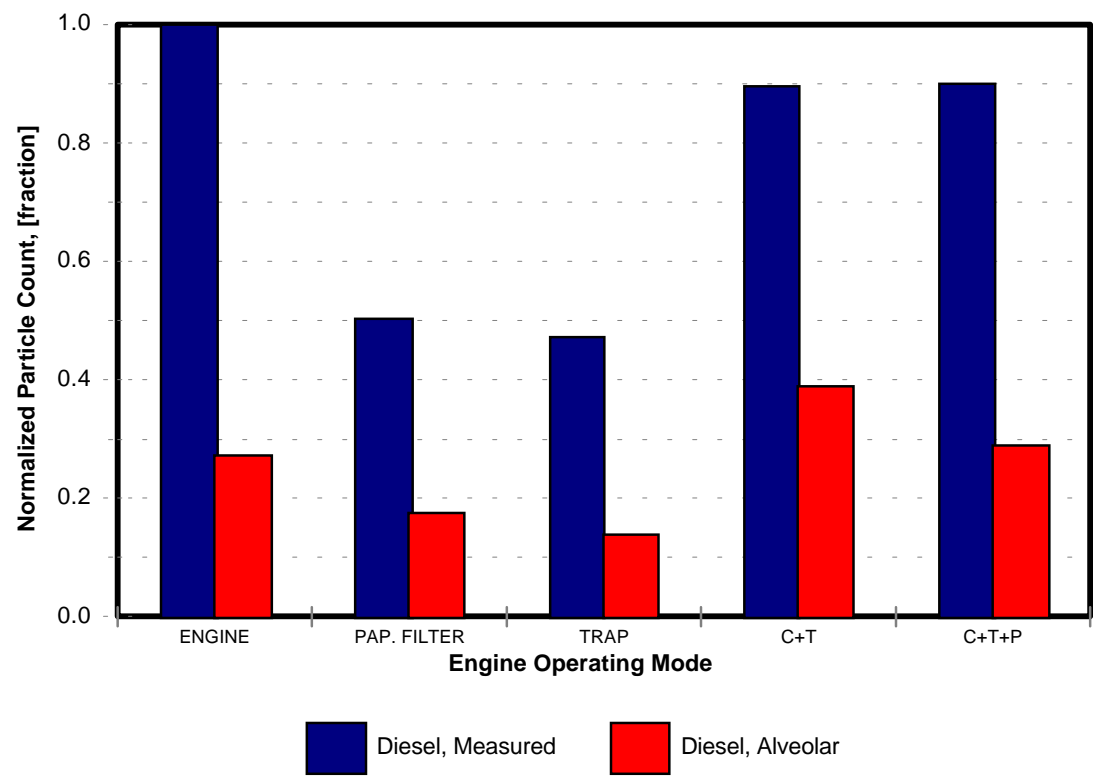

Figure 3.119 Isuzu C240, Steady-State, DR = 28, Normalized Particle Number, Regional Deposition of DPM in Man, Effects of After-Treatment Process, Deposition in Alveolar Region 


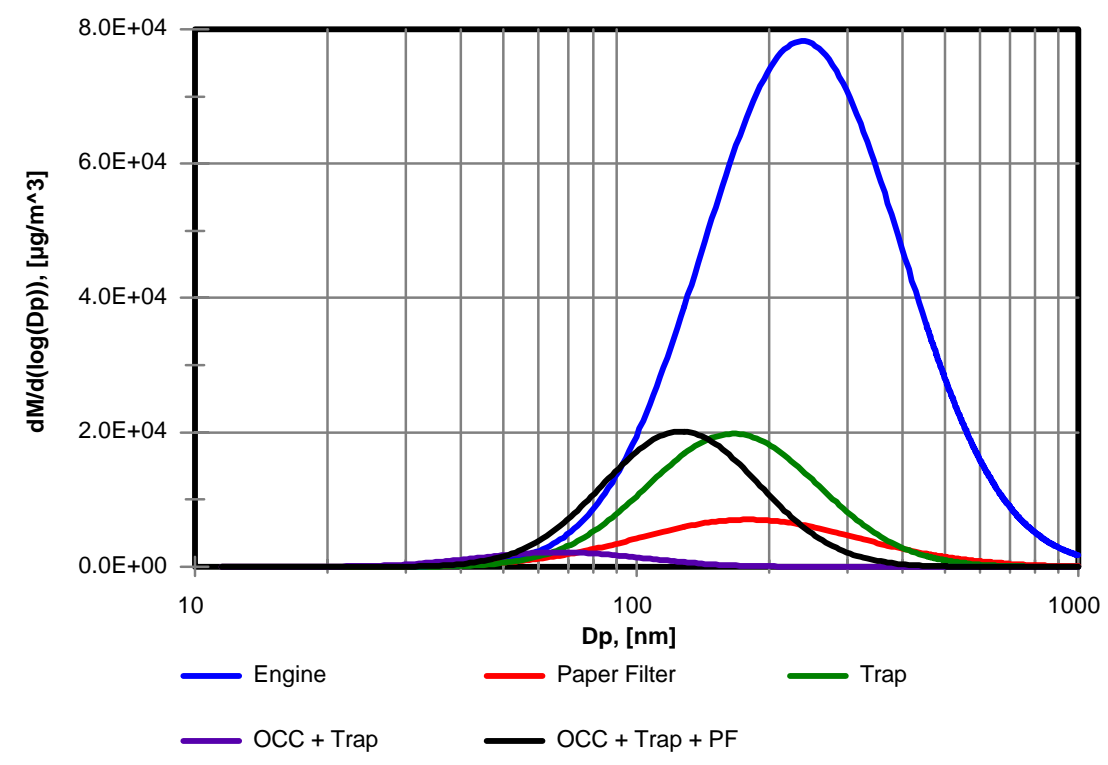

Figure 3.120 Isuzu C240, Steady-State, DR = 28, Mass Concentration, Regional Deposition of DPM in Man,

Effects of After-Treatment Process

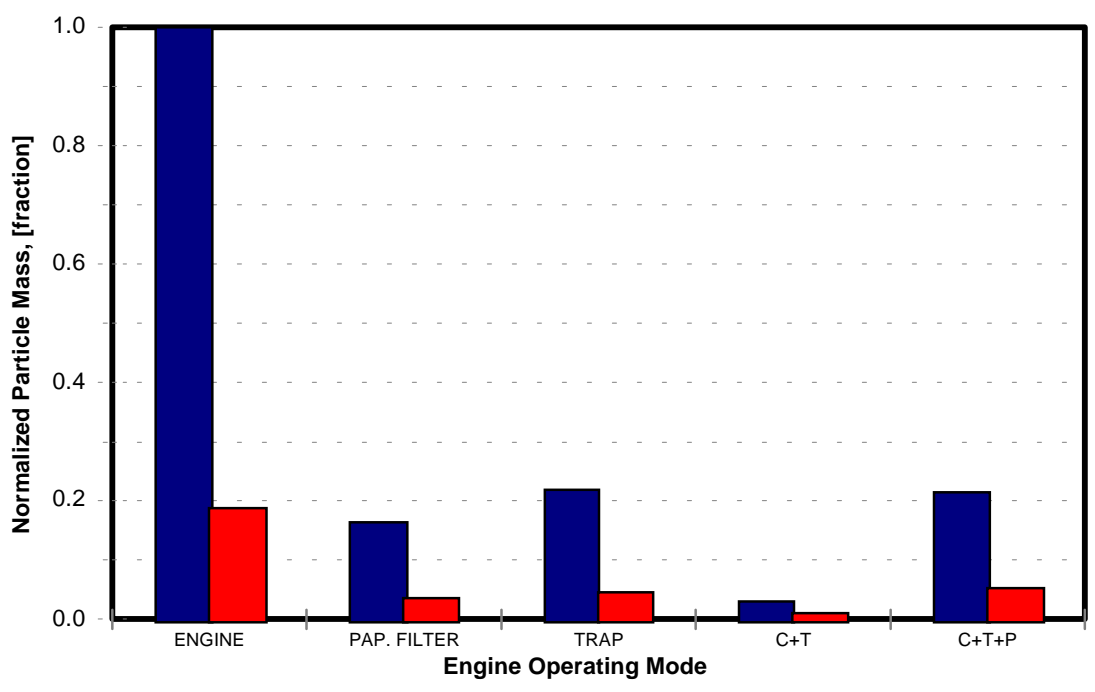

Diesel, Measured Diesel, Alveolar

Figure 3.121 Isuzu C240, Steady-State, DR = 28, Normalized Particle Mass, Regional Deposition of DPM in Man, Deposition in Alveolar Region, Effects of After-Treatment Process 


\subsubsection{Orion/DDC 6V92 Transit Buses}

The regional deposition of DPM in the human respiratory tract was also examined with the results of SMPS measurements from the Orion transit buses powered by DDC 6V92 engines. The test cases were selected carefully so that vehicle to vehicle variations ( $\left(1^{\text {th }}\right.$ case) and the effects of different fuel types and different steady-state speeds $\left(2^{\text {nd }}\right.$ case $)$ could be examined.

\section{The First Case}

The results of the size selective measurements of particulate matter performed for the vehicles 2048, 2030, and 2034 were used to study variation of regional deposition of PM emissions from different vehicles (Figures 3.122 and 3.124). The vehicle 2030 and 2034 were high-mileage vehicles without OCC. Vehicle 2048 was powered by an engine that was rebuilt and retrofitted with an OCC. The vehicles were operated at steady-state speed of $30 \mathrm{mph}$.

The results of the analysis are listed in Tables 3.12 and 3.13. The estimated numbers of the particles deposited in the alveolar region were normalized with respect to the total number of particle measured for the bus 2030 (see Table 3.12 and Figure 3.123). The estimated masses of the particles deposited in the alveolar region were normalized with respect to the total mass of particle emitted from the bus 2034 (see Table 3.13 and Figure 3.125).

The fractions of the total particle mass deposited in the alveolar region the from busses 2048 and 2030 were found to be significantly higher than from the bus 2034. Still, the mass of the particles deposited in the alveolar region for the bus 2034 was found to be by far the highest due to the largest mass of particles found in the exhaust of the bus 2034. On the contrary, the analysis performed on the count based distributions indicated that number of emitted particles as well as number of particles which was estimated to be deposited in the alveolar region were the highest in the exhaust from the bus 2030 . These variations in the mass and count emission trends pointing on the complexity of interpreting results of size selective PM measurement on the in-use vehicles even if those vehicles are powered with the same type of engine. This has for consequence introduction of high uncertainties in assessment of PM health effects. 
Table 3.12 Orion/DDC 6V92, Steady State, 30mph, Regional Deposition of DPM in Man, Vehicle to Vehicle Variation and Effects of Fuel Formulation and Driving Speed, Particle Number

\begin{tabular}{||l||c|c|c||c|c|c|c||}
\hline \hline Fuel & $\begin{array}{c}\text { Syn. } \\
\text { Diesel }\end{array}$ & $\begin{array}{c}\text { Syn. } \\
\text { Diesel }\end{array}$ & $\begin{array}{c}\text { Syn. } \\
\text { Diesel }\end{array}$ & Diesel & $\begin{array}{c}\text { Syn. } \\
\text { Diesel }\end{array}$ & Diesel & $\begin{array}{c}\text { Syn. } \\
\text { Diesel }\end{array}$ \\
\hline Vehicle & $\begin{array}{c}2048 \\
\text { (OCC) }\end{array}$ & 2030 & 2034 & 2034 & 2034 & 2034 & 2034 \\
\hline Driving Speed, [mph] & 30 & 30 & 30 & 20 & 20 & 40 & 40 \\
\hline \hline GM, [nm] & 41.847 & 58.646 & 72.050 & 84.252 & 77.946 & 99.425 & 96.337 \\
\hline$\sigma_{\mathrm{g}}$ & 1.568 & 1.529 & 1.873 & 1.947 & 1.807 & 1.739 & 1.821 \\
\hline $\begin{array}{l}\text { Total Particle Mass, } \\
\text { (TPM), [\#/cm }{ }^{3} \text { ] }\end{array}$ & 179480 & 396250 & 357440 & 95371 & 107220 & 165810 & 136180 \\
\hline \hline Total Deposit, [fraction] & 0.5812 & 0.4855 & 0.4406 & 0.4068 & 0.4197 & 0.3623 & 0.3726 \\
\hline Nasal Deposit, [fraction] & 0.0132 & 0.0096 & 0.0 .0095 & 0.0092 & 0.0088 & 0.0077 & 0.0082 \\
\hline Head Deposit, [fraction] & $5.30 \mathrm{e}-8$ & $1.47 \mathrm{e}-7$ & $9.98 \mathrm{e}-7$ & $2.22 \mathrm{e}-6$ & $1.02 \mathrm{e}-6$ & $1.80 \mathrm{e}-6$ & $2.18 \mathrm{e}-6$ \\
\hline Total Lung, [fraction] & 0.5680 & 0.4759 & 0.4311 & 0.3976 & 0.4109 & 0.3546 & 0.3643 \\
\hline $\begin{array}{l}\text { Tracheobronchial, } \\
\text { [fraction] }\end{array}$ & 0.1438 & 0.1071 & 0.0972 & 0.0868 & 0.0896 & 0.0719 & 0.0753 \\
\hline $\begin{array}{l}\text { Alveolar Region, } \\
\text { [fraction] }\end{array}$ & $\mathbf{0 . 4 2 4 2}$ & $\mathbf{0 . 3 6 8 7}$ & $\mathbf{0 . 3 3 4 0}$ & $\mathbf{0 . 3 1 0 8}$ & $\mathbf{0 . 3 2 1 3}$ & $\mathbf{0 . 2 8 2 7}$ & $\mathbf{0 . 2 8 9 1}$ \\
\hline $\begin{array}{l}\text { TPN in Alveolar Region, } \\
\text { [\#/cm }{ }^{3} \text { ] }\end{array}$ & 76143 & 146116 & 119372 & 29641 & 34454 & 46869 & 39364 \\
\hline $\begin{array}{l}\text { Normalized TPN0, } \\
\text { [fraction] }\end{array}$ & $\mathbf{0 . 4 5 3}$ & $\mathbf{1 . 0 0 0}$ & $\mathbf{0 . 9 0 2}$ & $\mathbf{0 . 5 7 5}$ & $\mathbf{0 . 6 4 7}$ & $\mathbf{1 . 0 0 0}$ & $\mathbf{0 . 8 2 1}$ \\
\hline $\begin{array}{l}\text { Normalized TPN in } \\
\text { Alveolar Region, } \\
\text { [fraction] }\end{array}$ & $\mathbf{0 . 1 9 2}$ & $\mathbf{0 . 3 6 9}$ & $\mathbf{0 . 3 0 1}$ & $\mathbf{0 . 1 7 9}$ & $\mathbf{0 . 2 0 8}$ & $\mathbf{0 . 2 8 3}$ & $\mathbf{0 . 2 3 7}$ \\
\hline \hline
\end{tabular}


Table 3.13 Orion/DDC 6V92, Steady State, Regional Deposition of DPM in Man, Vehicle to Vehicle Variation and Effects of Fuel Formulation and Driving Speed, Particle Mass

\begin{tabular}{|c|c|c|c|c|c|c|c|}
\hline Fuel & $\begin{array}{c}\text { Syn. } \\
\text { Diesel }\end{array}$ & $\begin{array}{c}\text { Syn. } \\
\text { Diesel }\end{array}$ & $\begin{array}{l}\text { Syn. } \\
\text { Diesel }\end{array}$ & Diesel & $\begin{array}{l}\text { Syn. } \\
\text { Diesel }\end{array}$ & Diesel & $\begin{array}{l}\text { Syn. } \\
\text { Diesel }\end{array}$ \\
\hline Vehicle & $\begin{array}{l}2048 \\
(\mathrm{OCC})\end{array}$ & 2030 & 2034 & 2034 & 2034 & 2034 & 2034 \\
\hline Driving Speed, [mph] & 30 & 30 & 30 & 20 & 20 & 40 & 40 \\
\hline GMM, [nm] & 76.783 & 100.727 & 234.812 & 319.143 & 222.790 & 249.101 & 283.055 \\
\hline$\sigma_{g}$ & 1.568 & 1.529 & 1.873 & 1.947 & 1.807 & 1.739 & 1.821 \\
\hline $\begin{array}{l}\text { Mass of Particles (TPM), } \\
{\left[\mu \mathrm{g} / \mathrm{m}^{3}\right]}\end{array}$ & 17.12 & 94.20 & 411.84 & 220.17 & 128.47 & 338.39 & 321.08 \\
\hline Total Deposit, [fraction] & 0.4155 & 0.3506 & 0.2552 & 0.2606 & 0.2514 & 0.2422 & 0.2469 \\
\hline Nasal Deposit, [fraction] & 0.0079 & 0.0067 & 0.0190 & 0.0342 & 0.0168 & 0.0180 & 0.0245 \\
\hline Head Deposit, [fraction] & $4.17 \mathrm{e}-7$ & $9.23 \mathrm{e}-7$ & $4.73 e-5$ & $1.49 \mathrm{e}-4$ & $3.49 \mathrm{e}-5$ & $3.73 e-5$ & $7.21 \mathrm{e}-5$ \\
\hline Total Lung, [fraction] & 0.4076 & 0.3439 & 0.2362 & 0.2263 & 0.2345 & 0.2241 & 0.2224 \\
\hline $\begin{array}{l}\text { Tracheobronchial, } \\
\text { [fraction] }\end{array}$ & 0.0859 & 0.0678 & 0.0377 & 0.0317 & 0.0378 & 0.0349 & 0.0327 \\
\hline $\begin{array}{l}\text { Alveolar Region, } \\
\text { [fraction] }\end{array}$ & 0.3217 & 0.2761 & 0.1985 & 0.1946 & 0.1967 & 0.1892 & 0.1896 \\
\hline $\begin{array}{l}\text { TPM in Alveolar Region, } \\
{\left[\mu \mathrm{g} / \mathrm{m}^{3}\right]}\end{array}$ & 5.51 & 26.01 & 81.73 & 42.80 & 25.30 & 64.00 & 60.90 \\
\hline $\begin{array}{l}\text { Normalized TPM, } \\
\text { [fraction] }\end{array}$ & 0.042 & 0.229 & 1.000 & 0.651 & 0.380 & 1.000 & 0.949 \\
\hline $\begin{array}{l}\text { Normalized TPM in } \\
\text { Alveolar Region, } \\
\text { [fraction] }\end{array}$ & 0.013 & 0.063 & 0.198 & 0.127 & 0.075 & 0.189 & 0.180 \\
\hline
\end{tabular}




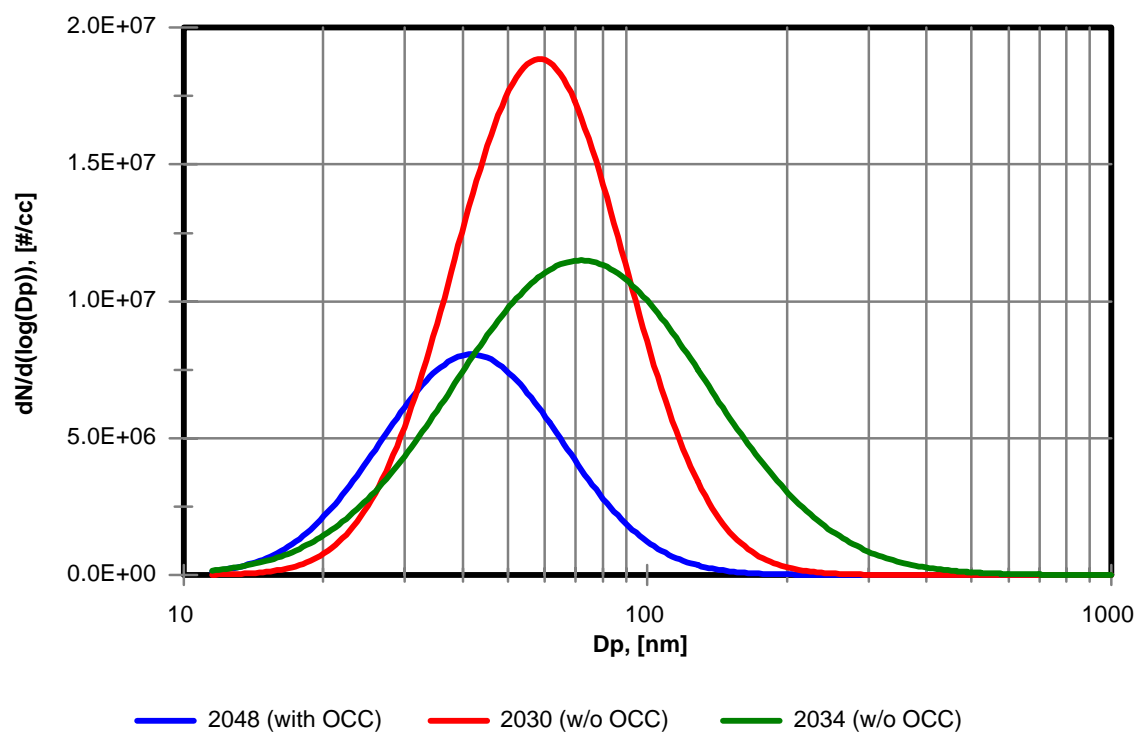

Figure 3.122 Orion/DDC 6V92, Steady-State, $30 \mathrm{mph}$, Mossgas Synthetic Diesel, Number Concentration, Regional Deposition of DPM in Man, Vehicle to Vehicle Variation

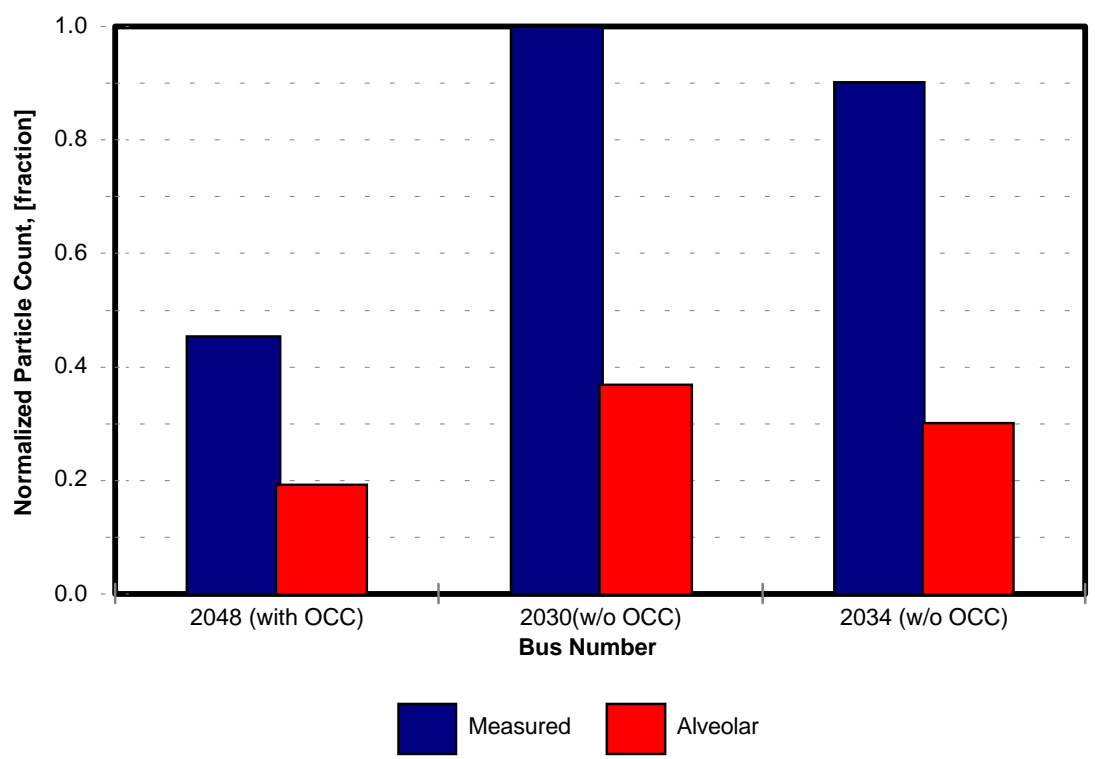

Figure 3.123 Orion/DDC 6V92, Steady-State, $30 \mathrm{mph}$, Mossgas Synthetic Diesel, Normalized Number Concentration, Regional Deposition of DPM in Man, Deposition in Alveolar Region, Vehicle to Vehicle Variation 


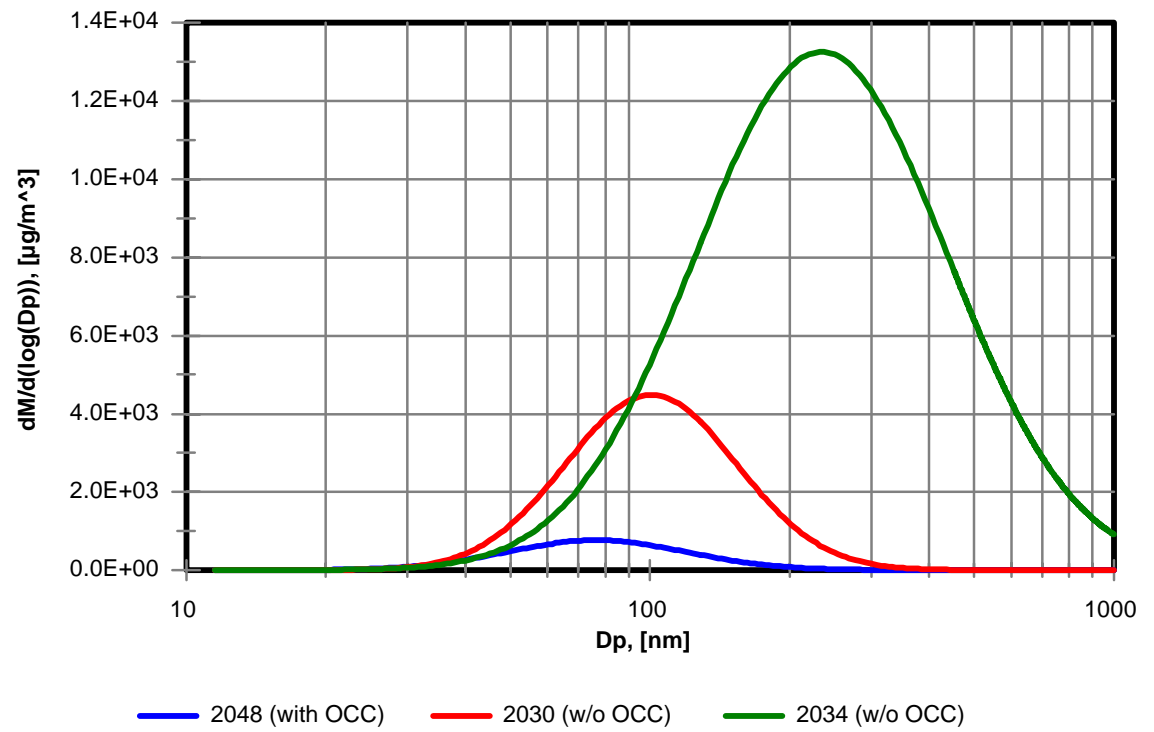

Figure 3.124 Orion/DDC 6V92, Steady-State, $30 \mathrm{mph}$, Mossgas Synthetic Diesel, Mass Concentration, Regional Deposition of DPM in Man, Vehicle to Vehicle Variation

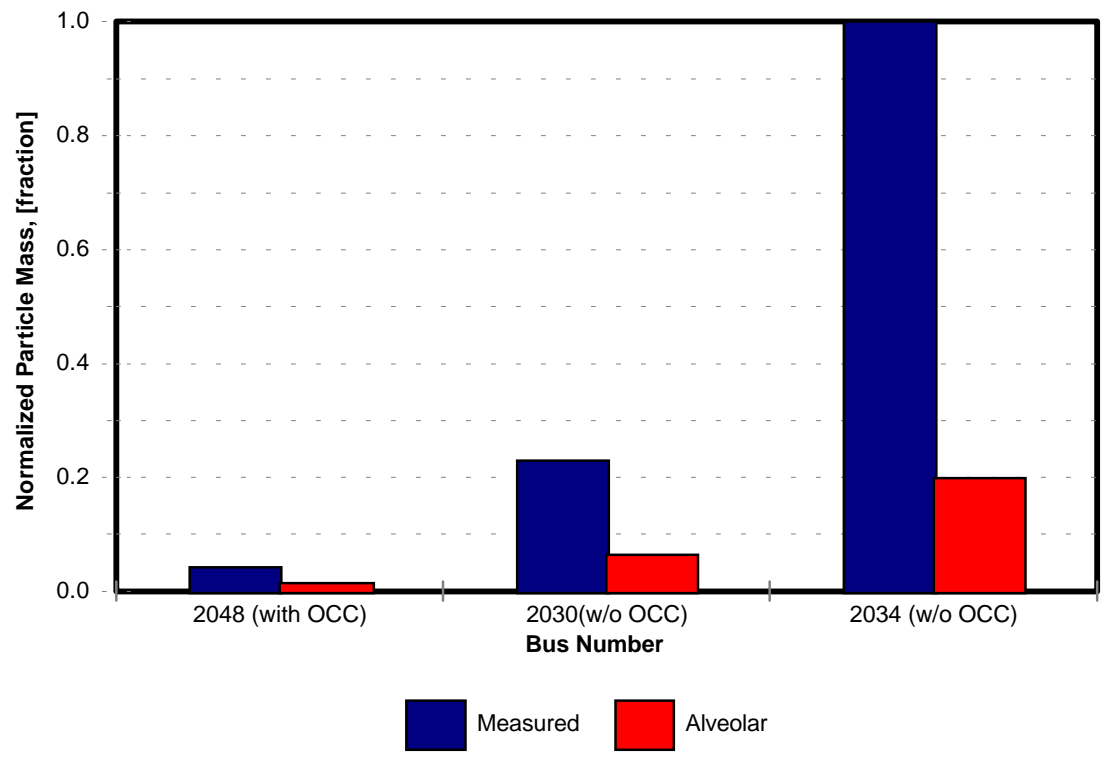

Figure 3.125 Orion/DDC 6V92, Steady-State, $30 \mathrm{mph}$, Mossgas Synthetic Diesel, Normalized Particle Mass, Regional Deposition of DPM in Man, Deposition in Alveolar Region,

Vehicle to Vehicle Variation 


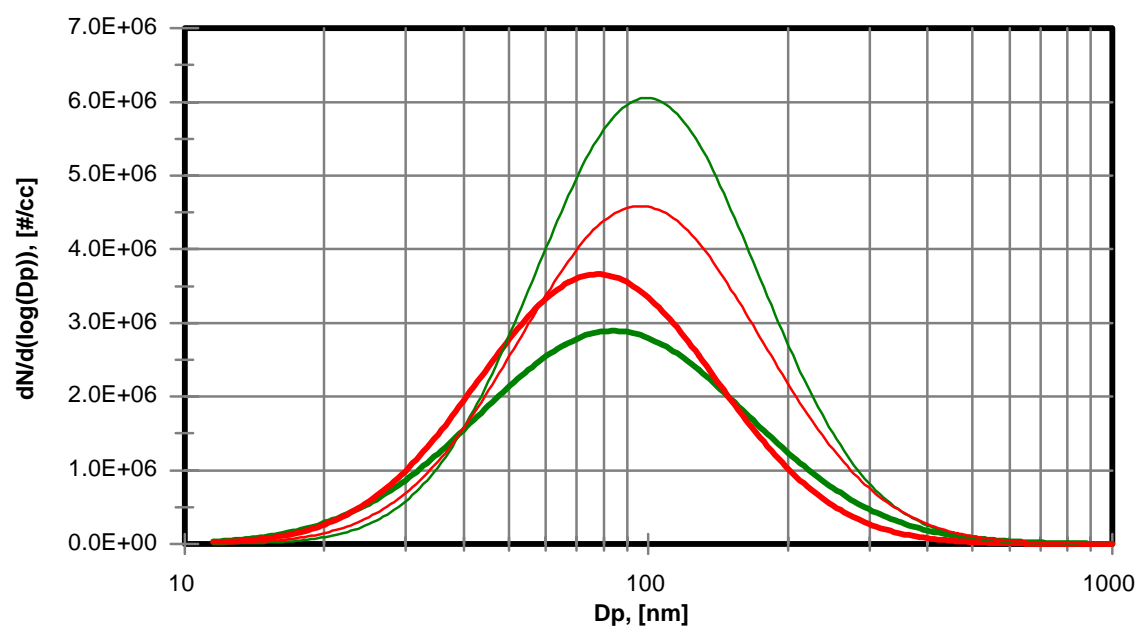

B 2034 (w/o OCC), Diesel, $20 \mathrm{mph}$ B 2034 (w/o OCC), Mossgas, $20 \mathrm{mph}$ B 2034 (w/o OCC), Diesel, $40 \mathrm{mph}$ B 2034 (w/o OCC), Mossgas, $40 \mathrm{mph}$

Figure 3.126 Orion/DDC 6V92, Bus 2034 With Out OCC, Steady-State, Number Concentration, Regional Deposition of DPM in Man, Effects of Fuel Formulation and Driving Speed

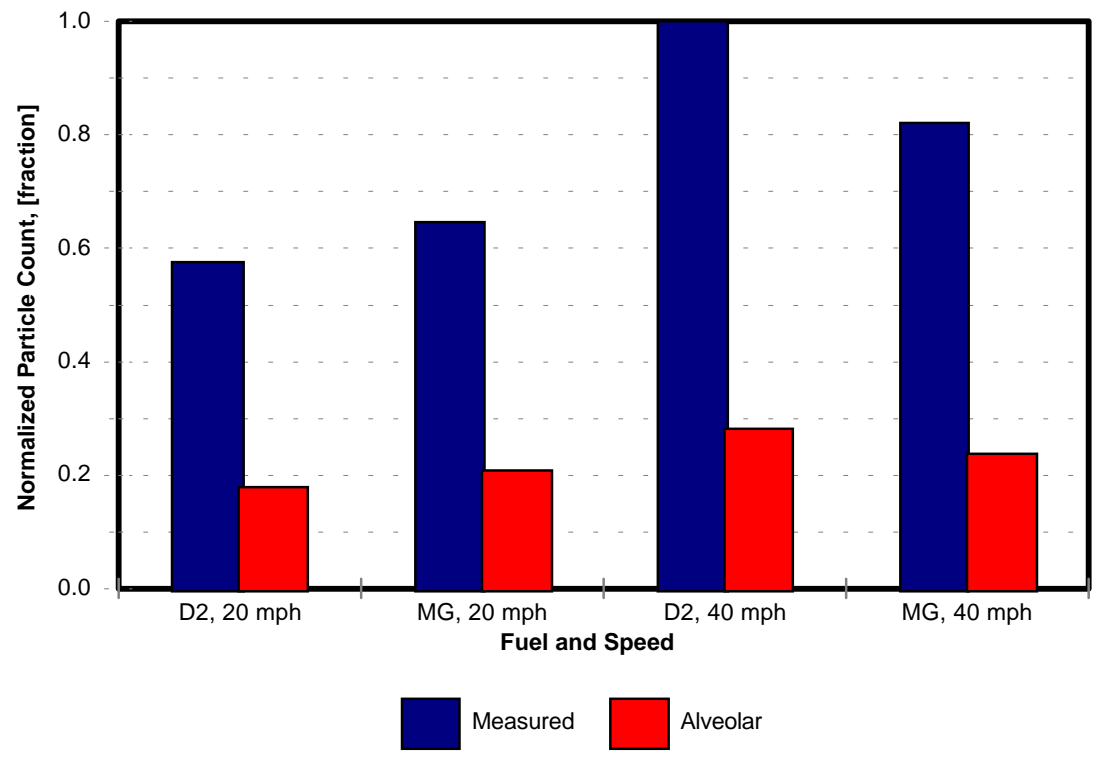

Figure 3.127 Orion/DDC 6V92, Bus 2034 With Out OCC, Steady-State, Normalized Particle Number, Regional Deposition of DPM in Man, Deposition in Alveolar Region, Effects of Fuel Formulation and Driving Speed 


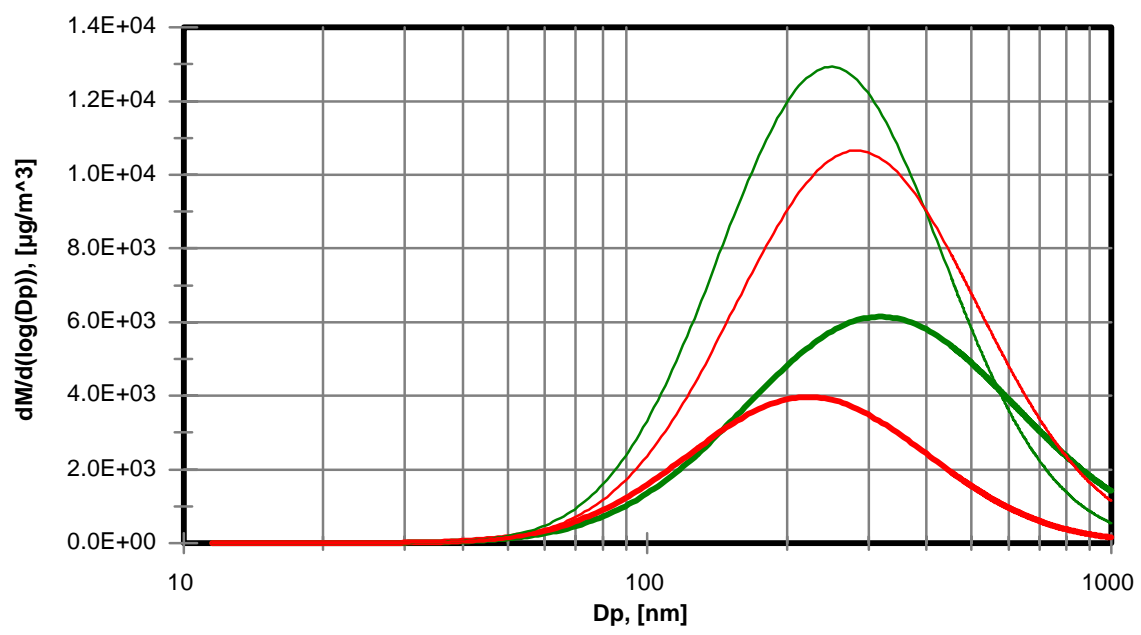

B 2034 (w/o OCC), Diesel, $20 \mathrm{mph}$

_ B 2034 (w/o OCC), Mossgas, $20 \mathrm{mph}$

B 2034 (w/o OCC), Diesel, $40 \mathrm{mph}$ B 2034 (w/o OCC), Mossgas, $40 \mathrm{mph}$

Figure 3.128 Orion/DDC 6V92, Bus 2034 With Out OCC,

Steady-State, Mass Concentration, Regional Deposition of DPM in Man, Effects of Fuel Type and Driving Speed

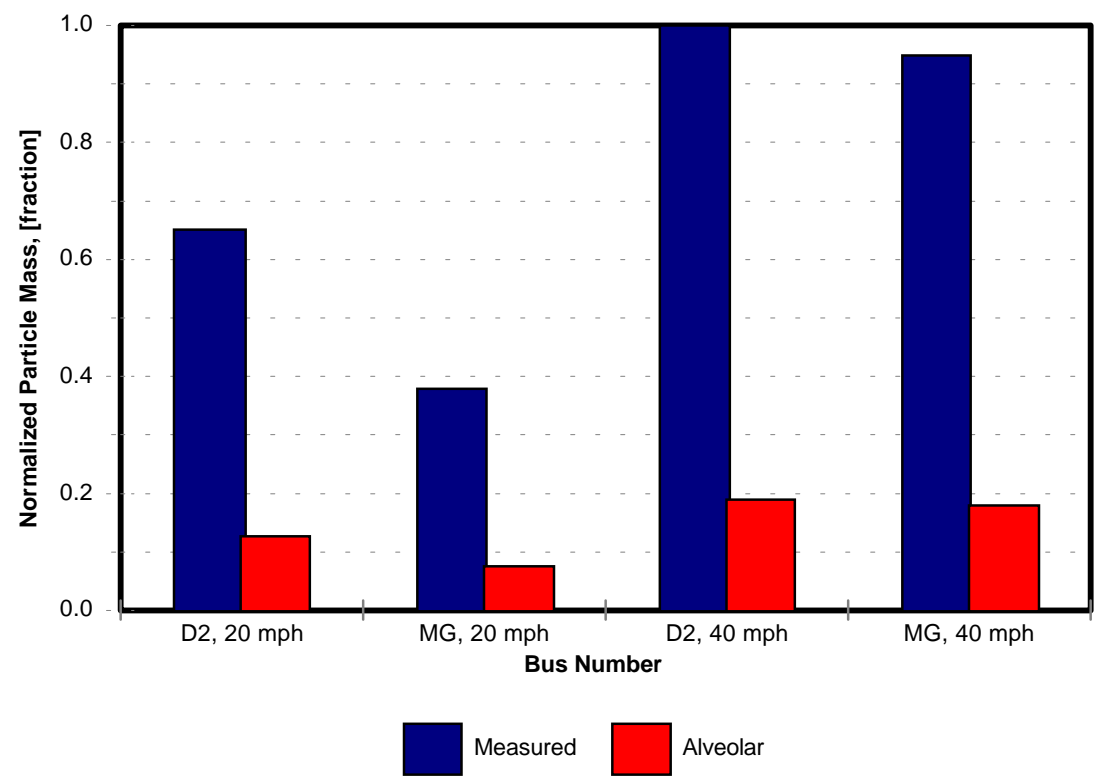

Figure 3.129 Orion/DDC 6V92, Bus 2034 With Out OCC,

Steady-State, Normalized Particle Mass,

Regional Deposition of DPM in Man, Deposition in Alveolar Region,

Effects of Fuel Type and Driving Speed 


\section{The Second Case}

The regional deposition analysis was also performed on the size and mass distributions presented in Figures 3.126 and 3.128. The study investigated the effects of fuel type and driving speed. The number and mass of the particles shown in Figures 3.127 and 3.129, were normalized with respect to the count and mass emissions from the bus 2034 driven at $40 \mathrm{mph}$ and fueled with diesel no. 2 .

The results show that fuel type and driving speed did not have any significant effect neither on the PM distributions nor the fractional deposition efficiency of the particles. The count and mass PM distributions for Mossgas are highlighted by slightly lower CMDs and MMDs than the corresponding distributions for diesel no. 2. The CMDs and MMDs were found to be slightly higher for $40 \mathrm{mph}$ than for $20 \mathrm{mph}$ steady-state driving speed. Consequently, the fractional depositions in the alveolar region, calculated on the mass and count basis, were found to be slightly higher for Mossgas than for diesel no. 2, and for $20 \mathrm{mph}$ than for $40 \mathrm{mph}$.

\subsubsection{Mack E7-400}

The regional deposition analysis was conducted on the results of size selective measurements of particulate matter emissions from Mack E7-400 on-highway engine. The engine was operated at R75, R50, and I50 steady-state conditions and fueled with diesel no. 2. The count and mass PM distributions are shown in Figures 3.130 and 3.132. While the CMDs and MMDs were not significantly affected by the engine operating conditions, the total number and total mass of emitted particles over test periods were found to be indeed affected by the observed engine operating conditions (see Figure 3.130). The peak concentrations were significantly higher for R50 than for R75 and I50 engine operating conditions.

The results on the regional deposition analysis are presented in Table 3.14 and Figures 3.131 and 3.133. The number and mass of the particles deposited in the alveolar region were normalized with respect to number and mass concentration of particles detected in the exhaust for the R50 engine operating conditions. From the results of the analysis on Mack E7 engine it appeared that fractions of DPM deposited in the alveolar region were not significant affect with Therefore, number and mass of 
particles deposited in the alveolar region were directly proportional to the number and mass of particles emitted. detected in the exhaust.

Table 3.14 Mack E7-400, Steady State, Engine, Regional Deposition of DPM in Man, Diesel, Effects of Engine Operating Mode, Number and Mass

\begin{tabular}{|c|c|c|c|c|c|c|c|}
\hline $\begin{array}{l}\text { Engine Operating } \\
\text { Mode }\end{array}$ & $\mathrm{R} 75$ & R50 & I50 & $\begin{array}{l}\text { Engine Operating } \\
\text { Mode }\end{array}$ & R75 & $\mathrm{R} 50$ & I50 \\
\hline GM, [nm] & 42.550 & 49.141 & 51.213 & GMM, [nm] & 190.650 & 172.942 & 196.803 \\
\hline$\sigma_{\mathrm{g}}$ & 2.028 & 1.911 & 1.954 & $\sigma_{\mathrm{g}}$ & 2.028 & 1.91 & 1.954 \\
\hline $\begin{array}{l}\text { Total Part. Number } \\
\text { (TPNJ), }\left[\# / \mathrm{cm}^{3}\right]\end{array}$ & 248000 & 923000 & 337000 & $\begin{array}{l}\text { Total Particulate } \\
\text { matted (TPM), } \\
{\left[\mu \mathrm{g} / \mathrm{m}^{3}\right]}\end{array}$ & 94.88 & 378.63 & 178.55 \\
\hline $\begin{array}{l}\text { Total Deposit, } \\
\text { [fraction] }\end{array}$ & 0.5383 & 0.5758 & 0.5280 & $\begin{array}{l}\text { Total Deposit, } \\
\text { [fraction] }\end{array}$ & 0.2806 & 0.2816 & 0.2724 \\
\hline $\begin{array}{l}\text { Nasal Deposit, } \\
\text { [fraction] }\end{array}$ & 0.0128 & 0.0152 & 0.0126 & $\begin{array}{l}\text { Nasal Deposit, } \\
\text { [fraction] }\end{array}$ & 0.0164 & 0.0127 & 0.0158 \\
\hline $\begin{array}{l}\text { Head Deposit, } \\
\text { [fraction] }\end{array}$ & $3.18 \mathrm{e}-7$ & $3.08 \mathrm{e}-7$ & $4.31 \mathrm{e}-7$ & $\begin{array}{l}\text { Head Deposit, } \\
\text { [fraction] }\end{array}$ & $4.05 e-5$ & $2.04 \mathrm{e}-5$ & $3.53 e-5$ \\
\hline $\begin{array}{l}\text { Total Lung, } \\
\text { [fraction] }\end{array}$ & 0.5255 & 0.5606 & 0.5154 & $\begin{array}{l}\text { Total Lung, } \\
\text { [fraction] }\end{array}$ & 0.2642 & 0.2690 & 0.2566 \\
\hline $\begin{array}{l}\text { Tracheobronchial, } \\
\text { [fraction] }\end{array}$ & 0.1349 & 0.1554 & 0.1316 & $\begin{array}{l}\text { Tracheobronchial, } \\
\text { [fraction] }\end{array}$ & 0.0459 & 0.0479 & 0.0439 \\
\hline $\begin{array}{l}\text { Alveolar Region, } \\
\text { [fraction] }\end{array}$ & 0.3906 & 0.4052 & 0.3838 & $\begin{array}{l}\text { Alveolar Region, } \\
\text { [fraction] }\end{array}$ & 0.2183 & 0.2211 & 0.2127 \\
\hline $\begin{array}{l}\text { TPN in Alveolar } \\
\text { Region, }\left[\# / \mathrm{cm}^{3}\right]\end{array}$ & 96879 & 374007 & 129357 & $\begin{array}{l}\text { TPM in Alveolar } \\
\text { Region, }\left[\mu \mathrm{g} / \mathrm{m}^{3}\right]\end{array}$ & 20.71 & 83.71 & 37.98 \\
\hline $\begin{array}{l}\text { Normalized TPN, } \\
\text { [fraction] }\end{array}$ & 0.269 & 1.000 & 0.365 & $\begin{array}{l}\text { Normalized TPM, } \\
\text { [fraction] }\end{array}$ & 0.251 & 1.000 & 0.472 \\
\hline $\begin{array}{l}\text { Normalized NC in } \\
\text { Alveolar Region, } \\
\text { [fraction] }\end{array}$ & 0.105 & 0.405 & 0.140 & $\begin{array}{l}\text { Normalized TPM } \\
\text { in Alveolar } \\
\text { Region, [fraction] }\end{array}$ & 0.055 & 0.221 & 0.100 \\
\hline
\end{tabular}




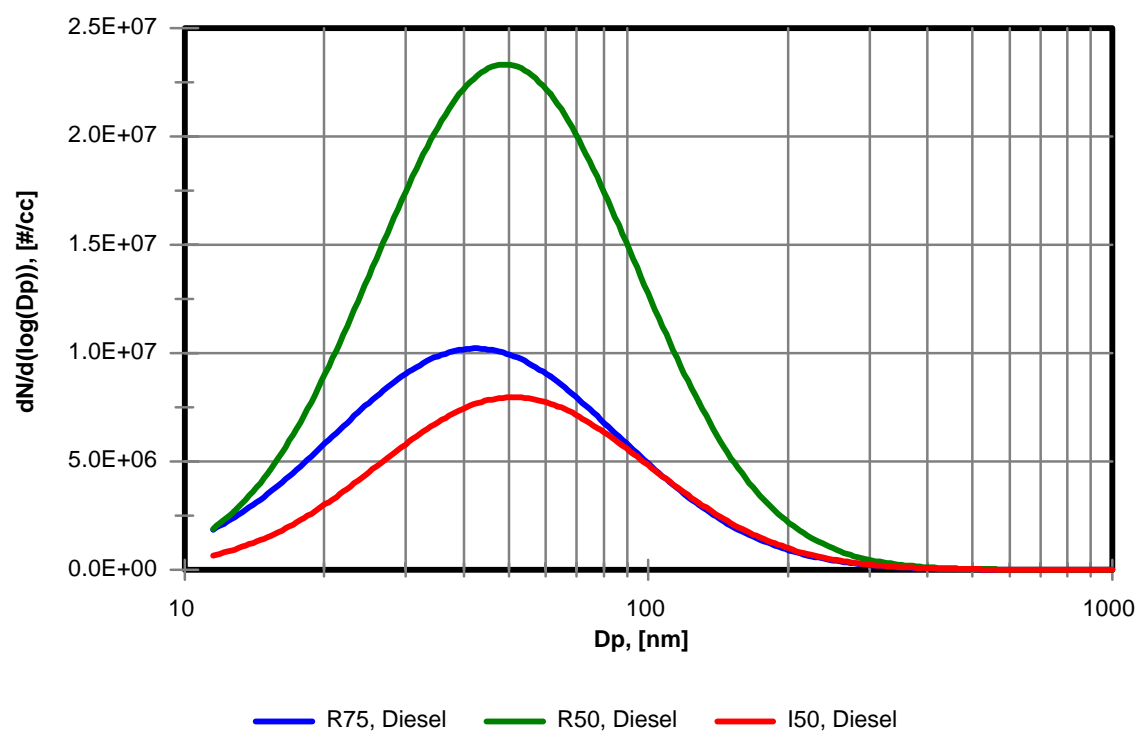

Figure 3.130 Mack E7-400, Steady-State, Diesel, DR = 4.3, Number Concentration, Regional Deposition of DPM in Man, Effects of Engine Operating Conditions

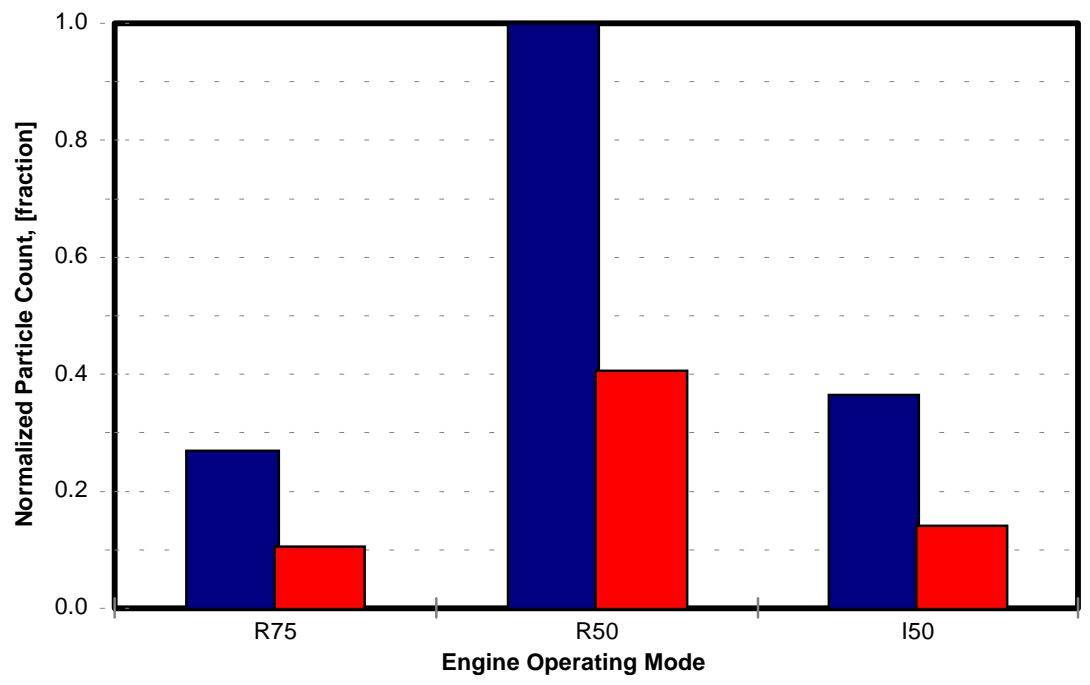

Measured Alveolar

Figure 3.131 Mack E7-400, Steady-State, Diesel, DR = 4.3,

Normalized Particle Number, Regional Deposition of DPM in Man, Deposition in Alveolar Region, Effects of Engine Operating Conditions 


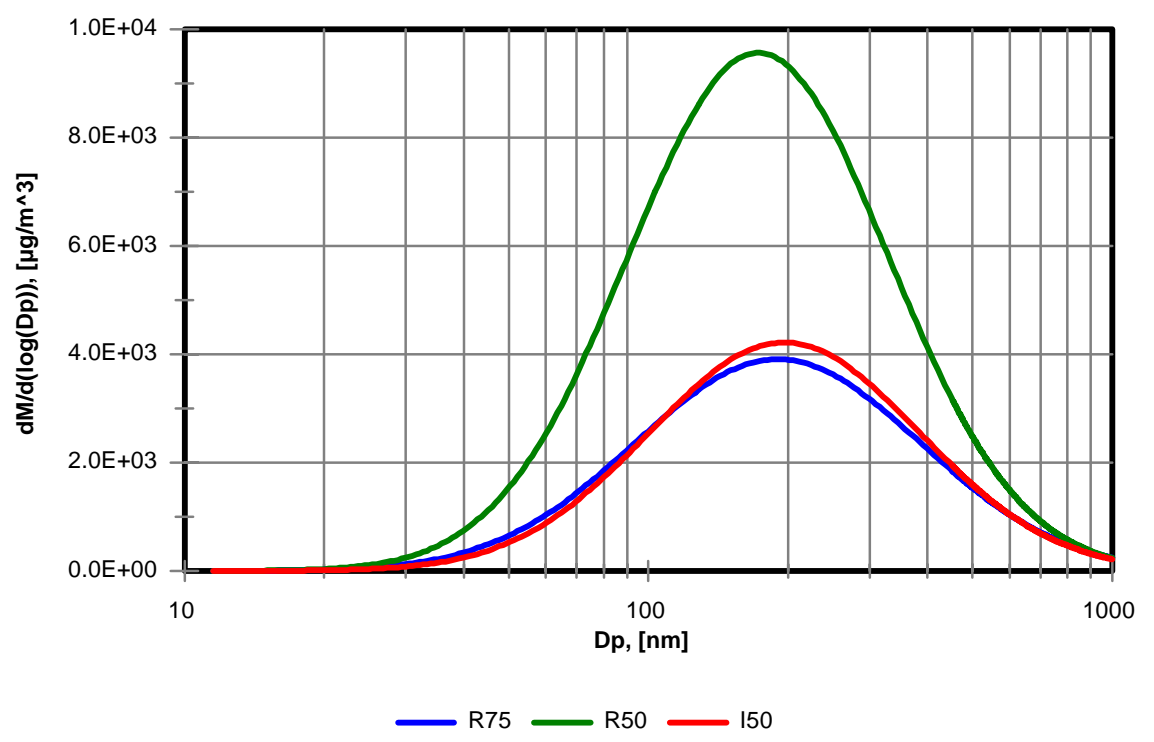

Figure 3.132 Mack E7-400, Steady-State, Diesel, DR = 4.3, Mass Concentration, Regional Deposition of DPM in Man, Effects of Engine Operating Conditions

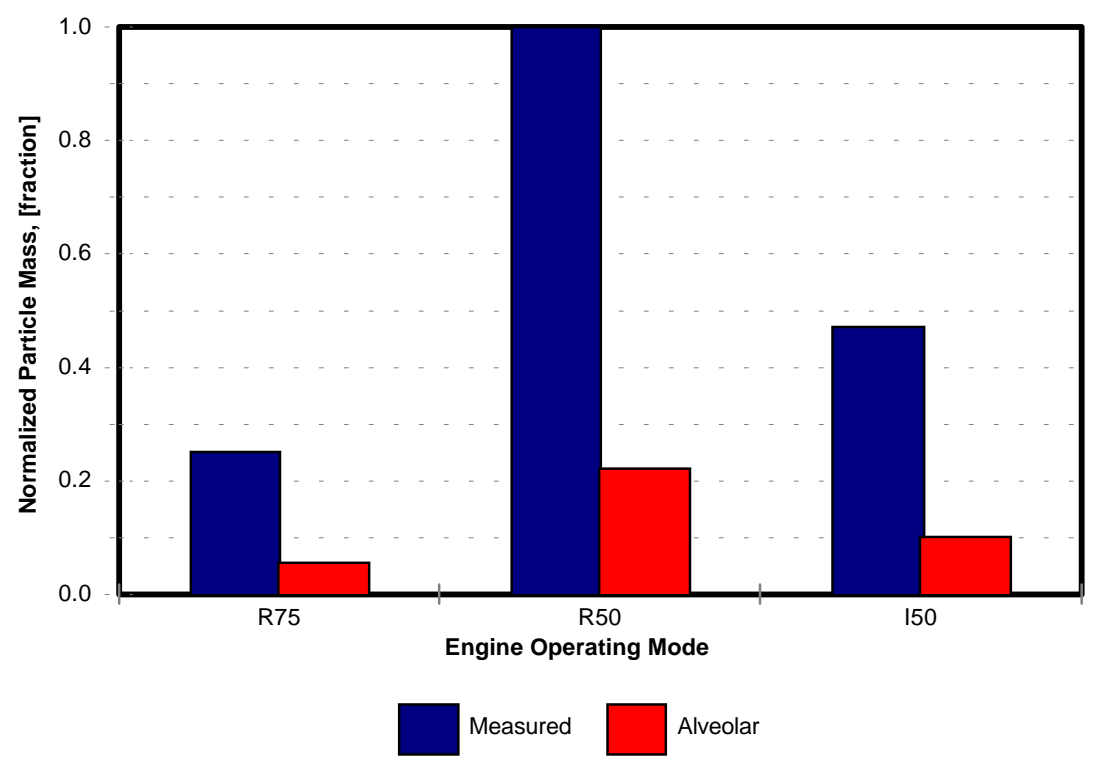

Figure 3.133 Mack E7-400, Steady-State, Diesel, DR = 4.3, Normalized Particle Mass, Regional Deposition of DPM in Man, Deposition in Alveolar Region, Effects of Engine Operating Conditions 
The size selective measurements indicated complexity of physical and chemical processes governing formation and transformation of diesel exhaust particulate matter. The study on the chemical analysis of size-resolved particulate matter was directed toward developing a better understanding of the sources and mechanisms of diesel exhaust PM formation and transformation. Resolving chemical composition of size segregated PM should also help in the assessment of health effects associated with diesel exhaust.

\subsubsection{Elemental and Inorganic Ions Analysis}

The results of the chemical analyses performed on the particulate matter collected on the FEP substrates and Teflo after-filters are presented in Tables B.1 through B.4. The corresponding uncertainties, are listed next to the results of analyses. The elemental analysis was done by X-ray fluorescence, anions (sulfate and chloride) were analyzed by ion chromatography, ammonium by automated colorimetry, and soluble potassium by flame atomic absorption.

The sulfate, chloride, ammonium, potassium, sulfur and silicon were found to be present in the quantities which were above the uncertainty levels for the respective techniques. Lognormal curves were fitted to the size resolved distributions of those species. The mass distributions of significant constituents are presented in Figures 3.134 through 3.137 and 3.139 through 3.146 as normalized mass frequencies and normalized mass concentrations. The PM mass distributions are plotted in Figures 3.147 and 3.148 as mass frequencies and mass concentrations.

\section{Sulfate}

The mass frequencies and mass concentration distributions of sulfates for the various modes, are plotted in Figures 3.136 and 3.137 respectively. It appeared that the engine operating conditions did not have significant effect on the mass frequencies plotted in Figure 3.134. Sulfate concentrations were associated with PM distributions that were characterized by MMDs range from 78 $\mathrm{nm}$ to $119 \mathrm{~nm}$ and GSDs ranging from 2.035 to 2.457. It should be noted that the MMDs for the PM 
emissions (Figures 3.147 and 3.148) ranged from $84 \mathrm{~nm}$ to $144 \mathrm{~nm}$ with GSDs ranging from 1.87 to 2.49. This indicated that aerosol containing sulfate tended to deposit on the stages with lower cut-off diameters relative to the total PM deposition in the MOUDI. The MMD of the sulfate distribution for the R50 engine operating conditions, $0.078 \mu \mathrm{m}$, was found to be significantly lower than the MMDs for the other operating conditions.

The sulfate distributions on a per stage basis is shown in Table 3.19. The sulfates were found to be present in range of 0.48 to 5.78 percent, on stages VI to XI depending on engine operating conditions. The size resolved mass concentrations of sulfate from the Mack E7 operated over FTP cycle, were found to be significantly lower than those for the other engine operating modes (see Table 3.19).

\section{Sulfur}

The distributions of elemental sulfur in the Mack E7-400 exhaust are presented in Figures 3.136 and 3.137. Again, Figures 3.136 and 3.137 show the PM distributions associated with elemental sulfur emissions. The MMDs characterizing sulfur distributions were found to be almost identical to those characterizing sulfate distributions and slightly lower than those describing total PM distributions. Additionally, the lognormal distributions of sulfur, particularly those for R75 and I50 engine operating conditions, had significantly lower GSDs than sulfate and TPM distributions. The peak mass concentrations were found to be lower for R50 and FTP than for I50 and R75 engine operating conditions (see Figure 3.137).

\section{Sulfate vs. Sulfur}

The size-resolved sulfate to sulfur ratios for each stage of the MOUDI are plotted in Figure 3.138 for various engine operating conditions. The ratios were found to range from 1.27 to 5.38 depending on the stage and engine operating conditions. Those values deviate significantly from expected ratio of 3 , obtained under the assumption that all of the sulfur is present as soluble sulfate $\left(\mathrm{MW}_{\mathrm{SO} 4} / \mathrm{MW}_{\mathrm{S}}=3\right)$. This migh be attributed to the high uncertainty associated with of the XRF analysis. 
Similar sulfate to sulfur ratios were also observed by Lowenhal et al. (1994) who reported ratio of sulfate to sulfur of 5.1 for the particles sampled with $2.5 \mu \mathrm{m}$ cut-off diameter cyclone. The samples were collected from the exhaust of the vehicles tested over the CBD cycle and fueled with diesel no. 2 (sulfur content of fuel was not published). Lowental et al. (1994) attributed the high ratio of sulfate to sulfur to low XRF sulfur concentrations. Heavy loading of filters resulted in excessive X-ray absorption.

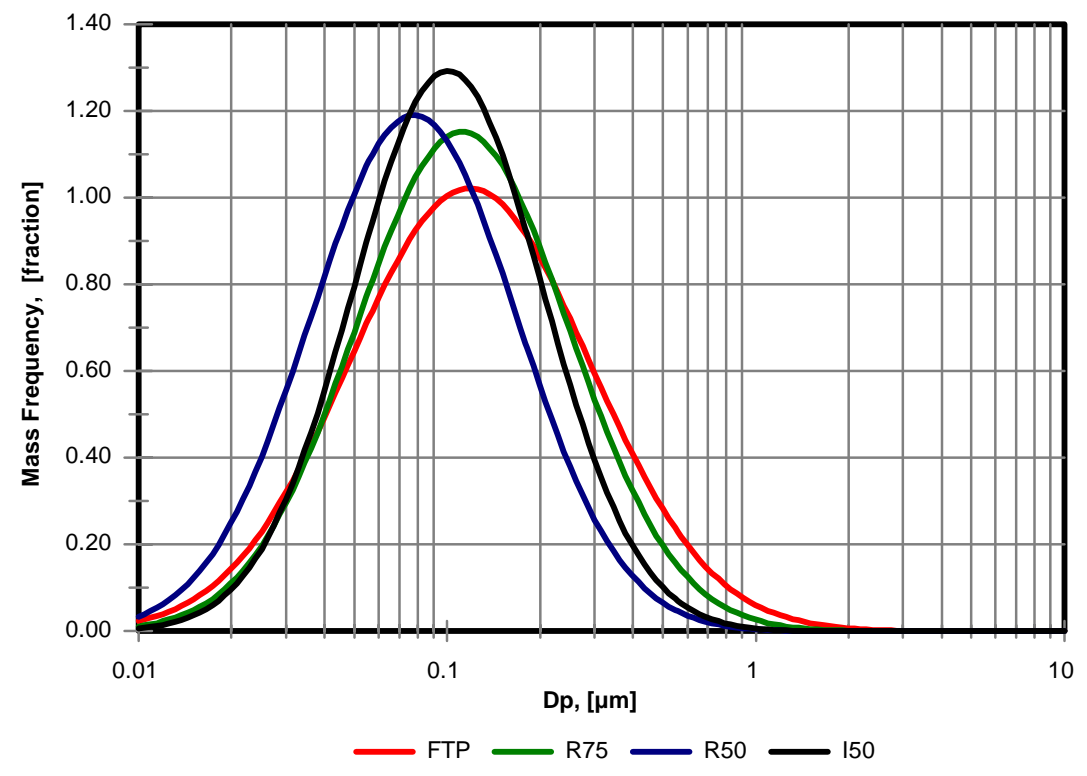

Figure 3.134 Mack E7-400, Diesel, MOUDI, Mass Frequency, $\mathrm{SO}_{4}^{--}$, Effects of Engine Operating Conditions 


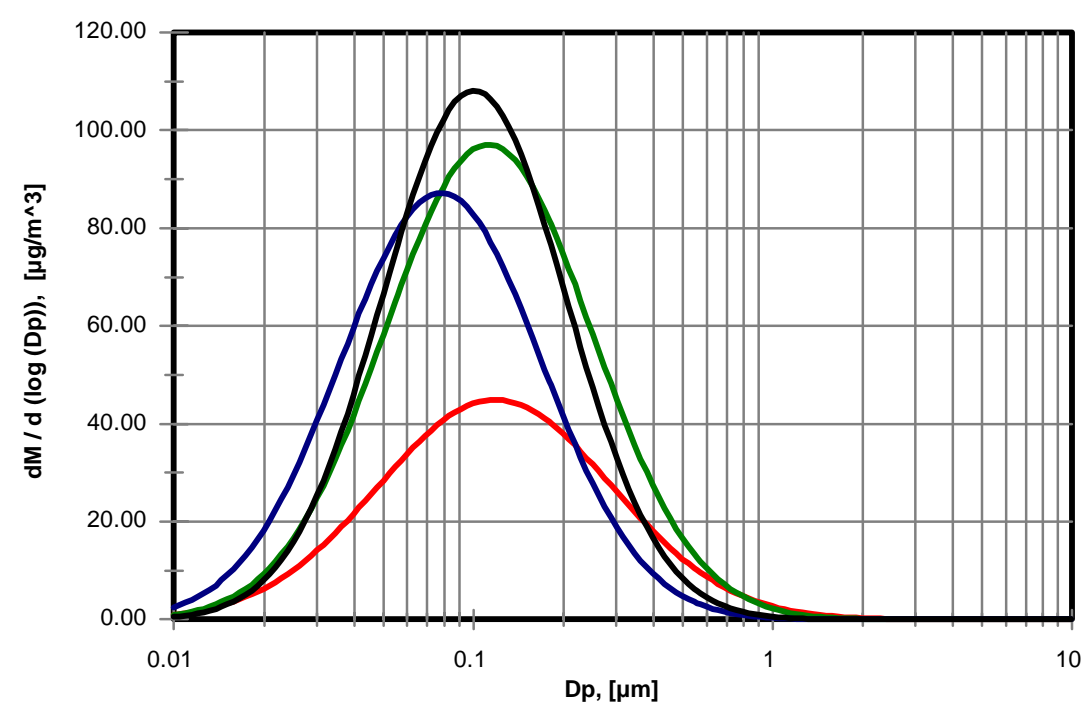

$\longrightarrow \operatorname{FTP}(\mathrm{GM}=0.119 \mu \mathrm{m}, \mathrm{GSD}=2.457) \quad \mathrm{R} 75(\mathrm{GM}=0.112 \mu \mathrm{m}, \mathrm{GSD}=2.219)$

$\mathrm{R} 50(\mathrm{GM}=0.078 \mu \mathrm{m}, \mathrm{GSD}=2.164) \quad-150(\mathrm{GM}=0.101 \mu \mathrm{m}, \mathrm{GSD}=2.035)$

Figure 3.135 Mack E7-400, Diesel, MOUDI, Mass Concentration, $\mathrm{SO}_{4}^{--}$, Effects of Engine Operating Conditions

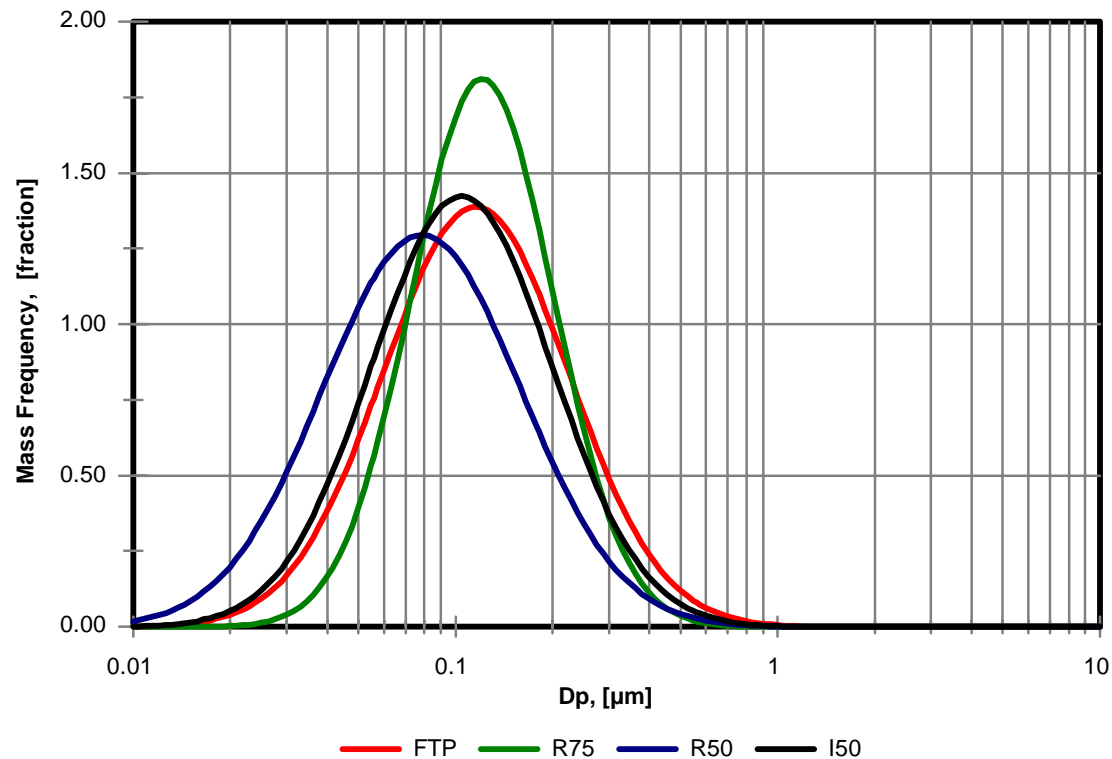

Figure 3.136 Mack E7-400, Diesel, MOUDI, Mass Frequency, Sulfur, Effects of Engine Operating Conditions 


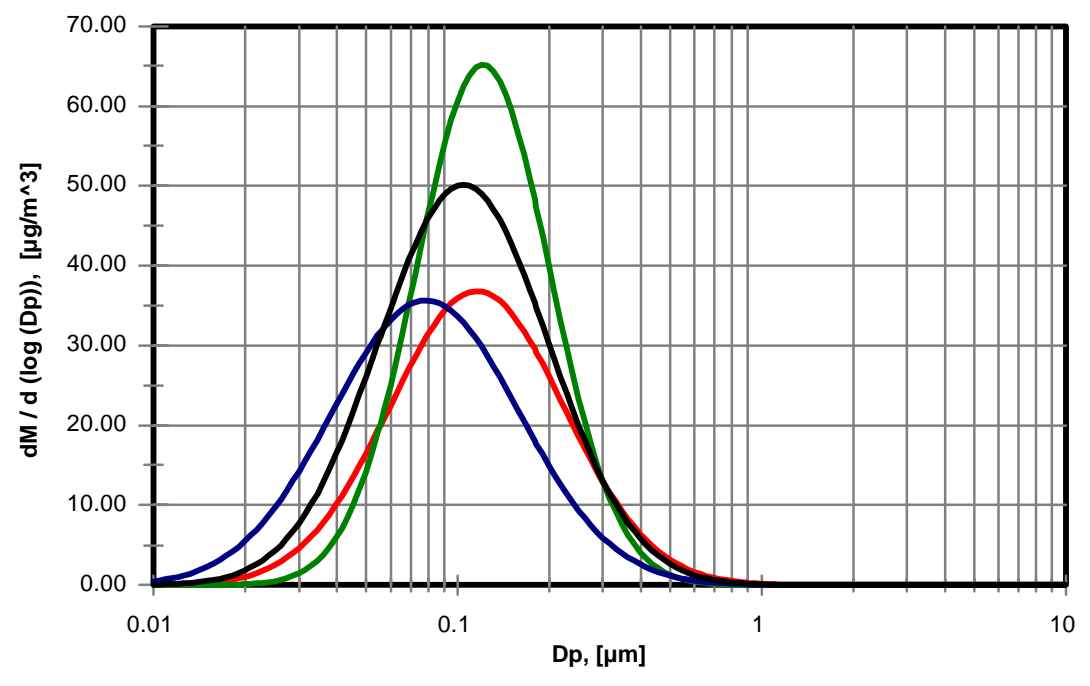

FTP $(\mathrm{GM}=0.116 \mu \mathrm{m}, \mathrm{GSD}=1.936) \quad \mathrm{R} 75(\mathrm{GM}=0.121 \mu \mathrm{m}, \mathrm{GSD}=1.660)$

R50 $(\mathrm{GM}=0.079 \mu \mathrm{m}, \mathrm{GSD}=2.031) \quad-150(\mathrm{GM}=0.105 \mu \mathrm{m}, \mathrm{GSD}=1.910)$

Figure 3.137 Mack E7-400, Diesel, MOUDI, Mass Concentration, Sulfur, Effects of Engine Operating Conditions

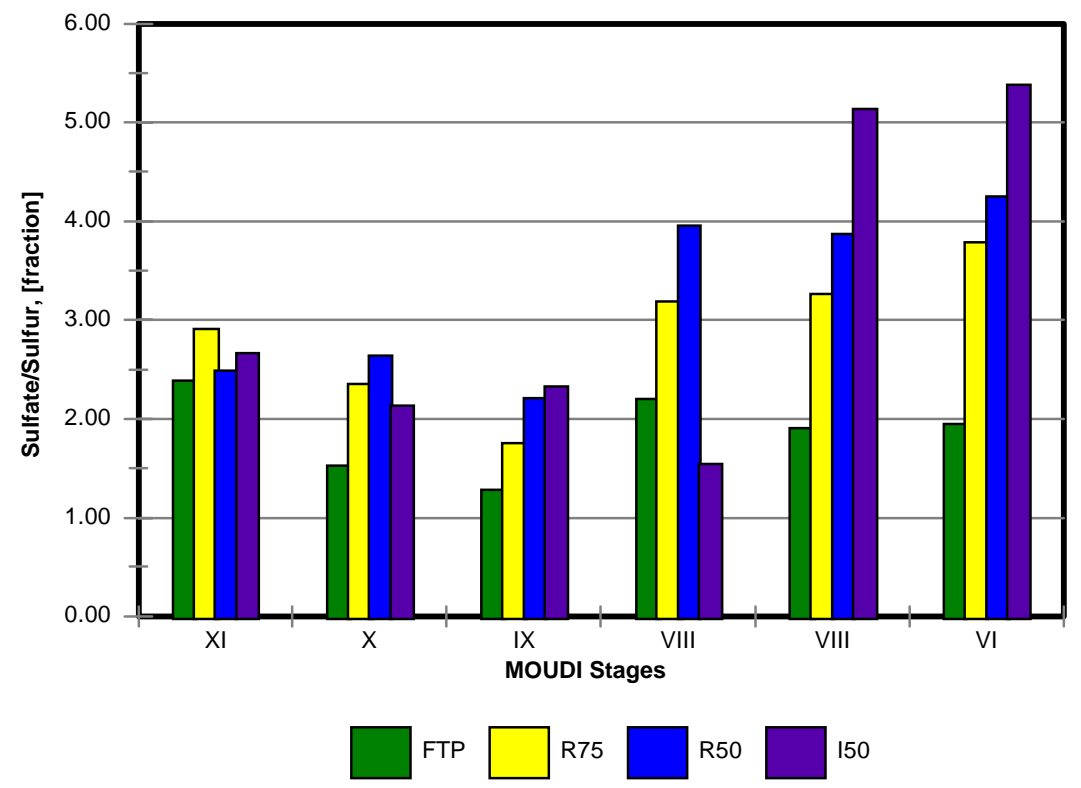

Figure 3.138 Mack E7-400, Diesel, MOUDI, $\mathrm{SO}_{4}^{--}$vs. Sulfur, Effects of Engine Operating Conditions 


\section{Ammonium}

The distributions of ammonium are given in Figures 3.139 and 3.140. The MMDs describing ammonium distributions were found to be in range from 82 to $123 \mathrm{~nm}$, while GSDs were relatively high, ranging from 2.831 to 3.602 (see Figure 3.138). The values of MMDs were slightly lower than those describing total PM distributions except for the case of engine operated at R50 mode. The results indicate that ammonium was present in the higher concentrations on the stages with smaller cut-off diameters relative to total PM except for the case of engine operated at R50 mode. The observed mass concentrations of ammonium were significantly lower in the exhaust from the engine operated over FTP cycle (see Table B.1).

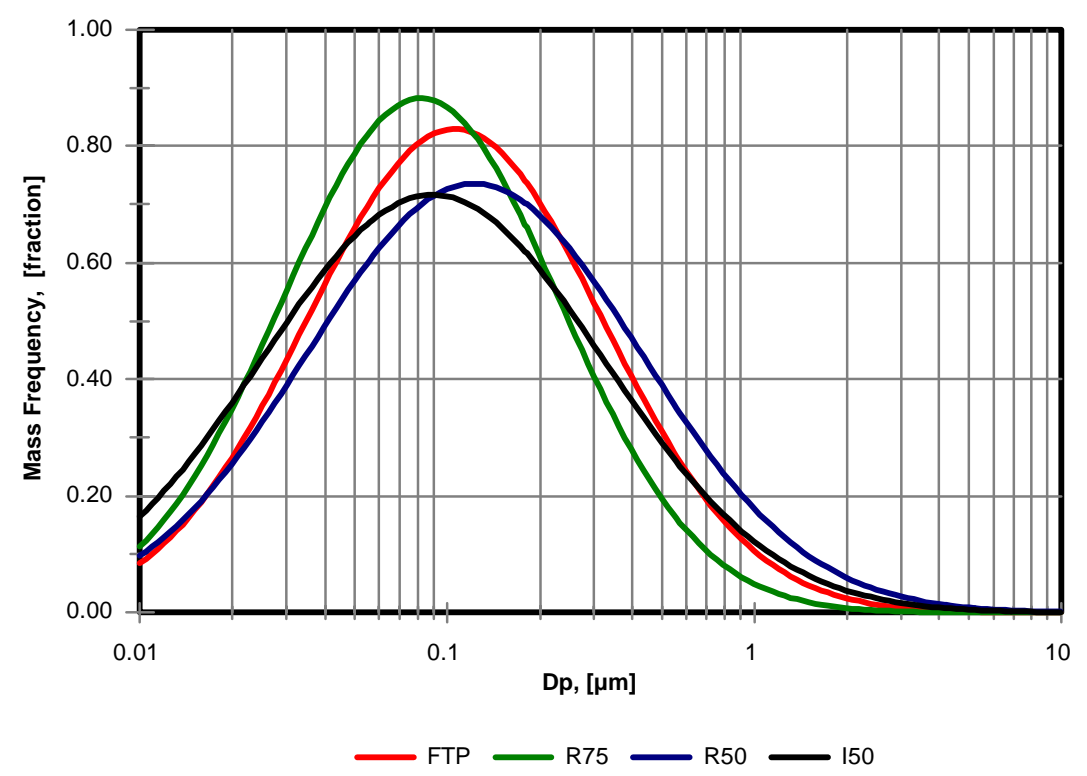

Figure 3.139 Mack E7-400, Diesel, MOUDI, Mass Frequency, $\mathrm{NH}_{4}^{++}$, Effects of Engine Operating Conditions 


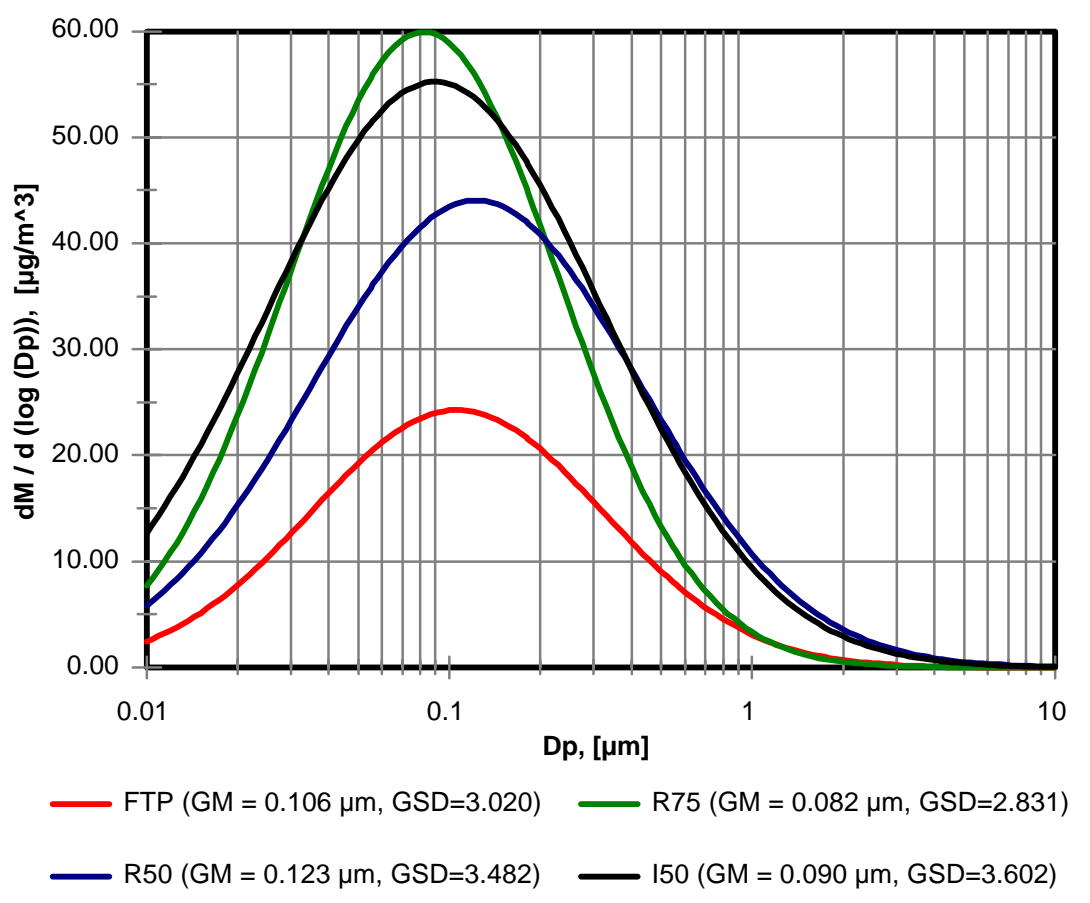

Figure 3.140 Mack E7-400, Diesel, MOUDI, Mass Concentration, $\mathrm{NH}_{4}{ }^{++}$, Effects of Engine Operating Conditions

\section{Chloride}

The distributions of chloride in the exhaust from Mack E7-400 engine for compared engine operating conditions are presented in Figures 3.141 and 3.142. The chloride distributions were described with MMDs in range from 168 to $206 \mathrm{~nm}$. The GSDs were relatively high ranging from 2.933 to 3.532 (see Figure 3.142). The values of MMDs were significantly higher than those describing total PM distributions. It appears that chloride tended to be deposited on the stages with larger cut-off diameters relative to the total PM. The higher values of GSDs indicate more even distribution of the chloride over all the stages. The normalized mass distributions were found to be unaffected by engine operating conditions, while the mass concentrations of chloride were significantly lower in the exhaust generated by the engine exercised over the FTP cycle.

The source of chlorides, in the exhaust, is the lubricating oil. The presence of chlorides in hydrocarbon rich exhaust does pose a potential treat of dioxin formation. Dioxin emission analysis was outside the scope of this study. 


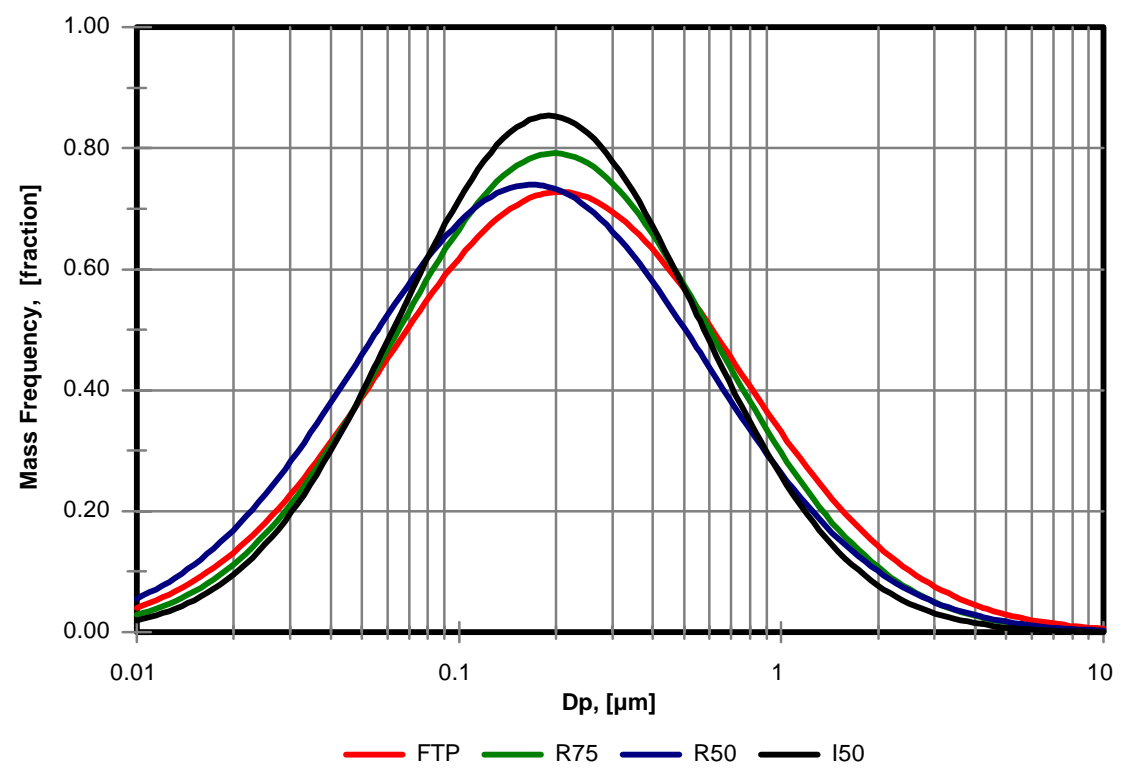

Figure 3.141 Mack E7-400, Diesel, MOUDI, Mass Frequency, $\mathrm{Cl}^{-}$, Effects of Engine Operating Conditions
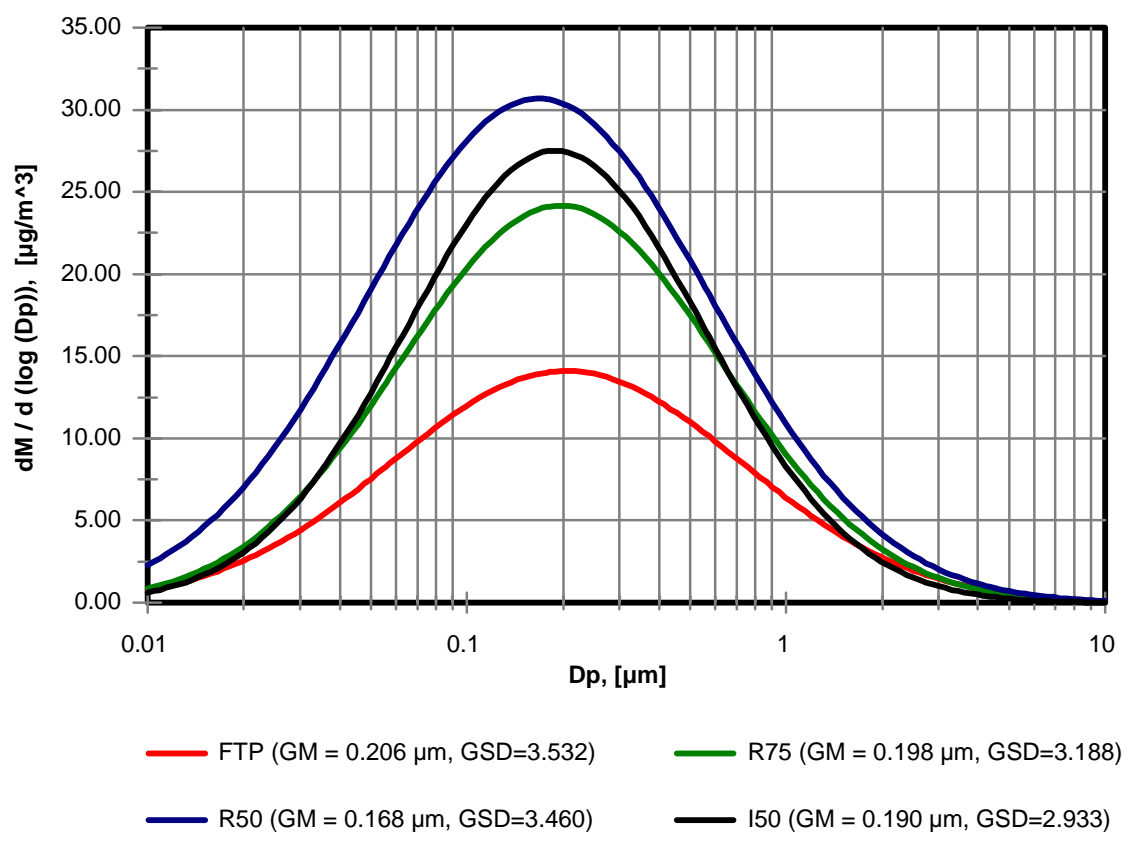

Figure 3.412 Mack E7-400, Diesel, MOUDI, Mass Concentration, $\mathrm{Cl}^{-}$, Effects of Engine Operating Conditions 


\section{Potassium}

The distributions of potassium in the exhaust from Mack E7-400 engine are presented in Figures 3.143 and 3.144. The potassium distributions were described with MMDs in range from 140 to $183 \mathrm{~nm}$. The GSDs were ranging from 2.964 to 4.540 (see Figure 3.144). The values of MMDs were somewhat higher than those describing total PM distributions. The higher values of GSDs indicate a more even distribution of potassium over stages. It appears that aerosol associated with potassium tended to be deposit on the stages with larger cut-off diameters relative to the total PM. The normalized mass distributions were found to be quite unaffected with engine operating conditions, while the mass concentrations of potassium were significantly lower in the exhaust generated by the engine exercised over FTP cycle.

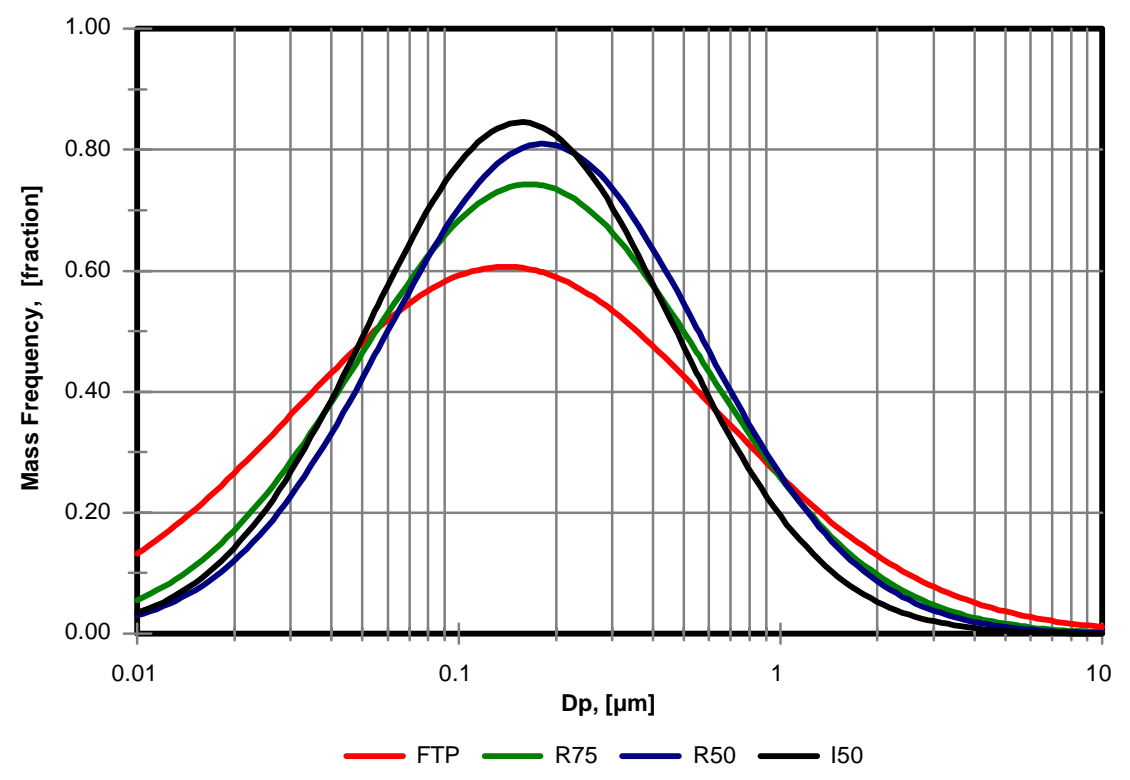

Figure 3.143 Mack E7-400, Diesel, MOUDI, Mass Frequency, $\mathrm{K}^{+}$, Effects of Engine Operating Conditions 


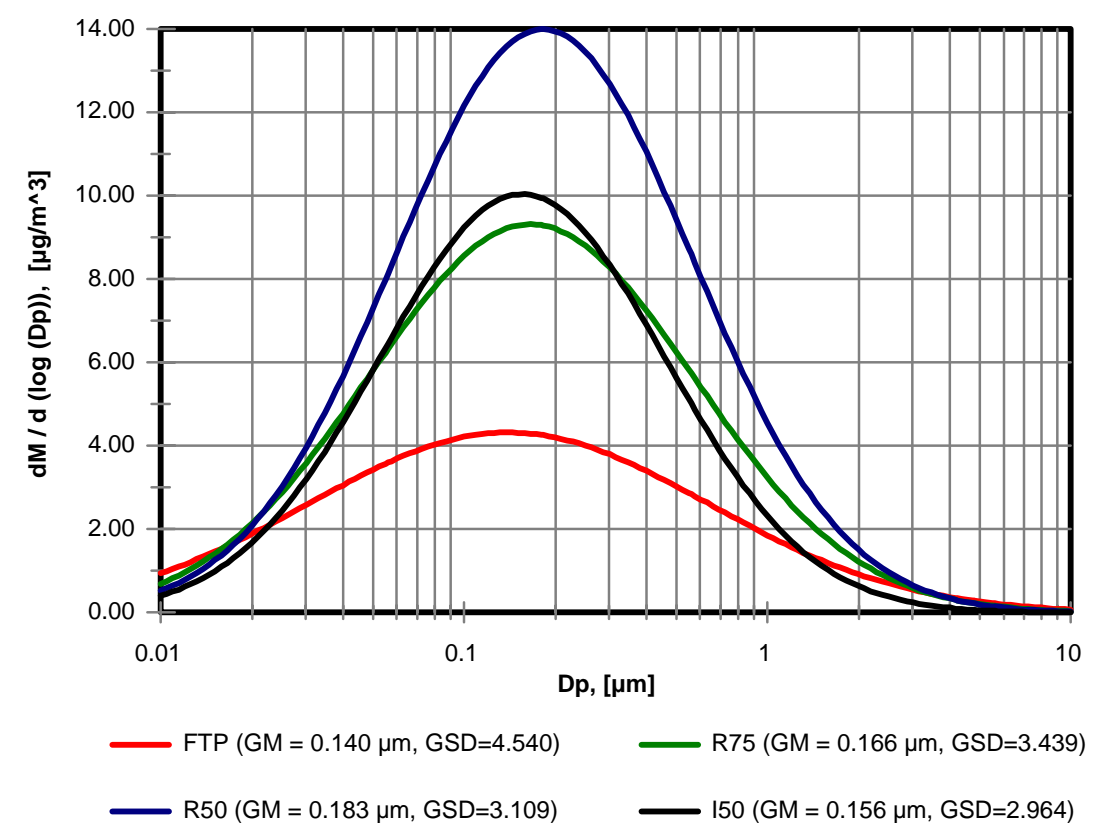

Figure 3.144 Mack E7-400, Diesel, MOUDI, Mass Concentration, $\mathrm{K}^{+}$, Effects of Engine Operating Conditions

\section{Silicon}

The mass frequencies and mass concentration distributions of silicon in the exhaust from the Mack E7-400 engine are plotted in Figures 3.145 and 3.146, respectively. The silicon distributions were described with MMDs ranging from $76 \mathrm{~nm}$ to $114 \mathrm{~nm}$ and GSDs ranging from 1.708 to 2.204. Those values are slightly lower than those describing total particulate matter distributions shown in Figures 3.147 and 3.148 (MMDs ranging from $84 \mathrm{~nm}$ to $144 \mathrm{~nm}$ and GSDs ranging from 1.869 to 2.490). This indicated that aerosol containing silicon tended to deposit slightly more on the stages with smaller cut-off diameters than to those for the total PM. The MMDs and mass concentrations of the silicon distributions in the exhaust from the engine operated at R50 and I50 conditions were found to be slightly lower than those in the exhaust from the engine operated at R75 mode and over FTP cycle. 


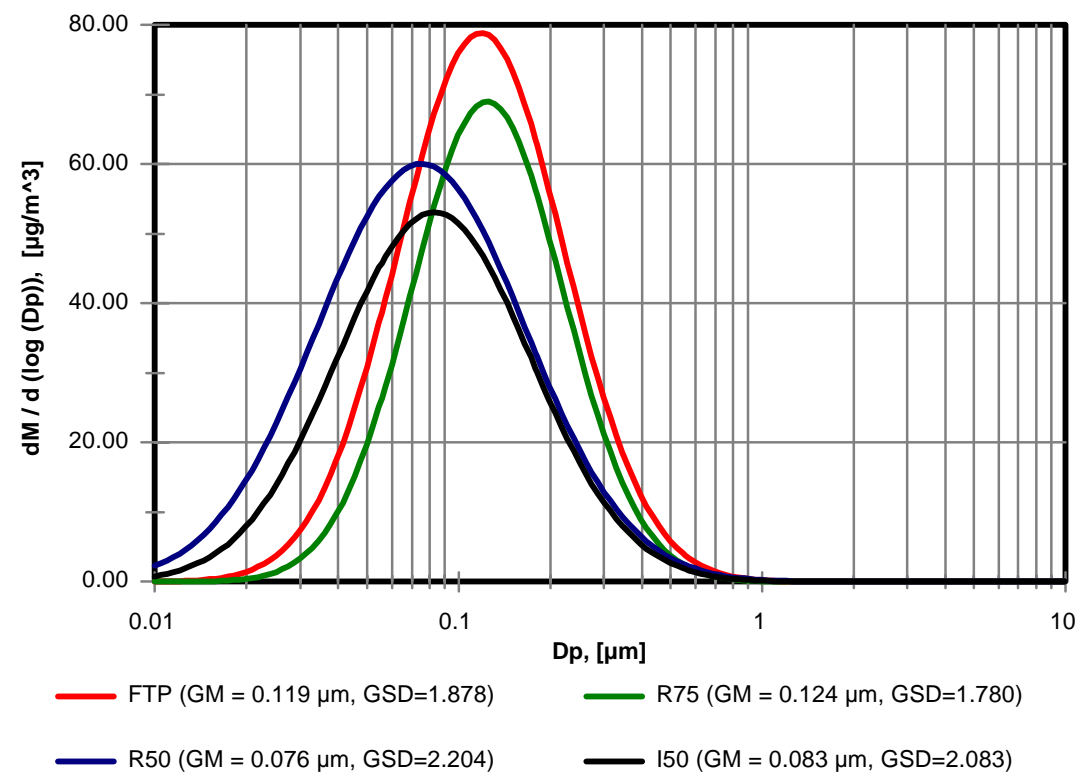

Figure 3.145 Mack E7-400, Diesel, MOUDI, Mass Frequency, Silicon, Effects of Engine Operating Conditions

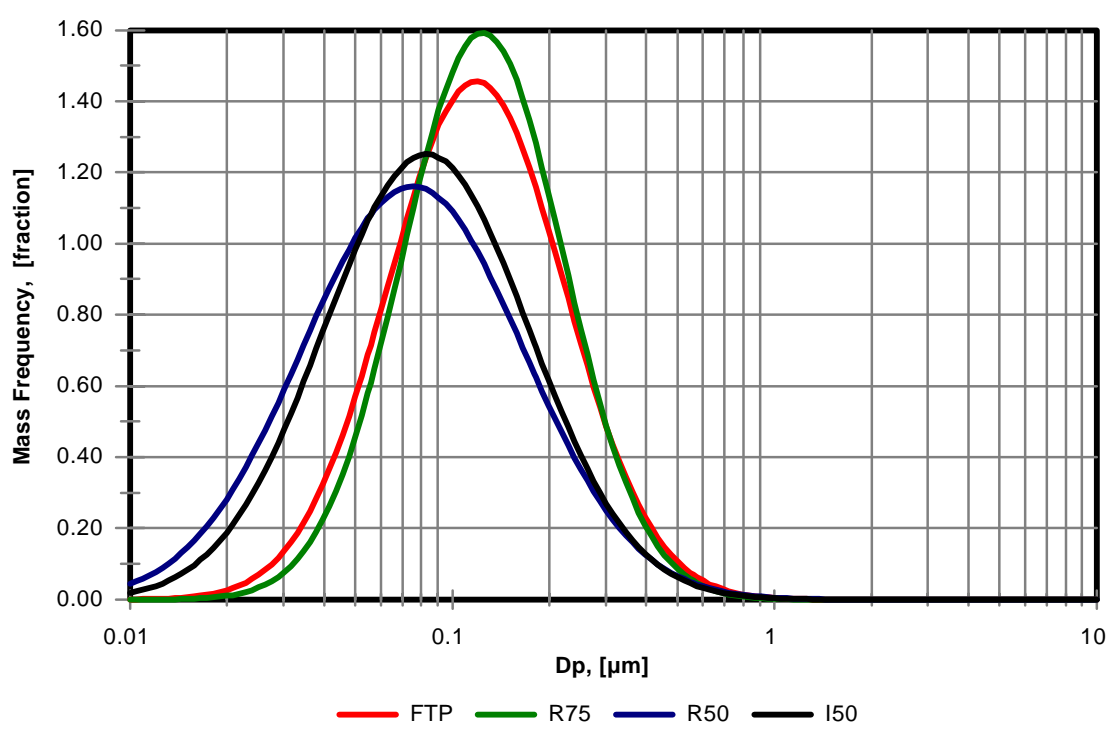

Figure 3.146 Mack E7-400, Diesel, MOUDI, Mass Concentration, Silicon, Effects of Engine Operating Conditions 


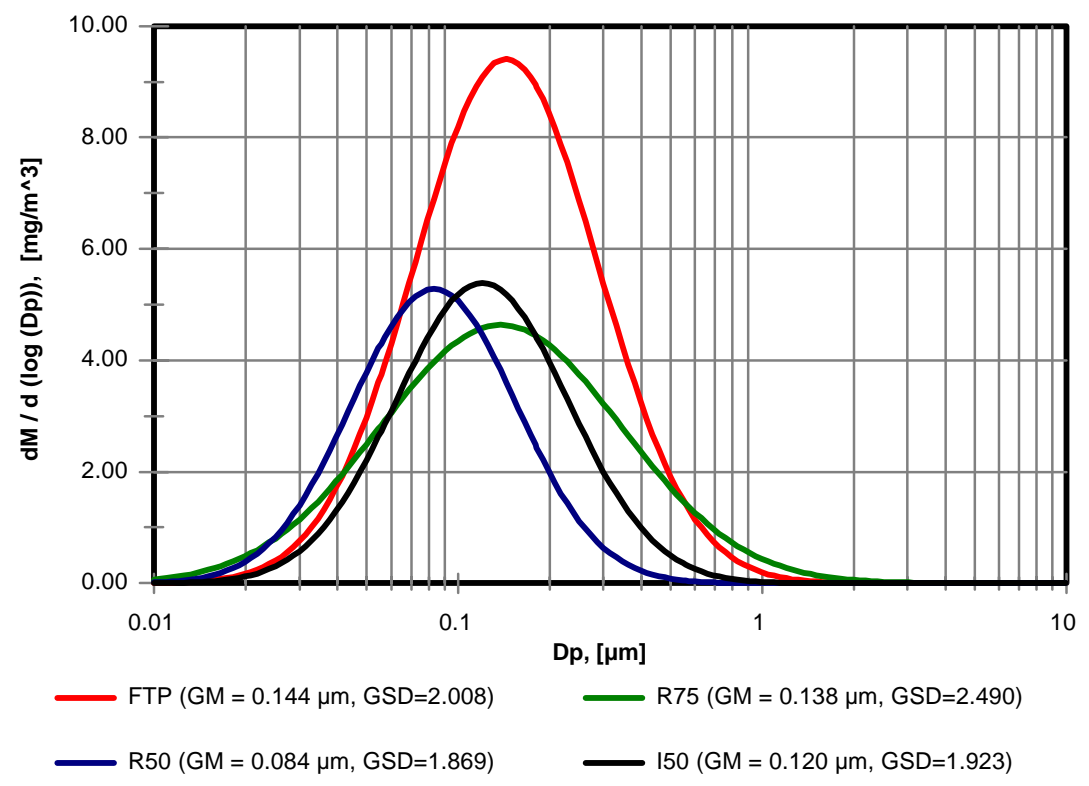

Figure 3.147 Mack E7-400, Diesel, MOUDI, Mass Frequency, Total Particulate Matter, Effects of Engine Operating Conditions

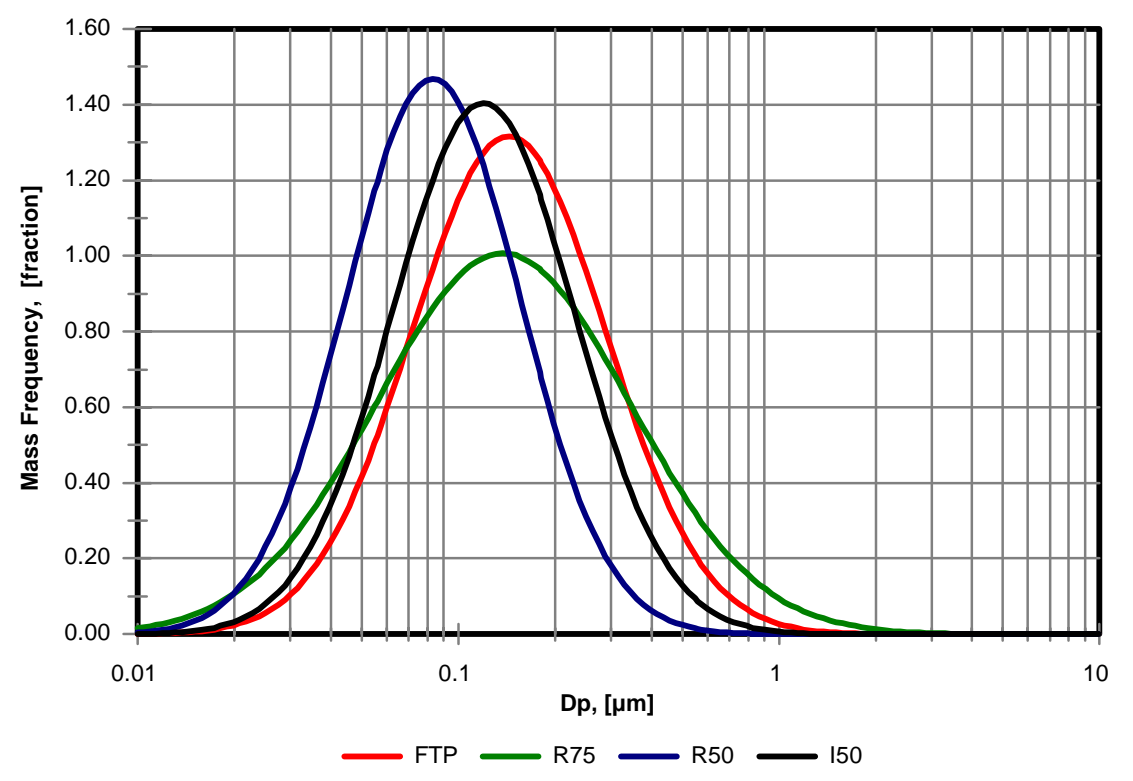

Figure 3.148 Mack E7-400, Diesel, MOUDI, Mass Concentration, Total Particulate Matter, Effects of Engine Operating Conditions 


\subsubsection{Carbon Analysis}

The bulk organic (OC) and elemental (EC) carbon were analyzed by Desert Research Institute (DRI) using the thermal/optical reflectance (TOR) technique. The carbon analysis was performed on the particulate matter collected on the last six stages of the MOUDI. The aluminum substrates and quartz after-filters were employed as collection media. The results of analysis are presented in Tables 3.15 through 3.18. The corresponding uncertainties are listed next to the results. The total carbon concentrations were found to be roughly equal to the total mass of PM per substrate/filter within experimental errors. Lognormal curves were fitted to the size resolved distributions. Mass distributions of organic, elemental and total carbon for selected engine operating conditions are presented in Figures 3.149, 3.151, 3.153, and 3.155.

The fractions of organic and elemental carbon were found to be related to the particle size (MOUDI stage) and engine operating conditions. The concentrations of organic carbon detected on the after-filters (stage XI, $\mathrm{d}_{\mathrm{p}}<0.056 \mu \mathrm{m}$ ) were found to be higher than corresponding concentrations of the elemental carbon, regardless of the engine operating condition (see Figures 3.150, 3.152, 3.154, and 3.156 and Table 3.19). The highest concentrations of organic carbon were observed under I50 steadystate conditions and the FTP cycle, $69 \%$ an $64 \%$, respectively. The organic carbon was also found to be dominant in the DPM collected on stage VI for R50 and FTP engine operating conditions. The organic carbon distributions for all the compared engine operating conditions are shown in Figure 3.159. The distributions were described with MMDs ranging from $89 \mathrm{~nm}$ to $157 \mathrm{~nm}$ and GSDs ranging from 2.760 to 3.526. The values of MMDs are slightly lower or comparable to those describing total carbon distributions shown in Figures 3.161 (MMDs ranging from $98 \mathrm{~nm}$ to $154 \mathrm{~nm}$ and GSDs ranging from 1.914 to 2.219) depending on the engine operating conditions. The GSDs for organic carbon distributions were found to be significantly larger than those for total and elemental carbon distributions indicating more uniform distributions of organic carbon than elemental over the stages. 
Table 3.15 Mack E7-400, Diesel, MOUDI, FTP, Carbon Analysis, [mg/m³]

\begin{tabular}{|c|c|c|c|c|c|c|c|c|c|}
\hline \multicolumn{3}{|c|}{ MOUDI Stage } & & VI & VII & VIII & IX & $\bar{X}$ & XI \\
\hline \multicolumn{2}{|c|}{ Cut-off Diameter } & $\mu \mathrm{m}$ & & 0.56 & 0.32 & 0.18 & 0.1 & 0.056 & $<0.056$ \\
\hline 1 & TPM & & grav. & 127.302 & 272.790 & 602.736 & 1080.768 & 449.454 & 213.036 \\
\hline 2 & Organic C & & TOR & 70.162 & 92.245 & 135.892 & 175.381 & 113.549 & 120.505 \\
\hline 3 & Organic C & uncert. & TOR & 6.254 & 7.813 & 10.931 & 14.048 & 9.372 & 9.892 \\
\hline 4 & Elemental C & & TOR & 98.094 & 212.926 & 527.543 & 894.381 & 348.022 & 68.327 \\
\hline 5 & Elemental C & uncert. & TOR & 6.775 & 14.828 & 36.911 & 62.632 & 24.181 & 4.696 \\
\hline 6 & Total C & & TOR & 168.826 & 305.741 & 664.005 & 1070.592 & 462.140 & 188.833 \\
\hline 7 & Total C & uncert. & TOR & 12.410 & 22.282 & 48.522 & 78.399 & 33.713 & 13.928 \\
\hline
\end{tabular}

Table 3.16 Mack E7-400, Diesel, MOUDI, R75, Carbon Analysis, [mg/m³]

\begin{tabular}{|r|l|l|r|r|r|r|r|r|r|}
\hline \multicolumn{2}{l}{$\begin{array}{l}\text { MOUDI Stage } \\
\text { Cut-off Diameter }\end{array}$} & \multicolumn{1}{c}{$\mu .56$} & \multicolumn{1}{c}{ VI } & \multicolumn{1}{c}{ VII } & \multicolumn{1}{c|}{ VIII } & \multicolumn{1}{c|}{ IX } & \multicolumn{1}{c|}{ X } & \multicolumn{1}{c|}{ XI } \\
\hline 1 & TPM & & grav. & 204.472 & 469.083 & 829.917 & 1719.972 & 974.250 & 1190.750 \\
\hline 2 & Organic C & & TOR & 160.044 & 146.814 & 192.519 & 425.858 & 339.258 & 384.694 \\
\hline 3 & Organic C & uncert. & TOR & 19.333 & 18.131 & 20.536 & 34.969 & 30.158 & 32.564 \\
\hline 4 & Elemental C & & TOR & 200.353 & 371.147 & 694.694 & 1415.158 & 679.058 & 280.247 \\
\hline 5 & Elemental C & uncert. & TOR & 13.322 & 25.350 & 48.203 & 98.719 & 47.000 & 19.336 \\
\hline 6 & Total C & & TOR & 363.036 & 520.600 & 888.650 & 1843.656 & 1020.956 & 664.942 \\
\hline 7 & Total C & uncert. & TOR & 29.788 & 40.613 & 65.871 & 134.430 & 74.291 & 50.050 \\
\hline
\end{tabular}

Table 3.17 Mack E7-400, Diesel, MOUDI, R50, Carbon Analysis, [mg/m³]

\begin{tabular}{|c|c|c|c|c|c|c|c|c|c|}
\hline \multirow{2}{*}{\multicolumn{2}{|c|}{$\begin{array}{l}\text { MOUDI Stage } \\
\text { Cut-off Diameter }\end{array}$}} & & & VI & VII & VIII & IX & $\mathrm{X}$ & XI \\
\hline & & \multicolumn{2}{|l|}{$\mu \mathrm{m}$} & 0.56 & 0.32 & 0.18 & 0.1 & 0.056 & $<0.056$ \\
\hline 1 & TPM & & grav. & 24.056 & 216.500 & 457.056 & 2008.639 & 1888.361 & 589.361 \\
\hline 2 & Organic C & & TOR & 128.772 & 157.639 & 167.261 & 307.986 & 315.203 & 549.475 \\
\hline 3 & Organic $\mathrm{C}$ & uncert. & TOR & 16.928 & 18.131 & 19.333 & 27.753 & 27.753 & 44.592 \\
\hline 4 & Elemental C & & TOR & 88.494 & 285.750 & 563.592 & 1986.478 & 1721.867 & 531.628 \\
\hline 5 & Elemental C & uncert. & TOR & 6.106 & 19.336 & 38.581 & 138.411 & 120.369 & 36.175 \\
\hline 6 & Total C & & TOR & 219.906 & 446.028 & 732.289 & 2297.103 & 2039.708 & 1081.103 \\
\hline 7 & Total C & uncert. & TOR & 22.571 & 35.802 & 55.046 & 166.905 & 148.863 & 78.917 \\
\hline
\end{tabular}

Table 3.18 Mack E7-400, Diesel, MOUDI, I50, Carbon Analysis, [mg/m³]

\begin{tabular}{|c|c|c|c|c|c|c|c|c|c|}
\hline \multirow{2}{*}{\multicolumn{2}{|c|}{$\begin{array}{l}\text { MOUDI Stage } \\
\text { Cut-off Diameter }\end{array}$}} & & & VI & VII & VIII & IX & $\mathrm{X}$ & XI \\
\hline & & \multicolumn{2}{|l|}{$\mu \mathrm{m}$} & 0.56 & 0.32 & 0.18 & 0.1 & 0.056 & $<0.056$ \\
\hline 1 & TPM & & grav. & 158.767 & 375.267 & 952.600 & 2049.533 & 779.400 & 158.767 \\
\hline 2 & Organic $\mathrm{C}$ & & TOR & 91.020 & 161.743 & 353.707 & 524.020 & 238.240 & 509.263 \\
\hline 3 & Organic $\mathrm{C}$ & uncert. & TOR & 18.870 & 21.757 & 31.860 & 43.407 & 24.643 & 43.407 \\
\hline 4 & Elemental C & & TOR & 64.337 & 296.713 & 954.873 & 1581.280 & 647.443 & 230.933 \\
\hline 5 & Elemental C & uncert. & TOR & 5.883 & 20.317 & 66.503 & 109.803 & 44.853 & 15.987 \\
\hline 6 & Total C & & TOR & 159.967 & 461.623 & 1311.747 & 2108.467 & 888.850 & 738.753 \\
\hline 7 & Total C & uncert. & TOR & 22.756 & 37.189 & 96.366 & 154.099 & 66.056 & 55.730 \\
\hline
\end{tabular}


The elemental carbon (EC) distributions are shown in Figure 3.158. The statistical parameters describing elemental carbon distributions are almost identical to those describing total carbon distributions. Elemental carbon was the primary constituent of the DPM collected on the MOUDI stages VII through X. EC made up approximately 64.1 to $86.5 \%$ of total particulate matter depending on the stage and engine operating conditions. This was reflected on the GSDs for the elemental carbon distributions which were found to be somewhat smaller than corresponding GSDs for total carbon distributions regardless of engine operating conditions (see Table 3.19). Figures 3.160 and 3.161 show a comparison of the fractional distribution of organic carbon and elemental carbon on stages VI to XI for steady-state modes R75, R50, and I50, and transient FTP cycle. The highest fraction of the elemental carbon, $86.5 \%$, was detected in the PM impacted on stage IX (cut-off diameter of $0.1 \mu \mathrm{m}$ ) for the R50 engine operating conditions.

The mass of the total carbon $(\mathrm{TC}=\mathrm{EC}+\mathrm{OC})$ determined by TOR analysis exceeded the mass of the soot determined by gravimetric analysis in the several instances (see Tables 3.15 through 3.18). Fact that this mostly occurred for lightly loaded substrates/filters indicate potential limitations of the analytical technique. 
Table 3.19 Mack E7-400, Results of Chemical Analyses: $\mathrm{SO}_{4}^{-}$, Organic vs. Elemental Carbon

\begin{tabular}{|c|c|c|c|c|c|}
\hline Stage & $\begin{array}{c}\text { Cut-Off } \\
\text { Diameter, } \mu \mathrm{m}\end{array}$ & $\begin{array}{c}\text { Engine } \\
\text { Operating } \\
\text { Conditions }\end{array}$ & $\begin{array}{c}\mathrm{SO}_{4}^{-}, \\
\%\end{array}$ & $\begin{array}{c}\text { Organic } \\
\text { Carbon (OC), \% }\end{array}$ & $\begin{array}{c}\text { Elemental } \\
\text { Carbon (EC), } \\
\%\end{array}$ \\
\hline \multirow{4}{*}{ VI } & \multirow{4}{*}{0.560} & FTP & 0.48 & 41.56 & 58.10 \\
\hline & & R75 & 0.58 & 44.08 & 55.19 \\
\hline & & R50 & N/A & 58.56 & 40.24 \\
\hline & & $\mathrm{I} 50$ & 1.97 & 56.90 & 40.22 \\
\hline \multirow{4}{*}{ VII } & \multirow{4}{*}{0.320} & FTP & 0.63 & 30.17 & 69.64 \\
\hline & & R75 & 1.73 & 28.20 & 71.29 \\
\hline & & $\mathrm{R} 50$ & 5.26 & 35.34 & 64.07 \\
\hline & & I50 & 2.74 & 35.04 & 64.28 \\
\hline \multirow{4}{*}{ VIII } & \multirow{4}{*}{0.180} & FTP & 0.44 & 20.47 & 79.45 \\
\hline & & R75 & 1.63 & 21.66 & 78.17 \\
\hline & & R50 & 5.78 & 22.84 & 76.96 \\
\hline & & I50 & 1.53 & 26.96 & 72.79 \\
\hline \multirow{4}{*}{ IX } & \multirow{4}{*}{0.100} & FTP & 0.49 & 16.38 & 83.54 \\
\hline & & R75 & 1.86 & 23.10 & 76.76 \\
\hline & & R50 & 1.40 & 13.41 & 86.48 \\
\hline & & I50 & 1.92 & 24.85 & 75.00 \\
\hline \multirow{4}{*}{$X$} & \multirow{4}{*}{0.056} & FTP & 0.77 & 24.57 & 75.31 \\
\hline & & R75 & 2.20 & 33.23 & 66.51 \\
\hline & & R50 & 1.87 & 15.45 & 84.42 \\
\hline & & I50 & 2.78 & 26.80 & 72.84 \\
\hline \multirow{4}{*}{$\begin{array}{c}\text { XI } \\
\text { (after-filter) }\end{array}$} & \multirow{4}{*}{$<0.056$} & FTP & 1.52 & 63.82 & 36.18 \\
\hline & & R75 & 3.80 & 57.85 & 42.15 \\
\hline & & R50 & 1.90 & 50.83 & 49.17 \\
\hline & & I50 & 2.34 & 68.94 & 31.26 \\
\hline
\end{tabular}




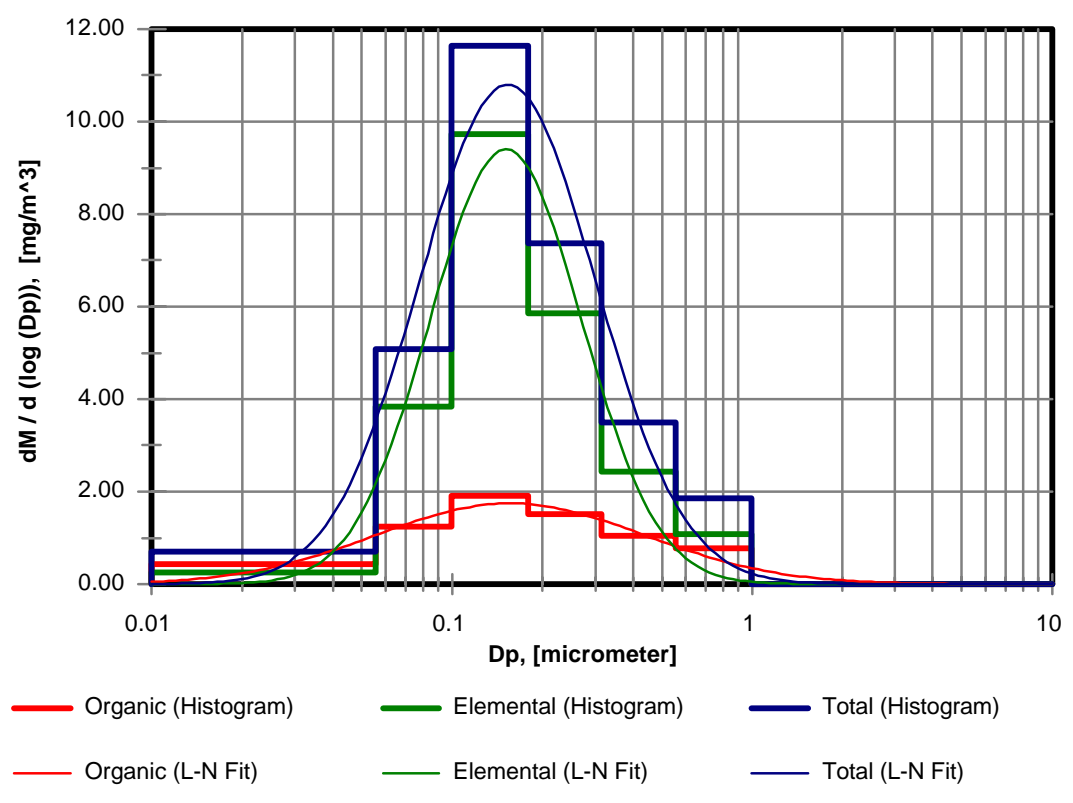

Figure 3.149 Mack E7-400, Diesel, MOUDI, Mass Concentration, Carbon Analysis, FTP

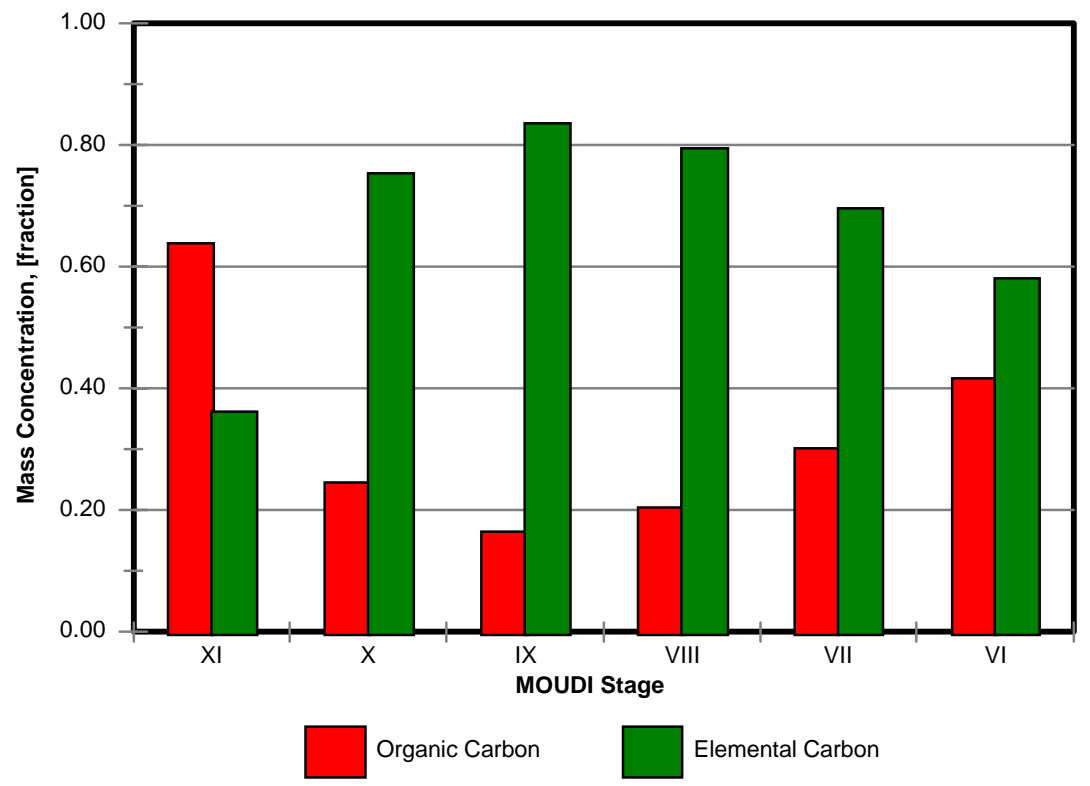

Figure 3.150 Mack E7-400, Diesel, MOUDI, Mass Fractions, Carbon Analysis, Organic vs. Elemental Carbon, FTP 


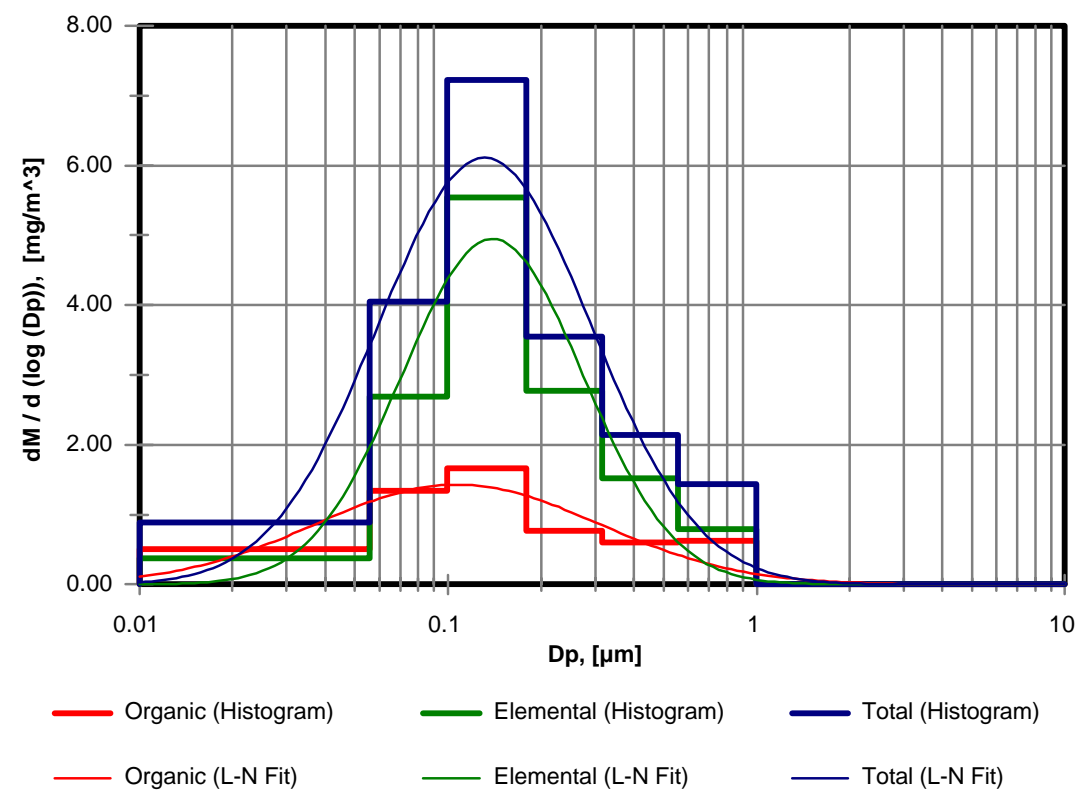

Figure 3.151 Mack E7-400, Diesel, MOUDI, Mass Concentration, Carbon Analysis, R75

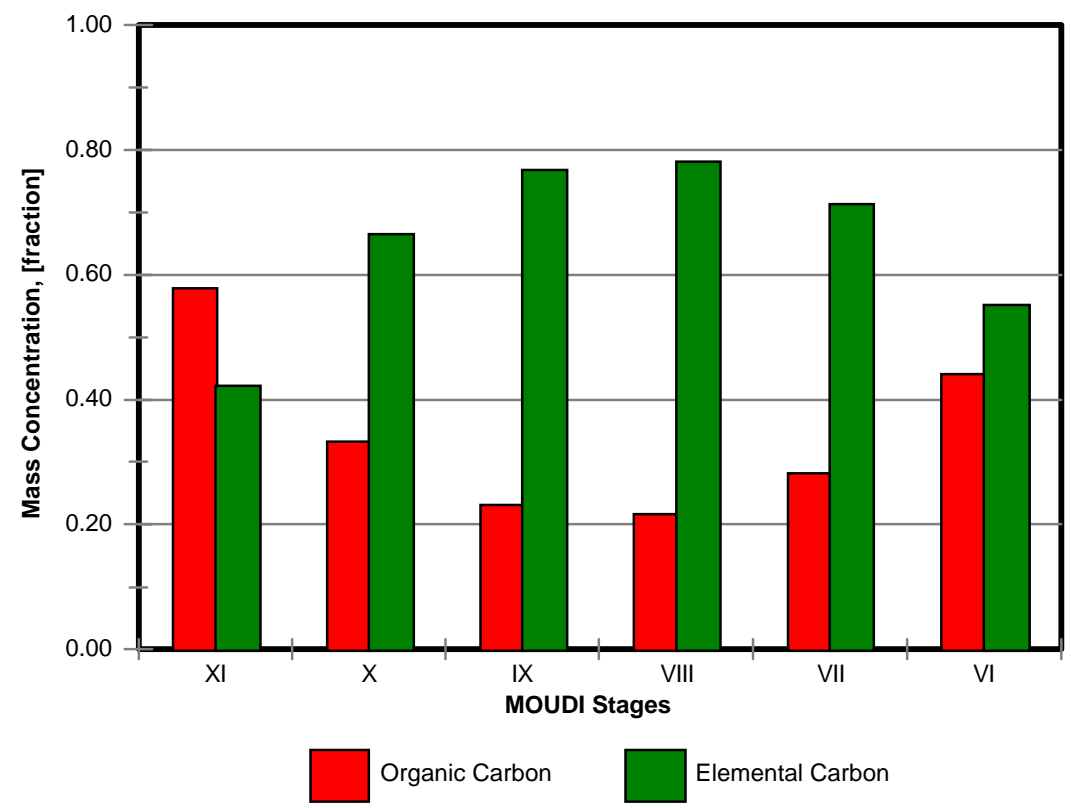

Figure 3.152 Mack E7-400, Diesel, MOUDI,

Mass Fractions, Carbon Analysis, Organic vs. Elemental Carbon, R75 


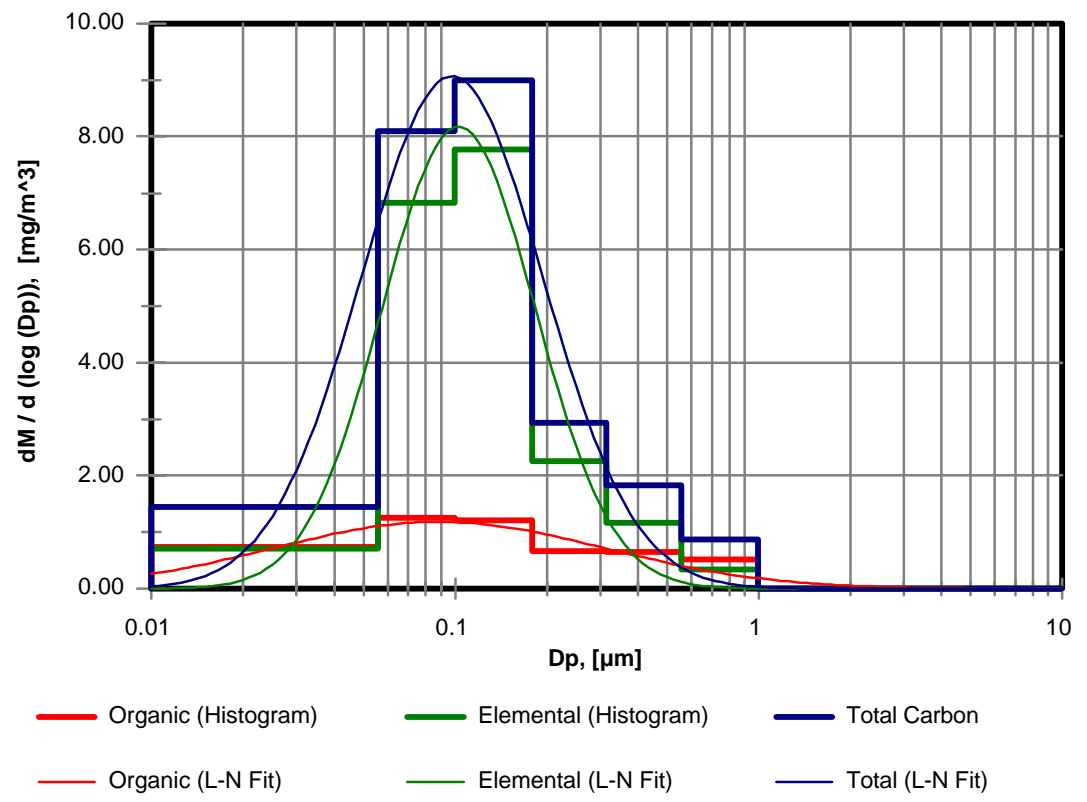

Figure 3.153 Mack E7-400, Diesel, MOUDI, Mass Concentration, Carbon Analysis, R50

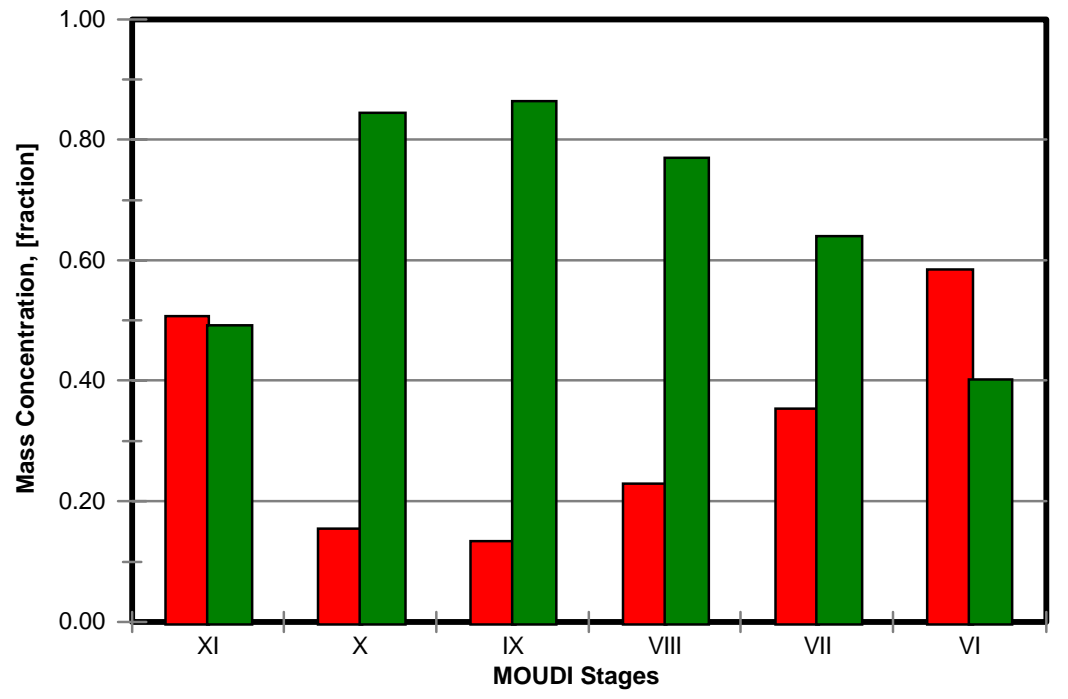

Organic Carbon Elemental Carbon

Figure 3.154 Mack E7-400, Diesel, MOUDI, Mass Fraction, Carbon Analysis, Organic vs. Elemental Carbon, R50 


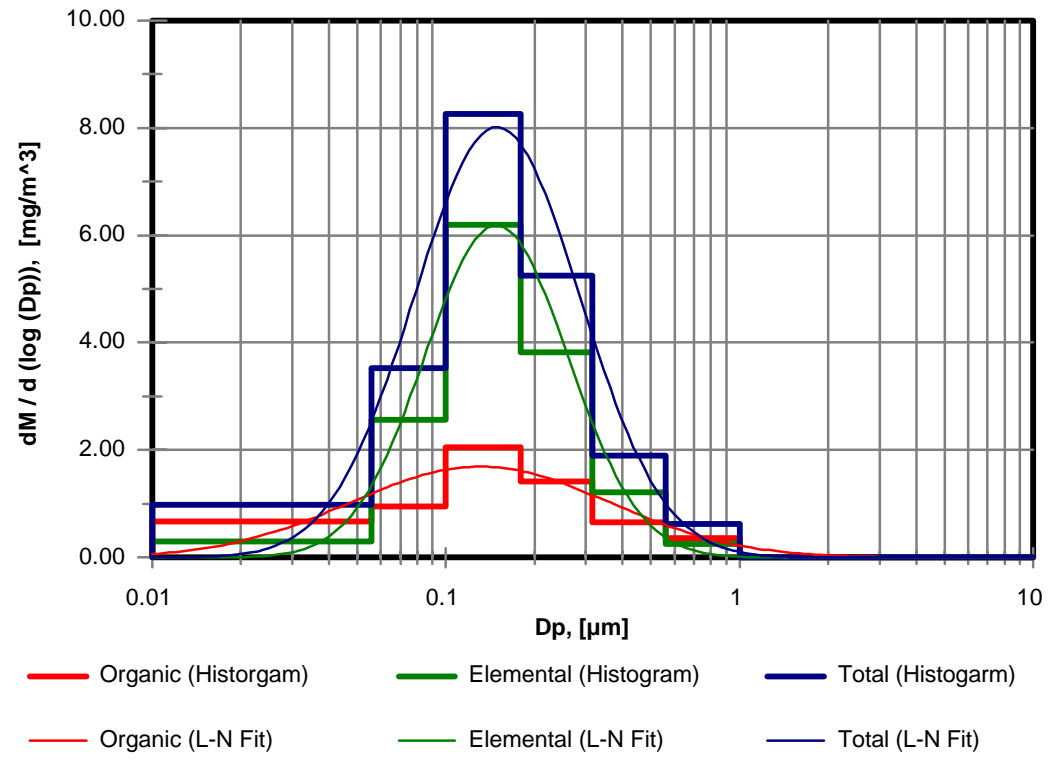

Figure 3.155 Mack E7-400, Diesel, MOUDI, Mass Concentration, Carbon Analysis, I50

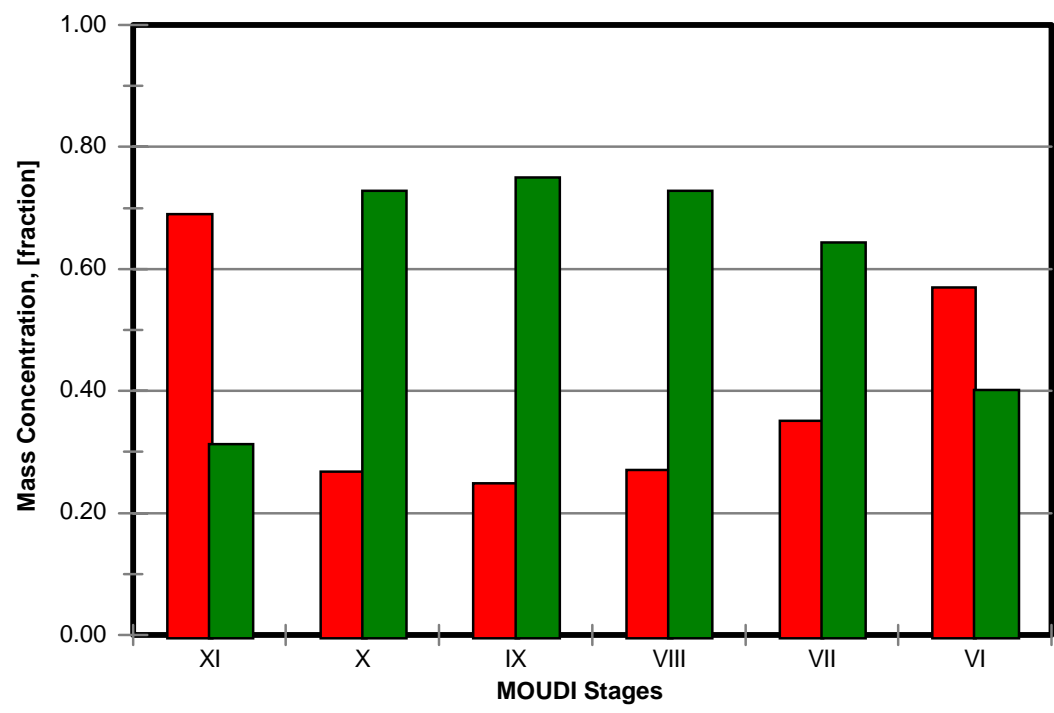

Organic Carbon

Elemental Carbon

Figure 3.156 Mack E7-400, Diesel, I50, MOUDI,

Normalized Mass Fraction, Carbon Analysis,

Organic vs. Elemental Carbon 


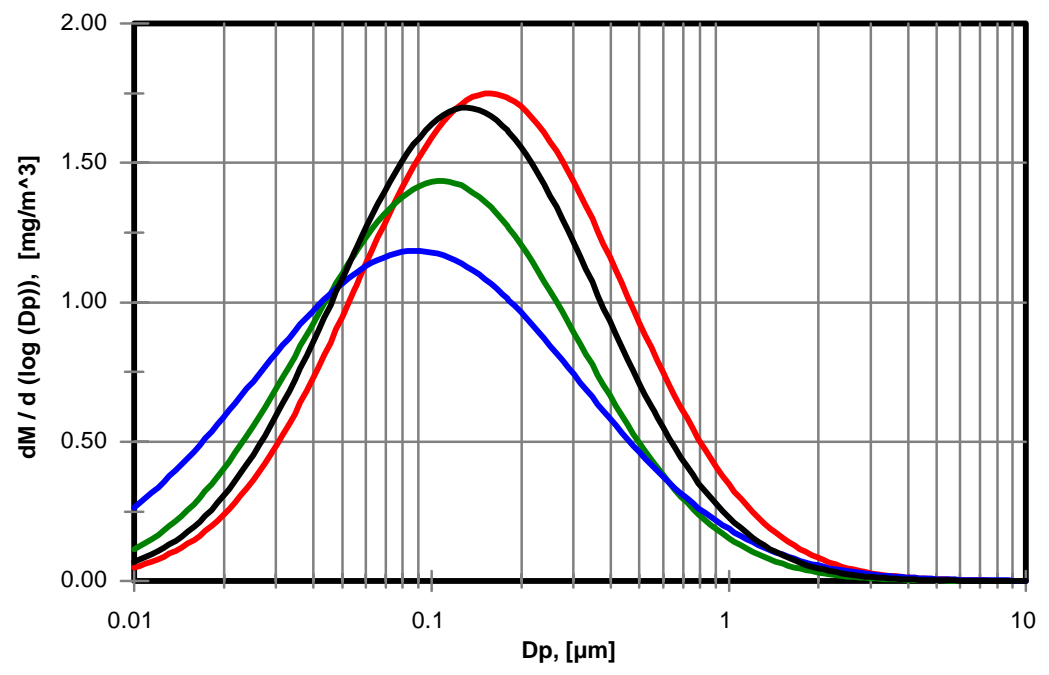

$\longrightarrow$ FTP $(\mathrm{GM}=0.157 \mu \mathrm{m}, \mathrm{GSD}=2.805)$

R75 $(\mathrm{GM}=0.108 \mu \mathrm{m}, \mathrm{GSD}=2.873)$

R50 $(\mathrm{GM}=0.089 \mu \mathrm{m}, \mathrm{GSD}=3.526)$ $150(\mathrm{GM}=0.131 \mu \mathrm{m}, \mathrm{GSD}=2.760)$

Figure 3.157 Mack E7-400, Diesel, MOUDI, Mass Concentration, Organic Carbon, Effects of Engine Operating Mode

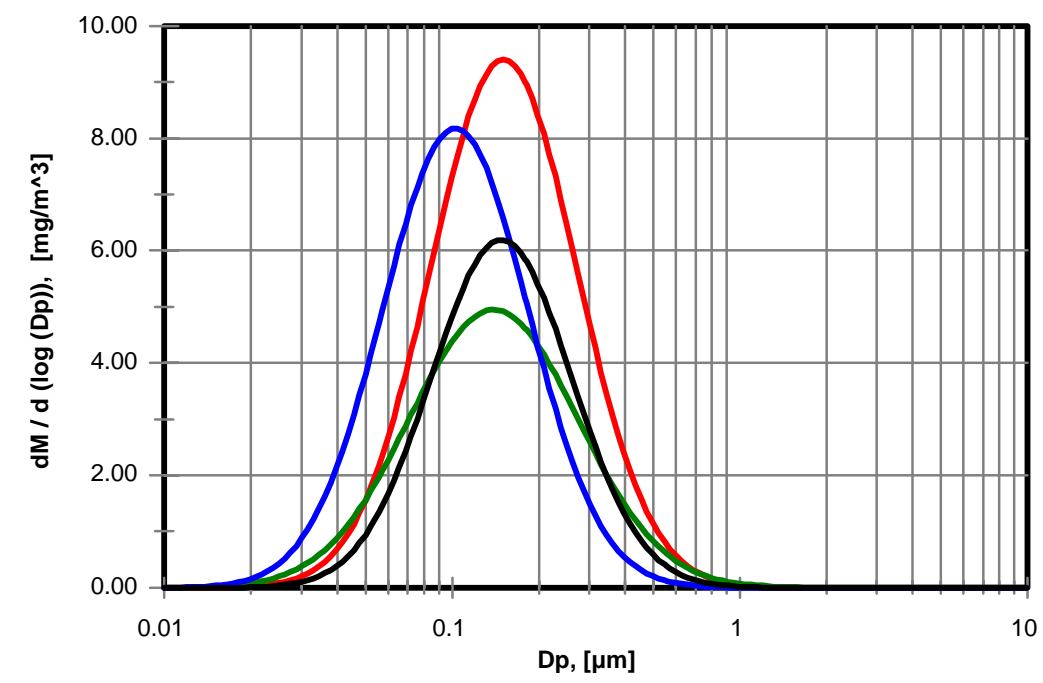

FTP $(\mathrm{GM}=0.152 \mu \mathrm{m}, \mathrm{GSD}=1.791)$

R75 $(\mathrm{GM}=0.140 \mu \mathrm{m}, \mathrm{GSD}=1.965)$

$\mathrm{R} 50(\mathrm{GM}=0.103 \mu \mathrm{m}, \mathrm{GSD}=1.789)$

I50 $(\mathrm{GM}=0.149 \mu \mathrm{m}, \mathrm{GSD}=1.750)$

Figure 3.158 Mack E7-400, Diesel, MOUDI, Mass Concentration, Elemental Carbon, Effects of Engine Operating Mode 


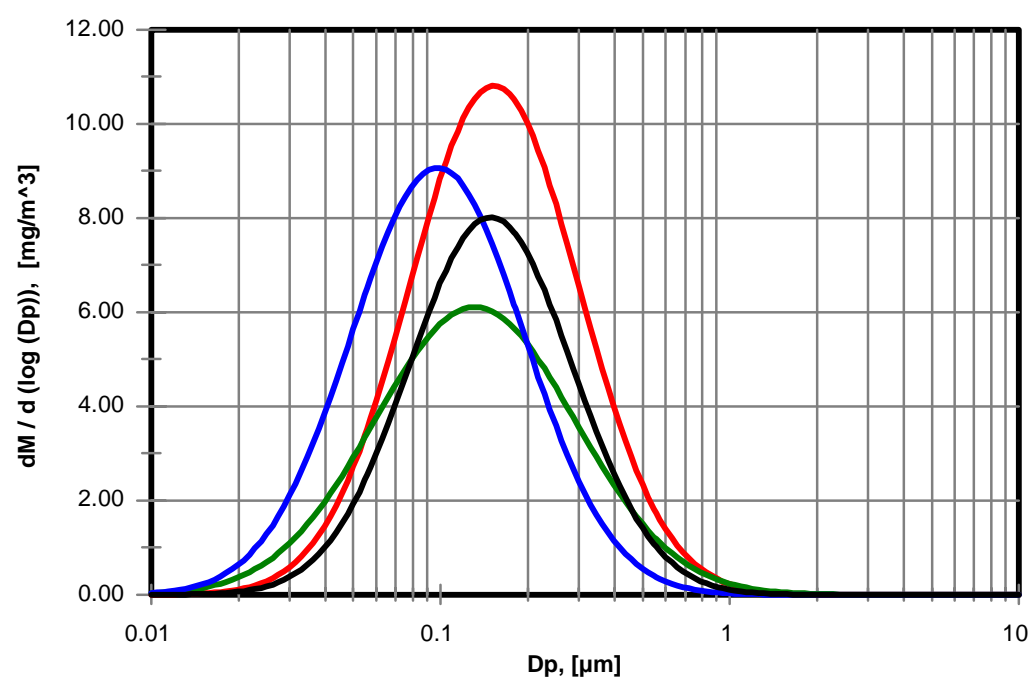

FTP $(\mathrm{GM}=0.154 \mu \mathrm{m}, \mathrm{GSD}=1.964)$ $\mathrm{R} 75(\mathrm{GM}=0.132 \mu \mathrm{m}, \mathrm{GSD}=2.219)$

R50 $(\mathrm{GM}=0.098 \mu \mathrm{m}, \mathrm{GSD}=1.994)$

$150(\mathrm{GM}=0.150 \mu \mathrm{m}, \mathrm{GSD}=1.914)$

Figure 3.159 Mack E7-400, Diesel, MOUDI, Mass Concentration,

Total Carbon, Effects of Engine Operating Mode

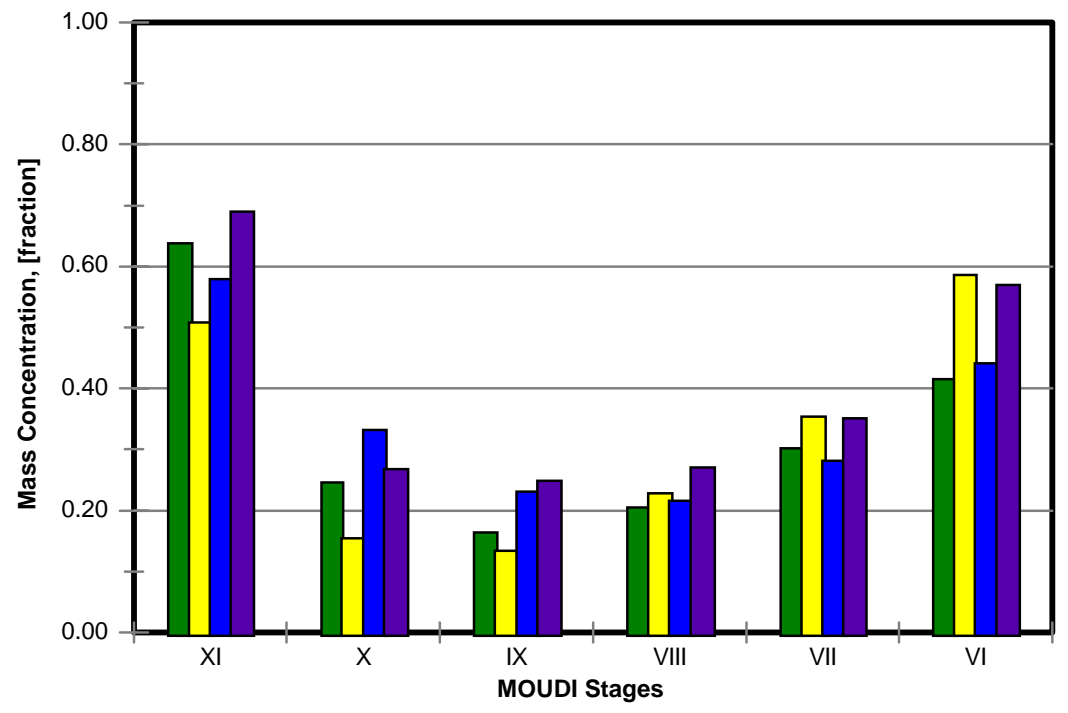

FTP (Organic)

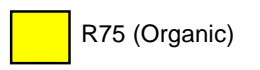

R50 (Organic)

150 (Organic)

Figure 3.160 Mack E7-400, Diesel, MOUDI, Normalized Mass

Fraction, Organic Carbon, Effects of Engine Operating Mode 

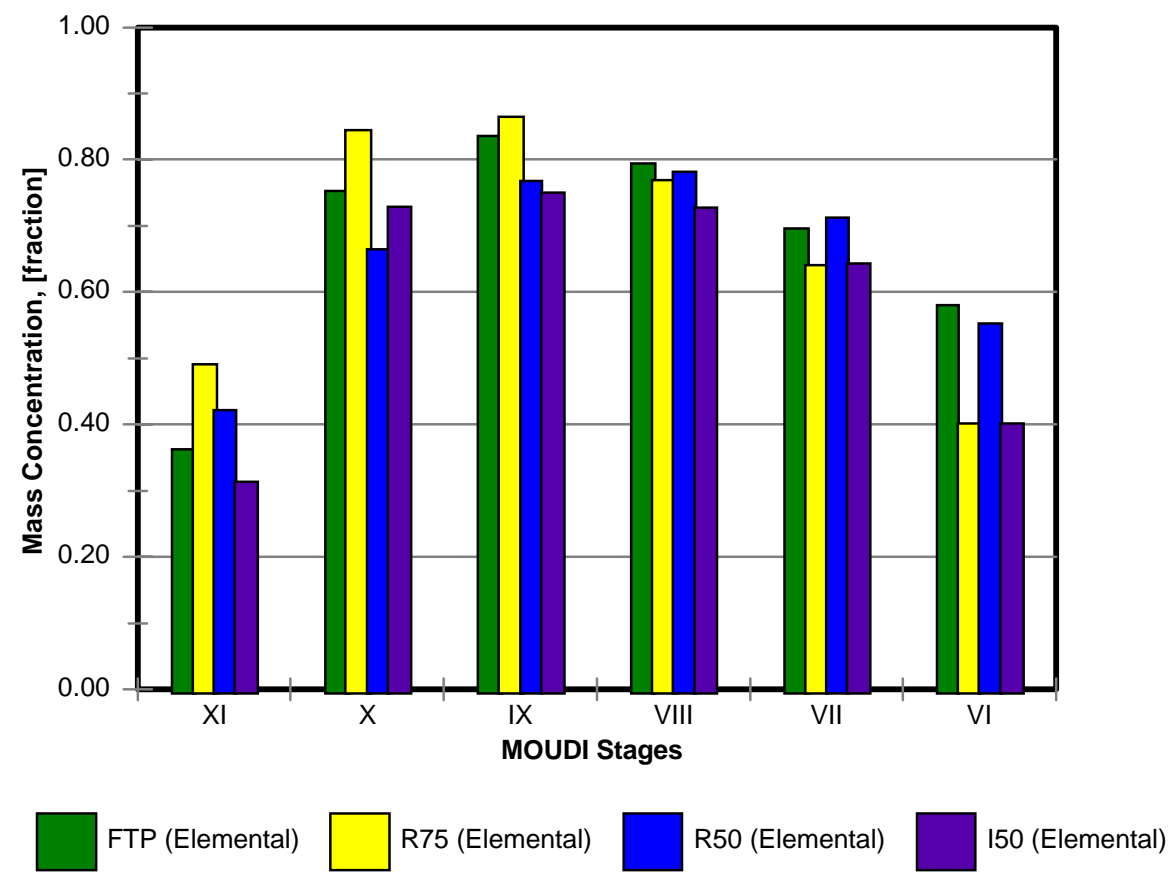

Figure 3.161 Mack E7-400, Diesel, MOUDI, Normalized Mass Fractions, Elemental Carbon, Effects of Engine Operating Mode 


\subsubsection{Hydrocarbon Speciation of Diesel Exhaust \\ 3.2.13.1 Effects of Engine Operating Conditions on Hydrocarbon Emissions}

The hydrocarbon analysis was performed on the samples of untreated diesel exhaust from Cummins ISM 370 ESP engine operated under three steady-state operating conditions (R75, R50, and I50) and over the FTP transient cycle for heavy duty diesel engines. The volatile phase was collected in Tedlar bags, semi-volatile phase on the PUF/XAD-2/PUF, and particulate bound hydrocarbons on Palflex TX40HI20 filters. The hydrocarbon analysis of the volatile samples collected in Tedlar bags was performed using the GC-FID. The GC/FID analysis failed to provide consistent and reliable results. Therefore, the results on volatile phase were not reported. GC-MS was employed for the analysis of polycyclic aromatic hydrocarbons (PAHs) captured on the adsorbent and filters. The reduced results of GS-MS analysis on the semi-volatile and particle bound PAHs are summarized in Tables C.1 and C.2, respectively.

\section{Semi-Volatile Phase}

The polycyclic aromatic hydrocarbons identified in the semi-volatile phase ranged from $\mathrm{C}_{10}$ to $\mathrm{C}_{24}$ (Table C.1). The extensive list of PAHs positively identified in this study includes mostly PAHs previously identified by Benner et al.(1989) and Venkataraman et al. (1994) in the aerosol sampled from roadway tunnels, and Westerholm et al. (1991), Bagley et al. (1993), Lowenthal et al. (1994), Gupta (1996), and Shauer et al. (1999) in the diesel exhaust source samples. The major PAHs detected in the PUF/XAD-2/PUF were naphtalene, 2-methylnaphtalene, 1-methylnaphtalene, 3-methylbyphenil, bibenzyl, phenantrene, 1-methylfluorene and 9-fluorenone. The PAH emission rates were found to be strong function of the engine operating conditions. The concentrations of PAHs extracted form the PUF/XAD2/PUF adsorbent were found to be significantly higher for the FTP transient cycle than any of the other steady-state conditions. Among the steady-state conditions, the mass emission rates $(\mathrm{kg} / \mathrm{kWh})$ of the semivolatile compounds were the highest at R50, followed by I50 and the R75 (FTP > R50 > I50 > R75). It should be noted that the mass emission rate of semi-volatiles at FTP was nearly twice as high as the rates at R50, I50, and R75 conditions. 


\section{Particle Bound Phase}

The polycyclic aromatic hydrocarbons identified as the particle bound compounds ranged from $\mathrm{C}_{10}$ to $\mathrm{C}_{24}$. The positively identified compounds are listed in Table C.2. The mass emission rates of the particle bound PAHs were found to be approximately two orders of magnitude lower than the mass emission rates of the semi-volatile PAHs. This was most probably caused by the fact that the sampling line was maintained at a fairly high constant temperature of $190^{\circ} \mathrm{C}\left(375^{\circ} \mathrm{F}\right)$. Hence, the hydrocarbons that would have normally been adsorbed on PM were now captured on the PUF/XAD-2/PUF cartridge downstream of the PM filters. The naphtalene, 1,3+1,6+1,7-dimethylnaphtalenes, 3-methylbiphenyl, acenaphtylene, phenantrene, antracene, 5 and 6 methylcrysene, and benzo(b)crysene had the highest mass emission rates of all detected particle bound hydrocarbons. The concentrations of the PAHs in the particle bound phase with respect to engine operating conditions can be ordered as: FTP > I50 > R50 > R75.

\subsubsection{Effects of Engine Operating Conditions on Ozone Forming Potential}

The ozone forming potential (grams of ozone/ gram of HC) of the identified compounds was determined for aforementioned steady state and transient engine operating conditions.

\section{Semi-Volatile Phase}

The total ozone forming potential for the semi-volatile PAHs, estimated on the basis of concentrations and MIR values of the compounds with known atmospheric chemical mechanisms, was found to be significantly higher for the exhaust from the engine operated over FTP transient cycle than for the rest of the test conditions (Table C.2). The semi-volatile PAHs identified in R50 mode exhaust exhibited the highest ozone forming potential of the all steady-state engine operating conditions tested in the study. The ozone forming potential of the semi-volatile PAHs was found to be slightly higher for I50 mode than for R75 mode. 


\section{Particle Bound Phase}

The mass emission rates and ozone forming potential of the identified particle bound PAHs were found to be negligible in comparison to those of the semi-volatile PAHs. The effects of engine operating conditions on the ozone forming potential of particle bound compounds can be described as follows: FTP > I50 > R50 > R75 (Table C.4). 


\subsection{CONCLUSIONS}

The custom built sampling system and developed sampling procedures were applied for size selective measurements of particulate matter emitted from various classes of diesel engines/vehicles exercised over different steady-state and transient operating conditions. DPM size distributions and concentration measurements were made by using SMPS and MOUDI. An extensive data base was developed and used for identification of the major parameters that affected the measurement process and governed the physical and chemical processes of diesel particulate matter formation and transformation.

Repeatability was examined on the results of the measurements with SMPS and MOUDI performed on Isuzu C240 and Mack E7-400 engines. The results of the consecutive measurements, performed immediately after establishing new engine and system operating conditions, showed that size distribution of the particulate matter in the exhaust was significantly affected with transitional processes in the engines and sampling system for a relatively long period of time. Once steady-state operating conditions for the engine and system were achieved, the repeatability of the SMPS measurements were found to be satisfactory. The results of measurements on Mack E7-400 engine showed that the results were not significantly influenced by selected scanning periods. The measurements with MOUDI were found to be quite involving, therefore, not suitable for conducting extensive testings such as this one. Repeatability of the measurements was proven to be excellent.

The effects of the dilution ratio on size selective measurement were examined on the results of the measurements performed with SMPS on the treated and untreated exhaust from different engines and vehicles. The exhaust was diluted in the partial dilution tunnel applying dilution ratios between 10 and 28. The results of analysis underlined the significance of good understanding of dilution ratio process and its impact on the distribution of particulate matter. The dilution process had an important impact on the formation and transformation of the nano and ultrafine particles. It was observed that lowering the dilution

ratio resulted in DPM distributions with slightly smaller CMDs and higher or comparable peak concentrations. The rather limited range of applied dilution ratios did not permit the author to draw general conclusions on the effects of dilution ratio on size selective measurements of diesel particulate matter. 
Results of measurements performed on the exhaust of Orion transit buses powered with DDC6V92 engine exhibited great vehicle-to-vehicle variability characteristic for in-use vehicles. The three of six buses were fitted with rebuilt engines and oxidation catalytic converter. The DPM distributions in the exhaust from the engines, which were fitted with rebuilt engines and oxidation catalytic converters, were characterized with significantly lower CMDs and lower or comparable peak count concentrations. The major vehicle-to-vehicle variations in size-resolved DPM emissions were also observed for the buses which were powered with engines with high milage accumulation and were not equipped with OCC. Those variations were attributed to the differences in the level of the tune of the engines. This study gave good insight into problems related to DPM emission measurements from in-use vehicle.

The effects of engine operating conditions (EOC) on the distribution of diesel particulate matter in the exhaust were studied on the results of measurements performed on Isuzu C240 and Mack E7-400 engine. The distribution of particulate matter in the untreated exhaust from the Isuzu C240 engine was found to be significantly affected with engine operating conditions. The emissions from the engine operated under I100 conditions were characterized with significantly higher CMDs and peak count concentrations than the emissions from the engine operated on the other steady-state conditions (R100, R75, and I50). The EOC did not have substantial effects on the CMDs of DPM distributions in the exhaust from the Mack E7-400 engine. The particle concentrations in the exhaust from the Mack E7 engine, operated at R50 conditions, were found to be significantly higher than concentrations observed for R75 and I50 engine operating conditions. The effects of driving speed on size resolved PM emissions from Orion/DDC 6V92 buses were found to be intimately related to the tested engine/vehicle conditions. A large variability in the state of tune of the test vehicles did not allow direct comparison and permit concrete conclusions to be drawn on the effects of EOC.

Results of SMPS and MOUDI measurements performed on the exhaust from the engines fueled with Federal diesel no. 2 and different types of synthetic diesel fuels yielded several interesting findings. The difference in the relevant properties of synthetic diesels and Federal no. 2 diesel resulted in the different size distribution and concentration profiles of PM. The higher sulfur content of diesel no.2 resulted in the higher concentrations of nanoparticles for the most test conditions. The distributions of the particles detected in the untreated exhaust from the Isuzu C240 engine fueled with F-T diesel were found to be characterized with slightly smaller CMDs and higher peak concentrations than those observed for 
the engine fueled with diesel no. 2. Accordingly, the reduction in the total mass of emitted PM was found to be significant. The size resolved DPM emissions from Orion/DDC 6V92 buses were found not to be significantly affected with the fuel type. The effects of lower content of sulfur in the Mossgas fuel (10 ppm vs 200ppm) were not observed on the results of size selective measurements with SMPS.

After-treatment of the exhaust from the Isuzu C240 engine in the oxidation catalytic converter, trap, paper filter, or their combinations resulted in significant reductions of TPM mass emission rates. The CMDs characterizing distributions of DPM in the exhausts treated in the variety of the devices were found to be significantly smaller than the CMDs characterizing distributions of DPM in the exhaust from bare engine. High concentrations of nanoparticles (up to $3 * 10^{7} \# / \mathrm{cm}^{3}$ ) were found where the exhaust was treated by the systems comprising of catalytic converter and catalyzed trap. Buses equipped with the engines that were rebuilt and retrofitted with oxidation converters emitted much lower total PM mass. High concentrations of the nanoparticles were observed only for the few test conditions.

The SMPS was used for real time tracking of the diesel exhaust particles with electrical mobility diameters ranging from 15 to $200 \mathrm{~nm}$. The transient measurements were performed on the exhaust from Orion/DDC 6V92 buses exercised over CBD cycle and from the Mack E7-400 engine exercised over the US EPA transient FTP schedule for heavy duty diesel engines. Particles with nominal diameters of 200 nm were found to be present in the highest concentrations (up to $2 * 10^{8} \# / \mathrm{cm}^{3}$ ), regardless of engine/vehicle type. Peak concentrations of the $200 \mathrm{~nm}$ and $100 \mathrm{~nm}$ particles measured in the exhaust from Orion/DDC 6V92 buses were found to coincide with the acceleration modes in the CBD cycle. The temporal distributions of peak concentrations for particles with nominal diameters of 15,30 , and $50 \mathrm{~nm}$ were found to be dependent on the thermodynamic properties of the exhaust. This was attributed to the different chemical compositions and physical properties of the particle classes. Nanoparticles which contain larger fractions of organic hydrocarbons and more sulfates were found to be more affected by temperature fluctuations over the test cycles.

The study on the regional deposition of DPM showed that using synthetic diesel instead of Federal diesel no. 2. for fueling the Isuzu C240 engine and Orion/DDC 6V92 buses resulted in the reduction of the particle mass and an increase of the particle numbers deposited in the alveolar region. The application of OCC and catalyzed trap in the treatment of diesel exhaust resulted in the reductions in the particle mass emissions and lowered mass deposition in the alveolar region. However, treatment of exhaust 
in the OCC and trap resulted also in a significant increase in the number of particles deposited in the alveolar region. Those findings emphasize the importance of conducting analyses on count based particulate matter emissions in addition to the analysis on regulated mass based emissions. Those findings also question health benefits from using zero sulfur synthetic diesel instead of Federal diesel fuel. The results of the analysis on the performance of after-treatment devices stressed the importance of designing after-treatment devices with optimized reductions in mass and number based PM emissions.

The size-resolved diesel particulate matter samples from the exhaust of the Mack E7-400 engine were collected by employing MOUDI and the partial dilution tunnel. The engine was operated at R75, R50, I50 steady-state conditions and over the FTP transient cycle. Samples collected on the last five stages and after-filters of the MOUDI were analyzed for elements, inorganic ions, and organic and elemental carbon content. The extent of the chemical analysis was limited by the amount of the material that was collected on the substrates. Analytical techniques such as ion chromatography, automated colorimetry, atomic adsorption and x-ray fluoroscence were employed for inorganic ion and elemental analysis. The distribution profiles of sulfate in diesel particulate matter were found to be characterized with smaller CMDs than the total particulate matter. This indicated a higher content of sulfate in class of nanoand ultra-fine particles. The presence of sulfate in these particle classes indicated the presence of sulfuric acid aerosol that is suspected to be main constituent and precursor for the formation of nonoparticles. The distributions of chloride were characterized with significantly larger CMDs than total PM regardless of engine operating conditions. Unfortunately, detection limits for the recognized health hazard elements, such as transitional metals, were not low enough to obtain reliable results and help draw meaningful conclusions on their distribution. A carbon analysis performed by TOR showed that organic carbon was the major constituent of the particulate matter collected on after-filters (cut-off diameter $56 \mathrm{~nm}$ ) regardless of the engine operating conditions. The concentrations of organic carbon and elemental carbon, detected in the PM collected on the stage VI (cut-off diameter of $1 \mu \mathrm{m}$ ), were found to be comparable. The elemental carbon was the dominant constituent of the PM collected on the stages VII through X, making up nearly $86.5 \%$ of the total carbon detected.

In order to obtain reliable results, sampling and analysis protocols were developed to speciate hydrocarbons from volatile, semi-volatile and particle bound phases of diesel exhaust. Tests were performed on the Cummins ISM 370 ESP engine operated on three steady-state operating conditions 
(R75, R50, and I50) and over the FTP transient cycle. The qualitative and quantitative profiles of PAHs adsorbed on PUF/XAD-2/PUF tube and Teflon filters were obtained by GC/MS. Results of the analyses were used for assessing the effects of engine operating conditions on hydrocarbon emissions. The concentration of PAHs in the semi-volatile phase and corresponding ozone forming potential were found to be the highest $(6.9 \mathrm{mg} / \mathrm{kWh}$ and $16.5 \mathrm{mg} / \mathrm{kWh}$, respectively $)$ at R50 engine operating conditions. As expected, analysis showed that relatively high temperature of the transfer line $\left(190{ }^{\circ} \mathrm{C}\right)$ resulted in two order of magnitude lower concentrations of PAH on the filters compared to the concentrations of PAHs captured on the PUF/XAD-2/PUF adsorbent. The mass emission rates of particle bound and semi-volatile PAH from the engine operated at higher load mode R75 were found to be significantly lower than for the R50 and I50. 


\subsection{RECOMMENDATIONS}

The complex physical and chemical processes leading to formation and transformation of the diesel exhaust particles needs more attention. Measurements performed on the raw exhausts diluted in laboratory systems need to be correlated with ambient measurements. Extensive research on defining the processes that govern formation and transformation of diesel particles after they have been released from exhaust pipe, into the ambient, should help engineers define design parameters for dilution systems and to build systems which will better mimic real-world dilution processes. Better definition of those processes should help reduce uncertainties related to the design of sampling systems and measurement instruments..

The size range of diesel particles makes the calibration of instruments such as SMPS very difficult in laboratory conditions and almost impossible in field conditions. Procedures for field calibration and quality assurance of the measurements need to be developed.

Assessment of the potential health hazards associated with exposure to diesel exhaust is a complex task which requires extensive multi-disciplinary work. Close cooperation of the experts in different fields related to the problem is needed on the defining tasks and strategy. The other available models need to be employed to estimate regional deposition of the diesel particulate matter in the human respiratory system. The results of the regional deposition study indicate that the existing mass based PM emission regulations need to be complemented with regulations based on PM count emissions. Also, performance of the after-treatment devices and effects of fuel formulations on reduction of PM emissions need to be reevaluated keeping in mind the adverse health effects of nano- and ultra-fine particles. The efficiency of after-treatment devices in reducing number based emissions was found to be as important as their efficiency in reducing PM mass emission rates.

A high volume sampling system needs to be developed for collection of the size segregated particulate matter samples for gravimetric and chemical analysis. Such a system should provide grounds for more accurate measurements, enable collection of substantial amount of material for reliable chemical analysis, and reduce the required sampling times. 
A joint effort of engineers, atmospheric chemists, analytic chemists, health workers and other researchers is required to achieve the ultimate goal of reduction of human exposure to harmful diesel exhaust hydrocarbon species and to tropospheric ozone whose formation is promoted by those hydrocarbons (in the presence of high $\mathrm{NO}_{\mathrm{x}}$ concentrations). To meet that goal, additional research is needed for identifying the parameters that affect the formation and transformation of hydrocarbons in the $\mathrm{CI}$ engines, predicting transformation of pollutants in the atmosphere, and assessing the impact on human health. Establishing standard sampling and analytical procedures might help in reducing uncertainties and allow comparison of the results obtained by different researchers. 


\section{REFERENCES}

Abdul-Khalek, I. S. and Kittelson, D. B. (1995): "Real Time Measurement of Volatile and Solid Exhaust Using a Catalytic Stripper", SAE Technical Paper Series, No. 950236.

Abdul-Khalek, I. S., Kittelson, D. B., Graskow, B. R., Wei, Q., and Brear, F. (1998): "Diesel Exhaust Particle Size: Measurement Issues and Trends", SAE Technical Paper Series, No. 980525.

Ahlvik, P., Ntziachristos, L., Keskinen, J., and Virtanen, A. (1998): "Real Time Measurement of Diesel

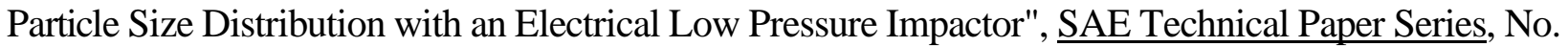
980410.

Alsberg, T, Stenberg, U., Westerholm, R., and Strandell, M. (1985): "Chemical and Biological Characterization of Organic Material from Gasoline Exhaust Particles", Environmental Science and Technology, Vol. 19, No. 1, pp. 43 - 50.

Bagley, S. T., Gratz, L. D., Leddy, D. G., and Johnson, J. H. (1993): "Characterization of Particle- and Vapor-Phase Organic Fraction Emissions from a Heavy-Duty Diesel Engine Equipped with a Particle Trap and Regeneration Controls", HEI Research Report No. 56.

Bailey, J. C., and Eggleston, H. S. (1992): "The generation of Speciated Hydrocarbons Emissions Data and the Use of Such Data in the Compilation of Emission Inventories", FISITA '92, The Vehicle and the Environment, Part 2, MEP, London.

Bata, R., Clark, N., Lyons, D., Long, T., Howell, A., Loth, J., Palmer, M., Rapp, B., and Wang, W. (1992): " Transportable Heavy-Duty Vehicle Emissions Testing Laboratory: A New Dimension in Vehicle Testing", ASME Paper 92-ICE-21. 
Baumgard, K.J. and Johnson, J.H.(1996): " The Effects of Fuel and Engine Design on Diesel Exhaust

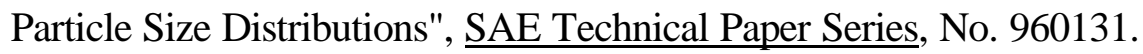

Beckwith, T. G., Marangoni, R. D., and Lienhard, J.H. (1993): Mechanical Measurements, Fifth Edition, Addison-Wesley Publishing Company, Reading, MA, pp. 83.

Benner, B. A. Jr., Gordon, G. E., and Wise, S. A. (1989): "Mobile Source of Atmospheric Polycyclic Aromatic Hydrocarbons: A Roadway Tunnel Study", Environmental Science and Technology, Vol. 23, No. 10, pp. 1269 - 1278.

Bischof, O. F.(1998): "The SMPS, the Most Widely Used Nanoparticle Sizer", ETH Workshop, Zürich, August 7, 1998.

Birmili, W., Stratmann, F., Wiedensohler, A., Covert, D., Russell, M., and Berg, O. (1997): "Determination of Differential Mobility Analyzer Transfer Functions Using Identical Instruments in Series", Aerosol Science and Technology, Vol. 27, pp. 215 - 223.

Black, F. and High, L. (1979): "Methodology for Determining Particulate and Gaseous Diesel

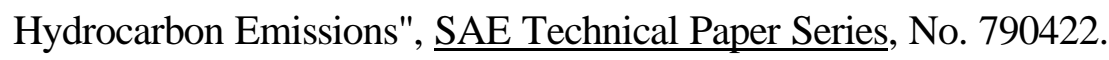

Brockmann, J. E. (1993): "Sampling and Transport of Aerosols", Aerosol Measurements, Principles, Techniques, and Applications, edited by Willike, K. and Baron P. A., Van Nostrand Reinhold, New York, pp.106-107.

California ARB (1998): "California ARB Identifies Diesel Particulate Emissions as a Toxic Air Contaminant", www.dieselnet.com/news/9808carb2.html.

Cantrell, B. (1998): Personal communications. 
Carter, W. P . L., Pierce, J. A., Luo, D., and Malkina, I. L. (1995): " Environmental Chamber Studies of Maximum Incremental Reactivities of Volatile Organic Compounds", Atmospheric Environment, Vol. 29, No. 18 , pp. 2499-2511.

Carter, W. P. L. (1998): "Updated Maximum Incremental Reactivity Scale for Regulatory Applications", Preliminary Report to California Air Resources Board, Contract No. 95-308, Air Pollution Research Center and College of Engineering, Center for Environmental Research and Technology, University of California, Riverside CA 92521, August 6, 1998.

Carter, W. P. L and Atkinson, R (1989): "Computer Modeling Study of Incremental Hydrocarbon Reactivity", Environmental Science and Technology, Vol. 23, No. 7, pp. 864 - 880.

Cass, G. R. (1998): "Characterization and Control of Organic Compounds Emitted from Air Pollution Sources", Final Report to California Air Resources Board, Contract No. 93-329, pp. 85-116, April 1998.

Chaffin, C. A. and Ullman, T. L. (1994): "Effects of Increased Altitude on Heavy-Duty Diesel

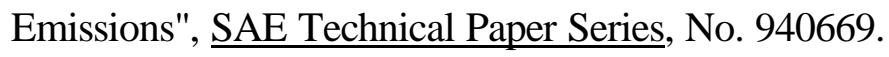

Cheng, Y. S. (1993): "Condensation Detection and Diffusion Size Separation Techniques", Aerosol Measurement: Principles, Techniques, and Applications. Willeke, K. and Baron, P. A.,(editors) Van Nostrand Reinhold, New York.

Chow, J. C., Watson, J. G., Pritchett L.C., Pierson, W. R., Frazier C. A., and Purcell R. G. (1993): "The DRI Thermal/Optical Reflectance Carbon Analysis System: Description, Evaluation and Application in U.S. Air Quality Studies", Atmospheric Environment, Vol. 27A, No. 8, pp. 1185 - 1201.

Clark, N., Gautam, M., Bata, R., and Lyons, D. (1995): " Design and Operation of a New Transportable Laboratory for Emissions Testing of Heavy-Duty Trucks and Buses", International Journal of Vehicle Design: Heavy Vehicles Systems, Vol. 2, pp. 285-299. 
Code of Federal Regulations (1994): "Protection of Environment", Office of the Federal Register National Archives and Records Administration, Title 40, Part 86-99.

CONCAWE (1998): "A Study of the Number, Size and Mass of Exhaust Particles Emitted from European Diesel and Gasoline Vehicles under Steady-state and European Driving Cycle Conditions", Report No. 98/51. Prepared for CONCAWE Automotive Emissions Management Group by Special Task Force AE/STF-10: Hall D. E. Chairman, Brussel, Belgium.

Den Ouden, C. J. J., Clark, R. H., Cowley, L. T., Stradling, R. J., Lange, W. W., and Maillerd C. (1994): "Fuel Quality Effects on Particulate Matter Emissions for Light- and Heavy-Duty Diesel Engines", $\underline{\text { SAE }}$ Technical Paper Series, No. 942022.

Dickens, C. J., Ball, M. H. E., Booker, D., Donald, J. R., Tope, A. M., and Hughes, M. (1997): "Evaluation of Instruments for Vehicle Emission Particle Sizing", AEA Technology Report, AEAT1180.

Dolan, D. F., Kittelson, D. B., and Pui, D. Y. (1980): "Diesel Exhaust Particle Size Distribution Measurement Techniques", SAE Technical Paper Series, No. 800187.

Donaldson, K. (1994): "The Effect of Ultrafine Titanium Dioxide on Epithelial Cells", Meeting of Aerosol Society, Birmingham, 1994.

Dzubay, T.G. and Hasan, H. (1990): "Fitting Multimodal Lognormal Size Distributions to Cascade Impactor Data", Aerosol Science and Technology, Vol. 13, pp. 144 - 150.

Engeljerhringer, K. and Schindler, W. (1997): " The Use of a Partial Flow Dilution System for Measurement of Gaseous and Particulate Emissions During Transient Test Cycles", unpublished AVL test report. 
Fanick, R. E., Whitney, K. A., and Bailey, B. K. (1996): "Particulate Characterization Using Five Fuels", SAE Technical Paper Series, No. 961089.

Ferin, G. O. and Penney, D. P. (1992): " Pulmonary Retention of Ultrafine and Fine Particles in Rats", American Journal of Respiratory Cell and Molecular Biology, Vol. 6, pp. 534-542.

Fissan, H., Hummers, D., Stratmann, F, Büscher, P., Neumann, Pui, D. Y., and Chen, D. (1996):

"Experimental Comparison of Four Differential Mobility Analyzers for Nanometer Aerosol Measurements", Environmental Science and Technology, Vol. 24, pp. 1 - 13.

Gautam, M., Miller, E. R., Ferguson, D. H., and Lyons, D. W. (1998): " Uncertainty in Real-World Particulate Matter Emission Measurements form a Transportable Heavy-Duty Vehicle Emissions Testing Laboratory", A Series of the Heavy Vehicle Systems, International Journal of Vehicle Design, Vol. 5. , No. 3/4, pp.1 - 21.

Gautam, M., Mehta, S., Bugarski, A., Byers, R, and Lyons, D. (1999): "Particle Size Distributions from In-Use Diesel and Natural Gas Heavy-Duty Vehicles", 1999 Spring Technical Conference, ICE Division of the ASME, April 25-28, Columbus, IN.

Gautam, M, Mehta, S, Byers, R., and Bugarski, A. (1998): "Issues in Measurement of Size Distribution of Diesel Particulate Matter from In-Use Heavy-Duty Vehicles", SecondETH Workshop on Nanopaticles Measurement", July 7, Zürich, Switzerland 1998.

Gautam, M., Kelly, B., Gupta, D., Clark, N., Atkinson, R., El-Gazzar, L., and Lyons, D. W. (1994): "Sampling Strategies for Characterization of the Reactive Components of Heavy Duty Diesel Exhaust

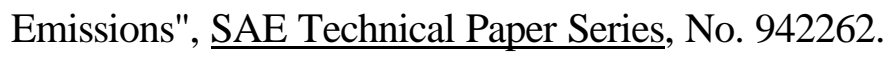

Gautam, M, Psaras, D., Lyons, D. W., Mucino, V., and Clark, N. N. (1998), "Emissions Reduction from Heavy-Duty Vehicle Operating at High Altitudes", $8^{\text {th }}$ CRC On-Road Vehicle Emissions Workshop, April 1998, San Diego, CA. 
Graskow, B. R., Kittelson, D. B., Abdul-Khalek, I. S., Ahmadi, M. R., and Morris, J. E. (1998): "Characterization of Exhaust Particulate Matter from Spark Ignition Engine", $\underline{\text { SAE Technical Paper }}$ Series, No. 980528.

Greenwood, S. J., Coxon, J. E. Biddulph, T, and Bennett, J. (1996): "An Investigation to Determine the Exhaust Particulate Size Distribution for Diesel, Petrol, and Compressed Natural Gas Fueled Vehicles", SAE Technical Paper Series, No. 961085.

Guerrieri, D. A., Rao, V., and Caffrey, P. J. (1996): "An Investigation of the Effects of Differing Filter Face Velocities on Particulate Mass Weight from Heavy-Duty Diesel Engines", SAE Technical Paper Series, No. 960253.

Gupta, D. (1996): "Speciation of Heavy-Duty Diesel Exhaust Emissions Under Transient and Steady State Conditions", M.S. Thesis, West Virginia University, Morgantown, WV.

Hammerle, R. H., Siegl, W. O., Hermann, H. M., and Wenclawiak, B. W.(1995): "A Method for the Speciation of Diesel Fuel and the Semi-Volatile Hydrocarbon Fraction of the Diesel-Fueled Vehicle Exhaust Emissions", SAE Technical Paper Series, No. 952353.

Hammerle, R. H., Ketcher, d. A., Horrocks, R. W., Lepperhoff, G., Hüthwohl, G., and Lüers, B. (1994): "Emissions from Current Diesel Vehicles", SAE Technical Paper Series, No. 942043.

Hare, C. T. and Bradow, R. L. (1979): "Characterization of Heavy Duty Diesel Gaseous and Particulate Emissions, and Effects of Fuel Composition", SAE Technical Paper Series, No. 790490.

Havránek, V., Kolman, B., Kučera, J, Kugler, J., Pekárek, V. Pŕybil, J., Schwarz, J., Smolik, J, and Vỳška, J. (1997): "Effects of Fuel on Particle Emissions from Gasoline Powered Vehicle", Journal of Aerosol Science, Vol. 28, Suppl. 1, pp. S547 - S548. 
Health Effects Institute HEI (1999): "Diesel Emissions and Lung Cancer: Epidemiology and Quantitative Risk Assessment", Special Report of the Institute's Diesel Epidemiology Expert Panel, June 1999.

Heintzenberg, J. (1994): "Properties of the Log-Normal Particle Size Distribution", Environmental Science and Technology, Vol. 21, pp. 46 - 48.

Heywood, J. B. (1988): Internal Combustion Engine Fundamentals, McGraw-Hill, Inc., New York.

Hildermann, L. M., Markowski, G. R., Jones, M. C., and Cass, G. R. (1991): "Submicrometer Aerosol Mass Distributions of Emissions from Boilers, Fireplaces, Automobiles, Diesel Trucks, and MeatCooking Operations", Environmental Science and Technology, Vol. 14, pp. 138 - 152.

Hildermann, L. M., Markowski, G. R., and Cass, G. R. (1991): "Chemical Composition of Emissions for Urban Sources of Fine Organic Aerosol", Environmental Science and Technology, Vol. 25, No. 4, pp. $744-758$.

Hinds, W. C. (1982): Aerosol Technology, Properties, Behavior, and Measurement of Airborne Particles, John Wiley and Sons, New York.

Hofeldt, D. L. and Chen, G, (1996): "Transient Particulate Emissions from Diesel Buses During the Centarl Business District Cycle", SAE Technical Paper Series, No. 960251.

Hsieh, D. P. H., Kado, N. Y., Okamoto, R., Kuzmicky, P. A., Rathbun, C, and Ito, J.(1993): "Measurements and Chemical Characterization of Vapor-Phase Mutagens in Diesel Exhaust", Final Report, Department of Environmental Toxicology, University of California, Davis, California.

Jokiniemi, J. (1998): "Aerosol Formation in Light- and Heavy-Duty Diesel Engines", International Seminar on Particle Size Distribution Measurement from Combustion Engines, Espoo, Finland, May 18 $-19,1998$. 
Kauffeldt, Th. and Schmidt-Ott, A. (1998): "Investigation of the Influence of Exhaust Aftertreatment on the Particulate Phase in Diesel Exhaust Gases", Journal of Aerosol Science, Vol. 29, Suppl.1, pp. S625 S626.

Kayes, D. and Hochgreb, S.(1998): "Investigation of the Dilution Process from Measurement of Particulate Matter from Spark-Ignition Engines", SEA Technical Paper Series, No. 982601.

Keady, P. B., Quant, F. R., and Sem, G. J. (1983): "Differential Mobility Particle Sizer: A New Instrument for High-Resolution Aerosol Size Distribution Measurement Below 1 mm", TSI Quarterly, Vol. IX, Issue 2.

Kelly, W. P. and McMurry, P. H. (1992): "Measurement of Particle Density by Internal Classification of Differential Mobility Analyzer - Generated Monodisperse Aerosol", Environmental Science and Technology, Vol. 17, pp. 199 - 212.

Kerminen, V-M., Mäkelä, T. E., Ojanen, C. H., Hillamo, R. E., Vilhunen, J. K., Rantanen, L., Havers, N, Bohlen von, A., and Klockow, D. (1997): "Characterization of the Particulate Phase in the Exhaust from a Diesel Car", Environmental Science and Technology Vol. 31, No. 7, pp. 1883 - 1889.

Keskinen, J., Pitarinen, K., and Lehtimaki, M. (1992): "Electrical Low Pressure Impactor", Journal of Aerosol Science, Vol. 23, No. 4, pp. 353 - 360.

Kittelson, D. B. and Johnson, J. H. (1990) "An Examination of the Sources of Variability in Particle Emission Measurements by the Transient Test Method for Heavy-Duty Diesel Engines", Report to Coordination Research Council and Engine Manufactures Association.

Kittelson, D. B. and Johnson, J. H. (1991): "Variability in Particle Emission Measurements in the Heavy

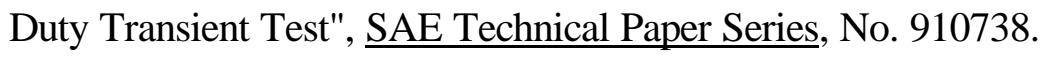


Kittelson, D. B., Sun, R., Blackshear, P. L. Jr., and Brehob, D.D. (1992): "Oxidation of Soot Agglomerates in a Direct Injection Diesel Engine", SAE Technical Paper Series, No. 920111.

Kittelson, D. B. (1998): "Engine and Nanoparticles: A Review", Journal of Aerosol Science, Vol. 29, No. 5/6, pp. 575 - 588 .

Kittelson, D. B., Arnold M., and Winthrop F. W. (1999): "Review of Diesel Particulate Matter Sampling Methods - Final Report", University of Minnesota, Minneapolis, MN.

Klein, H., Lox, E., Kreuzer, T, Kawanami, M., Ried, T., and Bächmann, K.(1998): "Diesel Particulate Emissions of Passenger Cars - New Insights Into Structural Changes During the Process of Exhaust Aftertreatment Using Diesel Oxidation Catalysts", SAE Technical Paper Series, No.980196.

Knutson, E. O. and Whitby, K. T. (1975): "Aerosol Classification by Electric Mobility: Apparatus, Theory, and Applications", Journal of Aerosol Science, Vol. 6, pp. 443 - 451.

Köbrich, R., Rudolf, G., and Stahlhofen, W. (1994): “A Mathematical Model of Mass Deposition in Man”, The Annals of Occupational Hygiene, Vol. 38, Supplement 1, pp. 15 - 23.

Koike, N., Ito, M., and Inoue, T. (1994): "A Comparison of Gas Chromatography-Based Methods of

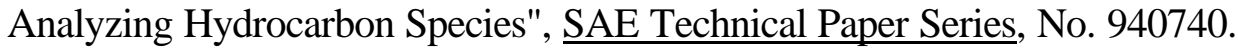

Kuoska, Y., Okuyama, K., and Adachi, M. (1985): "Determination of Particle Size Distribution of UltraFine Aerosol Using a Differential Mobility Analyzer", Environmental Science and Technology, Vol. 4, pp. $209-225$.

Lee, M. L., Novotny, M. V., and Bartle, K. D. (1981): Analytical Chemistry of Polycyclic Aromatic Compounds. Academic Press, New York. 
Leonardy, A., Burtscher, H., and Siegemann, H. C. (1992): "Size-Dependent Measurement of Aerosol Photoemission from Particles in Diesel Exhaust", Atmospheric Environment, Vol. 26A, No. 18, pp. 3287 $-3290$.

Levsen, K. (1988): "The Analysis of Diesel Particulate", Fresenius Z. Analytical Chemistry, Vol. 331, pp. $467-478$.

Li, X., Chippior, W.L., Gulder, O.L.(1996):" Effects of Fuel Properties on Exhaust Emissions of a single Cylinder DI Diesel Engine", SAE Technical Paper Series, No. 962116.

Lowenthal, D. H., Zielinska, B., Chow, C. C., Watson, J. G., Gautam, M., Ferguson, D. H., Neuroth, G. R., and Stevens, K. D. (1994): "Characterization of Heavy-Duty Diesel Vehicles Emissions", Atmospheric Environment, Vol. 28, No. 4, pp. 731 - 743.

Lüders, H., Krüger, M., Stommel, P., and Lüers, B. (1998): "The Role of Sampling Conditions in Particle

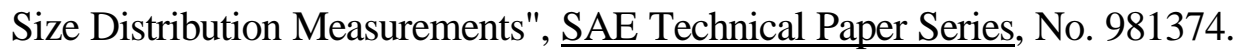

Maricq, M. M., Podsiadlik, D. H., and Chase, R. E. (1999): "Examination of the Size-Resolved and Transient Nature of Motor Vehicle Particle Emissions", Environmental Science and Technology, Vol. 33, pp. 1618 - 1626.

Maricq, M. M., Chase, R. E., Podsiadlik, D. H., and Vogt, R. (1999): "Vehicle Exhaust Particle Size Distributions: A Comparison of Tailpipe and Dilution Tunnel Measurements", $\underline{\text { SAE Technical Paper }}$ Series, No. 1999-01-1461.

Marple, V. A., Rubow, K. L., and Behm, S. M. (1991): "A Microorifice Uniform Deposit Impactor (MOUDI): Description, Calibration, and Use", Environmental Science and Technology, Vol. 14, pp. 434 - 446. 
Marshal, W. F. and Fleming, R. D. (1971): "Diesel Emissions Reinventored", RI 7530, U.S. Department of the Interior, Bureau of Mines, Washington, D.C.

Mauderly, J., Schlesinger, R., and Neas, L. (1995): "Measurement Needs Related to Health Effects", HEI Report.

Mayer, A., Egli, H., Burtscher, H., Czerwinski, W, and Gehrig D. (1995): "Particle Size Distribution

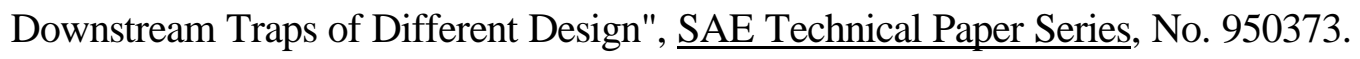

Mayer, A.(1998): "VERT: Curtailing Emissions of Diesel Engines in Tunnel Sites", DieselNet Technical Report, www.dieselnet.com / papers / 9804mayer.html, April 1998.

Mayer, A. (1998): " Selection Criteria for Diesel Particulate Trap System: VERT Experience", DieselNet Technical Report, www.dieselnet.com/papers/9812mayer.html, December 1998.

Mayer, A., Matter, U., Czerwinski, J., and Heeb, N. (1999): "Effectiveness of Particulate Traps on Construction Site Engines: VERT Final Measurements", DieselNet Technical Report, www.dieselnet.com/papers/9903mayer/index.html, March 1999.

McMillian, M. H. and Gautam, M. (1998): "Consideration for Fisher-Tropsch Derived Liquid Fuels as a Fuel Injection Emission Control Parameter", SAE Technical Paper Series, No. 982489.

Miller, E. S. (1997): "Measurement of Diesel Particulate Matter Emissions with a Modified Multi-Tube Type Mini-Dilution Tunnel", Master Thesis, West Virginia University, Morgantown, WV.

Mills, G. A, Howart, S, and Howard, A. G. (1983): "The Effects of Diesel Fuel Aromaticity on Polynuclear Aromatic Hydrocarbon Exhaust Emissions", Journal of Institute of Energy, Vol. 273.

Model 100 / Model 110 Micro-Orifice Uniform Deposit Impactor - Instruction Manual (1998), MSP Corporation, Minneapolis. 
Model 3934 SMPS (Scanning Mobility Particle Sizer), Instruction Manual (1996), TSI Incorporated, St. Paul, MN.

Nauss, K.(1997): "Diesel Exhaust: A Critical Analysis of Emissions, Exposure, and Health Effects", Summary of a Health Effects Institute (HEI) Special Report HEI Diesel Working Group, www.dieselnet.com,/papers/9710nauss.html, October 1997.

Newkirk, M. S. and Bass, E. A. (1995): "Reactivity Comparison of Exhaust Emissions from Heavy-Duty

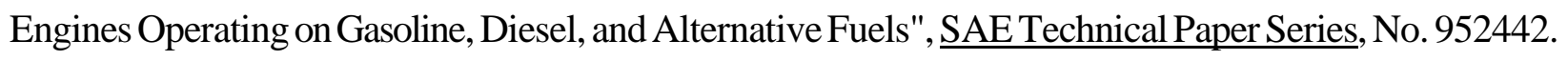

Niles, R. and Tan, Y. L. (1989): "Determination of Polynuclear Aromatic Hydrocarbons and Mononitrated Derivatives in Air and Diesel Particulates", Analytica Chemica Acta, 221, pp. 53 - 63.

Nine, R. D., Atkinson, C. M., McKain, D.1., El-Gazzar, L., Clark, N. N. and Lyons, D. W. (1996): "Speciation of Diesel Exhaust from a Medium Duty Diesel Engine", SAE Congress, Detroit, MI, SAE Technical Paper Series, No. 960322.

Nine, R. (1995): "Volatile and Semi-Volatile Hydrocarbon Speciation of a Current Low Emission Medium Duty Diesel Engine", MSME, West Virginia University, Morgantown, WV.

Norton, P., Vertin, K. Clark, N. N, Lyons D. W., Gautam, M., Goguen, S., and Eberhardt, J. (1999): "Emissions from Busses with DDC 6V92 Engines Using Synthetic Diesel Fuel", SAE Technical Paper Series, No. 1999-01-1512.

Opris, C. N., Gratz, L. D., Bagley, S. T., Baumgard, K. J., Leddy, D. G., and Johnson, J. H.(1993): "The Effect of Fuel Sulfur Concentration on Regulated and Unregulated Heavy-Duty Diesel Emissions", $\underline{\text { SAE }}$ Technical Paper Series, No. 930730.

Panne, U., Petzold, A., and Niessner, R. (1993): "Diesel Exhaust Particle Size Distribution Measurements Under Dynamic Conditions", Journal of Aerosol Science, Vol. 24 , Supp.1 , pp. S659- S660. 
Pataky, G. M., Baumgard, K. J., Gratz, L. D., Bagley, S. T., Leddy, D. G., and Johnson, J. H. (1994): "Effects of an Oxidation Catalytic Converter on Regulated and Unregulated Diesel Emissions", $\underline{\text { SAE }}$ Technical Paper Series, No. 940243.

Quant, F. R., Flagan, R. C., and Horton, K. D. (1993): "Implementation of a Scanning Mobility Particle Sizer (SMPS)", Journal of Aerosol Science, Vol. 24, Supp. 1, pp. S83 - S84.

Rayan, T.W. and Montalvo, D.A.(1997): "Emissions Performance of Fisher-Tropsch Diesel Fuels", Conference Paper: 1997 AIChE Spring Meeting, Huston, TX, March 9-13, 1997.

Reischl, G. P. (1991): "Measurement of Ambient Aerosols by the Differential Mobility Analyzer Method: Concepts and Realization Criteria for Size Range Between 2 and 500 nm", Environmental Science and Technology, Vol. 14, pp. 5 - 24.

Reischl, G. P. (1991): "The Relationship of Input and Output Aerosol Characteristics for an Ideal Differential Mobility Analyzer Particle Standard ", Journal of Aerosol Science, Vol. 22, No. 3, pp. 297 312.

Rickeard, D. J., Bateman, J. R., Kwon, Y. K., McAughey, J. J., and Dickens, C. J. (1996): "Exhaust Particulate Size Distribution: Vehicle and Fuel Influences in Light Duty Vehicles", SAE Technical Paper Series, No. 961980.

Rudolf, G., Köbrich, R., Stahlhofen, W., and James, A. C. (1994): "Regional Aerosol Deposition in Man A Statistical and Algebraic Model", The Annals of Occupational Hygiene, Vol. 38, Suppl. 1, pp. 1 - 14.

Schaberg, P.W., Myburgh, I.S., Botha, J.J., Roets, P.N. Viljoen, C.L., Dancuart, L.P., and Starr, M.E (1997): "Diesel Exhaust Emissions Using Sasol Slurry Phase Distillate Process Fuels”, SAE Technical Paper Series, No. 972898. 
Schilhabel, J. and Levsen, K. (1989): "Identification of Nitrated Polycyclyc Hydrocarbons in Diesel Particulate Extracts by Negative Ion Chemical Ionization and Tandem Mass Spectrometry", Frensenius Z Analytical Chemistry, No. 333, pp. 800 - 805.

Schlesinger, J.(1995): "Toxicological Evidence for Health Effects from Inhaled Particulate Pollution: Does it Support the Human Experience?", Inhalation Toxicology Vol.7, pp. 99 - 109.

Shauer, J. J., Kleeman, M. J., Cass, G. R., and Simoneit, B. R. T. (1999): "Measurements of Emissions from Air Pollution Sources. 2. $\mathrm{C}_{1}$ trough $\mathrm{C}_{30}$ Organic Compounds from Medium Duty Diesel Trucks", Environmental Science and Technology, Vol. 33, No. 10, pp. 1578 - 1587.

Shimpi, S. A. and Yu, M-L. (1981): "Determination of a Reliable and Efficient Diesel Particulate

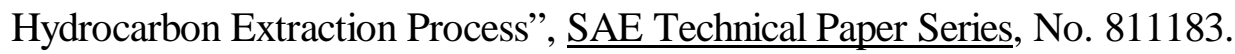

Stahlhofen, W., Rudolf, G., and James, A.C. (1989), “Intercomparison of Experimental Regional Aerosol Deposition Data", Journal of Aerosol Medicine, Vol.2, No. 3, pp. 285-308.

Venkataraman, C, Lyons, J. M., and Friedlander, S. K., (1994): “Size Distribution of Polycyclic Aromatic Hydrocarbons and Elemental Carbon. 1. Sampling, Measurement Methods, and Source Characterization", Environmental Science and Technology, Vol. 28, No. 4, pp. 555 - 562.

Venkataraman, C., and Friedlander, S. K.(1994): "Size Distribution of Polycyclic Aromatic Hydrocarbons and Elemental Carbon. 2. Ambient Measurements and Effects on Atmospheric Processes", Environmental Science and Technology, Vol. 28, No. 4, pp. 563 - 572.

Walsh, M. (1993): "Global Trends in Diesel Particulate Control, 1993 Update", $\underline{\text { SAE Technical Paper }}$ Series, No. 930126 
Wang, S. C. and Flagan, R. C. (1990): “Scanning Electrical Mobility Spectrometer”, Aerosol Science and Technology, Vol. 13, pp. 230 - 240.

Westerholm, R. N., Almén, J., Li H., Rannug, J. U., Egebäck, K-E., and Grägg, K. (1991): “Chemical and Biological Characterization of Particulate-, Semivolatile-, and Gas-Phase-Associated Compounds in Diluted Heavy-Duty Diesel Exhausts: A Comparison of Three Different Semivolatile-Phase Samplers", Environmental Science and Technology, Vol. 25, No. 2, pp. 332 - 338.

Wiedensohler, A. (1988): An Approximation of the Bipolar Charge Distribution for Particles in the Submicron Size Range, Journal of Aerosol Science, Vol. 19, No. 3, pp. 387 - 389.

Willeke, K. and Baron, P. A., editors (1993): Aerosol Measurement: Principles, Techniques, and Applications. Van Nostrand Reinhold, New York.

Winklmayr, W., Reischl, G. P., Lindner, A. O., and Berner, A. (1991): "A New Electormobility Spectrometer for the Measurement of Aerosol Size Distributions in the Size Range from 1 to 1000 nm”, Journal of Aerosol Science, Vol. 22, No. 3. 
APPENDIX 
Appendix A: Results of Fuel Analysis 
Table A.1 Results of the Fuel Analyses

\begin{tabular}{|c|c|c|c|c|c|c|}
\hline \multirow[t]{5}{*}{ Property } & \multirow[t]{5}{*}{ Test Method } & \multicolumn{5}{|c|}{ Engine/Vehicle } \\
\hline & & \multicolumn{2}{|c|}{ Isuzu C240 } & \multicolumn{3}{|c|}{ Orion/DDC 6V92 } \\
\hline & & \multicolumn{2}{|c|}{$\begin{array}{l}\text { Fuel } \\
\text { Type }\end{array}$} & \multicolumn{3}{|c|}{$\begin{array}{l}\text { Fuel } \\
\text { Type }\end{array}$} \\
\hline & & \multirow{2}{*}{$\begin{array}{l}\text { LS no. } 2 \\
\text { diesel } \\
\text { (BP) }\end{array}$} & \multirow{2}{*}{$\begin{array}{l}\text { Synthetic } \\
\text { diesel } \\
\text { (Shell) }\end{array}$} & \multirow{2}{*}{$\begin{array}{l}\text { LS no. } 2 \\
\text { diesel } \\
\text { (Exxon) }\end{array}$} & \multicolumn{2}{|c|}{$\begin{array}{l}\text { synthetic diesel } \\
\text { (Mossgas) }\end{array}$} \\
\hline & & & & & $\begin{array}{c}\text { Mossgas } \\
\text { analysis }\end{array}$ & $\begin{array}{c}\text { SwRI } \\
\text { analysis }\end{array}$ \\
\hline $\begin{array}{l}\text { Distilation, } \\
\left({ }^{\circ} \mathrm{C}\right) \\
\text { IBP } \\
10 \% \\
50 \% \\
90 \% \\
\text { FBP }\end{array}$ & D-86 & $\begin{array}{l}192 \\
221 \\
265 \\
316 \\
342\end{array}$ & $\begin{array}{l}196 \\
246 \\
286 \\
316 \\
324\end{array}$ & $\begin{array}{l}188 \\
212 \\
256 \\
307 \\
331\end{array}$ & $\begin{array}{l}321 \\
361\end{array}$ & $\begin{array}{l}230 \\
235 \\
255 \\
324 \\
361\end{array}$ \\
\hline $\begin{array}{l}\text { Viscosity, } \\
(\mathrm{cSt} @ \\
\left.40{ }^{\circ} \mathrm{C}\right)\end{array}$ & D-445 & 2.6 & 3.57 & - & - & 2.98 \\
\hline $\begin{array}{l}\text { Density, } \\
(\mathrm{kg} / \mathrm{l} @ \\
\left.15^{\circ} \mathrm{C}\right) \\
\text { API Gravity }\end{array}$ & D-1298 & $\begin{array}{r}0.8456 \\
35.6\end{array}$ & 0.7845 & $\begin{array}{r}0.8366 \\
\\
37.4\end{array}$ & - & $\begin{array}{r}0.8042 \\
44.0\end{array}$ \\
\hline $\begin{array}{l}\text { Sulfur, } \\
\text { (vol. \%) }\end{array}$ & D-4294 & 0.04 & $<0.001$ & 0.02 & $<0.001$ & - \\
\hline $\begin{array}{l}\text { Cetane } \\
\text { Number }\end{array}$ & D-613 & 47.0 & 73.7 & - & 51.4 & 48.9 \\
\hline $\begin{array}{l}\text { HC type, } \\
\text { (\% vol.) } \\
\text { Aromatics } \\
\text { Olefins } \\
\text { Saturates } \\
\text { Polynuclear } \\
\text { Aromatics, wt } \\
\%\end{array}$ & D-1319 & $\begin{array}{r}29.1 \\
2.1 \\
68.8\end{array}$ & $\begin{array}{r}0.1 \\
0.1 \\
99.8\end{array}$ & $\begin{array}{r}24.7 \\
1.5 \\
73.8\end{array}$ & $\begin{array}{r}10.1 \\
- \\
-\end{array}$ & \\
\hline
\end{tabular}


Appendix B: Size-Resolved Chemical Analysis of DPM, Mack E7-400, Elemental and Inorganic Ions Analysis, Tables 
Table B.1. Mack E7-400, Diesel, MOUDI, FTP, Elements and Inorganic Ions, $\left[\mu \mathrm{g} / \mathrm{m}^{3}\right]$ (Part 1)

\begin{tabular}{|c|c|c|c|c|c|c|c|c|c|}
\hline \multicolumn{3}{|c|}{ MOUDI Stage } & & VI & VII & VIII & IX & $\mathrm{X}$ & XI \\
\hline \multicolumn{2}{|c|}{ Cut-off Diameter } & $\mu \mathrm{m}$ & & 0.56 & 0.32 & 0.18 & 0.1 & 0.056 & $<0.056$ \\
\hline 1 & TPM & & grav. & 548.467 & 764.967 & 1342.300 & 2778.417 & 1205.183 & 505.167 \\
\hline 2 & $\mathrm{Cl}^{-}$ & & IC & 3.374 & 3.374 & 3.374 & 2.277 & 3.374 & 3.628 \\
\hline 3 & $\mathrm{Cl}^{-}$ & uncertainty & IC & 1.516 & 1.516 & 1.516 & 1.454 & 1.516 & 1.532 \\
\hline 4 & $\mathrm{SO}_{4}^{--}$ & & IC & 2.657 & 4.851 & 5.948 & 13.627 & 9.239 & 7.679 \\
\hline 5 & $\mathrm{SO}_{4}^{--}$ & uncertainty & IC & 1.406 & 1.406 & 1.406 & 1.406 & 1.406 & 1.406 \\
\hline 6 & $\mathrm{NH}_{4}^{++}$ & & $\mathrm{AC}$ & 2.608 & 3.041 & 3.496 & 6.592 & 6.375 & 7.143 \\
\hline 7 & $\mathrm{NH}_{4}{ }^{++}$ & uncertainty & $\mathrm{AC}$ & 2.750 & 2.763 & 2.779 & 2.916 & 2.904 & 2.959 \\
\hline 8 & $\mathrm{~K}^{+}$ & & AA & 1.295 & 1.010 & 0.681 & 0.856 & 1.382 & 1.898 \\
\hline 9 & $\mathrm{~K}^{+}$ & uncertainty & AA & 0.291 & 0.286 & 0.283 & 0.284 & 0.292 & 0.300 \\
\hline 10 & $\mathrm{Na}$ & & XRF & 2.229 & 0.539 & 1.134 & 0.000 & 2.256 & 0.000 \\
\hline 11 & $\mathrm{Na}$ & uncertainty & XRF & 3.346 & 3.399 & 3.094 & 3.995 & 3.369 & 1.572 \\
\hline 12 & $\mathrm{Mg}$ & & XRF & 1.382 & 1.176 & 0.000 & 0.000 & 0.000 & 0.000 \\
\hline 13 & $\mathrm{Mg}$ & uncertainty & XRF & 1.391 & 1.401 & 1.451 & 1.576 & 1.470 & 1.140 \\
\hline 14 & $\mathrm{Al}$ & & XRF & 0.919 & 0.217 & 0.393 & 0.309 & 0.139 & 0.000 \\
\hline 15 & $\mathrm{Al}$ & uncertainty & XRF & 0.279 & 0.844 & 0.877 & 1.045 & 0.941 & 0.651 \\
\hline 16 & $\mathrm{Si}$ & & XRF & 1.671 & 3.997 & 5.087 & 22.525 & 10.584 & 10.222 \\
\hline 17 & $\mathrm{Si}$ & uncertainty & XRF & 0.202 & 0.236 & 0.238 & 0.402 & 0.304 & 0.301 \\
\hline 18 & $\mathrm{P}$ & & XRF & 0.100 & 0.283 & 0.320 & 0.391 & 0.334 & 0.485 \\
\hline 19 & $\mathrm{P}$ & uncertainty & XRF & 0.372 & 0.377 & 0.382 & 0.504 & 0.439 & 0.104 \\
\hline 20 & $S$ & & XRF & 1.365 & 2.541 & 2.701 & 10.639 & 6.033 & 3.219 \\
\hline 21 & $\mathrm{~S}$ & uncertainty & XRF & 0.152 & 0.159 & 0.166 & 0.229 & 0.191 & 0.126 \\
\hline 22 & $\mathrm{Cl}$ & & XRF & 0.000 & 0.051 & 0.000 & 0.346 & 0.370 & 0.082 \\
\hline 23 & $\mathrm{Cl}$ & \begin{tabular}{|l|} 
uncertainty \\
\end{tabular} & XRF & 0.662 & 0.664 & 0.670 & 0.768 & 0.738 & 0.609 \\
\hline 24 & $\mathrm{~K}$ & & XRF & 0.000 & 0.000 & 0.000 & 0.000 & 0.052 & 0.000 \\
\hline 25 & $\mathrm{~K}$ & uncertainty & XRF & 0.663 & 0.670 & 0.674 & 0.722 & 0.713 & 0.411 \\
\hline 26 & $\mathrm{Ca}$ & & XRF & 0.547 & 0.596 & 0.000 & 0.289 & 0.725 & 0.797 \\
\hline 27 & $\mathrm{Ca}$ & uncertainty & XRF & 1.040 & 1.043 & 1.044 & 1.147 & 1.118 & 0.183 \\
\hline 28 & $\mathrm{Ti}$ & & XRF & 0.000 & 0.000 & 0.000 & 0.000 & 0.000 & 0.000 \\
\hline 29 & $\mathrm{Ti}$ & uncertainty & XRF & 4.850 & 5.000 & 4.859 & 5.317 & 5.168 & 2.360 \\
\hline 30 & $\mathrm{~V}$ & & XRF & 0.000 & 0.176 & 0.000 & 0.000 & 0.000 & 0.000 \\
\hline 31 & $\bar{V}$ & \begin{tabular}{|l|} 
uncertainty \\
\end{tabular} & XRF & 1.958 & 2.017 & 1.963 & 2.147 & 2.086 & 1.481 \\
\hline 32 & $\mathrm{Cr}$ & & XRF & 0.032 & 0.144 & 0.110 & 0.000 & 0.000 & 0.000 \\
\hline 33 & $\mathrm{Cr}$ & uncertainty & XRF & 0.388 & 0.392 & 0.392 & 0.421 & 0.411 & 0.500 \\
\hline 34 & $\mathrm{Mn}$ & & XRF & 0.000 & 0.018 & 0.026 & 0.000 & 0.107 & 0.000 \\
\hline 35 & $\mathrm{Mn}$ & uncertainty & XRF & 0.292 & 0.293 & 0.298 & 0.318 & 0.317 & 0.279 \\
\hline 36 & $\mathrm{Fe}$ & & XRF & 0.000 & 0.000 & 0.188 & 0.000 & 0.000 & 0.329 \\
\hline 37 & $\mathrm{Fe}$ & uncertainty & XRF & 0.250 & 0.242 & 0.261 & 0.265 & 0.260 & 0.072 \\
\hline 38 & $\mathrm{Co}$ & & XRF & 0.000 & 0.019 & 0.032 & 0.000 & 0.000 & 0.009 \\
\hline 39 & $\mathrm{Co}$ & uncertainty & XRF & 0.193 & 0.191 & 0.196 & 0.209 & 0.204 & 0.157 \\
\hline 40 & $\mathrm{Ni}$ & & XRF & 0.050 & 0.030 & 0.000 & 0.000 & 0.005 & 0.000 \\
\hline 41 & $\mathrm{Ni}$ & \begin{tabular}{|l|} 
uncertainty \\
\end{tabular} & XRF & 0.197 & 0.194 & 0.198 & 0.214 & 0.211 & 0.162 \\
\hline 42 & $\mathrm{Cu}$ & & XRF & 0.000 & 0.002 & 0.056 & 0.618 & 0.347 & 0.212 \\
\hline 43 & $\mathrm{Cu}$ & uncertainty & XRF & 0.203 & 0.201 & 0.207 & 0.076 & 0.074 & 0.062 \\
\hline 44 & $\mathrm{Zn}$ & & XRF & 0.058 & 0.084 & 0.149 & 0.465 & 0.219 & 0.507 \\
\hline 45 & $\mathrm{Zn}$ & uncertainty & XRF & 0.233 & 0.230 & 0.237 & 0.086 & 0.251 & 0.068 \\
\hline
\end{tabular}


Table B.1 Mack E7-400, Diesel, MOUDI, FTP, Elements and Inorganic Ions, $\left[\mu \mathrm{g} / \mathrm{m}^{3}\right]$ (Part 2)

\begin{tabular}{|c|c|c|c|c|c|c|c|c|c|}
\hline \multirow{2}{*}{\multicolumn{2}{|c|}{$\begin{array}{l}\text { MOUDI Stage } \\
\text { Cut-off Diameter }\end{array}$}} & & & \multirow{2}{*}{$\begin{array}{c}\mathrm{VI} \\
0.56\end{array}$} & \multirow{2}{*}{$\begin{array}{c}\text { VII } \\
0.32\end{array}$} & \multirow{2}{*}{$\begin{array}{l}\text { VIII } \\
0.18\end{array}$} & \multirow{2}{*}{$\begin{array}{l}\text { IX } \\
0.1\end{array}$} & \multirow{2}{*}{$\begin{array}{c}\mathrm{X} \\
0.056\end{array}$} & \multirow{2}{*}{$\begin{array}{c}11 \\
<0.056\end{array}$} \\
\hline & & $\mu \mathrm{m}$ & & & & & & & \\
\hline 46 & $\mathrm{Ga}$ & & XRF & 0.000 & 0.000 & 0.152 & 0.000 & 0.000 & 0.000 \\
\hline 47 & $\mathrm{Ga}$ & uncertainty & XRF & 0.354 & 0.359 & 0.346 & 0.380 & 0.358 & 0.159 \\
\hline 48 & As & & XRF & 0.000 & 0.000 & 0.007 & 0.000 & 0.000 & 0.000 \\
\hline 49 & As & uncertainty & XRF & 0.461 & 0.471 & 0.447 & 0.505 & 0.478 & 0.174 \\
\hline 50 & $\mathrm{Se}$ & & XRF & 0.000 & 0.153 & 0.048 & 0.000 & 0.000 & 0.000 \\
\hline 51 & $\mathrm{Se}$ & uncertainty & XRF & 0.255 & 0.261 & 0.253 & 0.276 & 0.255 & 0.100 \\
\hline 52 & $\mathrm{Br}$ & & XRF & 0.000 & 0.118 & 0.000 & 0.000 & 0.000 & 0.000 \\
\hline 53 & $\mathrm{Br}$ & uncertainty & XRF & 0.231 & 0.237 & 0.283 & 0.251 & 0.234 & 0.084 \\
\hline 54 & $\mathrm{Rb}$ & & XRF & 0.000 & 0.074 & 0.001 & 0.000 & 0.000 & 0.013 \\
\hline 55 & $\mathrm{Rb}$ & uncertainty & XRF & 0.232 & 0.236 & 0.227 & 0.250 & 0.235 & 0.082 \\
\hline 56 & $\mathrm{Sr}$ & & XRF & 0.000 & 0.000 & 0.047 & 0.000 & 0.000 & 0.023 \\
\hline 57 & $\mathrm{Sr}$ & uncertainty & XRF & 0.257 & 0.262 & 0.250 & 0.279 & 0.261 & 0.088 \\
\hline 58 & $Y$ & & XRF & 0.000 & 0.000 & 0.116 & 0.000 & 0.000 & 0.000 \\
\hline 59 & $\mathrm{Y}$ & uncertainty & XRF & 0.315 & 0.320 & 0.307 & 0.341 & 0.319 & 0.108 \\
\hline 60 & $\mathrm{Zr}$ & & XRF & 0.021 & 0.000 & 0.244 & 0.000 & 0.000 & 0.044 \\
\hline 61 & $\mathrm{Zr}$ & uncertainty & XRF & 0.375 & 0.380 & 0.364 & 0.407 & 0.381 & 0.128 \\
\hline 62 & Mo & & XRF & 0.000 & 0.061 & 0.000 & 0.000 & 0.000 & 0.000 \\
\hline 63 & Mo & uncertainty & XRF & 0.675 & 0.686 & 0.656 & 0.732 & 0.686 & 0.227 \\
\hline 64 & $\mathrm{Pd}$ & & XRF & 0.327 & 0.000 & 0.000 & 0.000 & 0.000 & 0.000 \\
\hline 65 & $\mathrm{Pd}$ & uncertainty & XRF & 1.624 & 1.614 & 1.596 & 1.790 & 1.719 & 0.771 \\
\hline 66 & $\mathrm{Ag}$ & & XRF & 0.000 & 0.000 & 0.000 & 0.000 & 0.000 & 0.050 \\
\hline 67 & $\mathrm{Ag}$ & uncertainty & XRF & 1.824 & 1.829 & 1.806 & 2.011 & 1.937 & 0.862 \\
\hline 68 & $\mathrm{Cd}$ & & XRF & 0.257 & 0.000 & 0.000 & 0.000 & 0.222 & 0.000 \\
\hline 69 & $\mathrm{Cd}$ & uncertainty & XRF & 1.803 & 1.837 & 1.800 & 1.995 & 1.930 & 0.917 \\
\hline 70 & In & & XRF & 0.000 & 0.000 & 0.000 & 0.735 & 0.000 & 0.000 \\
\hline 71 & In & uncertainty & XRF & 2.046 & 2.072 & 2.081 & 2.255 & 2.202 & 1.089 \\
\hline 72 & Sn & & XRF & 1.850 & 0.095 & 0.000 & 1.349 & 0.000 & 0.010 \\
\hline 73 & Sn & uncertainty & XRF & 2.722 & 2.725 & 2.731 & 2.967 & 2.910 & 1.300 \\
\hline 74 & $\mathrm{Sb}$ & & XRF & 0.073 & 0.256 & 0.437 & 1.595 & 0.162 & 0.000 \\
\hline 75 & $\mathrm{Sb}$ & uncertainty & XRF & 3.253 & 3.273 & 3.292 & 3.585 & 3.511 & 1.552 \\
\hline 76 & $\mathrm{Ba}$ & & XRF & 3.730 & 0.000 & 1.298 & 3.548 & 3.859 & 1.560 \\
\hline 77 & $\mathrm{Ba}$ & uncertainty & XRF & 12.304 & 12.351 & 12.371 & 13.507 & 13.113 & 5.324 \\
\hline 78 & $\mathrm{La}$ & & XRF & 0.000 & 0.000 & 0.000 & 0.000 & 0.000 & 2.956 \\
\hline 79 & $\mathrm{La}$ & uncertainty & XRF & 17.669 & 17.736 & 17.696 & 19.389 & 18.854 & 7.671 \\
\hline 80 & $\mathrm{Au}$ & & XRF & 0.000 & 0.000 & 0.216 & 0.000 & 0.000 & 0.000 \\
\hline 81 & $\mathrm{Au}$ & uncertainty & XRF & 0.602 & 0.611 & 0.590 & 0.650 & 0.602 & 0.287 \\
\hline 82 & $\mathrm{Hg}$ & & XRF & 0.011 & 0.169 & 0.364 & 0.000 & 0.000 & 0.011 \\
\hline 83 & $\mathrm{Hg}$ & uncertainty & XRF & 0.569 & 0.578 & 0.556 & 0.611 & 0.571 & 0.227 \\
\hline 84 & $\mathrm{Ti}$ & & XRF & 0.000 & 0.122 & 0.000 & 0.000 & 0.000 & 0.000 \\
\hline 85 & $\mathrm{Ti}$ & uncertainty & XRF & 0.553 & 0.564 & 0.542 & 0.594 & 0.556 & 0.207 \\
\hline 86 & $\mathrm{~Pb}$ & & XRF & 0.000 & 0.264 & 0.000 & 0.000 & 0.000 & 0.000 \\
\hline 87 & $\mathrm{~Pb}$ & uncertainty & XRF & 0.700 & 0.716 & 0.678 & 0.756 & 0.705 & 0.258 \\
\hline 88 & $\mathrm{U}$ & & XRF & 0.000 & 0.101 & 0.000 & 0.000 & 0.000 & 0.017 \\
\hline 89 & $\mathrm{U}$ & uncertainty & XRF & 0.572 & 0.582 & 0.556 & 0.619 & 0.580 & 0.199 \\
\hline 90 & SUM & & & 18.521 & 18.532 & 22.348 & 56.000 & 36.350 & 34.359 \\
\hline 91 & SUM & uncertainty & & 23.420 & 23.557 & 23.501 & 25.668 & 24.963 & 11.220 \\
\hline
\end{tabular}


Table B.2 Mack E7-400, Diesel, MOUDI, R75, Elements and Inorganic Ions, $\left[\mu \mathrm{g} / \mathrm{m}^{3}\right]$ (Part 1)

\begin{tabular}{|c|c|c|c|c|c|c|c|c|c|}
\hline \multirow{2}{*}{\multicolumn{2}{|c|}{$\begin{array}{l}\text { XI } \\
\text { Cut-off Diameter }\end{array}$}} & \multirow[b]{2}{*}{$\mu \mathrm{m}$} & \multirow{2}{*}{\multicolumn{2}{|c|}{$\begin{array}{c}\mathrm{VI} \\
0.56\end{array}$}} & \multirow{2}{*}{$\begin{array}{c}\text { VII } \\
0.32\end{array}$} & \multirow{2}{*}{$\begin{array}{l}\text { VIII } \\
0.18\end{array}$} & \multirow{2}{*}{$\begin{array}{l}\text { IX } \\
0.1\end{array}$} & \multirow{2}{*}{$\begin{array}{c}\mathrm{X} \\
0.056\end{array}$} & \multirow{2}{*}{$\begin{array}{c}\mathrm{XI} \\
<0.056 \\
\end{array}$} \\
\hline & & & & & & & & & \\
\hline 1 & TPM & & grav. & 757.750 & 360.833 & 721.667 & 1515.500 & 866.000 & 384.889 \\
\hline 2 & $\mathrm{Cl}^{-}$ & & IC & 3.796 & 7.452 & 3.796 & 5.624 & 5.624 & 4.218 \\
\hline 3 & $\mathrm{Cl}^{-}$ & uncertainty & IC & 2.424 & 2.656 & 2.424 & 2.527 & 2.527 & 2.449 \\
\hline 4 & $\mathrm{SO}_{4}^{--}$ & & IC & 4.429 & 6.257 & 11.742 & 28.196 & 19.055 & 14.626 \\
\hline 5 & $\mathrm{SO}_{4}^{--}$ & \begin{tabular}{|l} 
uncertainty \\
\end{tabular} & IC & 2.343 & 2.343 & 2.343 & 2.343 & 2.343 & 2.343 \\
\hline 6 & $\mathrm{NH}_{4}{ }^{++}$ & & $\mathrm{AC}$ & 1.388 & 3.950 & 7.667 & 16.904 & 12.827 & 25.183 \\
\hline 7 & $\mathrm{NH}_{4}{ }^{++}$ & uncertainty & $\mathrm{AC}$ & 4.504 & 4.571 & 4.704 & 5.209 & 4.958 & 5.825 \\
\hline 8 & $\mathrm{~K}^{+}$ & & AA & 1.463 & 2.560 & 1.573 & 2.194 & 2.377 & 2.360 \\
\hline 9 & $\mathrm{~K}^{+}$ & \begin{tabular}{|l} 
uncertainty \\
\end{tabular} & AA & 0.475 & 0.492 & 0.476 & 0.484 & 0.488 & 0.487 \\
\hline 10 & $\mathrm{Na}$ & & XRF & 1.144 & 0.000 & 0.000 & 4.913 & 4.525 & 3.450 \\
\hline 11 & $\mathrm{Na}$ & uncertainty & XRF & 5.530 & 4.480 & 5.564 & 6.699 & 6.021 & 3.812 \\
\hline 12 & $\mathrm{Mg}$ & & XRF & 1.712 & 0.843 & 0.000 & 1.757 & 0.000 & 0.000 \\
\hline 13 & $\mathrm{Mg}$ & uncertainty & XRF & 2.330 & 2.306 & 2.345 & 2.762 & 2.630 & 1.933 \\
\hline 14 & $\mathrm{Al}$ & & XRF & 0.927 & 0.000 & 0.000 & 1.261 & 0.077 & 0.611 \\
\hline 15 & $\mathrm{Al}$ & nty & XRF & 1.346 & 1.485 & 1.366 & 1.631 & 1.556 & 1.057 \\
\hline 16 & $\mathrm{Si}$ & & XRF & 1.384 & 3.228 & 4.939 & 18.471 & 8.488 & 6.779 \\
\hline 17 & $\mathrm{Si}$ & \begin{tabular}{|l} 
uncertainty \\
\end{tabular} & XRF & 0.298 & 0.332 & 0.360 & 0.542 & 0.414 & 0.338 \\
\hline 18 & $\mathrm{P}$ & & XRF & 0.094 & 0.166 & 0.344 & 0.445 & 0.502 & 0.402 \\
\hline 19 & $\mathrm{P}$ & uncertainty & XRF & 0.582 & 0.604 & 0.630 & 0.788 & 0.675 & 0.494 \\
\hline 20 & $\mathrm{~S}$ & & XRF & 1.169 & 1.917 & 3.682 & 16.076 & 8.106 & 5.023 \\
\hline 21 & $\mathrm{~S}$ & \begin{tabular}{|l} 
uncertainty \\
\end{tabular} & XRF & 0.250 & 0.278 & 0.263 & 0.373 & 0.321 & 0.197 \\
\hline 22 & $\mathrm{Cl}$ & & XRF & 0.337 & 0.249 & 0.000 & 0.000 & 4.935 & 0.000 \\
\hline 23 & $\mathrm{Cl}$ & uncertainty & XRF & 1.129 & 1.108 & 1.099 & 1.227 & 0.479 & 0.987 \\
\hline 24 & $\mathrm{~K}$ & & XRF & 0.339 & 0.000 & 0.000 & 0.562 & 0.726 & 0.000 \\
\hline 25 & $\mathrm{~K}$ & ncertainty & XRF & 1.185 & 1.101 & 1.121 & 1.252 & 1.214 & 0.694 \\
\hline 26 & $\mathrm{Ca}$ & & XRF & 0.401 & 0.000 & 0.000 & 1.512 & 0.683 & 2.025 \\
\hline 27 & $\mathrm{Ca}$ & ncertainty & XRF & 1.816 & 1.740 & 1.768 & 1.928 & 1.851 & 0.315 \\
\hline 28 & $\mathrm{Ti}$ & & XRF & 0.000 & 0.053 & 0.000 & 0.107 & 0.089 & 0.000 \\
\hline 29 & $\mathrm{Ti}$ & uncertainty & XRF & 8.551 & 7.992 & 8.106 & 9.044 & 8.666 & 3.628 \\
\hline 30 & $\mathrm{~V}$ & & XRF & 0.000 & 0.179 & 0.268 & 0.000 & 0.158 & 0.000 \\
\hline 31 & V & uncertainty & XRF & 3.451 & 3.227 & 3.275 & 3.649 & 3.498 & 1.524 \\
\hline 32 & $\mathrm{Cr}$ & & XRF & 0.019 & 0.378 & 0.180 & 0.505 & 0.000 & 0.000 \\
\hline 33 & $\mathrm{Cr}$ & uncertainty & XRF & 0.675 & 0.640 & 0.650 & 0.724 & 0.681 & 0.484 \\
\hline 34 & $\mathrm{Mn}$ & & XRF & 0.000 & 0.108 & 0.000 & 0.000 & 0.075 & 0.012 \\
\hline 35 & $\mathrm{Mn}$ & uncertainty & XRF & 0.506 & 0.484 & 0.488 & 0.540 & 0.518 & 0.404 \\
\hline 36 & $\mathrm{Fe}$ & & XRF & 0.000 & 0.000 & 0.000 & 0.000 & 0.000 & 0.485 \\
\hline 37 & $\mathrm{Fe}$ & uncertainty & XRF & 0.422 & 0.393 & 0.410 & 0.445 & 0.428 & 0.118 \\
\hline 38 & Co & & $\mathrm{XRF}$ & 0.000 & 0.320 & 0.061 & 0.006 & 0.000 & 0.165 \\
\hline 39 & Co & certainty & $\mathrm{XRF}$ & 0.332 & 0.321 & 0.324 & 0.355 & 0.336 & 0.262 \\
\hline 40 & $\mathrm{Ni}$ & & XRF & 0.046 & 0.000 & 0.020 & 0.148 & 0.054 & 0.000 \\
\hline 41 & $\mathrm{Ni}$ & certainty & XRF & 0.340 & 0.319 & 0.328 & 0.363 & 0.344 & 0.266 \\
\hline 42 & $\overline{\mathrm{Cu}}$ & & XRF & 0.000 & 0.000 & 0.000 & 0.183 & 0.206 & 0.000 \\
\hline 43 & $\mathrm{Cu}$ & uncertainty & XRF & 0.350 & 0.331 & 0.340 & 0.378 & 0.360 & 0.296 \\
\hline 44 & $\mathrm{Zn}$ & & XRF & 0.000 & 0.545 & 0.190 & 0.579 & 1.710 & 0.253 \\
\hline 45 & $\mathrm{Zn}$ & uncertainty & XRF & 0.395 & 0.127 & 0.390 & 0.144 & 0.142 & 0.325 \\
\hline
\end{tabular}


Table B.2 Mack E7-400, Diesel, MOUDI, R75, Elements and Inorganic Ions, $\left[\mu \mathrm{g} / \mathrm{m}^{3}\right]$

(Part 2)

\begin{tabular}{|c|c|c|c|c|c|c|c|c|c|}
\hline & & VI & VII & VIII & IX & $\mathrm{X}$ & $\mathrm{XI}$ \\
\hline \multicolumn{2}{|c|}{ Cut-off Diameter } & $\mu \mathrm{m}$ & & 0.56 & 0.32 & 0.18 & 0.1 & 0.056 & $<0.056$ \\
\hline 46 & $\mathrm{Ga}$ & & XRF & 0.000 & 0.484 & 0.000 & 0.081 & 0.208 & 0.000 \\
\hline 47 & $\mathrm{Ga}$ & uncertainty & XRF & 0.583 & 0.615 & 0.573 & 0.643 & 0.623 & 0.272 \\
\hline 48 & As & & XRF & 0.000 & 0.326 & 0.000 & 0.000 & 0.000 & 0.000 \\
\hline 49 & As & uncertainty & XRF & 0.782 & 0.799 & 0.769 & 0.865 & 0.812 & 0.306 \\
\hline 50 & $\mathrm{Se}$ & & XRF & 0.000 & 0.239 & 0.000 & 0.293 & 0.053 & 0.000 \\
\hline 51 & $\mathrm{Se}$ & uncertainty & XRF & 0.422 & 0.450 & 0.417 & 0.467 & 0.447 & 0.173 \\
\hline 52 & $\mathrm{Br}$ & & XRF & 0.000 & 0.064 & 0.000 & 0.206 & 0.178 & 0.000 \\
\hline 53 & $\mathrm{Br}$ & uncertainty & XRF & 0.386 & 0.510 & 0.379 & 0.533 & 0.515 & 0.146 \\
\hline 54 & $\mathrm{Rb}$ & & XRF & 0.000 & 0.194 & 0.000 & 0.303 & 0.000 & 0.000 \\
\hline 55 & $\mathrm{Rb}$ & uncertainty & XRF & 0.388 & 0.404 & 0.380 & 0.425 & 0.405 & 0.138 \\
\hline 56 & $\mathrm{Sr}$ & & XRF & 0.000 & 0.091 & 0.000 & 0.000 & 0.087 & 0.000 \\
\hline 57 & $\mathrm{Sr}$ & uncertainty & XRF & 0.431 & 0.444 & 0.422 & 0.467 & 0.452 & 0.150 \\
\hline 58 & $\mathrm{Y}$ & & XRF & 0.000 & 0.000 & 0.000 & 0.000 & 0.000 & 0.000 \\
\hline 59 & $\mathrm{Y}$ & \begin{tabular}{|l|} 
uncertainty \\
\end{tabular} & XRF & 0.527 & 0.541 & 0.518 & 0.571 & 0.551 & 0.185 \\
\hline 60 & $\mathrm{Zr}$ & & XRF & 0.000 & 0.071 & 0.000 & 0.000 & 0.108 & 0.000 \\
\hline 61 & $\mathrm{Zr}$ & \begin{tabular}{|l|} 
uncertainty \\
\end{tabular} & XRF & 0.629 & 0.642 & 0.616 & 0.678 & 0.656 & 0.220 \\
\hline 62 & Mo & & XRF & 0.000 & 0.000 & 0.000 & 0.000 & 0.378 & 0.004 \\
\hline 63 & Mo & uncertainty & XRF & 1.131 & 1.158 & 1.111 & 1.220 & 1.182 & 0.395 \\
\hline 64 & $\mathrm{Pd}$ & & XRF & 0.267 & 0.586 & 0.090 & 0.000 & 0.000 & 0.000 \\
\hline 65 & $\mathrm{Pd}$ & uncertainty & XRF & 2.888 & 2.710 & 2.662 & 3.169 & 2.883 & 1.309 \\
\hline 66 & $\mathrm{Ag}$ & & XRF & 0.640 & 0.701 & 0.000 & 0.000 & 0.000 & 0.000 \\
\hline 67 & $\mathrm{Ag}$ & uncertainty & XRF & 3.237 & 3.025 & 3.013 & 3.505 & 3.276 & 1.442 \\
\hline 68 & $\mathrm{Cd}$ & & XRF & 0.000 & 0.000 & 0.000 & 0.757 & 0.000 & 0.000 \\
\hline 69 & $\mathrm{Cd}$ & uncertainty & XRF & 3.229 & 3.001 & 3.023 & 3.463 & 3.233 & 1.517 \\
\hline 70 & In & & XRF & 0.000 & 0.000 & 0.000 & 0.499 & 0.000 & 0.000 \\
\hline 71 & In & \begin{tabular}{|l|} 
uncertainty \\
\end{tabular} & XRF & 3.654 & 3.436 & 3.462 & 3.892 & 3.694 & 1.811 \\
\hline 72 & Sn & & XRF & 0.000 & 2.200 & 0.125 & 0.261 & 0.000 & 0.676 \\
\hline 73 & $\mathrm{Sn}$ & \begin{tabular}{|l|} 
uncertainty \\
\end{tabular} & XRF & 4.747 & 4.518 & 4.567 & 5.100 & 4.874 & 2.238 \\
\hline 74 & $\mathrm{Sb}$ & & XRF & 0.000 & 3.380 & 2.718 & 0.000 & 0.000 & 0.000 \\
\hline 75 & $\mathrm{Sb}$ & \begin{tabular}{|l} 
uncertainty \\
\end{tabular} & XRF & 5.760 & 5.399 & 5.512 & 6.070 & 5.826 & 2.632 \\
\hline 76 & $\mathrm{Ba}$ & & XRF & 0.000 & 0.000 & 0.000 & 6.081 & 0.000 & 2.771 \\
\hline 77 & $\mathrm{Ba}$ & uncertainty & XRF & 21.609 & 20.327 & 20.649 & 22.967 & 22.025 & 9.071 \\
\hline 78 & $\mathrm{La}$ & & XRF & 1.627 & 0.000 & 0.000 & 0.000 & 0.000 & 0.974 \\
\hline 79 & $\mathrm{La}$ & uncertainty & XRF & 31.053 & 28.982 & 29.640 & 32.912 & 31.564 & 12.840 \\
\hline 80 & $\mathrm{Au}$ & & XRF & 0.000 & 0.832 & 0.000 & 0.119 & 0.099 & 0.000 \\
\hline 81 & $\mathrm{Au}$ & uncertainty & XRF & 1.000 & 1.050 & 0.981 & 1.099 & 1.060 & 0.481 \\
\hline 82 & $\mathrm{Hg}$ & & XRF & 0.000 & 0.933 & 0.000 & 0.755 & 0.757 & 0.000 \\
\hline 83 & $\mathrm{Hg}$ & uncertainty & XRF & 0.939 & 0.991 & 0.931 & 1.038 & 1.002 & 0.392 \\
\hline 84 & $\mathrm{Ti}$ & & XRF & 0.000 & 0.929 & 0.000 & 0.111 & 0.309 & 0.000 \\
\hline 85 & $\mathrm{Ti}$ & uncertainty & XRF & 0.917 & 0.975 & 0.896 & 1.008 & 0.985 & 0.354 \\
\hline 86 & $\mathrm{~Pb}$ & & XRF & 0.000 & 0.284 & 0.000 & 1.216 & 0.443 & 0.000 \\
\hline 87 & $\mathrm{~Pb}$ & \begin{tabular}{|l} 
uncertainty \\
\end{tabular} & XRF & 1.172 & 1.210 & 1.144 & 1.286 & 1.233 & 0.439 \\
\hline 88 & $\mathrm{U}$ & & XRF & 0.000 & 0.202 & 0.000 & 0.136 & 0.014 & 0.000 \\
\hline 89 & U & uncertainty & XRF & 0.955 & 0.987 & 0.935 & 1.042 & 1.003 & 0.343 \\
\hline 90 & SUM & & & 17.917 & 32.967 & 34.363 & 85.714 & 58.235 & 58.649 \\
\hline 91 & SUM & uncertainty & & 41.089 & 38.592 & 39.313 & 43.645 & 41.833 & 19.001 \\
\hline
\end{tabular}


Table B.3 Mack E7-400, Diesel, MOUDI, R50, Elements and Inorganic Ions, [ $\left.\mu \mathrm{g} / \mathrm{m}^{3}\right]$ (Part 1)

\begin{tabular}{|c|c|c|c|c|c|c|c|c|c|}
\hline \multirow{2}{*}{\multicolumn{2}{|c|}{\begin{tabular}{|l} 
XI \\
Cut-off Diameter \\
\end{tabular}}} & \multirow[b]{2}{*}{$\mu \mathrm{m}$} & & \multirow{2}{*}{$\begin{array}{c}\text { VI } \\
0.56\end{array}$} & \multirow{2}{*}{ VII } & VIII & IX & $\mathrm{X}$ & \multirow{2}{*}{$\begin{array}{l}\mathrm{XI} \\
0.056\end{array}$} \\
\hline & & & & & & 0.18 & 0.1 & 0.056 & \\
\hline 1 & TPM & & grav. & 0.000 & 84.194 & 108.250 & 1226.833 & 1214.806 & 962.222 \\
\hline 2 & $\mathrm{Cl}^{-}$ & & IC & 5.624 & 7.452 & 5.624 & 7.452 & 7.452 & 7.874 \\
\hline 3 & $\mathrm{Cl}^{-}$ & uncertainty & IC & 2.527 & 2.656 & 2.527 & 2.656 & 2.656 & 2.682 \\
\hline 4 & $\mathrm{SO}_{4}^{--}$ & & IC & 4.429 & 4.429 & 6.257 & 17.227 & 22.711 & 18.282 \\
\hline 5 & $\mathrm{SO}_{4}^{--}$ & uncertainty & IC & 2.343 & 2.343 & 2.343 & 2.343 & 2.343 & 2.343 \\
\hline 6 & $\mathrm{NH}_{4}{ }^{++}$ & & $\mathrm{AC}$ & 10.986 & 4.347 & 7.667 & 11.347 & 13.584 & 11.905 \\
\hline 7 & $\mathrm{NH}_{4}{ }^{++}$ & uncertainty & $\mathrm{AC}$ & 4.859 & 4.583 & 4.704 & 4.877 & 5.001 & 4.932 \\
\hline 8 & $\mathrm{~K}^{+}$ & & AA & 2.415 & 3.548 & 2.377 & 3.584 & 3.401 & 1.957 \\
\hline 9 & $\mathrm{~K}^{+}$ & uncertainty & AA & 0.488 & 0.511 & 0.488 & 0.512 & 0.507 & 0.482 \\
\hline \begin{tabular}{l|l}
10 \\
\end{tabular} & $\mathrm{Na}$ & & XRF & 0.915 & 0.000 & 7.937 & 0.000 & 4.109 & 0.656 \\
\hline 11 & $\mathrm{Na}$ & uncertainty & XRF & 5.690 & 5.670 & 1.826 & 6.034 & 5.634 & 3.648 \\
\hline 12 & $\mathrm{Mg}$ & & $\mathrm{XRF}$ & 0.000 & 1.881 & 5.266 & 1.081 & 1.245 & 0.000 \\
\hline 13 & $\mathrm{Mg}$ & uncertainty & $\mathrm{XRF}$ & 2.516 & 2.217 & 0.787 & 2.487 & 2.539 & 1.870 \\
\hline 14 & $\mathrm{Al}$ & & XRF & 1.354 & 1.422 & 1.476 & 0.796 & 0.000 & 0.492 \\
\hline 15 & $\mathrm{Al}$ & uncertainty & XRF & 1.405 & 0.441 & 0.464 & 1.566 & 1.629 & 1.121 \\
\hline 16 & $\mathrm{Si}$ & & $\mathrm{XRF}$ & 0.422 & 1.129 & 3.570 & 14.308 & 13.910 & 18.320 \\
\hline 17 & $\mathrm{Si}$ & uncertainty & XRF & 0.903 & 0.295 & 0.338 & 0.469 & 0.464 & 0.496 \\
\hline 18 & $\mathrm{P}$ & & XRF & 0.054 & 0.373 & 0.063 & 0.118 & 1.319 & 0.616 \\
\hline 19 & $\mathrm{P}$ & uncertainty & $\mathrm{XRF}$ & 0.599 & 0.562 & 0.616 & 0.710 & 0.231 & 0.158 \\
\hline 20 & $\mathrm{~S}$ & & $\mathrm{XRF}$ & 1.043 & 1.143 & 1.582 & 7.811 & 8.597 & 7.344 \\
\hline 21 & $\mathrm{~S}$ & uncertainty & XRF & 0.250 & 0.227 & 0.256 & 0.306 & 0.322 & 0.229 \\
\hline 22 & $\mathrm{Cl}$ & & XRF & 0.666 & 0.147 & 1.079 & 0.000 & 0.117 & 0.061 \\
\hline 23 & $\mathrm{Cl}$ & uncertainty & XRF & 1.146 & 1.101 & 1.184 & 1.140 & 1.190 & 1.016 \\
\hline 24 & K & & XRF & 0.247 & 0.107 & 0.380 & 0.023 & 0.000 & 0.000 \\
\hline 25 & $\mathrm{~K}$ & uncertainty & XRF & 1.162 & 1.115 & 1.181 & 1.194 & 1.167 & 0.683 \\
\hline 26 & $\mathrm{Ca}$ & & XRF & 0.871 & 0.599 & 0.272 & 0.488 & 0.665 & 1.663 \\
\hline 27 & $\mathrm{Ca}$ & uncertainty & XRF & 1.816 & 1.751 & 1.844 & 1.835 & 1.823 & 0.297 \\
\hline 28 & $\mathrm{Ti}$ & & XRF & 0.087 & 0.000 & 0.000 & 0.008 & 0.000 & 0.142 \\
\hline 29 & $\mathrm{Ti}$ & uncertainty & XRF & 8.599 & 8.199 & 8.672 & 8.540 & 8.548 & 3.387 \\
\hline 30 & $\mathrm{~V}$ & & XRF & 0.000 & 0.000 & 0.000 & 0.603 & 0.000 & 0.005 \\
\hline 31 & V & uncertainty & XRF & 3.468 & 3.310 & 3.500 & 3.450 & 3.453 & 1.435 \\
\hline 32 & $\mathrm{Cr}$ & & XRF & 0.090 & 0.013 & 0.099 & 0.107 & 0.000 & 0.000 \\
\hline 33 & $\mathrm{Cr}$ & uncertainty & XRF & 0.682 & 0.651 & 0.690 & 0.677 & 0.675 & 0.481 \\
\hline 34 & $\mathrm{Mn}$ & & XRF & 0.000 & 0.000 & 0.000 & 0.000 & 0.229 & 0.191 \\
\hline 35 & $\mathrm{Mn}$ & uncertainty & XRF & 0.515 & 0.492 & 0.518 & 0.510 & 0.516 & 0.408 \\
\hline 36 & $\mathrm{Fe}$ & & $\mathrm{XRF}$ & 0.000 & 0.000 & 0.087 & 0.095 & 0.000 & 0.710 \\
\hline 37 & $\mathrm{Fe}$ & uncertainty & $\mathrm{XRF}$ & 0.437 & 0.416 & 0.452 & 0.441 & 0.435 & 0.120 \\
\hline 38 & Co & & XRF & 0.063 & 0.011 & 0.248 & 0.094 & 0.298 & 0.093 \\
\hline 39 & Co & uncertainty & XRF & 0.338 & 0.324 & 0.348 & 0.336 & 0.339 & 0.259 \\
\hline 40 & $\mathrm{Ni}$ & & XRF & 0.000 & 0.078 & 0.130 & 0.008 & 0.176 & 0.000 \\
\hline 41 & $\mathrm{Ni}$ & uncertainty & XRF & 0.343 & 0.330 & 0.351 & 0.340 & 0.342 & 0.263 \\
\hline 42 & $\mathrm{Cu}$ & & XRF & 0.000 & 0.000 & 0.000 & 0.166 & 0.150 & 0.085 \\
\hline 43 & $\mathrm{Cu}$ & uncertainty & XRF & 0.352 & 0.342 & 0.358 & 0.356 & 0.354 & 0.298 \\
\hline 44 & $\mathrm{Zn}$ & & XRF & 0.000 & 0.000 & 0.000 & 0.358 & 0.338 & 0.793 \\
\hline 45 & $\mathrm{Zn}$ & uncertainty & XRF & 0.398 & 0.385 & 0.408 & 0.407 & 0.404 & 0.111 \\
\hline
\end{tabular}


Table B.3 Mack E7-400, Diesel, MOUDI, R50, Elements and Inorganic Ions, $\left[\mu \mathrm{g} / \mathrm{m}^{3}\right]$ (Part 2)

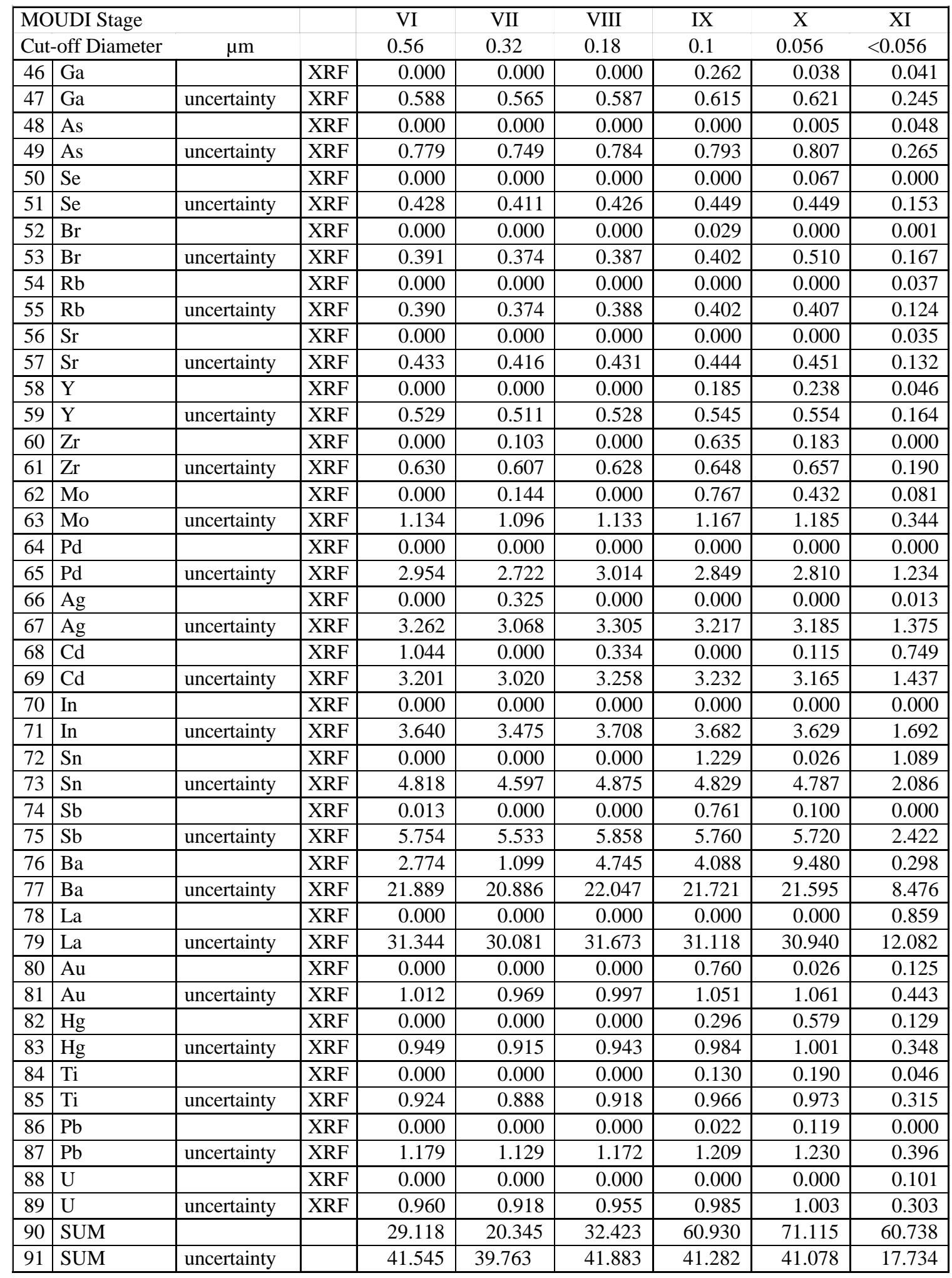


Table B.4 Mack E7-400, Diesel, MOUDI, I50, Elements and Inorganic Ions, $\left[\mu \mathrm{g} / \mathrm{m}^{3}\right]$ (Part 1)

\begin{tabular}{|c|c|c|c|c|c|c|c|c|c|}
\hline \multicolumn{3}{|c|}{ MOUDI Stage } & & VI & VII & VIII & IX & $\mathrm{X}$ & XI \\
\hline \multicolumn{2}{|c|}{ Cut-off Diameter } & $\mu \mathrm{m}$ & & 0.56 & 0.32 & 0.18 & 0.1 & 0.056 & $<0.056$ \\
\hline 1 & TPM & & grav. & 158.767 & 274.233 & 490.733 & 1529.933 & 822.700 & 562.900 \\
\hline 2 & $\mathrm{Cl}^{-}$ & & IC & 4.555 & 4.555 & 6.749 & 6.749 & 4.555 & 5.062 \\
\hline 3 & $\mathrm{Cl}^{-}$ & uncertainty & IC & 2.909 & 2.909 & 3.033 & 3.033 & 2.909 & 2.939 \\
\hline 4 & $\mathrm{SO}_{4}^{--}$ & & IC & 3.121 & 7.509 & 7.509 & 29.447 & 22.866 & 13.163 \\
\hline 5 & $\mathrm{SO}_{4}^{--}$ & uncertainty & IC & 2.812 & 2.812 & 2.812 & 2.812 & 2.812 & 2.812 \\
\hline 6 & $\mathrm{NH}_{4}^{++}$ & & $\mathrm{AC}$ & 9.200 & 5.649 & 6.082 & 17.167 & 13.617 & 25.370 \\
\hline 7 & $\mathrm{NH}_{4}^{++}$ & uncertainty & $\mathrm{AC}$ & 5.645 & 5.512 & 5.527 & 6.053 & 5.853 & 6.612 \\
\hline 8 & $\mathrm{~K}^{+}$ & & AA & 1.581 & 1.581 & 1.887 & 2.984 & 2.063 & 1.779 \\
\hline 9 & $\mathrm{~K}^{+}$ & uncertainty & AA & 0.567 & 0.567 & 0.571 & 0.587 & 0.573 & 0.571 \\
\hline 10 & $\mathrm{Na}$ & & XRF & 4.962 & 1.784 & 0.000 & 0.000 & 5.687 & 6.997 \\
\hline 11 & $\mathrm{Na}$ & uncertainty & $\mathrm{XRF}$ & 7.192 & 7.081 & 6.714 & 7.671 & 1.876 & 1.184 \\
\hline 12 & $\mathrm{Mg}$ & & $\mathrm{XRF}$ & 2.252 & 0.000 & 1.139 & 0.000 & 0.000 & 0.000 \\
\hline 13 & $\mathrm{Mg}$ & uncertainty & $\mathrm{XRF}$ & 2.699 & 2.485 & 2.647 & 2.905 & 3.100 & 2.493 \\
\hline 14 & $\mathrm{Al}$ & & XRF & 2.545 & 0.626 & 1.505 & 0.000 & 1.152 & 0.709 \\
\hline 15 & $\mathrm{Al}$ & uncertainty & XRF & 0.561 & 1.671 & 1.617 & 1.891 & 1.963 & 1.243 \\
\hline 16 & $\mathrm{Si}$ & & XRF & 1.299 & 1.788 & 2.959 & 12.814 & 12.369 & 11.174 \\
\hline 17 & $\mathrm{Si}$ & uncertainty & XRF & 0.332 & 0.352 & 0.377 & 0.530 & 0.528 & 0.447 \\
\hline 18 & $\mathrm{P}$ & & $\mathrm{XRF}$ & 0.000 & 0.000 & 0.049 & 1.016 & 0.003 & 0.279 \\
\hline 19 & $P$ & uncertainty & $\mathrm{XRF}$ & 0.688 & 0.671 & 0.707 & 0.281 & 0.833 & 0.632 \\
\hline 20 & $\mathrm{~S}$ & & XRF & 0.580 & 1.462 & 0.486 & 12.639 & 10.717 & 4.942 \\
\hline 21 & $\mathrm{~S}$ & uncertainty & XRF & 0.840 & 0.294 & 0.902 & 0.404 & 0.374 & 0.244 \\
\hline 22 & $\mathrm{Cl}$ & & XRF & 0.798 & 0.740 & 0.000 & 1.400 & 0.000 & 0.307 \\
\hline 23 & $\mathrm{Cl}$ & uncertainty & $\mathrm{XRF}$ & 1.374 & 1.352 & 1.377 & 1.526 & 1.416 & 1.235 \\
\hline 24 & $\mathrm{~K}$ & & $\mathrm{XRF}$ & 0.000 & 0.000 & 0.000 & 0.000 & 0.000 & 0.507 \\
\hline 25 & $\mathrm{~K}$ & uncertainty & XRF & 1.363 & 1.337 & 1.338 & 1.397 & 2.533 & 0.915 \\
\hline 26 & $\mathrm{Ca}$ & & XRF & 0.000 & 0.240 & 0.000 & 0.953 & 4.490 & 2.879 \\
\hline 27 & $\mathrm{Ca}$ & uncertainty & XRF & 2.126 & 2.100 & 2.063 & 2.165 & 0.764 & 0.394 \\
\hline 28 & $\mathrm{Ti}$ & & XRF & 0.000 & 0.000 & 0.000 & 0.000 & 0.000 & 0.000 \\
\hline 29 & $\mathrm{Ti}$ & uncertainty & XRF & 9.956 & 9.835 & 9.598 & 9.973 & 10.503 & 5.125 \\
\hline 30 & V & & XRF & 0.000 & 0.000 & 0.000 & 0.344 & 0.000 & 0.000 \\
\hline 31 & V & uncertainty & XRF & 4.020 & 3.971 & 3.883 & 4.030 & 4.242 & 3.187 \\
\hline 32 & $\mathrm{Cr}$ & & XRF & 0.150 & 0.000 & 0.000 & 0.113 & 0.000 & 0.000 \\
\hline 33 & $\mathrm{Cr}$ & uncertainty & XRF & 0.798 & 0.784 & 0.768 & 0.801 & 0.833 & 1.046 \\
\hline 34 & $\mathrm{Mn}$ & & XRF & 0.000 & 0.000 & 0.113 & 0.156 & 0.000 & 0.000 \\
\hline 35 & $\mathrm{Mn}$ & uncertainty & XRF & 0.599 & 0.595 & 0.587 & 0.611 & 0.631 & 0.577 \\
\hline 36 & $\mathrm{Fe}$ & & XRF & 0.000 & 0.000 & 0.000 & 0.000 & 0.817 & 1.054 \\
\hline 37 & $\mathrm{Fe}$ & uncertainty & XRF & 0.495 & 0.504 & 0.484 & 0.505 & 0.186 & 0.150 \\
\hline 38 & Co & & XRF & 0.000 & 0.000 & 0.085 & 0.003 & 0.056 & 0.029 \\
\hline 39 & Co & uncertainty & XRF & 0.395 & 0.387 & 0.384 & 0.398 & 0.414 & 0.319 \\
\hline 40 & $\mathrm{Ni}$ & & XRF & 0.000 & 0.000 & 0.003 & 0.199 & 0.000 & 0.000 \\
\hline 41 & $\mathrm{Ni}$ & uncertainty & XRF & 0.404 & 0.397 & 0.390 & 0.410 & 0.419 & 0.332 \\
\hline 42 & $\mathrm{Cu}$ & & XRF & 0.000 & 0.000 & 0.000 & 0.707 & 0.157 & 0.064 \\
\hline 43 & $\mathrm{Cu}$ & uncertainty & XRF & 0.413 & 0.407 & 0.404 & 0.144 & 0.437 & 0.368 \\
\hline 44 & $\mathrm{Zn}$ & & $\mathrm{XRF}$ & 0.000 & 0.000 & 0.250 & 0.501 & 0.000 & 0.482 \\
\hline 45 & $\mathrm{Zn}$ & uncertainty & XRF & 0.465 & 0.463 & 0.463 & 0.162 & 0.492 & 0.134 \\
\hline
\end{tabular}


Table B.4 Mack E7-400, Diesel, MOUDI, I50, Elements and Inorganic Ions, $\left[\mu \mathrm{g} / \mathrm{m}^{3}\right]$ (Part 2)

\begin{tabular}{|c|c|c|c|c|c|c|c|c|c|}
\hline \multicolumn{3}{|c|}{ MOUDI Stage } & & \multirow{2}{*}{$\begin{array}{c}\mathrm{VI} \\
0.56\end{array}$} & \multirow{2}{*}{$\begin{array}{c}\text { VII } \\
0.32\end{array}$} & \multirow{2}{*}{$\begin{array}{l}\text { VIII } \\
0.18\end{array}$} & \multirow{2}{*}{$\begin{array}{l}\text { IX } \\
0.1\end{array}$} & \multirow{2}{*}{$\begin{array}{c}\mathrm{X} \\
0.056\end{array}$} & \multirow{2}{*}{$\begin{array}{c}\mathrm{XI} \\
<0.056\end{array}$} \\
\hline Cut- & off Diameter & $\mu \mathrm{m}$ & & & & & & & \\
\hline 46 & $\mathrm{Ga}$ & & XRF & 0.000 & 0.000 & 0.387 & 0.013 & 0.000 & 0.000 \\
\hline 47 & $\mathrm{Ga}$ & uncertainty & XRF & 0.720 & 0.680 & 0.661 & 0.712 & 0.713 & 0.349 \\
\hline 48 & As & & XRF & 0.000 & 0.000 & 0.000 & 0.040 & 0.000 & 0.000 \\
\hline 49 & As & uncertainty & XRF & 0.934 & 0.909 & 0.860 & 0.931 & 0.980 & 0.390 \\
\hline 50 & $\mathrm{Se}$ & & XRF & 0.000 & 0.000 & 0.276 & 0.000 & 0.000 & 0.000 \\
\hline 51 & $\mathrm{Se}$ & uncertainty & XRF & 0.518 & 0.492 & 0.486 & 0.512 & 0.514 & 0.222 \\
\hline 52 & $\mathrm{Br}$ & & XRF & 0.026 & 0.000 & 0.062 & 0.000 & 0.000 & 0.000 \\
\hline 53 & $\mathrm{Br}$ & uncertainty & XRF & 0.472 & 0.446 & 0.541 & 0.466 & 0.472 & 0.188 \\
\hline 54 & $\mathrm{Rb}$ & & XRF & 0.000 & 0.000 & 0.247 & 0.000 & 0.000 & 0.000 \\
\hline 55 & $\overline{\mathrm{Rb}}$ & uncertainty & XRF & 0.471 & 0.449 & 0.436 & 0.462 & 0.471 & 0.180 \\
\hline 56 & $\mathrm{Sr}$ & & XRF & 0.000 & 0.000 & 0.139 & 0.000 & 0.000 & 0.049 \\
\hline 57 & $\mathrm{Sr}$ & uncertainty & XRF & 0.522 & 0.499 & 0.478 & 0.515 & 0.524 & 0.196 \\
\hline 58 & $\bar{Y}$ & & XRF & 0.000 & 0.000 & 0.476 & 0.000 & 0.000 & 0.000 \\
\hline 59 & $\mathrm{Y}$ & uncertainty & XRF & 0.639 & 0.611 & 0.587 & 0.631 & 0.644 & 0.240 \\
\hline 60 & $\mathrm{Zr}$ & & XRF & 0.048 & 0.000 & 0.486 & 0.000 & 0.000 & 0.000 \\
\hline 61 & $\mathrm{Zr}$ & uncertainty & XRF & 0.761 & 0.730 & 0.694 & 0.751 & 0.766 & 0.284 \\
\hline 62 & Mo & & XRF & 0.000 & 0.000 & 0.000 & 0.468 & 0.000 & 0.273 \\
\hline 63 & Mo & uncertainty & XRF & 1.370 & 1.312 & 1.256 & 1.357 & 1.383 & 0.514 \\
\hline 64 & $\mathrm{Pd}$ & & $\mathrm{XRF}$ & 0.000 & 0.445 & 1.757 & 0.000 & 0.025 & 0.000 \\
\hline 65 & $\mathrm{Pd}$ & uncertainty & $\mathrm{XRF}$ & 3.434 & 3.356 & 3.133 & 3.260 & 3.504 & 1.653 \\
\hline 66 & $\mathrm{Ag}$ & & $\mathrm{XRF}$ & 0.000 & 0.000 & 0.364 & 0.000 & 0.000 & 0.000 \\
\hline 67 & $\overline{\mathrm{Ag}}$ & uncertainty & $\mathrm{XRF}$ & 3.803 & 3.715 & 3.562 & 3.706 & 3.956 & 1.847 \\
\hline 68 & $\mathrm{Cd}$ & & $\mathrm{XRF}$ & 0.000 & 0.000 & 0.707 & 0.839 & 0.000 & 1.253 \\
\hline 69 & $\mathrm{Cd}$ & uncertainty & XRF & 3.761 & 3.679 & 3.533 & 3.709 & 3.914 & 1.953 \\
\hline 70 & In & & XRF & 0.000 & 0.000 & 0.000 & 0.599 & 2.065 & 0.000 \\
\hline 71 & In & uncertainty & XRF & 4.292 & 4.184 & 4.079 & 4.241 & 4.431 & 2.263 \\
\hline 72 & $\mathrm{Sn}$ & & XRF & 0.000 & 0.000 & 0.000 & 2.337 & 2.674 & 0.752 \\
\hline 73 & $\mathrm{Sn}$ & uncertainty & XRF & 5.628 & 5.477 & 5.410 & 5.639 & 5.828 & 2.793 \\
\hline 74 & $\mathrm{Sb}$ & & XRF & 1.318 & 0.000 & 1.549 & 1.827 & 0.000 & 0.000 \\
\hline 75 & $\mathrm{Sb}$ & uncertainty & $\mathrm{XRF}$ & 6.749 & 6.618 & 6.486 & 6.724 & 6.987 & 3.317 \\
\hline 76 & $\mathrm{Ba}$ & & XRF & 4.858 & 0.000 & 8.523 & 0.000 & 16.320 & 0.000 \\
\hline 77 & $\mathrm{Ba}$ & uncertainty & XRF & 25.320 & 25.050 & 24.316 & 25.397 & 26.305 & 11.454 \\
\hline 78 & $\mathrm{La}$ & & $\mathrm{XRF}$ & 0.000 & 0.000 & 0.000 & 0.000 & 0.000 & 6.257 \\
\hline 79 & $\mathrm{La}$ & uncertainty & XRF & 36.301 & 35.799 & 34.803 & 36.311 & 37.810 & 16.411 \\
\hline 80 & $\mathrm{Au}$ & & XRF & 0.000 & 0.000 & 0.837 & 0.000 & 0.000 & 0.000 \\
\hline 81 & $\mathrm{Au}$ & uncertainty & XRF & 1.220 & 1.152 & 1.133 & 1.210 & 1.215 & 0.631 \\
\hline 82 & $\mathrm{Hg}$ & & XRF & 0.029 & 0.000 & 0.660 & 0.195 & 0.000 & 0.000 \\
\hline 83 & $\mathrm{Hg}$ & uncertainty & XRF & 1.153 & 1.087 & 1.062 & 1.143 & 1.145 & 0.501 \\
\hline 84 & $\mathrm{Ti}$ & & XRF & 0.000 & 0.000 & 0.238 & 0.509 & 0.000 & 0.000 \\
\hline 85 & $\mathrm{Ti}$ & uncertainty & XRF & 1.121 & 1.058 & 1.042 & 1.117 & 1.114 & 0.450 \\
\hline 86 & $\mathrm{~Pb}$ & & XRF & 0.000 & 0.000 & 0.531 & 0.424 & 0.000 & 0.000 \\
\hline 87 & $\mathrm{~Pb}$ & uncertainty & XRF & 1.426 & 1.357 & 1.305 & 1.414 & 1.419 & 0.580 \\
\hline 88 & $\overline{\mathrm{U}}$ & & XRF & 0.000 & 0.000 & 0.055 & 0.000 & 0.000 & 0.000 \\
\hline 89 & $\mathrm{U}$ & uncertainty & XRF & 1.163 & 1.108 & 1.064 & 1.146 & 1.163 & 0.437 \\
\hline 90 & SUM & & & 30.613 & 24.219 & 43.069 & 79.292 & 83.833 & 69.020 \\
\hline 91 & SUM & uncertainty & & 48.142 & 47.517 & 46.243 & 48.262 & 50.107 & 24.016 \\
\hline
\end{tabular}


Appendix C. Hydrocarbon Speciation of Diesel Exhaust, Cummins ISM 370 ESP, Tables 
Table C.1 Cummins ISM 370 ESP, Polycyclic Aromatic Hydrocarbons, Semi-Volatile Phase (PUF/XAD-2/PUF), [ $\mu \mathrm{g} / \mathrm{kWh}]$ (Part 1)

\begin{tabular}{|c|c|c|c|c|c|c|c|}
\hline \# & Compound & $\mathrm{NC}$ & MW & R75 & R50 & 150 & FTP \\
\hline 1 & Naphthalene & 10 & 128.2 & 158.6710 & 379.7362 & 283.9710 & 1026.2449 \\
\hline 2 & 2-Methylnaphthalene & 11 & 142.2 & 206.0117 & 364.6824 & 292.3835 & 720.6637 \\
\hline 3 & 1-Methylnaphthalene & 11 & 142.2 & 126.6005 & 227.5547 & 161.0261 & 431.2177 \\
\hline 4 & Biphenyl & 12 & 154.2 & 23.2583 & 39.8129 & 33.1043 & 78.6089 \\
\hline 5 & 1+2-Ethylnaphthalene & 12 & 156.2 & 73.2224 & 112.8120 & 86.5014 & 206.2131 \\
\hline 6 & 2,6+2,7-Dimethylnaphthalene & 12 & 156.2 & 40.9333 & 72.0860 & 54.9704 & 140.0006 \\
\hline 7 & 1,3+1,6+1,7-Dimethylnaphthalene & 12 & 156.2 & 116.0897 & 177.0450 & 150.6549 & 363.5294 \\
\hline 8 & 1,4+1,5+2,3-Dimethylnaphthalene & 12 & 156.2 & 32.2387 & 50.8489 & 40.2966 & 94.5472 \\
\hline 9 & 1,2-Dimethylnaphthalene & 12 & 156.2 & 23.8301 & 31.6469 & 22.4762 & 69.7544 \\
\hline 10 & 2-Methylbiphenyl & 13 & 168.2 & 9.1991 & 35.3516 & 17.0819 & 24.7928 \\
\hline 11 & 3-Methylbiphenyl & 13 & 168.2 & 1929.3458 & 2386.4809 & 1795.2080 & 3590.8240 \\
\hline 12 & 4-Methylbiphenyl & 13 & 168.2 & 6.0879 & 7.3573 & 5.6512 & 30.6958 \\
\hline 13 & Bibenzyl & 14 & 182.3 & 1074.5570 & 1433.1095 & 1038.4015 & 2052.9817 \\
\hline 14 & A-Trimethylnaphthalene & 13 & 170.3 & 57.5319 & 102.7936 & 76.9650 & 168.8272 \\
\hline 15 & 1-Ethyl-2-Methylnaphthalene & 13 & 170.3 & 4.0025 & 4.8527 & 4.2705 & 8.2643 \\
\hline 16 & B-Trimethylnaphthalene & 13 & 170.3 & 39.7056 & 61.2326 & 49.4156 & 123.4721 \\
\hline 17 & C-Trimethylnaphthalene & 13 & 170.3 & 29.1443 & 49.4140 & 42.9296 & 91.7924 \\
\hline 18 & 2-Ethyl-1-Methylnaphthalene & 13 & 170.3 & 20.3153 & 32.7948 & 30.5677 & 69.9511 \\
\hline 19 & E-Trimethylnaphthalene & 13 & 170.3 & 17.1032 & 30.3424 & 24.9807 & 60.5063 \\
\hline 20 & F-Trimethylnaphthalene & 13 & 170.3 & 29.3798 & 51.9969 & 42.6406 & 88.2506 \\
\hline 21 & 2,3,5+l-Trimethylnaphthalene & 13 & 170.3 & 21.0048 & 33.8645 & 28.7053 & 78.8057 \\
\hline 22 & 2,4,5-Trimethylnaphthalene & 13 & 170.3 & 7.5173 & 11.0882 & 8.6373 & 23.1202 \\
\hline 23 & J-Trimethylnaphthalene & 13 & 170.3 & 16.5818 & 27.7595 & 20.6460 & 62.6707 \\
\hline 24 & 1,4,5-Trimethylnaphthalene & 13 & 170.3 & 10.9817 & 18.2367 & 12.7151 & 40.3375 \\
\hline 25 & 1,2,8-Trimethylnaphthalene & 13 & 170.3 & 0.0000 & 7.1747 & 0.0000 & 10.1336 \\
\hline 26 & Acenaphthylene & 12 & 152.2 & 17.7422 & 19.9326 & 30.4071 & 73.8865 \\
\hline 27 & Acenaphthene & 12 & 154.2 & 67.7568 & 134.9883 & 33.3932 & 30.8926 \\
\hline 28 & Fluorene & 13 & 166.2 & 27.9671 & 48.8400 & 38.4986 & 108.1242 \\
\hline 29 & Phenanthrene & 14 & 178.2 & 73.3065 & 121.0825 & 85.7950 & 218.9047 \\
\hline 30 & A-Methylfluorene & 14 & 180.2 & 21.7447 & 25.8810 & 18.8479 & 88.9393 \\
\hline 31 & 1-Methylfluorene & 14 & 180.2 & 99.9115 & 161.1824 & 120.6973 & 431.8079 \\
\hline 32 & 9-Fluorenone & 13 & 180.2 & 678.1064 & 387.9284 & 526.2968 & 1443.3936 \\
\hline 33 & A-Methylphenanthrene & 15 & 192.2 & 9.9558 & 8.8444 & 3.9173 & 0.0000 \\
\hline 34 & 2-Methylphenanthrene & 15 & 192.2 & 11.6039 & 19.1760 & 14.1600 & 9.3465 \\
\hline 35 & B-Methylphenanthrene & 15 & 192.2 & 7.0128 & 11.5578 & 9.9538 & 35.9102 \\
\hline 36 & C-Methylphenanthrene & 15 & 192.2 & 12.4952 & 18.5498 & 12.6830 & 19.3817 \\
\hline 37 & 1-Methylphenanthrene & 15 & 192.2 & 11.5703 & 18.8368 & 16.0865 & 23.6122 \\
\hline 38 & 3,6-Dimethylphenanthrene & 16 & 203.2 & 0.2859 & 2.6090 & 1.7981 & 7.5756 \\
\hline 39 & A-Dimethylphenanthrene & 16 & 203.2 & 2.4385 & 4.2265 & 3.7568 & 13.6754 \\
\hline 40 & B-Dimethylphenanthrene & 16 & 203.2 & 0.0000 & 0.6262 & 0.0000 & 0.0000 \\
\hline 41 & C-Dimethylphenanthrene & 16 & 203.2 & 8.6104 & 11.0620 & 15.5086 & 19.1849 \\
\hline 42 & 1,7-Dimethylphenanthrene & 16 & 203.2 & 1.4631 & 2.2437 & 1.1238 & 0.8854 \\
\hline 43 & D-Dimethylphenanthrene & 16 & 203.2 & 0.7568 & 1.8002 & 1.7018 & 0.8854 \\
\hline 44 & E-Dimethylphenanthrene & 16 & 203.2 & 3.0776 & 4.5396 & 2.8577 & 2.8531 \\
\hline 45 & Anthracene & 14 & 178.2 & 7.3828 & 9.9402 & 7.4493 & 8.7562 \\
\hline 46 & 9-Methylanthracene & 15 & 192.2 & 3.7334 & 2.3742 & 4.1100 & 26.1702 \\
\hline 47 & Fluoranthene & 16 & 202.2 & 13.0334 & 14.1667 & 12.2656 & 18.1027 \\
\hline 48 & Pyrene & 16 & 202.2 & 15.2533 & 19.8543 & 16.3755 & 22.5300 \\
\hline 49 & 1-MeFI+C-MePy/FI & 17 & 216.3 & 3.1785 & 4.5918 & 5.1695 & 7.8707 \\
\hline
\end{tabular}


Table C.1 Cummins ISM 370 ESP, Polycyclic Aromatic Hydrocarbons, Semi-Volatile Phase (PUF/XAD-2/PUF), [ $\mu \mathrm{g} / \mathrm{kWh}$ ] (Part 2)

\begin{tabular}{|r|l|r|r|r|r|r|r|}
\hline$\#$ & NC & MW & \multicolumn{1}{l|}{ R75 } & \multicolumn{1}{l|}{ R50 } & \multicolumn{1}{l}{ I50 } & FTP \\
\hline 50 & lethylpyrene & 17 & 216.3 & 2.6403 & 3.4699 & 3.8210 & 8.9530 \\
\hline 51 & B-MePy/MeFI & 17 & 216.3 & 0.6391 & 0.5479 & 1.5412 & 6.6901 \\
\hline 52 & Methylfluoranthene & 17 & 216.3 & 5.7683 & 9.4967 & 10.8207 & 34.3361 \\
\hline 53 & D-MePy/MeFI & 17 & 216.3 & 0.0841 & 0.5740 & 0.7385 & 0.3936 \\
\hline 54 & 4-Methylpyrene & 17 & 216.3 & 2.0349 & 3.2351 & 3.5320 & 2.7548 \\
\hline 55 & 1-Methylpyrene & 17 & 216.3 & 0.8913 & 3.7830 & 3.0182 & 8.6578 \\
\hline 56 & Benzo(c)phenanthrene & 18 & 228.3 & 1.1772 & 1.6697 & 3.5962 & 3.5418 \\
\hline 57 & Benzo(a)anthracene & 18 & 228.3 & 0.0673 & 0.5479 & 2.2155 & 0.0000 \\
\hline 58 & 7-Methyl Benzo(a)anthracene & 19 & 242.3 & 0.0505 & 1.2262 & 4.1420 & 0.3936 \\
\hline 59 & Chrysene & 18 & 228.3 & 2.0013 & 2.9221 & 3.8210 & 1.1806 \\
\hline 60 & 5+6-Methylchrysene & 19 & 242.3 & 0.4036 & 3.3656 & 10.0501 & 2.7548 \\
\hline 61 & Benzo(b+j+k)fluoranthe & 20 & 252.3 & 0.0000 & 2.7133 & 26.0724 & 0.0000 \\
\hline 62 & 7-methylbenzo(a)pyrene & 21 & 266.3 & 0.0673 & 1.7741 & 13.0362 & 0.0000 \\
\hline 63 & Benz(e)pyrene & 20 & 252.3 & 3.5316 & 4.3831 & 9.4079 & 32.8603 \\
\hline 64 & Perylene & 20 & 252.3 & 2.3712 & 6.6529 & 14.1279 & 25.5799 \\
\hline 65 & Benz(a)pyren & 20 & 252.3 & 0.2186 & 0.0000 & 2.1513 & 0.0000 \\
\hline 66 & Indeno[123-cd]pyrene & 18 & 226.3 & 0.0000 & 2.7394 & 17.4672 & 0.0000 \\
\hline 67 & Benzo(ghi)perylene & 24 & 302.4 & 0.0000 & 5.1919 & 14.6417 & 0.0000 \\
\hline 68 & Dibenzo(ah+ac)anthracene & 22 & 278.3 & 0.5045 & 7.4877 & 25.0449 & 0.7871 \\
\hline 69 & Benzo(b)chrysene & 22 & 279.3 & 0.8072 & 4.6961 & 13.4215 & 3.7386 \\
\hline 70 & Coronene & 24 & 300.3 & 3.5148 & 11.7665 & 18.3663 & 14.0689 \\
\hline TOT & & & 5198.4739 & 6883.1524 & 5508.0873 & 12415.5856 \\
\hline
\end{tabular}


Table C.2 Cummins ISM 370 ESP, Polycyclic Aromatic Hydrocarbons, Particle Bound Phase (Filter), $[\mu \mathrm{g} / \mathrm{kWh}]($ Part 1)

\begin{tabular}{|c|c|c|c|c|c|c|c|}
\hline$\#$ & Compound & $\mathrm{NC}$ & MW & $\mathrm{R} 75$ & R50 & 150 & FTP \\
\hline 1 & Naphthalene & 10 & 128.2 & 3.8680 & 1.1740 & 9.3758 & 16.7253 \\
\hline 2 & 2-Methylnaphthalene & 11 & 142.2 & 0.0000 & 0.0000 & 2.3439 & 1.9677 \\
\hline 3 & 1-Methylnaphthalene & 11 & 142.2 & 0.1514 & 0.0000 & 0.6743 & 3.2467 \\
\hline 4 & Biphenyl & 12 & 154.2 & 0.0000 & 0.1826 & 0.3853 & 2.4596 \\
\hline 5 & 1+2-Ethylnaphthalene & 12 & 156.2 & 0.2354 & 0.0783 & 0.7385 & 2.3613 \\
\hline 6 & 2,6+2,7-Dimethylnaphthalene & 12 & 156.2 & 0.0000 & 0.0000 & 0.0963 & 0.2951 \\
\hline 7 & 1,3+1,6+1,7-Dimethylnaphthalene & 12 & 156.2 & 0.4541 & 0.7044 & 4.9126 & 7.2805 \\
\hline 8 & 1,4+1,5+2,3-Dimethylnaphthalene & 12 & 156.2 & 0.0000 & 0.0000 & 0.4174 & 0.3935 \\
\hline 9 & 1,2-Dimethylnaphthalene & 12 & 156.2 & 0.0000 & 0.0000 & 0.0000 & 0.0000 \\
\hline 10 & 2-Methylbiphenyl & 13 & 168.2 & 0.0000 & 0.2870 & 0.6101 & 1.2790 \\
\hline 11 & 3-Methylbiphenyl & 13 & 168.2 & 0.0000 & 4.9832 & 4.1420 & 18.1027 \\
\hline 12 & 4-Methylbiphenyl & 13 & 168.2 & 0.6222 & 0.8349 & 2.8898 & 6.5917 \\
\hline 13 & Bibenzyl & 14 & 182.3 & 0.8072 & 3.1308 & 4.1099 & 3.9354 \\
\hline 14 & A-Trimethylnaphthalene & 13 & 170.3 & 0.1514 & 0.6522 & 1.4449 & 1.5741 \\
\hline 15 & 1-Ethyl-2-Methylnaphthalene & 13 & 170.3 & 0.1345 & 0.1305 & 0.1926 & 1.0823 \\
\hline 16 & B-Trimethylnaphthalene & 13 & 170.3 & 0.4877 & 0.3913 & 0.0642 & 0.3936 \\
\hline 17 & C-Trimethylnaphthalene & 13 & 170.3 & 0.6559 & 0.5740 & 0.0000 & 2.6564 \\
\hline 18 & 2-Ethyl-1-Methylnaphthalene & 13 & 170.3 & 0.0000 & 0.0000 & 0.2248 & 1.3774 \\
\hline 19 & E-Trimethylnaphthalene & 13 & 170.3 & 0.0000 & 0.0000 & 0.0000 & 0.0000 \\
\hline 20 & F-Trimethylnaphthalene & 13 & 170.3 & 0.0000 & 0.0000 & 0.0000 & 0.7871 \\
\hline 21 & 2,3,5+l-Trimethylnaphthalene & 13 & 170.3 & 0.2018 & 0.0522 & 0.3532 & 0.9838 \\
\hline 22 & 2,4,5-Trimethylnaphthalene & 13 & 170.3 & 0.1850 & 0.2870 & 0.4495 & 0.2951 \\
\hline 23 & J-Trimethylnaphthalene & 13 & 170.3 & 0.2186 & 0.5218 & 0.8027 & 0.8855 \\
\hline 24 & 1,4,5-Trimethylnaphthalene & 13 & 170.3 & 0.2354 & 1.0175 & 0.5779 & 1.5741 \\
\hline 25 & 1,2,8-Trimethylnaphthalene & 13 & 170.3 & 0.2691 & 0.0000 & 0.0000 & 0.1968 \\
\hline 26 & Acenaphthylene & 12 & 152.2 & 0.0000 & 0.0783 & 0.0000 & 0.4919 \\
\hline 27 & Acenaphthene & 12 & 154.2 & 1.1436 & 0.3392 & 1.8623 & 18.5947 \\
\hline 28 & Fluorene & 13 & 166.2 & 0.0000 & 0.0000 & 0.0000 & 0.0984 \\
\hline 29 & Phenanthrene & 14 & 178.2 & 2.3712 & 3.1569 & 6.6466 & 15.8398 \\
\hline 30 & A-Methylfluorene & 14 & 180.2 & 0.0000 & 0.4696 & 0.6101 & 0.3936 \\
\hline 31 & 1-Methylfluorene & 14 & 180.2 & 0.0000 & 0.0000 & 0.7706 & 0.0000 \\
\hline 32 & 9-Fluorenone & 13 & 180.2 & 2.7412 & 3.6786 & 2.6971 & 8.2642 \\
\hline 33 & A-Methylphenanthrene & 15 & 192.2 & 0.3700 & 0.0000 & 0.5780 & 0.9838 \\
\hline 34 & 2-Methylphenanthrene & 15 & 192.2 & 0.0336 & 0.0000 & 0.1926 & 0.1968 \\
\hline 35 & B-Methylphenanthrene & 15 & 192.2 & 0.0505 & 0.3913 & 0.2890 & 1.7709 \\
\hline 36 & C-Methylphenanthrene & 15 & 192.2 & 0.0505 & 0.2870 & 0.2247 & 1.2790 \\
\hline 37 & 1-Methylphenanthrene & 15 & 192.2 & 0.0505 & 0.0000 & 0.2248 & 0.2951 \\
\hline 38 & 3,6-Dimethylphenanthrene & 16 & 203.2 & 0.0673 & 0.4957 & 0.3853 & 0.0000 \\
\hline 39 & A-Dimethylphenanthrene & 16 & 203.2 & 0.2018 & 0.3392 & 0.1926 & 2.1644 \\
\hline 40 & B-Dimethylphenanthrene & 16 & 203.2 & 0.0505 & 0.0000 & 0.0321 & 0.0000 \\
\hline 41 & C-Dimethylphenanthrene & 16 & 203.2 & 0.7568 & 0.6262 & 0.1926 & 1.8693 \\
\hline 42 & 1,7-Dimethylphenanthrene & 16 & 203.2 & 0.0000 & 0.0522 & 0.0000 & 0.0000 \\
\hline 43 & D-Dimethylphenanthrene & 16 & 203.2 & 0.0841 & 0.1565 & 0.0000 & 0.0000 \\
\hline 44 & E-Dimethylphenanthrene & 16 & 203.2 & 0.0505 & 0.0522 & 0.2569 & 0.4919 \\
\hline 45 & Anthracene & 14 & 178.2 & 0.4373 & 0.7305 & 3.4999 & 2.8531 \\
\hline 46 & 9-Methylanthracene & 15 & 192.2 & 0.0000 & 0.0783 & 0.4174 & 0.0000 \\
\hline 47 & Fluoranthene & 16 & 202.2 & 0.0000 & 0.0000 & 0.0000 & 0.5903 \\
\hline 48 & Pyrene & 16 & 202.2 & 0.3868 & 0.1305 & 0.1284 & 1.2790 \\
\hline 49 & 1-MeFI+C-MePy/FI & 17 & 216.3 & 0.3532 & 0.3653 & 0.3853 & 1.5741 \\
\hline
\end{tabular}


Table C.2 Cummins ISM 370 ESP, Polycyclic Aromatic Hydrocarbons, Particle Bound Phase (Filter), [ $\mu \mathrm{g} / \mathrm{kWh}]$ (Part 2)

\begin{tabular}{|r|l|r|r|r|r|r|r|}
\hline$\#$ & NC & \multicolumn{1}{|c|}{ MW } & R75 & R50 & \multicolumn{1}{l|}{ I50 } & FTP \\
\hline 50 & Methylpyrene & 17 & 216.3 & 0.2523 & 0.7566 & 0.4174 & 0.4919 \\
\hline 51 & B-MePy/MeFI & 17 & 216.3 & 0.4541 & 0.2087 & 0.4495 & 0.7871 \\
\hline 52 & Methylfluoranthene & 17 & 216.3 & 0.4372 & 0.3913 & 0.5459 & 1.7709 \\
\hline 53 & D-MePy/MeFI & 17 & 216.3 & 2.5730 & 0.9131 & 0.8669 & 1.5741 \\
\hline 54 & 4-Methylpyrene & 17 & 216.3 & 1.7826 & 0.0000 & 0.3853 & 0.1968 \\
\hline 55 & 1-Methylpyrene & 17 & 216.3 & 0.1514 & 0.6001 & 0.6743 & 1.3774 \\
\hline 56 & Benzo(c)phenanthrene & 18 & 228.3 & 0.1850 & 0.4435 & 0.5780 & 1.1806 \\
\hline 57 & Benzo(a)anthracene & 18 & 228.3 & 0.2859 & 0.8349 & 1.1238 & 0.7871 \\
\hline 58 & 7-Methyl Benzo(a)anthracene & 19 & 242.3 & 0.0000 & 0.7827 & 0.3532 & 1.0823 \\
\hline 59 & Chrysene & 18 & 228.3 & 0.6391 & 1.2262 & 0.4816 & 0.6887 \\
\hline 60 & 5+6-Methylchrysene & 19 & 242.3 & 1.4631 & 2.3481 & 3.9815 & 9.3465 \\
\hline 61 & Benzo(b+j+k)fluoranthe & 20 & 252.3 & 0.8072 & 2.7916 & 6.8071 & 6.0014 \\
\hline 62 & 7-methylbenzo(a)pyrene & 21 & 266.3 & 0.0000 & 0.0000 & 0.0000 & 0.0000 \\
\hline 63 & Benzo(e)pyrene & 20 & 252.3 & 0.1345 & 0.8349 & 2.3440 & 0.0984 \\
\hline 64 & Perylene & 20 & 252.3 & 0.2523 & 0.5740 & 1.0275 & 1.1806 \\
\hline 65 & Benzo(a)pyrene & 20 & 252.3 & 0.0000 & 0.0000 & 0.7385 & 0.0000 \\
\hline 66 & Indeno[123-cd]pyrene & 18 & 226.3 & 0.0000 & 0.1565 & 1.3486 & 0.0000 \\
\hline 67 & Benzo(ghi)perylene & 24 & 302.4 & 0.3700 & 0.6783 & 2.4082 & 0.2951 \\
\hline 68 & Dibenzo(ah+ac)anthracene & 22 & 278.3 & 0.1682 & 0.4174 & 3.0824 & 0.0000 \\
\hline 69 & Benzo(b)chrysene & 22 & 279.3 & 0.1345 & 0.0000 & 0.8027 & 0.0000 \\
\hline 70 & Coronene & 24 & 300.3 & 1.1772 & 1.5393 & 5.0732 & 1.0823 \\
\hline TOTAL $[\mu$ g/kWh] & & & 29.1443 & 41.9261 & 87.8820 & 163.4161 \\
\hline
\end{tabular}


Table C. 3 Cummins ISM 370 ESP, Ozone Forming Potential, Semi-Volatile Phase (PUF/XAD-2/PUF), [ $\mu \mathrm{g} / \mathrm{kWh}]$ (Part 1)

\begin{tabular}{|c|c|c|c|c|c|c|c|c|}
\hline$\#$ & Compound & NC & MW & $\operatorname{MIR}(g / g)$ & $\mathbf{R 7 5}$ & R50 & 150 & FTP \\
\hline 1 & Naphthalene & 10 & 128.2 & 3.49 & 553.7620 & 1325.2793 & 991.0589 & 3581.5947 \\
\hline 2 & 2-Methylnaphthalene & 11 & 142.2 & 4.89 & 1007.3972 & 1783.2970 & 1429.7555 & 3524.0457 \\
\hline 3 & 1-MethyInaphthalene & 11 & 142.2 & 4.89 & 619.0764 & 1112.7427 & 787.4176 & 2108.6544 \\
\hline 4 & Biphenyl & 12 & 154.2 & 2.08 & 48.3773 & 82.8109 & 68.8569 & 163.5065 \\
\hline 5 & 1+2-Ethylnaphthalene & 12 & 156.2 & 4.89 & 358.0577 & 551.6509 & 422.9916 & 1008.3822 \\
\hline 6 & 2,6+2,7-Dimethylnaphthalene & 12 & 156.2 & 5.85 & 239.4596 & 421.7029 & 321.5770 & 819.0035 \\
\hline 7 & 1,3+1,6+1,7-Dimethylnaphthalene & 12 & 156.2 & 5.85 & 679.1247 & 1035.7132 & 881.3312 & 2126.6469 \\
\hline 8 & 1,4+1,5+2,3-Dimethylnaphthalene & 12 & 156.2 & 5.85 & 188.5966 & 297.4661 & 235.7354 & 553.1010 \\
\hline 9 & 1,2-Dimethylnaphthalene & 12 & 156.2 & 5.85 & 139.4060 & 185.1341 & 131.4860 & 408.0630 \\
\hline 10 & 2-Methylbiphenyl & 13 & 168.2 & 1.33 & 12.2347 & 47.0176 & 22.7189 & 32.9744 \\
\hline 11 & 3-Methylbiphenyl & 13 & 168.2 & 1.33 & 2566.0299 & 3174.0196 & 2387.6266 & 4775.7960 \\
\hline 12 & 4-Methylbiphenyl & 13 & 168.2 & 1.33 & 8.0969 & 9.7852 & 7.5160 & 40.8255 \\
\hline 13 & Bibenzyl & 14 & 182.3 & 1.33 & 1429.1608 & 1906.0357 & 1381.0740 & 2730.4656 \\
\hline 14 & A-Trimethylnaphthalene & 13 & 170.3 & 5.37 & 308.9464 & 552.0016 & 413.3021 & 906.6020 \\
\hline 15 & 1-Ethyl-2-Methylnaphthalene & 13 & 170.3 & 5.37 & 21.4935 & 26.0590 & 22.9324 & 44.3792 \\
\hline 16 & B-Trimethylnaphthalene & 13 & 170.3 & 5.37 & 213.2191 & 328.8191 & 265.3617 & 663.0451 \\
\hline 17 & C-Trimethylnaphthalene & 13 & 170.3 & 5.37 & 156.5051 & 265.3531 & 230.5318 & 492.9253 \\
\hline 18 & 2-Ethyl-1-Methylnaphthalene & 13 & 170.3 & 5.37 & 109.0930 & 176.1081 & 164.1483 & 375.6375 \\
\hline 19 & E-Trimethylnaphthalene & 13 & 170.3 & 5.37 & 91.8441 & 162.9385 & 134.1465 & 324.9186 \\
\hline 20 & F-Trimethylnaphthalene & 13 & 170.3 & 5.37 & 157.7695 & 279.2232 & 228.9801 & 473.9056 \\
\hline 21 & 2,3,5+1-Trimethylnaphthalene & 13 & 170.3 & 5.37 & 112.7957 & 181.8523 & 154.1477 & 423.1864 \\
\hline 22 & 2,4,5-TrimethylNaphthalene & 13 & 170.3 & 5.37 & 40.3681 & 59.5434 & 46.3823 & 124.1557 \\
\hline 23 & J-Trimethylnaphthalene & 13 & 170.3 & 5.37 & 89.0445 & 149.0684 & 110.8691 & 336.5417 \\
\hline 24 & 1,4,5-Trimethylnaphthalene & 13 & 170.3 & 5.37 & 58.9716 & 97.9312 & 68.2802 & 216.6125 \\
\hline 25 & 1,2,8-Trimethylnaphthalene & 13 & 170.3 & 5.37 & 0.0000 & 38.5280 & 0.0000 & 54.4172 \\
\hline 26 & Acenaphthylene & 12 & 152.2 & $\mathrm{~N} / \mathrm{A}$ & $\mathrm{N} / \mathrm{A}$ & $\mathrm{N} / \mathrm{A}$ & $\mathrm{N} / \mathrm{A}$ & $\mathrm{N} / \mathrm{A}$ \\
\hline 27 & Acenaphthene & 12 & 154.2 & $\mathrm{~N} / \mathrm{A}$ & $\mathrm{N} / \mathrm{A}$ & $\mathrm{N} / \mathrm{A}$ & $\mathrm{N} / \mathrm{A}$ & $\mathrm{N} / \mathrm{A}$ \\
\hline 28 & Fluorene & 13 & 166.2 & 2.1 & 58.7310 & 102.5640 & 80.8470 & 227.0608 \\
\hline 29 & Phenanthrene & 14 & 178.2 & 6.94 & 508.7473 & 840.3126 & 595.4170 & 1519.1986 \\
\hline 30 & A-Methylfluorene & 14 & 180.2 & 2.1 & 45.6640 & 54.3502 & 39.5806 & 186.7725 \\
\hline 31 & 1-Methylfluorene & 14 & 180.2 & 2.1 & 209.8141 & 338.4831 & 253.4644 & 906.7967 \\
\hline 32 & 9-Fluorenone & 13 & 130.2 & $\mathrm{~N} / \mathrm{A}$ & $\mathrm{N} / \mathrm{A}$ & $\mathrm{N} / \mathrm{A}$ & $\mathrm{N} / \mathrm{A}$ & $\mathrm{N} / \mathrm{A}$ \\
\hline 33 & A-Methylphenanthrene & 15 & 192.2 & 6.94 & 69.0934 & 61.3802 & 27.1859 & 0.0000 \\
\hline 34 & 2-Methylphenanthrene & 15 & 192.2 & 6.94 & 80.5312 & 133.0811 & 98.2705 & 64.8646 \\
\hline 35 & B-Methylphenanthrene & 15 & 192.2 & 6.94 & 48.6689 & 80.2108 & 69.0791 & 249.2167 \\
\hline 36 & C-Methylphenanthrene & 15 & 192.2 & 6.94 & 86.7169 & 128.7357 & 88.0202 & 134.5087 \\
\hline 37 & 1-Methylphenanthrene & 15 & 192.2 & 6.94 & 80.2978 & 130.7274 & 111.6406 & 163.8686 \\
\hline 38 & 3,6-Dimethylphenanthrene & 16 & 203.2 & 6.94 & 1.9841 & 18.1062 & 12.4787 & 52.5747 \\
\hline 39 & A-Dimethylphenanthrene & 16 & 203.2 & 6.94 & 16.9233 & 29.3322 & 26.0719 & 94.9072 \\
\hline 40 & B-Dimethylphenanthrene & 16 & 203.2 & 6.94 & 0.0000 & 4.3456 & 0.0000 & 0.0000 \\
\hline 41 & C-Dimethylphenanthrene & 16 & 203.2 & 6.94 & 59.7565 & 76.7706 & 107.6297 & 133.1433 \\
\hline 42 & 1,7-Dimethylphenanthrene & 16 & 203.2 & 6.94 & 10.1540 & 15.5714 & 7.7993 & 6.1450 \\
\hline 43 & D-Dimethylphenanthrene & 16 & 203.2 & 6.94 & 5.2520 & 12.4933 & 11.8102 & 6.1450 \\
\hline 44 & E-Dimethylphenanthrene & 16 & 203.2 & 6.94 & 21.3583 & 31.5049 & 19.8323 & 19.8008 \\
\hline 45 & Anthracene & 14 & 178.2 & 9.08 & 67.0357 & 90.2570 & 67.6392 & 79.5060 \\
\hline 46 & 9-Methylanthracene & 15 & 192.2 & 9.08 & 33.8996 & 21.5574 & 37.3184 & 237.6254 \\
\hline 47 & Fluoranthene & 16 & 202.2 & 9.08 & 118.3432 & 128.6338 & 111.3716 & 164.3721 \\
\hline 48 & Pyrene & 16 & 202.2 & $\mathrm{~N} / \mathrm{A}$ & $\mathrm{N} / \mathrm{A}$ & $\mathrm{N} / \mathrm{A}$ & $\mathrm{N} / \mathrm{A}$ & $\mathrm{N} / \mathrm{A}$ \\
\hline 49 & 1-MeFI+C-MePy/FI & 17 & 216.3 & $\mathrm{~N} / \mathrm{A}$ & $\mathrm{N} / \mathrm{A}$ & $\mathrm{N} / \mathrm{A}$ & $\mathrm{N} / \mathrm{A}$ & $\mathrm{N} / \mathrm{A}$ \\
\hline
\end{tabular}


Table C.3 Cummins ISM 370 ESP, Ozone Forming Potential, Semi-Volatile Phase (PUF/XAD-2/PUF), [ $\mu \mathrm{g} / \mathrm{kWh}$ ] (Part 2)

\begin{tabular}{|c|c|c|c|c|c|c|c|c|}
\hline$\#$ & Compound & NC & MW & $\operatorname{MIR}(g / g)$ & R75 & R50 & 150 & FTP \\
\hline 50 & Methylpyrene & 17 & 216.3 & $\mathrm{~N} / \mathrm{A}$ & $\mathrm{N} / \mathrm{A}$ & $\mathrm{N} / \mathrm{A}$ & $\mathrm{N} / \mathrm{A}$ & $\mathrm{N} / \mathrm{A}$ \\
\hline 51 & B-MePy/MeFI & 17 & 216.3 & $\mathrm{~N} / \mathrm{A}$ & $\mathrm{N} / \mathrm{A}$ & $\mathrm{N} / \mathrm{A}$ & $\mathrm{N} / \mathrm{A}$ & $\mathrm{N} / \mathrm{A}$ \\
\hline 52 & Methylfluoranthene & 17 & 216.3 & $\mathrm{~N} / \mathrm{A}$ & $\mathrm{N} / \mathrm{A}$ & $\mathrm{N} / \mathrm{A}$ & $\mathrm{N} / \mathrm{A}$ & $\mathrm{N} / \mathrm{A}$ \\
\hline 53 & D-MePy/MeFI & 17 & 216.3 & $\mathrm{~N} / \mathrm{A}$ & $\mathrm{N} / \mathrm{A}$ & $\mathrm{N} / \mathrm{A}$ & $\mathrm{N} / \mathrm{A}$ & $\mathrm{N} / \mathrm{A}$ \\
\hline 54 & 4-Methylpyrene & 17 & 216.3 & $\mathrm{~N} / \mathrm{A}$ & $\mathrm{N} / \mathrm{A}$ & $\mathrm{N} / \mathrm{A}$ & $\mathrm{N} / \mathrm{A}$ & $\mathrm{N} / \mathrm{A}$ \\
\hline 55 & 1-Methylpyrene & 17 & 216.3 & $\mathrm{~N} / \mathrm{A}$ & $\mathrm{N} / \mathrm{A}$ & $\mathrm{N} / \mathrm{A}$ & $\mathrm{N} / \mathrm{A}$ & $\mathrm{N} / \mathrm{A}$ \\
\hline 56 & Benzo(c)phenanthrene & 18 & 228.3 & $\mathrm{~N} / \mathrm{A}$ & $\mathrm{N} / \mathrm{A}$ & $\mathrm{N} / \mathrm{A}$ & $\mathrm{N} / \mathrm{A}$ & $\mathrm{N} / \mathrm{A}$ \\
\hline 57 & Benzo(a)anthracene & 18 & 228.3 & $\mathrm{~N} / \mathrm{A}$ & $\mathrm{N} / \mathrm{A}$ & $\mathrm{N} / \mathrm{A}$ & $\mathrm{N} / \mathrm{A}$ & $\mathrm{N} / \mathrm{A}$ \\
\hline 58 & 7-Methyl Benzo(a)anthracene & 19 & 242.3 & $\mathrm{~N} / \mathrm{A}$ & $\mathrm{N} / \mathrm{A}$ & $\mathrm{N} / \mathrm{A}$ & $\mathrm{N} / \mathrm{A}$ & $\mathrm{N} / \mathrm{A}$ \\
\hline 59 & Chrysene & 18 & 228.3 & $\mathrm{~N} / \mathrm{A}$ & $\mathrm{N} / \mathrm{A}$ & $\mathrm{N} / \mathrm{A}$ & $\mathrm{N} / \mathrm{A}$ & $\mathrm{N} / \mathrm{A}$ \\
\hline 60 & 5+6-Methylchrysene & 19 & 242.3 & $\mathrm{~N} / \mathrm{A}$ & $\mathrm{N} / \mathrm{A}$ & $\mathrm{N} / \mathrm{A}$ & $\mathrm{N} / \mathrm{A}$ & $\mathrm{N} / \mathrm{A}$ \\
\hline 61 & Benzo $(b+j+k)$ fluoranthene & 20 & 252.3 & $\mathrm{~N} / \mathrm{A}$ & $\mathrm{N} / \mathrm{A}$ & $\mathrm{N} / \mathrm{A}$ & $\mathrm{N} / \mathrm{A}$ & $\mathrm{N} / \mathrm{A}$ \\
\hline 62 & 7-methylbenz(a)pyrene & 21 & 266.3 & $\mathrm{~N} / \mathrm{A}$ & $\mathrm{N} / \mathrm{A}$ & $\mathrm{N} / \mathrm{A}$ & $\mathrm{N} / \mathrm{A}$ & $\mathrm{N} / \mathrm{A}$ \\
\hline 63 & Benz(e)pyrene & 20 & 252.3 & $\mathrm{~N} / \mathrm{A}$ & $\mathrm{N} / \mathrm{A}$ & $\mathrm{N} / \mathrm{A}$ & $\mathrm{N} / \mathrm{A}$ & $\mathrm{N} / \mathrm{A}$ \\
\hline 64 & Perylene & 20 & 252.3 & $\mathrm{~N} / \mathrm{A}$ & $\mathrm{N} / \mathrm{A}$ & $\mathrm{N} / \mathrm{A}$ & $\mathrm{N} / \mathrm{A}$ & $\mathrm{N} / \mathrm{A}$ \\
\hline 65 & Benz(a)pyrene & 20 & 252.3 & $\mathrm{~N} / \mathrm{A}$ & $\mathrm{N} / \mathrm{A}$ & $\mathrm{N} / \mathrm{A}$ & $\mathrm{N} / \mathrm{A}$ & $\mathrm{N} / \mathrm{A}$ \\
\hline 66 & Indeno[123-cd]pyrene & 18 & 226.3 & $\mathrm{~N} / \mathrm{A}$ & $\mathrm{N} / \mathrm{A}$ & $\mathrm{N} / \mathrm{A}$ & $\mathrm{N} / \mathrm{A}$ & $\mathrm{N} / \mathrm{A}$ \\
\hline 67 & Benzo(ghi)perylene & 24 & 302.4 & $\mathrm{~N} / \mathrm{A}$ & $\mathrm{N} / \mathrm{A}$ & $\mathrm{N} / \mathrm{A}$ & $\mathrm{N} / \mathrm{A}$ & $\mathrm{N} / \mathrm{A}$ \\
\hline 68 & Dibenzo(ah+ac)anthracene & 22 & 278.3 & $\mathrm{~N} / \mathrm{A}$ & $\mathrm{N} / \mathrm{A}$ & $\mathrm{N} / \mathrm{A}$ & $\mathrm{N} / \mathrm{A}$ & $\mathrm{N} / \mathrm{A}$ \\
\hline 69 & Benzo(b)chrysene & 22 & 279.3 & $\mathrm{~N} / \mathrm{A}$ & $\mathrm{N} / \mathrm{A}$ & $\mathrm{N} / \mathrm{A}$ & $\mathrm{N} / \mathrm{A}$ & $\mathrm{N} / \mathrm{A}$ \\
\hline 70 & Coronene & 24 & 300.3 & $\mathrm{~N} / \mathrm{A}$ & $\mathrm{N} / \mathrm{A}$ & $\mathrm{N} / \mathrm{A}$ & $\mathrm{N} / \mathrm{A}$ & $\mathrm{N} / \mathrm{A}$ \\
\hline \multicolumn{5}{|c|}{ TOTAL $[\mu \mathrm{g} / \mathrm{kWh}]$} & 10731.8016 & 16548.4988 & 12673.6846 & 30555.8928 \\
\hline
\end{tabular}


Table C.4 Cummins ISM 370 ESP, Ozone Forming Potential, Particle Bound Phase (Filter), $[\mu \mathrm{g} / \mathrm{kWh}]($ Part 1$)$

\begin{tabular}{|c|c|c|c|c|c|c|c|c|}
\hline$\#$ & Compound & NC & MW & $\operatorname{MIR}(g / g)$ & R75 & R50 & 150 & FTP \\
\hline 1 & Naphthalene & 10 & 128.2 & 3.49 & 13.4992 & 4.0974 & 32.7215 & 58.3714 \\
\hline 2 & 2-MethyInaphthalene & 11 & 142.2 & 4.89 & 0.0000 & 0.0000 & 8.1803 & 6.8673 \\
\hline 3 & 1-MethyInaphthalene & 11 & 142.2 & 4.89 & 0.7401 & 0.0000 & 2.3533 & 11.3310 \\
\hline 4 & Biphenyl & 12 & 154.2 & 2.08 & 0.0000 & 0.6373 & 1.3447 & 8.5839 \\
\hline 5 & 1+2-Ethylnaphthalene & 12 & 156.2 & 4.89 & 1.1513 & 0.2732 & 2.5773 & 8.2408 \\
\hline 6 & 2,6+2,7-Dimethylnaphthalene & 12 & 156.2 & 5.85 & 0.0000 & 0.0000 & 0.3362 & 1.0300 \\
\hline 7 & 1,3+1,6+1,7-Dimethylnaphthalene & 12 & 156.2 & 5.85 & 2.6563 & 2.4584 & 17.1451 & 25.4088 \\
\hline 8 & 1,4+1,5+2,3-Dimethylnaphthalene & 12 & 156.2 & 5.85 & 0.0000 & 0.0000 & 1.4568 & 1.3733 \\
\hline 9 & 1,2-Dimethylnaphthalene & 12 & 156.2 & 5.85 & 0.0000 & 0.0000 & 0.0000 & 0.0000 \\
\hline 10 & 2-Methylbiphenyl & 13 & 168.2 & 1.33 & 0.0000 & 1.0016 & 2.1291 & 4.4637 \\
\hline 11 & 3-Methylbiphenyl & 13 & 168.2 & 1.33 & 0.0000 & 17.3912 & 14.4558 & 63.1783 \\
\hline 12 & 4-Methylbiphenyl & 13 & 168.2 & 1.33 & 0.8276 & 2.9137 & 10.0854 & 23.0051 \\
\hline 13 & Bibenzyl & 14 & 182.3 & 1.33 & 1.0736 & 10.9264 & 14.3436 & 13.7345 \\
\hline 14 & A-Trimethylnaphthalene & 13 & 170.3 & 5.37 & 0.8128 & 2.2763 & 5.0427 & 5.4937 \\
\hline 15 & 1-Ethyl-2-Methylnaphthalene & 13 & 170.3 & 5.37 & 0.7225 & 0.4553 & 0.6723 & 3.7771 \\
\hline 16 & B-Trimethylnaphthalene & 13 & 170.3 & 5.37 & 2.6190 & 1.3658 & 0.2241 & 1.3735 \\
\hline 17 & C-Trimethylnaphthalene & 13 & 170.3 & 5.37 & 3.5220 & 2.0032 & 0.0000 & 9.2708 \\
\hline 18 & 2-Ethyl-1-Methylnaphthalene & 13 & 170.3 & 5.37 & 0.0000 & 0.0000 & 0.7845 & 4.8071 \\
\hline 19 & E-Trimethylnaphthalene & 13 & 170.3 & 5.37 & 0.0000 & 0.0000 & 0.0000 & 0.0000 \\
\hline 20 & F-Trimethylnaphthalene & 13 & 170.3 & 5.37 & 0.0000 & 0.0000 & 0.0000 & 2.7469 \\
\hline 21 & 2,3,5+1-Trimethylnaphthalene & 13 & 170.3 & 5.37 & 1.0837 & 0.1821 & 1.2327 & 3.4335 \\
\hline 22 & 2,4,5-Trimethylnaphthalene & 13 & 170.3 & 5.37 & 0.9934 & 1.0016 & 1.5688 & 1.0300 \\
\hline 23 & J-Trimethylnlaphthalene & 13 & 170.3 & 5.37 & 1.1740 & 1.8211 & 2.8015 & 3.0904 \\
\hline 24 & 1,4,5-Trimethylnaphthalene & 13 & 170.3 & 5.37 & 1.2643 & 3.5511 & 2.0170 & 5.4937 \\
\hline 25 & 1,2,8-Trimethylnaphthalene & 13 & 170.3 & 5.37 & 1.4450 & 0.0000 & 0.0000 & 0.6867 \\
\hline 26 & Acenaphthylene & 12 & 152.2 & $\mathrm{~N} / \mathrm{A}$ & $\mathrm{N} / \mathrm{A}$ & $\mathrm{N} / \mathrm{A}$ & $\mathrm{N} / \mathrm{A}$ & $\mathrm{N} / \mathrm{A}$ \\
\hline 27 & Acenaphthene & 12 & 154.2 & $\mathrm{~N} / \mathrm{A}$ & $\mathrm{N} / \mathrm{A}$ & $\mathrm{N} / \mathrm{A}$ & $\mathrm{N} / \mathrm{A}$ & $\mathrm{N} / \mathrm{A}$ \\
\hline 28 & Fluorene & 13 & 166.2 & 2.1 & 0.0000 & 0.0000 & 0.0000 & 0.2066 \\
\hline 29 & Phenanthrene & 14 & 178.2 & 6.94 & 16.4564 & 21.9086 & 46.1271 & 109.9284 \\
\hline 30 & A-Methylfluorene & 14 & 180.2 & 2.1 & 0.0000 & 0.9862 & 1.2812 & 0.8265 \\
\hline 31 & 1-Methylfluorene & 14 & 180.2 & 2.1 & 0.0000 & 0.0000 & 1.6183 & 0.0000 \\
\hline 32 & 9-Fluorenone & 13 & 180.2 & $\mathrm{~N} / \mathrm{A}$ & $\mathrm{N} / \mathrm{A}$ & $\mathrm{N} / \mathrm{A}$ & $\mathrm{N} / \mathrm{A}$ & $\mathrm{N} / \mathrm{A}$ \\
\hline 33 & A-Methylphenanthrene & 15 & 192.2 & 6.94 & 2.5677 & 0.0000 & 4.0111 & 6.8277 \\
\hline 34 & 2-Methylphenanthrene & 15 & 192.2 & 6.94 & 0.2335 & 0.0000 & 1.3370 & 1.3655 \\
\hline 35 & B-Methylphenanthrene & 15 & 192.2 & 6.94 & 0.3501 & 2.7159 & 2.0055 & 12.2900 \\
\hline 36 & C-Methylphenanthrene & 15 & 192.2 & 6.94 & 0.3501 & 1.9917 & 1.5597 & 8.8763 \\
\hline 37 & 1-Methylphenanthrene & 15 & 192.2 & 6.94 & 0.3501 & 0.0000 & 1.5599 & 2.0482 \\
\hline 38 & 3,6-Dimethylphenanthrene & 16 & 203.2 & 6.94 & 0.4669 & 3.4402 & 2.6740 & 0.0000 \\
\hline 39 & A-Dimethylphenanthrene & 16 & 203.2 & 6.94 & 1.4005 & 2.3539 & 1.3370 & 15.0213 \\
\hline 40 & B-Dimethylphenanthrene & 16 & 203.2 & 6.94 & 0.3501 & 0.0000 & 0.2228 & 0.0000 \\
\hline 41 & C-Dimethylphenanthrene & 16 & 203.2 & 6.94 & 5.2521 & 4.3456 & 1.3370 & 12.9727 \\
\hline 42 & 1,7-Dimethylphenanthrene & 16 & 203.2 & 6.94 & 0.0000 & 0.3622 & 0.0000 & 0.0000 \\
\hline 43 & D-Dimethylphenanthrene & 16 & 203.2 & 6.94 & 0.5835 & 1.0863 & 0.0000 & 0.0000 \\
\hline 44 & E-Dimethylhenanthrene & 16 & 203.2 & 6.94 & 0.3501 & 0.3622 & 1.7827 & 3.4137 \\
\hline 45 & Anthracene & 14 & 178.2 & 9.08 & 3.9703 & 6.6330 & 31.7786 & 25.9065 \\
\hline 46 & 9-Methylanthracene & 15 & 192.2 & 9.08 & 0.0000 & 0.7107 & 3.7902 & 0.0000 \\
\hline 47 & Fluoranthene & 16 & 202.2 & 9.08 & 0.0000 & 0.0000 & 0.0000 & 5.3601 \\
\hline 48 & Pyrene & 16 & 202.2 & $\mathrm{~N} / \mathrm{A}$ & $\mathrm{N} / \mathrm{A}$ & $\mathrm{N} / \mathrm{A}$ & $\mathrm{N} / \mathrm{A}$ & $\mathrm{N} / \mathrm{A}$ \\
\hline 49 & 1-MeFI+C-MePy/FI & 17 & 216.3 & $\mathrm{~N} / \mathrm{A}$ & $\mathrm{N} / \mathrm{A}$ & $\mathrm{N} / \mathrm{A}$ & $\mathrm{N} / \mathrm{A}$ & $\mathrm{N} / \mathrm{A}$ \\
\hline
\end{tabular}


Table C.4. Cummins ISM 370 ESP, Ozone Forming Potential, Particle Bound Phase (Filter), $[\mu \mathrm{g} / \mathrm{kWh}]($ Part 2)

\begin{tabular}{|c|c|c|c|c|c|c|c|c|}
\hline \# & Compound & NC & MW & $\operatorname{MIR}(g / g)$ & R75 & R50 & 150 & FTP \\
\hline 50 & MethylPyrene & 17 & 216.3 & $\mathrm{~N} / \mathrm{A}$ & $\mathrm{N} / \mathrm{A}$ & $\mathrm{N} / \mathrm{A}$ & $\mathrm{N} / \mathrm{A}$ & $\mathrm{N} / \mathrm{A}$ \\
\hline 51 & B-MePy/MeFI & 17 & 216.3 & $\mathrm{~N} / \mathrm{A}$ & $\mathrm{N} / \mathrm{A}$ & $\mathrm{N} / \mathrm{A}$ & $\mathrm{N} / \mathrm{A}$ & $\mathrm{N} / \mathrm{A}$ \\
\hline 52 & Methylfluoranthene & 17 & 216.3 & $\mathrm{~N} / \mathrm{A}$ & $\mathrm{N} / \mathrm{A}$ & $\mathrm{N} / \mathrm{A}$ & $\mathrm{N} / \mathrm{A}$ & $\mathrm{N} / \mathrm{A}$ \\
\hline 53 & D-MePy/MeFI & 17 & 216.3 & $\mathrm{~N} / \mathrm{A}$ & $\mathrm{N} / \mathrm{A}$ & $\mathrm{N} / \mathrm{A}$ & $\mathrm{N} / \mathrm{A}$ & $\mathrm{N} / \mathrm{A}$ \\
\hline 54 & 4-Methylpyrene & 17 & 216.3 & $\mathrm{~N} / \mathrm{A}$ & $\mathrm{N} / \mathrm{A}$ & $\mathrm{N} / \mathrm{A}$ & $\mathrm{N} / \mathrm{A}$ & $\mathrm{N} / \mathrm{A}$ \\
\hline 55 & 1-Methylpyrene & 17 & 216.3 & $\mathrm{~N} / \mathrm{A}$ & $\mathrm{N} / \mathrm{A}$ & $\mathrm{N} / \mathrm{A}$ & $\mathrm{N} / \mathrm{A}$ & $\mathrm{N} / \mathrm{A}$ \\
\hline 56 & Benzo(c)phenanthrene & 18 & 228.3 & $\mathrm{~N} / \mathrm{A}$ & $\mathrm{N} / \mathrm{A}$ & $\mathrm{N} / \mathrm{A}$ & $\mathrm{N} / \mathrm{A}$ & $\mathrm{N} / \mathrm{A}$ \\
\hline 57 & Benzo(a)anthracene & 18 & 228.3 & $\mathrm{~N} / \mathrm{A}$ & $\mathrm{N} / \mathrm{A}$ & $\mathrm{N} / \mathrm{A}$ & $\mathrm{N} / \mathrm{A}$ & $\mathrm{N} / \mathrm{A}$ \\
\hline 58 & 7-Methylbenz(a)anthracene & 19 & 242.3 & $\mathrm{~N} / \mathrm{A}$ & $\mathrm{N} / \mathrm{A}$ & $\mathrm{N} / \mathrm{A}$ & $\mathrm{N} / \mathrm{A}$ & $\mathrm{N} / \mathrm{A}$ \\
\hline 59 & Chrysene & 18 & 228.3 & $\mathrm{~N} / \mathrm{A}$ & $\mathrm{N} / \mathrm{A}$ & $\mathrm{N} / \mathrm{A}$ & $\mathrm{N} / \mathrm{A}$ & $\mathrm{N} / \mathrm{A}$ \\
\hline 60 & 5+6-Methyl Chrysene & 19 & 242.3 & $\mathrm{~N} / \mathrm{A}$ & $\mathrm{N} / \mathrm{A}$ & $\mathrm{N} / \mathrm{A}$ & $\mathrm{N} / \mathrm{A}$ & $\mathrm{N} / \mathrm{A}$ \\
\hline 61 & Benzo $(b+j+k)$ fluoranthene & 20 & 252.3 & $\mathrm{~N} / \mathrm{A}$ & $\mathrm{N} / \mathrm{A}$ & $\mathrm{N} / \mathrm{A}$ & $\mathrm{N} / \mathrm{A}$ & $\mathrm{N} / \mathrm{A}$ \\
\hline 62 & 7-methylbenzo(a)pyrene & 21 & 266.3 & $\mathrm{~N} / \mathrm{A}$ & $\mathrm{N} / \mathrm{A}$ & $\mathrm{N} / \mathrm{A}$ & $\mathrm{N} / \mathrm{A}$ & $\mathrm{N} / \mathrm{A}$ \\
\hline 63 & Benzo(e)pyrene & 20 & 252.3 & $\mathrm{~N} / \mathrm{A}$ & $\mathrm{N} / \mathrm{A}$ & $\mathrm{N} / \mathrm{A}$ & $\mathrm{N} / \mathrm{A}$ & $\mathrm{N} / \mathrm{A}$ \\
\hline 64 & Perylene & 20 & 252.3 & $\mathrm{~N} / \mathrm{A}$ & $\mathrm{N} / \mathrm{A}$ & $\mathrm{N} / \mathrm{A}$ & $\mathrm{N} / \mathrm{A}$ & $\mathrm{N} / \mathrm{A}$ \\
\hline 65 & Benzo(a)pyrene & 20 & 252.3 & $\mathrm{~N} / \mathrm{A}$ & $\mathrm{N} / \mathrm{A}$ & $\mathrm{N} / \mathrm{A}$ & $\mathrm{N} / \mathrm{A}$ & $\mathrm{N} / \mathrm{A}$ \\
\hline 66 & Indeno[123-cd]pyrene & 18 & 226.3 & $\mathrm{~N} / \mathrm{A}$ & $\mathrm{N} / \mathrm{A}$ & $\mathrm{N} / \mathrm{A}$ & $\mathrm{N} / \mathrm{A}$ & $\mathrm{N} / \mathrm{A}$ \\
\hline 67 & Benzo(ghi)perylene & 24 & 302.4 & $\mathrm{~N} / \mathrm{A}$ & $\mathrm{N} / \mathrm{A}$ & $\mathrm{N} / \mathrm{A}$ & $\mathrm{N} / \mathrm{A}$ & $\mathrm{N} / \mathrm{A}$ \\
\hline 68 & Dibenzo(ah+ac)anthracene & 22 & 278.3 & $\mathrm{~N} / \mathrm{A}$ & $\mathrm{N} / \mathrm{A}$ & $\mathrm{N} / \mathrm{A}$ & $\mathrm{N} / \mathrm{A}$ & $\mathrm{N} / \mathrm{A}$ \\
\hline 69 & Benzo(b)chrysene & 22 & 279.3 & $\mathrm{~N} / \mathrm{A}$ & $\mathrm{N} / \mathrm{A}$ & $\mathrm{N} / \mathrm{A}$ & $\mathrm{N} / \mathrm{A}$ & $\mathrm{N} / \mathrm{A}$ \\
\hline 70 & Coronene & 24 & 300.3 & $\mathrm{~N} / \mathrm{A}$ & $\mathrm{N} / \mathrm{A}$ & $\mathrm{N} / \mathrm{A}$ & $\mathrm{N} / \mathrm{A}$ & $\mathrm{N} / \mathrm{A}$ \\
\hline \multicolumn{5}{|c|}{ TOTAL $[\mu \mathrm{g} / \mathrm{kWh}]$} & 66.2660 & 99.2519 & 223.8949 & 471.8349 \\
\hline
\end{tabular}




\section{VITA}

Aleksandar Bugarski was born in Sarajevo, Bosnia and Herzegovina on September 16, 1964. He received elementary and secondary education in Sarajevo. He entered College of Civil and Environmental Engineering, University of Sarajevo in 1984 and graduated in 1989. He joined Energoinvest, Sarajevo in September 1989 as engineer and worked on designing hydrotechnical structures. From 1991 to 1994 he worked for Institute of Water Resources at College of Civil Engineering, Sarajevo. He was admitted to Petroleum and Natural Gas Engineering graduate program at West Virginia University in August 1994 and received his Master's degree in August of 1996. He continue his studies in the Department of Mechanical and Aerospace Engineering at West Virginia University where he worked as teaching and research assistant and was enrolled in the Doctoral program. He accepted a position with NIOSH Pittsburgh Research Center, Pittsburgh, Pennsylvania in December 1999. 